University of South Florida

DIGITAL COMMONS Digital Commons @ University of @ UNIVERSITY OF SOUTH FLORIDA South Florida

City, County, and Regional Histories E-Book Collection

Floridiana - General

1926

\title{
The cultivation of citrus fruits
}

Harold Hume

Follow this and additional works at: https://digitalcommons.usf.edu/regional_ebooks

\section{Recommended Citation}

Hume, Harold, "The cultivation of citrus fruits" (1926). City, County, and Regional Histories E-Book Collection. 26.

https://digitalcommons.usf.edu/regional_ebooks/26

This Text is brought to you for free and open access by the Floridiana - General at Digital Commons @ University of South Florida. It has been accepted for inclusion in City, County, and Regional Histories E-Book Collection by an authorized administrator of Digital Commons @ University of South Florida. For more information, please contact digitalcommons@usf.edu. 


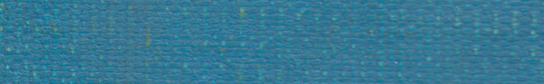




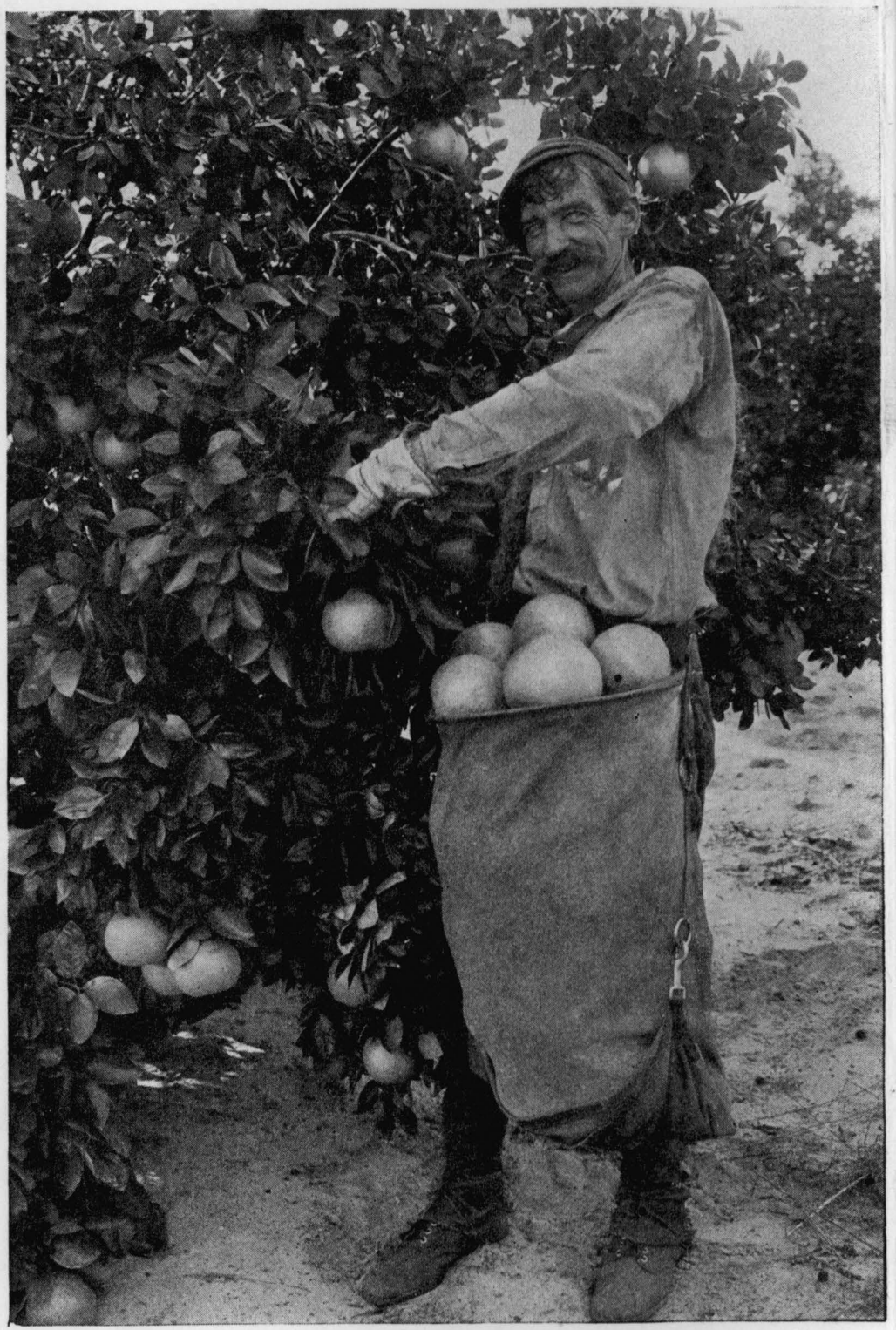

Fig. 1. The Grapefruit Picker

Grapefruit is an outstanding contribution to citrus culture, and first became commercially important in Florida 


\title{
THE CULTIVATION OF CITRUS FRUITS
}

\author{
BY \\ H. HAROLD HUME
}

聠ew 具ork

THE MACMILLAN COMPANY

1926

All rights reserved 
Copyright, 1926

BY THE MACMILLAN COMPANY

Set up and electrotyped

Published April, 1926

Harrisburg, Pa. 


\section{N TRODUCTION}

T N THE author's intimate contact with the growing of citrus fruits, extending over a period of more than a quarter of a century, there have been numerous changes in every phase of cultural practice. Many theories have been propounded, tried out in their growing, and abandoned or adopted as a part of production routine. It has been a period of investigation, progress, and development that covers one of the most interesting chapters in American horticulture.

In 1904, the methods then in use were covered in a volume called "Citrus Fruits and their Culture." This book is now out of print, and also very much out-of-date in most particulars. The intervening years have seen the industry standardized in every department. Citrus culture has become a great specialized commercial industry and holdings of hundreds or thousands of acres are common. Gone are the numerous varieties that made up the plantinglists of that period; in their stead a brief list of fruits remains, sufficient only to cover the harvest season. Gone are the individually operated and crudely equipped packinghouses. They have been replaced by community packingplants in which fruits are handled in large quantities. This has made for greater uniformity in the product marketed and better returns to the grower. Gone are most of the old-time sprays - wonderful compounds that often did more harm to tree than to insect life. They have been replaced by more efficient mixtures. New insects and new diseases have appeared and, fortunately, have been conquered or controlled. The old problems, never quite solved, remain and to these problems new ones, either already solved or in process of solution, have been added. There is no fruit industry in which a husbandman may engage that calls for 
greater special technical knowledge, if success is to be assured. And so, this new volume has been prepared to replace the older one. It is hoped it will be as helpful as was the earlier book in its day and time.

Illustrations are an important part of any horticultural work; a single picture may tell more than a page, or indeed several pages, of print. Considerable care and attention have been given to this feature. Numerous photographs have been made especially for this book; others have been acquired from different sources, and friends interested in different phases of citrus culture have been very helpful in contributing or permitting the use of others. Indeed, what merit this volume possesses in this particular in several chapters is largely due to the help they have given. To be more specific, the Florida Experiment Station, through its Director, Wilmon Newell, has supplied the photographs from which figures 153, 195, 196, 197, 198, 199, 200, 203, 207 in part, 209, 210, 211, 212, 214 in part, 215, 217, 218, 234, 235, and 237 were made. From the United States Department of Agriculture, Bureau of Entomology, the material for figures 205 in part, 225, 226, 227, 228, 229, and 230 was obtained. The photograph for figure 150 came from the Weather Bureau, and those for figures 147 and 157 were furnished by the Bureau of Plant Industry. The material for figures 177, 178, 179, 182, 185, and 186 was supplied by the Bureau of Agricultural Economics, while No. 152 was secured from the California Experiment Station. Dr. O. F. Burger, of the Florida Experiment Station, has checked the manuscript of Chapter XXIX. All of this assistance is sincerely appreciated.

H. HAROLD HUME

Glen Saint Mary, Florida

March 1, 1926 


\section{CON TE N'TS}

\section{CHAPTER I}

paees
$1-9$
$6-9$
$7-8$
8
8
8
9
9
9
9

The Commercial Importance of Citrus Fruits _. . . . . . 1-9

Citrus areas of the United States . . . . . . . . . . . . . $6-9$

Florida . . . . . . . . . . . . . . $7-8$

California _............. . . . 8

Texas . . . . . . . . . . . . . . . 8

Arizona . . . . . . . . . . . .

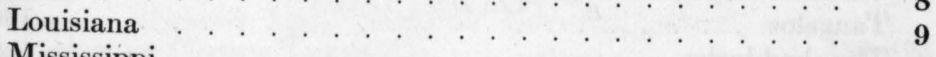

Mississippi . . . . . . . . . . . . . . . . . 9

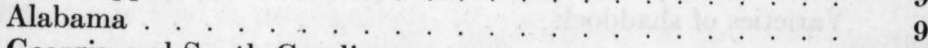

Georgia and South Carolina

CHAPTER II

Botany of Citrus Fruits and Their Relatives . . . . . . 10-33

Poncirus, Fortunella, Citrus, and their species . . . . . . . 14-25

Citrus relatives . . . . . . . . . . . . . $\quad . \quad 25-33$

\section{CHAPTER III}

The Trifoliate Orange and Its Hybrids . . . . . . . . . . 34-42

Varieties of Poncirus, and hybrids with it . . . . . . . . . 39-42

\section{CHAPTER IV}

The Bigarade Oranges

Varieties

\section{CHAPTER V}

The Sweet Orange

Spanish oranges

Mediterranean oranges $52-54$

Blood oranges

Navel oranges

Varieties of the sweet orange group

Spanish oranges

Mediterranean oranges

Blood oranges

69-71

Navel oranges

71-73 


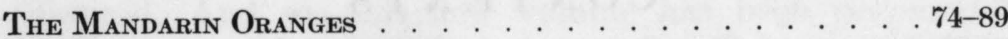

Varieties of mandarin oranges . . . . . . . . . . . . . . . 81-88

Hybrid varieties . . . . . . . . . . . . . . . . . . . . . . . . . . 88-89

\section{CHAPTER VII}

The Pomelos and Shaddocks . . . . . . . . . . . . . . . 90-111

Horticultural status of the pomelo . . . . . . . . . . . . . 95-99

Varieties of pomelo or grapefruit . . . . . . . . . . . . . 99-106

Tangelos . . . . . . . . . . . . . . . . . 106-108

The shaddocks . . . . . . . . . . . . . . . . . . . . 108-111

Varieties of shaddock . . . . . . . . . . . . . . . . 110-111

\section{CHAPTER VIII}

The Kumquats $\ldots \ldots \ldots$

Varieties of kumquat . . . . . . . . . . . . . 116-118

\section{CHAPTER IX}

The Citrons

Varieties of citron

\section{CHAPTER X}

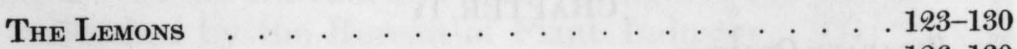

Varieties of lemons . . . . . . . . . . . . . . . . 126-130

CHAPTER XI

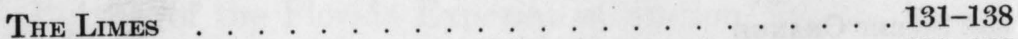

Varieties of limes . . . . . . . . . . . . . . . . . . 133-138

\section{CHAPTER XII}

Varieties for Planting; Breeding New Varieties . . . . . 139-150

Seedless citrus fruits . . . . . . . . . . . . . . . . . . . . 140-141

Breeding new varieties . . . . . . . . . . . . . . . . 141-150

The parts of the flower . . . . . . . . . . 143-145

Mode of operation . . . . . . . . . . . . . 145-150 
Judging Citrus Fruits .

Florida rules for judging

151-153

Florida pomelo scale

California scales and rules

154-158

California orange scale

154-155

California lemon scale

156-157

California pomelo score-card 157

Pomelo standards 158

\section{CHAPTER XIV}

Propagation of Citrus Trees

159-198

Citrus seeds used in propagation 160-163

Extracting and handling citrus seeds

162-163

The seed-bed and its management . . . . . . . . . . . . . 163-167

The seedling stock nursery and its care . . . . . . . . . 167-169

Cuttings

169-170

Selecting, cutting, and keeping budwood and cions . . . . 170-175

Bud variations

$173-175$

Materials and tools required . . . . . . . . . . . . . . 175-179

Waxes and cloth . . . . . . . . . . . . . . 175-178

Tools

$178-179$

Budding

179-190

Time

179-181

Methods of budding

181-187

Care of the budded nursery

187-189

Budding old stocks

189-190

Grafting

190-195

Cleft-grafting

191-193

Whip-grafting

193

Crown-grafting

193-194

Side-grafting

194

Inarching

194-195

Top-working

195-198

Top-working young trees.

196-197

Top-working old trees

197-198

\section{CHAPTER XV}

Citrus-Tree Stocks

Sour orange stock (Citrus Aurantium) 200-203

Rough lemon (Citrus Limonia) as a stock

203-206 
Citrus-Tree Stocks, continued

PAGES

Trifoliate orange (Poncirus trifoliata) as a stock . . . . . 206-211

Sweet orange (Citrus sinensis) as a stock . . . . . . . . . 211-212

Pomelo (Citrus paradisi) as a stock . . . . . . . . . . . . . . . 212-213

Summary of stock adaptations . . . . . . . . . . . . . 213

\section{CHAP'TER XVI}

Solls for Citrus Groves . . . . . . . . . . . . . . . . . . . . 214-220

Florida soils . . . . . . . . . . . . . . . . . . . . . . 215-218

Western Florida, southern Alabama and Mississippi . . . . 218

Louisiana . . . . . . . . . . . . . . . . . . . . . . 218

Texas . . . . . . . . . . . . . . . . . . . . 218-219

California . . . . . . . . . . . . . . . . . . . . . . 219

Cuba . . . . . . . . . . . . . . . . . 220

\section{CHAPTER XVII}

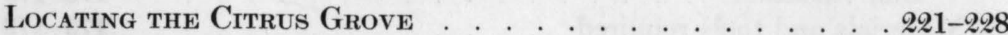

Windbreaks . . . . . . . . . . . . . . . . . 225-227

Location with respect to pests . . . . . . . . . . . . . 228

\section{CHAP'TER XVIII}

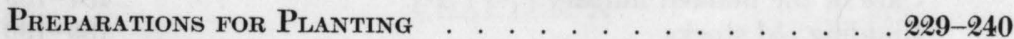

Grove plans . . . . . . . . . . . . . . . . . . . . . . . . . . . . . 231-236

Triangular system . . . . . . . . . . . . . . . . . . . . . 231-232

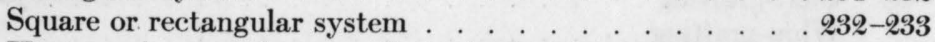

Hexagonal, septuple or equilateral triangle system . . . . 233

Quincunx system . . . . . . . . . . . . . 234

Hedge plantings . . . . . . . . . . . . . . . . . . . . 235

Double planting . . . . . . . . . . . . . . . . . . . . 235-236

Leveling and smoothing . . . . . . . . . . . . . . 236-237

Distances for planting . . . . . . . . . . . . . . . . 237-238

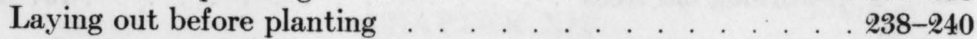

Laying out squares or rectangles with the plow . . . . . 238

Laying out in rectangles with a wire . . . . . . . . . . 239

Laying out in triangles . . . . . . . . . . . . . . . . . 239

Laying out in hexagons . . . . . . . . . . . . . . 239-240

Laying out in quincunx . . . . . . . . . . . . . . 240 
Purchasing trees .

Time to plant

Planting

244-246

Labels and maps

\section{CHAP'TER XX}

Cultivation of Citrus Groves

Clean versus no cultivation

. 253-267

Humus and its value

256-258

Problems of cultivation

258-260

260-267

Florida

260-261

California and Arizona

261-262

Frequency of cultivation

262-263

Methods of cultivating young groves

263-264

Cultivation in relation to dormancy and frosts

264-265

The die-back problem

Rejuvenation of neglected trees

\section{CHAPTER XXI}

Cover-Crops

Valuable cover-crop plants for the South 268-280

Velvet bean

Beggarweed

Crotalarias

274-277

Other cover-crops

277-278

Cover-crops in California

279-280

\section{CHAPTER XXII}

Fertilizers and Fertilizing

The functions of phosphorus, potash, nitrogen, and lime 281-303

Phosphorus

Potash . 282-286

Nitrogen 282-283

Lime

Citrus fruit analyses 
Fertilizers and Fertilizing, continued

Sources of plant-food . 289-293

Sources of phosphoric acid . . . . . . . . . . . . . 290-291

Sources of potash . . . . . . . . . . . . . . 291-292

Sources of nitrogen . . . . . . . . . . . . . . . . . . . 292-293

Cautions in application of fertilizers . . . . . . . . . . . 293-294

Leaching of fertilizers . . . . . . . . . . . . . . . . . 294-297

Formulas; amounts required . . . . . . . . . . . . . . 297-300

Applying fertilizer . . . . . . . . . . . . . . . 300-303

\section{CHAP'TER XXIII}

\section{The Irrigation of Citrus Groves}

304-317

Rainfall in Florida . 305-306

Irrigation in Rio Grande area, Texas 306-307

The southwestern area

Sources of Florida irrigation water $307-310$

Distribution of water .

The furrow system

Check system of irrigation

313-315

Drainage in relation to irrigation

The irrigation season

\section{CHAPTER XXIV}

Frost Considerations

318-345

How frosts form .

$320-321$

Forewarnings

Tree factors affecting cold resistance

324-329

Diseases

Food

Insects

Dormaney

Stocks

326-327

Varieties in relation to frost injury

Soil conditions and frost

Fall cultivation 
Frost Considerations, continued

Protection against frost damages 334-344

Wrapping

Banking with earth for frost-protection

Protecting by fires

Wood-fires

Oil-heaters for frost-protection

339-342

Coke-heaters

342-343

Lighting torch

344

Walls, windbreaks, and water for frost-protection

$344-345$

\section{CHAP'TER XXV}

Pruning Citrus Trees . 346-362

High versus low-headed trees $346-347$

Pruning newly-planted and young trees $347-349$

Pruning older trees 349-350

Pruning frozen trees

350-353

Wiring sprouts from frozen trees . . . . . . . . . . . . . 353-354

Pruning neglected trees

$354-355$

Pruning for insect treatment and sun-protection

$355-356$

Pruning in relation to die-back

Pruning for other diseases

$356-357$

Wound-protection

$357-359$

When to prune

359

Pruning tools . . . . . . . . . . . . . . . . . . . 359-361

Disposal of prunings

361-362

\section{CHAPTER XXVI}

Pot Culture of Citrus Fruits $\ldots \ldots \ldots 368$

Pruning pot plants . . . . . . . . $\quad 366$

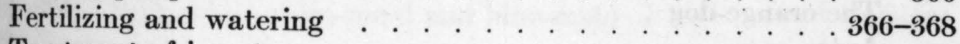

Treatment of insects . . . . . . . . . . . . . . . . 368

\section{CHAPTER XXVII}

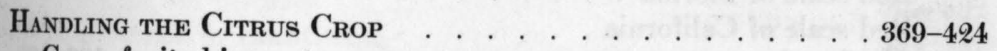

Green fruit shipments . . . . . . . . . . . . 374-378

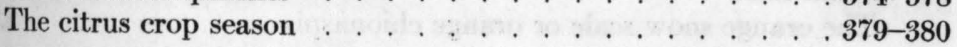


Handling the Citrus Crop, continued

Picking citrus fruits 381-389

Picking equipment

381-385

Injuries to fruit due to picking $385-388$

Filling the field-boxes

Hauling

Weather conditions

Packing the fruit

Packing-houses

390-392

Delivery of fruit 392

Washing

392-393

Drying

Grading

393-398

Sizers

398-399

Citrus packages

399-402

Paper for wrapping fruits

402

Packing conveniences

Packing the fruit

Marking the boxes

408-409

Grading and packing lemons

409-411

Coloring citrus fruits

411-414

Pre-cooling and refrigeration

Loading

Marketing citrus fruits

416-424

Methods of selling

\section{CHAPTER XXVIII}

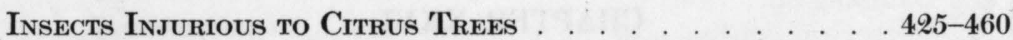

Biting insects . . . . . . . . . . . . . . 426-431

Grasshoppers and katydids . . . . . . . . . . . . . 426-428

The orange-dog . . . . . . . . . . . . . . . . . . . 428-431

Ants . . . . . . . . . . . . . 431

Armored scales . . . . . . . . . . . . . . . . . . . . . . . 432-437

The purple scale . . . . . . . . . . . . . . . .432-434

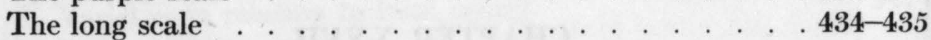

Red scale of Florida . . . . . . . . . . . . . . . . . . . 435-436

Red scale of California . . . . . . . . . . . . . . . . . 436

Chaff scale . . . . . . . . . . . . . . . . . . 436-437

The orange snow scale or orange chionaspis . . . . . . . 437 
Insects Injurious to Citrus Trees, continued

PAGES

Unarmored scales

$437-446$

The turtle-back scale

$437-438$

The black scale

438-439

The hemispherical scale

439

The wax or white scale

439-441

The barnacle scale

441-442

The cottony cushion scale

442-444

The mealy-bug

444-446

Sucking insects other than scales

446-460

The common citrus whitefly

446-449

Cloudy-winged whitefly

449-450

Woolly whitefly

450-452

Citrus aphis

$452-453$

Orange rust mite and lemon silver mite

454-455

The six-spotted mite

$455-457$

Purple mite or red-spider

Thrips

457-458

Pumpkin-bug .

459-460

\section{CHAPTER XXIX}

Citrus Diseases .

461-502

Fungous diseases

461-486

Foot-rot or mal-di-goma

462-466

Scaly bark

466-469

Gum diseases

469-471

Damping-off

471-472

Wither-tip, anthracnose, bloom-blight, leaf-spot

472-475

Citrus scab

$476-480$

Melanose, stem-end rot

$480-483$

Ripe fruit rots - green-mold and blue-mold

483-484

Sooty-mold .

$485-486$

Bacterial diseases

486-493

Citrus canker .

487-491

Black-pit, citrus blast

491-493

Physiological diseases

493-502

Die-back or exanthema

494-497

Frenching, or mottled leaf

500-502

Disease resistance of citrus

502 
Spraying, Dusting, Fumigating

Insecticidal sprays

Wound disinfectants . . . . . . . . . . . . . . . . . . . . . . . 516-518

Dusting

Tents $522-523$

Poles, derricks, and tackle 523-524

Gas generators $524-527$

Dosage tables 527-530

How to measure the trees 530

Strengths of gas

Fumigation practice $532-534$

Climatic conditions

\section{CHAPTER XXXI}

Fungous and Insect Friends . . . . . . . . . . . . . . . . . . . 535-546

The entomogenous fungi . . . . . . . . . . . . . . . . . 537-544

The red fungus . . . . . . . . . . . . . . . . . . . $538-539$

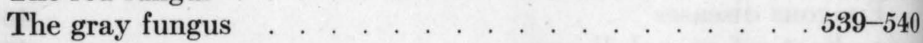

The black fungus . . . . . . . . . . . . . . . . . . . 540-541

The red Aschersonia . . . . . . . . . . . . . . . . . . . 541-542

The brown fungus . . . . . . . . . . . . . . . . . . 542-543

The Entomopthora fungus . . . . . . . . . . . . . . 543-544

Beneficial insects . . . . . . . . . . . . . . . . .544-546 


\section{LIST OF ILLUSTRATIONS}

FIGURE

1. The grapefruit picker

2. Harvesting the orange crop

PAGE

3. Citrus districts of the United States _ . . . . . . . . 7

4. Large old orange tree . . . . . . . . . . . . . . . . . . . . . . . 11

5. Poncirus fruit . . . . . . . . . . . . . . . . . .

6. Poncirus leaf 15

7. Fortunella margarita . . . . . . . . . . . . . . . . . . . . . . . 16

8. Fortunella margarita . . . . . . . . . . . . . . . . . . . . . . . . . . . . . . 16

9. Fortunella japonica . . . . . . . . . . . . . . . . . . . . . . . 16

10. Fortunella japonica

11. Fortunella crassifolia _ . . . . . . . . . . . . . . 17

12. Fortunella crassifolia _ . . . . . . . . . . . . . . . 17

13. Fortunella Hindsii . . . . . . . . . . . . . . . . . . . . . . . . 17

14. Citrus medica . . . . . . . . . . . . . . . . 19

15. Citrus medica .

16. Citrus Limonia

17. Citrus Limonia

18. Citrus aurantifolia . . . . . . . . . . . . . . . . . . . . . . . 19

19. Citrus aurantifolia

20. Citrus maxima

21. Citrus paradisi

22. Citrus paradisi

23. Citrus Aurantium . . . . . . . . . . . . . . . . . . . . . . . . . . . . . . 21

24. Citrus Aurantium …

25. Citrus sinensis . . . . . . . . . . . . . . 22

26. Citrus sinensis . . . . . . . . . . . . . . . . . . . . . 23

27. Citrus sinensis . . . . . . . . . . . . . . . . . . . . 23

28. Citrus nobilis

29. Citrus nobilis . . . . . . . . . . . . . . . . . . . 23

30. Citrus nobilis var. deliciosa . . . . . . . . . 24

31. Citrus nobilis var. deliciosa. . $_{2}$. . . . . . . . . . . . . . . . . . . . . . . 24

32. Citrus nobilis var. Unshiu . . . . . . . . . . . . . . . . . . . . . . . . . 24

33. Citrus nobilis var. Unshiu . . . . . . . . . . . . . . . . . . 24

34. Citrus mitis . . . . . . . . . . . . . . . . . . . 25

35. Citrus mitis

36. Citrus ichangensis . . . . . . . . . . . . . 25

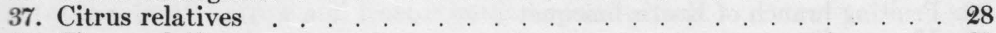

38. Citrus relatives

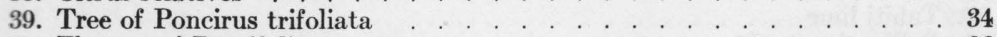

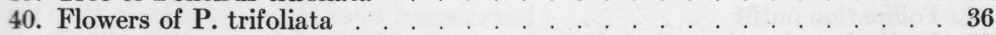

41. Fruiting branch of P. trifoliata _. . . . . . . . . . . . . . . . . 37

42. Rusk citrange tree . . . . . . . . . . . . . . . . . . . . . . . . 38

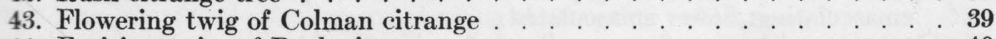

44. Fruiting twigs of Rusk citrange . . . . . . . . . . . . . . . . . . . . . . 40

45. Thomasville citrangequat . . . . . . . . . . . . . . . . . . . . . . 41

46. Leaves and fruit of the sour orange . . . . . . . . . . . . . . . . 44

47. A sour orange grove near Cordoba, Spain _ . . . . . . . . . . . . . . . . 46

48. Flowers of the sweet orange . . . . . . . . . . . . . . . . . . . . . 49

(xvii) 
FIGURE

49. A sweet orange tree, more than 250 years old, in a grove near Cordoba, Spain

50. A Pineapple orange tree in full bearing

51. Parson Brown orange . . . . . . . . . . . . . . . . . . . . . . . 61

52. Fruiting branches of Pineapple orange . . . . . . . . . . . . . . 66

53. Valencia oranges . . . . . . . . . . . . . . . . . . 68

54. Fruiting twigs of Ruby orange . . . . . . . . . . . . . . 70

55. Bahia navel oranges

56. Flowers of Owari Satsuma orange . . . . . . . . . . . . . 75

57. A bearing tree of Dancy tangerine . . . . . . . . . . . . . . . 76

58. Tree of Temple orange from which propagation was started $. \quad . \quad . \quad 78$

59. G. L. Taber examining the fruit of Owari Satsuma . . . . . . . . . . 80

60. Dancy tangerine . . . . . . . . . . . . . . . . . . . . . 83

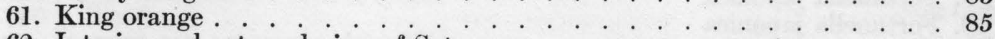

62. Interior and external view of Satsuma

63. The Temple orange

64. Inside of grapefruit tree showing how the fruit is borne 92

65. Flowering twig of Marsh pomelo . . . . . . . . . . . . . . 94

66. The famous large grapefruit tree in the Davy grove, Pinellas County, Fla. . 96

67. Duncan, one of the finest Florida grapefruits . . . . . . . . . 100

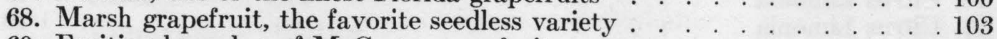

69. Fruiting branches of McCarty grapefruit . . . . . . . . . . . 104

70. Tresca shaddock

71. Cross-section of Pink shaddock . . . . . . . . . . . . . . 111

72. Flowering branches of Nagami kumquat

73. Nagami kumquat tree

74. Marumi kumquat fruit $\quad . \quad \ldots$

75. Meiwa kumquat .

76. Fruiting branches of Nagami kumquat .

77. Fruit of the citron of commerce . . . . . . . . . . . 120

78. Fruit of seedling Etrog grown in Florida

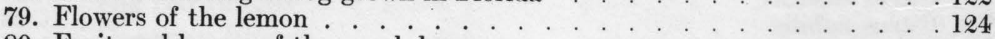

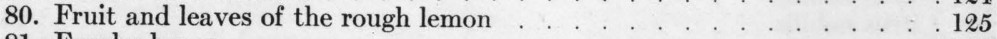

81. Eureka lemon . . . . . . . . . . . . . . . . . 126

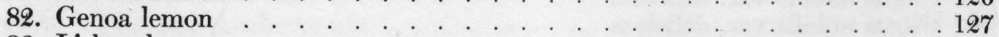

83. Lisbon lemon

84. Villafranca lemon

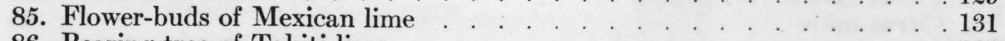

86. Bearing tree of Tahiti lime . . . . . 132

87. Calamondin fruit

88. Fruiting branch of Eustis limequat . . . . . . . . . . 135

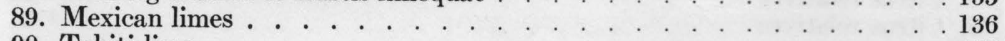

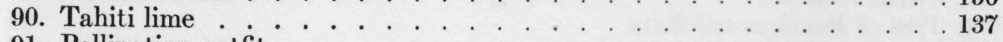

91. Pollination outfit . . . . . . . . . . . . . . . 141

92. Vertical section through a citrus flower . . . . . 144

93. Open citrus flower, showing petals, stamens, and pistil; bud ready for emasculating; flower emasculated . . . . . . . . 146

94. Citrus tree with many flowers pollinated and inclosed in paper sacks . . 148

95. An orange, the result of cross-pollination, inclosed in mosquito net sack for protection

96. An illustration of polyembryony $\quad 159$

97. An exhibit of citrus fruits

98. Seeds of citrus used as stocks _. . . . . . . . . . . . . . 161 
FIGURE

PAGE

99. Citrus seed-bed grown in the open . . . . . . . . . . . . 164

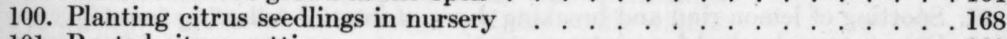

101. Rooted citrus cutting . . . . . . . . . . . . . . . . . . . . . . . . . . . . 169

102. Rooted lemon leaf . . . . . . . . . . . . . . . . 170

103. Citrus bud-sticks . . . . . . . . . . . . . . . . . . . . 171

104. Making budding cloth . . . . . . . . . . . . . 177

105. Two types of budding-knives . . . . . . . . . . . . 179

106. Budder and tier at work in a nursery row . . . . . . . . . . . . 180

107. Budding citrus trees . . . . . . . . . . . . . . . . . . . . . . . . . 183

108. Budding citrus trees . . . . . . . . . . . . . . 185

109. Right-angled budding . . . . . . . . . . . . . . . . 186

110. A box of citrus trees, ready for shipment as soon as the tops are covered with burlap . . . . . . . . . . . . . 187

111. Stake-trained citrus trees in nursery row . . . . . . . . . 188

112. Budding with curved incision . . . . . 190

113. Cleft-grafting . . . . . . . . . . . . . . 192

114. Whip-grafting . . . . . . . . . . . . . . . . . 193

115. Crown-grafting . . . . . . . . . . . . . . . 193

116. Side-grafting . . . . . . . . . . . . 194

117. Inarching . . . . . . . . . . . . . . . . . 194

118. Tree with three sprouts from base inarched in trunk above . . . 195

119. Citrus tree stocks

120. Root system of trifoliate orange . . . . . . . . . . . . . . . 207

121. Union of orange and Poncirus . . . . . . . . . . . 209

122. Citrus grove on high pine land in Florida . . . . . . . . . . 216

123. Citrus groves on a lake shore . . . . . . . . . . . . . . . . . 222

124. A windbreak of bamboo

125. Triangular system of planting . . . . . . . . . . . . . . . . . . . . . . . 231

126. Rectangular planting system . . . . . . . . . . . . . . . . . 232

127. Planting in hexagons . . . . . . . . . . . . . . . . 233

128. Quincunx system of planting . . . . . . . . . . . . . . . . . . . 234

129. Float for smoothing land . . . . . . . . . . . . . . . . . . . . . 236

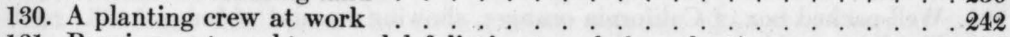

131. Pruning roots and tops and defoliating trees before planting $\quad . \quad .247$

132 The planting-board in use . . . . . . . . . . . . 249

133. Pruning roots and tops of a one-year citrus tree for planting $\quad . \quad 250$

134. Pruning indicated by cross lines for a two-year citrus tree . . . . . . 251

135. Zigzag cultivation of a six-year-old orange grove . . . . . . . . . . . 254

136. Cultivating with a tractor-drawn disc harrow . . . 262

137. Tree-rows cultivated, center producing a cover-crop $\quad . \quad . \quad . \quad . \quad 264$

138. Spring-tooth harrow and tractor outfit for cultivating $\quad . \quad . \quad . \quad 267$

139. Beggarweed cover-crop in an orange grove . . . . . . . . . . . . 270

140. Velvet bean . . . . . . . . . . . . . . . . 273

141. Root system and nodules of beggarweed 276

142. Crotalaria striata cover-crop in young orange grove .277

143. Flowers, leaves, pods, and root system showing nodules of Crotalaria striata 279

144. A well-fertilized citrus grove, showing clean spring cultivation . . . . 281

145. Distributing fertilizer by hand . . . . . . . . . . . 301

146. Diagram showing origin of artesian wells 310

147. Distributing water in furrows

148. The check system of irrigation, two trees in a check .314

149. Disastrous results from a freeze . . . . . . . . . . . . . . . . 319

150. The sling psychrometer . . . . . . . . . . . . . . . . . 323 
FIGURE

PAGE

151. Section of frozen orange showing hesperidin crystals _. . . . . . . 333

152. Spotting of lemon rind and breaking down of interior following freezing . 334

153. Orange trees banked for winter protection . . . . . . . . 336

154. Piles of wood for firing citrus grove $\quad . \quad$. . . . . . . . . . . . . . . . . . . 338

155. A high-stack oil-heater . . . . . . . . . . . . . . . . . . . . . 340

156. The can-heater . . . . . . . . . . . 341

157. Protecting citrus trees with high-stack heaters in California $\quad .341$

158. The Skinner coke-heater . . . . . . . . . . . . . 342

159. Coke-heaters in use in a Florida citrus planting . . . . . . . . . . . 343

160. Torch for lighting fires . . . . . . . . . . . . . . . . . . . . . 344

161. A low-headed citrus tree . . . . . . . . . . . . . . . . . . 346

162. Well-headed young tree .

163. Cutting to remove a branch without splitting the trunk $\quad . \quad . \quad . \quad 349$

164. A frozen orange grove . . . . . . . . . . . . . . . . . . . . . . 351

165. The healing of a well-made wound on a citrus tree . . . . . 358

166. Curved blade pruning saw . . . . . . . . . . . . . . . . . . . . . 360

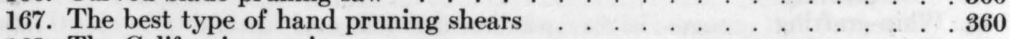

168. The California pruning saw . . . . . . . . . . . . . . . . . . . . 361

169. Pot-grown kumquat in flower . . . . . . . . . . . . . . . . . . . . 364

170. Tub-grown orange in fruit . . . . . . . . . . . . . . 367

171. The Florida citrus box, bulge packed, with grapefruit . . . . . . . . . 371

172. Different types of clippers . . . . . . . . . . . . . . . . . . . 382

173. The proper way to empty a picking-sack

174. A modern citrus packing-house with executive office at right $\quad . \quad . \quad 389$

175. The interior of an up-to-date packing-house showing a battery of sizers and other equipment . . . . . . . . . . . . . . . . . . . 390

176. A citrus fruit-washing machine

177. Grading-belt and graders at work . . . . . . . . . . . . . . . . . . . 394

178. United States grades for Florida citrus . . . . . . . . . . . . . . . . . . . . . . 396

179. A citrus box-making machine in operation . . . . . . . . . . . . . . 401

180. Citrus fruit-packer at work . . . . . . . . . . . . . . . 403

181. Florida citrus fruit-packing diagrams . . . . . . . . . 405

182. Well-packed box of California oranges, showing amount of bulge . . . 408

183. Heading machine or press in use . ... . . . . . . . . . . . . . . . . . 409

184. Trucking fruit to refrigerator car . . . . . . . . . . . . . . 416

185. Condition of improperly loaded and braced car on arrival in market . . 417

186. Interior of well-loaded car on arrival at destination . . . . . . 417

187. Selling citrus fruit by box from grocery . . . . . . . . . . . . . . 421

188. The street-corner fruit-stand . . . . . . . . . . . . . . . . . . . .422

189. The push-cart market . . . . . . . . . . . . . . . . . 423

190. The lubberly grasshopper eating citrus leaves

191. Katydid injury to an orange

192. Eggs of the broad-winged katydid on the margin of an orange leaf . . . 428

193. The orange-dog; larva, larva preparing to pupate, pupa, the butterfly which has just issued from the pupa case above it . . . . . . . 429

194. The purple scale on citrus twig and leaf

195. Long scale infested leaf and twig . . . . . . . . . . . . . . . . . . . 435

196. The Florida red scale . _. . . . . . . . . . . . . . . . . . . . 436

197. Chaff scale on citrus twig . . . . . . . . . . . . . . . . . . . 437

198. A heavy infestation of orange snow scale . . . . . . . . . . 438

199. The wax scale .

200. A colony of cottony cushion scale . . . . . . . . . . . . . . . . . . . . . . . . 442

201. Mealy-bug on lemon fruit and leaf . . . . . . . . . . . 445 
FIGURE

202. Whitefly adults and pupa on under side of citrus leaf . . . . . . . . 447

203. Eggs and larvæ, in two stages, of the woolly whitefly

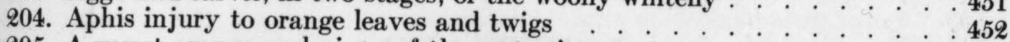

205. A russet orange and views of the rust mite . . . . . . . . . . . . . . 454

206. Scars of irregular shape caused by thrips . . . . . 458

207. Left, citrus tree affected by foot-rot. Right, soil excavated for treatment and aëration . . . . . . . . 463

208. Citrus tree attacked by foot-rot. An inarched sprout at the left 465

209. Scaly bark on orange twigs and fruit ....... . . . . . . . . . 467

210. Citrus branches affected by gum disease . . . . . . . . . 469

211. Grapefruit decayed by Diplodia stem-end rot . . . . . 470

212. Anthracnose on pomelo fruit and leaf .

213. Citrus scab on sour orange and twigs, Satsuma fruit, and pomelo fruit and leaves . . . . . . . . . . . . . . .

214. Two fruits at left showing melanose spotting. Fruit at right with melanose stem-end rot. Above, leaf attacked by melanose . . . . . . . 482

215. Blue-mold on orange. Right, germinating blue-mold spores . . . . . . . 484

216. Sooty-mold fungus . . . . . . . . . . . 485

217. Citrus twigs, fruits and leaf attacked by canker

218. Diseased tree, multiple buds, and distorted twigs caused by die-back . . . 494

219. Ammoniated and split oranges caused by die-back . . . . . . . . 496

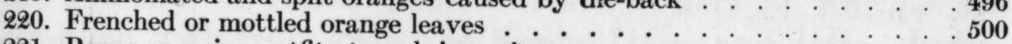

221. Power spraying outfit at work in a citrus grove

222. Orange fruit injured by spraying with too strong a mixture . . . . . 508

223. Power dusting for rust mite . . . 519

224. Citrus trees covered with tents for fumigation $\quad .520$

225. Fumigation tent marked, a tent over a tree showing marks, and tapemeasure drawn around tent for calculating dosage . . . . 523 226. Cart outfit for handling cyanide, acid, and water used in generating gas by
the "pot method"

227. Machine for generating hydrocyanic-acid gas $\quad . \quad 525$

228. Pump for using liquid gas . . . 526

229. Placing a small-sized tent over a citrus tree and measuring the tent dosage ................ 532

230. Covering a large citrus tree with a tent by means of derricks $\quad . \quad 533$

231. The gray fungus

232. Fruiting bodies of gray fungus on purple scale on orange twig $\quad . \quad 540$

233. Crust-like bodies of the black fungus on chaff scale

234. A culture of red Aschersonia grown in a bottle of sterilized sweet potato . 542

235. Red Aschersonia and brown fungus on whitefly pupæ on under side of

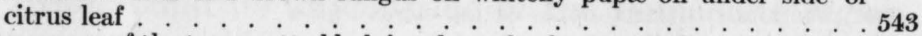

236. Pupa cases of the two-spotted ladybeetle on dead orange twig . . . . 545

237. Five ladybeetle friends ............... . . . . . 546 


\section{The Cultivation of Citrus Fruits}

\section{CHAPTER I}

\section{THE COMMERCIAL IMPORTANCE OF CITRUS FRUITS}

China has contributed many plants to the gardens and orchards of the world, and of these none is more important than the Citrus group. That the different species of Citrus had their native home in Cochin-China and adjacent sections of China proper is fairly well established. At this time they have been introduced and their growth attempted in almost every part of the world which offers any chance for their success. In Australia and South Africa considerable areas are planted in citrus fruits. The markets of Europe are supplied with fruit grown in Spain, Italy, and Jaffa. India, China, and Japan have important citrus industries, the fruit being consumed in the same general regions. Introduced into the American continents, citrus fruits soon found in Brazil and other parts of South America, in the West Indies, and in the southern United States, a congenial home where their cultivation has become important.

For many years citrus fruits were grown in the United States to a limited extent. Only in localities easily reached by water was production attempted on a commercial scale. Even with this means of transportation, the methods of growing and handling the product were so crude that little of the fruit found its way outside of the immediate region.

The oranges and lemons used in America in the early days were mostly imported from abroad. They came largely from the regions of the Mediterranean, and, even within very recent years, nearly all the lemons were brought from Italy. Large importations of citrus fruits are still made, but these have by no means kept pace with the increase in population. It is safe to say that had it not been for the very large increase in citrus-fruit production in the United States during 
the last two decades, oranges, grapefruit, and lemons would now be a luxury, and a large part of the population would have to do without these wholesome and healthful fruits. The cultivation of citrus fruits in America has extended until, at the present time, by far the greater portion of the product consumed in the country is grown at home.

The development of the lemon industry in California has been noteworthy, and the place secured in the markets by the Florida pomelo, which until 1880 or 1885 was almost unknown in the fruit trade and then only in a very limited way in a few of the larger cities, is equally important. The production on a large commercial scale of these two fruits is among the most interesting of American horticultural achievements during the last thirty-five years.

The following statistics show graphically the development of the industry. These figures do not cover all the fruit produced either in Florida or in California, as no account has been taken of the fruit consumed locally in either area.

Table I. Total Citrus Crop Movement as Reported by Railroads in Boxes

\begin{tabular}{|c|c|c|c|c|c|c|c|}
\hline \multicolumn{2}{|l|}{ Season } & Florida & \multirow{2}{*}{$\begin{array}{r}\text { California } \\
840,560\end{array}$} & \multicolumn{2}{|c|}{ Season } & Florida & \\
\hline $1886-87$ & & $1,260,000$ & & $1905-06$ & . & $3,794,133$ & $10,155,542$ \\
\hline $1887-88$ & & $1,450,000$ & 957,600 & 1906-07 & & $3,801,101$ & $11,388,029$ \\
\hline $1888-89$ & & $1,950,000$ & $1,067,040$ & $1907-08$ & & $3,250,000$ & $12,327,944$ \\
\hline $1889-90$ & & $2,150,000$ & $1,333,800$ & $1908-09$ & & $4,634,000$ & $15,460,912$ \\
\hline $1890-91$ & & $2,450,000$ & $1,541,280$ & $1909-10$ & & $6,100,000$ & $12,815,272$ \\
\hline $1891-92$ & & $2,713,180$ & $1,691,760$ & $1910-11$ & . & $4,600,000$ & $17,960,544$ \\
\hline 1892-93 & & $3,450,000$ & $2,255,680$ & 1911-12 & 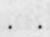 & $4,750,000$ & $15,827,162$ \\
\hline 1893-94 & & $5,055,367$ & 2,230, & $1912-13$ & & $8,125,000$ & $7,212,996$ \\
\hline 1894-95 & & $2,808,187$ & 360 & $1913-14$ & ${ }^{\circ}$ & $7,946,926$ & $19,160,724$ \\
\hline $1895-96$ & & 147,000 & 500 & $1914-15$ & ${ }^{\circ}$ & $9,700,000$ & $18,458,880$ \\
\hline 1896-97 & & 218,379 & 000 & $1915-16$ & . & $8,370,000$ & $18,203,114$ \\
\hline $1897-58$ & & 358,966 & 5,7 & $1916-17$ & & $7,649,049$ & $23,192,722$ \\
\hline $8-59$ & & 252,000 & $3,933,380$ & $1917-18$ & & $5,581,309$ & $10,355,733$ \\
\hline $1899-00$ & & 274,000 & $6,767,420$ & 1918-19 & & $8,407,680$ & $22,092,184$ \\
\hline $1900-01$ & & 352,600 & $9,156,860$ & $1919-20$ & & $12,495,925$ & $20,408,582$ \\
\hline $1901-02$ & & 974,033 & $7,747,060$ & $1920-21$ & & $12,109,320$ & $26,838,776$ \\
\hline $1902-03$ & ${ }^{\circ}$ & $1,147,491$ & $8,921,220$ & $1921-22$ & & $11,888,280$ & $16,981,129$ \\
\hline 1903-04 & . & $1,954,954$ & $11,114,656$ & $1922-23$ & T & $16,886,701$ & $23,409,887$ \\
\hline $1904-05$ & $0^{\circ}$ & $2,961,192$ & $11,559,542$ & $1923-24$ & & $20,399,614$ & $24,292,800$ \\
\hline
\end{tabular}




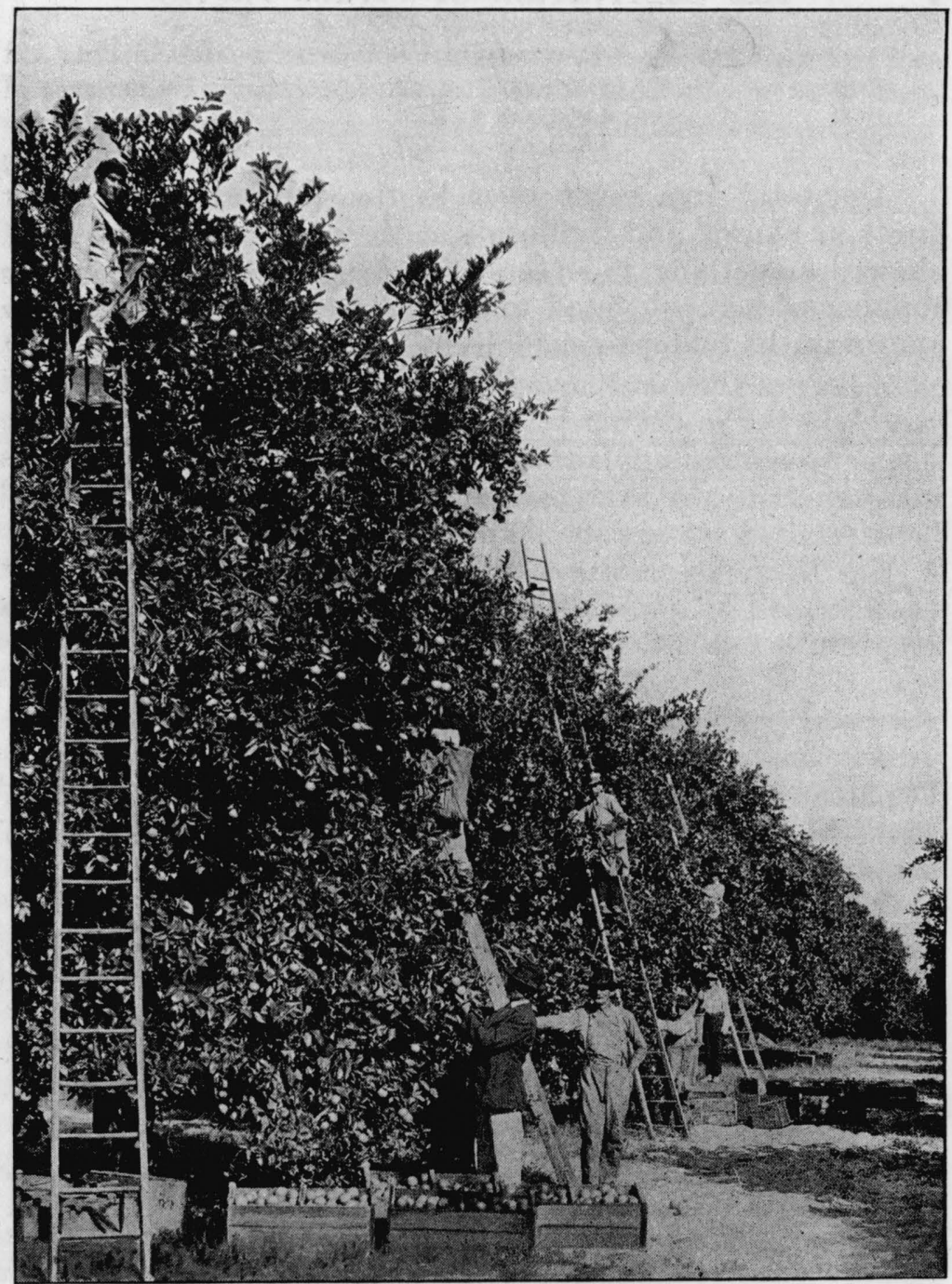

Fig. 2. Harvesting the orange crop

(3) 
Table II. California lemon Crop in Boxes

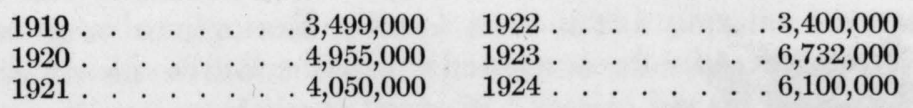

The total area given over to the cultivation of citrus fruits in Florida and California at the close of the year 1923 showed something in excess of a half million acres. The number of acres devoted to the different kinds of fruits is shown in the following exhibit.

Table III. Florida Citrus Acreage. December 31, 1923

\begin{tabular}{|c|c|c|c|}
\hline Variety & Bearing & Non-Bearing & Total \\
\hline $\begin{array}{l}\text { Oranges } \\
\text { Grapefruit } \\
\text { Tangerines } \\
\text { Lemons }\end{array}$ & $\begin{array}{r}106,626 \\
49,413 \\
6,151 \\
960 \\
1,798 \\
103\end{array}$ & $\begin{array}{r}57,337 \\
26,624 \\
3,430 \\
259 \\
798 \\
71\end{array}$ & $\begin{array}{r}163,963 \\
75,037 \\
9,581 \\
1,219 \\
2,596 \\
174\end{array}$ \\
\hline & 165,051 & 88,519 & 252,570 \\
\hline
\end{tabular}

A census of citrus trees in Florida, given out by the State Department of Agriculture, Tallahassee, September 11, 1925, gave the following information on the number of trees in the state.

Table IV. Florida Citrus Acreage. September 11, 1925

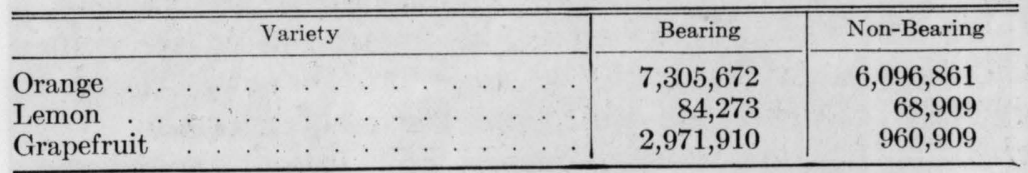

Table V. California Citrus Acreage. December 31, 1923

\begin{tabular}{|c|c|c|c|c|}
\hline 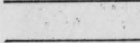 & Variety & Bearing & Non-Bearing & Total \\
\hline $\begin{array}{l}\text { Oranges } \\
\text { Grapefruit } \\
\text { Lemons }\end{array}$ & 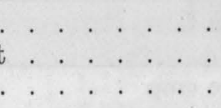 & $\begin{array}{r}190,153 \\
4,237 \\
48,627\end{array}$ & $\begin{array}{r}15,002 \\
2,972 \\
7,712\end{array}$ & $\begin{array}{r}205,155 \\
7,209 \\
56,339\end{array}$ \\
\hline & & 243,017 & 25,686 & 268,703 \\
\hline
\end{tabular}


In Arizona some citrus fruit is produced, and more or less is grown all round the Gulf Coast. Recently a very considerable area has been opened up in the Rio Grande Valley of Texas.

As the industry has grown in years, it has reached a higher stage of development along all lines. The methods of combating insects and fungous diseases, of tillage, fertilizing, irrigating, frost-protection, handling and marketing the crops, are far in advance of those of ten to fifteen years ago. Much still remains to be learned, and never, so long as the fruit is produced, will the last chapter be read, the book closed. But the fact remains that the grower of citrus fruits has now more useful knowledge at his disposal than ever before, and the chances for his success are better. New problems have arisen, but these have been solved in such a way as to lead the student of the situation to believe that any emergency which may arise will be met and dealt with successfully.

In growing citrus fruits, as in any other industry in which a man may engage, the individual himself is the most potent factor in the success of the enterprise. The personal element is most important in determining the difference between profit and loss. The successful grower must bring to his work a thorough knowledge of every phase of the industry, backed by a fixed determination to succeed in spite of all difficulties. In no line of fruit-growing is this so true as in the genus Citrus. The bringing of the trees into bearing, the production of high-grade fruit, and the placing of the citrus grove on a paying basis demands skill, insight, knowledge, close observation, and attention to details such as are not commonly required in the growing of many other fruits.

Two things have contributed greatly to the commercial success of citrus fruit-growing in America and have exercised a very important influence on the financial returns. These are the establishment of cooperative marketing agencies, first the California Fruit Exchange and later the Florida 
Citrus Exchange, and the investigations conducted under the direction of the United States Department of Agriculture into the causes of decay in harvesting and forwarding the crop to market. It would be difficult to overestimate the value of these agencies and investigations to the industry.

There has been an apparent over-supply of citrus fruits in American markets in recent years. This in reality is not the case. The crop of 1923-24, for example, totaled $44,692,414$ boxes of all kinds of citrus fruits, and the prices received did not, in many instances, cover the cost of production. The crop was poorly distributed, many markets were undersupplied, or supplied not at all; many others were overstocked. There was great competition among shippers themselves which should have been eliminated by cooperative distribution, and much of the product was of such poor quality that it should never have been shipped.

Not all American markets have been supplied adequately, and into many the pomelo, either fresh or canned, has not yet penetrated. The great northwestern portion of the continent, across the Canadian line, is being populated rapidly, and there will be new markets for years to come, both in the United States and Canada. The people of the American continent are fruit-consuming and have the means at their disposal for satisfying their tastes. The Volstead Act has greatly increased the consumption of juicy fruits and fruit juices, and the citrus-fruit market has been greatly augmented thereby.

On the whole, the growing of citrus fruits offers as good inducements for honest effort as any branch of horticultural work in which a man may engage.

\section{CITRUS AREAS OF THE UNITED STATES}

The largest citrus-fruit producing sections in the United States are in Florida and California. There are secondary areas in southeastern Texas, Arizona, and southern Alabama. Southern Louisiana and Mississippi plant small acreages of 
citrus fruits, and they are grown as a home product along the Atlantic Coast and the adjoining islands in Georgia and South Carolina.

\section{Florida.}

In Florida, the earlier citrus groves were planted along the Indian River, the St. Johns River, on the Gulf Coast, and in the more northerly counties, usually at points easily reached by water transportation. Some of the first plantings were at Mandarin, Saint Augustine, Daytona, New Smyrna, Palatka, Sanford, St. George's Island, and in Pinellas and Marion counties. With the advent of the railroad, isolated sections and those farther south were opened up. By 1894 the crop had reached large volume, but the two freezes of 1894-95 and 1899 gave further impetus to this southward movement. Many of the more northerly sections were abandoned entirely after these freezes. Now, by far the greatest portion of the Florida citrus crop is produced below the middle of the state. Polk, DeSoto, Manatee, Hillsborough,

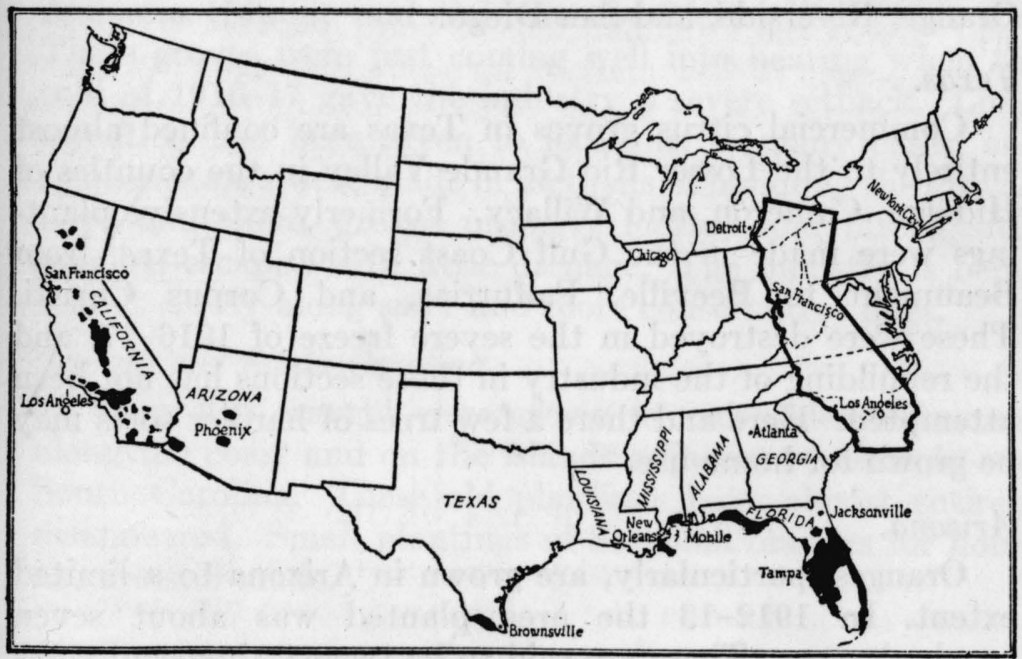

FIg. 3. Citrus districts (shaded) of the United States. Outline of California is placed on the eastern states to show location longitudinally 
and Pinellas counties are very heavy fruit-producing centers. Since the Florida citrus industry is still expanding, there may be a further shift in the center of production. In northern and western Florida, the Satsuma orange is attracting attention because of its superior quality and early ripening habit. Plantings of considerable extent are being made.

California.

Citrus fruits are grown in California, here and there, almost throughout the entire length of the state. This is the more remarkable when note is made of the fact that the southern boundary of California is about the latitude of Charleston, South Carolina, and the northern about Detroit, Michigan. There are groves all the way from San Diego County in the south to Shasta County in the north. The topography of the state, the mountain barrier along the north and east, and the proximity to the Pacific make this possible. The largest areas are in the southern part in the counties of Tulare, Ventura, Los Angeles, San Bernardino, Orange, Riverside, and San Diego.

Texas.

Commercial citrus groves in Texas are confined almost entirely to the Lower Rio Grande Valley in the counties of Hidalgo, Cameron, and Willacy. Formerly extensive plantings were made in the Gulf Coast section of Texas, from Beaumont to Beeville, Falfurrias, and Corpus Christi. These were destroyed in the severe freeze of 1916-17, and the rebuilding of the industry in those sections has not been attempted. Here and there a few trees of hardier sorts may be grown for home use.

Arizona.

Oranges, particularly, are grown in Arizona to a limited extent. In 1912-13 the area planted was about seven hundred acres. There are said to be twenty thousand acres suitable for cultivation in the Salt River Valley. 
Louisiana.

For many years oranges have been grown in Louisiana. Their cultivation has been attempted over considerable areas, but at this time it is believed that any further plantings should be along the Mississippi River south of New Orleans. For home or local use hardy varieties on trifoliate orange stock may be planted elsewhere.

Mississippi.

In southern Mississippi, Satsuma oranges, kumquats, calamondins, and limequats may be produced. Small commercial orchards of Satsuma oranges are growing in the vicinity of Gulfport. Only hardy varieties should be planted, and localities chosen that are as free as possible from frosts. A difference of a few feet in elevation is well worth considering.

Alabama.

Satsuma oranges were extensively planted in southern Alabama (Mobile and Baldwin counties) a few years ago. These groves were just coming well into bearing when the cold of 1916-17 gave the industry a severe setback. Little attention had been given to locations in many cases, and some mistakes were made in methods of handling the groves. Here and there, groves properly located and intelligently handled escaped with little damage. The industry is being rebuilt slowly along safer and more conservative lines.

Georgia and South Carolina.

Years ago oranges were grown to a considerable extent along the coast and on the islands adjacent to Georgia and South Carolina. These old plantings have almost entirely disappeared. Small plantings of Satsuma oranges for home use are still made. 


\section{CHAPTER II}

\section{BOTANY OF CITRUS FRUITS AND THEIR RELATIVES}

No more complex problem confronts the systematic pomologist or botanist than the classification of the citrus fruits. This is due not only to the peculiarities of the plants themselves - and they are surely perplexing enough-but the difficulty has been greatly increased by the many attempts made during a period of several centuries to group the numerous varieties and species of Citrus in some sort of orderly arrangement. In truth, it may be said that most of these classifications, instead of elucidating the problems with which they deal, have only made them more complicated.

At the bottom of the whole trouble appears to have been the disposition on the part of many writers on citrus subjects to take the plants, not as they found them growing, but as they imagined or supposed them to have been thousands of years ago. No one, at all intimately acquainted with these fruits, doubts for a moment that in years gone by two or more of the present distinct forms were represented by a single one. Indeed, if the common theory of plant evolution is accepted, and we could trace the various forms of Citrus back far enough, we would arrive at a single plant, or at least at a very limited number of different plants. Variations may have arisen as bud-sports, mutations, or by crosspollination, and these have been perpetuated. It is characteristic of the citrus group that seedlings are produced with very infrequent variations from the specific type, and when variations do arise they are very likely to be perpetuated from one seedling generation to another. This is particularly true of those which have originated from cross-pollination. It is also a fact that cross-pollination does not take place with the same freedom that it does in some other groups of arborescent plants. 
Granted, then, that several forms distinct from one another, as known today, have had a common origin in ages past, what advantage is there in placing the sour orange, sweet orange, pomelo, kumquat, and other distinctly different citrus trees in a conglomerate species, stretching an imaginative description over them, and then placing each of the aforementioned plants as subspecies and varieties of this species, as has been done by some botanists? There is no indication in the plants themselves that the orange and the pomelo: for example, belong to the same species, and

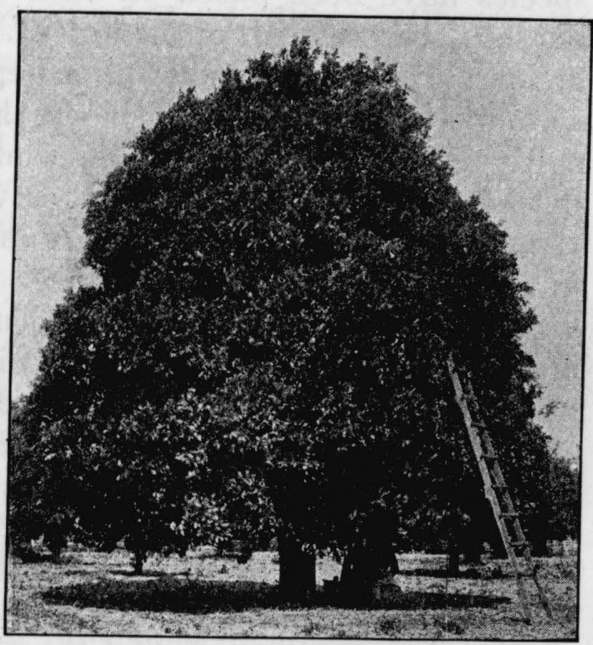

Frg. 4. Large old orange tree although these and other kinds of citrus fruits may exist for centuries upon centuries in the future, even as they have in the past, it is highly improbable that they will merge into one another, or that their specific relationships will be changed or modified. There is nothing to be gained by aggregating the many different forms of Citrus into a single species. This disposition of the problem complicates rather than simplifies it; and the only sensible plan of classification is to take the plants as we find them growing today and to base our descriptions and grouping on them. It may be argued that intermediate forms occur. Certainly they do, and so do intermediate forms occur between many other species of plants in the same genus without affecting their specific standing.

The botanical study of the various kinds of Citrus is 
further involved by the fact that the original, or wild forms have never been discovered by modern botanists, or they do not exist. In most instances the descriptions of the different species have been based on cultivated specimens from the gardens and orchards of the Orient. If the wild forms should be found they would, perhaps, differ in a marked degree from the cultivated ones, and the farther removed in time the cultivated sorts are from the wild ones, the greater these differences are likely to be. It is well known that many of the citrus fruits in which we are interested today have been in cultivation for many centuries. That a certain variety or kind of plant found its way into cultivation may have been, and in all probability was, due to its being different in some noteworthy particular from its relatives. There was something peculiar about it which attracted the attention of the original planter. After the plants were brought into cultivation such variations as arose in different ways were likely to be noticed, and if advantageous to the grower, they were perpetuated by one means or another.

For these reasons some of the cultivated citrus fruits may be far removed from their wild progenitors. But these are not known, and there is no law against establishing a species on a cultivated form. Since classification is a basic necessity, in dealing with these plants in many ways, nothing else can be done than to use the material in hand and base our grouping on it, disregarding for the time the possible existence of older or more primitive types from which present-day Citrus have been derived. If these older forms should be discovered, they may be entitled to specific rank, distinct from their cultivated descendants, or they may have to be classified as varieties of the cultivated species. This alternative is not unknown in systematic botany.

In the last decade, Citrus and related genera of the family Rutaceæ have been the subjects of very careful and searching botanical study by Walter T. Swingle, who has brought together in the greenhouses of the United States Department 
of Agriculture at Washington, D. C., a very large and interesting collection of living plants representing these groups. The results of these studies have been set forth in various publications, as in Sargent's "Plantæ Wilsonianæ" and Bailey's "Standard Cyclopedia of Horticulture." The most noteworthy changes in classification are the separation of the kumquats into different species, placing them in a new genus, Fortunella, named after the noted English plant explorer, Robert Fortune, who brought the first oblong kumquat plants to England in 1846, and the reestablishment of the name Poncirus trifoliata, Raf., for the trifoliate orange. Besides this, the botanical names of several species of Citrus have been changed to conform to the accepted rules of priority, all of which entailed an enormous amount of research work. In dealing with the genus Citrus, Swingle has followed, in a large measure, the suggestion made in 1904 by the author, that the different varieties and subspecies of Citrus should be classified as species. But he has not gone far enough. There is no doubt that the Satsuma orange represents a distinct species, the China mandarin and Dancy tangerine represent another species, and the pomelo is evidently a good species. There is no more reason why pomelos (grapefruit) should be included with the shaddocks or pummelos than that the lemons and limes should be placed with the citrons, as has so often been done. It is true there may be intermediate forms between the pomelos and the pummelos or shaddocks, but up to the present time, apparently, no counterpart of the pomelo as known in America has been discovered in the Orient. In view of these facts, the grapefruit, or pomelo, is here classified as a separate species. Swingle has accomplished an excellent work on the classification of citrus fruits (genera Citrus, Fortunella, and Poncirus) and a further revision or division along the lines indicated would leave little to be desired. Swingle's classification is followed in this work.

These fruits are referred to three genera, Citrus, For- 
tunella, and Poncirus. For many years these have all been placed in the genus Citrus, and the name "citrus fruits" applied to them in American horticulture. It seems best to continue the practice of using this as an English group name.

PONCIRUS, FORTUNELLA, CITRUS, AND THEIR SPECIES

Family Rutaces.-Trees or shrubs, rarely herbs, with aromatic alternate or opposite, usually compound leaves, dotted with translucent glands containing an essential oil: flowers usually in axillary or terminal cymes, though sometimes occurring singly; sepals 4 or 5 , or lacking; petals 4 or 5 , hypogynous or perigynous; stamens as many or twice as many as the petals (in Citrus and Egle more), separate or united, inserted on the receptacle; anthers 2-celled, opening along the inner face, generally versatile; pistils 2 or 5 , or 1 and compound with 2-5 or more carpels, inserted on the more or less elongated receptacle: fruit a capsule, berry, drupe, or samara; seeds oblong or kidney-shaped; embryo straight or curved; endosperm fleshy, sometimes lacking; cotyledons fleshy or foliaceous.-Plants mostly native of tropical and subtropical countries, largely in the Old World. Three genera are of special significance in this book:

Leaves of 3 leaflets, deciduous Poncirus

Leaves usually of 1 leaflet (apparently simple), persistent.

Ovary 3-5- or 6-celled

Fortunella

Ovary 8-celled or more

Citrus

Poncirus (from the French, poncire a kind of citron).Small spiny trees or shrubs with deciduous trifoliolate leaves: flower-buds produced in summer, protected by budscales; flowers nearly sessile, borne on wood of the previous season's growth; petals narrowed and claw-like at the base, opening wide and flat; stamens numerous, free; ovary 6-8celled, the wall at maturity showing orange-yellow elevated cells: fruit finely pubescent; juice-vesicles with hair-like attachments containing an oily sticky aromatic fluid; seeds with 2 cotyledons, and seedlings with spirally arranged bract- 
like rudimentary leaves at first.-One' species, native of North China.

P. trifoliata, Raf. (Citrus trifoliata, Linn.). Trifoliate Orange.A small densely branched tree of rather upright habit, 12-15 feet in height; younger branches smooth, dark green, angled, older ones rounded, thorny, the thorns stout, stiff, sharp, $1-1 \frac{1}{2}$ inches long, flattened at the base: leaves deciduous, trifoliate; leaflets thin, more or less elliptical, crenate, borne singly or in tufts: flowerbuds protected by scales, formed in summer; flowers produced singly or in pairs, axillary, usually appearing before the leaves, but occasionally with or after them; nearly sessile; sepals 5 , light greenish yellow, small, oval, pointed, about $1 / 4$ inch long;

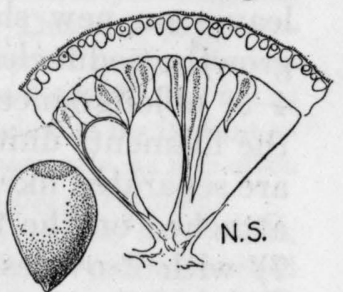

FIg. 5. Poncirus fruit corolla large, white, $11 / 2-13 / 4$ inches across when expanded; petals obovate, claw-like at the base, thin, striated, polypetalous; stamens 21-23,

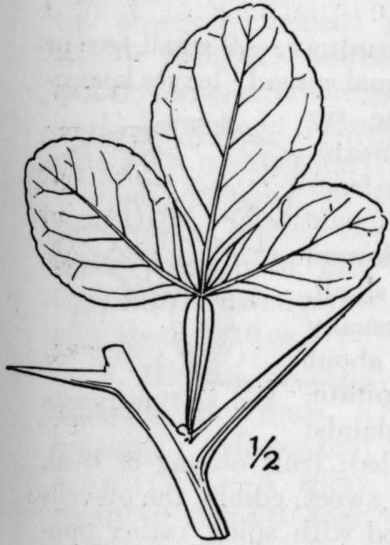

Fig. 6. Poncirus leaf

filaments separate, anthers adnate, oval, 2celled; pistil oblong, club-shaped, hairy, style short; ovary 6-7-loculed: fruit-stems short, stout, persistent for several seasons; fruit light orange, rough, densely covered with short hair; oil of the rind aromatic, sticky; pulp rather sparse, acid; juice-sacs slender, pointed; seeds numerous, oval, rounded at the ends, plump, cotyledons 2, embryo 1 ; time of flowering variable, extending in the citrus districts from the first of March to the middle of April; fruit ripening in September and October; tree very hardy.

Parts of Poncirus, or trifoliate orange, are shown in Figs. 5 and 6. The former is part of a cross-section of fruit showing rind, oil-cells, juice-vesicles, seed, natural size. Fig. 6 shows two thorns and a single leaf, natural size.

Fortunella (after Robert Fortune, noted English horticultural explorer who introduced the kumquat into Europe in 1846). KumQuat.-Small evergreen trees or shrubs, densely branched; branchlets angular or rounded; spines small, axillary, at one side of the bud, or lacking: leaves unifoliolate, blunt-pointed, thick, dark green above, paler 
beneath, thickly dotted with glands on lower surface; petioles narrowly winged, articulated or not articulated with the blade: flowers white, generally smaller than those of Citrus, borne singly in pairs or clusters in the axils of the leaves on new shoots or on shoots of the previous year's growth; peduncles bracted with 1 or 2 small bracts; petals 4-5, oblong-lanceolate; stamens 16-20, irregular in length, the filaments united in a ring except at the tips, where they are separated like teeth for a short distance, with the anthers attached on the teeth; ovary usually 3-6-celled (sometimes 7) with 2 ovules in each cell; stigma capitate, cavernous: fruit small, oblong or globose; rind thick, sweet, edible; juicevesicles small; seeds small, the coats not reticulated; cotyledons greenish, hypogeous.- Species few, native in southeastern China.

F. margarita, Swingle. Nagami or Oval Kumquat.-A small tree or shrub, reaching a height of 10-15 feet, with an equal spread: leaves lanceo-

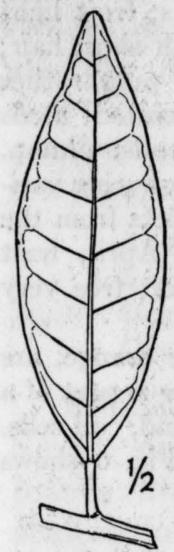

Fig. 7 late, tapering at both ends, the tip rounded or emarginate, base cuneate, margin usually obscurely crenate from center to apex, dark green above, pale beneath: flower-buds angled; flowers white, axillary, single or in clusters, small, those appearing first in spring usually without pistils; style persistent, about the length of the ovary; stigma capitate, cavernous, with deep-seated oil-glands;

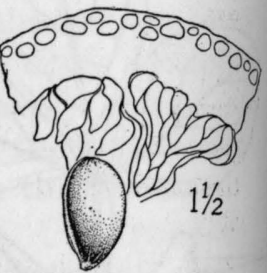

FIG. 8. F. margarita ovary 4-5-celled, each cell 2-ovuled: fruit oblong or oval, orange-yellow; rind thick, fleshy, sweet, edible, the oil-cells found in it very conspicuous, filled with spicy, rather pungent oil; pulp well supplied with fusiform juice-vesicles, containing an agreeable acid juice; seeds usually $3-5$; cotyledons light green.-The Nagami kumquat is a very ornamental species.

F. margarita

F. japonica, Swingle. MARUMI, or Round Kumquat.-A very densely-branched shrub, usually with small, sharp spines: leaves small, bluntpointed, tapered gradually toward the base: flowers small, white, axillary: fruit small, round, deep orange colored, $1 / 2-1 \frac{1}{4}$ inch in diameter; style not persistent; segments

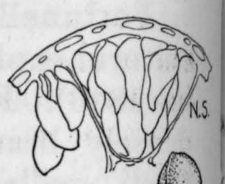

FIg. 9

F. japonica 


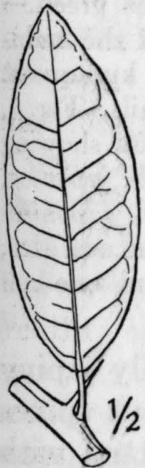

Fig. 10 F. japonica

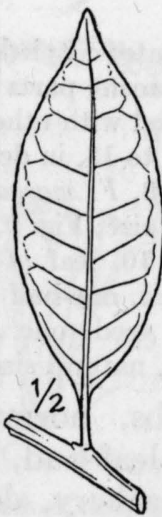

Fig. 11

F. crassifolia

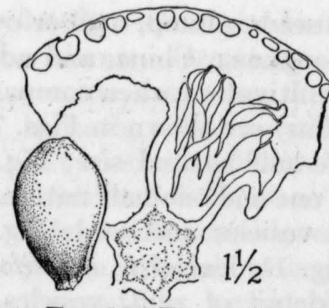

Fig. 12. F. crassifolia

$5-6$, pulp acid, rind sweet, edible; oil-cells in rind very prominent; seeds 3-6, small, oval, blunt, cotyledons green. - This is a very ornamental species of compact growth, but not so valuable for its fruit as margarita, as it is often very variable in size and time of ripening.

F. crassifolia, Swingle (crassi, thick; folia, leaf). Merwa Kumquat. - A much-branched shrub; spines few or none: leaves thick, stiff, curved on the margins which are usually bent upward toward the midrib, abruptly pointed, tapering, rounded toward the base, slightly crenate toward the tip, obscurely veined; petioles articulated or not articulated, slightly winged: flower-buds more or less angled; flowers axillary, single or in pairs, white: fruit ovate or broadly oval, 5-7-celled; juice-sacs few and difficult to dissect out; pulp scant, sweet; rind thick, sweet; seeds few, medium, wrinkled at the tips; cotyledons green.Of Chinese origin, recently introduced into the United States, probably about 1910 or 1912 .

F. Hindsii, Swingle (after R. B. Hinds, a botanist). HoNGKong KUMQUAT.-A spiny shrub or small tree: leaves oval-elliptic, tapering at both ends, dark green above, paler below; petioles winged, not always articulated: flowers short, broad, not opening widely; style cavernous; stigma capitate: fruit small, subglobose, orange-red, sections $3-4$; juice-vesicles

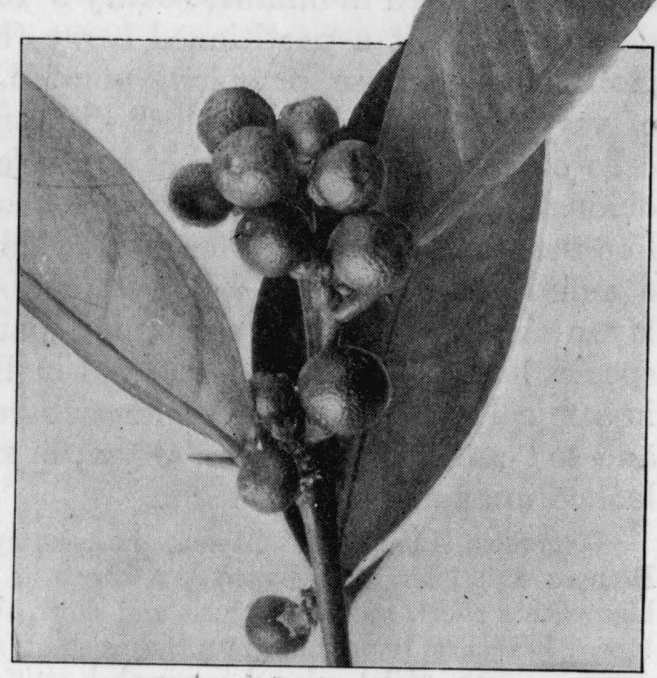

Fıc. 13. Fortunella Hindsii 
few, small; pulp scant; seeds plump, oval or ovate; cotyledons green.Native on hills about Hongkong, China, and adjacent parts of the mainland. Not valuable for cultivation when compared with other kumquats.

Kumquats (Fortunellas) are shown in Figs. 7 to 13, in details. Fig. 7, leaf of $\boldsymbol{F}$. margarita, one-half natural size; Fig. 8, $\boldsymbol{F}$. margarita showing rind, pulp-vesicles, seed, one and one-half natural size; Fig. 9, $F$. japonica, natural size, with rind, vesicles and seed; Fig. 10, leaf of $F$. japonica, one-half natural size; Fig. 11, leaf of $\boldsymbol{F}$. crassifolia, one-half natural size; Fig. 12, F . crassifolia, detail of rind, vesicles, seed, one and one-half natural size; Fig. 13, fruiting twig of $\boldsymbol{F}$. Hindsii, natural size.

Citrus. - Evergreen trees or shrubs, normally spiny with a single spine at the side of each leaf-bud, but spines sometimes lacking: leaves thick and leathery, dotted with translucent oil-cells, unifoliate, the petioles usually winged, generally articulated with both blade and twig: flowers axillary, solitary or clustered or in small terminal cymes, white or white with purplish pink on the outer surface of the petals, scented; calyx small, cupped, or represented by a mere disc; petals normally 5 , imbricated, thick, strap-shaped, dotted with oil-cells; stamens numerous, commonly $15-60$, polyadelphous, united in bundles; ovary 8-15-celled; style usually deciduous: fruit a partitioned berry (hesperidium Fig. 25), globose, subglobose, or oblong pointed, covered with a skin of varying thickness and filled with small stalked fusiform cells or sacs containing juice; seeds few to many, oval or oblong, $1 / 4^{-3} / 4$ inch long, light-colored, covered by parchmentlike testa and containing fleshy cotyledons and usually with a number of embryos.-Natives of Cochin-China, the Malayan Archipelago, and adjoining parts of Asia. Several species have become domesticated in Florida and elsewhere in tropical and subtropical regions where satisfactory climatic and soil conditions prevail. Often, in such regions, they are looked upon as being endemic.

C. medica, Linn. (from Media, the country whence the Greeks and Romans first knew it). Citron.-A shrub or small tree, about 10 feet high with a short, indistinct trunk and short, thick, irregular, straggling, thorny branches; bark light gray; thorns short, sharp, rather stout; young shoots smooth, violet colored or purplish, stiff: leaves large, not articu- 


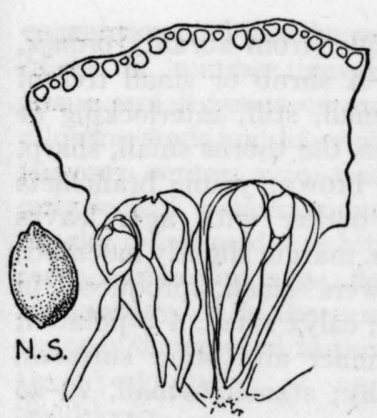

Frg. 14. C. medica

lated, 4-6 inches long, ovaloblong, serrate or somewhat crenate, dark green above, lighter beneath, petioles without wings: flowers small, axillary, in compact clusters of 3-10, often unisexual; calyx small, cupped; corolla white within, tinged with purple on the outside; petals oblong, the tips incurved; stamens short, irregular in length, 40-45 in number; pistil large, ovary 9-12loculed, or occasionally more: fruit lemon-yellow, large, 6-9 inches long, oblong, rough or warty, sometimes ridged, apex blunt pointed; rind thick, white except for the outer colored rim; pulp sparse, juice

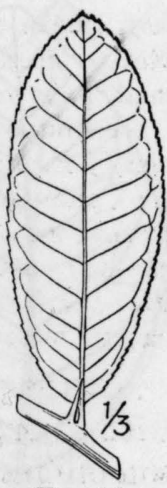

Fig. 15 C. medica scant, acid and somewhat bitter, or sweetish; juice-sacs small, slender; seeds oval, plump, light colored, smooth.-Either native of India, or introduced there from farther east. Tender.

C. Limonia, Osbeck (from the Arabic word linum for lemon). LEMON. -A small tree, 10-20 feet in height, with rather open head of short, round or angular branches, thorny; bark grayish; young shoots purplish, smooth: leaves evergreen, alternate, $2-3$ inches in length, ovate-oval, sharp-pointed, light green, margin serrate; petioles entirely wingless: flowers solitary,

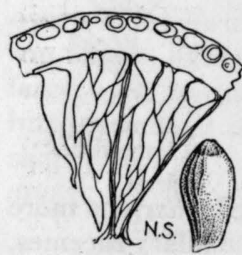

Fig. 16

C. Limonia

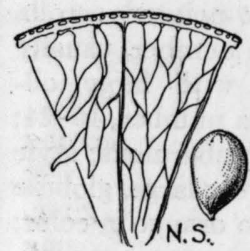

Fig. 18

C. aurantifolia occasionally in pairs, axillary, on distinct peduncles; calyx persistent; segments $4-5$; corolla large, $1 \frac{1}{2}-2$ inches across, white inside, purplish outside, petals oblong spreading, strongly reflexed; stamens 20-26, separate, or more or less united in small groups; ovary considerably elevated on a prominent disk, 7-10loculed: fruit ripening at all seasons, ovoid or oblong and pointed at both base and apex, about 3 inches long, smooth or rough, light yellow in color, rind thin; flesh light colored, pulp acid, juice-sacs long and pointed; seeds oval, pointed at the micropylar end, quite smooth. - Native of the same regions as the citron.

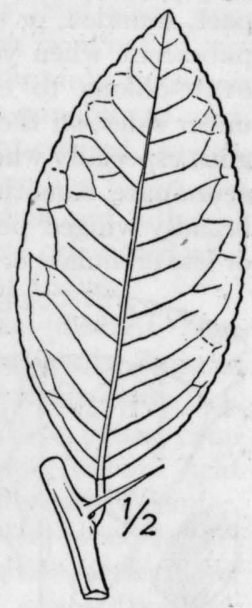

Fig. 17

C. Limonia 


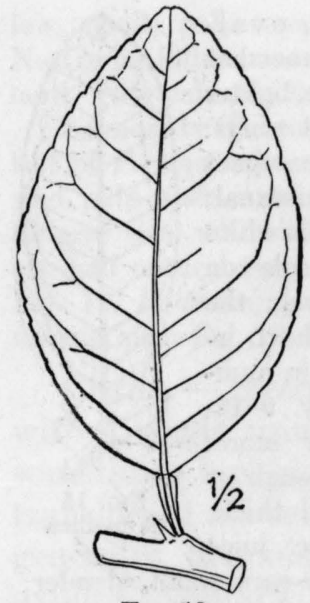

Fig. 19

C. aurantifolia

C. aurantifolia, Swingle (from auranti, orange, and folia leaf). LIME.-A shrub or small tree of straggling habit, with small, stiff, interlocking or drooping thorny branches, the thorns small, sharp, numerous; bark grayish brown; young branchlets light green, becoming darker with age: leaves elliptic-oval, glossy green, margin slightly indented; petioles margined: flowers small, produced in axillary clusters of 3-10; calyx small, 4-5-pointed; corolla white on both inner and outer surfaces; petals 4-5, oblong, fleshy; stamens small, 20-25 united in a number of groups; ovary about 10loculed: fruit rounded oblong or oblong, frequently mammillate, light yellow; maturing irregularly throughout the year: rind thin; pulp greenish, acid; juicesacs small, slender, pointed; seeds small, oval, pointed.Native of India and southeastern Asia; widely distributed and naturalized in the tropics.

C. maxima, Merrill (maxima, large). Known also as $C$. grandis and $C$. decumana. Shaddock, Pummelo, Pompelmous. - A tender tree 15-30 feet high, with compact, rounded, or somewhat flattened head; branchlets pubescent when young: leaves large, 4-8 inches long, ovate-oblong to elliptic, sparingly pubescent on the under sides, on the midrib and veins and along the margins, especially when young; apex rounded or somewhat acuminate, sometimes emarginate; base rounded to the

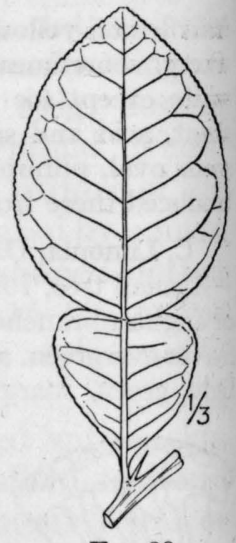

Fig. 20 C. maxima broadly winged petiole; veins depressed, distinctly defined; margins more or less crenulate or entire: flowers large, crowded in short axillary racemes,

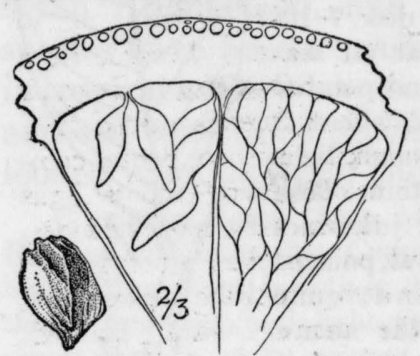

FIG. 21. C. paradisi usually borne throughout the year in favorable climates; pedicels pubescent; calyx about $1 / 4$ inch across, 4 -or 5 -pointed; corolla white, the petals 4 or 5 in number, usually 4 , obtuse, thick, dotted with large oilglands; stamens variable in number, 16-24; ovary stipitate, minutely puberulous; style terete club-shaped: fruit very large, globose or pyriform, light lemon to orange in color; rind very thick white, spongy, smooth, dotted on the surface with large, scattered 
conspicuous oil-glands; segments large, commonly 11-14 in number, covered with thick, leathery tissue, usually open or uncovered on the inner end, allowing seeds and loose pulp-vesicles to project into the open center; juice-vesicles large, long tapering, only loosely adhering; pulp light colored or pink, tough; flavor acid and bitter with scant sweetness; seeds numerous, large, flattened or wedge-shaped. -A native of Malay and Polynesia, widely but sparsely distributed in the tropics. Introduced into the West Indies at an early date by Captain Shaddock.

C. paradisi, Macf. (paradisi, of paradise or gardens). Known also as C. maxima var. uvacarpa. Pomelo, Grapefruit.-A tree 30-50 feet in height, with a rounded or conical head and a trunk $1 \frac{1}{2^{-}}$ $21 / 2$ feet in diameter; bark smooth, grayish brown; young leaves and shoots smooth, light green: leaves ovate, blunt, pointed or rounded, emarginate,

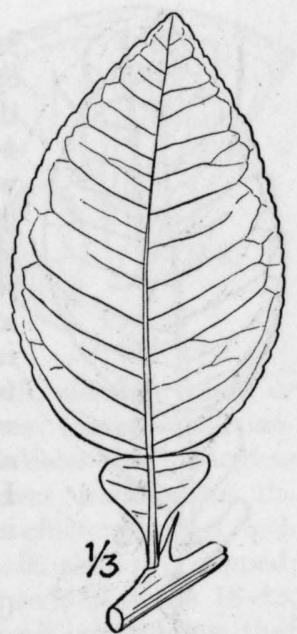

Frg. 22. C. paradisi smooth, dark glossy green, leathery, margin crenate; petioles articulated, broadly winged: flowers produced singly or in cymose clusters of 2-20, or more, sweet-scented; calyx cupped, large; sepals 4-5, pointed; corolla white, $1 \frac{1}{2}-13 / 4$ inches across; petals $4-5$, slightly reflexed, fleshy, oblong; stamens $20-25$, anthers large, abundantly supplied with pollen, proterandrous; pistil stout; stigma covered with a sticky, milky fluid when ripe; ovary 11-14-loculed: fruit large, oblate, globose, pyriform from out of season bloom, light lemon or orange colored; flesh grayish or pink; juice-sacs large, spindle-shaped closely packed together; flavor a mingling of acid, bitterness, and sweetness or subacid; seeds large, light-colored, wedgeshaped or irregular, ridged with prominent ridges surrounding broad, flat areas; cotyledons white.-Native of southeastern China and adjacent

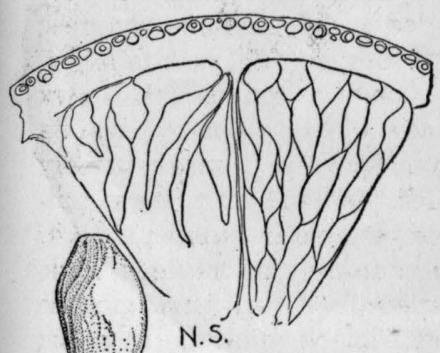

Fig. 23

C. Aurantium parts of Asia or may have originated as a seedling sport in the West Indies.

C. Aurantium, Linn. (derived from aurum, gold). Sour, Bigarade, or SevilleE Orange.-A small to medium-sized tree, 20-30 feet in height, with a dense, compact, rounded head; young shoots light green, thorny; thorns alternate, slender, long, sharp-pointed, on older wood larger, strong, stiff: leaves unifoliate, articulated, evergreen, alternate, ovate, pointed, strongly and peculiarly scented; petiole $1 / 2-$ 


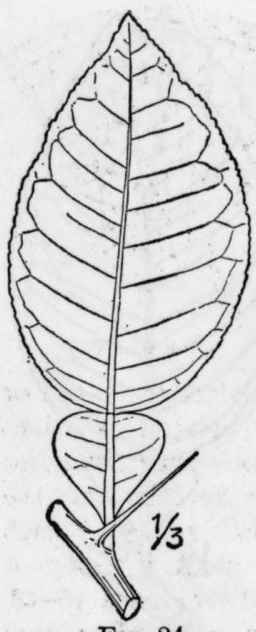

FIG. 24

C. Aurantium

$3 / 4$ inch long, broadly winged: flowers in small axillary cymes, white, strongly sweet scented, somewhat larger than those of C. sinensis; calyx cupped, segments 4-5, blunt; petals linear-oblong, conspicuously dotted with oil-cells; stamens 20-24; filaments united in groups; pistil club-shaped, smooth; ovary 10-12loculed: fruit orange-colored or frequently reddish when well matured, inclined to be rough; rind strongly aromatic, bitter; pulp acid, juice-sacs spindle-shaped, rather small; core hollow when fully ripe; seeds flattened and wedged toward the micropylar end, marked with ridged lines.-Native of southeastern Asia, probably in Cochin-China. Hardier than the sweet orange. Introduced into Florida at an early date and now naturalized in many of the forests.

C. sinensis, Osbeck (sinensis, of China). SweET Orange.-A tree 25-40 feet in height, with a compact, conical head; bark greyish brown; thorns generally present, $1 / 2$ to 2 inches long, sharp, stout: leaves oval or ovate-oblong, 3-4 inches long, smooth, shining, somewhat lighter below than above, margins entire, or very slightly serrate; petiole $1 / 2^{-1}$ inch long, slightly winged (occasionally with quite a broad wing): flowers axillary, in clusters of 1-6, white, sweet-scented, smaller than those of $C$. Aurantium; calyx cupped; sepals 4 or 5 , awlshaped, thick, greenish, persistent; petals usually 5 , oblong, $1-1 \frac{1}{4}$ inches long, thick, fleshy, recurved; stamens 20-25, hypogynous; filaments flattened, united in groups, shorter than the petals; pistil distinctly divided into stigma, style, and ovary; stigma knob-like; style long and slender; ovary rounded, 10-14-loculed: fruit globose or oblate, light orange to reddish, rind smooth; pulp juicy, subacid; juice-sacs spindle-

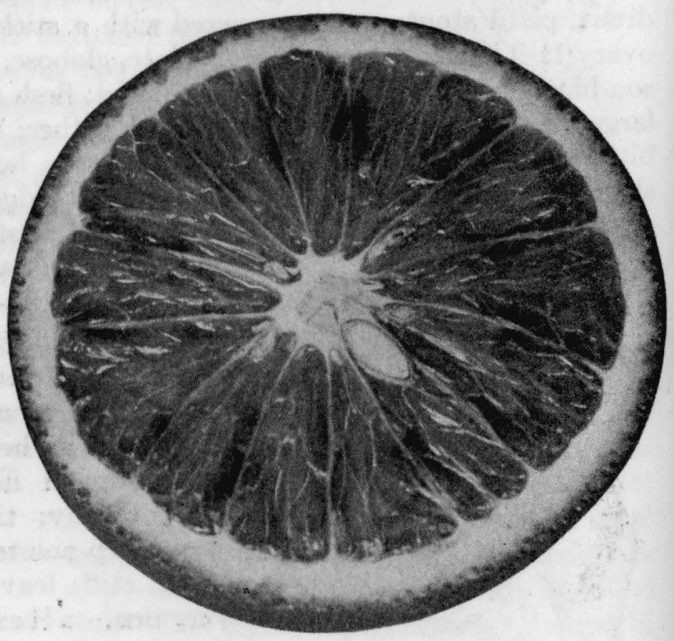

Fig. 25. C. sinensis 
shaped, sometimes larger than those of C. Aurantium; seeds few or many, oblong-ovoid, planoconvex, generally broad, wedged or pointed at the micropylar end, marked with oblique ridges surrounding one or two plain areas.-Native of China or Cochin-China.

C. nobilis, Lour. (nobilis, famous or noble). King Orange. - A small tree, 12-20 feet high, with a dense head of upright or willowy drooping branches; bark dark brownish or streaked with

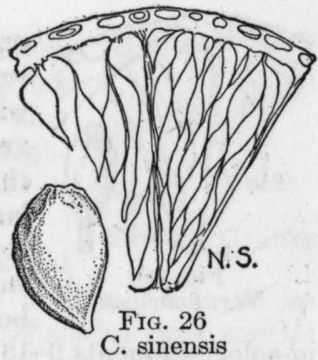
gray; branchlets light green or dark in color, small, slender, round or angled, thornless or provided with small sharp spines: leaves small, lan-

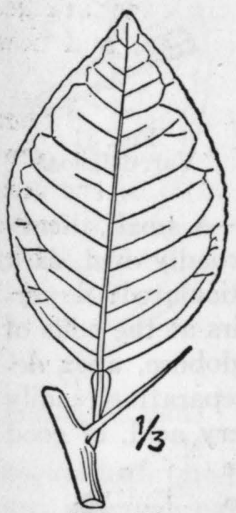

FIg. 27

C. sinensis ceolate to oval, slightly crenate; petioles short, wingless or with very small wings: flowers terminating the branchlets or axillary, sometimes clustered, $3 / 4-1$ inch across, sweet-scented; calyx small, shallow, cupped; petals small, white, fleshy, recurved; stamens 18-23, shorter than the petals; pistil small, resembling that of C. sinensis; ovary 9-15-loculed: fruit distinctly oblate, orange to reddish in color; pulp sweet or subacid; juice-sacs broad and blunt; seeds top-shaped, beaked; cotyledons white; embryos 1 or more; sections separating readily from each other and from the rind; rind rather thick, rough, orange tinted within, oil-cells somewhat balloon-shaped or oval.-Native of Cochin-China.

Var. deliciosa, Swingle (deliciosa, delicious). MaNdarin Orange, Tangerine Orange. - A small tree with a very dense top of slender branches: leaves long and narrow to ovate pointed, slightly margined articulated petioles: flowers white, smaller than those of $C$. sinensis: fruit flattened or depressed globose, yellow or highly colored reddish orange; segments 10-14;

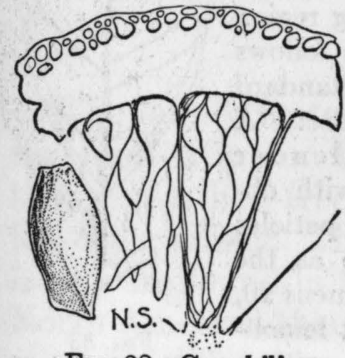

Frg. 28. C. nobilis seeds small, beaked with greenish cotyledons. - Native in China. Generally admitted to be hardier than the sweet orange. The favorite varieties of this species are the reddish orange fruited sorts and of these Dancy is the most noteworthy.

Var. Unshiu, Swingle (Un-

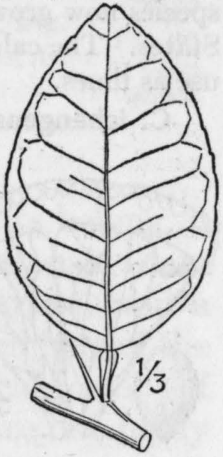
shiu, Japanese name for this FIG. 29. C. nobilis 


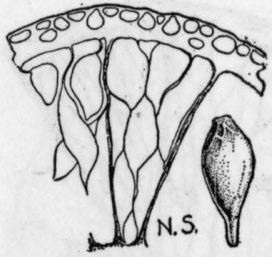

FIg. 30

Var. deliciosa

orange). Satsuma Orange.-A small, spreading, rather dwarf tree, when matured usually having a greater width than height of top; thornless: leaves very distinct, large, broad, strongly veined, rounded toward the apex: flowers small, white: fruit depressed globose, of medium size, deep orange in color; segments 9-13; pulp deep orange, of fine quality; pith hollow; seeds few or none, top-shaped; cotyledons green.-Native home southern China. Introduced into Japan at an early date. Oranges of this group are favorite fruits in China and Japan, where many varieties are cultivated. It is the hardiest of all the edible oranges now grown in the United States, and its culture has attracted a great deal of attention in northern Florida and in the Gulf of Mexico citrus regions generally.

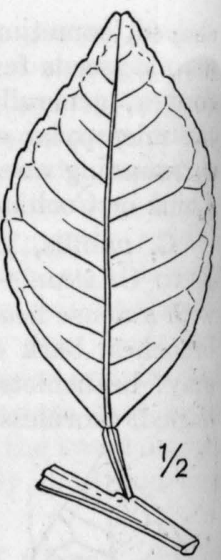

Fig. 31

Var. deliciosa

C. mitis, Blanco (mitis, mild, gentle). Calamondin.-A small, densetopped ornamental tree with upright branches: leaves broadly oval, dark green above, paler beneath; petioles narrowly winged, articulated: flowerbuds angled; flowers white, small, borne singly or in pairs at the ends of the branchlets; stamens normally 20 : fruit small, subglobose, apex depressed, bright reddish orange in color; segments $7-10$, separating readily from each other and from the loose, thin rind; pulp very acid, of good flavor; seeds usually $2-5$, small; cotyledons green.- Native in the Philippine Islands, whence it was introduced into Panama and from there into the United States. It is very hardy; in fact, it may be the hardiest of the edible citrus species now growing in the citrus districts of the United States. The calamondin is a valuable fruit for the same use as limes.

C. ichangensis, Swingle (native of the Ichang region

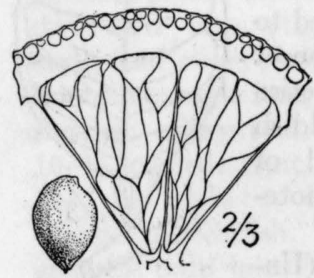

FIG. 32. Var. Unshiu in China).-Described as follows by Swingle in Bailey's Standard Cyclopedia of Horticulture: "A small tree, with long, slender spines: leaves narrow, with oblong, broadly winged petioles nearly or quite as large as the blade: flowers white; stamens 20 , cohering in bundles: fruit lemonshaped, 3-4 inches long, with a

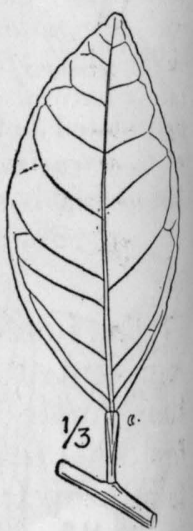

Fig. 33 Var. Unshiu 


\section{1

very broad, low apical papilla surrounded by a shallow circular furrow; segments 8-11; pulp acid, of good flavor; seeds very large, thick, cuneate-ovate, $1 / 2^{-3} / 4$ inch long and $1 / 4^{-3} / 4$ inch thick, white within." -Native in highland regions in China; it is growing as an ornamental or curiosity in Florida, Alabama, and Mississippi.

Detail characters of the species and botanical

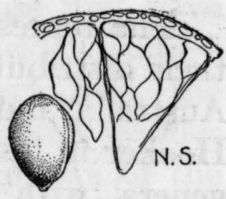

FIg. 34. C. mitis

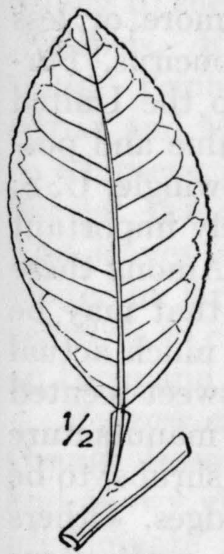

Frg. 35. G. mitis varieties of Citrus are displayed in Figs. 14 to 36 inclusive. Fig. 14, C. medica, natural size of rind, vesicles and seed; Fig. 15, C. medica leaf, one-third natural size; Fig. 16, C. Limonia parts natural size; Fig. 17, C. Limonia leaf, one-half natural size; Fig. 18, C. aurantifolia, fruit details natural size; Fig. 19, leaf of C. aurantifolia, onehalf natural size; Fig. 20, C. maxima, leaf one-third natural size; Fig. 21, fruit detail, two-thirds natural size, of $C$. paradisi; Fig. 22, leaf of $C$. paradisi, one-third natural size; Fig. 23, fruit detail of $C$. Aurantium, natural size; Fig. 24, leaf of $C$. Aurantium, one-third natural size; Fig. 25, cross-section of $\boldsymbol{C}$. sinensis showing structure of hesperidium, rind, oil-cells, sections, juicevesicles, pith, seed; Fig. 26, fruit detail of C. sinensis, natural size; Fig. 27, leaf of $C$. sinensis, one-third natural size; Fig. 28, fruit detail, natural size, of $C$. nobilis; Fig. 29, $C$. nobilis leaf, one-third natural size; Fig. 30, detail of $C$. nobilis var. deliciosa, natural size; Fig. 31, leaf of var. deliciosa, onehalf natural size; Fig. 32, fruit of $C$. nobilis var. Unshiu, twothirds natural size; Fig. 33, leaf of var. Unshiu, one-third natural size; Fig. 34, detail of fruit of $C$. mitis, natural size; Fig. 35, leaf, one-half natural size, of $C$. mitis; Fig. 36, leaf of $C$. ichangensis, one-third natural size.

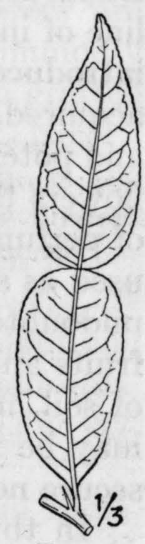

FIg. 36

C. ichangensis

\section{CITRUS RELATIVES}

The family Rutaceæ, to which the citrus fruits belong, is represented in the United States by the prickly ash (Zanthoxylum), hop-tree (Ptelea), torch-wood (Amyris), and a few other plants. Though comparatively few members of the family are found in the temperate and subtropical regions of North America, this does not mean that there are not many others in different parts of the world. 
The representatives of the family are mostly tropical in their distribution, in tropical Africa, southeastern Asia and Australia, numbering in all upward of a thousand species. Hooker in his "Flora of India," 1875, accepts twenty-three genera, with at least seventy-eight species native of that country.

Since the year 1900 many of the plants more or less closely related to the citrus fruits (genera Poncirus, Fortunella, and Citrus) have been introduced into the United States. In some measure their horticultural value and possibilities have been investigated by Walter T. Swingle, U. S. Department of Agriculture. This is an extremely important line of investigation and should be continued. Among these introduced citrus relatives, and among others that may be acquired, are plants which in themselves have much actual and potential value. Many of them have very sweet-scented flowers that would make them valuable in the manufacture of perfumes. Some are valuable as ornamental shrubs, to be used as specimens, in mass plantings, or for hedges. Others undoubtedly have value as stocks on which to graft citrus fruits and other related species, thereby widening the range of soil, moisture, and climatic adaptability. Many of them may be very valuable for crossing purposes in the effort to secure new, different, and worth-while plants.

In this connection it may be pointed out that Poncirus trifoliata has proved of great value as a stock for some kinds of citrus fruits, in addition to its use as an ornamental shrub and hedge plant. One of the most valuable citrus fruits ever introduced is the Eustis limequat, obtained by crossing the lime and the kumquat. It is a very hardy citrus which will some day be a valuable factor in acid-fruit production.

The fruits closely allied to Citrus, or at least closely enough akin to allow of their possible use as stocks, and which, perhaps, may be interpollinated with Citrus, may be divided into three groups: those that have berry-like or 
drupe-like fruits with a leathery covering; those that have hard-shelled fruits; and those that bear hesperidia fruitsberry-like fruits covered with a thick leathery rind, the interior divided by sections and filled with stalked vesicles containing watery or oily juice, as in the members of the genus Citrus. The more important species, so far studied, belong to the genera Clausena, Murræa or Chalcas, Feronia, Eglopsis, Egle, Chætospermum, Balsamocitrus, Hesperethusa, Triphasia, Severinia, Citropsis, Atalantia, Eremocitrus, and Microcitrus.

Clausena is represented in America by Clausena Lansium, Skeels. It is a native of South China and is grown in Hawaii. The leaves are pinnately compound and the flowers are white, in large panicles. The Wampi, as it is commonly called, is so closely related to Citrus that it has been grafted on them and it may have value as a stock. (Fig. 37, No. 1.)

Murroea exotica, Linn., or Chalcas exotica, Millsp., is the Orange Jessamine, noted for its very fragrant white flowers and showy clusters of little berries. The dark green leaves are pinnate with five to nine leaflets, and the flowers are white and the fruits red. It makes a beautiful pot plant and can be grown outdoors in southern Florida and California. It can also be used as a stock for citrus trees. (Fig. 37, No. 2.)

Feronia Limonia, Swingle. The Wood Apple from India, Ceylon, and Indo-China, has been introduced into California and Florida. It is a spiny deciduous tree with oddpinnate leaves, three to seven leaflets, and dull red flowers in terminal or axillary panicles. The fruit is hard-shelled and contains at maturity a single cell filled with a pinkish edible pulp. It is used in making jellies. Citrus fruits can be grafted on it, and it is now being tested as a stock. (Fig. 37, No. 3.)

Feroniella lucida, Swingle, from Java, is a small closely branched evergreen spiny tree with compound leaves made up of six to twelve small leaflets. It is valuable as an orna- 


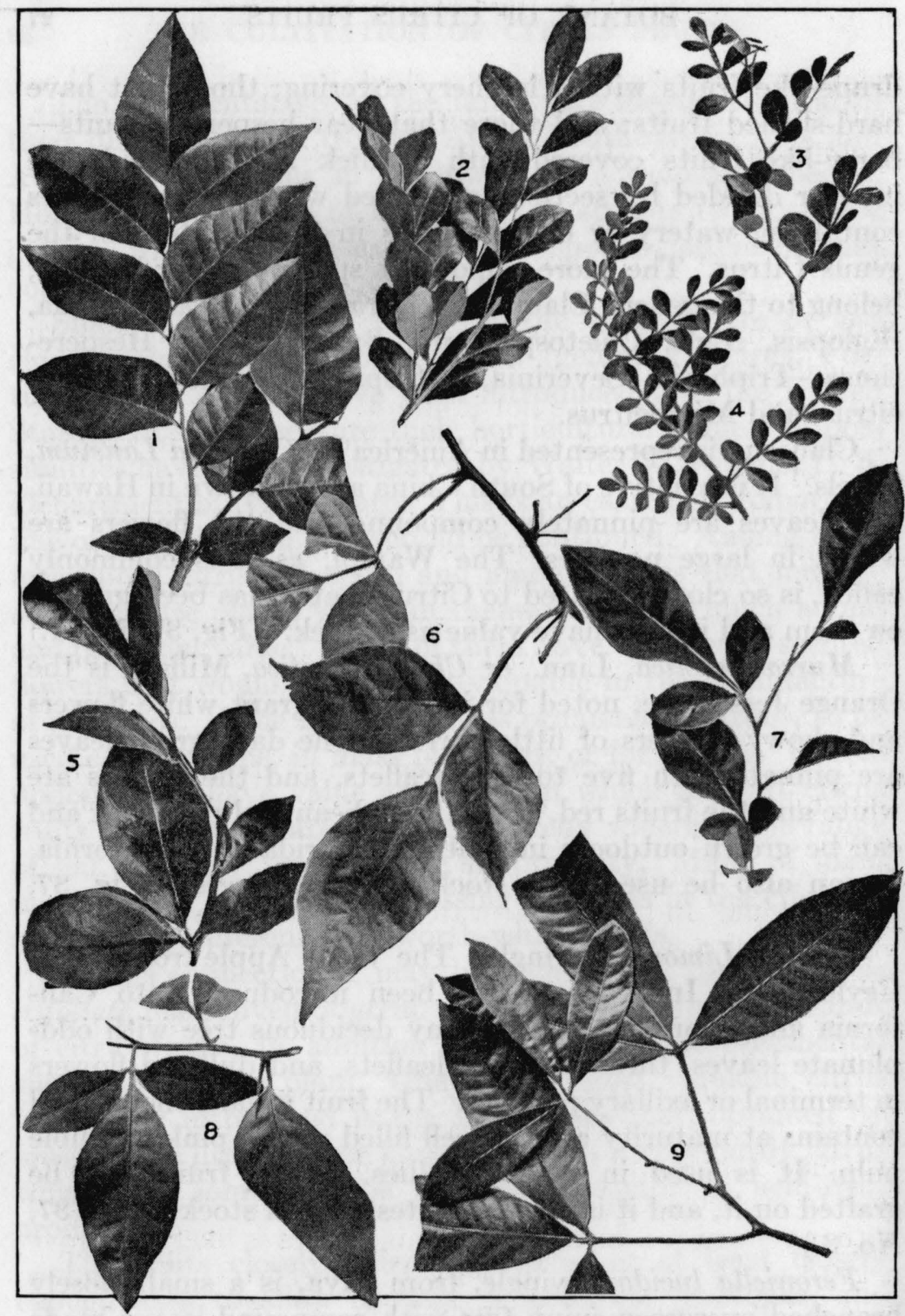

Frg, 37. Citrus relatives, twigs and leaves of

1 Clausena Lansium 2 Murræa exotica 3 Feronia Limonia
4 Feroniella lucida

5 Aglopsis Chevalieri

6 Egle Marmelos
7 Chætospermum glutinosa

8 Balsamocitrus paniculata

9 Lavanga scandens 
mental and is being tested as a stock for citrus fruits. The fruit is globose, about $2 \frac{1}{4}$ inches in diameter, and filled with a glutinous pulp. In Java it is sometimes eaten by the natives. (Fig. 37, No. 4.)

Eglopsis Chevalieri, Swingle, is a shrub or small tree from the west coast of tropical Africa. Like Citrus, it has simple leaves subtended by thorns, flowers in panicles, and hardshelled fruits divided within. The segments are filled with a mucilaginous substance. It is said to grow in low ground, and brackish water does not injure it. The plant may prove of value as citrus stock for alkaline conditions in the tropics. (Fig. 37, No. 5.)

Egle Marmelos, Correa, is the Bael fruit of India, where it is widely cultivated. The leaves are trifoliate and deciduous, and the fruit is large (four to six inches in diameter), hardshelled, segmented, and filled with a mucilaginous gummy substance. It is used in making drinks and sherbets and is valued in medicine in cases of dyspepsia and dysentery. It is highly esteemed by the Hindus. (Fig. 37, No. 6.)

Choxtospermum glutinosa, Swingle, the Tabog, comes from the Philippine Islands. It is an evergreen tree with trifoliate leaves and a pair of sharp spines at the base of each leaf. The fruit is two to three inches long, about one-and-a-half inches wide, and contains watery or juicy tissue. It is a vigorous grower, and it has been determined that citrus fruits of different kinds may be grown on it. The tabog is one of the most interesting of the near-citrus relatives. (Fig. 37, No. 7.)

Balsamocitrus Dawei, Stapf, is native in east central Africa, near Lake Albert Nyanza. It is a large tree with trifoliate leaves and large oval or globose hard-shelled fruits four to six inches in diameter, the interior of which is filled with a yellowish colored gum. This species is likely to prove a good stock on which to work the bael fruit. Two other species, B. paniculata, Swingle (Fig. 37, No. 8), and B. gabonensis, Swingle, have also been introduced. 
Lavanga scandens, Buch.-Ham., is a shrubby evergreen climbing plant distantly related to the citrus fruits. Its leaves are trifoliate and distinctly veined. The flowers are white and fragrant, and the yellowish fruit, about an inch in diameter, is filled with a resinous pulp. Its native home is in the peninsula of Malay and in India. (Fig. 37, No. 9.)

Hesperethusa crenulata, Roem., is a very beautiful spiny ornamental shrub or small tree from Ceylon, Burma and Indo-China. The leaves are very interesting, being oddpinnately compound, of five to nine leaflets with winged petiole and rachis. The flowers are small, white, and fragrant and the fruit is small, dark-colored and bitter. It makes a good pot plant and may be grafted on Citrus and some related species. (Fig. 38, No. 10.)

Triphasia trifolia, P. Wilson, is a shrub or small tree of unknown nativity, but probably from Malaya. Its leaves are trifoliate, dark green, each with a pair of very sharp short spines. The flowers are white, sweet-scented, axillary, borne singly in the leaf-axils and the fruit is a thick-skinned berry, with spicy mucilaginous pulp. It is grown in southern Florida as an ornamental plant and is said to be tolerant to salt in the soil in considerable quantities. Its common name is Lime-Berry. (Fig. 38, No. 11.)

Severinia buxifolia, Ten. This spiny shrub or small tree is native of southern China and is-sufficiently hardy to grow in the climate of the Gulf Coast regions. The leaves are obovate, emarginate, dark green, and there is a single spine at each leaf. The fruit is a dark two- or three-celled berry. It makes a good ornamental and hedge plant, and may have value as a stock for Citrus. (Fig. 38, No. 12.)

Paramignya monophylla, Wight, is an evergreen climbing woody plant related to Citrus. The leaves are simple with sharp recurved spines at the petioles. These spines assist it in holding its place among other plants over and through which it climbs. It has possible value as a citrus stock. Native in India. (Fig. 38, No. 13.) 


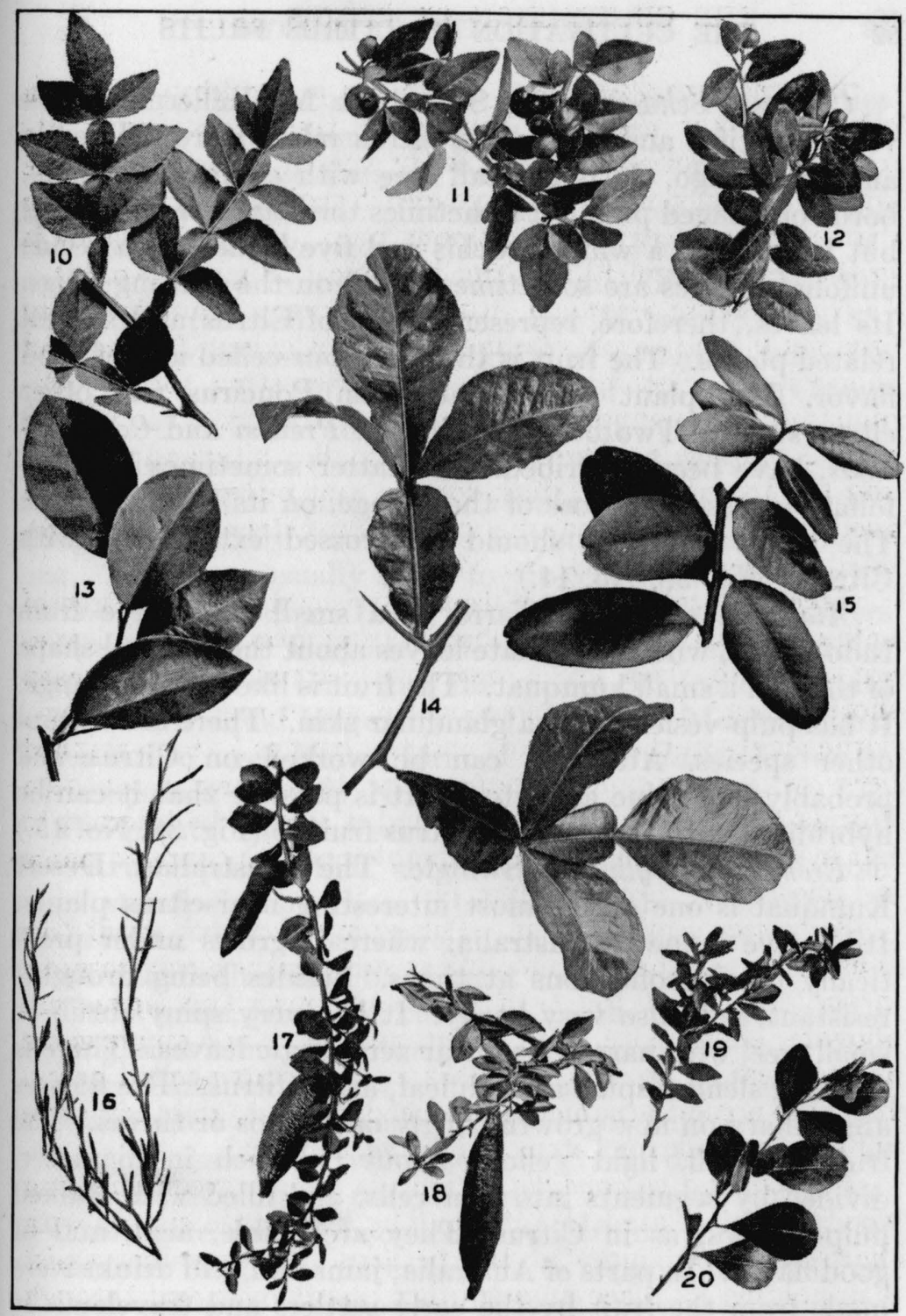

Fig. 38. Citrus relatives, twigs and leaves of

10 Hesperethusa crenulata 11 Triphasia trifolia

12 Severinia buxifolia

13 Paramignya monophylla
14 Citropsis Schweinfurthi

15 Atalantia citrioides

16 Eremocitrus glauca

17 Microcitrus australasica
18 Microcitrus australasica var, sanguinea

19 Microcitrus virgata 20 Microcitrus australis 
Citropsis Schweinfurthi, Swingle \& M. Kellerman, is a very beautiful and interesting citrus relative from Uganda and the Congo. It is a small tree with compound leaves, borne on winged petioles; sometimes the leaves are trifoliate, but forms with a winged rachis and five leaflets also occur; unifoliate leaves are sometimes found on the fruiting twigs. Its leaves, therefore, represent those of Citrus and several related plants. The fruit is three- to four-celled and of good flavor. This plant grows readily on Poncirus and other citrus stocks. Two other species, C. Preussi and C. gabonensis, have been described. The latter sometimes has unifoliate leaves, like those of the orange, on its fruiting twigs. The genus Citropsis should be crossed extensively with Citrus. (Fig. 38, No. 14.)

Atalantia citrioides, Pierre, is a small spiny tree from Indo-China, with emarginate leaves about the size and shape of those of a small kumquat. The fruit is like a small orange. It has pulp-vesicles and a glandular skin. There are several other species. Atalantia can be worked on Citrus and probably has value as a stock. It is possible that it can be hybridized with the different citrus fruits. (Fig. 38, No. 15.)

Eremocitrus glauca, Swingle. The Australian Desert Kumquat is one of the most interesting near-citrus plants. Its native home is Australia, where it grows under practically desert conditions at times. Besides being droughtresistant, it is also very hardy. It is a very spiny shrub or small tree, with narrow or linear xerophytic leaves. There is one long slender spine at each leaf, as in Citrus. The flowers are axillary on new growth, singly or in twos or threes. The fruit is small, light yellow, about half-inch in diameter, divided by segments into four cells, and filled with stalked pulp-vesicles, as in Citrus. They are edible, acid, and of good flavor. In parts of Australia, jams and acid drinks were made from the fruit by the early settlers and travelers. It grows readily on citrus stocks of different kinds and Citrus grows readily when budded or grafted on it. Because of its 
resistance to drought and cold it has very great possibilities in American horticulture. (Fig. 38, No. 16.)

Microcitrus australasica, Swingle (Fig. 38, No. 17), Australian Finger Lime. This and four other species of the same genus, $\boldsymbol{M}$. Garrowayi (Garroway's Finger-Lime), $\boldsymbol{M}$. australis (Round-fruited Australian Lime) (Fig. 38, No. 20), $M$. inodora (Russell River Lime) and M. virgata (Fig. 38, No. 19), are interesting citrus fruits of potential value for stocks and for hybridizing with fruits of the genus Citrus. They are trees or shrubs with small blunt ovate leaves, and sharp spines longer than the leaves. The flowers are small and axillary. The fruits of $M$. australasica are long, slender, straight, or slightly curved, two and one-half to three inches long. They are usually five- to six-celled and filled with stalked juice-vesicles. The fruit of the other species differs in shape and size. They are believed to be very much hardier than the lemon or lime, and the species $M$. inodora is said to bear fruit equal in quality to that of the Mexican lime. There is also a red-fruited form of $M$. australasica known as var. sanguinea (Fig. 38, No. 18.)

The plants briefly described above are by no means all the citrus relatives that should be carefully studied from every standpoint by those interested in the cultivation of citrus fruits. There are in foreign countries many more littleknown plants that may be of great economic value.

Citrus areas, from one cause or another, are constantly shifting, and it may eventually become necessary to develop new forms and secure new root-systems if the industry is to be maintained and extended. The citrus fruits have been intimately associated with the growth and development of the human race over a period of many centuries, and in the light of more recent knowledge concerning their value in the human diet, it is unreasonable to suppose that interest in them will ever become less. It is all the more necessary, therefore, that those plants closely related to the true edible citrus fruits should receive most careful investigation. 


\section{CHAPTER III}

\section{THE TRIFOLIATE ORANGE AND ITS HYBRIDS}

As a commercial fruit, the trifoliate orange is worthless. It is, however, valuable as a hedge plant, as an ornamental tree, as a stock on which to work other varieties of citrus, and as a parent in hybridization. At present, the seed required for growing stocks is secured mostly from local sources in Florida, Georgia, Alabama, and Louisiana. Formerly it was imported from Japan in considerable quantities. It is not native in Japan, but was taken there from China many centuries ago.

In the "Cheng lei pen $t$ s'ao" it was described and illustrated as long ago as 1108. The Chinese name for it is Kou Chu. What appears to be the first reference to it in occidental citrus literature is that made by Kaempfer in his Amœnitatum Exoticarum in 1712. An illustration (page 802), ac-

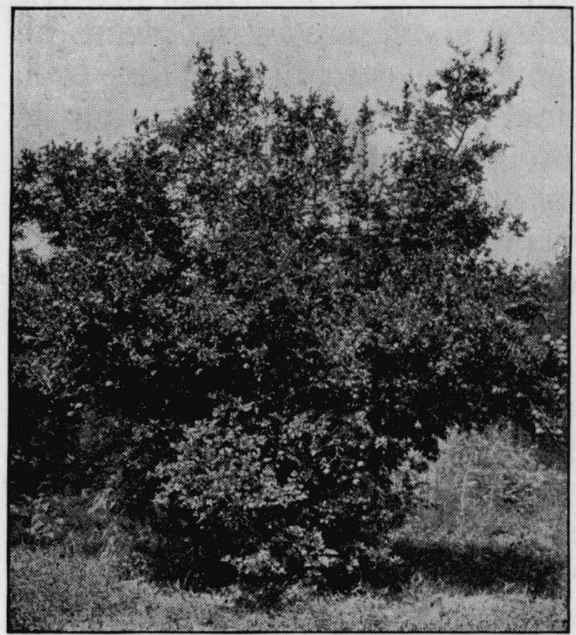

Frg. 39. Tree of Poncirus trifoliata companying his brief description, leaves no room to doubt the identity of his $S i$, vulgo Karatats banna with the trifoliate orange. In 1763, Linnæus described the trifoliate orange in the second edition of his Species Plantarum, and the name applied by him, Citrus trifoliata, was for many years accepted. Thunberg, a successor, in his Flora Japonica, 1784, adopted the name $C$ itrus trifoliata. DeCandolle, 
in his Prodromus Systematis Naturalis, 1824, placed the trifoliate orange in the genus $E g l e$, naming it Egle sepiaria. It has been placed in a number of other genera, such as Pseudogle, Limonia, and Poncirus. Rafinesque called it Poncirus trifoliata (Silva Tell. 143. 1838.), and this is now accepted as the correct botanical name for it. Poncirus differs from the true Citrus in having deciduous leaves of three leaflets, flower-buds formed in summer and protected by scales, flowers produced on wood of the previous season's growth, free stamens, a six- to eight-celled ovary, finely pubescent fruit, and an oily matter in the pulp-vesicles. These and other characters separate it definitely and distinctly from the genus Citrus.

The native home of the trifoliate orange is in northern China, and it is widely distributed, wild or cultivated, throughout that country. It has been largely used for hedges and as a stock on which to bud citrus fruits for cultivation in those colder parts of China where they are grown commercially. The dried fruit is used as a medicine. Apparently there are three or more different strains of Poncirus trifoliata already growing in America. One has very stout branches and thorns; another is distinguished by its inconspicuous flowers, due to the partial conversion of some of the petals into stamens; a third form is stronger in its growth and has very large conspicuous white flowers in early spring.

The trifoliate orange is said to have been first introduced into America in 1869 by the late William Saunders of the United States Department of Agriculture. It is now widely distributed in the southern states and has been found to be hardy as far north as Washington and Philadelphia. The variety with large white early flowers is very ornamental.

For many years, it has been the hope of citrus fruitgrowers that varieties might be secured which would resist many degrees of frost. The production of hybrid varieties with this object in view was undertaken, in Florida, in 189293, by H. J. Webber and Walter T. Swingle of the United 
States Department of Agriculture. Most of the early results were lost, but the work was again taken up in 1896-97 and vigorously pushed, resulting in the production of many thousands of hybrids, a number of which possess the desired hardiness. From time to time the work of originating new varieties of citrus fruits by crossing and hybridizing has been further prosecuted by Walter T. Swingle, E. M. Savage, and Frank W. Savage of the United States Department of Agriculture.

Many of the varieties have been fruited for the Depart-

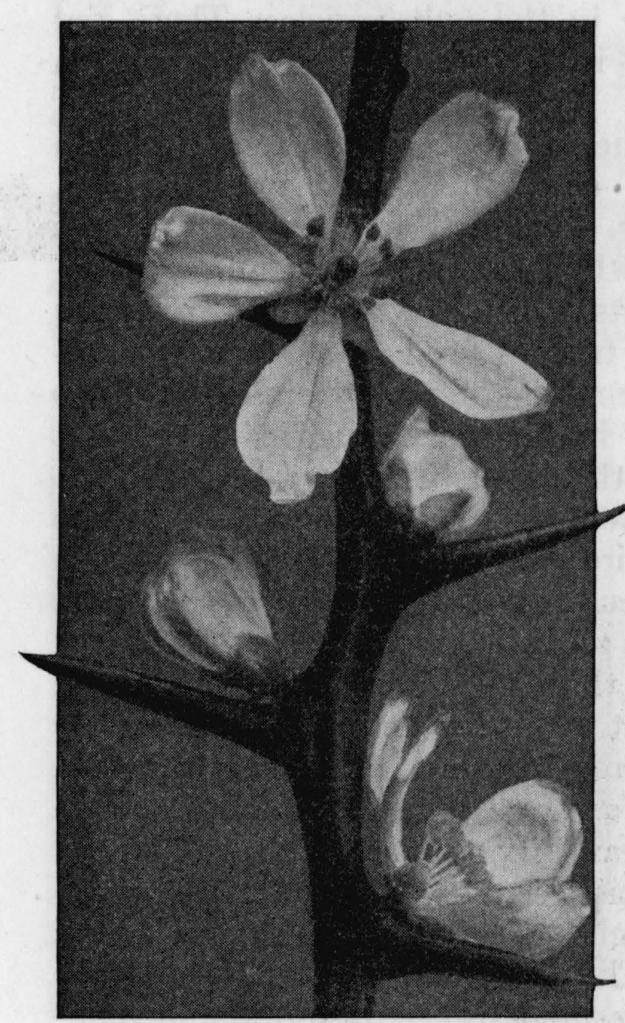

Fig. 40. Flowers of $P$. trifoliata (natural size) ment of Agriculture by the Glen Saint Mary Nurseries in northern Florida and by different experiment stations in the southern states. It has been clearly demonstrated that the hardy varieties will stand, uninjured, temperatures that would prove fatal to ordinary oranges. The work has now pro. gressed so far that something definite can be said concerning the quality of the fruit and some estimation can be placed on the work from the standpoint of future and further developments.

Everything pointed to Poncirus trifoliata as the parent which would impart the desired hardiness. With this as the 
pistillate or female parent (in most cases) the work was undertaken. Crossing was not as easily performed as might be expected. Only about two per cent of the fruit set, and many of these produced a considerable proportion of defective seed. A large number of the progeny cannot be distinguished from the trifoliate orange; others are exactly like sweet orange seedlings; while still others combine characters of both parents. Many proved to be evergreen, like the orange, but with trifoliate leaves like those of Poncirus trifoliata. The proportion of those showing intermediate characters was probably less than twenty-five per cent. For example, out of forty plants raised from seed of a single fruit, twenty-nine closely resembled the trifoliate orange, the remaining eleven being intermediate in character.

The hybrids have proved to be vigorous growers and in size far surpass seedling Poncirus trifoliata trees of the same age. Those varieties that have fruited have proved to be prolific. The flowers are very different from those of either of the par-, ents, but, for the most part, sweetscented like those of the orange. They have been named citranges (cit citrus, and range orange).

The fruit varies considerably in size, that pro-
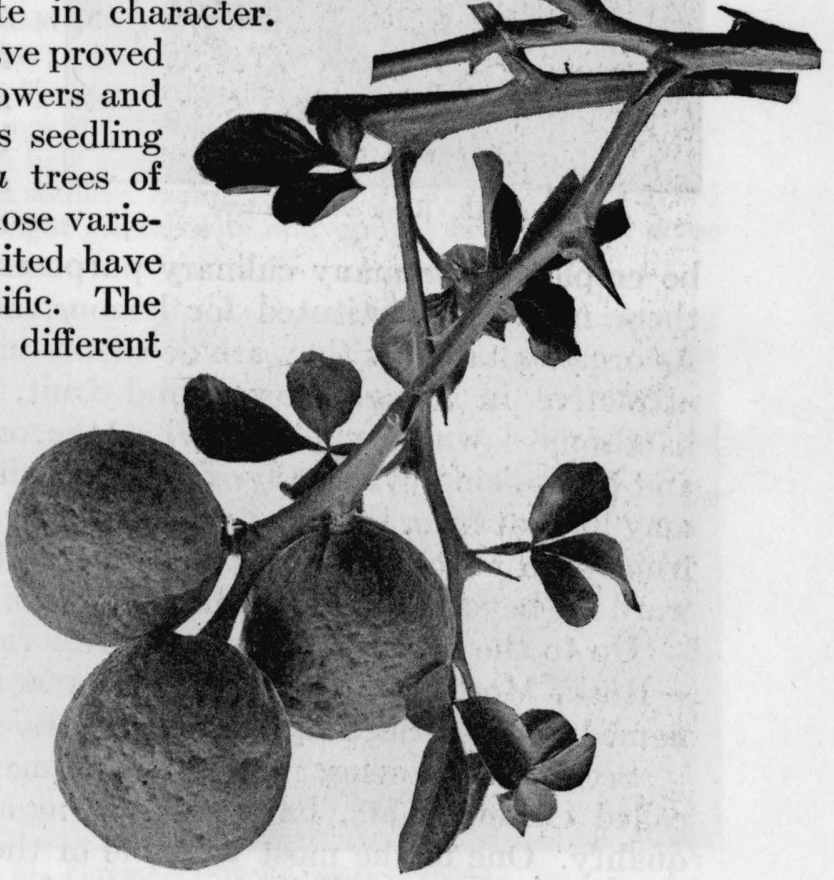

FIG. 41. Fruiting branch of $P$. trifoliato 
duced by some varieties being but little larger than Poncirus trifoliata fruit. Others bear fruit equal in size to that of the common orange, and one variety, at least, has fruit so closely resembling that of the sweet orange that in appearance it

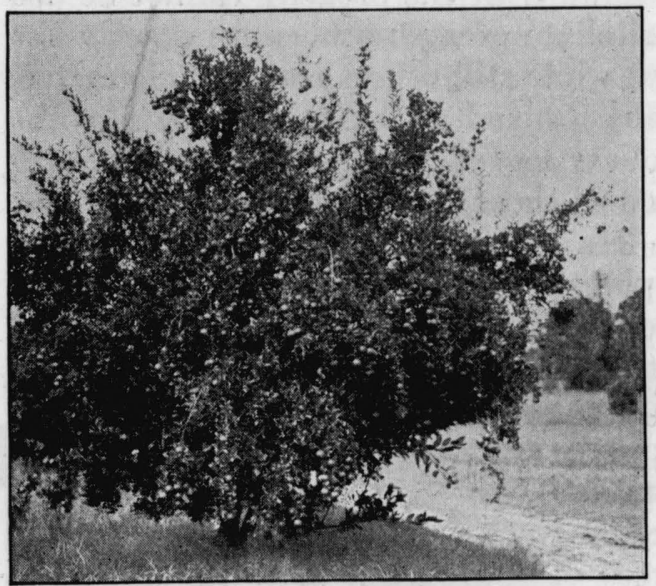

Frg. 42. Rusk citrange tree cannot be readily distinguished.

In quality, the fruits are not so good as the sweet oranges. They are intermediate in character, retaining some of the flavor of the Poncirus trifoliata fruit, and, for the most part, are sour. They can be used for making a very fine quality of ade and may also

be employed for many culinary purposes; in fact, some of them may be substituted for lemons, as commonly used. As ornamental trees they are decidedly valuable, being very attractive in foliage, flower, and fruit, and making very handsome lawn specimens. What the outcome of crossing and hybridizing eventually will be is difficult to say, but it may be that from this fruit will spring a race of hardy edible fruits with which the citrus industry can be extended northward far beyond its present limits.

Up to the present, five noteworthy varieties of citranges -Rusk, Morton, Colman, Savage, and Rustic-have been named and described by the originators.

Secondary crosses, between citranges and kumquats, called citrangequats, have resulted in acid fruits of good quality. One of the most valuable of these is the Thomasville citrangequat. It is the result of a cross between the 
Willits citrange and Nagami kumquat, Willits being the pollen parent. Telfair and Sinton are other citrangequats.

\section{VARIETIES OF PONCIRUS, AND HYBRIDS WITH IT}

Trifoliate.-Form round or sometimes slightly pyriform; size small, $13 / 4$ by 2 inches, $21 / 8$ by 2 inches; color lemon-yellow or light orange; apex creased, depressed, or with a slight creased elevation set in a ringed depression, generally terminated by a small dark speck; base elevated, creased, and ridged; calyx represented by a ring minus the points of the segments; rind about $1 / 8$ inch thick, rough, pitted, covered with minute hairs, rather easily detached; oil-cells depressed, oval or nearly globose, filled with a sort of resinous, strongly aromatic oil; sections quite regular, not clearly defined, 6-8 in number, flesh greenish; juice-sacs very slender, pointed with hair-like attachments containing a sort of resinous oil in their enlarged tips; juice clear, acid; flavor rather good when not mingled with the oil of the rind and pulp; pith small, compact; seeds numerous, 25-30, oval, plump, rounded at one end, blunt pointed at the other, the rounded end marked with a round brown spot. Season, September to October.

Colman (Hybrid 772).-Form round and slightly flattened, sometimes lopsided, large, $27 / 8$ by $33 / 4$ inches; calyx small; color light yellowish orange; rind smooth, thin, $1 / 8$ inch thick, sometimes slightly furrowed, covered with very short hairs; flesh light lemon-colored; juice-sacs slender; flavor acid, bitter, peculiar; almost seedless. Season, September to November. (Fig. 43.) foliage.

Tree a strong upright grower with stiff upright branches and dense

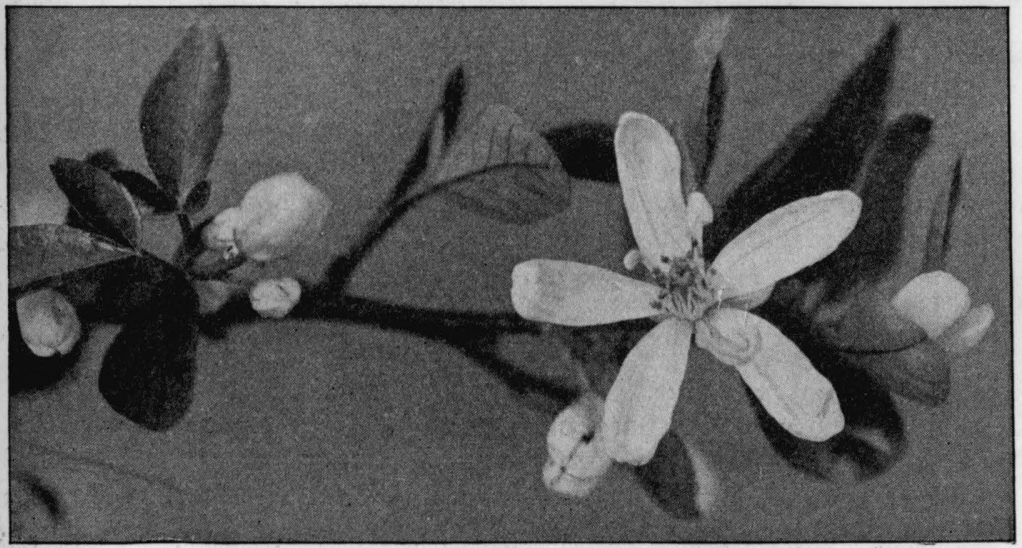

FIG. 43. Flowering twig of Colman citrange 
Morton (Hybrid $77_{1}$ ).-Form rounded or slightly flattened; size large, 3 by $3 \frac{1}{4}$ inches; calyx, small; color light orange; rind slightly furrowed, smooth or somewhat roughened with depressed oil-cells; sections 9 or 10; flesh light orange-yellow, tender; flavor acid, slightly bitter; practically seedless. Season, October to November.

Tree resembling Poncirus trifoliata but with larger trifoliate leaves. Very hardy and one of the most desirable hybrids.

Rusk (Hybrid 716).-Form nearly round; size small, $13 / 8$ by $2 \frac{1}{4}$ inches; color deep orange; calyx thin, greenish, large; rind smooth, bright, thin, $1 / 8$ inch thick; oil-

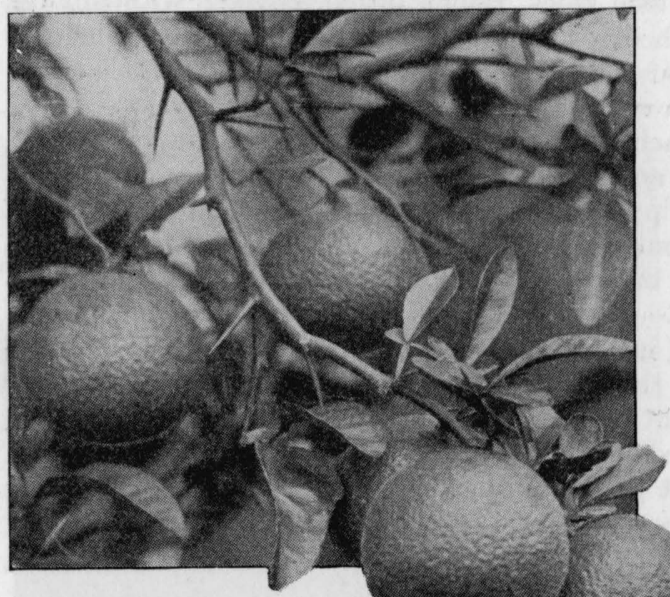

FIG. 44. Fruiting twigs of Rusk citrange

ness, bitter; oil-cells elevated, ballooncells small, globular; sections 10; flesh yellow, tender, juicy; flavor strongly acid and somewhat bitter; seeds few in number. Season, September to November. (Figs. 42, 44.)

Foliage dense, trifoliate, dark green and glossy. A strong grower and prolific.

Rustic (Hybrid 783). - Form round or very slightly flattened; size medium, $2 \frac{1}{2}$ by $27 / 8$ inches; calyx small; color light yellow; rind of medium thickshaped; sections 6-12; flesh greenish yellow, tender; flavor acid bitter; seeds few to many, or sometimes seedless. Season, September to November.

Tree a spreading vigorous grower, with dark green trifoliate leaves. Very hardy.

Savage (Hybrid 7779).-Form oblate, frequently furrowed; size medium, $21 / 2$ by 3 inches; calyx small; color light orange; rind thin, $1 / 8-$ $\frac{3}{16}$ inch, covered with very fine hairs; oil-cells spherical; sections 8-10; flesh light yellow, tender, juicy; flavor acid, rather bitter; seeds 3 or 4 to each fruit. Season, September to November.

This variety is prolific, vigorous and hardy, with both trifoliate and unifoliate leaves.

Sinton citrangequat.-Fruits varying from slightly flattened to slightly 
elongated; growing in clusters; diameter varying from 11/2-17/8 inches; calyx small, persistent, slightly protruding; sunken pistil surrounded by a very small raised circle; color variable, ranging from a light orangeyellow to a light flame-scarlet; rind very thin, smooth, highly colored, $\frac{1}{16}$ inch in thickness and much like kumquat, showing almost none of the flavor of the trifoliate orange; oil-cells few, variable in number; segments 7-8; no seed in 100 fruits, occasionally one or a few; pulp pale, varying from orange-buff to a light cadmium; flavor sharply acid, decidedly limelike, with only faint suggestion of citrange flavor given by the oil from the rind, no citrange flavor in the juice; makes a good ade; core very small and segment walls very thin.

Tree much more hardy than the lime; bearing twigs spineless: leaves on bearing branches unifoliate, rather thin, $2-3$ inches in length by $13 / 8$ nches in width; petiole $1 / 2$ inch long, slightly winged; midrib heavy, prominent on upper surface; leaves tapering slightly toward the apex. (Swingle and Robinson.)

The Sinton citrangequat is a hybrid between Nagami kumquat and Rusk citrange, the result of a cross made in the early spring or summer of 1909 by Walter T. Swingle. It has been known as C. P. B. No. 48050.

Telfair citrangequat.-Fruit spherical (sometimes slightly flattened or elongated), mature fruits having a diameter of $1 \frac{1}{4}-1 \frac{1}{2}$ inches; calyx persistent with 5 long points;

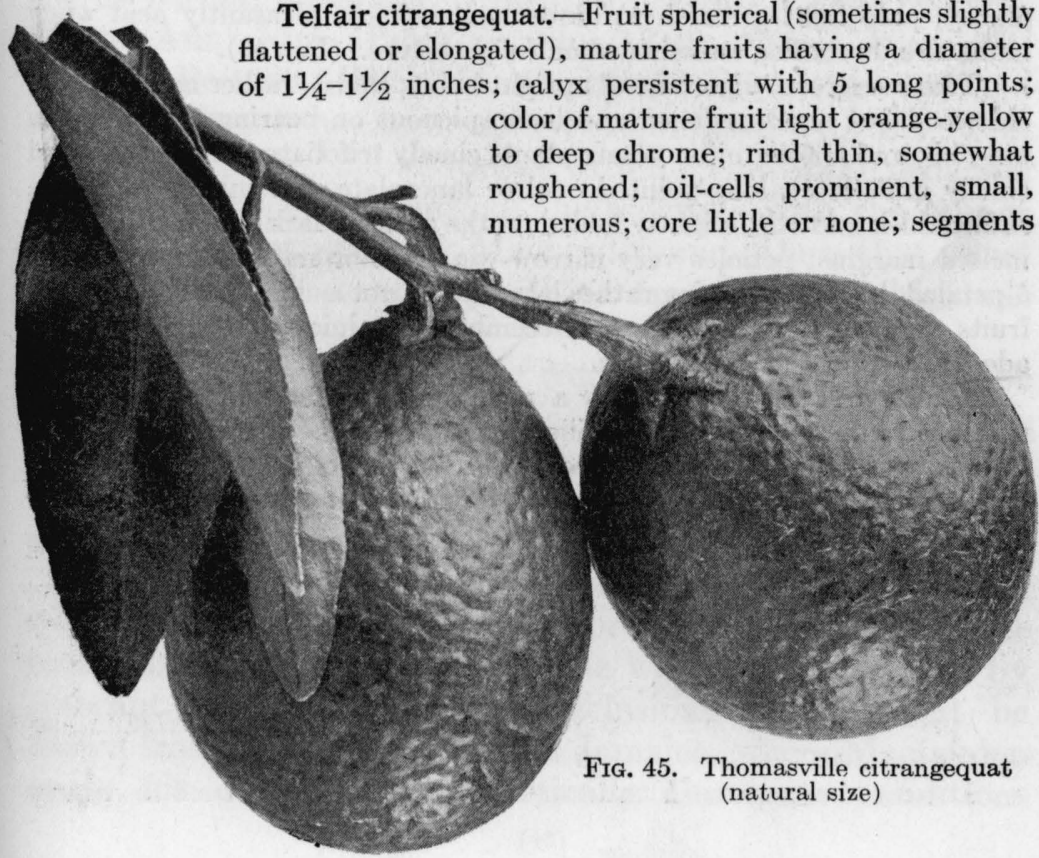


4-6 (usually 5); seeds few, variable in size, usually undeveloped; pulp pale yellow, Pinard yellow, sharply acid, and retaining this quality when mature; rind slightly bitter.

Tree evergreen, vigorous, of upright habit: leaves uni-, bi-, and trifoliate, generally obovate, $11 / 2-21 / 2$ inches in length, finely serrated; plant fairly thorny, thorns smaller in size on the fruiting twigs; bloom often occurring over a long period, giving a semi-everbearing fruiting habit. (Swingle and Robinson.)

Telfair citrangequat is a cross made by Swingle at the same time as Sinton, in the spring of 1909 , between the Nagami kumquat and Willits citrange, and has been known as C. P. B. No. 48005 .

Thomasville citrangequat.-Fruit oval or nearly spherical, mature fruits having a long diameter of $13 / 4-2$ inches, diameter in cross-section $1 \frac{1}{2}-17 / 8$ inches; calyx strongly persistent with usually 5 long claw-like points; fruit-spur long, swollen, and characteristically bent downward apparently by the weight of the fruit; color of mature fruit yellow to orange-yellow; rind thin ( $1 / 8 \mathrm{inch})$, somewhat roughened or "pebbly"; oilcells small, depressed; segments usually 7 or 8 , thin-walled; core little or none; seeds varying from none to 12 , usually not more than 6 , small and plump; pulp light greenish to amber color, juicy, pleasantly acid when immature, becoming sweetish when fully mature. (Fig. 45).

Tree evergreen, vigorous, of upright habit; thorns rather numerous on old wood but much reduced and inconspicuous on bearing twigs: leaves uni-, bi-, and trifoliate (on young plants chiefly trifoliate, on bearing wood chiefly unifoliate), long-pointed oval or lanceolate, 2-3 inches in length, rather thick and stiff, slightly folded on the midrib, dark green, with finely incised margins; petioles very narrow-winged: flowers small, pure white, 5-petaled, bloom appearing rather late though not as late as the kumquat: fruits ripening from October to December, but juicy and serviceable as ade fruits from July to October.

Thomasville citrangequat is a very hardy variety of Citrus. It is possible to grow it at Thomasville, Georgia, where the temperatures at times are sufficiently low to damage all other ordinary kinds of citrus. With this fruit as a starting-point it should be possible to obtain other hardy edible citrus. 


\section{CHAPTER IV}

\section{THE BIGARADE ORANGES}

In America the oranges of this group are commonly referred to as sour oranges, but for certain reasons it has been deemed best not to adopt this name, although the sour orange is the most important variety in the group. They have also been called Seville oranges, but this cognomen has also been given to some of the sweet oranges. All these appellations have here been discarded as a group name in favor of the French bigarade.

The sour orange (Citrus Aurantium) was described and named by Linnæus (Species Plantarum, 782, 1753). Subsequently it has been named and renamed many times, Citrus florida, Salisbury (Prodr. 378, 1796), Citrus vulgaris, Risso (Ann. Mus. Paris xx 190, 1813), Citrus Bigaradia, Risso \& Poiteau (Hist. Nat. Orang. 72 t. 30, 1818-22) and others. Often it has been united or confused with the sweet orange and placed in one species with it. One of the principal reasons advanced for uniting the bigarade with the orange is the statement made by Macfayden and others that sweet orange seed frequently produces trees bearing bigarade oranges.

In view of evidence to the contrary, there appears to be no reason for believing that Macfayden's observations were accurate. In Porto Rico, orange trees have been used to a considerable extent for affording shade in the coffee plantations. The plantings are invariably mixed, here a sweet orange, there a bigarade. The plantings are indiscriminate, no notice being taken as to the kind of tree from which the seed was procured. Moreover, the work was performed by ignorant laborers and any conclusions which might be drawn from it are worthless. In Jamaica, where Macfayden made his observations, practically the same conditions 


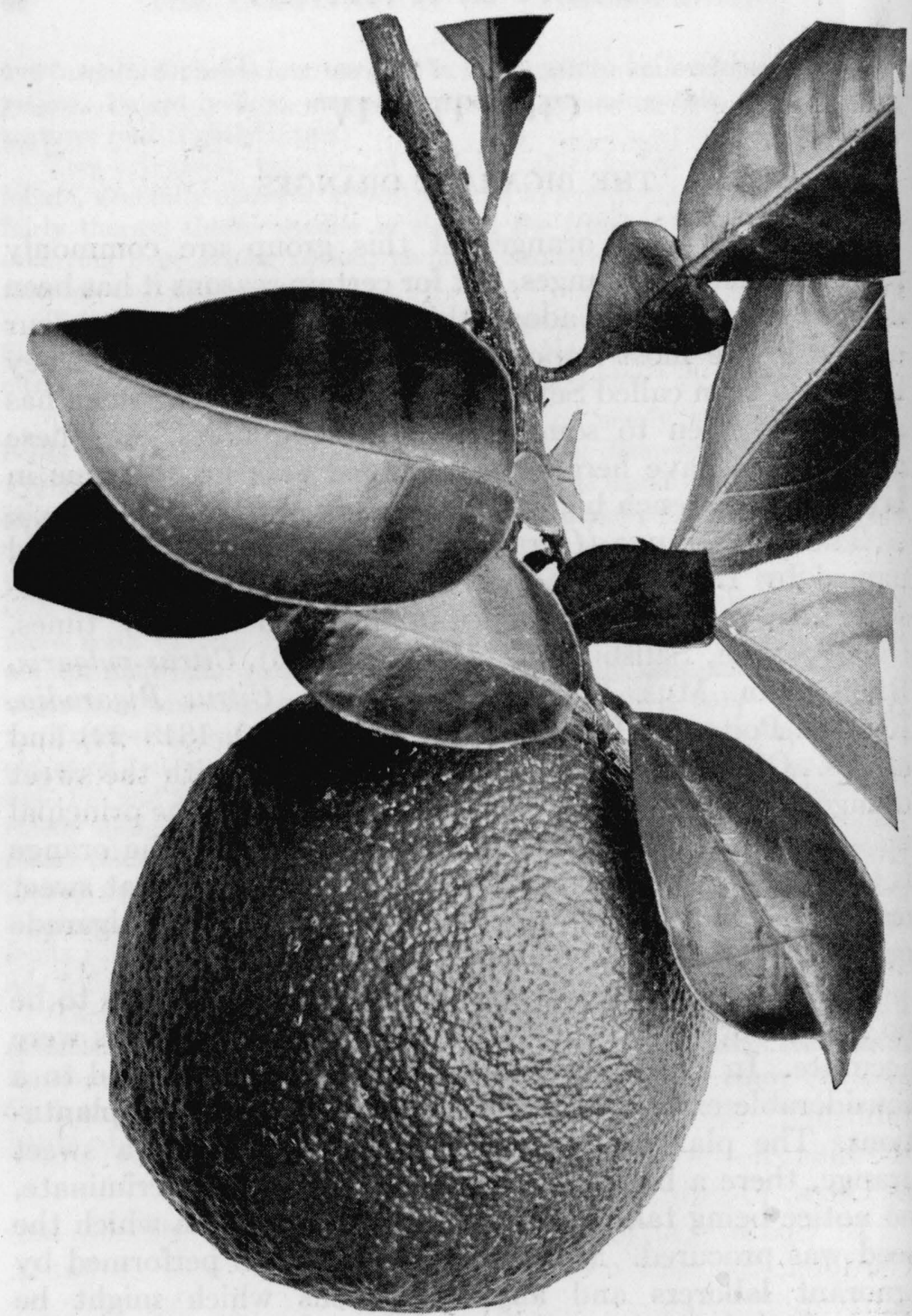

FIg. 46. Leaves and fruit of the sour orange (about natural size) 
prevail, and the laboring class is the same. The natives were probably the first to aver that sweet orange seed produced trees bearing bigarade fruit, and this myth, like many another, found its way into writings and obtained an abidingplace in botanical and horticultural literature.

Sour oranges, or bigarades, are distinguished from the sweet varieties by their broadly winged petioles, the distinctly different odor of the essential oil, the hollow center in the fruit, the taste of the fruit, and their strong resistance to diseases of many kinds.

Even though the difference between the bigarade and the sweet orange is slight, if it has remained specifically distinct through a period of about eight centuries, reproducing itself true to seed without the interference of man throughout that period, it certainly is entitled to specific rank, and the history of the group shows that it has done so.

The Spaniards brought the first bigarade oranges to America. The fruit was obtained by the Indians and they carried it about on their journeys. The seeds were dropped where the fruit was eaten, and finding in Florida and other regions a soil and climate adapted to their growth, produced trees where they had been deposited. As a result, wild groves were formed on the shores of lakes and rivers. Natural groves, where four to five hundred trees grew on an acre, were not uncommon at one time in many parts of Florida, and even to this day the sour orange grows wild in many of the hammocks. By top-working these natural groves, many of the early sweet orange groves were established. Some of the latter are still in existence. One of the most noteworthy is a part of the old Bishop-Hoyt grove at Citra, Florida.

In Spain, particularly in the vicinities of Seville and Cordoba, the sour orange is planted in groves or orchards, cultivated, irrigated, and given good care. As the trees are extremely resistant to diseases of various kinds, and not affected there by "scab," these plantings are very uniform 


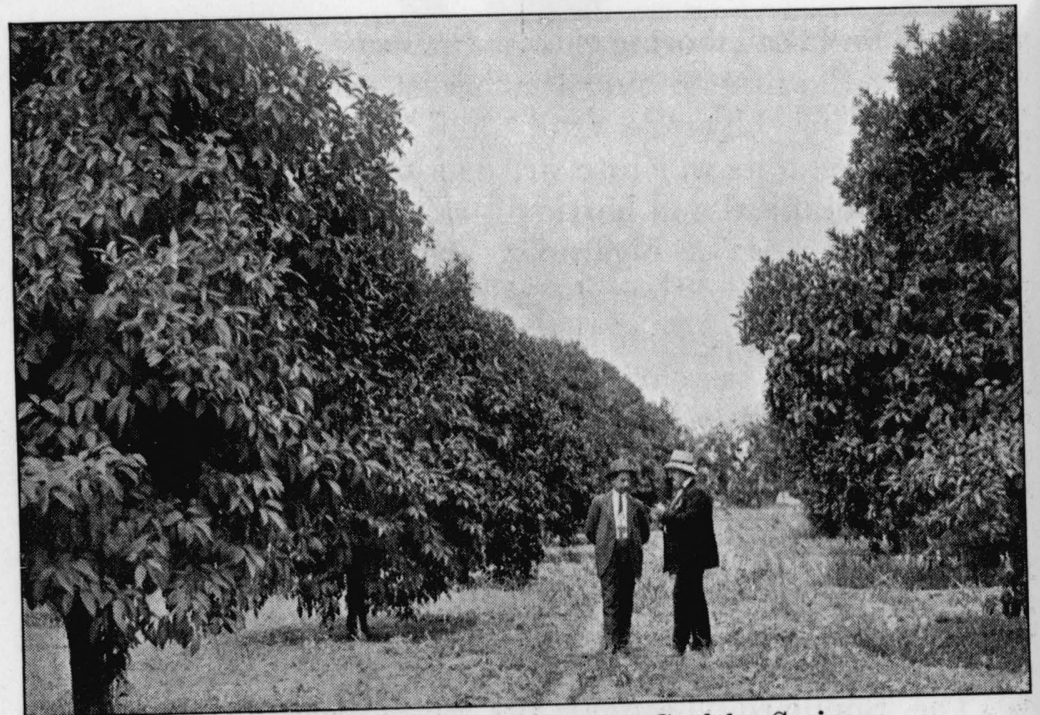

FIG. 47. A sour orange grove near Cordoba, Spain

and among the most beautiful in Spain. Many of the groves are very old and the trees have reached large size. The variety appears to differ from that grown in Florida and Cuba - the leaves are longer, narrower, and more pendulous. The fruit is exported from Spain to Great Britain and other countries, where it is manufactured into preserved products.

In America the bigarade oranges are unimportant commercially. The greatest use to which the sour orange, the most important variety of the group, is put is for stocks upon which to work other citrus fruits, and for this purpose, the seed is in considerable demand at a fair price. Orange marmalade of the finest quality may be manufactured from the fruit, while a refreshing drink, "orangeade," may be made from the juice.

\section{VARIETIES}

Bitter-Sweet.-Form oblong, flattened at the ends; size medium or large, $23 / 4$ by $27 / 8$ inches, 3 by $3 \frac{5}{8}$ inches; color deep orange; apex flattened, depressed; base flattened, rough, depressed; calyx small, set in a de- 
pression; rind smooth or somewhat uneven, $1 / 4$ inch thick, adhering rather loosely; oil-cells of medium size; flesh dark orange; sections 8-10; juicesacs of medium size, spindle-shaped; juice abundant, colored; pulp melting; flavor of juice sweet or sweetish, inner rind and partitions very bitter, somewhat musky, peculiar; pith $1 / 2^{-3 / 4}$ inch across; seeds $5-8$, wedged. Season, January to March.

The history of this variety in Florida goes back to the first Spanish explorations and settlements. In tree and external appearance of the fruit, the Bitter-Sweet is indistinguishable from the sour orange, and the only striking difference is in the flavor of the fruit, the juice being of sweet and pleasant taste, with bitter rind and partitions. On careful comparison, the seeds show some slight differences. By some persons the Bitter-Sweet orange is regarded as a hybrid between the sour orange, C. Aurantium, and the sweet orange, $C$. sinensis.

Sour.-Form rounded-oblate; size large, $23 / 4$ by $3 \frac{1}{4}$ inches; color yellow or orange-yellow, sometimes reddish-orange when fully matured; apex flattened; base somewhat roughened, slightly depressed; the calyx set in the depression; rind smooth or slightly rough, with many of the oilcells depressed, $\frac{3}{16}$ inch thick; oil-cells small, slightly compressed; flesh dark yellow, sections 10-12; juice-sacs spindle-shaped and of medium size; juice plentiful, slightly colored; pulp melting; flavor sour, when thoroughly ripened rather agreeable, peculiar and distinct; pith $3 / 4$ inch across; seeds numerous, many abortive, wedge-shaped, slightly ridged. Season, January to March. (Fig. 46.)

This variety is probably one of the first fruits the Spaniards brought to Florida shores. In many parts of the state it became domesticated, forming dense thickets in the hammocks on the shores of rivers and lakes. The fruit is useful for making marmalades and orangeade, and the tree is extensively used as a stock for citrus trees. 


\section{CHAPTER V}

\section{THE SWEET ORANGE}

This group of citrus fruits has been known by a number of names, usually derived from the localities from which they were secured. They have been referred to as Portugal oranges, Malta oranges, and others, but sweet orange is now the name generally accepted. It can scarcely be considered descriptive, however, as the taste of a good fruit of this group is not sweet; sweetness should preponderate, but it should be modified by acid and blended with it. Nevertheless, usage has established the name; for it is used everywhere, and has been for hundreds of years.

These fruits were known to Ferrari as Aurantium vulgare medulla dulci, while Volkamer in 1713 called them Aurantium fructu dulci. They have often been confused and placed with the sour oranges, from which they are distinct. Linnæus (Species Plantarum, 783, 1753) placed the sweet orange as a variety of sour orange, naming it Citrus Aurantium var. sinensis. Later Citrus Aurantium was applied to the sweet orange by Loureiro (Fl. Cochin 11.466, 1790) and by others. Osbeck separated it from other citrus and named it Citrus sinensis (Dagbok Ost Ind. Resa 41, 1775), now accepted as the correct name for the group.

The researches of Gallesio go to prove that sweet oranges were not known in Europe until early in the fifteenth century. They were rapidly disseminated after their introduction, however, and in a comparatively short time were cultivated in all parts of southern Europe suited to their growth. Later their culture was still further extended, the fruit being grown in houses, of which both Ferrari and Volkamer give illustrations, so that by the end of the seventeenth century they were raised under cover in many parts of Europe, where their culture could not be successfully accomplished in the open air. 


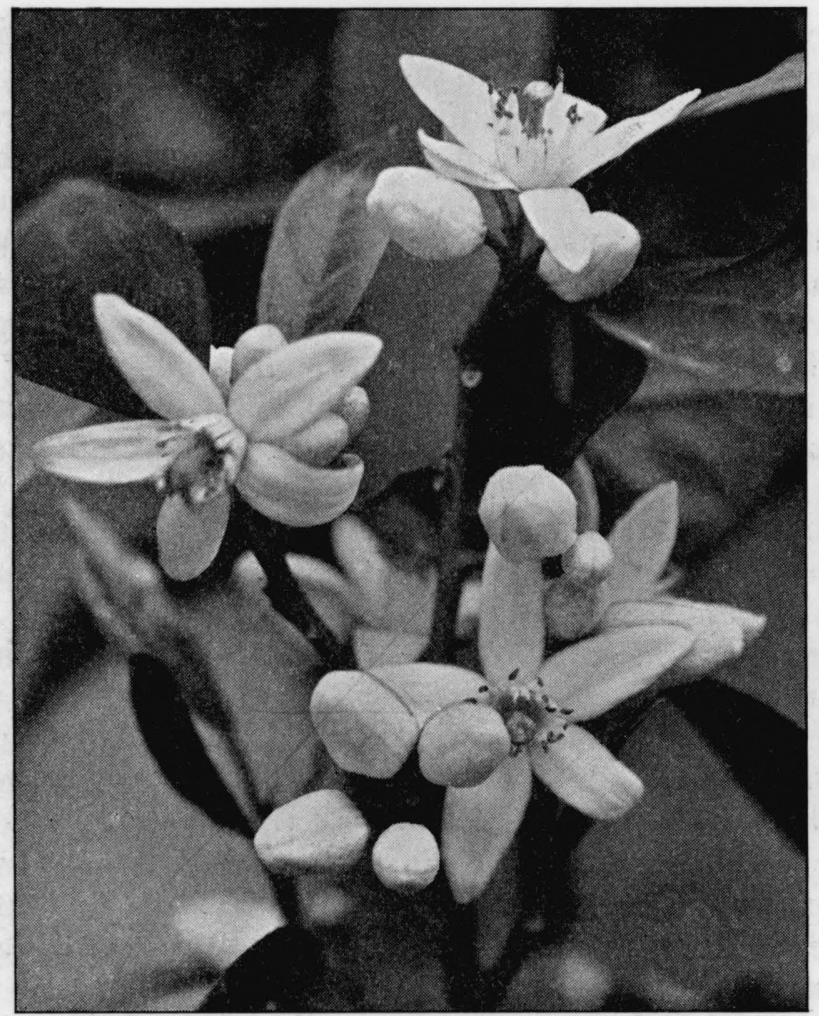

Fig. 48. Flowers of the sweet orange (enlarged 1/4)

The date of their introduction into America is merely a matter of conjecture. The Spaniards, undoubtedly, were responsible for their being brought into many parts of the New World. On the authority of Acosta and Piso, who wrote concerning their travels in the West Indies and Brazil, respectively, we must conclude that oranges of some sort were well established prior to the years 1600 and 1648 in those parts of America which they visited. In Florida the early settlers found sweet orange trees growing in the hammocks in some places. The whole strain of oranges now 
largely grown on the Indian River had their origin in one of these wild groves. But the fact remains that the sweet orange was not so widely distributed throughout Florida as the sour orange; at least, it was not found so abundantly in the native woods. This may be accounted for by the fact that the sweet orange, being less hardy, was not as capable of making a place for itself among the native trees as the sour variety. It is not improbable that the sweet orange was introduced at a later date than the sour orange, which might also, in a measure, account for its not being so common. But groves were established and in a thorough state of cultivation early in the nineteenth century, and even before that time considerable attention was given to citrus culture.

The introduction of the orange into California is thus told by B. M. Lelong:

"In 1767 the Jesuits were expelled from the missions in Lower California, their possessions were turned over to the Franciscans, and Junipero Serra was selected as President of the Missions. A dispute arose between the Franciscans and Dominicans over the division of the property. The latter claimed an interest in the mission work. In consequence of this a division was made, and in 1769 the Franciscans started northward, entering and occupying what is now the State of California. . . .

"Jose del Galvez, 'visitor-general' and secular head, with Father Serra, made arrangements for the establishment of settlements. Twenty-one missions were established, all but three of which had gardens and orchards. The mission orchards were very small, and some consisted of but few trees, but those trees played an important part in the horticultural advancement of the State, for they showed the possibilities in fruit culture, and furnished seeds, stocks and scions for many orchards. ... The chief fruits brought by the Fathers were oranges, figs, grapes and olives. . . ."

Of all the citrus fruits cultivated in America at the present time, the sweet orange is the most important. Its culti- 
vation represents more capital than all the others combined, and it is likely to maintain its present position.

It is used mainly as a dessert fruit, and, for the most part, is consumed without cooking. In fact, cooking spoils the sweet orange, as it loses its flavor and becomes insipid. As a raw fruit, it is unsurpassed.

The number of varieties of sweet oranges which have been brought before the public is considerably over one hun-

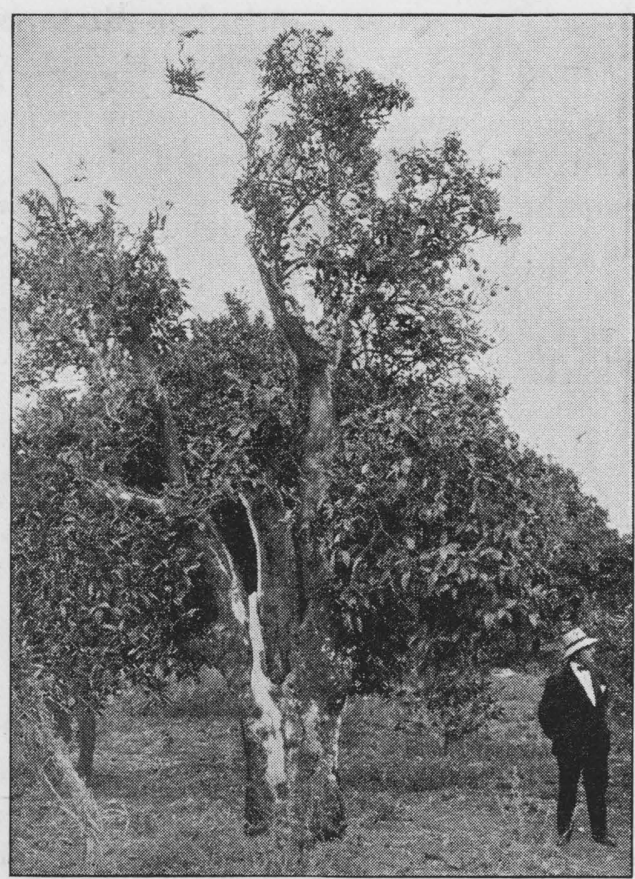

Fig. 49. A sweet orange tree, more than 250 years old, in a grove near Cordoba, Spain dred, but descriptions of them, such as may be found for apples, pears, and other fruits, are comparatively few. Again, the origin of many of them is lost in obscurity, and, as a result, many varieties have received a number of names. Unfortunately, it has not been possible to obtain specimens of all the sweet oranges, but a goodly number have been secured and are described in the section on varieties.

Great difficulty has been encountered in grouping the sweet oranges, but it has finally been decided to class them as Spanish oranges, Mediterranean oranges, Blood oranges and Navel oranges. This classification is, in some respects, unsatisfactory, and further study of the group may produce something better. 


\section{SPANISH ORANGES}

Tree large and of strong vigorous growth, well foliaged; the leaves oval, pointed, petioles frequently strongly winged; fruit of rather coarse grain, but of good quality, large, ripening for the most part in midseason; seeds numerous, large, wedged and flanged. The name has been given because these oranges have come from the Spanish introductions of two or three centuries ago. The great mass of Florida seedling fruit comes from trees of this group.

Most of the Spanish oranges have originated as seedlings in America, the larger number of the varieties having come from the seedling groves of Florida. Generally they produce fruit in abundance, and the greater part of the fruit at present shipped from Florida, Cuba, and Porto Rico is of this class. In California they have not proved desirable in most cases.

\section{MEDITERRANEAN ORANGES}

Tree standard or half dwarf, generally distinct in habit of growth, many of them not distinguishable from blood oranges; foliage abundant, leaves small, closely set, or larger and resembling those of the Spanish oranges; fruit heavy, rich, vinous, of excellent quality, fine-grained, round, oblate or somewhat oval, ripening in midseason or later; seeds oval, plump, pointed.

The fruits are of the same general nature as the blood oranges, lacking the blood color, but are larger, and many of them are more prolific, although in these respects they may be similar to the bloods.

Most varieties of this group have been introduced from the Mediterranean region; others have come from the Azores and some from Palestine; and some have originated in Florida and other parts of America.

They are here called the Mediterranean oranges because they have come either directly or indirectly from the citrus districts of southern Europe. Some kinds have been im- 


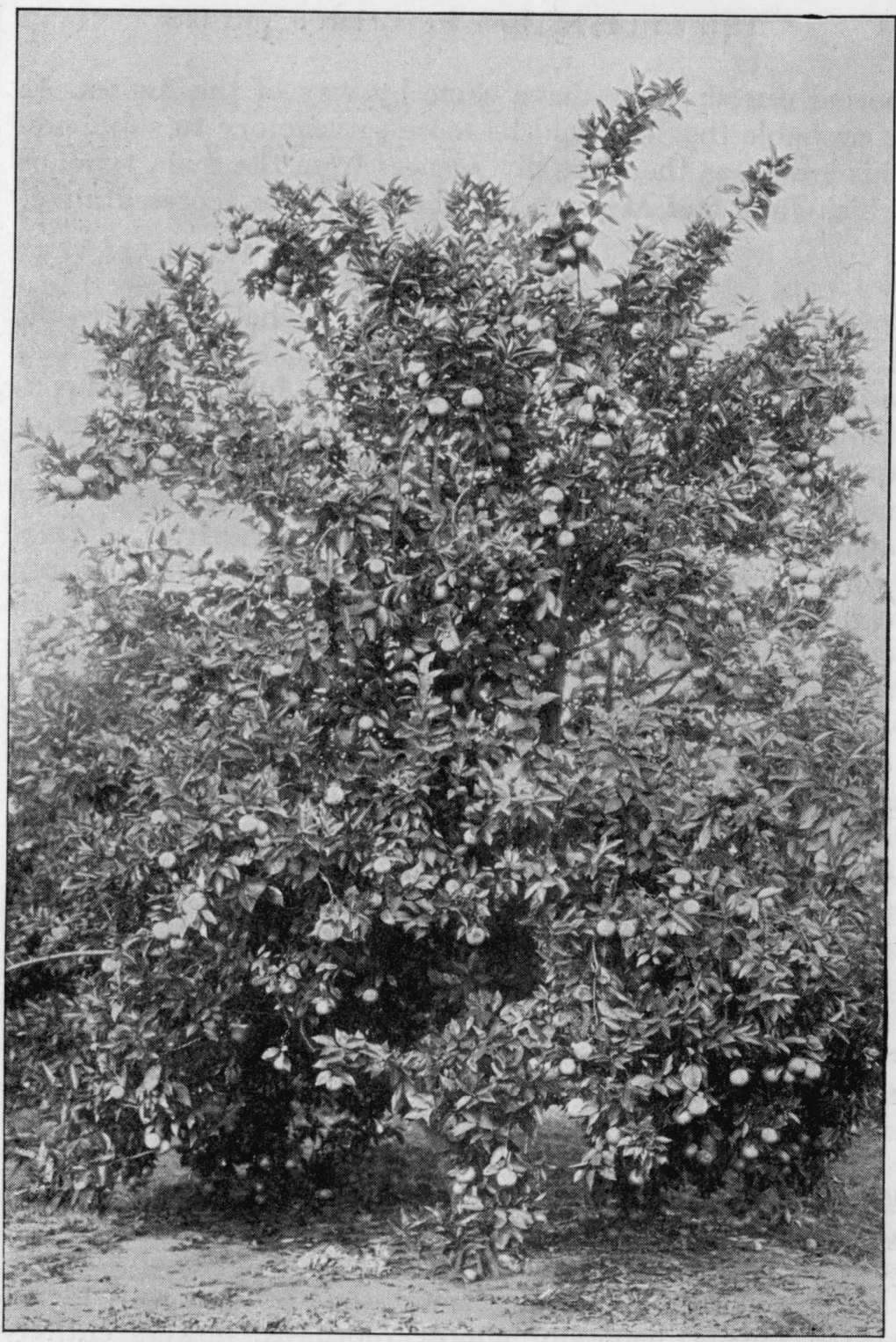

FIG. 50. A Pineapple orange tree in full bearing. Pineapple is the most noteworthy of the Florida varieties

(53) 
ported direct; others have come by way of the Azores. It is probable that it would be more satisfactory to subdivide this group, as there are divergences from the main type, of which Jaffa and Majorca may be said to be representative.

\section{BLOOD ORANGES}

Tree dwarfish, compact, distinct in habit of growth; foliage abundant, the leaves small, oval, rounded, petioles usually almost without wings; fruit when fully matured containing ruby-red pulp or pulp streaked with red, of superior quality, edible earlier in the season, but not showing blood markings until late, generally small or medium-sized; rind assuming a reddish blush at maturity. The fruit of trees worked on trifoliate orange stock show blood markings earlier in the season than on other stocks. Fruits with colored pulp are also found among the grapefruits and shaddocks.

This sub-group contains the best oranges known, the quality of the fruit being equaled by few others and certainly surpassed by none. Seeds are generally few in number, small and plump. The small size of the fruit of some varieties is objectionable. Except for the differences in the fruit, the general characteristics of the group are almost the same as those of the Mediterranean oranges. Most of the varieties now grown in America came originally from the Mediterranean citrus districts, the late General Sanford and Mr. Charles Armory being responsible for their introduction.

Gallesio, in his "Traite du Citrus," Paris, 1811, mentions the blood orange as one of the varieties cultivated extensively in his day in Malta and Provence, and by amateurs and seedsmen in Liguria.

\section{NAVEL ORANGES}

Tree rather dwarf, with well-rounded top and glossy green foliage, generally almost thornless; flowers entirely lacking in pollen or only poorly supplied, pistils proliferous, 
giving rise to an umbilical mark of greater or less extent on the apex of the fruit; fruit of superior quality, but perhaps not quite equal to the best of the Mediterranean and blood types. A few varieties not included with those of the navel type are sometimes navel marked. Among these may be mentioned Ruby, Boone, St. Michael, Blood, and the Cleopatra mandarin. There appears to be nothing constant about these markings.

In Florida the navel oranges have not been a success, owing to the small crops which they usually produced. $\mathrm{Mr}$. E. H. Hart, however, long ago called attention to a cross between Sustain and Botelha which is prolific in the abovementioned district. This tendency toward shy bearing can be overcome in part in Florida by a judicious choice of stocks. The Bahia navel orange is the variety par excellence of the California districts, and there seems at present to be no good reason why any other orange of its season should be planted. All things considered, the Bahia is the most noteworthy of the whole group of navel oranges.

Mr. D. J. Browne ("Trees of America," page 58, 1846) says that he introduced navel orange trees from Brazil in 1835 and caused them to be planted on the estate of $\mathrm{Mr}$. Z. Kingsley, Drayton Island, Lake George, East Florida. When he wrote, in 1846, they were still believed to be there. So far as known at the present time, all trace of this introduction has long since been lost. Navel oranges have never been prolific or satisfactory bearers in Florida, and on this account this introduction probably was not favorably received by early settlers.

Regarding the first mention of the navel orange in citrus literature, Lelong ${ }^{1}$ says: "The first illustration of the Navel orange appears in a volume, 'Table xvi.-Historiæ Naturalis de Arboribus et Fructibus, Libri Decem. Johannis Jonstoni, Medicinæ Doctoris. Francofurti, o-m., MDCLXII' ('The Natural History of Trees and Fruits. Ten Books. By

${ }^{1}$ Lelong, B. M. Culture of the Citrus in California, pp. 52-53, 1902. 
John Johnson, Doctor of Medicine. Frankfort on Main, 1662'), referred to as Aurantium foetiferum. . . . Although no description of the navel orange appears in the text, this is the earliest reference known."

In 1646, Baptiste Ferrari, a monk of the Society of Jesus, published at Rome his famous work, "Hesperides sive de Malorum aureorum cultura et usu, Libri Quattuor.” On page 403 he describes and on page 405 illustrates a variety of orange, "Aurantium foemina sive foetiferum." Of it Ferrari says: "This Aurantium imitates to some extent the fertility of the tree which bears it in that it struggles, though unsuccessfully, to produce the fruit upon itself. ... On the end of the fruit is another, sometimes with a thin rind investing it, but more frequently naked, so far at least as the pulp (of the larger part) is concerned; this (second fruit). is composed of an inner medulla of about four spikes: the young brood, as it were, of fruits half seen pushing out through the gaping umbilicus, which is sometimes more and sometimes less closely compressed." This is a navel orange both by description and illustration.

There is such a striking resemblance between the illustration given by Ferrari and that reproduced by Lelong from Jonston's work that the writer is compelled to believe that Jonston copied his illustration directly from Ferrari's "Hesperides."

Many writers since the days of Ferrari have referred to the navel orange, notable among whom may be mentioned Volkamer, who in his "Hesperidium Norimbergensium, 1713," referred to two varieties of navel oranges, "Aranzo de fior doppio," and "Aranzo di fiore Scorza doppio," which he described on pages 201 and 202 and illustrated on pages 202b and 202c.

A closer study of citrus literature may bring to light still earlier references to this interesting type of fruits. Apparently they were not so favorably regarded in Europe as other varieties because they did not become commercially important. 


\section{VARIETIES OF THE SWEET ORANGE GROUP}

\section{Spanish oranges}

Acme (Beach's Acme).-Form oblate; size medium to large, $25 / 8$ by 3 inches; color orange; apex rounded, very slightly depressed, scarred; base slightly creased; calyx small; rind smooth, thin and leathery; oil-cells large, flush with the surface; sections 11, rather irregular in size; flesh of medium grain, orange-yellow; juice-sacs rather large; juice plentiful, colored; pulp melting, free from rag; acidity and sweetness well blended; flavor rich and vinous; quality very good; pith small; seeds about 14, oval, pointed, of medium size. Season December and January. Introduced by the late A. J. Beach.

Arcadia. - Form oblate or rounded oblate; medium to large, 3 by $3_{16}^{\frac{8}{16}}$ inches, $23 / 4$ by $31 / 4$ inches; color orange; apex rounded; base slightly creased, rounded; calyx small; rind smooth or slightly pitted, thin; oilcells flush with the surface, or sometimes sunken; sections about 13 , clearly marked; flesh coarse-grained, orange-yellow; juice-sacs long, spindle-shaped; juice abundant, colored; pulp melting; acidity and sweetness not well blended, the acid being deficient; flavor rather insipid; quality fair; pith large; seeds 24 , oval, pointed or oblong, $1 / 2$ by $3 / 8$ inch. Season December and January.

Arcadia is supposed to have originated as a seedling at Arcadia, Florida, and was introduced into cultivation by the Rev. William Watkin Hicks.

Boone (Boone's Early).-Form rounded; size medium, $27 / 8$ by $31^{1}$ inches, $2 \frac{9}{16}$ by 3 inches; color deep yellow; apex rounded, scarred, slightly depressed; base flattened; calyx rather large, segments pointed; rind smooth, $1 / 8^{-\frac{3}{16}}$ inch thick; oil-cells flush with the surface; sections 11; flesh yellowish orange, medium coarse; juice-sacs spindle-shaped, elongated or rather short; juice abundant, colored; pulp melting; acidity and sweetness fairly good, but the acid not strongly developed; flavor very good; pith medium size, 1/2inch across; seeds 25 , short, pointed, of medium size. Season October to middle of November. Should be shipped as soon as colored, as it is likely to drop.

This variety is said to have been originated by "Old Man Giddings," 3 to 4 miles south of Webster, Florida. The seed from which the trees came were given him by a man who passed that way about thirty years ago. The variety, according to W. S. Hart, was propagated and sold by David Collins, of Webster, for many years under the name of "The Giddings." Under the name "Boone," it was brought to notice by C. A. Boone, of Orlando, in the fall of 1889.

Dummitt. - Form rounded or slightly oblate; size large, $3 \frac{1}{8}$ by $3 \frac{1}{16}$ 
inches; color light orange; apex rounded; base slightly creased; calyx of medium size, segments pointed; rind slightly pitted, thin; oil-cells flush with the surface or somewhat sunken; sections 11, rather regular in size; flesh yellow, coarse-grained; juice-sacs of medium size, spindle-shaped; pulp melting; acidity and sweetness fairly well blended; flavor fairly good; quality medium; pith small, $1 / 4^{-1 / 2}$ inch; seeds about 14, large, oblong, creased or ridged. Season December to February.

In a letter from W. S. Hart, of Hawk's Park, Florida, dated July 12, 1903, he says: "This variety was budded from a wild sweet tree into the Captain Dummitt grove between Mosquito Lagoon and Indian River. These wild sweet trees were found in Turnbull Hammock back of Hawk's Park, by John D. Sheldon in 1832. He transplanted 600 of them to the Sheldon place, now known as the Packwood place, on the Hillsborough River, now known as Indian River North. Most of the Indian River fruit came from these trees."

Early Oblong (St. Michael's Egg).-Form oblong rounded; size medium to large, 3 by 3 inches; color yellow to orange; apex rounded, sloping abruptly, slightly depressed; base flattened, slightly shouldered, smooth or somewhat creased; calyx small, elevated; rind smooth, $1 / 8-\frac{3}{16}$ inch thick; oil-cells flush with the surface or slightly elevated; sections 11-13; flesh yellow to orange-yellow, of medium grain; juice-sacs spindle-shaped, broad at the base; juice plentiful, colored; pulp melting; acidity and sweetness quite well combined; flavor sweet, good; pith compact, $1 / 2$ inch across; seeds 22 , oval, pointed or rounded, plump, rather large. Season September and October.

A variety originally from the May's Grove, Orange Mills, Florida, and apparently identical with the St. Michael's Egg from Rivers' English Nurseries.

Enterprise (Enterprise Seedless).-Form roundish, oblong; size large, $2 \frac{1}{6}$ by $3 \frac{1}{4}$ inches; color orange; apex slightly depressed; base creased, shouldered; calyx depressed; rind pitted, $1 / 8$ inch or more in thickness; oil-cells large; sections 12, rather irregular in size; flesh coarse, orange; juice-sacs large, spindle-shaped; juice abundant, colored; acidity and sweetness well combined; flavor rich, quality very good; pith rather open, $1 / 2$ inch across; seeds 6 , large, oval, pointed. Season October and November.

Said to have come from the old Dummitt grove originally. Its seedlessness was discovered by one of the Starkes, of Glenwood, Florida. The variety was named after the town of Enterprise, of the same state.

Foster.-Form rounded, oblate; size medium to large, $25 / 8$ by $27 / 8$ inches, $25 \%$ by 3 inches; color orange; apex rounded and slightly depressed; base rounded, smooth; calyx rather large, $3 / 8$ inch across, $1 / 8$ inch thick; 
oil-cells slightly elevated or flush with the surface; sections 12, well defined; flesh rather coarse, orange; juice-sacs large; juice abundant, colored; pulp melting; acid well defined; flavor rich, quality excellent; pith $1 / 2$ inch across, solid; seeds 13, oval, pointed, large. Season October and November.

According to Reasoner, the original tree of this variety was grown from seed obtained from Havana about 1847, and in 1887 it was still standing in the grove of Col. C. H. Foster, Manatee, Florida. It was introduced by Reasoner Bros., Oneco, about 1883.

Hick (Hick's Sweet Seville).-Form rounded oblate; size medium, $27 / 8$ by 3 inches; color bright orange; apex rounded, scarred; base smooth; calyx small; rind smooth or with the large conspicuous oil-cells projecting a little above the surface, $1 / 8$ inch or slightly more in thickness; sections 10 , regular; flesh fairly coarse-grained, yellowish orange in color; juice-sacs medium to large, spindle-shaped; juice abundant, colored; acidity and sweetness not very well combined, scarcely enough acid; flavor agreeable but lacking in character; pith compact, $3 / 8$ inch across; seeds 10 , oblong, ridged, large, $5 / 8$ by $1 / 4$ inch. Season early.

Hick is supposed to be a seedling originated at Arcadia, Florida.

Homosassa.-Form round or slightly oblate; size medium to large, $23 / 4$ by $2 \frac{1}{16}$ inches, 3 by $31^{7}$ inches; color yellow or orange-yellow, apex rounded, slightly depressed and scarred; base round or somewhat flat, sometimes slightly creased; calyx small, slightly pointed; rind 1/8 inch thick, tough, smooth; oil-cells slightly sunken or flush with the surface; sections 11, large, fairly regular; flesh coarse-grained, yellow; juice-sacs large, spindle-shaped; pulp melting; remarkably free from rag; acidity and sweetness well blended; flavor sprightly, rich and vinous; quality excellent; pith $\frac{9}{16}$ inch across, solid; seeds 20-24, plump, beaked or pointed, large, $3 / 4$ by $3 / 8$ inch. Season December to February.

This variety is one of the best of the Florida seedlings. According to Reasoner, it originated in the grove of Hon. Mr. Yulee at Homosassa, Florida.

Indian River.-Form rounded; size medium to large, 3 by $3{ }_{16}^{1}$ inches; color bright orange; apex rounded, smooth; base rounded; rind $1 / 8$ inch thick, smooth; oil-cells flush with the surface or slightly indented; sections 10, well defined, fairly regular; flesh fine-grained, orange-yellow; juice-sacs small; juice abundant, colored; pulp melting; acidity and sweetness well blended; flavor rich, excellent, and sprightly; pith solid, 1/2 inch across; seeds 17-20, long oval, pointed. Season December to February.

A native seedling variety, originated on the Indian River, Florida, hence its name. Its origin is probably the same as that given by W. S. Hart for the Dummitt orange.

Madame Vinous.-Form roundish-oblate; size small, medium or large, 
$2 \frac{11}{16}$ by $27 / 8$ inches, $23 / 4$ by $3 \frac{3}{16}$ inches; color orange; apex rounded or slightly depressed; base rounded, flat, sometimes creased; calyx small, segments pointed; rind fairly smooth, $\frac{3}{16}$ inch thick; oil-cells flush with the surface or slightly sunken, small; sections 11; flesh coarse-grained, orange; juice-sacs large, broad, and elongated; juice plentiful, colored; pulp melting; acidity normal, sweetness well combined with the acid; flavor rich and good; pith $1 / 2$ inch across, solid; seeds present, roundish flattened, plump and pointed, $1 / 2$ by $3 / 8$ inch. Season December and January.

An Indian River seedling originated by Major Magruder, of Rockledge, Florida, and introduced about 1882.

Magnum Bonum.-Form oblate; size large, $23 / 4$ by $31 / 4$ inches; color orange-yellow; apex indented, scarred; base rounded, quite smooth; calyx rather large, the segments blunt pointed; rind quite pitted, leathery, $1 / 8$ inch thick; oil-cells small, flush with the surface or slightly sunken; sections 13, clearly defined; flesh medium-grained, orange; juice-sacs spindle-shaped, of medium size; juice abundant, colored; pulp melting; acidity and sweetness well blended; flavor sweet, rich; quality excellent; pith $1 / 2^{-3} / 4$ inch across; seeds 13 , large, plump, wedge-shaped. Season December to middle of February.

According to Moore, the Magnum Bonum orange probably originated at Homosassa, Florida.

May (Dr. May's Best).-Form rounded; size medium to large, 3 by $3 \frac{1}{1} \frac{1}{6}$ inches; color rather light yellow to orange; apex rounded; base rounded, somewhat flattened; calyx small, pointed; rind smooth, $1 / 8$ inch thick, tough and leathery; oil-cells flush with the surface; sections 11, well defined, regular in size; flesh rather coarse-grained, orange; juice-sacs large, spindle-shaped; juice abundant, colored; pulp melting; acidity and sweetness fairly well blended, but not strong in character; flavor very good; pith small; seeds 6 or more, some abortive, plump, oval, pointed, about $5 / 8$ by $3 / 8$ inch. Season December and January.

Originated in the grove of Dr. May at Orange Mills, Florida.

Nonpareil.-Form rounded-oblate; size medium to large, $25 / 8$ by 3 , $3 \frac{1}{16}$ by $31 / 2$ inches; color yellow to orange; apex rounded, somewhat flat, slightly depressed just at the tip; base rounded, somewhat depressed, creased; calyx of medium size, segments pointed; rind rather pitted, $1 / 8^{-}$ $\frac{3}{16}$ inch thick; oil-cells small, sunken or flush; sections 10, regular, welldefined; flesh of medium grain, deep yellow; juice-sacs of medium size, spindle-shaped; pulp melting; acidity and sweetness well blended; flavor rich, vinous; quality excellent; pith small, $3 / 8$ inch across; seeds $11-15$, oval, pointed, large, plump, about $5 / 8$ by $3 / 8$ inch. Season December and January. 
Nonpareil originated as a Florida seedling on the St. Johns River, and was introduced by the late A. J. Bidwell.

Old Vini (Beach's No. 4; Buena Vista).-Form oblate or oblate rounded; size medium to large, $27 / 8$ by $2 \frac{15}{16}$ inches, $27 / 8$ by $21 / 4$ inches; color yellow to orange; apex rounded, slightly depressed; base smooth; calyx of medium size, with a rather stout stem; rind smooth, $1 / 8$ inch thick, tough and leathery; oil-cells flush with the surface, or very slightly depressed; sections 11, clearly defined, fairly regular; flesh coarse, orange-yellow; juice-sacs large; juice abundant, colored; pulp melting; acidity and sweetness well blended; flavor very good and of good character; pith solid, $1 / 2$ inch across; seeds 16 , oval, pointed at both ends, plump, $1 / 2$ by $3 / 8$ inch. Season December to February.

A seedling variety, originated by the late Col. F. L. Dancy, of Orange Mills, Florida.

Osceola.-Form rather oblate or rounded; size large, 3 by $3 \frac{1}{16}$ inches; color bright orange; stems stout; apex with a small scar, set in a slight depression; base slightly shouldered and roughened; calyx of medium size; segments short, pointed; rind fairly smooth, $\frac{3}{16}$ inch thick; oil-cells rather sunken; sections 12, variable in size, clearly defined; flesh coarse-grained, orange; juice-sacs large, elongated; juice plentiful; pulp rather melting; acidity and sweetness well blended and of good character; quality very good; pith small, $3 / 8$ inch across; seeds $6-10$, oval, pointed, plump, large. Season December and January.

The original tree was a seedling raised by L. H. Van Pelt, Mandarin, Florida.

Parson Brown. - Form rounded, somewhat oblong; nedium to large, $2 \frac{13}{16}$ by 3 inches, $3 \frac{3}{16}$ by $3 \frac{5}{16}$ inches; color yellow-orange to yellow; apex rounded; base rounded; calyx small; rind smooth, bright, $1 / 8-\frac{3}{16}$ inch thick; oil-cells flush with the surface; sections 16, regular, well defined; flesh rather coarse-grained, yellow; juicesacs spindle-shaped, medium to large; juice abundant, colored; pulp melting; acidity and sweetness not well blended unless picked quite early; pith

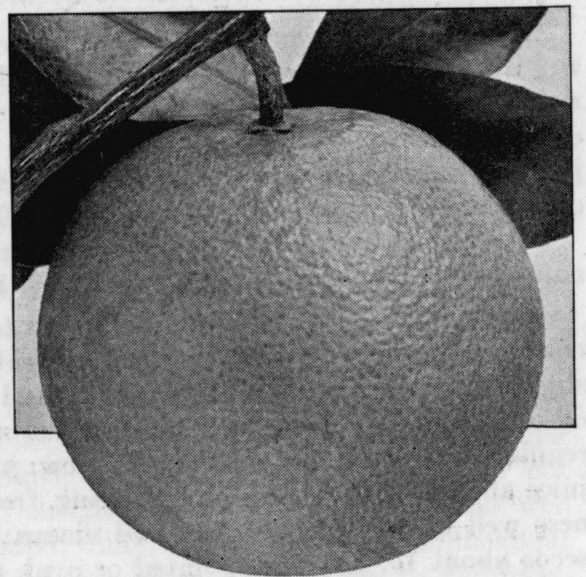

Fig. 51. Parson Brown orange (reduced 1/3) 
small; seeds 10-19, oval, flattened, pointed, sometimes rectangular, large, $\frac{9}{16}$ by $3 / 8$ inch. Season about October and November. (Fig. 51.)

The Parson Brown orange, according to F. D. Waite, was introduced by Capt. J. L. Carney, of Lake Weir, Florida, about 1878, and originated at Webster, in the seedling grove of Parson Brown.

Stark (Stark's Favorite).-Form round or roundish-oblate; size small to medium, $21 / 2$ by $27 / 8$ inches, $2 \frac{9}{16}$ by $27 / 8$ inches; color light orange; apex rounded; base rounded; calyx small, segments pointed; rind smooth, silky, thin; oil-cells medium size, flush with the surface; sections 10, rather irregular in size; flesh rather fine-grained, yellow; juice-sacs of medium size; juice plentiful, colored; pulp melting; acidity and sweetness well blended, the sweetness predominating slightly; flavor rich and good; quality very good; pith compact, $3 / 8-1 / 2$ inch across; seeds 18 , oval, pointed, plump, medium to large, about $5 / 8$ by $3 / 8$ inch. Season December to February.

This variety is a native Florida seedling.

Whitaker.-Form slightly oblate; size medium, $23 / 8$ by $27 / 8$ inches; color yellowish orange; apex rounded, smooth; base slightly roughened; calyx of medium size; rind thin, smooth, tough, closely attached; oil-cells of medium size, somewhat elevated; sections about 12, well defined, small; pulp melting; acidity and sweetness not very well combined; flavor slightly flat, owing to the specimen being a little over-ripe; seeds few, large, oval, pointed. Season December to February.

Introduced by Reasoner Bros., Oneco, Florida, about 1884.

\section{Mediterranean oranges}

Bessie.-Form round or slightly oblate; size small to medium, $25 / 8$ by $23 / 4$ inches; color orange; apex rounded, slightly scarred; base smooth or somewhat roughened; calyx small; rind smooth, thin, tough, $1 / 4$ inch thick, closely attached; oil-cells rather depressed; sections 10, small, well defined; juice abundant; acidity and sweetness well blended; flavor rich, vinous; quality excellent; seeds about 14. Season March and April.

Originated by the late Dudley W. Adams, of Tangerine, Florida, and named after his sister-in-law, Miss Bessie Hustis.

Centennial.-Form round; size small to medium, $2 \frac{1}{2}$ by $2 \frac{15}{1} \frac{5}{6}$ inches; color orange; apex scarred, set in a slight depression; base streaked or slightly ridged, rounded; calyx small; rind smooth, thin, $1 / 8$ inch or less; oil-cells pitted or flush with the surface; sections 11, well-defined, fairly regular; flesh fine-grained, orange-yellow; juice-sacs small, spindle-shaped; juice abundant, colorless; pulp melting, free from rag; acidity and sweetness well blended; flavor rich and vinous; quality excellent; pith small; seeds about 10 , long and pointed or oval, plump, $5 / 8$ by $3 / 8$ inch. Season November to December. 
This variety was brought to notice by E. H. Hart about 1876. Though the fruit ripens early, it can be held until quite late, and, on the whole, it is a very desirable variety. Introduced by E. S. Hubbard, of Federal Point, Florida.

Circassian.-Form rounded or depressed; size medium to large, $23 / 4$ by 3 inches, 3 by $3 \frac{3}{16}$ inches; color light yellow; apex rounded; base rounded, smooth; calyx small, the lobes short and blunt; rind thin, $1 / 8$ inch thick, quite smooth; oil-cells slightly elevated, numerous, and of good size; sections 10-15, clearly marked, quite regular; flesh fine-grained, yellow; juice-sacs long, spindle-shaped, slender; juice plentiful, colored; pulp melting; acidity and sweetness normal and well blended; flavor very good; pith solid, $3 / 4$ inch across; seeds 10-21, oblong or oval, pointed, $5 / 8$ by $3 / 8$ inch. Season December to February.

Circassian is a foreign introduction through the Rivers' Nurseries.

Du Roi.-Form oblong; size medium to large, $27 / 8$ by 3 inches, $3 \frac{3}{16}$ by $3 \frac{1}{16}$ inches; color yellow, deep orange or reddish when fully matured; apex rounded; base creased, flat; calyx of good size, segments pointed; rind creased or almost ribbed, rough, $1 / 8-\frac{3}{16}$ inch thick; oil-cells flush with the surface or sometimes rather sunken; sections 11, small, well-defined; flesh fine-grained, yellowish orange; juice-sacs long, spindle-shaped; juice abundant, colored; pulp melting; acidity and sweetness well blended; flavor rich, vinous; quality excellent; pith small; seeds about 14, size large, $5 / 8$ by $\frac{5}{16}$ inch, oval-pointed or oblong-wedged. Season February and March. Probably introduced through Rivers' Nurseries.

Everbearing.-Form oblong, tapering to the stem; size small to medium, about $23 / 4$ by $21 / 2$ inches; color orange-yellow; apex rounded; base rather rough; calyx depressed; rind pitted, $\frac{3}{16}$ inch thick; oil-cells small; sections 10, small; flesh coarse-grained, yellow; juice-sacs rather broad and short; juice plentiful; pulp melting; acidity and sweetness fairly well blended, frequently with the acid predominating; flavor quite good; quality good; pith small, $1 / 4$ inch across; seeds 10 , plump, oval, pointed, $3 / 8$ by $1 / 4$ inch. Season October to June.

Origin not known, but probably imported into America.

Exquisite.-Form round or oblate; $27 / 8$ by $27 / 8$ inches, $23 / 4$ by $3 \frac{1}{16}$ inches; color orange-yellow; apex rounded; base rounded, smooth; calyx very small; rind smooth, tough, leathery, $1 / 8$ inch thick; oil-cells flush with the surface or slightly elevated; sections 13, well-defined, rather irregular in size; flesh rather coarse-grained, orange; juice abundant; pulp not melting, containing a little too much rag; acidity and sweetness well blended; flavor very good; pith solid, small, $1 / 4-1 / 2$ inch across; seeds about 28, oval, pointed, ridged, $5 / 8$ by $3 / 8$ inch. Season December to February. Reasoner, in Bulletin No. 1, Division Pomology, United States De- 
partment of Agriculture, says that this variety was imported by General Sanford.

Hamlin.-Form rather oblate; size medium, packing 176 to 216 to the box; color deep golden yellow early in season, changing to orange-red with full maturity; apex rounded and very slightly scarred; base smooth, rounded; calyx small; rind very smooth, bright and satiny, 1/8 inch thick; oil-cells small, flush with the surface; sections 11-12, uneven in size; flesh deep orange-yellow; juice-sacs spindle-shaped, small; juice abundant, deep orange; acidity and sweetness well blended; flavor excellent; seeds usually 1-5, but many fruits are seedless. Season October and November and later.

The Hamlin orange was found in an orange grove planted in 1879 by Isaac Stone, near Glenwood, Florida, for the late Mrs. Mary H. Payne. Later this grove came into the possession of A. G. Hamlin, who lived in De Land for many years. It is an early orange of remarkably fine quality and has the smoothest rind of any of the sweet varieties. This, added to its excellent quality, makes it a very attractive early orange.

Jaffa.-Form rounded-oblate or occasionally very slightly roundedoblong; size medium to large, $23 / 4$ by $3 \frac{1}{16}$ inches, 3 by 3 inches; color orangeyellow to orange-red; apex rounded, smooth; base rounded; calyx small, pointed; rind smooth, leathery, $1 / 8$ inch thick; oil-cells of medium size, flattened; sections 11, well-defined, fairly regular; flesh yellow, fine-grained; juice-sacs narrow, elongated; juice abundant, colored; pulp melting; acidity and sweetness normal and well blended; flavor rich; quality excellent; pith small; seeds about 9 , plano-convex, short, rounded, plump, $1 / 2$ by $1 / 4$ inch. Season December to February.

Imported by the late General Sanford from Palestine about 1883.

Joppa (Joppa Late).-Form oblong, shouldered, largest below the median line, tapering toward the calyx; size medium, $27 / 8$ by $2 \frac{13}{16}$ inches; color orange; apex rounded, smooth; base slightly roughened and creased; calyx 3 inches across; rind somewhat rough; oil-cells slightly indented in some cases, but usually flush with the surface; thickness $\frac{3}{16}$ inch; sections 10, well-defined; flesh fine-grained, orange; juice-sacs small, pointed; juice plentiful, colored; pulp melting; acidity and sweetness normal; flavor good, quality fair; pith small, $1 / 4^{-3} / 8$ inch in diameter; seeds few, small, plump, roundish. Season January to March.

Originated at San Gabriel, California, by A. B. Chapman, from seed secured from Joppa, Palestine.

Lue Gim Gong.-Form oblong, carrying the size well out to the rounded ends; size large, 3 by $31 / 4$ inches, packing 126 to 176 to a box; color deep orange-red; skin thin, smooth on current crop, becoming rougher on two- and three-year-old fruit; sections 10-11, well-defined; flesh deep 
orange; juice-sacs large; juice abundant, even in old specimens; flavor a rich blending of sweet and subacid; quality best; pith medium; seeds 4 to 8, large, flat and wedge-shaped. Season June to September. A fine shipping fruit and a good keeper.

The Lue Gim Gong orange is thought to be the result of a handpollination of Valencia (Hart's Late) with pollen from what was thought to be Mediterranean Sweet, made near De Land, Florida, by a Chinese horticulturist, Lue Gim Gong, in 1886. This hardy thrifty-growing variety is very resistant to cold; in fact, it may be the hardiest of all the sweet orange varieties now commonly cultivated in America. It is a noteworthy fruit because of the length of time the fruit may be held on the tree. The Lue Gim Gong was introduced and catalogued by the Glen Saint Mary Nurseries Co. in their catalogue for 1912.

Majorca.-Form rounded or slightly oblate; size small to medium, $25 / 8$ by $27 / 8$ inches, $27 / 8$ by $3 \frac{1}{16}$ inches; color orange; apex rounded; base rounded, smooth; calyx small; rind smooth, thin, tough, $1 / 8$ inch thick; oil-cells small, flush with the surface; sections 13, small, regular; flesh fine-grained, orange-colored, composed of slender, spindle-shaped juicesacs; juice abundant, colored; pulp melting; acidity and sweetness well blended; flavor sprightly, rich and vinous; pith small, $3 / 8$ inch across, compact; seeds about 5 or 6 , small, plump, oval. Season February and March.

Imported by the late General Sanford. The variety takes its name from the island of the same name in the Mediterranean Sea.

Maltese Oval.-Form oblong or rounded oblong; size medium to large, $25 / 8$ by $27 / 8$ inches, $3 \frac{5}{16}$ by $3 \frac{5}{16}$ inches; color yellow or orange-yellow; apex rounded; base flat, shouldered, smooth; calyx small, segments pointed; rind smooth, 1/8-1/4 inch thick; oil-cells large and conspicuous; sections 11-13, well-defined; flesh yellow, coarse-grained; juice-sacs large, spindle-shaped; juice plentiful, colored; pulp melting; acidity and sweetness well blended; flavor sweet, vinous, and of excellent quality; pith small, about $\frac{7}{16}$ inch across, rather open; seeds $6-13$, flattened, oval, pointed, large, $\frac{9}{16}$ by $3 / 8$ inch. Season March and April.

Introduced into America from the Mediterranean by General Sanford.

Marquis.-Form slightly oblate; size medium, $2 \frac{5}{8}$ by $23 / 8$ inches; color orange, rather light; apex rounded; base rounded, smooth; calyx small; rind thin, smooth, closely attached; oil-cells small, numerous; sections about 11, well-defined, variable in size; juice abundant, colored; flesh coarse-grained, orange; acidity and sweetness well blended; flavor sweet and rich, quality very good; seeds about 4 , medium size. Season December to February.

Imported from the Island of Malta by Colonel Church, of Orlando, Florida. 
Paper Rind (Paper Rind St. Michael).-Form oblong; size medium to large, $23 / 4$ by $23 / 4$ inches, 3 by $2 \frac{15}{16}$ inches; color orange; apex rounded; base rounded, shouldered; calyx small; rind slightly pitted, $1 / 8-\frac{3}{16}$ inch thick; oil-cells depressed; sections 10, partitions thin; flesh coarse-grained, orange; juice-sacs small; juice plentiful, colored; pulp melting; acidity and sweetness well blended; flavor rich, vinous, quality excellent; pith small, $1 / 4^{-1 / 2}$ inch across; seeds 6 , oblong or oval, pointed, large or medium. Season February and March.

Imported from the Island of St. Michael into California and thence into all the American citrus districts.

Pineapple.-Form somewhat variable, varying from nearly round to slightly oblate, occasional specimens being quite compressed; size medium to large, $21 / 2$ by $23 / 4$ inches, $2 \frac{15}{16}$ by $31 / 4$ inches; color deep orange, full ripe well-colored specimens show a reddish tinge; apex rounded or very slightly depressed and scarred; base rounded, very smooth; calyx small, segments rounded, blunt; rind smooth, bright, glossy and satiny, $1 / 8$ inch thick; oil-cells small, quite conspicuous, flush with the surface or slightly elevated; sections 11, slightly irregular; flesh of medium grain, orange-

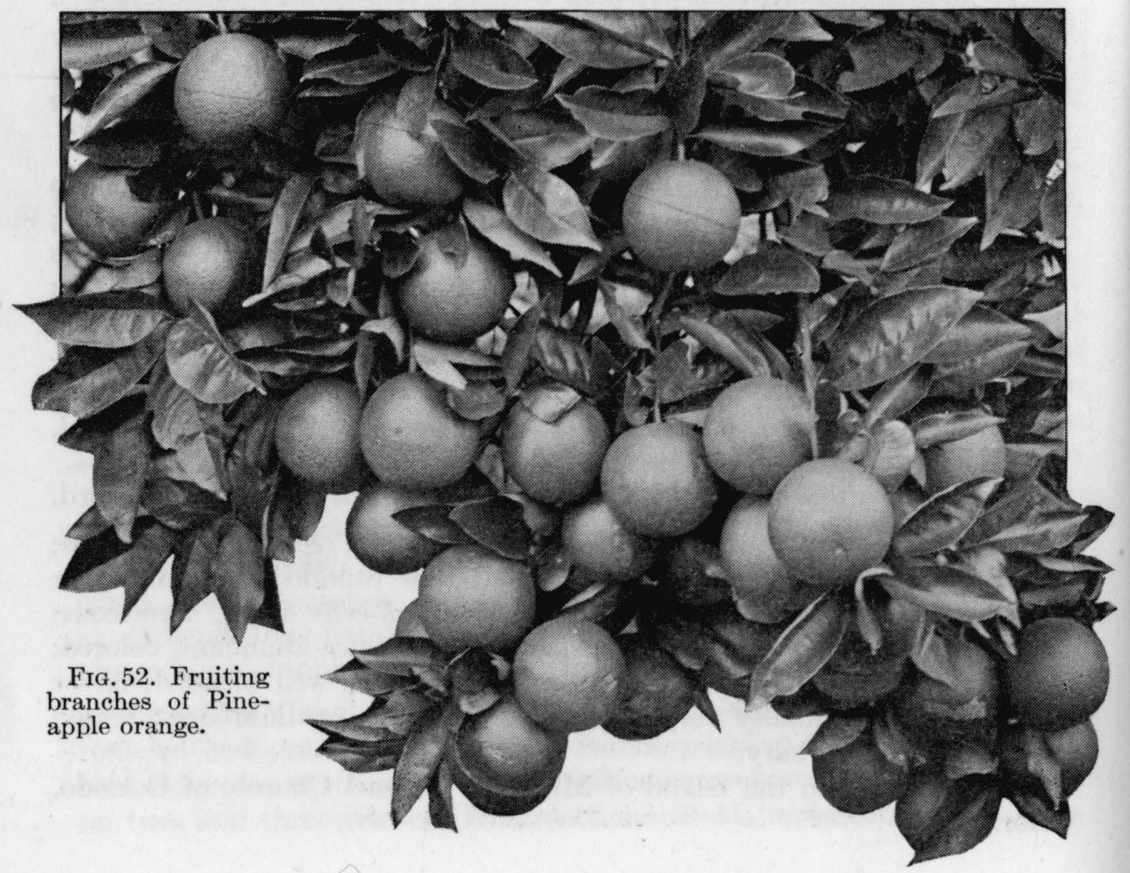


yellow; juice-sacs pointed, spindle-shaped, small; juice abundant, yellowish in color; pulp melting; acidity and sweetness well blended; flavor excellent, rich, vinous, sprightly; pith solid, $1 / 4-1 / 2$ inch; seeds $13-23$, flattened, plump, pointed, large, $\frac{11}{16}$ by $\frac{5}{16}$ inch. Season January and February, although it may sometimes be held later. (Figs. 50 and 52.)

It originated in the heart of the old citrus belt near Citra, Marion County, Florida, in the grove of James B. Owens. Because of its peculiarly fine flavor and its fancied resemblance in flavor to a pineapple, it was so named. The fruit was first marketed in quantity by Bishop, Hoyt \& Co. It s-on established a reputation as a high-quality, highly colored fruit, and it remains today Florida's most important midseason sweet orange. The old Bishop Hoyt grove, although injured in the freezes of the 1890 's, has been brought back into bearing and continues to produce the same quality of Pineapple fruit that first made the variety famous.

Prata (Silver).-Form rounded; size medium to large, 3 by $31 / 8$ inches; color light orange; apex rounded; base rounded, smooth; rind smooth, tough and leathery, adhering closely to the pulp; oil-cells small; sections about 11, well-defined; flesh rather coarse-grained, orange; juice-sacs medium size, spindle-shaped; juice abundant, colored; pulp melting; acidity and sweetness well combined; flavor rich and good; quality very fair; pith $1 / 2$ inch across; seeds about 30 , plump, oval, large. Season December to February.

Imported into Florida through the Rivers' Nurseries.

Star Calyx.-Form round or rounded-oblate; size medium to large, $2 \frac{9}{1.6}$ by 3 inches, 3 by $3 \frac{1}{8}$ inches; color orange or orange-yellow; apex flattened; base rounded, smooth; calyx large, conspicuous, usually 5pointed, $1 / 2$ inch across; rind smooth, $1 / 8-\frac{3}{16}$ inch thick; oil-cells flush with the surface or slightly elevated; sections 13, fairly regular; flesh rather coarse-grained, orange; acidity and sweetness well blended; flavor and quality excellent; pith $1 / 2$ inch across; seeds about 18 , oval, plump, large. Season December to February.

Said to have been imported from the nurseries of Thomas Rivers, England.

Valencia (Valencia Late; Hart's Late; Hart's Tardiff).-Form round or sometimes slightly oval; size medium to large, $31 / 8$ by $31 / 8$ inches; color deep golden orange; apex rounded, slightly flattened, scarred, base smooth, rounded; calyx small, sharp pointed; rind thin, smooth, tough; sections clearly marked, nine or more in number; flesh orange in color, of medium grain; juice-sacs spindle-shaped, of medium size; juice abundant, colored; acidity and sweetness well combined; pulp melting; flavor rich, sprightly and vinous; quality excellent; seeds few, about 6 , large, oval, plump. Season late March to June. (Fig. 53.) 


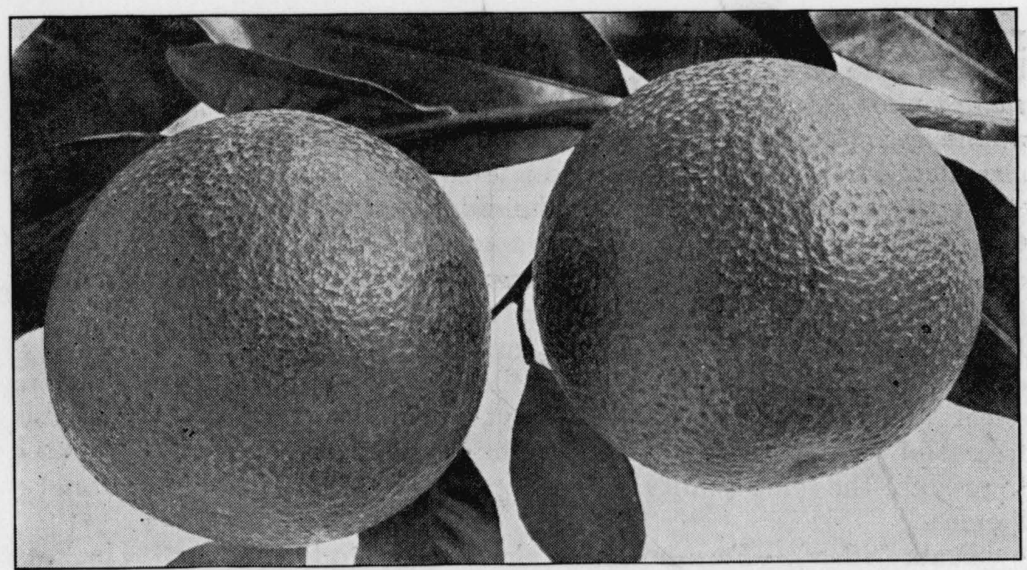

Frg. 53. Valencia oranges. Valencia is the most important late orange in California and Florida

The Valencia orange was introduced through the Thomas Rivers' Nurseries, London, England, into Florida and California about the same time. There appear to have been two introductions into Florida, one about 1870 by Gen. Sanford, Palatka, and one shortly afterward by E. H. Hart, Federal Point. Hart's introduction came directly from Parsons' Nursery, Flushing, New York, which had received it from Rivers, In Florida it came to be known as the Hart, or Hart's Late orange. It was introduced into California in 1876 by A. B. Chapman and George $\mathrm{H}$. Smith from the Rivers' Nurseries. After the variety was established in Florida, introductions were then made from that state into California, and when it had fruited there, a Spanish citrus-grower identified it as being the same as the late orange grown in Spain, and it came to be known as Valencia. In Florida, the name Hart, or Hart's Late, was retained for it until very recent years, but this has given place now to the name Valencia, which is commercially applied. The history of the orange has been very carefully investigated by A. D. Shamel, United States Department of Agriculture. ${ }^{1}$ Lee and Scott have raised the question as to whether Valencia oranges did not come from China. ${ }^{2}$

White.-Form round or slightly oblate; medium to large, $2 \frac{5}{8}$ by 3 inches, $2 \frac{1}{16}$ by $3 \frac{1}{16}$ inches; color light yellow; apex rounded, scarred; base

${ }^{1}$ Shamel, A. D., Scott, L. B., and Pomeroy, C. S., Citrus Fruit Improvement: A study of Bud Variation in the Valencia Orange. Bull. No. 624, U. S. Dept. Agr., July 25, 1918.

${ }^{2}$ Lee, A. H., and Scott, L. B., Are Valencia Oranges from China? The Journal of Heredity, Vol. II, No. 7, Sept.-Oct., 1920, pp. 329-333. 
rounded, smooth; calyx small; rind smooth, thin, $1 / 8$ inch or slightly less; oil-cells flush with the surface; sections 13, small, fairly regular; flesh finegrained, yellow; juice-sacs small, spindle-shaped; juice abundant, colored; pulp melting; acidity and sweetness well blended; flavor rich, vinous, and of excellent quality; pith small, close; seeds 20-27, oval and pointed, or wedge-shaped and oblong, $5 / 8$ by $3 / 8$ inch, plump. Season December to February.

\section{Introduced from the Rivers' Nurseries.}

\section{Blood oranges}

Maltese.-Form round, or oblong-rounded; size medium to large, 3 by 3 inches; color deep orange; apex slightly indented; base creased; calyx set in a slight depression; stem of medium size; rind smooth, medium thick; oil-cells elevated or indented, balloon-shaped, large; flesh dark orange, streaked with red, sometimes varying to blood-red, fine-grained; sections 11, well defined; juice-sacs spindle-shaped, small to medium; juice yellowish or yellowish red; flavor sweet, well blended with acid; quality very good; pith small; seeds 4-8, small, roundish.

An orange of very good quality, with small, bright characteristic foliage. The blood marking in the fruit shows only on old trees, and then not until late in the season, sometimes not at all. Its greatest failing lies in its not being sufficiently prolific. Introduced from southern Europe.

Ruby.-Form round or slightly oblong; small to large, $23 / 4$ by $31 / 4$ inches, $2 \frac{1}{2}$ by $23 / 4$ inches; color deep yellow or orange, reddish when fully matured; apex rounded, scarred, sometimes navel marked; base rounded, smooth; calyx small, lobes short and blunt; rind smooth, shiny, $1 / 8$ inch thick; oil-cells small, almost globular; sections 12, small, regular; flesh fine-grained, yellow early in the season, streaked with red in midseason, and blood-red when fully ripe; juice-sacs small; juice plentiful, colored; pulp melting; acidity and sweetness well blended; flavor rich, vinous; quality excellent; pith small, compact, $\frac{5}{16}$ inch across; seeds 11 , plump, oval, pointed, of medium size, $\frac{7}{16}$ inch in length. Season February and March. (Fig. 54.)

An imported variety, probably brought from some one of the Mediterranean districts. It has no superior and few equals in quality. Imported by General Sanford.

Sanford Blood (Sanford's Sweet Blood).-Form rounded-oblate; size medium, $23 / 4$ by $3 \frac{1}{16}$ inches; color at first lemon-yellow, gradually deepening to reddish; apex rounded, slightly scarred; base rounded, smooth; calyx of medium size; rind smooth, bright, glossy, thin and leathery; oilcells small, numerous, flush with the surface; sections 11, regular in size, orange in color at first, becoming streaked with blood markings and 


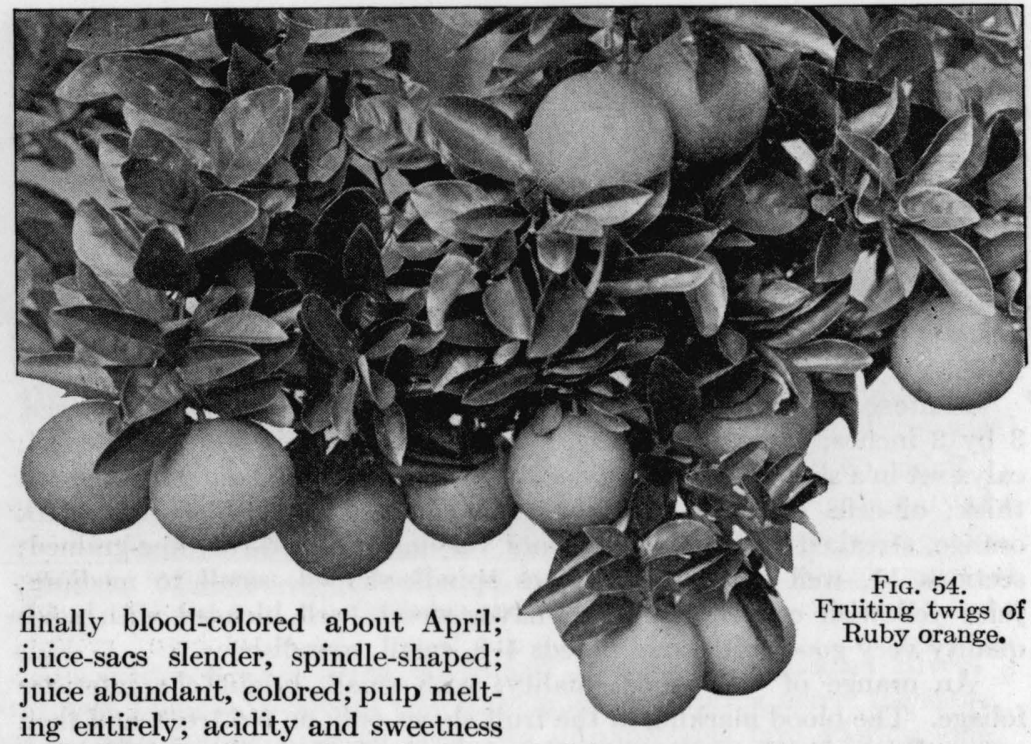
well blended; flavor rich, vinous; pith $1 / 2$ inch across, solid; seeds about 14, plump, oval, pointed, smooth, large. Season January to March.

Imported by General Sanford.

Saul Blood (John Saul's Sweet Blood).-Form oblate; size small to medium, $23 / 4$ by $27 / 8$ inches; color dark orange; apex rounded, very slightly scarred; base smooth; calyx small; rind thin, about 1/8 inch thick, smooth and tough, rather easily detached; sections about 10 , not clearly marked; flesh fine-grained, yellow at first, becoming blood-marked when fully matured; juice-sacs small, elongated; acidity and sweetness well blended; flavor rich, vinous, and sprightly; quality excellent; pith small, solid; seeds about 16, of medium size, oval and pointed. Season December to February.

Introduced by John Saul, of Washington, D. C.

St. Michael (Blood).-Form oblong-rounded; size medium, $2 \frac{15}{16}$ by $2 \frac{15}{16}$ inches; color yellow, with deep orange-red blotches appearing on the rind as it nears maturity, orange-red throughout when fully ripened; apex rounded, slightly scarred; base smooth, rounded; rind thin, $1 / 8$ inch thick; oil-cells rather conspicuous, flush with the surface or somewhat elevated; sections distinctly marked, regular in size; flesh fine-grained, wine-red in color; juice-sacs rather large, spindle-shaped; juice plentiful, yellow in color, the coloring matter of the flesh apparently being located in the 
tissue of the juice-sacs; pulp melting; acidity and sweetness well blended; flavor excellent; pith solid, $1 / 4$ inch across; seeds present, rounded, short, plump, oval, medium-sized. Season January and February.

A fine variety of medium size, imported from the Mediterranean by General Sanford.

\section{Navel oranges}

Australian.-Fruit seedy, varying in size from large to small, and splits at the navel, which is usually large and prominent. Tree strong grower, but a very shy bearer. (Lelong.)

Introduced from Australia by Lewis Wolfskill, of Los Angeles, in 1874. Once largely planted in California, but now replaced by Bahia.

Bahia) (Washington Navel; Riverside Navel).-Form rounded, somewhat tapering toward the apex; size large, $3 \frac{1}{4}$ by $3 \frac{1}{4}$ inches, $3 \frac{5}{8}$ by $3 \frac{1}{2}$ inches; color orange or orange-yellow; apex terminating in an umbilicus, tapering slightly outward, flattened on the tip; base rounded or somewhat flattened and frequently creased; calyx small; rind smooth, tough, leathery, $1 / 8^{-1 / 4}$ inch thick; oil-cells large, almost globose; sections 9-11, well-defined; flesh rather coarse, deep orange-yellow; juice-sacs rather large, spindle-shaped; juice plentiful, but in poor specimens inclined to run slack in the stem end; pulp melting; acidity and sweetness well blended; flavor rich, vinous; quality excellent; seeds absent. Season December to February

This is the great combut in Florida it has not the fact that it is not planted in the latter either on rough lemon

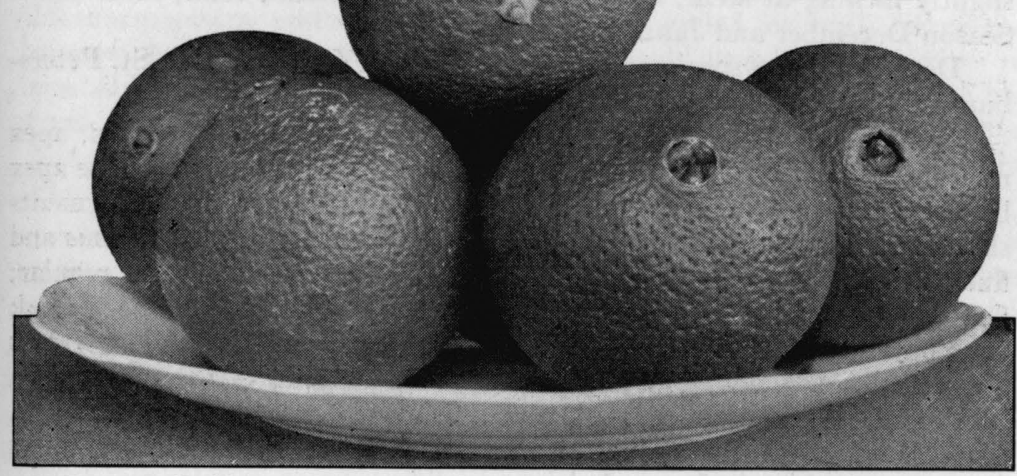

FIG. 55. Bahia navel oranges. This variety is very valuable in California mercial orange of California, been a success, owing to sufficiently prolific. When state, it should be worked or trifoliate stock. 
According to some writers, the Bahia navel orange was planted in Florida previous to 1835 , but disappeared in the freeze of that year. The Bahia of today was received by the late William Saunders, of the United States Agricultural Department, in 1870. Trees of this importation were distributed and two were received by Mrs. Tibbetts, of Riverside, California, in 1874. Alexander Craw also received trees about the same time. Fruit from Mrs. Tibbett's trees was exhibited at the Riverside Citrus Fair in 1879 and attracted a great deal of attention. The variety was propagated rapidly and planted so extensively that it has become the most important California orange of its season.

The variety was also sent to Florida, and although some fruit is produced, it has received but little attention, as it has not proved to be a prolific variety for that state.

Double (Imperial).-Form rounded; size small, $2 \frac{1}{2}$ by $2 \frac{1}{2}$ inches; color bright golden yellow; apex rounded, umbilicus hidden; base rounded, smooth; calyx small, pointed; rind smooth, closely attached; sections 11, somewhat irregular, well-defined; juice fairly abundant; pulp not entirely melting, sweetness predominating; flavor very good; seeds 6 , oval, medium size. Season December to February.

Introduced by Major Rountree, of New Orleans, Louisiana. It was originally imported from Brazil. It is inclined to hold its fruit better than most navel oranges in Florida, but is inferior to Bahia in California.

Egyptian.-Form oblong-rounded, shouldered; size large, $33 / 8$ by $33 / 8$ inches, heavy; color deep orange; apex navel marked, navel frequently included; base flat, creased and rough; calyx small, blunt; stem rather slender; rind rough, pebbled, $\frac{3}{16}$ inch thick, adhering tightly; oil-cells elevated or depressed, balloon-shaped, medium size; flesh not meaty, fiber scant, orange, coarse-grained; juice yellowish, abundant, sometimes slightly lacking at stem; quality excellent; pith small, solid; seeds none. Season December and January.

Described from specimens from the grove of C. W. Butler, St. Petersburg, Florida. Fruits well on rough lemon stock.

Melitensis.-Form rounded-oval; size large, $3 \frac{1}{1} \frac{1}{6}$ by $31 / 2$ inches; apex navel marked, umbilicus not constricted outward as in the Bahia, the apex being rounded instead; base flattened or rounded; calyx small, segments sharp pointed; rind $1 / 8$ inch thick, smooth; oil-cells large, conspicuous and flush with the surface; sections 8 or more, well-defined, quite regular; flesh rather coarse, deep yellow; juice-sacs rather large, spindle-shaped; juice plentiful, colored; pulp melting. free from rag; acidity and sweetness not well blended, not quite acid enough, rather flat in taste; quality fair; pith small, $1 / 4$ inch or more; seeds none. Season November and December.

This variety was introduced from Paris, France, by the United States Department of Agriculture. It is not prolific. 
Parson.-Form rounded-oblate; medium size, $23 / 4$ by $31 / 8$ inches, 3 by $3 \frac{7}{16}$ inches; color bright light yellow; apex rounded or somewhat flattened, navel marked; base rounded, sometimes creased; calyx small, blunt pointed; rind smooth, thin, $1 / 8-\frac{3}{16}$ inch; oil-cells flush with the surface; sections 10, well-defined; flesh rather coarse, orange-yellow; juice-sacs broad at the base, spindle-shaped; juice abundant, fruit being well filled out; pulp melting; acidity and sweetness well blended; flavor rich, vinous, excellent; pith close, $1 / 2$ inch across; seeds 12 , oval, flattened, pointed, large, $5 / 8$ by $3 / 8$ inch. Season December and January.

According to Reasoner, this variety was introduced into Florida in 1869 by S. B. Parsons of Flushing, Long Island, New York, who imported it from the Rivers' Nurseries, England. It is not prolific in Florida.

Surprise.-Form rounded or very slightly oblate; size medium, packing 150 to 176 to the box, $2 \frac{15}{16}$ by $2 \frac{15}{16}$ inches, $2 \frac{3}{8}$ by 3 inches; heavy, sinking in water leaving a space the size of a silver dollar not immersed; color deep orange; base rounded or very slightly flattened; calyx $3 / 8$ inch across; stem small; apex navel-marked, navel small, $1 / 8^{-3} / 8$ inch across, rounded, occasionally flattened or protruding, as in Bahia, $3 / 4$ inch inside, the rind of the fruit incurved; rind smooth, tough, satiny, thin, $1 / 8$ inch thick, adhering closely; oil-cells prominent and slightly elevated above the surface; sections 13, clearly defined, the dividing septa thin, variable in size; juice-sacs spindle-shaped, small; flesh fine-grained, yellow; juice abundant, acidity and sweetness well blended; flavor rich, vinous; quality excellent; seeds none. Season November to February.

Surprise is an excellent orange, fully equal in quality to the best, and it is juicy and heavy. E. S. Hubbard who fruited and introduced it, says that it bears better than Hart's Late, even when budded on sour stock. It must, therefore, be looked upon as a decided acquisition of Florida planters, and is unreservedly recommended for trial. Surprise is distinct from the other navel oranges, though occasional specimens resemble Bahia. No seeds have been found in any of the fruits. The bud from which this navel orange originated was discovered among a lot of King mandarin orange trees propagated by E. S. Hubbard, Federal Point, Florida, from budwood obtained originally from California.

Sustain.-Form rounded; size small to medium, $23 / 4$ by $2 \frac{5}{8}$ inches; color yellow; apex navel marked, the navel small and not protruding; base flattened, rounded; calyx small, blunt pointed; rind thin, $1 / 8$ inch thick, smooth; oil-cells small; sections 11, well-defined; flesh fine-grained, orange; juice-sacs small; juice abundant; pulp melting; acidity normal, wellblended with sweetness; pith $1 / 2$ inch across; seeds $3-4$, with some abortive, oval, flattened, pointed, medium size. Season December and January. 


\section{CHAPTER VI \\ THE MANDARIN ORANGES}

This group, as represented in America, is distinct in habit of growth and in fruit from the sweet oranges, Citrus sinensis, Osbeck, and the sour oranges, C. Aurantium, Linn. The leaves of the mandarin oranges are generally quite small and pointed, while the skin is easily separated from the pulp of the fruit and the sections of the pulp from one another. One noteworthy point, and one which needs to be explained away by those who desire to throw the two groups together, is that the cotyledons of the seeds of the mandarin oranges, with the exception of those of King, are pistache-green or greenish in color, while those of the sweet oranges are white. Of course, it must be granted that one species may shade off into the other, but when such is the case any variety in question should be relegated to the group of which it possesses the greatest number of marked characteristics.

Walter T. Swingle, ${ }^{1}$ in 1914, determined that the botanical name, Citrus nobilis, Lour., according to the original description, should apply only to the King orange, and that this variety was, and is now, the only one representing the species in general cultivation in America. Under deliciosa as a botanical variety of $C$. nobilis, he placed the mandarin and tangerine oranges, and under var. Unshiu the Satsuma orange and its horticultural variations. This disposition is an improvement over the old classification and would leave little to be desired if these varieties had been raised to specific rank.

The reason for adopting the group-name mandarin is that it has been longer in use and is probably more widely known than any other. As used here it is intended to include the loose-skinned oranges classified under Citrus nobilis and its

${ }^{1}$ Swingle in Plantæ Wilsonianæ, II, page 142. 


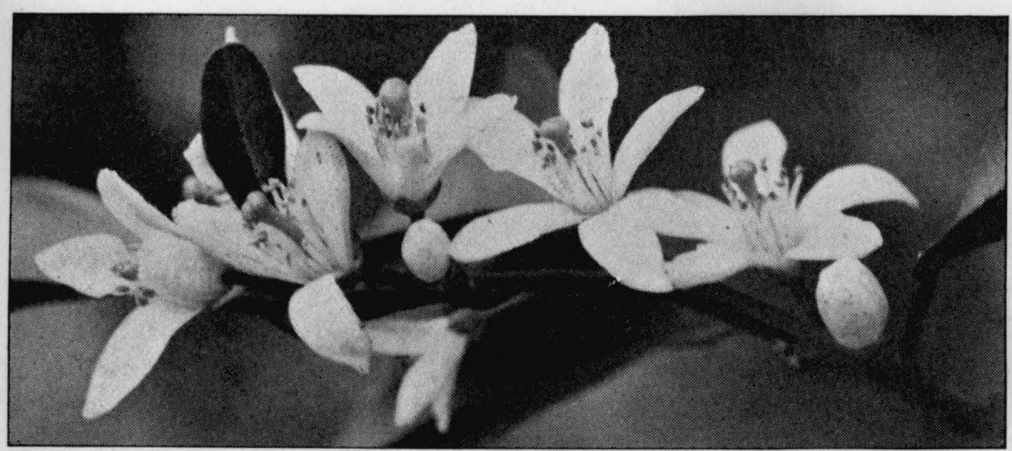

Fig. 56. Flowers of Owari Satsuma orange (natural size)

botanical varieties. Many have referred to the tangerines as a group, or sub-group, distinct and separate from the mandarins. There may be reasons of greater or less weight for this division, but here tangerine has been discarded in favor of the older name. No distinction can be made between the so-called mandarin and the tangerine oranges, more than between any two distinct varieties of fruits in recognized pomological groups. Moreover, the fact must not be overlooked that in some of the world's citrus-growing districts the two names are used interchangeably.

Two explanations have been given for the name mandarin as applied to this group of oranges. It was given, either because the fruit was regarded as the best of the citrus family, just as the Chinese mandarin or grandee stood in social rank above his fellowmen, or because this orange was the fruit of the rich and therefore only within the reach of the nobility. As the fruit is extensively cultivated in China and Japan, and is there held in such high esteem, one is led to the belief that the first explanation is the more correct.

One other name, "kid-glove oranges," has been applied to the group. In explanation of the origin of this name, the remarks of E. $\mathrm{H}$. Hart before the twenty-second meeting of the American Pomological Society, at Ocala, Florida, in 1889, are self-explanatory. "The term 'kid-glove' orange, as 


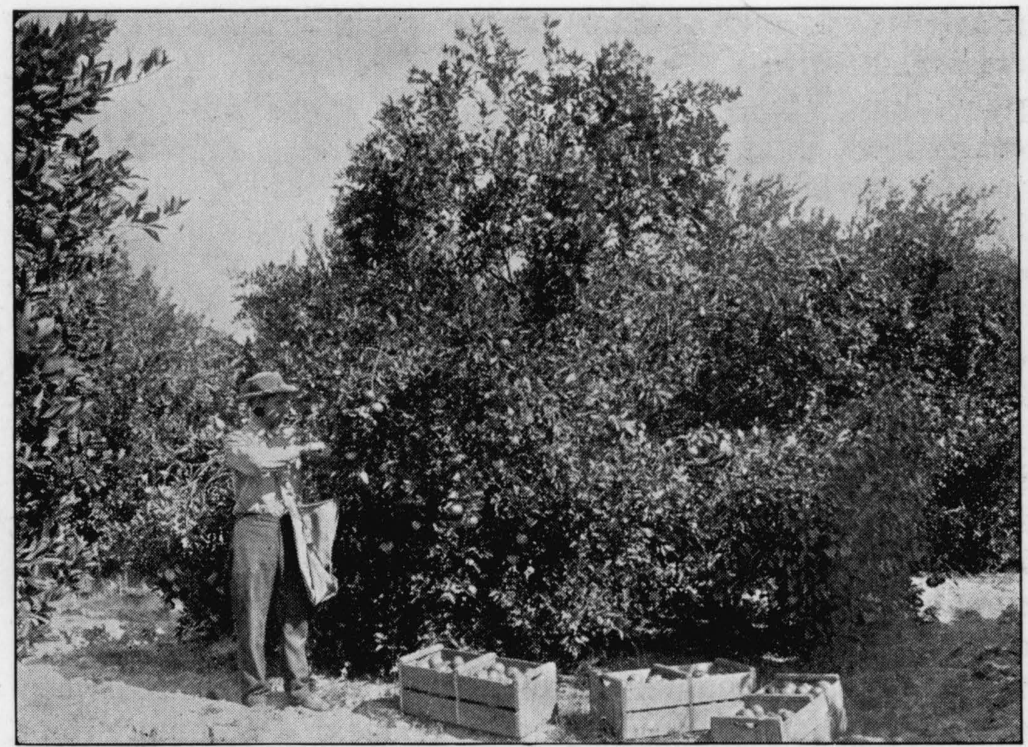

Fig. 57. A bearing tree of Dancy tangerine

applied to Citrus nobilis, originally a joke of our facetious countryman, Colonel Dancy, of Orange Mills, was gravely accepted as a synonym by our first nomenclature committee, and, like many another whimsical what-do-you-call-him, it stuck, where one more dignified would have glanced off."

The investigations of De Candolle and others indicate that the mandarin oranges had their origin in Cochin-China, and from that center they have been carried into many parts of the world.

Several gaps occur in the history of these oranges, and yet it has been possible to trace it with a fair degree of accuracy. The first mention of an orange which is believed to belong to this group is in Steerbeck's Citricultura, where it is mentioned as the "Muscat apple."1 It is well within the limits of probability that some member or members of the

${ }^{1}$ Steerbeck, F. Van., Citricultura, 27. 1682. 
group were known to Rumphius and indeed Loureiro, in his original description of Citrus nobilis in 1790, refers to this possibility. Referring to the same dates and cuts, Bonavia comes to the conclusion that the Aurantium sinense of Rumphius must be grouped with the suntara oranges of India. Recently Merrill identifies the Aurantium sinensis of Rumphius as $C$. nobilis. ${ }^{1}$

In 1805, two varieties of mandarin oranges were introduced into England from Canton by Sir Abraham Hume and fruit produced from these trees was illustrated in $1817^{2}$ and 1824. ${ }^{3}$ According to $\mathrm{Du}$ Breuil, ${ }^{4}$ the mandarin orange was introduced into continental Europe about 1828. In the vicinity of Parma it was grown on a large scale as early as 1842 and its cultivation in the county of Niza and the region surrounding Genoa dates back to 1849 or 1850. The conclusions reached by $\mathrm{Du}$ Breuil are further substantiated by the fact that Gallesio appears not to have known this tree, and Risso and Poiteau make no mention of its cultivation in Europe in the first edition of their work. Du Breuil states that in commerce a distinction was made between the mandarins of Parma and those of Spain, Algeria, Niza, and the coast of Italy.

Bonavia writes that the mandarin orange was probably introduced into India from Egypt with a collection of orange trees in $1847^{5}$ and that a second introduction was made by himself in $1863 . .^{5}$ It is not improbable that the mandarin oranges found their way into Egypt from some one of the countries of southern Europe.

The Chinese mandarin, according to the best information which can be secured, was brought to Louisiana by the Italian consul at New Orleans some time between 1840 and 1850. The first trees were planted on the ground of the con-

1Interpretation of Rumphius' Herbarium Amboinense, 298. 1917.

${ }^{2}$ Bot. Reg., 3:211. 1817.

${ }^{3}$ Bot. Reposit., 9:608. 1824.

${ }^{4}$ Hist. Cult. Orang., Risso \& Poiteau, 49. 1872.

${ }^{5}$ The Cultivated Orange of India and Ceylon, 56 and 231.1888. 


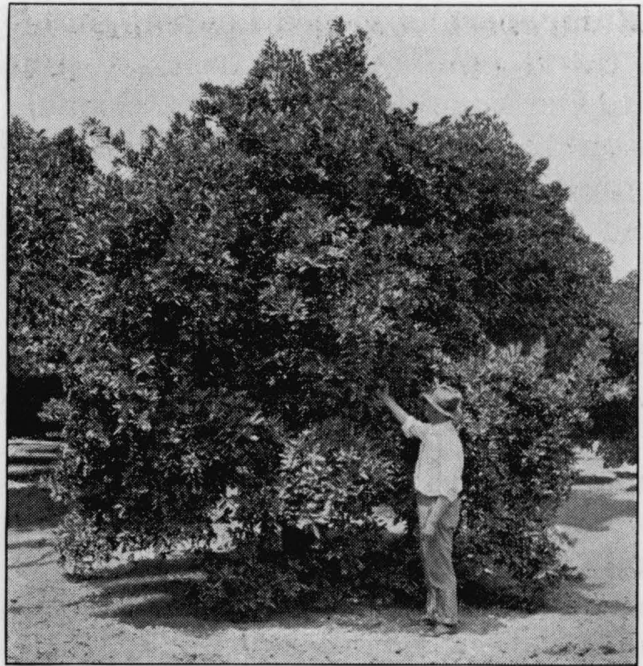

Fig. 58. Tree of Temple orange from which propagation was started

sulate at Algiers, across the river from New Orleans. It has been impossible to obtain the name of the consul or the exact date. Shortly after, or about $\mathbf{1 8 5 0 \text { , }}$ some one of the mandarin oranges was known to northern nurserymen, for Buist $^{1}$ in 1854 refers to one of them as a recent introduction, valuable for pot cultivation.

The introduction of the Chinese mandarin from Louisiana into Florida is credited to Major Atway by the committee of the Florida Fruit Growers' Association, and at the time their report was made the original tree was growing in the grove of Dr. Moragne at Palatka. The accidental substitution of one word for another, a typographical error, in Stubbs and Morgan's bulletin, "The Orange and Other Citrus Fruits," has twisted the phraseology as quoted by Moore, Reasoner, and others to read, "Tree of original variety introduced by Major Atway, of Bayou Sara, La." Since their bulletin was written in Louisiana, this reading conveys an erroneous idea.

It has not been possible to fix the date of introduction of the mandarin oranges into Florida, but if the report of the Fruit Growers' Association is correct, it was, of course, subsequent to the Louisiana introduction and presumably some time after it. The origin and introduction of each of the mandarin oranges is given under the varieties.

${ }^{1}$ Buist, R., American Flower-Garden Directory, 224. 1854. 
At the present time the sweet oranges, lemons, pomelos, and mandarin oranges are the four important groups cultivated in America.

Of these four important groups, the sweet oranges occupy the first place and are destined to do so throughout the whole future of citrus culture. They are a staple fruit, as is the apple, and are always in demand, being considered the dessert fruit of America par excellence.

More attention has been given to the cultivation of mandarin oranges in Florida than in California. It must be borne in mind, however, that the mandarin orange is essentially a fancy fruit and as such commands a fancy price in its season, but it would be useless to attempt to place it on the same plane with the sweet orange as a staple fruit. Generally speaking, the fruit is smaller than the sweet orange and the bearing capacity of the tree seldom reaches, and rarely exceeds, twelve straps. All the members of the group require careful cultivation and fertilization to secure the best quality. Of course, this may be said of sweet oranges or any other citrus fruit, but it is peculiarly true of oranges of the mandarin group.

Mandarin orange cultivation is on a staple basis in America at the present time, and the number of trees may be conservatively increased, but should not be out of all proportion to other citrus trees. The object of every grower should be, not so much to increase the output, as to produce a fruit of high quality, else there is no room for the fruit on the market. A good mandarin orange is an excellent fruit; a poor one is worthless. It should be in all respects a fancy fruit.

There is another matter which must not be overlooked in considering the horticultural status of this group. At present it contains the hardiest known, large-fruited, edible variety of Citrus, the Satsuma. This variety extends the cultivation of citrus fruits on a safe basis far into the more exposed sections of the country. In northern Florida and 


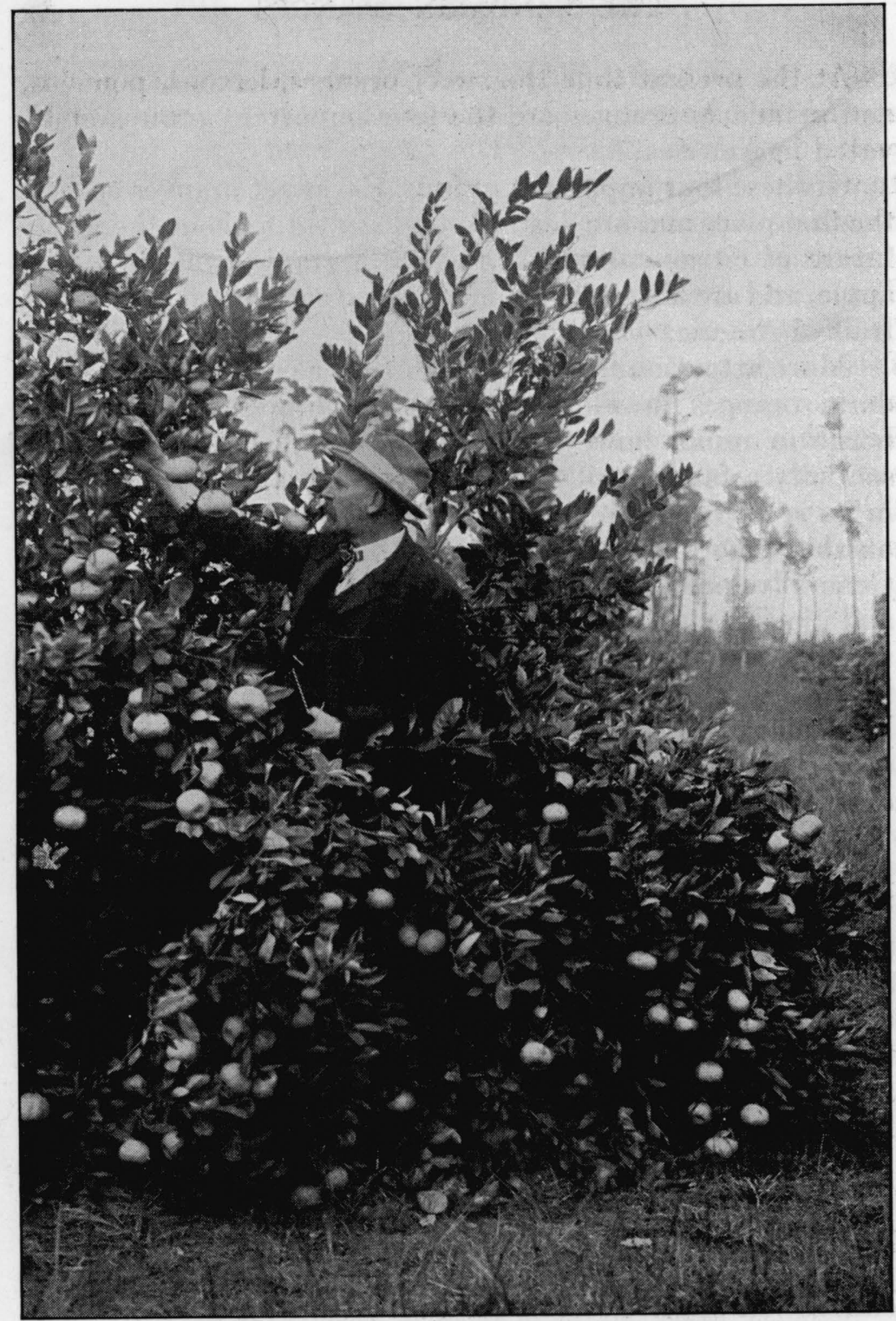

FIg. 59. G. L. Taber examining the fruit of Owari Satsuma. The establishment of the Satsuma orange industry was largely due to his efforts.

(80) 
California it withstands frost well, and a considerable amount of this fruit has been produced in the northern and northwestern parts of Florida. The tree is hardy, the fruit matures early, and is very desirable for shipment during the months of October and November.

Along the coast of Alabama, Mississippi, Louisiana, and Texas, and in southeastern Texas, the Satsuma on Poncirus trifoliata stock has been planted to a considerable extent. If the trees are banked each winter while young (young trees are more likely to be injured by cold) and allowed to branch low, they will, when they have increased in age and size sufficiently, stand considerable cold. For a number of years this orange was known in the markets under the names mandarin and tangerine. Recently, however, it has been quoted in market reports under its own name-Satsuma.

\section{VARIETIES OF MANDARIN ORANGES}

Beauty (Beauty of Glen Retreat).-Form oblate, decidedly flattened; sections showing through the rind; size medium, $21 / 8$ by $2 \frac{15}{16}$ inches, $2 \frac{3}{16}$ by $2 \frac{13}{16}$ inches; stem small and slender; apex flat or with a very slight depression; base slightly depressed and ridged about the calyx; color deep reddish orange, not so highly colored as Dancy, glossy; rind smooth, very thin, $\frac{1}{16}$ inch or slightly more in thickness; oil-cells flush with the surface, large, conspicuous, elliptical, oval or much flattened, frequently set in the pithy lining of the rind from which they may be detached easily; sections 10 or more, clearly defined, regular; rag almost entirely lacking; flesh orange; juice-sacs broad, blunt; pulp melting; juice plentiful, orange; flavor distinct, rich, vinous; acidity and sweetness well blended; seeds few, small, top-shaped; core small, open, $1 / 2$ inch or less in diameter. Season December and January.

Tree thornless, branches and branchlets slender and willowy; leaves small, resembling those of Dancy; petioles characteristically small and slender, $3 / 4$ of an inch long.

The fruit of this variety is very heavy, and though it floats in water it sinks almost below the surface. The color, while not possessing quite so much of the reddish tinge as Dancy, is decidedly darker than China. In flavor it resembles Dancy, though it is distinct. Unfortunately, it seems to have disappeared from cultivation in Florida.

According to the late G. B. Brackett, Beauty was introduced from Australia by the United States Department of Agriculture in 1893, and 
trees were at one time growing in the grove owned by Cyrus W. Butler, at St. Petersburg, Florida. In a letter to the writer dated April 18, 1902, W. J. Allen, Government fruit expert for Sydney, New South Wales, Australia, says: "This mandarin was raised by W. H. Parker within a few miles of Brisbane (Queensland), Australia, and is, I believe, a seedling from either the Emperor or Scarlet mandarin. The original tree was raised some time in 1888 or 1889 . The fruit is of good size, solid, with a beautiful, thin, tough rind and carries well. It is usually a good cropper and proves a profitable variety to grow."

China (China Celestial; China Mandarin; Kid Glove; Tangerine; Willow-leaved).-Form oblate, compressed; size medium, $17 / 8$ by $21 / 2$ inches, $2 \frac{15}{16}$ by 3 inches, usually about 2 by $2 \frac{9}{16}$ inches; color dark orange, shiny; apex slightly scarred, with very shallow and rather broad depression; base nearly smooth, somewhat necked or creased, the number of creases frequently corresponding with the number of sections; stem small; calyx small, set in a slight depression; rind smooth, generally marked with depressions corresponding to the number of sections, 1/8 inch or less in thickness, very loosely attached; oil-cells conspicuous, slightly depressed or flush with the surface; sections 10-13, rather irregular in size, welldefined; flesh coarse-grained in appearance, orange; juice-sacs short, broad, and blunt; pulp melting; juice plentiful, colored; acidity and sweetness well combined; flavor vinous, peculiar, and distinct (musky?); seeds 1525, brownish white, top-shaped, roundish, beaked, plump; core open, spongy, $3 / 4$ inch in diameter. Season November and December.

Tree very willowy in growth, almost thornless; leaves small, narrow, deep green; fruit usually borne singly at the tips of slender branches.

China is not so extensively cultivated in Florida as the variety Dancy, but in Louisiana it predominated before the freeze, and New Orleans is one of the best markets. The fruit is frequently in good condition for the Thanksgiving trade.

It was introduced into Louisiana from Italy between 1840 and 1850, and from thence it is said to have been brought to Florida by Major Atway at an unknown date. The original tree was growing on the Atway place when it was purchased by Dr. Moragne, of Palatka.

Cleopatra (Spice Tangerine).-Form oblate flattened and irregular in circumference outline; size small, $1 \frac{3}{16}$ by $1 \frac{3}{4}$ inches, $1 \frac{1}{4}$ by $21 / 8$ inches; color dark orange-red, not so bright as Dancy; stem slender, base flat, slightly depressed or sometimes slightly elevated, roughened about the calyx; apex depressed, generally navel marked; rind rough or inclined to roughness, $1 / 8$ inch or less in thickness, loosely attached, in very ripe specimens separating entirely from the pulp-ball; oil-cells small, numerous; sections 15, small; flesh orange, coarse-grained; juice-sacs typically broad and blunt; juice abundant, colored; flavor vinous; acidity and sweetness 
normal; quality good; seeds about 20, small, top-shaped; pith small, open. Season January and February.

Tree thornless, forming a dense top, upright but inclined to be willowy; leaves small; fruits produced singly or in bunches. As an ornamental this variety is very beautiful, but as a commercial variety it is not worthy of cultivation. The fruit is small and the trees not sufficiently prolific to make up for the deficiency in size by an abundance of fruit.

In Bulletin 1, United States Department of Agriculture, Division of

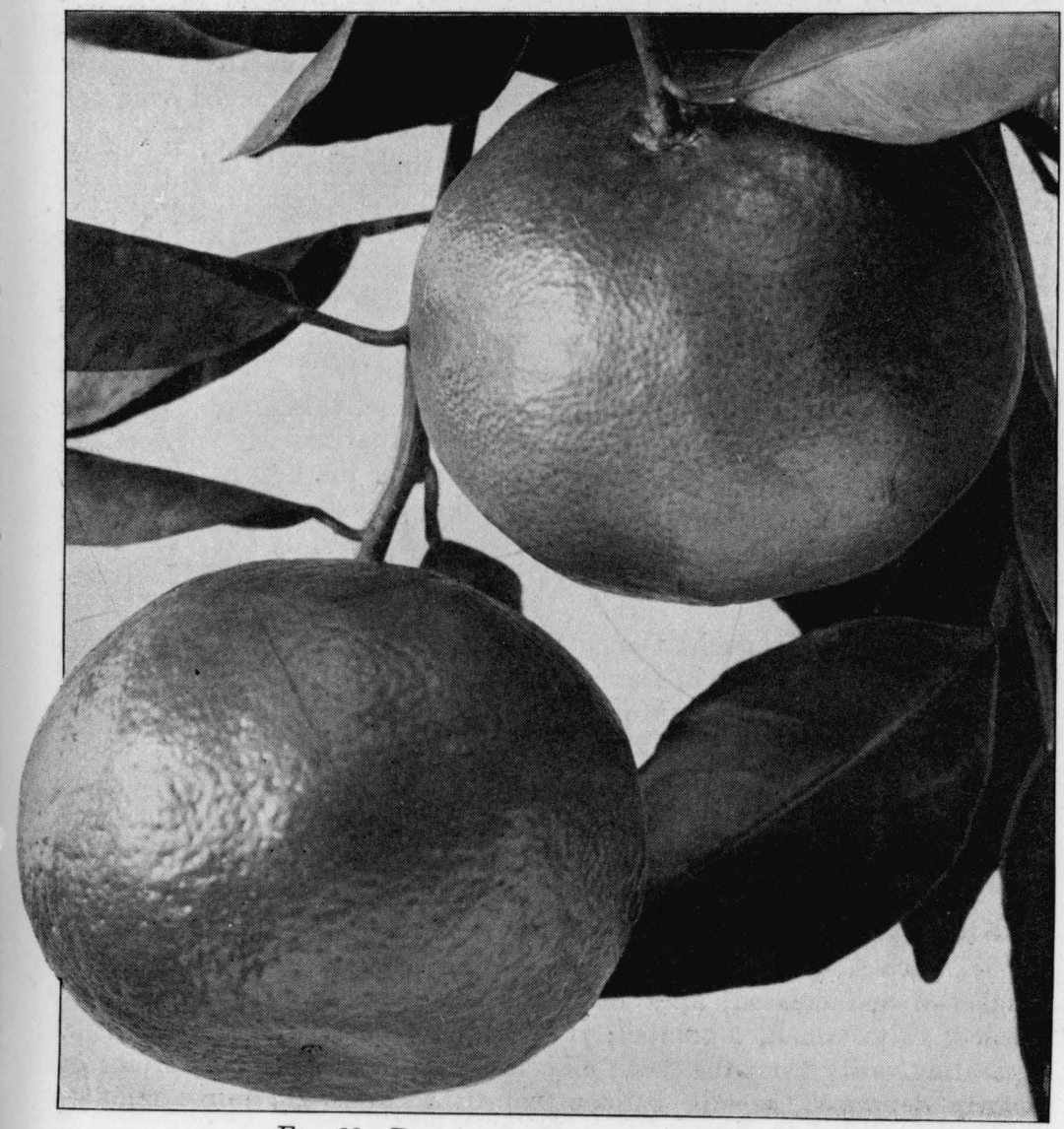

FIG. 60. Dancy tangerine (about natural size) 
Pomology, Reasoner states that the Spice tangerine was introduced into Florida by Colonel Codrington from Jamaica, but it had been known for a long time in Florida under the name Cleopatra.

Dancy (Tangerine; Dancy's Tangerine; Bijou; Moragne's Tangerine). -Form oblate, sections showing through the rind; size medium, $13 / 4$ by $25 / 8$ inches, $21 / 8$ by $3 \frac{1}{16}$ inches; color deep orange-red, almost tomato-red, shiny; stem slender; base sometimes smooth, frequently nippled or more or less corrugated; calyx small; segments blunt pointed; apex terminating in a broad shallow depression, sometimes scarred; rind smooth, $\frac{1}{16}-1 / 8$ inch thick, leathery, easily removed, attached by a few strings to the flesh; oilcells small, usually flush with the surface, though sometimes slightly depressed; sections 11-14, fairly regular in size, easily detached from one another; flesh dark orange, coarse-grained; juice-sacs short, broad and blunt; juice abundant, colored; rag almost entirely absent; pulp melting; acidity and sweetness well blended; flavor rich and sprightly; quality excellent; pith open, $3 / 4$ inch across; seeds $7-20$, rather small, short and blunt or top-shaped and beaked. Season December and January. (Figs. 57 and 60.)

Tree compactly headed, rather upright, though tending to spread as the head is opened from year to year by the weight of the fruit, densely foliaged, fruit exposed on the outer portion of the tree. Dancy has been more generally planted than any other orange of this group. Its high color, combined with excellent quality, make it a particularly fine sort. It is commonly known throughout Florida and in the markets as Tangerine. The variety Dancy is said to have originated as a seedling at Buena Vista, St. Johns County, Florida. The parent tree was raised by Col. George L. Dancy and was introduced into cultivation in 1871 or early in 1872. It has proved to be a very prolific variety.

Pliny Reasoner thought Dancy to be a seedling of China, but this is doubtful. Every seedling of Dancy that has been observed bears a strong resemblance to the parent. Moreover, in a letter dated January 1, 1903, Miss S. W. Moragne, of Palatka, Florida, states that a tangerine tree was growing on her father's place when it was purchased, about 1843, and that China was not the first of the group grown in Florida. Twigs of trees propagated from the original strongly resemble Dancy and the author believes that it originated from this variety.

King (King of Siam). ${ }^{1}-$ Form oblate; size large, $23 / 8$ by 3 inches, $3 \frac{1}{16}$ by $3 \frac{3}{4}$ inches, $3 \frac{3}{8}$ by $4 \frac{1}{4}$ inches; color deep orange; base somewhat roughened and creased; apex flattened, scarred, and very slightly depressed; calyx small, 5-pointed; rind rough, pitted, $1 / 8-1 / 4$ inch thick, separating easily from the flesh; oil-cells large, flush with the surface or slightly depressed, mostly balloon-shaped; sections 13, fairly regular,

${ }^{1}$ Bull. Div. Pomology, U. S. Dept. Agr., 1:73, 1887. 
easily detached from one another; flesh orange, rather coarse-grained; juice-sacs spindle-shaped, not so broad and blunt as in other members of the group; juice abundant, colored; pulp melting; acidity and sweetness well blended; flavor agreeable, sprightly; quality very good; seeds 18-20, large, resembling those of the sweet oranges, cotyledons white. Season late, March and April. (Fig. 61.)

Tree stiff and upright in growth, generally thorny, though some specimens have fewer thorns than others; foliage dark green, resembling that of the sweet oranges.

The King mandarin has been extensively planted in Florida, but at the present time is not held in quite as high esti-

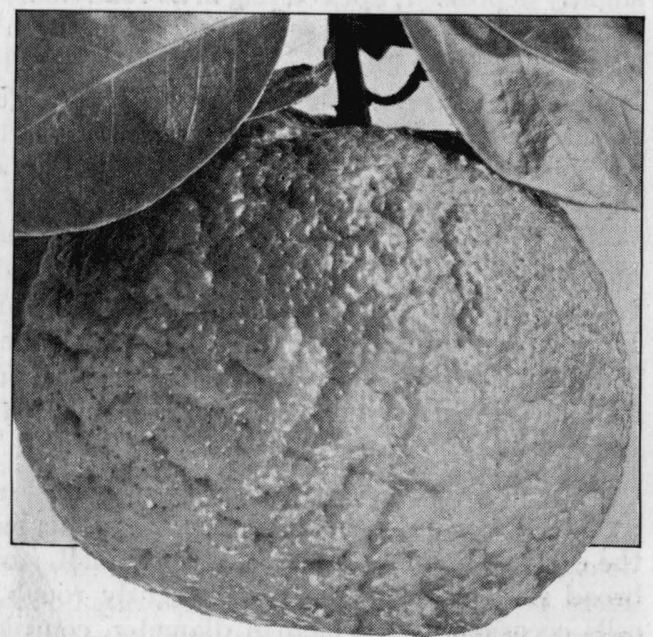

FIG. 61. King orange. The rough skin is characteristic mation as formerly. The wood appears to be brittle, and frequently the trees bear so heavily that they are almost stripped of their branches by the weight of the fruit. This might be obviated by thinning. The fruit is much exposed to the sun and is frequently badly sunburned and rendered unsalable. On the other hand, it must be stated in its favor that the variety is prolific, of good quality, and since it matures late in the season, always commands good prices. The variety was introduced into California from Cochin-China in the year 1882 by R. Magee, of Riverside, and into Florida, from California, in the same year, by John Carville Storin, of Winter Park.

Kinneloa.-Form roundish oblate; size medium, $1 \frac{1}{4}$ by 2 inches, $27 / 8$ by $27 / 8$ inches; color deep reddish orange; base somewhat nippled; apex with a small dot in a medium small basin; surface undulating, rough; oilcells numerous, depressed; rind loosely attached, $1 / 8$ inch in thickness, pungent, aromatic; flesh translucent, tender; juice-cells small to medium, irregular; tissue thin; juice abundant, translucent; flavor and acidity medium; seeds 10, plump, straw-colored, of medium size; fruit heavy and of good quality. Description from specimens from J. E. Cutler, Riverside, California, by Division of Pomology, U. S. Department of Agriculture. 
Kino Kuni.-Form oblate, much flattened; size small to medium, $13 / 8$ by 2 inches, $15 / 8$ by $25 / 8$ inches; color deep orange or orange-red; stem slender; base usually creased or roughened with 4 or 5 ridges; calyx small, slightly depressed; apex ending in a broad shallow depression nearly $\frac{3}{16}$ inch deep; rind rather rough, separating readily from the pulp, $1 / 8$ inch or slightly less in thickness; oil-cells conspicuous, depressed; sections usually 13, irregular in size; flesh coarse-grained, reddish orange in color; juice-sacs short, broad, blunt; juice abundant, colored; pulp melting; acidity and sweetness well blended; flavor sprightly; quality quite good; pith open; seeds 13-14, top-shaped, beaked; cotyledons green. Season November and December.

Tree compactly headed, resembling Cleopatra; leaves small; fruit of quite good quality, but not of much commercial importance.

It is not known when the variety Kino Kuni was first introduced into Florida, but at present the tree in the grove formerly owned by John Thomson, at Clearwater Harbor, is the only one known to the writer. It is a Japanese variety, and Thomson received his tree from J. L. Normand, of Marksville, Louisiana, in August, 1894.

Mikado.-Form oblate; size medium to large, $13 / 8$ by $25 / 8$ inches, $2 \frac{1}{8}$ by 3 inches; color orange-yellow; stem stout; base slightly depressed about the calyx, rough or corrugated; calyx small, sunken; apex terminated by a broad shallow depression; rind slightly rough, $1 / 8$ inch in thickness; oilcells occasionally $\frac{1}{16}$ inch in diameter, conspicuous, slightly elevated or sometimes depressed; sections 13-14, well-defined, rather irregular, separating easily; flesh orange, coarse-grained; juice-sacs elongated, or broad and blunt; juice abundant, orange-colored; pulp melting; acidity and sweetness well blended; flavor rich, sprightly; quality very good; pith open, $3 / 4$ inch across; seeds 9 , top-shaped, distinctly beaked, large, $3 / 4$ by $1 / 4$ by $\frac{5}{16}$ inch; cotyledons green. Season October and November.

Tree inclined to be upright, in general resembling Satsuma but not so reclinate. This variety closely resembles Satsuma, of which it is a seedling. It differs in its more upright habit, in having distinctly flanged leaves, in the larger and more distinct oil-cells of the rind, in the shape and number of the seeds, and the larger broader depression about the apex. It cannot, however, be considered in any way superior to Satsuma. Originated by Rev. Lyman Phelps, of Sanford, Florida.

Oneco. ${ }^{1}$ - Form oblate, flattened at the apex and tapering from about the middle to the base; size medium to large, $2 \frac{5}{16}$ by $27 / 8$ inches, $21 / 2$ by $31 / 4$ inches; color deep orange-yellow; base slightly ridged or smooth; calyx very small; apex ending in a broad shallow depression; rind 1/8 inch thick, generally inclined to be rough though frequently smooth, easily detached; oil-cells large and conspicuous; sections 12, fairly regular, clearly defined;

${ }^{1}$ Reasoner's Catalogue, 1900. 
flesh coarse-grained, orange-yellow in color; juice-sacs broad, short; juice abundant, colored; rag absent; pulp melting; acidity and sweetness well blended; flavor distinct, rich, vinous; quality excellent; pith open; seeds 12-14, small, top-shaped, beaked; cotyledons green. Season January to March.

Tree rather upright, thorny, but with many thornless branches; foliage small with a pronounced fragrance when bruised. The fruit is excellent in flavor and is not surpassed in quality by any of the mandarin group. The flavor may be said to resemble a combination of Dancy, King, and Satsuma.

This variety was raised from seed received from northwestern India and planted by the late P. W. Reasoner in 1888. The original seedling tree is still standing on the grounds of the Royal Palm Nurseries, at Oneco, Florida.

Satsuma (Oonshiu). Owari Satsuma.-Form oblate, sections frequently showing through the rind; size variable, $17 / 8$ by $25 / 8$ inches and $25 / 8$ by $3 \frac{7}{16}$ inches representing the variation in size; color orange-yellow; base usually slightly creased; calyx small; apex scarred with a round brownish spot situated in a broad shallow depression; rind $1 / 8$ inch thick, inclined to be rough; oil-cells large, conspicuous, frequently depressed though sometimes flush with the surface; flesh deep orange, coarse-grained; juice-sacs short, broad; juice abundant, yellowish-orange; pulp melting; acidity and sweetness well balanced; flavor sprightly, agreeable; quality excellent; pith open with the sections frequently separated at the inner edges; generally seedless though occasionally from 1-4 seeds are found, top-shaped, broad, plump, not distinctly beaked as in others of the group. Season October and November. (Figs. 56,59 and 62.)

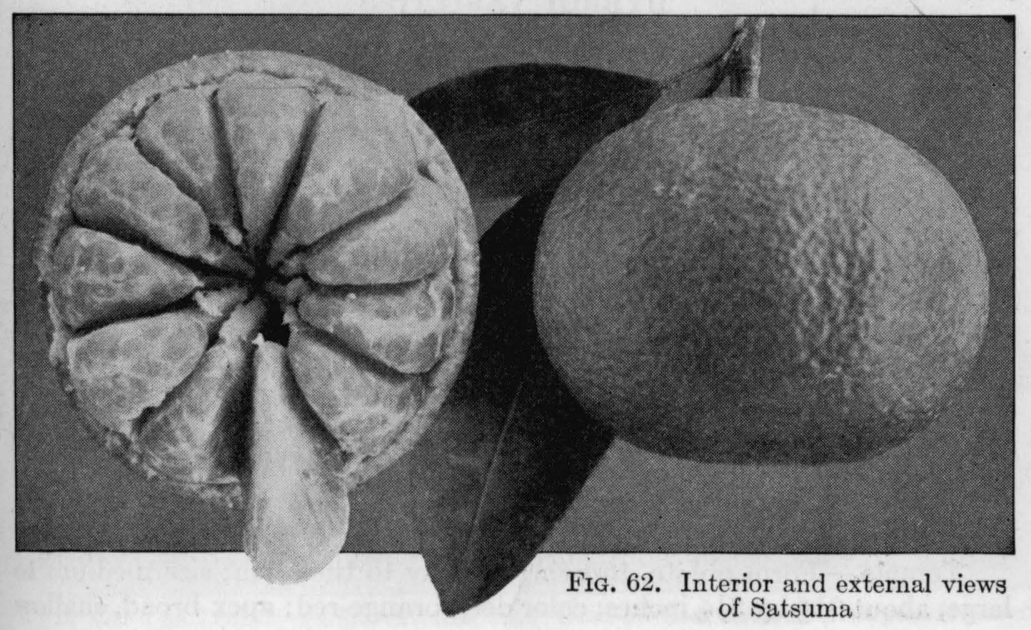


The Satsuma is a Japanese variety introduced into Florida by George R. Hall in 1876, and again by Mrs. Van Valkenburg in 1878.

Tree thornless and of spreading dwarf habit, branches reclinate, branchlets angled; leaves broad, tapering abruptly toward the apex, generally pointing upward and thus either following the direction of the branches or at right angles to them, petioles scarcely margined. The smaller fruits ripen first, the larger ones later, and they are at their best just when they reach maturity. In the extreme southern part of Florida they do not color well, but remain green or greenish for a considerable time after the juice has acquired its best flavor. As it is very hardy in northern Florida, it is strongly recommended for planting there. The fruit is well received in the markets and the trees bear regularly a fair crop. Fruit and leaves are sometimes attacked and distorted by the attacks of citrus scab.

Recent investigations have shown that Satsuma, rather than being the name of a single variety, should be used as a group name. In it are comprised several varieties from Japan, mostly of unkrown origin, and one of the most important of these is Owari, the only variety at present planted in commercial groves in the southeastern states. When the Satsuma orange was introduced from Japan, Owari was the variety imported. This was very fortunate, as it is one of the finest sorts. Other more or less welldefined varieties of Japanese origin are Mori, Hira, Ikiriki, Wase, Ikeda, and Zairai. Wase is said to be earlier in ripening than Owari. When these varieties are thoroughly tested, some may be found to possess characteristics which will make them valuable additions to American lists.

\section{HYBRID VARIETIES}

Tangerona.-Form roundish-oblate; size small, $2 \frac{3}{16}$ by $2 \frac{1}{2}$ inches, sinking $\frac{5}{6}$ when placed in water; color orange-yellow; base rounded, very - slightly irregular; calyx small, lobes pointed; stem small; apex scarred, slightly depressed; rind pebbled because of the elevated oil-cells, $1 / 8$ inch thick, tightly attached; oil-cells convex at the outer sides, elevated above the rind so as to give it a pebbled appearance and feeling; sections 11, distinctly marked, firmly attached to each other, small, rather irregular in size; juice-sacs broad and blunt, like those of the mandarin oranges, of medium size; flesh coarse-grained, melting, orange-yellow; juice abundant; acidity and sweetness well blended; flavor rich and vinous; quality very good; pith proportionately large, $1 / 2-5 / 8$ inch across; seeds present, wedged, broad and flat or oval, large, $5 / 8$ by $\frac{5}{16}$ inch; cotyledons white or sometimes a greenish one is found. Season September and October.

Tangerona was introduced into Florida from Brazil, but because it is tender and the fruit is small it is not grown to any extent.

Temple.-Form oblate, tapering slightly to the stem; size medium to large, about $2 \frac{1}{2}$ by $31 / 8$ inches; color deep orange-red; apex broad, shallow 
depression sometimes navel marked; stem end of fruit tapering and usually creased; calyx small; stem slender; skin smooth or pebbled, leathery, thin, separating easily from the pulp, in this particular intermediate between tangerine and round oranges; oil-cells spherical or slightly flattened; sections $10-12$, with very thin partitions; flesh orange, melting, free from rag, very juicy; juice-sacs slender, spindle-shaped, of medium size; acidity and

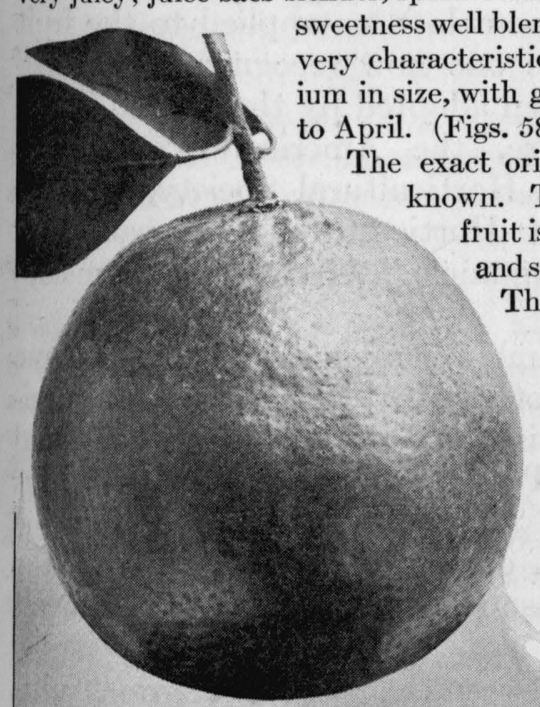
sweetness well blended; flavor spicy, rich, vinous and very characteristic; seeds about 20 , small to medium in size, with green cotyledons. Season January to April. (Figs. 58 and 63.)

The exact origin of the Temple orange is unknown. There is every indication that this ruit is a hybrid between a sweet orange and somevariety of the Mandaringroup. The original tree from which propagation was started is budded, but no one knows where the bud came from. It stands on the old Temple place near Winter Park, Florida, and was named for the late William Chase Temple, who did much for the citrus industry in Florida. It was introduced and catalogued by the Buckeye Nurseries,Tampa, Florida, in 1917.

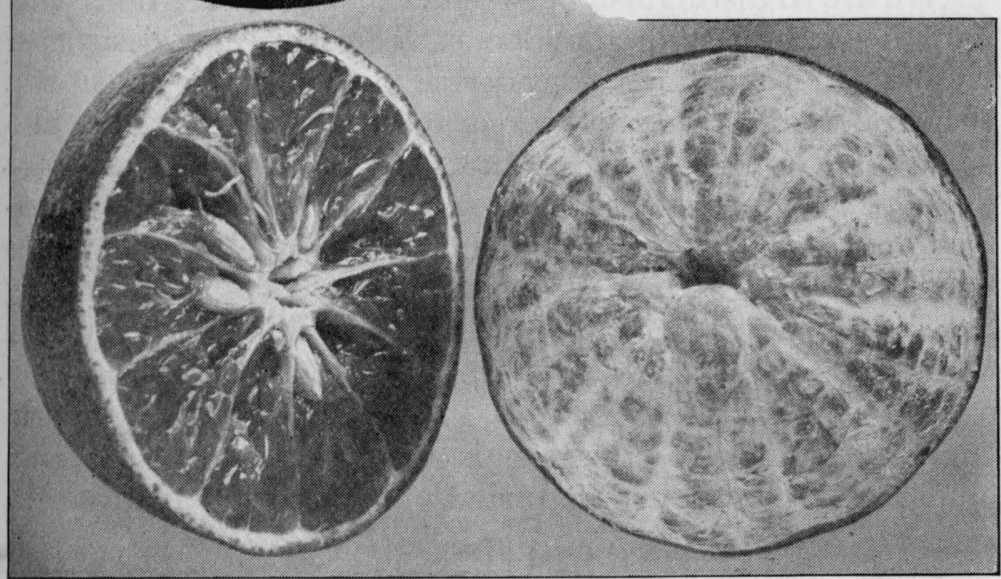

Fig. 63. The Temple orange, external view, cross-section, and end with peel removed 


\section{CHAPTER VII}

\section{THE POMELOS AND SHADDOCKS}

The name pomelo (pl. pomelos), as applied to the fruit under consideration, is the one now recognized by horticultural writers and has been adopted by the United States Department of Agriculture, the American Pomological Society, the Florida State Horticultural Society, and the California State Board of Horticulture. The word has been variously spelled "pummelo," "pumalo," "pumelo," "pumelow."

From the Dutch pompelmoes has come our modern name pomelo. The explanation offered by Bonavia ${ }^{1}$ of the derivation of the Dutch name is that they probably first found the fruit at the village of Pompelmousses in the Mauritius and gave the name of the village to it. Harris ${ }^{2}$ offers the explanation that pomelo is derived from pomum melo, the melon-apple. Which of these is correct it would be difficult to say.

We are to distinguish between the pomelos or grapefruits, and the pummelos or shaddocks. The fruit now designated by the name shaddock, considered horticulturally, is entirely distinct from the pomelo or grapefruit, and they are also separable botanically. In this book, the pummelos or shaddocks are referred to the species Citrus maxima (formerly known as $C$. decumana and $C$. grandis), and the pomelos or grapefruits to Citrus paradisi (see page 21). In tracing the history of these fruits, however, it is difficult to separate the references, as names are often indefinitely applied.

Commercially, the fruit is known as grapefruit, and in market quotations reference is nearly always made to it under this name. This appellation was given because the

${ }^{1}$ Gardener's Chronicle, 27:450-451. 1900.

${ }^{2}$ Bailey's Cyc. Am. Hort., 3:1397. 1901. 
fruit is so frequently borne in grape-like clusters of from three or four to a dozen and a half. A glance at Fig. 64, which shows the fruit hanging in bunches like grapes on the inner branches of a grapefruit tree, proves that the name is not altogether inapplicable. Not only is the fruit known in the market as grapefruit, but it is the name generally applied throughout the citrus districts of the United States, and many persons know it by none other. Whether the term grapefruit will ever be superseded in common use by the correct horticultural name, pomelo, is extremely doubtful.

When and where this cognomen was first used it would be difficult to say, but John Lunan, ${ }^{1}$ speaking of the shaddock, says, "There is a variety known by the name of grapefruit on account of its resemblance in flavor to the grape." The Chevalier de Tussac, ${ }^{2}$ calls attention to the fruit in these words: "J'ai eu occasion d'observer a la Jamaique, dans le jardin botanique d'East, une espece de chadec dont les fruits, qui n'excedent pas en grosseur une belle orange sont disposes en grappes; les Anglaise de la Jamaique donnent a ce fruit le non de forbidden fruit, fruit defendu, ou smaller shaddoc, petit chadec." 3 From this we must conclude that the name grapefruit originated in the West Indies, as it is not found in any other of the older works, except where the authors mentioned above are referred to or quoted.

The pomelo is sometimes referred to as the shaddock, variously spelled "shaddock," "chaddock," and "chadec." Bonavia, in his work on the oranges and lemons of India and Ceylon makes the name shaddock synonymous with pomelo. In Thomas' Fruit Culture in the section on Sub-tropical Fruits, written by E. H. Hart, of Federal Point, Florida (1897), the name shaddock is used, while pomelo, spelled pummelo in his article, is made synonymous.

${ }^{1}$ Lunan, John. Hortus Jamaicensis, 2:171. 1814.

${ }^{2}$ de Tussac, Chevalier. Flora Antillarum, 3:74. 1824.

3Translation: "I have had an opportunity to observe in Jamaica, in the East Botanic Garden, a variety of shaddock, the fruit of which, not larger than a fine orange, is arranged in bunches (grappe de raisins-bunch of grapes); the English in Jamaica call this fruit the forbidden fruit, or smaller shaddock." 


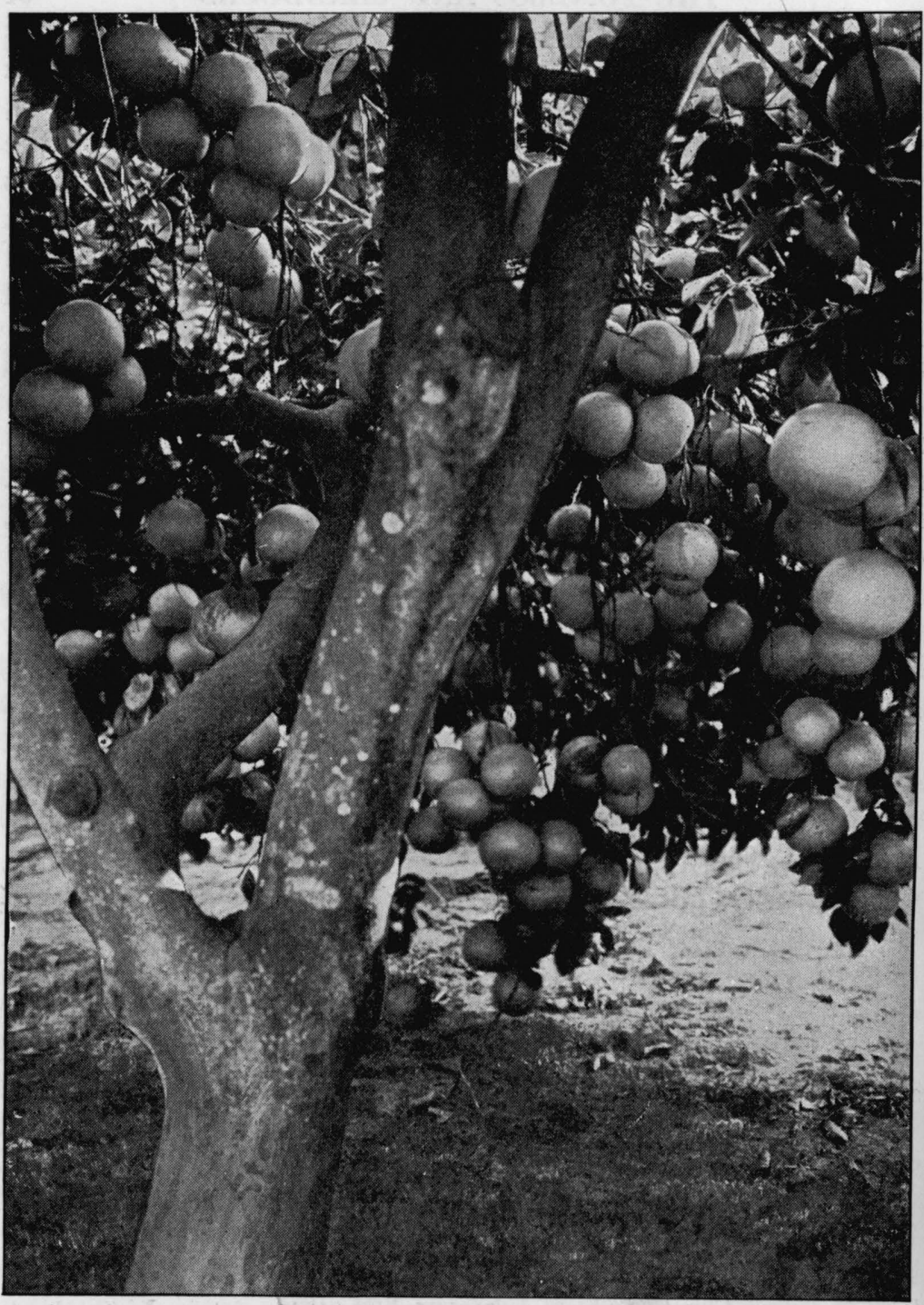

FIg. 64. Inside of grapefruit tree showing how the fruit is borne 
However, we have no better name for this fruit than pomelo. It is of older origin than either of the others (if with some writers we allow the synonymy of shaddock), the Dutch word Pompelmoes, from which it is derived, having been in use more than two centuries ago. The name pomelo has been adopted by the best authorities and it is by all means advisable that they be followed and that we have some constant name by which to designate the fruit. The names shaddock and pummelo are more properly applied to varieties with large coarse-grained fruit, borne singly on the tree. There are other points of distinction between the two which may be mentioned incidentally. The fruit of the shaddock is much larger than that of the grapefruit, often weighing fifteen pounds or more, and the oil-glands of the rind are fewer in number and larger in size. The tree is smaller than the grapefruit, the leaves on mature trees are larger, somewhat pubescent and the tree itself is not nearly so hardy as the grapefruit.

Whence came the pomelo (grapefruit) of today? Captain Shaddock, an East Indian sea captain, is credited with bringing seed of the shaddock (pummelo) to the West Indies. The seed which he introduced was undoubtedly, in part at least, that of the true shaddock as we know it. Hans Sloane, who was a keen observer, illustrates this fruit in his work: "A Voyage to the Islands of Madeira, Barbados, etc." But could Shaddock's seed have been mixed and could part of it have come from a pomelo or grapefruit tree that grew in the Far East, and which no botanist, explorer, or traveler has since found? Can it be that the grapefruit still exists in the East and has not been brought to light? Or is it possible that grapefruit was introduced into the West Indies by some other traveler, and that Captain Shaddock had nothing to do with it? Griffiths Huges, ${ }^{1}$ under the name, "Forbidden-Fruit-Tree," described a citrus fruit which was probably a grapefruit. Unfortunately, his accompanying

${ }^{1}$ The Natural History of the Island of Barbados, 127. 1750. 
Plate VII is too crude to make identification certain. If this be grapefruit, it is one of the earliest references to it as distinguished from the shaddock. No mention is made of

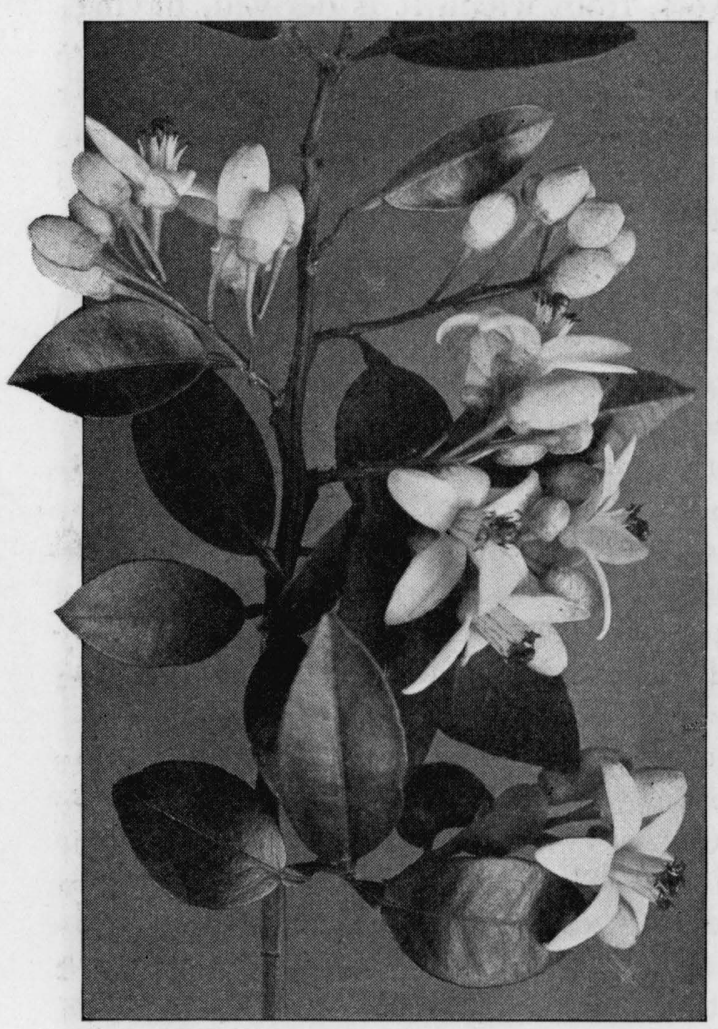

Frg. 65. Flowering twig of Marsh pomelo (about $3 / 4$ natural size) grapefruit by European writers on Citrus until within comparatively recent years, though they knew the pummelo or shaddock. In whatever way it reached the western hemisphere, the grapefruit did not come from European groves or orangeries.

The grapefruit may have come into existence as a mutant or seedling in the West Indies, perhaps from the seed introduced by Shaddock. It may have originated as an American fruit on American soil. In Jamaica, in 1814, a citrus fruit was known as grapefruit, and it probably was not materially or specifically different from American grapefruit as found in cultivation today. Certainly it was distinct and markedly different from the shaddock, or it would not have attracted the attention and favorable comment of many early authors who have mentioned it in their writings. 


\section{HORTICULTURAL STATUS OF THE POMELO}

No fruit of importance now grown in the United States has such a meager American literature as the pomelo. Nor is this strange when it is remembered that only since $\mathbf{1 8 8 5}$ has the pomelo been regarded as a commercial fruit. After having been neglected for years, while the whole attention of growers of citrus fruits was directed to the orange, and all their energies put forth in bringing that fruit to perfection, it has only very recently taken its present position, to which the critical taste of fruit consumers has raised it.

The exact details of the introduction of the pomelo (grapefruit) into Florida are unknown. In all probability, it was brought to Florida together with other members of the genus by the Spaniards, who, under the leadership of Ponce de Leon, first landed upon the east coast of Florida in the year 1513. From that time until 1821 they disputed the possession of the state with their enemies in the Old World and the aborigines of the country, except for a period of twenty years (1763-83), during which time Great Britain controlled the territory.

During the Spanish régime, different citrus fruits were introduced and cultivated in Florida. These, through the agency of the Indians, were carried into all parts of the state, and to this day the common lime (generally known as the Mexican lime), the rough lemon, and the sour orange are growing luxuriantly in southern Florida under such conditions as would lead one, ignorant of their origin and native home, to believe them indigenous.

About 1809, Don Phillippe, a Spanish nobleman, came to Florida and settled near Green Springs, in what is now Pinellas County. He brought grapefruit seeds with him and planted them. With the trees obtained from these seeds, and with other trees, he set out a citrus grove at that point and brought it into bearing. One of the grapefruit trees planted by him is still living (1925). This was one of the earliest, 
if not the earliest, grapefruit planting in Florida. Seeds from his grove were given to neighbors, and many of the old seedling trees of Florida doubtless owe their existence to the

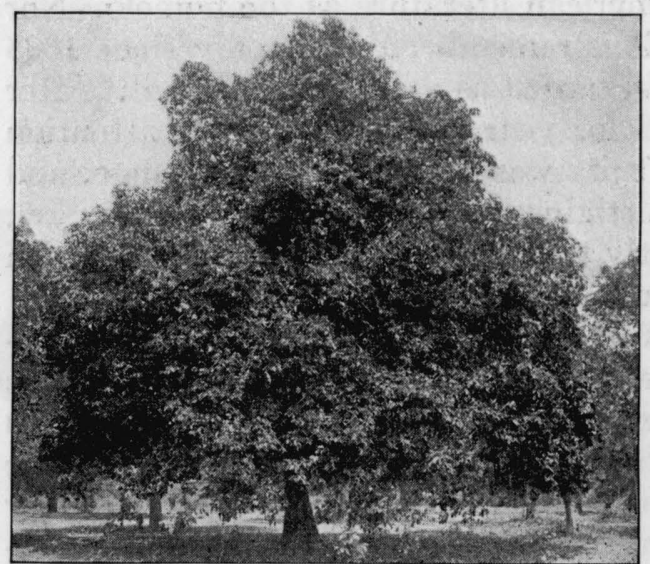

FIG. 66. The famous large grapefruit tree in the Davy grove, Pinellas County, Florida old Spaniard's generosity and enterprise. Two old trees in the same vicinity are seedlings from the surviving tree. One of them, a giant in stature and production, is the largest grapefruit tree in Florida, with a branch-spread of more than sixty feet (Fig. 66); the other is the original Duncan tree. Can it be possible that Don Phillippe brought the first grapefruit seed to Florida and grew and planted the first trees?

Following the time of introduction, in many groves and gardens throughout Florida, pomelo trees were found, annually laden with hundreds of fruits. By the inhabitants, the fruit was considered refreshing and tonic, but that it might have a commercial value did not enter the minds of the owners; or if it did, the crude state of transportation rendered any attempt to place this unknown and unappreciated fruit on the market, with an expectation of profit, a precarious and uncertain undertaking. Consequently, the ground beneath the trees, during a certain part of the year, was covered with the yellow fruit left to rot in the sun.

This group of fruits was either unknown or disliked by horticultural writers, or confounded with the shaddock, even within very recent years. George Don ${ }^{1}$ says, "The

${ }^{1}$ Don, George. Gardener's Dictionary, p. 596. 1831. 
shaddock is certainly the least useful of the species and is cultivated chiefly for show." Alexander Watson ${ }^{1}$ in 1859 wrote the following: "Shaddock is a still larger fruit [than the citron], in form more resembling the orange, curious, but worthless." W. N. White ${ }^{2}$ in 1868 says: "Pulp dry, sweetish or subacid, but not very desirable, except for its showy appearance." Rev. T. W. Moore, in his "Hand Book of Orange Culture," 1881, does not mention it. Thomas, in his "Fruit Culturist," makes no reference to it up to as late as the edition of 1885 . William A. Spalding, ${ }^{3}$ in 1885 , makes the following remark: "Meanwhile the Pumalo and its congeners, when allowed growing space, continue to load themselves down with fruit as large as footballs. They are matters of wonder and that is all." Charles Downing ${ }^{4}$ in 1885, under the head of shaddock, has the following note: "The pulp is sweetish or subacid and the juice is rather refreshing. It is, however, more showy than useful, and certainly makes a magnificent appearance in a collection of tropical fruits." All of this was true of the shaddock as we know it, but not of the pomelo or grapefruit.

Northern visitors to Florida learned to know and like the pomelo and a certain demand was created by their desire for the fruit on their return. Somewhere between 1880 and 1885 the first pomelos were shipped from the state, sold in New York and Philadelphia, and netted the shippers about 50 cents a barrel. This was the beginning, and better prices were soon realized. The freeze of 1894-95 greatly reduced the Florida crop, and the small amount of fruit sold that year brought an enormous price, in some cases as much as $\$ 15$ to $\$ 20$ a box.

Very extensive plantings have been made in Florida, California, and elsewhere. For many years the supply of fruit was usually inadequate to the demand, but with the

${ }^{1}$ The American Home Garden, p. 363. 1859.

${ }^{2}$ Gardening for the South, p. 384. 1868.

${ }^{3}$ The Orange in California, p. 89. 1885.

${ }^{4}$ Downing's Fruits and Fruit Trees of America, p. 579. 1885. 
increase in the amount of fruit produced a state of equilibrium between supply and demand has been reached. It is safe to predict that with a favorable climate the future price realized for pomelos will be lower than in the past, for the tree is a heavy bearer, is no harder to propagate and care for than an orange tree, comes into bearing as early, and heavy plantings have been made.

There are many markets in which the pomelo is not known, and as it becomes more widely disseminated, the demand will increase. This is likely to maintain the present prices for some time to come, but though it is believed that a balance has already been reached, and that after a time the ruling price may be lower than at present, to the careful painstaking grower this need cause no uneasiness. There will always be a good demand for first-class fruit, well colored, well grown, carefully selected, well packed, and placed on the market in inviting condition.

At present it seems probable that Florida will retain control of the pomelo market for some time, probably indefinitely, if the growers are careful to maintain the present excellence of the product. The California grapefruit has not, up to this time, met with the same favor in the markets, though it is possible that varieties may yet be brought forward better suited to the soil and climate of that state.

As a breakfast fruit, the pomelo stands without an equal, for it is an excellent appetizer and stomachic, and probably contains tonic properties as well. It is frequently stated that it contains an alkaloid peculiar to itself, but its presence has not yet been demonstrated by the chemist. The partitions of the fruit contain a bitter principle which some have though it would be better to have eliminated, and that those varieties in which the bitterness is almost lacking are the better ones. However, with this entirely absent, the fruit would not be a pomelo. The ideal fruit should have the bitter taste rather pronounced; the flavor should be characteristic of the pomelo - a pleasant indescribable blending 
of bitter, sweet, and acid and, lacking this, it falls short of the standard of excellence and must be classed as inferior.

In Cuba, pomelos of excellent quality are produced. They closely resemble the Florida fruit in flavor and general character. The favorite varieties at the present time are Duncan, Marsh Seedless, and Walters, and these give excellent satisfaction. Plantings of considerable extent have been made, most of the trees having been supplied from Florida nurseries.

Tangelos are hybrid fruits, crosses between the tangerine and pomelo. One of these, Nocatee, occurred as a natural seedling in the grove which formerly belonged to T. J. Watkins, Nocatee, Florida. Other varieties have been originated by the United States Department of Agriculture from hand-pollinations. The most noteworthy are Sampson and Thornton.

It was thought at one time that the tangelos might become important commercial fruits, but they have never secured a place of any consequence in commercial plantings. Some of them are more susceptible to citrus scab than the grapefruit.

\section{VARIETIES OF POMELO OR GRAPEFRUIT}

Aurantium (Orange).-Form oblate; size $21 / 2$ by $37 / 8$ inches, frequently smaller; stem small; color light yellow; rind smooth, but with the oilcells slightly depressed; sections 11, regular; flesh grayish green; bitter principle not marked or present only in a very slight degree; acidity medium; sweetness good; seeds 35, of medium size. Season late.

Aurantium is generally regarded as a hybrid. James Mott, who introduced the variety, wrote the author as follows regarding its origin: "In the winter of 1888, I found with J. C. Clouser, Longwood, Florida, what seemed to me was a very superior pomelo, two quite large trees, from buds he then told me he supposed were orange when he took the buds from a small tree which he found in an old abandoned seedling nursery. The nursery was planted by a Mr. Henkle at an early date from sweet orange seed procured from the noted Dummitt grove at or near the head of Indian River."

This variety, as already noted, is considered a hybrid between the sweet orange and the pomelo, and the character of the fruit, so different 
from that of the pomelo, gives color to this view. The quality is good, but falls short of the standard of excellence for pomelos.

DeSoto.-Form oblate; size $37 / 8$ by $47 / 8$ inches; stem stout; base creased; rind medium thick, compact; color light yellow; oil-cells very slightly elevated; sections 15, large, irregular, flesh light grayish; juicesacs large, well-filled, irregular; bitterness decidedly marked; acidity medium; flavor and quality both good, though slightly lacking in character; seeds 43, wedge-shaped, large and plump. Season late. A good seedling variety.

In reference to the origin of this variety, John Thomson, of Clearwater, Florida, wrote: "The variety is one that I came across on the banks of the Peace River, near Zolfo, Florida. My attention was first called to it in 1892-93. . . The fruit attracted my attention and I decided that it had distinctive merit of its own, hence I brought budwood from the tree with me to Clearwater in the spring of 1895."

Duncan.-Form oblate; size $33 / 8$ by $4 \frac{1}{8}$ inches, $4 \frac{1}{2}$ by $5 \frac{1}{4}$ inches, or larger; color light yellow; stem large; calyx-segments broad, blunt; apex slightly scarred; rind medium thick, firm; oil-cells large, sunken; sections 14; flesh light grayish green; juice-sacs closely packed, large; bitterness well marked; acidity and sweetness good; core $5 / 8$ inch across, somewhat open; seeds about 50, large, plump, blunt, not winged. Season late. (Fig. 67.)

Duncan is a variety of superior quality. The large juice-sacs make it possible to remove the pulp from the sections. It is the hardiest of the grapefruits, so far as tested. Originated in Pinellas County, Florida, as

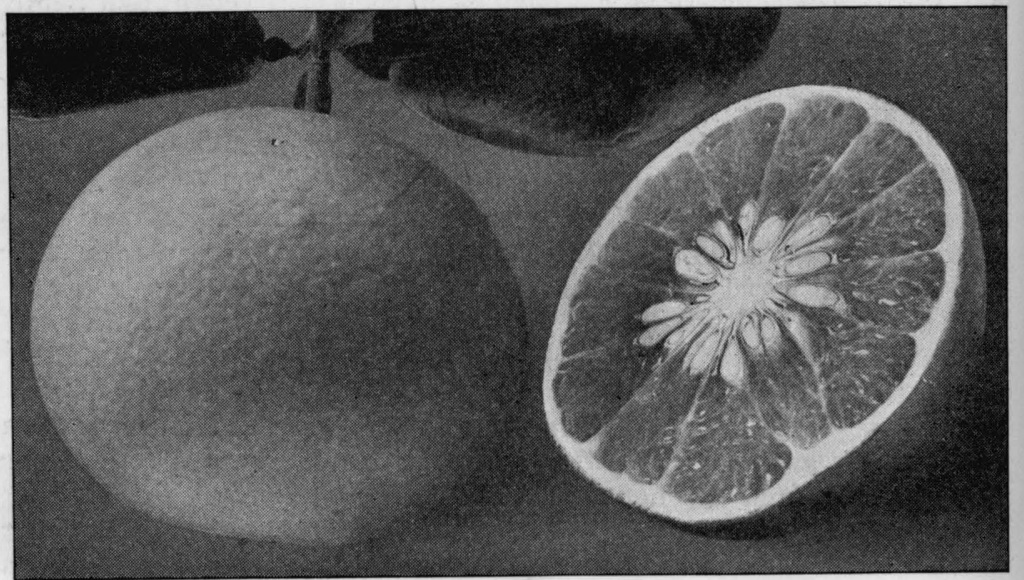

FIG. 67. Duncan, one of the finest Florida grapefruits ( $1 / 2$ natural size) 
a seedling from a tree grown by Don Philippe. The original Duncan tree, now nearly a hundred years of age (1925), is still living in the planting known as the Snedicor grove, near Green Springs, Florida. It was introduced and propagated by A. L. Duncan, Dunedin, Florida, about 1892.

Excelsior (Excelsior Late).-Form oblate; size 4 by $43 / 4$ inches; color lemon-yellow; rind very slightly pitted; oil-cells large, slightly sunken; sections 13, large, irregular; flesh light grayish; bitter principle well marked; acidity normal; quality good; seeds 31, wedge-shaped, large, plump. Season late.

In a letter to the author, dated June 5, 1903, C. M. Marsh writes: "This particular fruit, one of a number of old seedlings, was brought to the notice of the manager of the Lakeland Nursery Co. in 1886 or 1887. He propagated about one hundred trees. In the year $1890 \mathrm{my}$ personal attention was called to the desirability, quality, and especially the bearing capacity, and after repeated demands for the variety, I propagated it for the first time in my nurseries located at Fort Meade in 1891."

Foster.-In the winter 1906-7, I. B. Foster, of Manatee, Florida, discovered a branch bearing pink-fleshed fruit on a Walters grapefruit tree in the Atwood grove at Manavista. It was catalogued and introduced to the trade by the Royal Palm Nurseries, Oneco, in 1914.

The pink color in this variety is confined to the section membranes, and often shows through the rind. It does not differ materially from Walters (which see), except in flesh-color and in its earlier maturity.

Hall (Silver Cluster; Hall's; Klemm's Silver Cluster).-Form oblate; size $4 \frac{1}{8}$ by $4 \frac{5}{8}$ inches, or larger; stem large; color light yellow, but slightly darker than that of most pomelos; base smooth, or sometimes slightly creased; rind $\frac{3}{16}$ inch thick; oil-cells slightly indented; sections 14, large, variable in size; bitter principle strongly developed; acidity and sweetness well marked; juice almost transparent; seeds 32, small, roundish, plump, quite a number aborted. Season February and March.

There has been considerable discussion over the origin of this variety, but it seems to be well established that it was originated by John W. Hall, of Caloosa, Florida. The original tree was grown from seed sown by him when he first came to the state, about 1885. The synonymy as given above may be open to some objections, but in naming it the credit has been given to Dr. Hall, to whom it is believed to be due.

Josselyn.-Form roundish obovate; size $31 / 8$ by $31 / 2$ inches; stem medium; color yellow, darkest of all the varieties which have come under observation; rind smooth; oil-cells slightly sunken; sections 12, rather irregular, dividing tissue thick; flesh grayish green; pulp melting; bitterness strongly marked; acidity and sweetness well developed; core $1 / 2$ inch in diameter, solid; seeds 48 , whitish, small, plump. December to January. 
This variety was introduced by J. W. and F. D. Waite, of the Magnolia Nurseries, Belleview, Marion County, Florida, in 1888. The original tree stood in the old Josselyn grove at Eastlake, on Lake Weir.

Leonardy.-Form slightly oblate or rounded; size medium, $3 \frac{3}{4}$ by $41 / 2$ inches, $37 / 8$ by $4 \frac{5}{16}$ inches; color lemon-yellow; apex smooth, not depressed, scar small; base smooth, slightly depressed; calyx small, $3 / 8$ inch across, lobes not conspicuous; rind smooth, shiny, $1 / 4$ inch thick; oil-cells flush with the surface, large and conspicuous; sections 10, well-defined, large and regular; flesh coarse, light grayish in color; juice-sacs large; juice plentiful, colorless; pulp melting; acidity and sweetness well balanced; quality excellent; pith open, $3 / 4$ inch across; seeds 28, large, broad, flat. Season January.

Manville (Manville's Improved).-Form oblate; size medium to large, $3 \frac{5}{8}$ by $4 \frac{1}{8}$ inches; stem small; color lemon-yellow; rind $1 / 4$ inch thick, smooth, the oil-cells being flush with the surface or only slightly sunken; sections 13, large, fairly regular; flesh light grayish green; juice-sacs large, irregular; bitterness well marked; acidity and sweetness good; core $5 / 8$ inch in diameter, compact; seeds 60-70, large. Season late.

In relation to the origin of this variety, Reasoner Brothers made the following statement: “Manville's Improved was sent us by the late A. H. Manville, from East Florida, years ago.”

Thus far, this variety has not been catalogued, but the fruit appears to be very desirable.

Marsh (Marsh's Seedless).-Form oblate-roundish; size $31 / 8$ by $47 / 8$ inches, $31 / 2$ by $4 \frac{1}{2}$ inches, $3 \frac{5}{8}$ by $47 / 8$ inches; stem small; color light yellow; rind $1 / 8$ inch thick, smooth; oil-cells small, scarcely or not at all indented; sections 13, regular, partitions thin; juice-sacs small; flesh grayish green; bitter principle not strongly marked; acidity and sweetness medium; pith $5 / 8$ inch in diameter, open; seeds $2-6$, or none, large, plump. Season February and March. (Fig. 68.)

This variety was introduced by C. M. Marsh, Lakeland, Florida, about 1895 or 1896 . The original tree was a seedling, growing in Lakeland, and was, at the time of the freeze, fully sixty years old. This pomelo has not the distinct pronounced flavor of the typical fruit, but the quality is good, and the fact that it is so nearly seedless is a very desirable feature. The absence of seeds makes it possible to hold the fruit on the trees very late.

Two pink-fleshed forms of the Marsh pomelo have been brought to notice, one found in California, the other in Florida, and both originated as bud-sports on Marsh trees. The California one was found near Riverside, and described by A. D. Shamel, ${ }^{1}$ whose attention was directed to it

${ }^{1}$ Shamel, A. D. Origin of a Grapefruit Variety Having Pink-fleshed Fruits. Journal of Heredity, 11:N. 4, 157. Apr., 1920. 


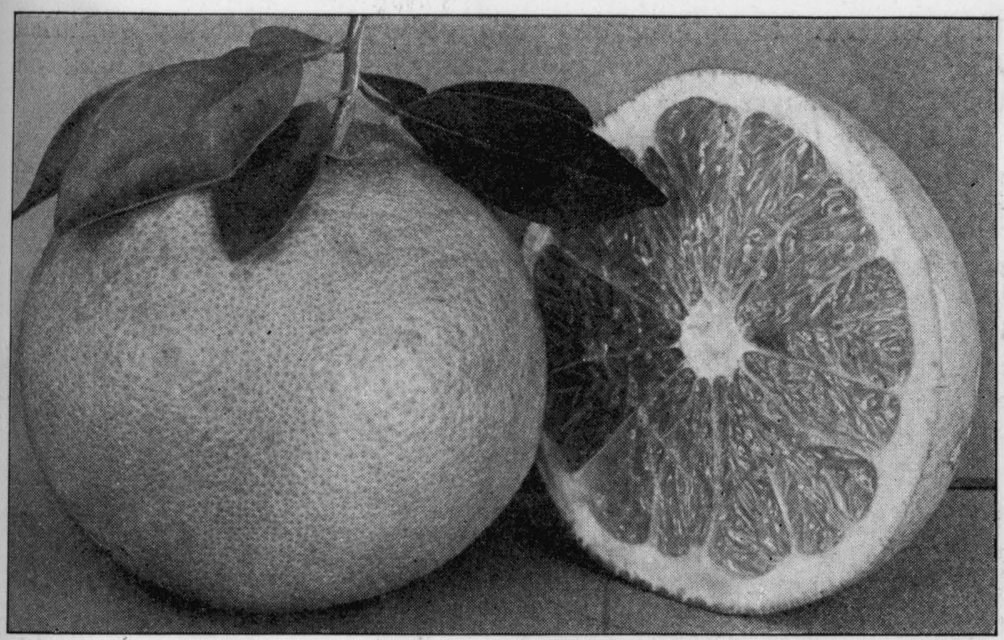

FIG. 68. Marsh grapefruit, the favorite seedless variety ( $1 / 2$ natural size)

in July, 1919, by L. V. W. Brown. The Florida variety was discovered by S. A. Collins in a grove belonging to W. B. Thompson, near Oneco, in 1913, and T. Ralph Robinson ${ }^{1}$ called attention to it in an article published in May, 1921. Both of these seem to be typical Marsh grapefruit, except in color of flesh. Under the name Thompson, the Florida pink Marsh has been introduced by Reasoner Brothers, Oneco, Florida (catalogue, 1924), and a grove of it has been planted in Pinellas County.

May (May's).-Form oblate-rounded; size small to medium, $3 \frac{1}{4}$ by $31 / 2$ inches, $3 \frac{5}{16}$ by $3 \frac{3}{4}$ inches; heavy; color light yellow; base rounded, scarcely depressed; calyx small; stem small; apex rounded, with a very slight depression marked with a small dark spot; rind smooth, glossy, tightly attached, $1 / 4$ inch thick; oil-cells conspicuous, medium-sized, just level with the surface; sections 12, clearly defined, regular and of medium size; juice-sacs large, broad, blunt; flesh coarse-grained, light grayish; juice abundant; acidity and sweetness normal, bitterness marked; flavor and quality excellent; pith $5 / 8$ inch across; seeds 44 , and some abortive, thick, plump, of medium size, $\frac{9}{16}$ by $3 / 8$ inch, light yellowish. Season November to February.

The May pomelo is an excellent variety, formerly well known in Florida, but for some time after 1895 it disappeared almost entirely. Previous to that time it won prizes wherever exhibited. According to

${ }^{1}$ Robinson, T. Ralph. The Bud-sport Origin of a New Pink-fleshed Grapefruit in Florida. Journal of Heredity, 12:N. 5, 195. May, 1921. 
E. S. Hubbard, the original tree was probably set in 1824 by Zephariah Kingsley with the orange trees in the May's grove, at Orange Mills, on the St. Johns River.

McCarty (Indian River).-Form oblate; size large, $4 \frac{1}{4}$ by 5 inches; stem small; base slightly creased; color very light yellow; rind $3 / 8$ inch thick; oil-cells large, slightly depressed; sections 13, large, rather irregular;

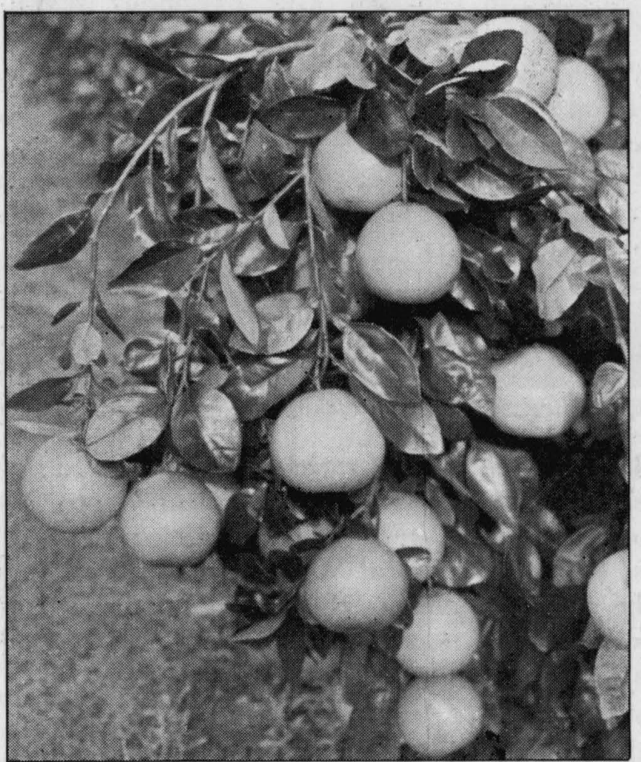

FIG. 69. Fruiting branches of McCarty grapefruit showing the fruit borne singly

flesh grayish green; bitterness marked; acidity and sweetness normal; pulp melting; juice plentiful; juice-sacs large; quality excellent; seeds 49-59, large, long, creased ; core $7 / 8$ inch, open. Season January to March.

The origin of this variety is unknown. The late C. T. McCarty, of Eldred, Florida, from whom specimens were first received, and after whom it was named, wrote as follows regard. ing it: "This pomelo is known here as the Stand. ard, or Indian River; I don't know its origin. It came here from Rockledge sixteen years ago [about 1886]." One of the very best varieties. Its fruiting habit is worthy of note because it bears its fruit singly on the branches. (Fig. 69.)

McKinley.-Form oblate, or slightly oblate-conical; size $37 / 8$ by $43 / 4$ inches; color pale yellow; rind smooth, thin; oil-cells large, conspicuous, scarcely indented; sections 14, large, slightly irregular; bitterness marked; acidity normal; sweetness good; quality of the best; core $3 / 4$ inch in diameter, pithy; seeds 62, wedge-shaped, large. Season late.

This is a pomelo of considerable merit and worthy of propagation. The variety originated as a seedling in the grove of A. A. Gardner, Fort Myers, Florida.

Pernambuco.-Form oblate; size $33 / 4$ by $4 \frac{3}{4}$ inches, $37 / 8$ by $4 \frac{1}{2}$ inches; stem stout; calyx medium in size; color very light yellow; rind $1 / 4$ inch 
thick, compact, closely attached, smooth; oil-cells large, sunken; sections 12, uniform in size, well-defined; flesh grayish green; bitterness well marked; acidity and sweetness good; character well marked; seeds 6075 , whitish, wedge-shaped, irregular. Season late.

This variety was imported by the United States Department of Agriculture from Pernambuco, Brazil. It produces fruit of very fine quality, but the tree is very easily affected by "dieback" and "Frenching" and has almost disappeared from commercial lists.

Royal.-Form slightly oblate; size 3 by $3 \frac{1}{2}$ inches, 3 by $3 \frac{5}{8}$ inches; stem stout; color light yellow; rind $1 / 8$ inch thick; oil-cells small; sections 11 or 12 , small, regular; flesh grayish green; bitter principle almost entirely lacking; acidity medium; sweetness good - can be eaten from the hand like an orange; seeds 40 , grayish in color, roundish and plump; core $3 / 4$ inch in diameter, pithy. Season medium early.

In a personal letter, E. N. Reasoner, says: "The Royal pomelo was brought from Cuba [probably] about thirty years ago, and is a large, fine tree yet, in this neighborhood. We budded from it and named it in 1891; listed it in 1892."

The fruit is desirable, but lacks the character of the pomelo. The tree is a good bearer, probably a hybrid.

Triumph.-Form oblate or slightly oblate-oblong, somewhat flattened at base and apex; size $3 \frac{5}{8}$ by 4 inches; stem small; color light yellow; rind very smooth, $1 / 8$ inch thick; oil-cells slightly depressed; sections 11; bitter principle not so strongly marked as in some; acidity and sweetness normal; juicy; pulp melting; seeds 37 , medium, plump, roundish; core $5 / 8$ inch in diameter, open or pithy. Season medium early.

The original tree of this variety grew in the yard of the Orange Grove Hotel, at Tampa, Florida, but was killed during the severe winter of 189495. Propagation of the Triumph pomelo was begun in 1884 .

Walters (Walter).-Form oblate; size $33 / 4$ by $4 \frac{7}{8}$ inches; stem small; color pale yellow; rind smooth, $1 / 4$ inch thick; oil-cells almost flush with the surface; sections 13, large; bitter principle strongly marked; acidity and sweetness good; quality very good; seeds 58, large, plump, wedgeshaped or irregular; core $3 / 4$ inch in diameter, solid. Season medium.

The Walters pomelo was introduced in 1887 by a Mr. Walters, assisted by Waite Brothers. The original tree grew near the village of Belleview, Marion County, Florida.

In habit of growth this tree very closely resembles the Hall, and by some they are thought to be the same, but the origin of the two is entirely different, as may be noted from the descriptions. The seeds show a distinct varietal difference.

Some years ago (winter of 1906-07) a pink-fleshed variety of Walters, now named Foster, was found in the Atwood grove, Manatee, Florida. 
It originated as a bud-sport on a Walters tree and was introduced by the Royal Palm Nurseries in 1914. It is similar to Walters in most particulars, but earlier.

\section{TANGELOS}

Nocatee.-Form roundish or somewhat oblate; size small, $23 / 8$ by $23 / 4$ inches, $21 / 2$ by 3 inches, $25 / 8$ by $31 / 4$ inches; stem small; calyx small; apex slightly marked; color lemon-yellow, occasionally somewhat deeper; rind $1 / 8-\frac{3}{16}$ inch, easily detached; oil-cells minute, slightly indented; sections 12, variable in size, separating easily; flesh yellowish gray; tissue thin, translucent; juice almost transparent; acidity medium; bitter principle lacking; juice-sacs small, short, plump, in shape resembling those of the tangerine; flavor a commingling of pomelo and tangerine; pith small, $3 / 8$ inch in diameter; seeds $3-23$, small, slightly winged at the tip; cotyledons white or green, or partly green and partly white; season late; a good keeper.

This variety appears to be a well-marked hybrid between the tangerine and the pomelo, the fruit in general appearance more closely resembling the latter.

It originated at Nocatee, Florida, and T. J. Watkins, the owner of the tree, in 1902 wrote the following notes regarding it: "The original tree is about twenty years old, and somewhat larger than an average sour orange tree of the same age. It is a hybrid of accidental origin, showing marks of grapefruit, tangerine, and bitter-sweet orange. It is a distinct type, having fruit, bloom, wood, habit of growth, and leaf different from all others, and is as easily recognizable as the tangerine or grapefruit. It is a strong, vigorous grower, with limbs long and somewhat slender. The leaves are medium size, broad, slightly bent upward from midrib and slightly curved backward, giving a shape bearing some resemblance to an apple leaf, but in color and texture it resembles the leaf of the common orange. In habit of growth it is loose, open-headed, and the foliage less dense than a grapefruit or common orange. The wood is almost thornless and the tree prolific, being laden with fruit every year. All characteristics of the tree and fruit are retained in budded trees. . . . growth of budded trees has been more rapid and vigorous than that of grapefruit buds under similar conditions.

"The fruit is of medium size, running about 150 to the box, in color a clear pure yellow; has few seeds, many of the fruits being entirely seedless; has loose rind, separating from the fruit a little less easily than tangerines. . . . It is good any time after December, and will hang on the trees until August, but reaches full maturity about April, when it develops a rare combination of rich and delicate flavor."

The leaves of this variety are different from those of the orange or 
grapefruit. On some leaves the wings are entirely absent, in others the wing is cut in on one side only, leaving the other entire, while other leaves have a well-marked wing on both sides.

The fruit is certainly unique and interesting, and possesses a considerable degree of merit.

Sampson.-Fruit compressed-spherical, slightly drawn out at stem end, like tangerine; of medium size, averaging $21 / 2$ inches in diameter and about $23 / 4$ inches in height; weight from 163 to 248 grams; calyx persistent as in common orange; color chrome-yellow, considerably darker than the pomelo, though not so red as the tangerine; specific gravity about the same as water; skin thin, about $1 / 8$ inch in thickness, loose and easily removable, like the skin of the tangerine; surface smooth and glossy; oilglands large and conspicuous, rendering the rind translucent; larger glands oblate-spherical, smaller ones nearly spherical; segments 9-11, separating easily like tangerine; membranes thin and tender; axes small and compact, about $1 / 2$ inch in diameter; rag very slight; quality excellent; texture very tender and juicy; flavor sprightly subacid, somewhat sweeter than pomelo, but with more acid than the tangerine and with a slight bitter taste derived from the pomelo; color of pulp ochraceous-buff to orange-buff, differing in this respect from both parents; seeds 10-15, medium in size; aroma slight, giving suggestion of both parents; in general appearance very attractive, resembling small pomelo, but of rather darker orange color; tree evergreen, tender, vigorous, and productive, having general character of ordinary tangerine; leaves unifoliate, with comparatively narrow petioles like tangerine. (Webber ${ }^{1}$ and Swingle.)

Thornton.-Fruit oblate, flattened at the apex and tapering from about the middle to the base; size medium large, $31 / 4$ to $33 / 4$ inches in diameter by $27 / 8$ to $31 / 4$ inches high; color orange, about the same shade as the ordinary Florida sweet oranges; surface somewhat rough, similar to the King orange, but not so markedly rough as in that variety; skin medium thick, $1 / 8^{-1 / 4}$ inch . . . flexible and tough, being easily removable, like the skin of the tangerine; oilglands large and conspicuous; segments 10-12, separating easily, like tangerine, and with considerable adhering white, soft membrane, as in that fruit; separating membranes comparatively thin and tender; axis small, except in old fruits, $1 / 2$ inch in diameter, mainly hollow, as in tangerine; quality excellent; texture tender, very juicy; flavor a mild rich subacid, very attractive but characteristic, not like any other citrus fruit; no indication of bitterness from pomelo; pulp orange-colored; seeds $5-12$ to a fruit, resembling orange in shape but with greenish cotyledons, similar to the tangerine; aroma not unlike ordinary orange, with suggestion of bitter-sweet orange,

${ }^{1}$ Yearbook of the U. S. Dept. Agr., 1904, pp. 236, 237. 
attractive; tree evergreen, having general characters of ordinary sweet orange; leaves unifoliate. Time of ripening midseason. (Webber ${ }^{1}$ and Swingle.)

\section{THE SHADDOCKS}

All the fruits described by early writers as belonging to the species now recognized by the botanical name Citrus maxima, Merrill (Citrus grandis, Osbeck) belong here. In 1646, Ferrari apparently referred to a fruit of this group as Aurantium maximum. His description is given on pages 437 and 438 of his work, Hesperides, followed by two illustrations on pages 439 and 441 . In cross-section the skin is very thick, proportionately as thick as that of a citron, and much thicker than one generally finds in shaddock fruits grown in America. Volkamer, in 1713, described the shaddock on page 181 of his Hesperidium Norimbergensium, and called it Malum Aurantium Indicum Maximum vulgo Pompelmos; and on page 189 again referred to it with a third plate, page 190a. The illustrations on 182a and 182 certainly look like the shaddock as now known. The large juice-vesicles and the absence of coverings around the inner ends of the sections are typical. There is little reason to doubt that the fruits which these writers described and illustrated are shaddocks, and not grapefruit. Apparently the latter were not grown in Europe until very recent times, and in the works of Risso, Gallesio, and others, no mention is made of grapefruit as known in America.

The shaddock was introduced into Barbados at an early date and from there carried to the adjoining islands and the adjacent mainland. Plukenet ${ }^{2}$ uses the name shaddocks and from this we must conclude that the tree was growing in the West Indies before the close of the seventeenth century. Hans Sloane ${ }^{3}$ tells of the origin of the name and also of the

1 Yearbook of the U. S. Dept. Agr., 1906, pp. 336, 337.

2 Almagestum Botanicum, etc. 2:239. 1696. 1707 .

${ }^{3}$ Sloane, Hans. A Voyage to the Islands of Madeira, Barbados, etc. 1:41. 
introduction of the shaddock into the Barbados in these words: "The Seed of this was first brought to Barbados by one Captain Shaddock, Commander of an East India Ship, who touched at that Island in his Passage to England and left its Seed there." The date, unfortunately, is not given. A good illustration of the fruit, a twig with leaves, and a seed is given by Sloane. The fruit was named for Captain Shaddock and the name has come into general use.

As a group, the shaddocks are not of commercial importance in North America, and the few trees found in Cali-

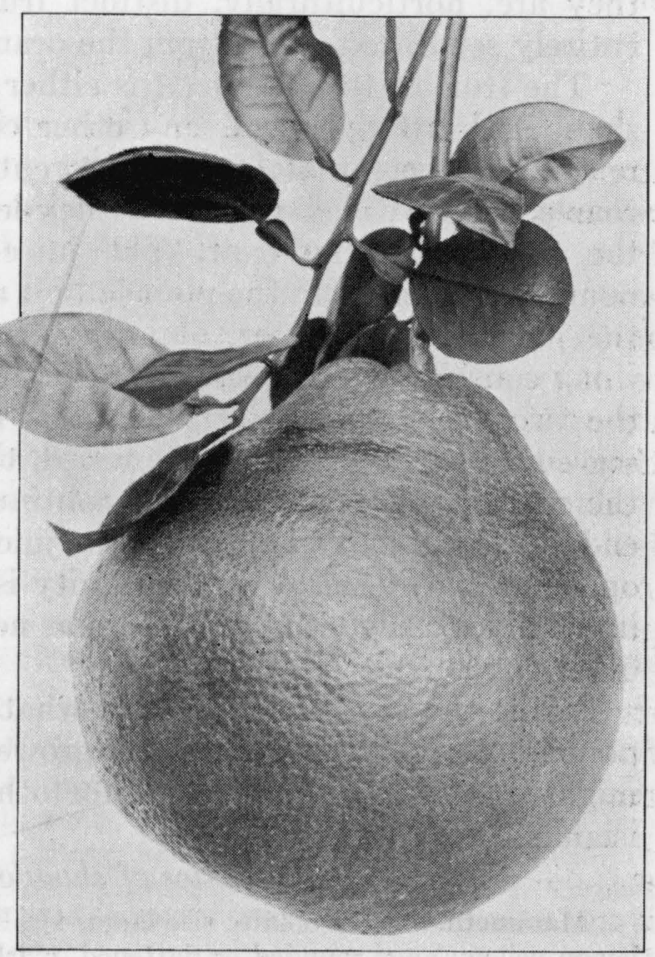

Fig. 70. Tresca shaddock ( $1 / 2$ natural size). Note its pyriform shape fornia and Florida are regarded somewhat as curiosities. As an ornamental, the tree is of considerable value, but the pomelo has the advantage of combining utility with beauty. Shaddock fruit is used extensively for decorative purposes by the Chinese, who annually import thousands of them into California to bedeck their homes and joss-houses for their New Year festivities. To them it is known as gon lack and $y u$ shu.

As already pointed out, the pomelo and shaddock have 
been regarded by some writers as one and the same fruit, and though both have been placed with the sweet oranges, they are, horticulturally, distinct fruits and belong to an entirely separate species from the oranges.

The fruit of the shaddock is either pyriform or oblate in shape and is larger than any other citrus fruit, sometimes reaching a weight of fifteen to twenty pounds. It is very coarse, with a thick rind and thick leathery septa between the sections of the fruit. The juice-sacs are not tightly bound together, as in the pomelo, but are loosely united, and the juice is acid, bitter, and comparatively scant. Everything considered, it is very much inferior to the pomelo. In the two varieties usually grown in Florida it has been observed, in every specimen examined, that the septa between the sections of the fruit is not continuous around the inner end, but the uncovered ends of the juice-sacs project into the open core. Whether this peculiarity is constant or not, it is impossible to say, but the writer has never observed it in any other citrus fruit.

While the shaddock is a somewhat smaller tree than the pomelo, and not such a rapid grower, it is likely that it might prove useful as a stock for other citrus fruits in the islands.

\section{Varieties of shaddock.}

Mammoth.-Form oblate; size large, $47 / 8$ by 6 inches, or larger; color lemon-yellow; apex rounded or flattened, marked with a large scar; base gradually rounded, with a broad, shallow depression, not creased; calyx large, irregular; rind $3 / 4$ inch thick, fungous; oil-cells large, conspicuous, globular; flesh coarse, white; juice-sacs large, pointed, with the membrane thick; pulp not melting, but inclined to be tough; acid and bitter, sweetness slightly developed; flavor sweetish bitter; pith open; sections not covered with membrane on the inner edge; seeds 12, large, wedge-shaped. Season winter.

Pink.-Form oblate-pyriform, necked; size large, 6 by $65 / 8$ inches; color lemon-yellow; apex slightly depressed, scarred; base depressed, slightly ridged; calyx set in a depression, segments blunt; rind thick, $1 / 2^{-}$ $3 / 4$ inch, fungous; oil-cells large, conspicuous; sections 12, irregular in size, distinct, separated by thick, leathery partitions; flesh coarse, pink or 
reddish; juice-sacs large, spindle-shaped, 1/2-11/4 inches long, not tightly fastened together; juice fairly abundant, not colored, the coloring matter of the flesh confined to the tissue; pulp not melting, rather tough; flavor bitter and acid with some sweetness; pith large, $1 \frac{1}{4}$ inches across, notlined with membrane; seeds 3-7, medium size, $3 / 8$ by $1 / 2$ inch, blunt, rather oval, pointed. Season winter. (Fig. 71.)

Tresca.-Form roundish, necked or with a distinct tendency to pyriform shape; size large, 4 by $4 \frac{15}{16}$ inches, $4 \frac{1}{4}$ by $4 \frac{9}{16}$ inches; color dark lemon-yellow; apex broad, flat, scarcely depressed, scarred; base ridged and slightly roughened; rind smooth, $1 / 4^{-}$ $5 / 8$ inch thick; oil-cells

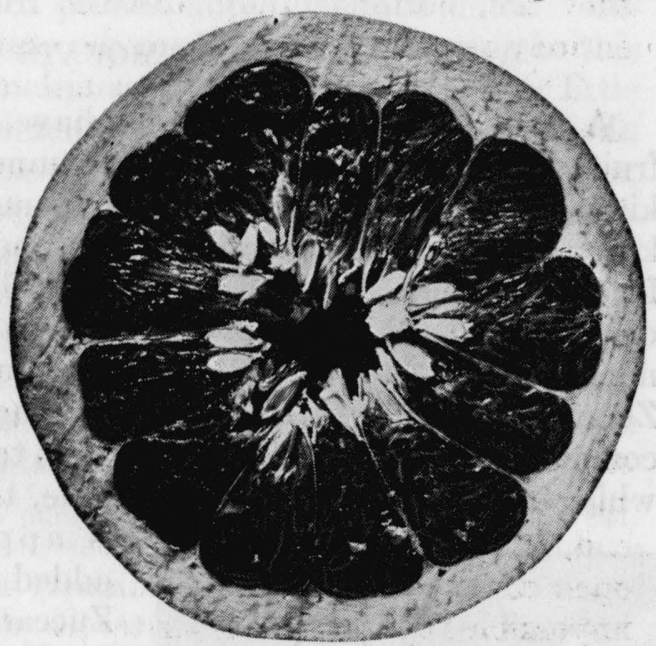

Frg. 71. Cross-section of Pink shaddock showing absence of septa at the center rather small; sections 15 , distinctly marked, irregular in size; flesh coarse, pink or pinkish, the coloring matter apparently located in the walls and in the juice-sacs, the inner rind and section divisions; juice-sacs large, spindle-shaped; juice plentiful, colorless; pulp melting; acidity, sweetness and bitterness normal, well blended; flavor excellent; pith solid, $3 / 4$ inch across; seeds 72 , pinkish, small, wedge-shaped or roundish. Season February and March. (Fig. 70.)

As to its origin, E. N. Reasoner says: "We found the Tresca pomelo in the grove of Capt. Fred Tresca about the year 1887; the Captain had brought seeds from the Bahamas some years previously and that season was their first crop. The color and flavor were so novel that we got buds and propagated from it." The Tresca grove was located in Manatee County, Florida. When this variety was introduced, and for many years afterward, it was classed as a pomelo. It is better to place it with the shaddocks, for it is either a straight shaddock or a shaddock-pomelo cross. The constant pyriform shape of the fruit, the very thick rind in the neck, the leaf characters, and its extreme susceptibility to frost indicate that it is not a true grapefruit. 


\section{CHAPTER VIII}

\section{THE KUMQUATS}

A number of common names have been applied to this fruit. Thunberg (1794) gives the common name in Japan as kinkan. Loureiro earlier gives the common names kin kuit, kin, and kuit $\mathrm{xu}$ for the round fruit and chu tsu and chantu for the oblong form. Kaempfer, still earlier, adopts the common names kin kan and fime tats banna, while Roxburgh, much later, uses the common name, kumquat. Siebold and Zuccarini, in their Flora of Japan, page 35, 1826, give the common names kin kan or kin kit to the round variety, while to the elliptical, or oblong one, the name too kin kan

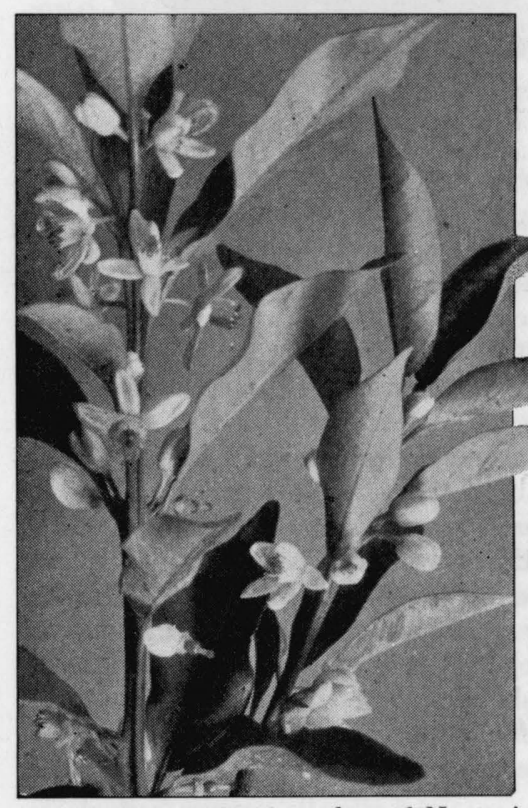

Fig. 72. Flowering branches of Nagami kumquat (about natural size) is applied. It might be added that Siebold and Zuccarini have a better illustration of this fruit than has been published in any other of the older works on Citrus. The commonly accepted name for this fruit throughout the United States is kumquat, and this appears to be the common word in India. Kumquat, sometimes spelled "comquot," "kum quat" and "cumquot," is a Chinese word, meaning "gold orange" and the Japanese equivalent is "kin kan."

The kumquat was prob(112) 
ably first mentioned in occidental horticultural literature by Kaempfer, ${ }^{1}$ who gave the following description of it in 1712: "Malus Limonia fructu pumilo aureo, medulla dulci." Besides, he used the common name, kin kan in referring to this fruit. That it was also known to Rumphius ${ }^{2}$ there is little room to doubt for he described and illustrated it in 1741. In 1784, Thunberg described it under the name, Citrus japonica, and since that time it has been repeatedly described by different botanical and horticultural writers. To some of these the fruit was known, to others it was not, and they apparently based their remarks upon the descriptions published by previous writers. It may be interesting to give here a list of some of the scientific names which, in years past, have been applied to the kumquats.

Malus Limonia fructu pumilo aureo Kaemp. Amoenit. Exotic, 801. 1712.

Limonellus Madurensis, Rump., Fl. Amboin. 2:110, t. 31. 1741.

Citrus japonica, Thunb. Fl. Jap., 292. 1784.

Citrus japonica, Murr. Linn., 2:697. 1784.

Citrus Madurensis, Lour. Fl. Cochin-China, 2:467. 1790.

Citrus Margarita, Lour. L. c. above.

Citrus japonica, Willd. Spec. Plant. Linn., 3:1426. 1803.

Acrumen japonicum, Gall. Traite du Citrus, 182. 1811.

Citrus inermis, Roxb. Fl. Ind., 393. 1832.

In 1915, Walter T. Swingle separated the kumquats from Citrus and placed them in a new genus, Fortunella, named for Robert Fortune. Each of the four known forms, which up to that time had been regarded for the most part as horticultural varieties, were described as species and named Fortunella margarita (Nagami kumquat), Fortunella japonica (Marumi kumquat), Fortunella crassifolia (Meiwa kumquat), and Fortunella Hindsii (Hong Kong wild kumquat). This disposition of the kumquats is followed here.

The introduction of the kumquat into Europe appears to have been recent. Gallesio seems not to have known it

${ }^{1}$ Kaempfer. Amoenitatum Exoticarum, p. 801. 1712.

${ }^{2}$ Rumphius. Herbarium Amboinense, 1:110, tab. 31. 1741. 
except from the writings of others. Risso and Poiteau make no mention of it in their exhaustive work, Histoire et Culture des Orangers. Since none of these writers refers to the kumquats, we are safe in concluding that they were not grown in Europe at the time they wrote. So far as now known, the kumquat was introduced into Europe by Robert Fortune, a collector for the London Horticultural Society, who brought it with him from China to London, England, May 6, 1846. It was one plant of a lot collected in the districts of Foochow-foo, Chusan, and Ningpo, China.

The Nagami (oblong) variety appears to have been the only one introduced by him, for in his remarks, published in the "Journal of the London Horticultural Society," page 239,1848 , he says, "The fruit ripens late in the autumn, being then about the size of a large oval gooseberry." Very soon afterward specimens of the kumquat must have been forwarded to America. A. J. Downing, in his "Horticulturist," of February, 1850, pages $375-377$, gives a description of the variety Nagami, with illustrations, and quotes largely from the remarks of Mr. Fortune. He further makes the following statement: "We have a small tree growing on our own grounds, which was kindly sent us by Mr. Ranch, exotic florist, near Greenwood Cemetery, Brooklyn. We believe Mr. Buist, of Philadelphia, and probably other men, now have it for sale, so that amateurs can make trial of it in various parts of the country." Some time later, probably very shortly after this date, it was brought to Florida. Since then several importations have been made by various nurserymen. The original trees imported by G. L. Taber, of Glen St. Mary, Florida, in 1885, were still standing in his grove in the autumn of 1901. Reasoner Brothers, of Oneco, imported the variety Nagami in $\mathbf{1 8 8 5}$ and the Marumi in 1890 from Japan.

Fortune saw large numbers of these plants in southern China, where they were grown in pots, and said that it was a common plant in the nursery gardens of Fa-Tee. He 
thought, however, that it was of more northern origin, for he had met with numerous groves of it on the island of Chusan and elsewhere in that portion of China. There it grew in far greater perfection than in the vicinity of Canton. Thus it would appear that the cultivation of the kumquat in China extends at least from latitude 20 to 30 degrees, a range of 10 degrees. It might be noted here that the main portion of Japan lies between 30 and 48 degrees, but the kumquat is cultivated probably only in the southern parts of that country. It must be borne in mind, however, that neither the climate of Japan nor of those portions of China to which reference has just been made, is by any means so variable as that of some of the citrus districts in our own country.

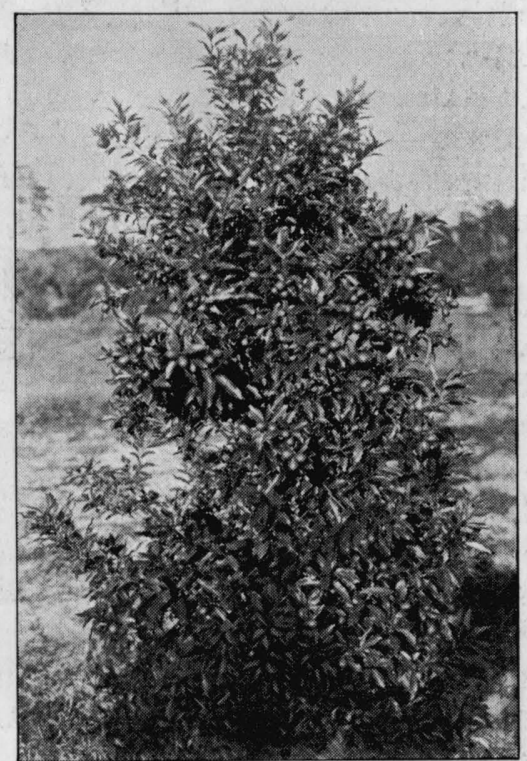

Fig. 73. Nagami kumquat tree The kumquat appears to be considerably hardier than most other members of the citrus family, and particularly so in northern Florida. This natural hardiness is increased by using Poncirus trifoliata as a stock, the low dwarfish habit of the tree giving every opportunity for successful and economical protection.

Kumquats are very ornamental citrus fruits and are valuable additions to the lists of shrubs available for landscape work. Their dense branching habit, dark green leaves, and golden yellow fruits make them objects of beauty in any shrubbery planting. When full grown they reach a height of 10 to 12 feet, with a spread nearly as great. 
The fruit is very decorative, and gathered on the twigs, with leaves attached, is largely used for Christmas decorations. Excellent preserves, marmalades, jellies, and candied

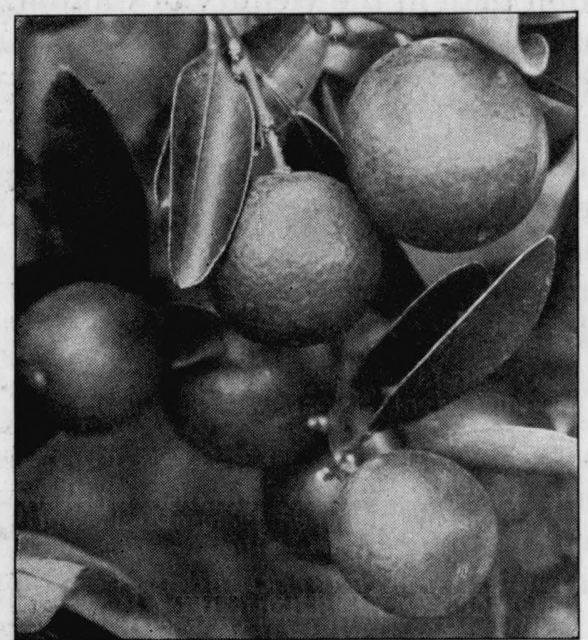

Fig. 74. Marumi kumquat fruit (about $3 / 4$ natural size) fruit are also made from it, for it contains a large amount of pectin, which makes it easy to handle in preserving processes. The Chinese export considerable quantities of preserved kumquats put up in stone jars.

The fruit may be eaten raw, and, when served in small glasses holding three or four fruits, make a very pretty addition to the table. If cut with leaves attached they may be used as table decorations. In eating the fruit, the skin is not removed, and the spicy aromatic rind and acid pulp make a very delightful and palatable combination.

The kumquat cannot be regarded as anything else than a fancy fruit, and in most cases a demand must be created. Any market in the country could very easily be glutted by large shipments, but in a small way the fruit is profitable. It is a comparatively new fruit and few persons know what it is. As its merits become better known, the demand for it will undoubtedly increase.

\section{VARIETIES OF KUMQUAT}

Hongkong (Hongkong wild kumquat).-Fruit small, $1 / 2^{-3} / 4$ inch in diameter, subglobose; color bright orange-red; skin thin, not very fleshy; segments 3 or 4 ; juice-sacs few in number, small, almost juiceless; seeds plump, thick, small; cotyledons green. (See Fig. 13.) 
Native on the hills about Hongkong, China, and on adjacent parts of the mainland.

Marumi (Round).-Tree similar to Nagami, except that it is slightly thorny, and has leaves somewhat smaller and rounder at the apex; leaves oval; apex obtuse; base obtuse; margin crenate half way down the length; veins slightly more conspicuous than in Nagami, borne on short, rigid, inconspicuously winged petioles, $1 / 4-1 / 2$ inch in length; fruit spherical or somewhat oblate, 1-11/4 inches in diameter; golden yellow, short stalked; calyx small; rind smooth, thin, spicy to the taste and aromatic when bruised; oil-cells large; pulp sparse; juice acid; sections 4-7; seeds 1-3, small, oval, greenish; cotyledons 2, greenish. Season same as Nagami. (Fig. 74.)

When eaten raw, both Nagami and Marumi have a very pleasant flavor or combination of flavors. The juice is acid, the rind has an agreeable spicy taste, while the soft, white, granular inner portion of the rind is decidedly sweet. There is a slight difference in flavor between the two varieties, but it is better determined by taste than described in words. Of the two, Nagami is generally considered to be the more desirable, though among growers there is a difference of opinion. The fruit of the Nagami is more regular in size on young plants. Large plants of both varieties bear about the same amount of fruit of uniform size and both are very prolific.

Meiwa. - Fruit globose, larger than that of Marumi, $1-1 \frac{1}{2}$ by $1-1 \frac{1}{8}$ inches; color deep orange; skin thick, sweet; segments 6 or 7 ; juice-vesicles few, much mixed with the inner skin; oval or ovate; juice scant; flavor sweet; quality good, one of the best to eat raw; seeds oyal, blunt; cotyledons green. (Fig. 75.)

The introduction of Meiwa kumquat was much more recent than that of Nagami and Marumi. It is a valuable addition to this group of fruits

$\mathrm{Nag}$ a mi (Oblong, oliveshaped).-Tree dwarf, 8-12 feet, bushy; young branches

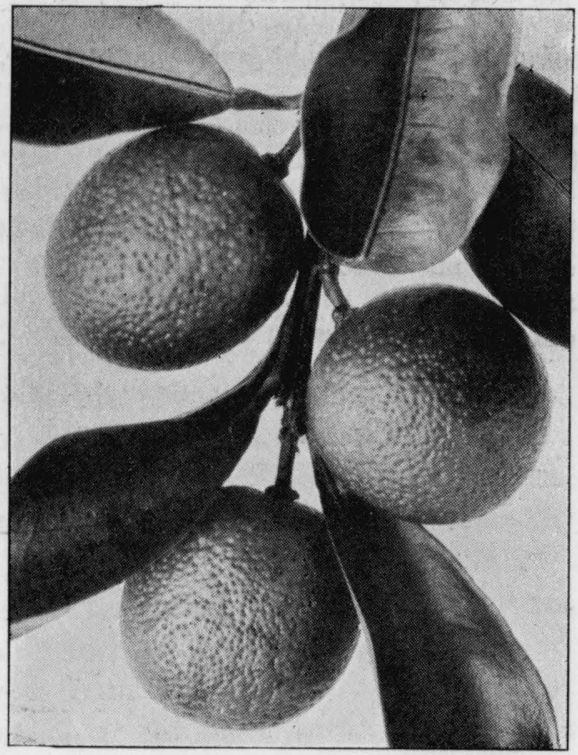

Fig. 75. Meiwa kumquat (about $3 / 4$ natural size) 


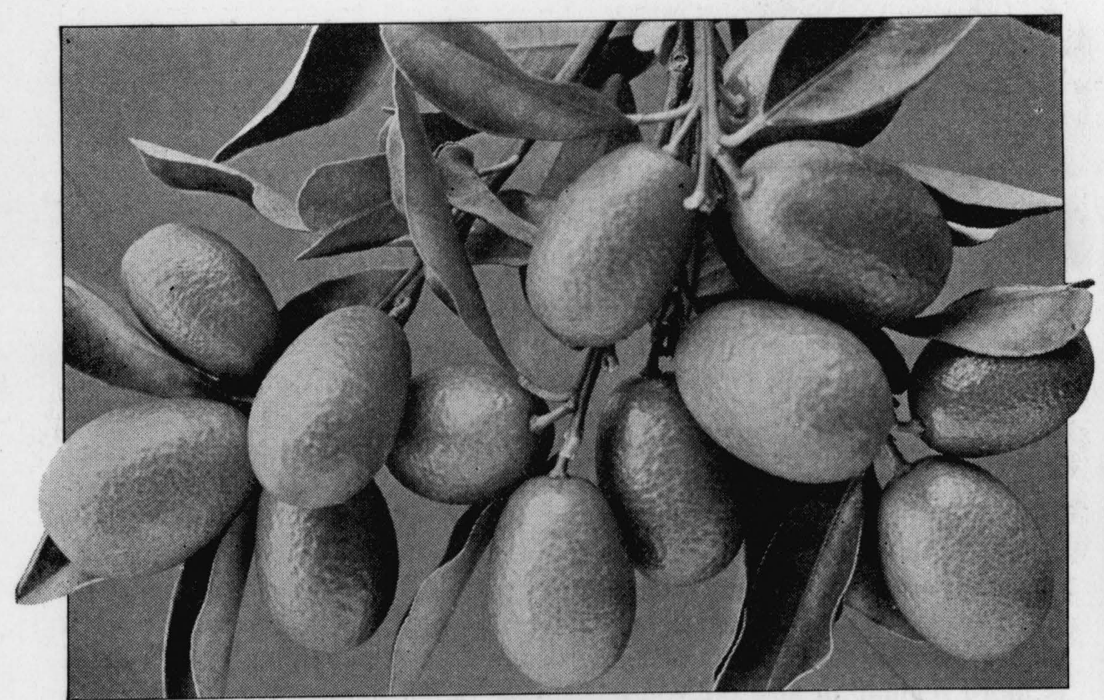

FIG. 76. Fruiting branches of Nagami kumquat ( $3 / 4$ natural size)

somewhat angled, light green; leaves $11 / 2$ by $3,1 / 2$ or $3 / 8$ by $1 \frac{1}{4}$ inches, lanceolate, apex obtuse; base acute or obtuse; margin crenate down about halfway from the apex; veins inconspicuous, surface dark green, glossy; lower lighter; borne on rather stout, usually very slightly margined petioles, $1 / 4-$ $5 / 8$ inch in length; fruit small; obovate or oblong; $11 / 4$ by $3 / 4$ inches, $1 \frac{1}{2}$ by 1 inch, $1 \frac{3}{4}$ by $1 \frac{1}{8}$ inches, $13 / 4$ by $1 \frac{3}{16}$ inches, golden yellow; stem short; calyx small; rind smooth, aromatic, spicy; oil-glands large; juice acid, sparse; sections usually 5 ; seeds $2-5$, oval, $1 / 2$ inch long, greenish; cotyledons 2 , green. Season October to January. (Figs. 72, 73, 76.) 


\section{CHAPTER IX}

\section{THE CITRONS}

The cultivation of few fruits antedates that of the citron. Of all the citrus fruits it was the only one known to classical writers. In Media and Persia, and later in Palestine, it was cultivated at a very early date, and in these countries the Greeks and Romans probably first met with it. The Greek writer, Theophrastus, shortly after the time of Alexander the Great, gave a minute and unmistakable description of the citron tree, or, as it was then called, the Median or Persian apple. Its name (Citrus medica) is derived from the country Media. Virgil was one of the first Roman writers to mention it and used the same name as Theophrastus. By Pliny's time, the fruit had been sufficiently long in cultivation to receive a number of names, and he is the first to make use of the name Citrus, the botanical name afterward adopted by Linnæus for all the related fruits as well as the citron. It appears, however, that the fruit was known by the Romans and imported into Rome long before it was cultivated there. But when it was finally established in Greece, Italy, and the adjacent islands in the Mediterranean, it became one of the important fruits in those regions into which it was introduced and there it is grown to this day.

When the citron was first introduced into America is merely a matter of conjecture, but it must have been brought to the West Indies and to South America (Brazil) shortly after the discovery of the continent. The early Spanish writers on the history of the New World bear testimony to this fact.

The citron did not receive the attention bestowed on the orange. This may be attributed to the fact that the most important product obtained from the citron is the candied peel, a commodity restricted in its uses and of little im- 


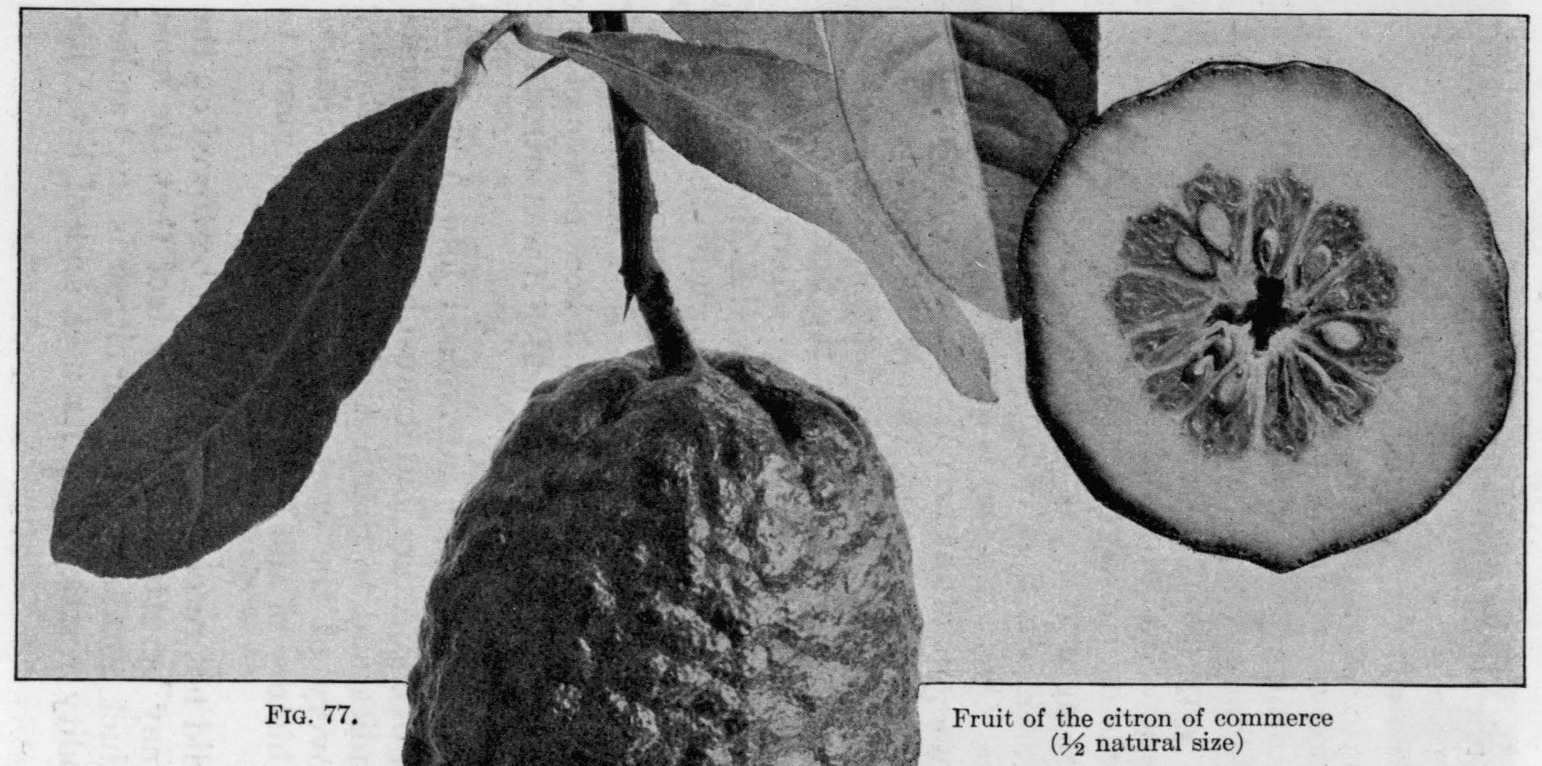


portance to pioneers. On the other hand, the luscious orange was at all times a much-appreciated addition to their limited bill of fare, while the acid of the lemon and lime is particularly refreshing in warm climates.

Citron peel is imported into the United States, both candied and in brine. In 1913 , there were 515,686 pounds of the candied peel imported, and 1,773,187 pounds were brought into the country in brine. When imported in brine, the salt is steeped out and the peel is candied, principally in the cities of New York and Chicago. The candied peel is used in confections and in cooking.

More or less interest has always been taken in the citron and its culture. The varieties cultivated in Europe have been imported and grown, small plantings having been made both in Florida and California. At present, interest in the citron has died out almost entirely in Florida, but in California it still receives attention. Experimental lots of candied citron peel of excellent quality, fully equal to the imported product, have been produced. Whether its cultivation will ever be increased sufficiently to produce enough peel to supply the American demand is somewhat problematical. There is a possibility, however, that such will be the case, but the industry will need the fostering care of a protective tariff on the peel imported in brine. The citron succeeds well in the lemon districts of California, and there alone large quantities of fruit could be grown. In the warmer parts of Florida and in the islands the citron could also be raised, if its production were placed on a remunerative basis

\section{VARIETIES OF CITRON}

Etrog.-A small citron, grown on the Island of Corfu and in Palestine, used by the Jewish people in the religious ceremonies connected with the Feast of Tabernacles. The fruit is very fragrant, about the size of an ordinary lemon, but longer and with the style usually attached. Seedling fruit of the variety has not reproduced true to type in Florida. (Fig. 78.)

Lemon (Sorrento).-Form oblong; size variable, large specimens $73 / 4$ 
by 5 inches or larger, and weighing 3-8 pounds; color bright lemon-yellow; apex nippled, nipple small, abrupt; base rounded; rind pleasantly aromatic, rather smooth, with slight broad elevations, 1-11/4 inches thick; inner rind white, coarse, with very little bitterness; oil-cells slightly elevated or flush with the surface; sections 12, clearly defined, the partitions thick; pulp bitter, lacking in juice; juice-sacs narrow, elongated, pointed, pith small; seeds present, small, oval, blunt; fruiting throughout the whole year in favorable sections.

The Lemon citron is an imported variety now grown in California and to a less extent in Florida.

Lyman.-Form oval-oblong; size medium; color orange-yellow; quality good. (Cat. Fla. Hort. Soc., 1902.)

Orange.-Fruit somewhat cone-shaped, more pointed than common variety; color that of an ordinary orange; rind cream-colored; pulp yellowish; rind sweet and highly aromatic; fruit possesses less bitterness than the common variety; tree a small stiff erect grower. (Moore from Fla. Fr. Gr. Association Report.)

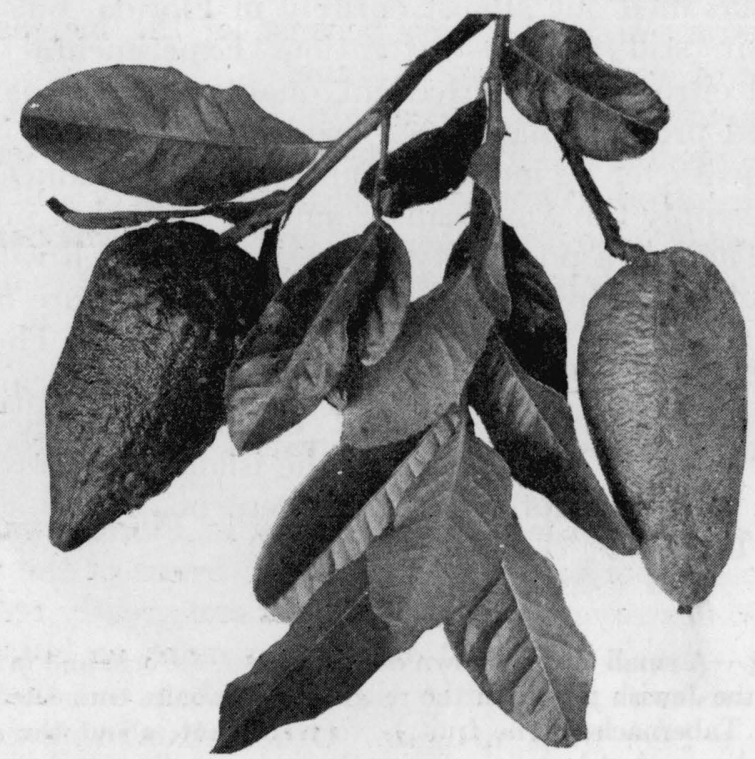

FIg. 78. Fruit of seedling Etrog grown in Florida ( $1 / 2$ natural size) 


\section{CHAPTER X}

\section{THE LEMONS}

The lemon was probably introduced into Europe about the same time as the sweet orange. Numbers of them are described by Ferrari, Volkamer, Commelyn, Sickler, and other writers. As a commercial industry, lemon-culture assumed very considerable proportions in Sicily, Corsica, Genoa, and other parts of southern Europe many years ago. Most of the world's markets have been supplied with these lemons, even within very recent years. There has been no falling off in their cultivation, and the European markets are still supplied from the same districts. There has been a considerable decrease in the amount of fruit exported from the Mediterranean to America because of the increase in the number of lemons grown at home.

Lemons were introduced into America at an early date by the Spaniards. The everbearing and rough lemons are Spanish introductions, and the latter variety still grows in a wild state in southern Florida and in different parts of the West Indies. It is an interesting fact that the rough lemon grows wild in South Africa much as it does in southern Florida. The fruit of these varieties is of no commercial importance, and nearly all the lemons now cultivated in America-Genoa, Lisbon, Villafranca-were introduced recently from Europe.

Before 1894, the lemon industry in Florida was of considerable importance, but the severe freeze of the winter of 1894-95 destroyed most of the trees and greatly reduced the output. Previous to that disaster, as many as 140,000 boxes of lemons were shipped in a single season, but the industry has never been built up again. Other citrus fruits were found to be more dependable and profitable.

Ever since the introduction of the disease, citrus scab 
has been a serious drawback to lemon-culture. In addition, the curing of lemons in the moist summer climate of Florida has been found exceedingly difficult. Anthracnose was re-

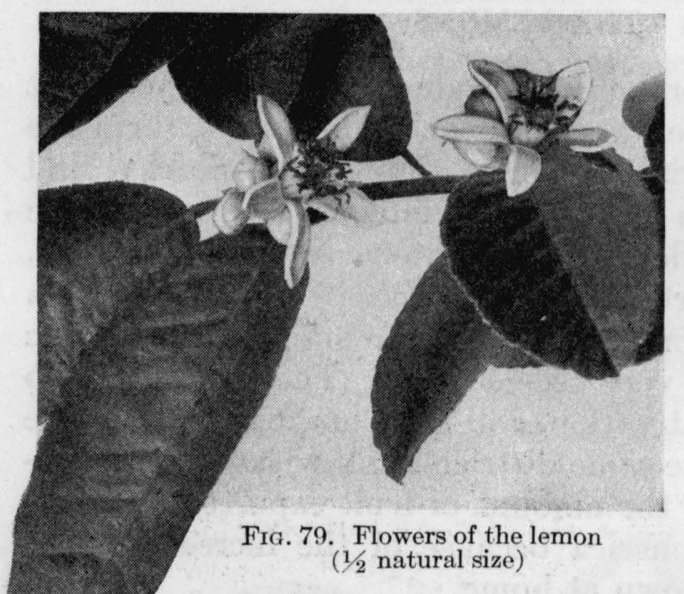
sponsible for heavy losses in the curingrooms and in transit. In the growing of lemons there is always a double problem; first the production of high-grade fruit, and then the coloring and curing of it for market. It is questionable whether lemon-growing will ever become a stable and profitable industry in any citrus region where scab is prevalent and where the harvesting and curing season is moist.

The success which has attended the cultivation of the lemon in California is quite remarkable. In the southern and central parts of the state, on the mesas and foothills, it grows and fruits well. The industry there has been placed on a paying basis wherever suitable soil and climatic conditions are found, and where sufficient water has been secured. The fruit is of superior quality and has been well received in the American markets. As a result of the great increase in the California lemon industry, there has been a material decrease in shipments of lemons from abroad. The California crop for 1923 was $6,732,000$ boxes. Since this is the only section in the United States where lemons are likely to be grown commercially, it will always be an important branch of fruit-growing in that region.

The lemon is utilized in more different ways than any 
other citrus fruit. From the rind lemon-oil is extracted and it is also used in making candied lemon-peel, most of which is manufactured in Italy. From the pulp, citrate of lime, citric acid, and lemon juice are obtained. The fruit is also extensively employed in making lemonade and for flavoring food and drinks of different kinds. In fact, by far the greatest number of lemons are used for the lastmentioned purposes.

As pointed out in the chapter on Citrus-Tree Stocks, the rough lemon is very valuable as a stock for certain kinds of soil and is now extensively used in Florida and the Islands. It is the only variety of the group possessing a fair degree of resistance to

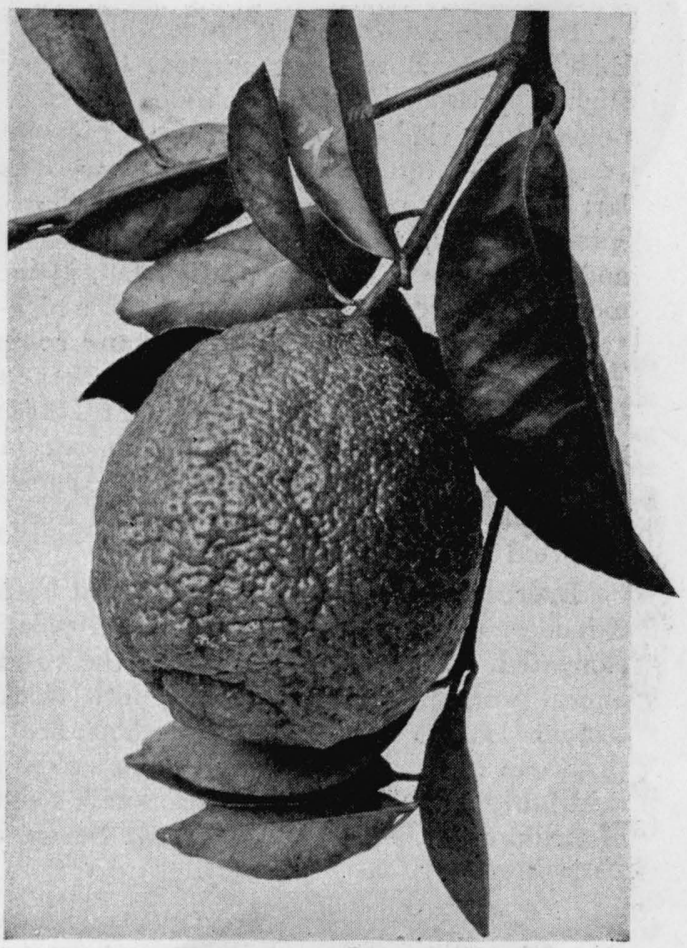

FIg. 80. Fruit and leaves of the rough lemon ( $1 / 2$ natural size)

the attacks of mal-di-goma. The so-called Otaheite orange, or Otaheite, which has been classified as C.taitensis, Risso, is commonly used as a greenhouse or house plant. When well grown it is a very decorative subject. Its foliage characters, its flowers, purple tinted on the outer surface of the petals, and its susceptibility to citrus scab indicate close relationship with the true lemons. It differs from the acid lemons in the odor of its essential oil, the orange color of 
its pulp, and its insipid mawkish taste. It is placed here provisionally.

\section{VARIETIES OF LEMON}

Eureka.-Form oblong; size medium, $27 / 8$ by 2 inches, 3 by $21 / 4$ inches; color lemon-yellow; apex nippled, the nipple small and abrupt; base slightly tapered, frequently oblique; calyx of medium size, 4-5-pointed, points blunt; rind smooth, $1 / 4$ inch thick uncured, $1 / 8$ inch thick when cured, sweet; oil-cells quite large, depressed; sections ten, well defined and regular; flesh fine-grained, pale grayish yellow in color; juice-sacs small, spindle-shaped, elongated; juice abundant, clear; pulp melting; acid pure and strong; flavor excellent; pith small, $1 / 4$ inch across; seeds present, but mostly abortive, elongated, somewhat wedge-shaped, small. (Fig. 81.)

The tree is half-dwarf in habit and comparatively free from thorns. The fruit keeps well and is one of the best varieties grown in California. It has a tendency to bear the fruit at the end of the branches, and is poorly covered with foliage. It is an extremely prolific variety. It was introduced by T. A. Garey, of Los Angeles, and originated by C. R. Workman at the same p'ace, the seed from which it grew having been imported from Hamburg in 1872.

Everbearing.-Form oval, pointed at both ends; size medium, $3 \frac{9}{16}$ by 2 inches; color yellow; apex pointed, point about $5 / 8$ inch long; base elongated, somewhat ridged about the calyx; calyx small; rind rough, almost warty; when uncured $\frac{3}{16}$ inch thick; oil-cells depressed, large; sections 11, not clearly defined, regular; flesh fine-grained, greenish gray; juice-sacs elongated and narrow; juice plentiful, colorless; pulp melting; acid fairly good; flavor fair; pith small, about $\frac{3}{16}$ inch across; seeds 19, of medium size, shape oval, pointed. Season all the year round.
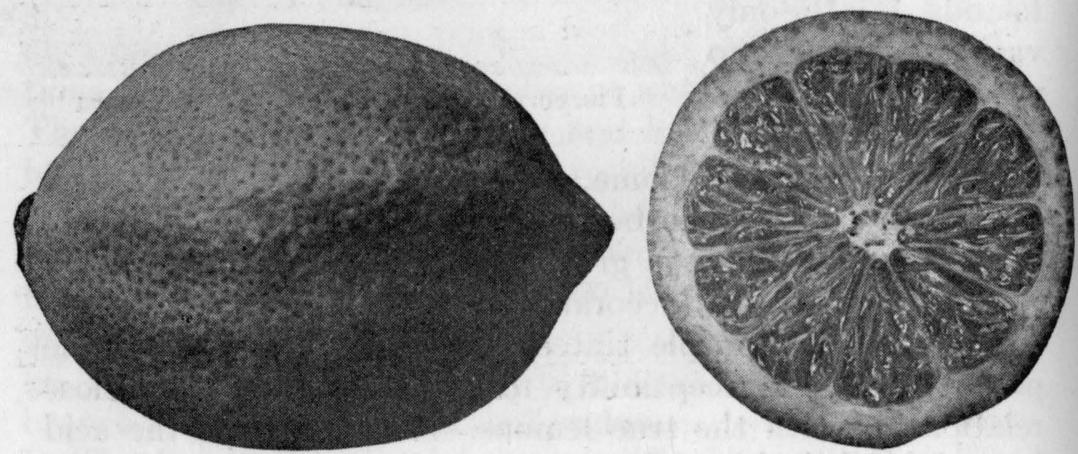

Fig. 81. Eureka lemon and cross-section, uncured 

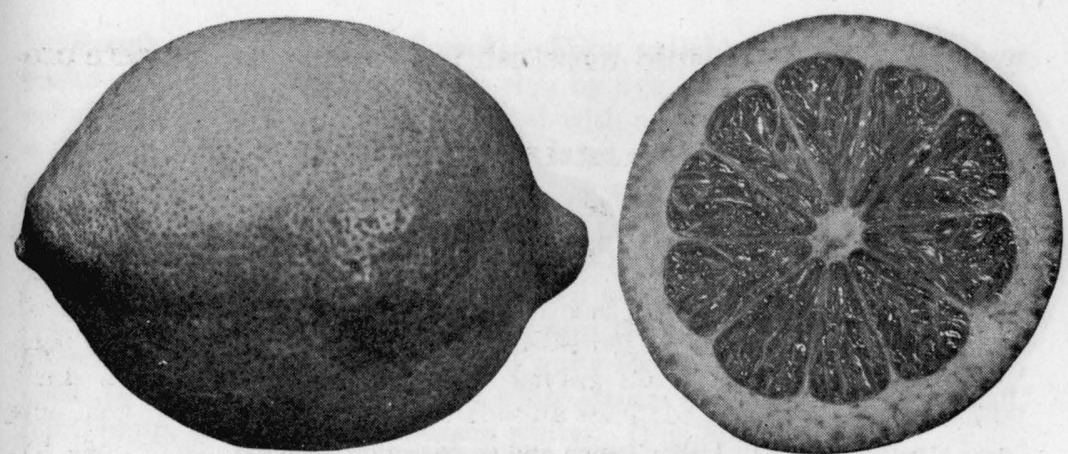

Fig. 82. Genoa lemon and cross-section, uncured

The Everbearing lemon is too rough and contains too many seeds to make it a desirable market variety, but it is quite valuable for domestic use and especially so as it is always in flower and fruit. It has a strong tendency to produce an abundance of water-sprouts and suckers, hence forms a bushy growth. It has been grown in Florida for many years, and is probably a Spanish introduction.

Genoa.-Form oblong, pointed at both ends; size medium, $3 \frac{3}{8}$ by 2 inches, $3 \frac{5}{16}$ by $2 \frac{5}{16}$ inches; color bright lemon-yellow; apex nippled, nipple small and rather sharp-pointed; base necked; calyx large, 4-5-pointed, points rounded; rind smooth, sweet, $1 / 4$ inch thick or slightly more uncured, $1 / 8$ inch thick cured; oil-cells small, fairly conspicuous; sections 7-10, regular; flesh fine-grained, grayish yellow; juice-sacs fairly large, spindleshaped; juice abundant, clear; acid clear and strong; flavor excellent; pith very small, $1 / 8$ inch or less; seeds few, abortive, oblong, small. (Fig. 82.)

The tree is thornless, dwarf in habit, and the fruit keeps excellently. Uncured specimens, when placed in water sink about four-fifths of the diameter beneath the surface; when cured five-sixths of the distance or more. The Genoa lemon was imported from Genoa by Don Jose Rubio, of Los Angeles, and from thence into Florida by A. I. Bidwell about 1881 .

Lisbon.-Form oblong; size medium, $3 \frac{1}{4}$ by $21 / 8$ inches, color lemonyellow; apex nippled; base somewhat necked; calyx quite large and prominent; rind fairly smooth, sweet to the taste, $1 / 8$ inch thick in cured specimens, $1 / 4$ inch thick in uncured; oil-cells small and prominent; sections 10-11, small, regular in size; flesh fine-grained, grayish yellow; juice-sacs elongated, narrow, spindle-shaped; juice abundant; pulp melting; acid clear, pure, strong; flavor excellent; pith small, $1 / 4$ inch or less; seeds $1-5$, usually abortive, oval, somewhat plano-convex. (Fig. 83.)

This variety is a strong vigorous grower, prolific, thorny, and well 

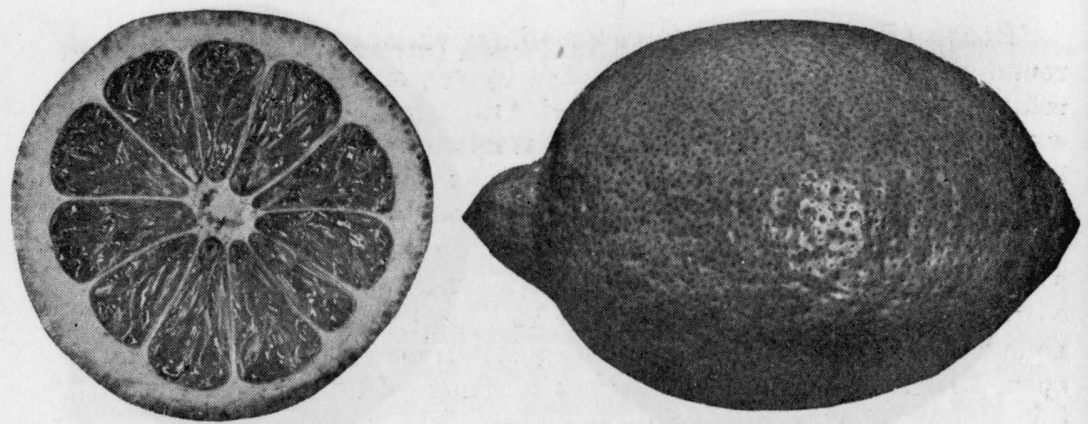

Fig. 83. Lisbon lemon and cross-section, uncured

covered with foliage. The fruit is very uniform in size, ripens evenly, and keeps well. The Lisbon lemon was imported from Portugal and was first grown at Riverside, California, by D. N. Burnham.

Otaheite.-Form almost globose, usually measuring $21 / 8$ by $21 / 8$ inches or $21 / 8$ by 2 inches; color deep yellow; apex slightly nippled and somewhat roughened; the base somewhat roughened and slightly elevated to the calyx; calyx small, $4-5$ blunt pointed; rind roughened because of the small depressed oil-cells, thin, the inner portion yellow tinted; sections 8 or $\mathbf{9}$, regular in size and shape; flesh fine-grained, orange in color; juice-sacs slender, spindle-shaped; juice plentiful; flavor insipid or mawkish, distasteful; pith small, solid, or slightly open when very ripe; seeds absent or few and abortive. Season December to February.

The tree is dwarf and when allowed to grow at will forms a scraggly, open, spiny bush. Its origin is unknown to the writer.

Ponderosa.-Form necked, oblong, obovate pyriform; size large, $4 \frac{3}{8}$ by $4 \frac{1}{8}$ inches; color lemon-yellow; apex flat or roundish with a very slight indication of a nipple; base necked, rather rough, elevated about the calyx, which is quite depressed; rind rough, $1 / 2$ inch thick; oil-cells large, balloon-shaped or oblong; sections 12, distinct, separating tissues thick; flesh grayish, identical in color with that of the pomelo, coarse-grained; juice-sacs large, spindle-shaped, or cylindrical and blunt; juice plentiful, colorless; pulp melting; acid quite strong; flavor agreeable, not exactly like a lemon; pith small; seeds 25 , oval, blunt-pointed, somewhat wedgeshaped, of medium size. Season winter.

This lemon appears to resemble the pomelo and there is a possibility of its containing some of the pomelo strain. The leaves are rounded at the apex and wingless. This variety has been extensively advertised as a novelty by northern nurserymen for pot culture and trees of it are found here and there in the southeastern citrus districts. 
Rough (Florida Rough; French).-Form variable, slightly obovate or round-ovate; size medium to large, $2 \frac{7}{16}$ by $2 \frac{5}{16}$ inches, $33 / 4$ by $33 / 4$ inches; color lemon-yellow, sometimes shaded with a reddish tinge; apex rough, with a slightly depressed ring in which is set a roughened elevation having 3 or 4 ridges; base rough and elevated so as to surround the calyx; rind decidedly rough and warty, $1 / 4$ inch thick; oil-cells large, balloon-shaped or globular, frequently extending entirely through the rind; sections 9-12, well-defined, separating freely from each other and from the rind; flesh coarse-grained, greenish yellow; juice-sacs large, broad, and blunt; juice abundant, clear; pulp melting; acid quite strong; flavor agreeable; pith open, $1 / 2^{-1}$ inch across, filled with white strings of tissue; seeds 23 , small, full, plump, blunt-pointed. Season winter. (Fig. 80.)

This variety of lemon is presumably of Spanish introduction and has become naturalized in the forests of southern Florida. It is somewhat useful for home consumption, but as a commercial variety it is worthless. The rough lemon is extensively used as a stock on which to work different varieties of citrus trees. When growing apart it reaches a height of twenty-five feet and upward, the bark of the tree being brownish gray and smooth.

It is known as Mozoe lemon in Rhodesia where, although introduced, it now grows wild along the Mozoe River. In the Cape districts of South Africa it is called the Cape lemon. No other citrus stock is used so extensively in those sections. The fruit is also sold in the local markets for culinary purposes.

Sicily.-Form oblong; size medium, $21 / 2$ by $31 / 4$ inches; color bright light lemon-yellow; apex nippled, nipple short, abrupt; base rounded; calyx rather large; rind thin, smooth, sweet; oil-cells usually flush with the surface; sections 12, distinctly marked, quite regular; flesh grayish yellow, fine grained; juice-sacs small, spindleshaped; juice abundant; pulp melting; acid strong, clear; flavor good; pith small; seeds 12, of medium size.

Sweet.-Size very small; form

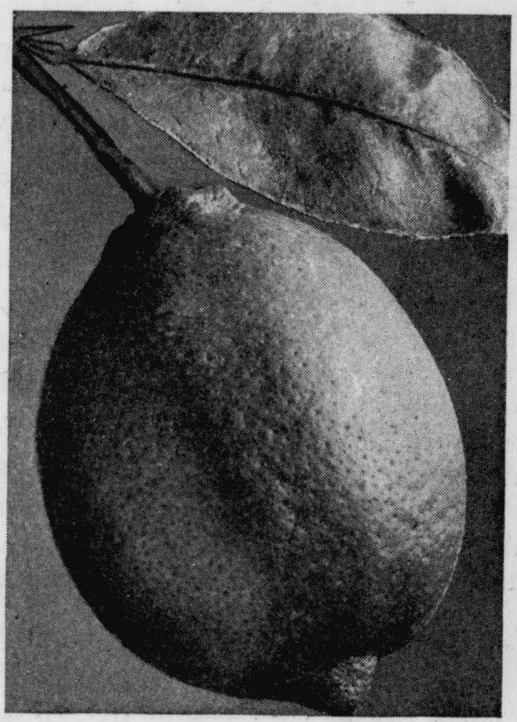

FIG. 84. Villafranca lemon (about $2 / 3$ natural size) 
much flattened; color rusty, grayish yellow; instead of eye, a marked nipple set in a deep cavity; stem inserted in a slight depression; thickness of skin $\frac{2}{16}$ inch; longitudinal diameter 2 inches, transverse $21 / 8$ inches; flesh dark lemon; grain of pulp coarse; juice sweet and insipid, with slight lemon flavor. Curious, but unworthy of cultivation. (Moore.)

Placed here provisionally; it should, doubtless, be grouped differently.

Villafranca.-Form oval-oblong; size medium to large, 3 by $2 \frac{5}{16}$ inches; color bright lemon-yellow; apex pointed, blunt, abrupt, about 1/2 inch long; base rounded; calyx of medium size, segments not distinetly marked; rind smooth, $1 / 8$ inch thick when cured; oil-cells depressed or flush with the surface; sections 11, well-defined and regular; flesh fine-grained, light grayish yellow; juice-sacs slender, pointed; juice colorless, abundant; pulp melting; acid clear, pure, strong; flavor good; pith small, $1 / 4$ inch across or less; seeds 30, of medium size, oval, pointed. (Fig. 84.)

The tree has but few thorns, is a good grower and very productive. The variety was imported by General Sanford and is, perhaps, the most commonly planted in Florida. 


\section{CHAPTER XI}

\section{THE LIMES}

The acid limes (Citrus aurantifolia, Swingle), the only ones grown on a commercial scale in America, have generally been confused with the lemons, from which they are distinct. In habit of growth, in the winged petioles, in the clustered blossoms, in the flavor of the fruit, in their immunity from citrus scab, the limes are a class by themselves.

Due to their having been grouped with the lemons, it is difficult to trace their early history, because writers may have been referring to them or they may have had lemons in mind, or both. It is impossible to tell. They are mentioned by a number of the early writers on citrus fruitsFerrari, Rumphius, Volckamer, and others. Sloane enumerates a number of varieties in his Catalogue of the Plants of Jamaica.

The lime was introduced into the West Indies and other parts of the New World by the Spaniards at an early date. It has become naturalized, and may be found in many parts of tropical and subtropical America, growing side by side with the native trees. It has a very wide distribution in all parts of the tropics and is the most important acid fruit of those regions. Outside the tropics and the warmer subtropical sections, it has never been successfully cultivated to any extent, for it is the tenderest of all the citrus fruits. It responds in growth very readily to rises in tem

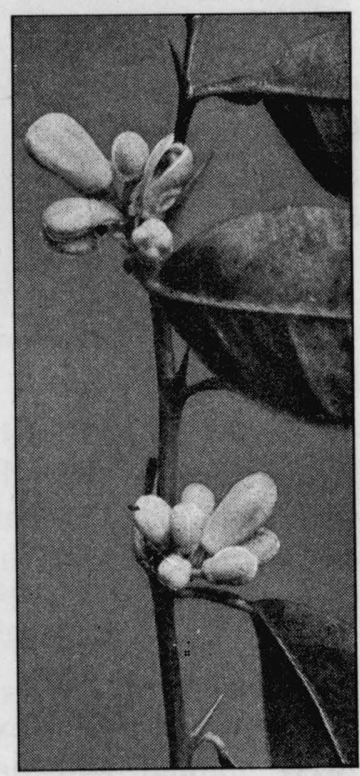

Fig. 85. Flower-buds of Mexican lime 
perature and in this condition is easily injured by cold which leaves other citrus trees untouched. Its cultivation, therefore, is confined to districts exempt from injurious frosts.

No other species of Citrus succeeds so well on poor sandy soils, or on the rocky soils of the Florida Keys, as the lime.

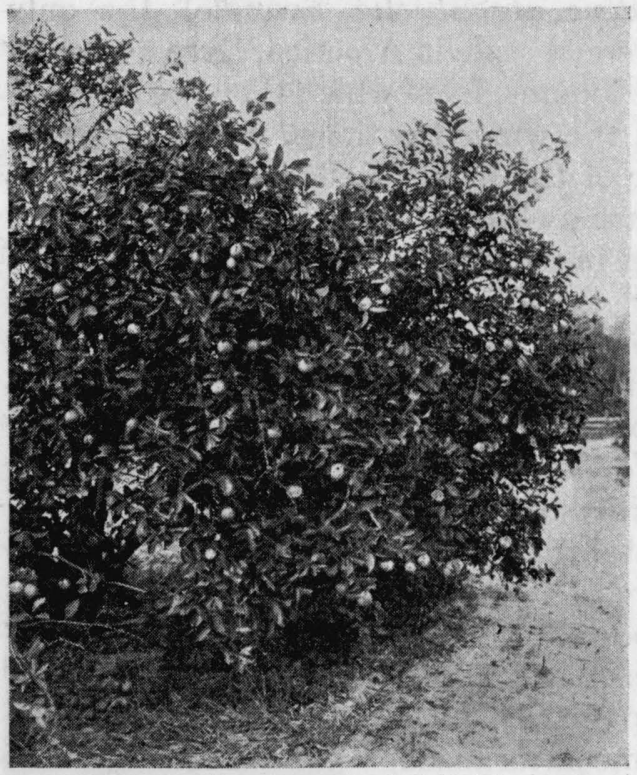

FIg. 86. Bearing tree of Tahiti lime

It grows and fruits well when poorly cultivated and cared for, or even neglected entirely.

The Mexican, also called the West Indian, lime, thecommonest variety in Florida and the Islands, is propagated entirely from seed, as a result of which it has varied greatly and at present the name Mexican is little better than a group name, embracing a conglomeration of distinct forms. The fruit is very variable in size and shape, that borne by some trees being scarcely larger than a pigeon's egg, while others produce fruit as large as an ordinary mediumsized lemon. - The name stands for no definite fruit.

If more attention were paid to the propagation of this group of limes, good fruit of uniform size and quality could readily be secured by selection, but under the present careless system, much of it is very inferior. Some years ago two varieties of the Mexican group, Palmetto and Everglade, were named and described. They do not seem to have entered into lime plantings. Most of the groves which have 
been set in Florida are of the Tahiti variety, and in California one or two other varieties are planted to some extent.

The so-called Rangpur lime is a prolific variety of Citrus, the fruit of which is well-flavored and very acid. It is hardier than the true limes, but, unfortunately, it is severely attacked by citrus scab, to which the limes are not subject. Properly it should not be classed with the limes, but since it is the only fruit of its kind of any importance in America, and since it is used as a lime, it is placed here.

The calamondin orange (Citrus mitis) makes a beautiful ornamental shrub or small tree. It bears a small, tangerinelike acid fruit of fine quality which is often used in place of the lemon and lime. It is very hardy, ranking in this respect with the Satsuma orange and kumquat. For convenience, the fruit is placed and described with the limes.

Attempts by Walter T. Swingle, of the United States Department of Agriculture, to secure a hardy lime by crossing the lime with the kumquat have met with a considerable degree of success. One of these, Eustis by name, will stand as much, or even more cold than the sweet orange, and produces a fruit of high-grade lime quality. This hybrid makes it possible to have acid fruit similar to the lime, and equal to it, wherever the sweet orange may be grown. A lime industry could be built up throughout the citrus districts on this fruit.

The lime is used in much the same way as the lemon in the making of "limeade" and for seasoning food. Citric acid, citrate of lime, concentrated lime juice, and lime-oil are important materials obtained from the lime. At present most of the product is manufactured or the raw materials obtained in the West Indies. The islands of Montserrat and Dominica are important lime-producing centers.

\section{VARIETIES OF LIME}

Calamondin.-Form oblate, or depressed globose, the segments often showing through the skin; size small to medium, $11 / 8$ by $11 / 8$ to $11 / 4$ by $1 \frac{1}{4}$; color deep tangerine-red; stem small; calyx small, almost a mere 


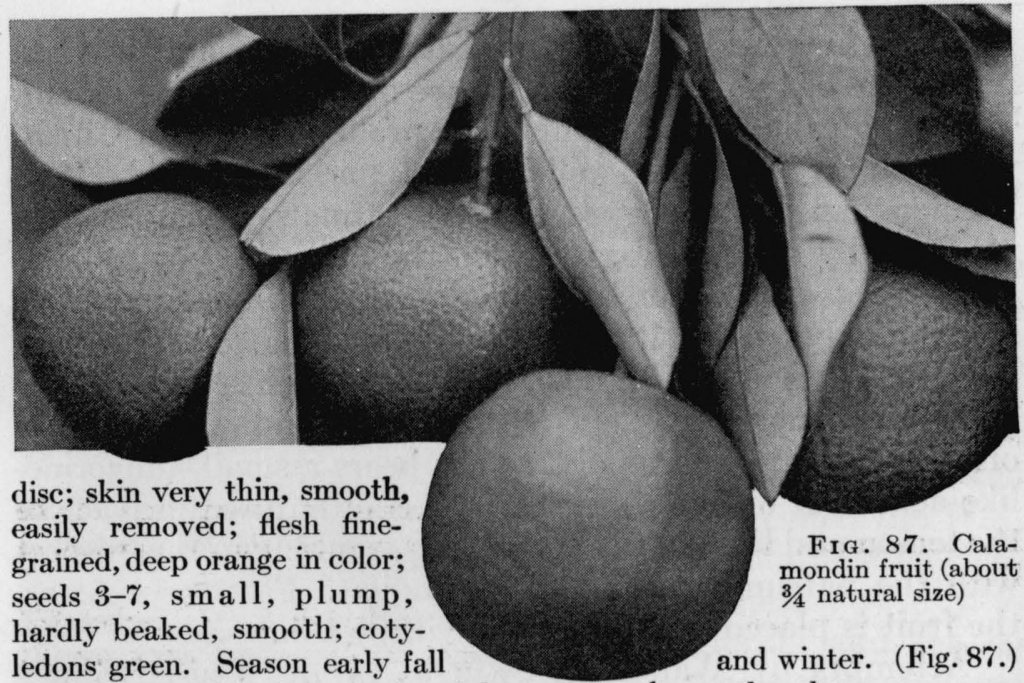

Tree a densely branched upright grower, almost thornless, very ornamental. It is as hardy as or hardier than the Satsuma orange. Introduced from the Philippines, where it is native, into Panama and from Panama into Florida by the United States Department of Agriculture.

Eustis limequat.-Fruit oval (occasionally nearly spherical), slightly asymmetrical, mature fruits having a long diameter averaging $15 / 8-17 / 8$ inches, diameter in cross-section $11 / 8-1 \frac{1}{2}$ inches; calyx persistent; color light yellow ("picric yellow"-Ridgeway's Pl. IV-d-23); rind thin, $\frac{1}{16}$ inch, very smooth and glossy, translucent; oil-cells spherical, rather prominent, having no bitter flavor; segments $6-9$; seeds $5-12$, usually averaging 1 to the segment, small to medium size, $1 / 4^{-3} / 8$ inch in length; pulp of light greenish color, closely resembling lime, tender and juicy; flavor sharply acid; like the lime, the fruit can be used when full sized but not fully colored. Tree evergreen, vigorous, having tendency to produce long shoots which bend downward with the weight of the fruit; much more hardy than the lime, but not as hardy as the kumquat; resembles lime in producing a succession of crops, though not so markedly everbearing; spines on bearing twigs very small, not injuring fruit; flowers 5-petaled, pure white (not streaked with pink as with the lime and most other limekumquat hybrids); leaves unifoliate, rather thick, dark green above, lighter below, tapering at both base and apex, 2-3 inches long, slightly folded along the midrib, having short narrow petioles, closely resembling leaves of the round kumquat (F, japonica) except for larger size. (Swingle and Robinson.) (Fig. 88.) 
Originated by Walter T. Swingle in 1909 at Eustis, Florida, by crossing the Marumi kumquat on the West Indian lime. Two other varieties, the Lakeland and Tavares limequats, have been named and described by Swingle and Robinson, but so far as known they have not been propagated and offered to the trade by nurserymen.

Kusaie.-Form oval, spherical, or oblate; apex flattened or depressed, with a small sharp-pointed nipple; size medium to large, the diameter ranging from 2-21/4 inches; rind medium to thin, light lemon-yellow, and colors irregularly; oil-cells numerous; segments vary from 6-10, dividing tissues thin; pulp-vesicles spindle-shaped; flesh usually of a clear honeyyellow; juice abundant, colorless or transparent, with a characteristic flavor; central pith usually open; seeds plump and few in number. (W.T. Pope.)

It is said to have originated on the island of Kusaie, one of the Hawaiian group, and it is regarded as an important lime for planting in Hawaii.

Mexican.-Form oblong or oval; size small, $2 \frac{1}{16}$ by $13 / 4$ inches, $23 / 8$ by $2 \frac{1}{16}$ inches, very variable; color light lemon-yellow; apex usually smooth, sometimes slightly nippled and ridged, the nipple pointed or blunt, short and small; base usually smooth, sometimes elevated and

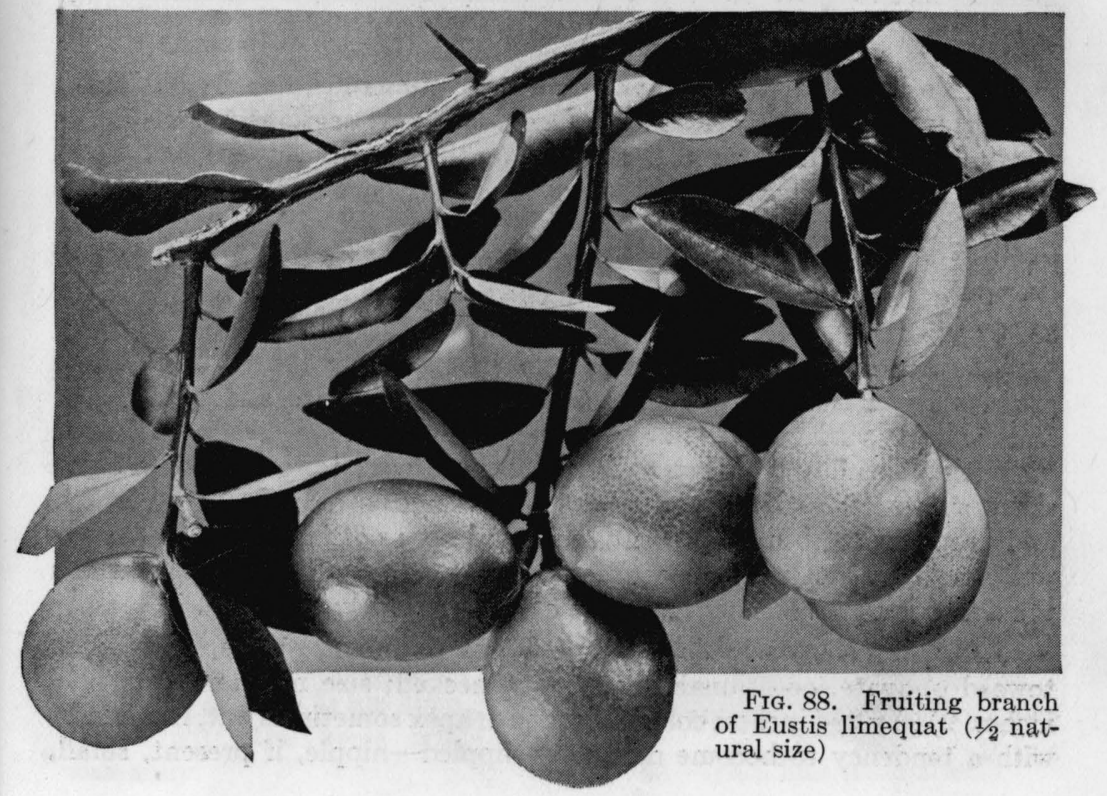




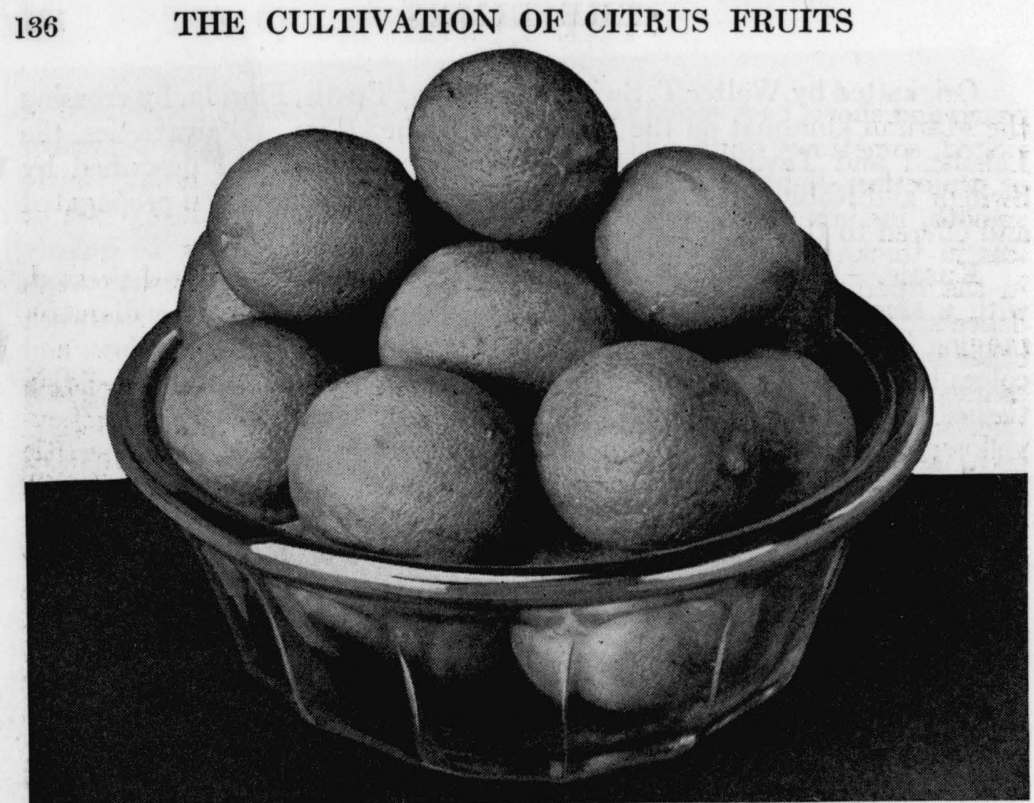

Frg. 89. Mexican limes (about $3 / 4$ natural size)

ridged; rind smooth, very thin; oil-cells very numerous, usually flush with the surface, the larger ones sometimes depressed; sections 10, distinctly marked, regular in size; dividing tissue thin; flesh fine-grained, light grayish green; juice-sacs small, spindle-shaped; juice plentiful, colorless or translucent; pulp melting; acid very strong; flavor distinctly of the lime; pith open, small; seeds few or none, pointed, broad and flat, or slightly wedge-shaped, $3 / 8-1 / 2$ by $\frac{3}{16}$ inch. Season all the year round. (Figs. 85,89 .)

The Mexican lime was probably introduced by the Spaniards and grows wild in the forests of southern Florida. In size and quality the fruit is very variable as it is propagated entirely from seeds. The tree grows as a shrubby bush ten to fifteen feet high, well provided with small sharp spines. This lime might be greatly improved by proper selection and propagation, but at present the name does not stand for any single well-marked variety, but rather for a conglomeration of varieties for which the description given above may be considered fairly accurate.

Rangpur (Rungpur; Rungpore).-Form roundish, oblate, or tending toward obovate, occasionally somewhat necked; size medium, 2 by $21 / 8$ inches, $25 / 8$ by $25 / 8$ inches; color orange-red; apex sometimes flat, frequently with a tendency to become distinctly nippled-nipple, if present, small, 
sharp and short; base sometimes quite smooth, occasionally corrugated or ridged, sometimes quite rough, especially when necked; calyx depressed or projecting slightly around the point of attachment; rind usually fairly smooth, inclining to be rough about the base and apex, thin, $1 / 8$ inch or less in thickness, separating readily from the pulp, coloring irregularly in the ripening process; oil-cells rather conspicuous, the primary ones depressed; sections 7 , fairly regular in size, separating readily from each other and from the rind; flesh coarse-grained, deep orange; juice-sacs large, long, $1 / 2^{-3 / 4}$ inch, narrow and pointed; juice plentiful, slightly colored (orange); pulp melting; acid clear, pure, strong; flavor distinct, not at all like a lime, very pleasant and agreeable; pith small, open, $1 / 4$ inch in diameter; seeds 14 , ovate, scarcely pointed, $3 / 8$ inch long by $1 / 4$ inch wide; cotyledons greenish. Season autumn and winter, remaining on the trees well on toward spring.

The Rangpur lime was grown from seed obtained from northwestern India, by Reasoner Brothers, Oneco, Florida. The variety appears to have come true from seed and to be identical with that described by Bonavia. The tree has very much the habit of the lime, but in nearly all respects the tree and fruit are distinct from the true lime group. By Bonavia it has been classed with the Indian group, "Suntara," which is closely related to the mandarin group. It has been placed with the limes provisionally.

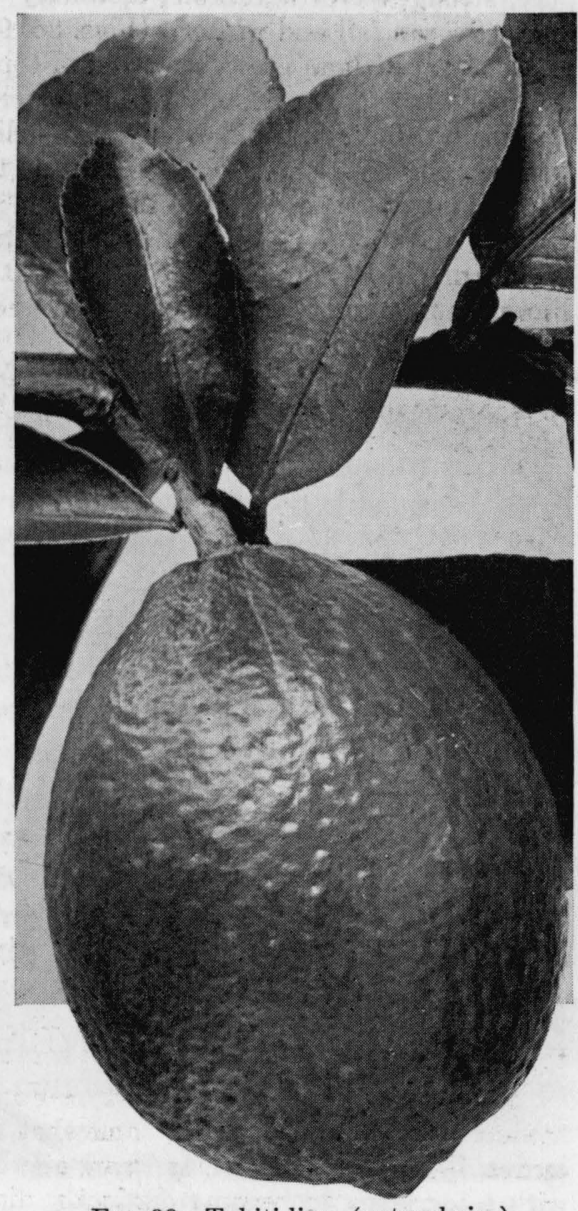

FIG. 90. Tahiti lime (natural size) 
Tahiti.-Form broadly oval; size large, 3 by $25 / 8$ inches; color lemonyellow; apex nippled, the nipple broad at the base, abrupt and sharp pointed; base rounded, slightly elevated about the calyx, creased or ridged; calyx adhering firmly to the fruit, blunt pointed; rind smooth, thin, $\frac{1}{16}$ inch when cured; oil-cells small, slightly depressed; sections 10 , well-defined, irregular; flesh fine-grained, greenish; juice-sacs cylindrical, narrow and pointed; juice plentiful, almost colorless; pulp melting; acid pure, strong; flavor agreeable, distinctly "lime;" pith open, small; seeds none. Season fall and winter. (Figs. 86, 90.)

The Tahiti lime grows as a round-topped tree, 12-15 feet in height. The fruit is produced singly or in clusters of two or three, usually well covered by the foliage. Branches are inclined to droop. The undesirable feature of the variety in Florida is that the fruit tends to decay on the trees about the time it matures.

In California, a seedless variety, Bearss, is grown to some extent. It is evidently a form of Tahiti. Persian, at one time listed by some of the Florida nurserymen, either belongs here or is identical with Tahiti. 


\section{CHAPTER XII}

\section{VARIETIES FOR PLANTING; BREEDING NEW VARIETIES}

The citrus industry in America was started with seedling varieties. Later, many new sorts were introduced from foreign citrus districts where the industry was older and where it was believed varieties of greater merit could be secured. Many seedling oranges and grapefruit of local origin came into prominence, and, in consequence, when propagation was undertaken by budding there were many varieties from which to choose. The amateur spirit among the growers was strong and, as a result, a very large number of varieties entered into the older citrus plantings. In 1904, for example, one Florida nurseryman offered forty-four varieties of oranges and pomelos to the tree-planting trade.

As time has gone on and the industry has assumed large commercial proportions, varieties have been measured by a new set of standards. Greater uniformity of product was necessary, and it also became needful to give more attention to season of ripening, market quality, resistance to diseases and insects, and to other characters which formerly were left out of consideration. The whole trend has been toward simplification. In consequence, the number of varieties now propagated and planted has been reduced to the smallest that will cover the citrus fruit season. In Florida it is, and always will be, necessary to use a larger number of varieties than will answer for planting in California. It is not possible to cover the entire eastern shipping season (October to June inclusive) with as few sorts as will suffice in California. Due to climatic influences, a variety of citrus fruit cannot be held on the trees in marketable condition as long in Florida as in California.

In the citrus districts of the Gulf of Mexico, the following varieties usually make up recent plantings. The list could be 
reduced further were it not that some sorts are hardier than others, and therefore better adapted for colder sections. For planting in the home-garden the list may be extended considerably.

Sweet Oranges: Parson Brown, Hamlin, Pineapple, Valencia, Lue Gim Gong.

Mandarin Oranges: Satsuma, Dancy, Temple, King.

Grapefruit: Triumph, Duncan, Marsh Seedless, McCarty.

Lemon: Villafranca.

Limes: Mexican, Tahiti, Eustis Limequat.

Kumquats: Nagami, Marumi.

It is interesting to note that all the fruits listed above are of American origin, except Valencia and Satsuma oranges, Villafranca lemon, Tahiti lime, and the two kumquats. Six have been introduced from the Old World and eleven have originated in the New.

In California, where a lesser number of varieties covers the citrus season (November to September inclusive) the following list is now recommended for planting:

Oranges: Bahia, Valencia.

Grapefruit: Marsh Seedless.

Lemon: Eureka.

Limes: Tahiti, Bearss.

Kumquat: Nagami.

\section{SEEDLESS CITRUS FRUITS}

Seedlessness in some citrus fruits is advantageous while in others it is not of much importance. Pomelos with seeds are not particularly objectionable, so far as making use of the fruit is concerned. The pomelo is used very largely as a breakfast fruit, and because of its large size it nearly always goes through the kitchen before being eaten. The presence or absence of seeds, therefore, makes little difference. However, the seeds in pomelos are objectionable if the fruit is to be held very late on the trees. When this is done, the seeds 
germinate in the fruit and the root-growth spoils the flavor. Also, it takes a considerable amount of plant-food or fertilizer from the soil to develop and perfect the seeds.

The presence of seeds in oranges is objectionable because they are so very generally eaten out-of-hand.

There is some objection to seeds in limes and lemons, but since the juice is commonly strained before using, the presence of seeds is not so troublesome as in oranges.

While the factor of seedlessness is well worth considering, it should be remembered that the principal points in favor of any variety are adaptability, vigor, fruitfulness, high color, and fine quality. It is also well to bear in mind that seedlessness in citrus fruits is very often due to lack of pollination, and a change of environment or circumstances may sometimes cause a usually seedless variety to become seedy.

\section{BREEDING NEW VARIETIES}

The day has come when a knowledge of the art and science of crossing plants should be as much a part of a horticulturist's education as that of budding and grafting. So great are the improvements, along certain lines, which may be brought about in citrus fruits through cross-pollination and consequent cross-fertilization, that it has been deemed advisable to give specific directions for the use of those who desire to experiment in this interesting and inviting field. The operations necessary for the performance of the work are so simple that any novice may perform them. All that is

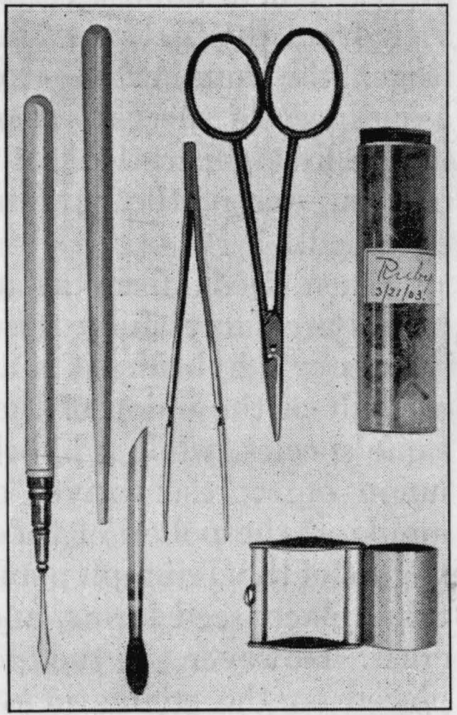

FIg. 91. Pollination outfit: scalpel, brush and handle, tweezers, scissors, phial for pollen, hand-lens. 
necessary is a knowledge of the methods, a little patience, and a considerable amount of care.

While something may be done in improving varieties by bud-selection, any radical improvements in the fruits under discussion must be brought about by raising, fruiting, and selecting seedlings. Seeds may be selected from fruits of desirable trees or they may be produced as a result of handpollination. The method of selecting and propagating desirable seedlings is the one by which all the varieties now cultivated commercially in America were produced, and it is, perhaps, not too much to say that their origin has been, in a large measure, due to chance. If attempts are made at improvement by cross-pollination, the parent plants may be chosen at will, and there is always a strong probability of the offspring inheriting some of the desirable characteristics of the parent varieties. After persistent efforts for a number of years, it is almost certain that the desired end, held in view from the first, may be attained in the ideal fruit. The larger the number of crosses made, the greater are the assurances of success. If a desirable variety is not secured in the first generations, it is best to continue the work by crossing one of the parents on the cross or hybrid already obtained.

When seeds form as a result of cross-pollination and plants are successfully raised, the offspring is termed either a cross or a hybrid. It is a cross if the seedling is formed as a result of the union of the elements of two varieties of the same species, while a hybrid is the plant resulting from the union of representatives of two distinct species. For example, if the pollen of the Duncan pomelo is placed on the stigma of the Triumph pomelo and following this fecundation takes place, seed forms, and a plant is raised, this plant is a cross. However, if the pollen of the Duncan pomelo is placed on the stigma of a Lemon citron and as a result a seedling is raised, it will be a hybrid. In the first case, the two pomelos belong to the same species, $C$. paradisi, while 
in the latter case two species are represented, $C$. paradisi and C. medica. By some plant-breeders these two terms, cross and hybrid, have been discarded and hybrid used in the place of them, but the usage as given above is the longestablished one and the best to follow.

It is characteristic of citrus seeds (Poncirus trifoliata excepted) that frequently more than one seedling is produced from a single seed, and as many as ten seedlings have been obtained from one seed. This is brought about by what is known as polyembrony, or the development of a number of embryos in the embryo-sac by adventitious bud development. When fertilization takes place, the true sexual embryo develops and, along with it, the false embryos also grow. Hence, in crossing, when a number of seedlings are secured from a single seed, one is the result of the cross, the others are bud offshoots from the mother parent plant, and when grown to maturity probably will not differ in any particular from it. It may also be possible, when only a single seedling is grown from a seed, that the so-called false hybrid has germinated and the true hybrid has perished. As the seedlings, unless the cross is a very wide one, resemble one another, they should be grown to maturity to make sure of the one in which variations appear. If a variety or species that produces only a single embryonic plant in its seeds is employed in crossing or hybridizing, it should be used, if possible, as the mother parent, thus eliminating the false hybrid seedlings.

The parts of the flower.

A knowledge of the structure of the citrus flower on the part of the operator is indispensable. On examining a flower the first part noticed is the large, white, showy portion, usually composed of five parts. This is the corolla, and each part or segment is termed a petal (Fig. 92-E). Outside the corolla, at its base, is a much smaller, yellowish or greenish, somewhat cupped part, the calyx. In the calyx of some 
flowers, five points may be made out (oftener only three or four), which represent the parts of the calyx, but in the citrus flower these are fused into one. These parts are each known as a sepal. The calyx and corolla constitute the floral envelopes or protective part of the flower.

Inside the corolla, standing up in a ring, are the stamens (Fig. 92-D). Each consists of a white stem or filament, sur-

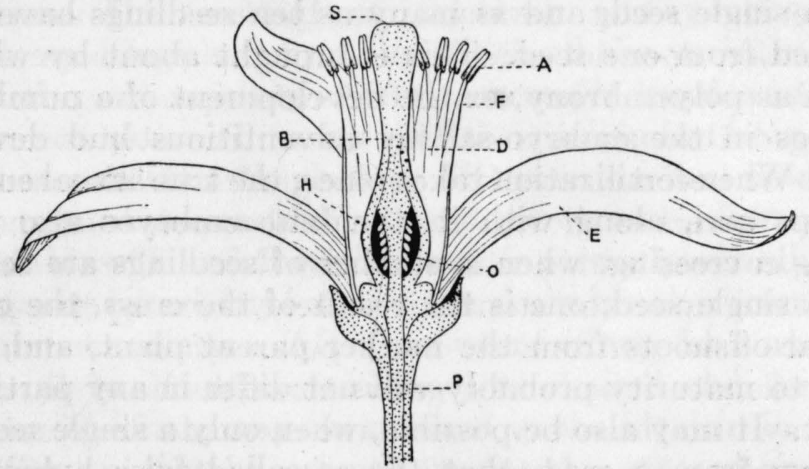

Fig. 92. Vertical section through a citrus flower. A, anther; B, pistil; $\mathrm{D}$, stamens; E, petals; $\mathrm{F}$, filaments; $\mathrm{O}$, ovary showing ovules; $\mathrm{P}$, peduncle expanding into the calyx just above; S, stigma. (Enlarged $2 \frac{1}{2}$ times)

mounted by a yellow pointed knob, the anther. If the anthers are ripe, a yellow dust, the pollen, will be found on them. The stamens are usually about twenty in number and the filaments are more or less united, so as to form a ring. The filaments of Poncirus trifoliata are not joined together.

Within the ring of stamens the pistil (Fig. 92-B) rises straight up from the bottom of the flower. Its upper knoblike end, the stigma, rises above, or to, the level of the stamens. Below the stigma is a rather thick straight part, the style, joined to a round greenish body, the ovary, at its base. This ovary, when fully developed, forms the fruit. If the ovary is cut through from top to bottom with a sharp knife and the section examined with a hand-lens, a number of small light-colored bodies, attached along the central column, may be made out. These are the ovules (Fig. 92-O), 
which, after being fertilized, grow and form the seed. The stamens and pistil are called the essential organs of the flower, because they are the parts which form the seed for the reproduction of the tree. It is with them that one making crosses is most concerned, for through their agency seed is produced and through them only can the work be done.

As already indicated, the ovary grows and forms the fruit while the ovules develop into the seed. However, seedformation does not commence until the ovules are acted on by the pollen. When the anthers are ripe, the pollen is discharged through slits in the sides. The stigma must also ripen or become receptive to the pollen. This condition in citrus flowers is shown by its viscid appearance and by its being covered with a whitish sticky fluid. Then if the pollen is placed upon the stigma it is held there by the adhesive surface and germinates, each pollen-grain sending out a little slender tube, which grows through the style and finds its way into the ovary, where the contents are emptied into the ovules. Then fertilization or fecundation is accomplished and seed-development begins.

\section{Mode of operation.}

Having now become acquainted with the different parts of the citrus flower, the operator is ready for the actual work.

If any considerable amount of pollination, i. e., transferring the pollen from the anther to the stigma, is to be done, the pollen should be collected and prepared some time before. It has generally been observed that the anthers of citrus flowers open and expose their pollen very shortly or within a few hours after the flowers open. In some cases the anthers are ripe as soon as they are exposed, by the separation of the petals inclosing them. Hence in collecting pollen, one may be certain of securing mature pollen from flowers which are just on the point of opening. It will not do to take pollen from open flowers, for some insect may have visited them and deposited foreign pollen in some part of the 
flower. This pollen might unwittingly be gathered and used by the operator. Gather the flowers in paper sacks and afterwards spread them out in a thin layer on a smooth sheet of paper in a warm dry place, where the air is still. In two or three days the flowers will dry and shrivel, all the anthers will open, and the pollen will be liberated. Then carefully gather the whole mass and replace it in the sacks. Each one should be labeled. For use in the field, the dried flowers and pollen together should be placed in widemouthed loosely-stopped phials. These should be labeled with the name of the variety of pollen and the date of collection. (Fig. 91.)

A sufficient number of bags should be provided with which to cover the flowers to prevent insects from visiting them. For this purpose, two-pound manila bags, such as grocers use, are the most convenient. These should be prepared by punching a hole through the two edges while the sacks are still flat. In the hole in one of the edges tie a string about ten inches long and draw one end through the hole in the other edge.

Every precaution must be taken to prevent the access of foreign pollen to the stigma of the flower to be operated upon. It is best to select the flowers near the tips of branches as it is much easier to cover them with the bags. Remove all

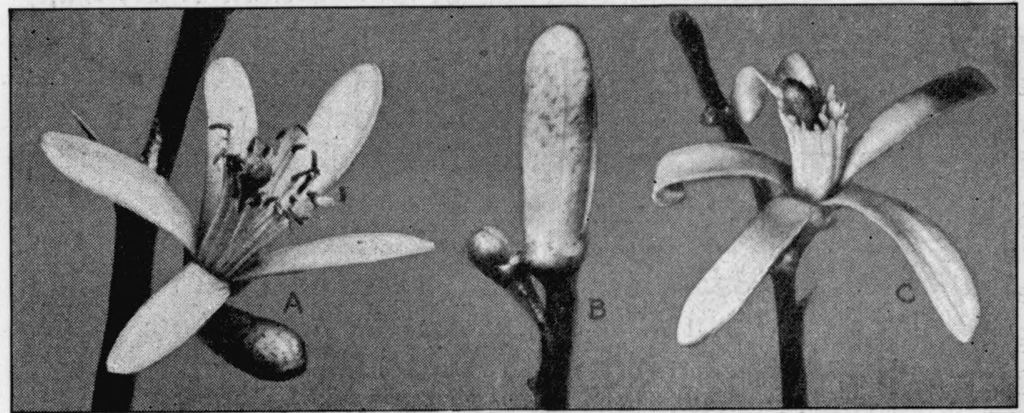

Fig. 93. A, open citrus flower, showing petals, stamens, and pistil; B, bud ready for emasculating; C, flower emasculated 
open flowers and those which are immature. No flower should be worked upon after it is open. Choose them in the stage shown in Fig. 93-B just before they are ready to open. If possible, select the blossoms so as to be able to place a number under the same sack.

In performing the work, gently hold the unopened flowerbud in the fingers. With a pair of tweezers carefully pry the petals apart so as to expose the anthers and stigma. If the flower is in the proper stage, it will be found that the stigma is on a level with the anthers or slightly above them and that its surface is viscid or sticky, as already noted. Then remove the anthers by catching the filaments some distance below them and nipping them off, or a pair of surgeons' scissors (Fig. 91) may be used. This operation of removing the anthers is termed emasculation. Be careful to remove all the anthers and do not allow any of them to drop down between the filaments and the pistil. When the emasculation is completed the stamens present the appearance of those shown in Fig. 93-C. Usually it will be found that the stigma is ready for the pollen at this stage. Hence it is not necessary to place a bag about the emasculated flower or flowers to await the ripening of the pistil or pistils, as must be done with the flowers of many other plants.

Pollination may be performed immediately after emasculation. The pollen may be placed on the stigma by grasping one of the dried flowers by the base and bringing the anthers in contact with the stigma. More often, a small soft camel's hair brush (Fig. 91), fitted with a wooden handle four to five inches long, is employed. A fresh one should be provided for each different kind of pollen to be used. The brush is dipped into the phial containing the dried flowers and pollen and twirled around so as to fill it with the pollengrains. This method is rather wasteful of pollen, and the one given above is preferable when only a small amount of pollen can be secured. After filling the brush with pollen, it is gently applied to the stigma. See that plenty of pollen 


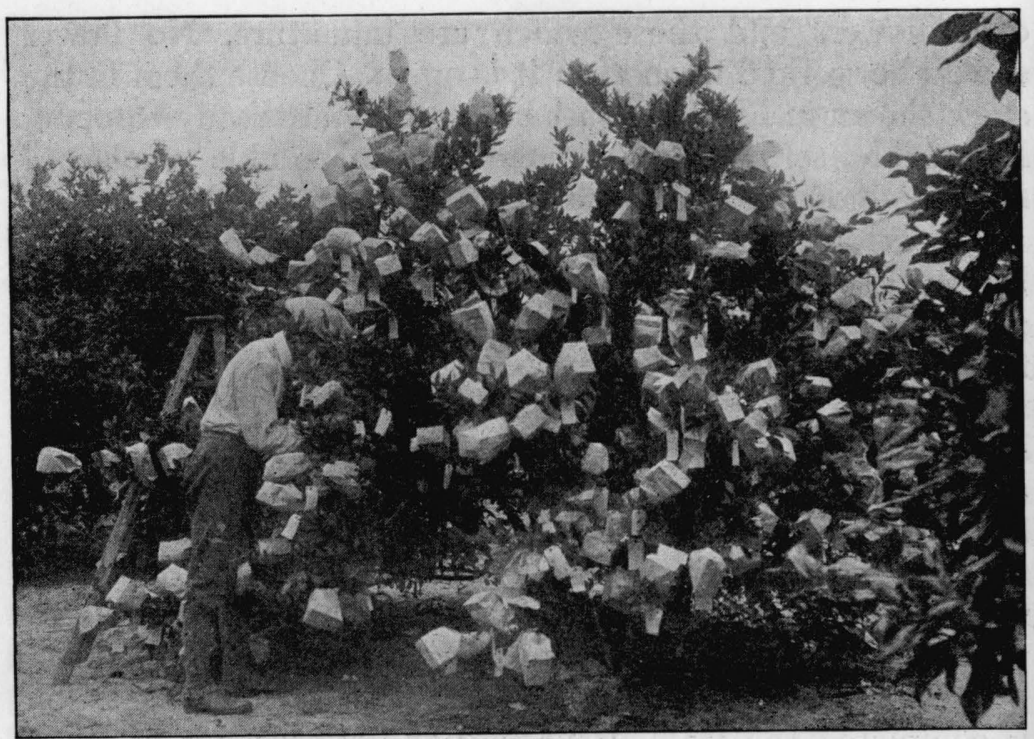

Frg. 94. Citrus tree with many flowers pollinated and inclosed in paper-sacks. Walter T. Swingle, who has been crossing citrus for many years, at work

adheres to its surface. Then carefully cover the pollinated flower or flowers, if a number are together, with a paper bag, tie it tightly around the branch and below the sack place a label indicating the pollen used and the date.

Nothing more needs to be done until the fruit has set. This is indicated by the dropping of the style from the ovary. If at this time the ovary is deep green in color, one may feel reasonably certain that the fruit will stay and that seeds have commenced to grow. At this time, about ten days or two weeks after pollinating, the paper bags should be removed and replaced by sacks about 6 by 8 inches, made of mosquito-netting. For pomelos or other large citrus fruits, the sacks should be 8 by 10 inches, or larger, if a number of fruits are included under one sack. These mosquito-netting sacks admit the air freely, prevent many insect attacks on the young fruit, and frequently save the fruit by holding it if it should drop after it is matured and before picking. (Fig. 95.) 
When the fruit is ripe it should be gathered carefully and the seed saved. If injury to the young plants from cold can be prevented, the seeds may be sown immediately. If there is danger from this source, the seeds should be stratified, as described later, and kept until the time is suitable for planting. In most citrus-growing districts this can be done safely by March. Give the seedlings good care and by August they will have attained a height of about two and a half to three feet.

Some seeds will give more than one plant, due to the presence of more than one embryo in the seed. One of these probably will be the true cross or hybrid, while the additional plants will

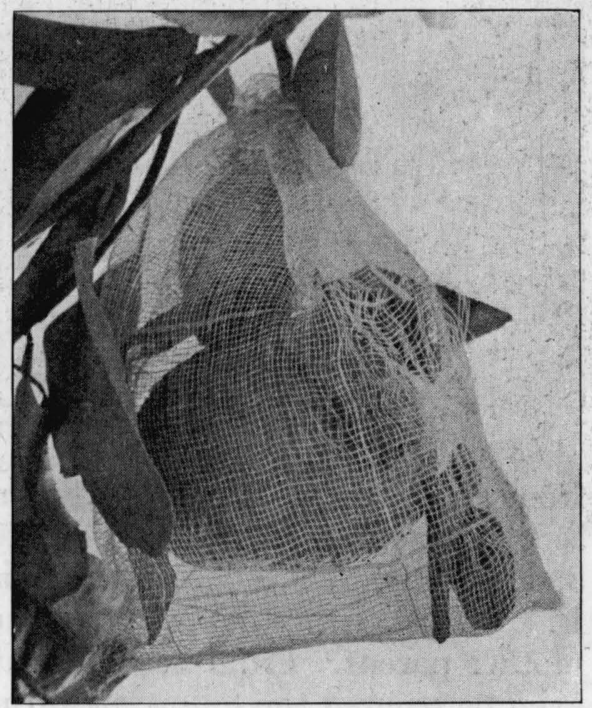

Fig. 95. An orange, the result of cross-pollination, inclosed in mosquito net sack for protection.

have come from adventitious embryonic buds and, as already stated, will in no way differ from the mother parent. All the plants should be saved as it is not always possible to separate the true crosses, or hybrids, when the seedlings are small. Fig. 96 is an interesting illustration of polyembryony. The six seedlings at the left were raised from a single seed resulting from pollinating a Satsuma flower with $\boldsymbol{P}$. trifoliata pollen. The fourth seedling from the left is a true hybrid with trifoliate leaves. The other five are false hybrids. Seventh and eighth from the left are seedlings from a single Triumph pomelo seed, formed by crossing with P. trifoliata. No. 8 is a hybrid, while No. 7 developed 


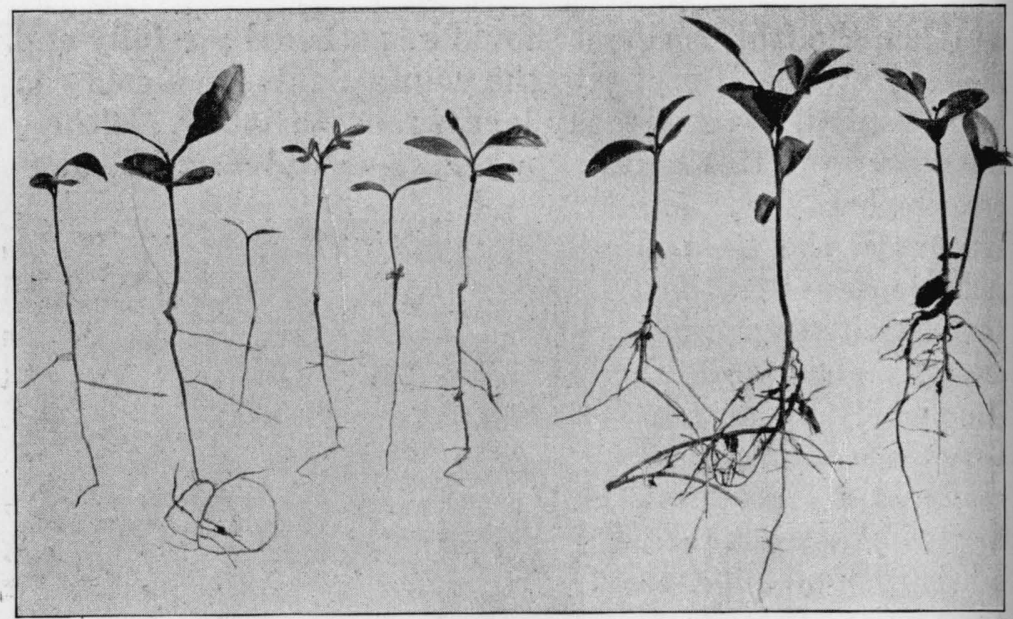

Fig. 96. An illustration of polyembryony

from an embryonic bud of the mother pomelo. The two seedlings at the right have the same parentage as Nos. 7 and 8 . The one with the trifoliate leaf is a hybrid, C. paradisi $X$ $P$. trifoliata, while No. 10 is a bud development from the mother parent. From seeds planted in winter buds may even be secured the following autumn and inserted in stocks to start growth the next spring. In spring, buds may be inserted in the tops of bearing trees. This will enable one to secure fruit sooner. It may reasonably be expected that fruit will be produced the third or fourth season after top-working. Five or six years must usually elapse from the time of pollinating until fruit is secured. Then, and not until then, can the results be known.

If desirable fruit is produced, well and good; if not, further work must be done, and it will generally be best to use one or more crosses or hybrids already obtained, as one of the parents of the next generation, provided the hybrid or cross obtained possesses a sufficient number of desirable qualities. 


\section{CHAPTER XIII}

\section{JUDGING CITRUS FRUITS}

Rules and regulations for the judging of most of the citrus fruits were adopted by the Florida State Horticultural Society in 1892 and by the Executive Committee of the Los Angeles (California) Chamber of Commerce in 1894, and these, at present, are the standards for the respective states. In neither of these sets of scales is any provision made for the pomelo, and since it has come to take its place with the orange and lemon as an exceedingly important citrus fruit, it seems but right that standards should be provided for judging it.

Such a provision is here made by the scale for pomelos which has been prepared after having gone over the ground carefully with G. L. Taber, E. N. Reasoner, and E. S. Hubbard:

Official Scale and Rules of the Florida State Horticultural Society for Judging Citrus Fruits

ScALE

PoInts

Size, $21 / 2$ to $31 / 4$ inches . . . . . . . . . . . . . . . . . . . 10

Appearance, skin fancy and silky . . . . . . . . . . . . . 10

Juiciness, must sink in water . . . . . . . . . . . . . . . . 10

Thickness of peel, $\frac{3}{32}$ inch . . . . . . . . . . . . . . . . . . . 10

Seedlessness, one point off for two seeds . . . . . . . . . . . . 10

Sweetness . . . . . . . . . . . . . . 15

Acid . . . . . . . . . . . . . 15

Tissue . . . . . . . . . . . . . . . . 10

Bouquet . . . . . . . . . . . . . . . 10

Total ..................... 100

FLORIDA RULES FOR JUDGING

1. The executive committee of the Florida Horticultural Society shall choose a superintendent of exhibition and three judges, with a substitute and a secretary. The executive committee, including ex officio members and competing exhibitors, shall not be eligible as superintendent and 


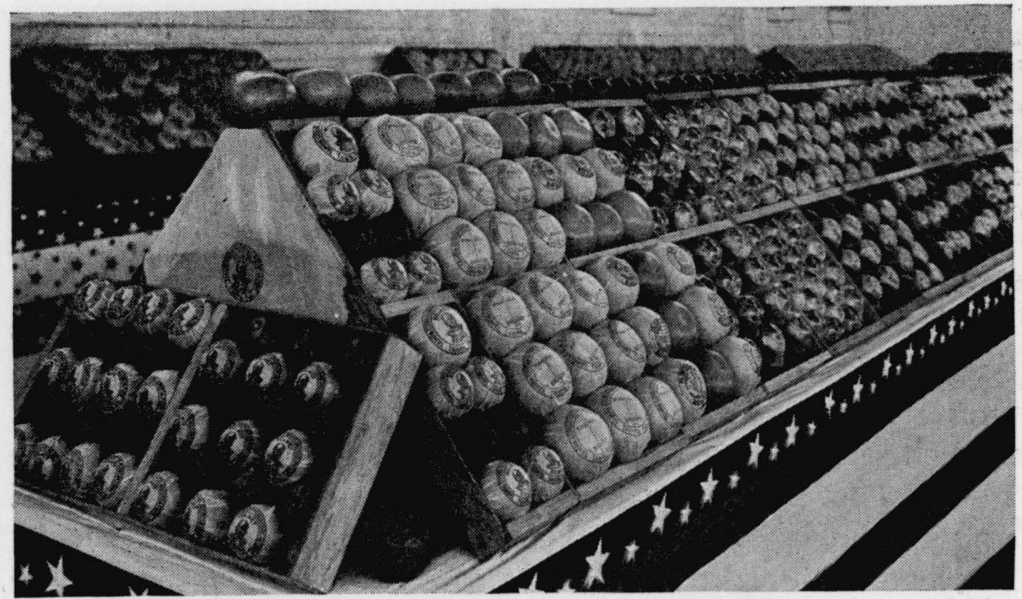

Fig. 97. An exhibit of citrus fruits

judges. The three judges shall conduct tests, and their decision shall be final.

2. The deliberation of these judges shall be secret. The superintendent of exhibition, on application of the chairman of judges, shall from time to time supply the judges with specimens for judgment, and shall use diligence to secure them from intrusion.

3. Each exhibitor is expected to be present with and in charge of his own exhibit. His selection for entries, when ready, must be formally turned over to the superintendent of exhibits, who will then enter them by name and number in a book of record, and furnish him a duplicate card to accompany each entry. Entries will be delivered to the judges in the order of their reception and entry by the superintendent. Responsibility for wasted fruit shall rest with the exhibitor, but poor specimens can be replaced or entries withdrawn by consent of the superintendent, before fruit is delivered to the judges. If an exhibitor is unable to be present, he can make a written statement of exhibits as to his fruit and entries, and the superintendent can make selections if necessary.

4. Diplomas or cash premiums, at the disposal of the Society, shall be divided into classes, 1 st, $2 \mathrm{~d}, 3 \mathrm{~d}, 4 \mathrm{th}$, in ratio of merit as to premium with ratio of 3 and 2 for single plate premiums. Seven specimens shall constitute a plate to entitle to entry, and two of the specimens must be delivered to the judges, who will examine both and score the best. These scores will be eligible both for single plate and collection premiums. The judges reserve the right to debar unworthy or bogus specimens.

5 . The judges shall use the amended scale giving ten points each to 
the following scores and standards of perfection: (1) Size, $21 / 2$ to $31 / 4$ inches, diameter; (2) appearance - specimen must be fancy and skin silky; (3) for juiciness, it must sink below the surface of water, emergence the size of a silver dollar to count 9, one-half the bulk zero; (4) thickness of peel, $\frac{3}{32}$ inch; (5) two seeds to count one point off and two rudiments as one seed; (6) absence of tissue, membranes to be very tender and core porous, $1 / 8$ to $1 / 4$ inch in diameter, as to size of fruit; qualities of flavor, acid, 15; sweetness, 15 , and bouquet, 10 ; to be judged by the taste. Specimens of varieties excelling in balance and richness of flavor to be used as standards for reference. Lemons and limes to count 20 for acid and 20 for flavor.

6. These rules must be published with premium list, and after the judges have made the awards with the superintendent of exhibit, they shall deliver the entry book and scores to the executive committee and will receive their discharge.

Florida pomelo scale.

Scale

PoInts

External characters-

Size . . . . . . . . . . . . . . . . . . . . 10

Color and form . . . . . . . . . . . . . . . . . . . . . . . 10

Weight or juiciness . . . . . . . . . . . . . . . . 15

Rind ....................... 10

Internal characters-

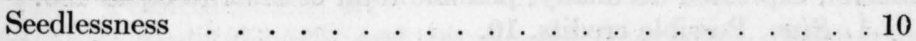

Freedom from fiber or tissue . . . . . . . . . . . . . 10

Juice qualities-

Flavor

Sweetness . . . . . . . . . . . . . . . . 15

Acidity . . . . . . . . . . . . . . . . . . 10

Bitterness . . . . . . . . . . . . . . . . 10

1. Size Standard -4 to 5 inches.

2. Color Standard-Bright, uniform, light yellow.

3. Form Standard-Round or slightly oblate.

4. Weight of Juiciness Standard-Heavy, sinking almost entirely in water.

5. Rind Standard $-\frac{3}{16}$ inch in thickness.

6. Seedlessness Standard-No seeds. Deduct 1 point for each five seeds.

7. Freedom from Fiber and Tissue Standard-Free from rag.

8. Flavor Standard-A harmonious blending of sweetness, acidity and bitterness. 


\section{CALIFORNIA SCALES AND RULES}

The following regulations have been adopted by the Executive Committee of the Los Angeles Chamber of Commerce in reference to the judging of citrus fruits:

No person will be allowed to serve as judge in any class in which he is a competitor.

Any exhibitor who addresses a judge while the latter is in discharge of his duty will be debarred from competition.

A majority of the judges present shall constitute a quorum for decision in any class.

Preliminary classification. Season-Early, from December to April; Middle, February to July; Late, June to December.

Size: Large, medium, small.

(The managing committee from each competing state or section is to nominate varieties to any or all of the above classes, with months, and, when practicable, days, for tests of its own fruit. Fruit to be judged by standards of its class. So far as practicable, no committee is to judge fruit of more than one size, as in above classification.)

\section{California orange scale.}

Divisions: Size, form, color, weight, peel, fiber, grain, seed, taste; to be considered in order named. Counts, credits, points to be units and tenths thereof, expressed decimally; possible total of same to equal 100.

1. Size. Possible credits, 10.

Standards-

Large 126's $-3 \frac{1}{4}$ inches in diameter.

Medium, 176's - $2 \frac{15}{16}$ inches in diameter.

Small, 250's $-2 \frac{7}{16}$ inches in diameter.

Tangerines, etc. $-21 / 8$ inches in diameter.

One unit discount for each $1 / 8$ inch deficiency or excess in any size.

2. Form. Possible credits, 5 .

Standards: Round, oval, ovate, pyriform.

Discount for lack of symmetry and for form blemishes. Navel marks not to be discounted, except when of abnormal size or of bad form.

3. Color. Possible credits, 19, divided as follows: Bloom, 2; peel, 10; flesh, $\%$.

Standards: Bloom to be perceptible, and to be discounted according to degree of deficiency or of injury thereto; peel to be of rich deep orange color, in natural condition, and to be discounted according to degree of deviation therefrom, 1 or more points; rust, scale, and smut to be discounted 5 to 10 points, and fruit that gives visible evidence of having 
been cleaned of the same to be subject to equal penalty; also that has been rubbed or "polished," giving a gloss at the expense of breaking or pressing the oil-cells, to suffer the same discount. Flesh to be rich, clear, and uniform, in any of the shades common to fine fruit. (Omit consideration of "flesh color" until after concluding division 5, "peel.")

4. Weight. Possible credits, 10.

Standards: Specific gravity, 1 , with buoyancy of $3 / 4$ ounce allowed to "large" fruit, $1 / 2$ ounce to "medium," and $1 / 4$ ounce to "small," all without discount.

One point to be discounted for first half-ounce of buoyancy in excess of allowance, and thereafter 2 points for each additional half-ounce.

(Note.-Buoyancy may be easily determined by clasping weights to the fruits with light rubber bands, and then placing in water.)

5. Peel. Possible credits, 10, divided as follows: Finish, 3; protective quality, 7 .

Standards: Of finish, smoothness and uniformity of surface, and pleasant touch; of protective quality, firm and elastic texture, abundant, compact and unbroken oil-cells; $1 / 8$ to $\frac{3}{16}$ inch thickness. Discount $1 / 2$ point for first $\frac{1}{32}$ inch above maximum or below minimum, and 2 points for second $\frac{1}{32}$ inch, provided that too long-picked and fully-cured oranges the minimum shall be lowered to $\frac{3}{32}$ inch; and that to fresh-picked and to slightly-cured "large" fruit the maximum shall be raised 1/4 inch.

Breaking oil-cells, breaking of peel and abrasions of same to be subject to 1 to 10 discounts, according to degree.

(Here consider "Color of Flesh"-see Division 3.)

6. Fiber. Possible credits, 4.

Standards: Septa delicate and translucent; maximum diameter of core $\frac{3}{16}$ inch in "large" fruit and $1 / 8$ inch in other.

7. Grain. Possible credits, 4.

Standards: Fineness, firmness, compactness.

8. Seed. Possible credits, 4.

Standard: Absence of seed.

Discount 1 point for each seed. Each rudiment to be considered as a seed if any growth has been developed; otherwise allowed without discount.

9. Taste. Possible credits, 30, divided as follows: Sweetness, 15; citrus quality, 15.

Standards: Clearness and definability of elements; sweetness rich, delicate rather than heavy; citrus quality pronounced.

Deficiency of absence to be cause for discounts against any element, and excess to be like cause against sweetness and against acid in "citrus quality."

Staleness and flavors of age or decay to be discounted from aggregate of points in this division. 


\section{California lemon scale.}

Divisions: Size, form, color, weight, peel, fiber, grain, seed, taste.

Rules of counts and discounts as in scale for oranges. Total credits, 100.

1. Size. Possible credits, 10.

Standards-

Large, 250's-23/8 inches in diameter.

Medium, 300's-21/8 inches in diameter.

Small, 360 's $-17 / 8$ inches in diameter.

All sizes between 250's and 360's allowed.

Larger fruit to be discounted 1 point for each $1 / 4$ inch in excess. Smaller to be discounted 1 point for 400's ( $13 / 4$ inches), and 4 points for 450 's (11/2 inches).

2. Form. Possible credits, 15.

Standard: Oblong, with allowance of well-formed points at stem and tip. Symmetry required.

3. Color. Possible credits, 15.

Standard: Bright clear lemon.

Discounts according to degree for green splashes, dashes of bronze or deep shades, or for sunburn.

Rust, scale, and smut, with fruit that gives evidence of having been cleaned of the same, to be discounted 5 to 10 counts.

Rubbing or dusting, if heavy enough to press oil from the cells, to be causes for discount.

4. Weight. Possible credits, 10.

Standard: Specific gravity, 1 (equal to that of water), with buoyancy of $1 / 2$ ounce allowed to "large" lemons and $1 / 4$ ounce to "medium" and "small," all without discount.

One point to be discounted for first $1 / 2$ ounce in excess of allowance, and 2 points for each $1 / 2$ ounce thereafter.

5. Peel. Possible credits, 10; subdivisions of which are: Finish, 3 credits; protective quality, 7 credits.

Standard: For protective quality, to be strong, elastic and reasonably firm texture; abundant, compact, and unbroken oil-cells and thickness of $\frac{3}{32}$ to $\frac{3}{16}$ inch.

To be discounted 2 counts for first $\frac{1}{32}$ inch below minimum, and 5 counts for second $\frac{1}{32}$ inch; 1 count for first $\frac{1}{32}$ inch above maximum, and 2 for each succeeding $\frac{1}{32}$ inch.

Fresh-picked lemons not allowed.

6. Fiber. Possible credits, 8.

Standard: Septa delicate and translucent. Core not to exceed $\frac{3}{16}$ inch in "large" and $1 / 8$ inch in "medium" and "small" fruit.

7. Grain. Possible credits, 8, divided as follows: Fineness, firmness, and compactness, 4 credits; color, 4 credits. 
Standard: Grain to be water-colored, shading to blue rather than to gray.

8. Seed. Possible credits, 4.

Standard: Absence of seed.

One-half point to be discounted for each seed. (A discount of $1 / 4$ credit for each seed is now recommended as sufficient.)

Rudiments are to be considered as seed if any growth has been developed; otherwise allowed without discount.

9. Taste. Possible credits, 30, divided as follows: Acidity, 20 credits; absence of bitterness, 10 credits.

In interstate competitions the standard of acidity shall be the highest percentage of strength of acid found in any fruit, determined by chemical test. In other competitions such tests may be applied as committees or competitors may require.

Bitterness to be determined by slicing fruit (including peel) thin, covering with hot water, and cooling slowly; to stand twenty-four hours when practicable (no sugar to be used). Should a trace of bitterness appear to the taste, discount 1 point; should the bitterness be fairly defined, discount 2 points; if pronounced, discount 5 points; and if strong, 10 points.

California pomelo score-card.

SCALE

PoInts

Size (uniformity)

Form (typicalness)

Stem

Color . . . . . . . . . . . . 2

Location . . . . . . . . . . . . . . 1

Size . . . . . . . . . . . . . 2

Rind

Color . . . . . . . . . . . . . . 5

Texture . . . . . . . . . . . . . . . . 5

Thickness . . . . . . . . . . . . . 10

Smoothness . . . . . . . . . . . . . 5

Freedom from blemishes . . . . . . . . . . . 10

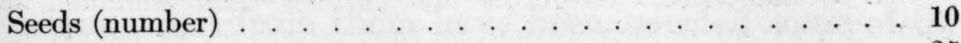

Juice _. . . . . . . . . . . . . . . . 25

Abundance . . . . . . . . . . . . . . . . . 10

Color . . . . . . . . . . . . . . . 5

Flavor . . . . . . . . . . . . . . 10

Rag (tenderness) . . . . . . . . . . . . . . . . . 10

Total ...................... 100 
Pomelo standards.

Size. Pomelos may be exhibited in any size from large (28's) to small (96's). Ths most desirable size is the 54's, in which the fruits are $4 \frac{1}{2}$ inches in diameter. Sizing should be accurate. One-half unit discount for each fruit varying $1 / 4$ inch from standard.

Form. Fruit must have shape typical of variety and be free from irregularities.

Stem. Stem must be present, cut close and square, sepals green and plump. For each missing stem deduct 1 point.

Rind. The color should be ivory-white, the texture smooth and fine. Thickness should be $1 / 4$ to $\frac{5}{16}$ inch. Fruit must be free from all blemishes.

Seeds. Seedlessness is the standard for pomelos. Cut $1 / 4$ point for each average seed to a fruit.

Juice. The largest possible amount of juice is desirable. When placed in water the fruit should not rise more than $1 / 4$ inch above the water. Flavor must be characteristic of the variety with acidity and sweetness well blended.

Rag. Should be tender enough to cut easily with a spoon. 


\section{CHAPTER XIV}

\section{PROPAGATION OF CITRUS TREES}

Citrus trees may be propagated by budding, grafting, seeds, cuttings, or layering. The last method is little used, except for the citron, though in South Africa some of the old orange groves were planted with trees grown by layering, and the method is still employed to some extent in the citrus districts of that region. In greenhouse practice some ornamental sorts are propagated from cuttings, but in America this means is seldom employed for multiplying commercial citrus varieties. Budding is by far the most common method in all the citrus districts.

Seedling trees are not planted in such numbers as formerly. Fifty years or so ago, and even not so far back, it was the rule to plant seedling citrus trees; now it is the exception. In 1885 a Florida nurseryman advertised for sale 50,000 seedling nursery trees, grown from seeds of special sweet oranges. Now it would be impossible to purchase such trees in any quantity. The beginning of any tree-fruit industry is usually marked by the planting of seedlings. Budded or grafted trees represent adaptation to new conditions, divergence, specialization, progress. However, the planting of seeds as a method of propagation should not be discountenanced entirely. The seedling groves of Florida and other citrus districts of America produce good fruit in abundance, and from them have been selected some of the prominent varieties now so commonly planted. Planting seeds for the purpose of originating new varieties is certainly commendable, but better results probably can be obtained by cross-fertilization of existing varieties as well as species, and the planting of seeds, the embryos of which are of known parentage.

Seedling trees may be depended on to give fruit of good 
quality, but they do not produce fruit true to the variety from which the seed was obtained, and they may not be prolific, or the fruit may be undersized or undesirable for some other reason. Generally, however, the fruit is good, so far as its eating quality is concerned. This cannot be said for the fruit of seedling trees of most other kinds-seedling plums, apples, or pears may be quite unfit to eat. This is rarely true of the orange or pomelo. The real reason lies in the fact that large numbers of citrus seedlings are produced from embryonic buds from the mother parent.

On the other hand, the advantages of budded trees are many: They bear at an earlier age. A crop of fruit of uniform size and quality can be secured. Varieties ripening at different seasons may be planted and a continual crop from September to June, or later, may thus be maintained. The grower, besides having his selection of varieties, has a choice of stocks, and better results can be obtained on different soils than would otherwise be the case. In addition, maldi-goma, that one-time dreaded enemy of the sweet orange and lemon, and other root and trunk diseases may be avoided by using resistant stocks.

\section{CITRUS SEEDS USED IN PROPAGATION}

There is considerable difference in the size and shape of the kinds of citrus seeds commonly used in growing stocks. Every propagator should be acquainted with them, in order that substitutions may be avoided. The seeds of the pomelo, trifoliate orange, sweet orange, rough lemon, and sour orange are shown in Fig. 98, and these illustrations, with the accompanying descriptions, will be useful.

Pomelo.-Plano-convex or wedge-shaped, pointed or broad and flat at the micropylar end; $\frac{11}{16}$ inch long by $1 / 2$ inch wide by $\frac{3}{16}$ inch thick, $5 / 8$ inch long by $\frac{7}{16}$ inch wide by $1 / 4$ inch thick; smooth on two sides over considerable areas, marked with anastomosing lines or ridges on the other parts.

Trifoliate orange.-Ovoid, pointed or rounded, sometimes planoconvex, smooth or when somewhat dry the outer integument contracts, 


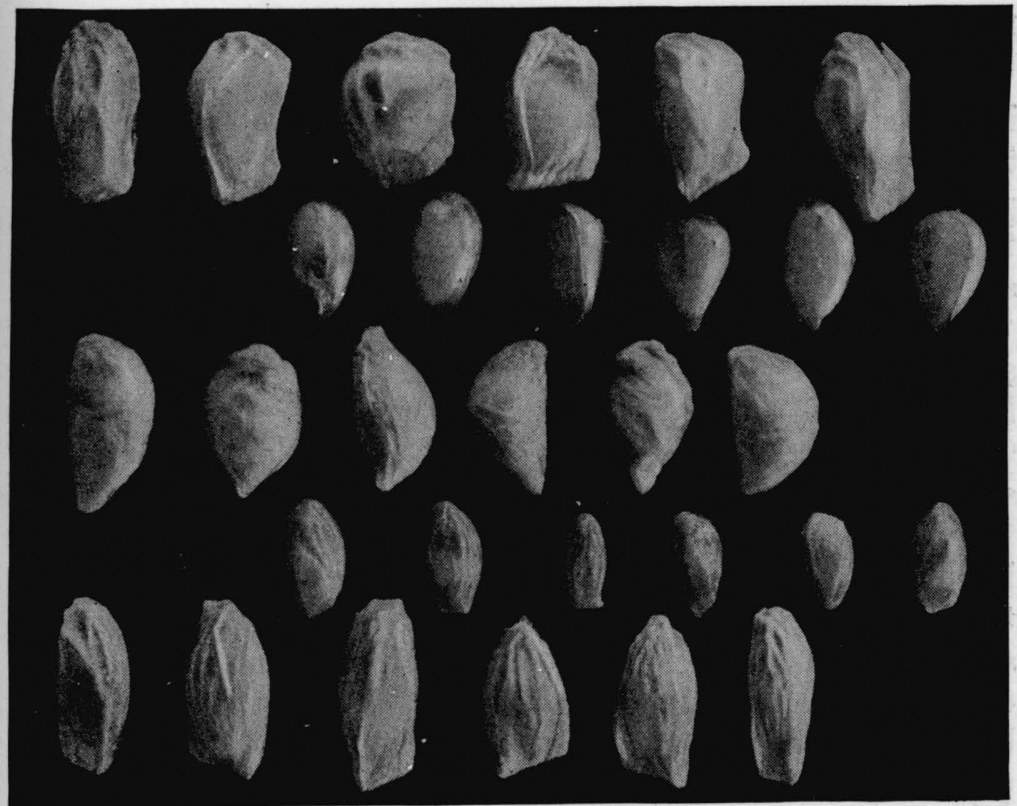

Fig. 98. Seeds of citrus used as stocks. From top to bottom, six seeds each of pomelo, trifoliate orange, sweet orange, rough lemon, and sour orange (enlarged $1 / 5$ )

giving a wrinkled appearance; $1 / 2$ inch long by $1 / 4$ inch wide by $1 / 8$ inch thick; usually quite uniform in size and shape; embryo 1, cotyledons 2. The others contain 1 or more embryos and 2 or more cotyledons.

Sweet orange.-Oblong-ovoid, plano-convex or roundish and plump, sometimes very slightly beaked; $\frac{9}{16}$ inch long by $\frac{5}{16}$ inch wide by $1 / 4$ inch thick, $1 / 2$ inch long by $\frac{5}{16}$ inch wide by $1 / 4$ inch thick, or larger; lines not prominent, generally oblique in direction, with one or two areas smooth.

Rough lemon.-Ovoid or slightly tapering; small, $3 / 8$ inch long by $1 / 4$ inch wide by $\frac{3}{16}$ inch thick, $1^{\frac{7}{6}}$ inch long by $\frac{3}{16}$ inch wide by $\frac{3}{16}$ inch thick; frequently marked with a prominent ridge along one edge, other lines small, rather inconspicuous, anastomosing.

Sour orange.-Plano-convex or double-convex, pointed or flattened and wedged toward the micropylar end, long and narrow or slightly rounded; $\frac{11}{16}$ inch long by $\frac{5}{16}$ inch wide by $\frac{3}{16}$ inch thick, $\frac{9}{16}$ inch long by $1 / 4$ inch wide by $\frac{3}{16}$ inch thick. When plano-convex, there is a large smooth area on the flattened side, the rounded side being ridged with long more or less parallel ridges which unite at the ends. 
Extracting and handling citrus seeds.

The production of well-developed vigorous-growing stocks is of great importance, and careful attention should be given to the quality and vigor of all seeds used. They should be procured from strong-growing healthy trees, and after being taken from the fruit all immature or poorly developed seeds should be discarded.

To give some idea of the number of fruits and pounds of seeds necessary to secure a given number of seedlings, it may be estimated roughly that a sour orange fruit will contain 20 seeds; a pomelo or grapefruit, 55 seeds; a Florida sweet seedling orange, 18 seeds; a rough lemon, 20 seeds; and a trifoliate orange, 25 seeds. The number of seeds present is influenced by pollination and other conditions under which the fruit was produced. A quart contains 2,100 sour orange seeds, or 1,400 pomelo seeds, or 2,000 sweet orange seeds, or 6,500 rough lemon seeds, or 2,600 trifoliate orange seeds. A bushel of citrus seeds weighs about thirty-two pounds, depending on the amount of moisture present. Poncirus trifoliata seed is heavier than any of the others and weighs about forty pounds to a measured bushel.

In estimating the seeds required for a certain number of stocks, it is best to plant twice as many seeds as stocks needed. To permit selection of only the best and most vigorous seedlings, this number should be greatly increased. In fact, if three or four times the number of seeds required for stocks is planted, it will make it possible to grade out the finest seedlings and greatly increase the quality of the nursery trees grown.

Seeds may be separated from the fruit by cutting it in halves and squeezing them out into a sieve. This will allow the juice to run through and the seeds may be washed free from the pulp afterward. Another method is to place the fruit in barrels and allow it to rot, after which the seed is washed free from the pulpy mass with running water, using a sieve as before. If care is exercised in using running water, 
most of the poorly developed seeds may be separated and floated away, as they rise to the top while the good heavy seeds sink to the bottom.

If citrus seeds are allowed to become too dry, the cotyledons separate, and they will not germinate, so unless they are to be planted immediately, they should be stratified in damp sand or earth. The former, washed free from all impurities, is preferable, as organic substances in the soil may contain decay-producing organisms. These sometimes attack the seed.

If the seeds are to be kept or stored for any considerable time, the best plan is to dry them off quickly after extracting and washing; then mix the seed with an equal bulk of finely ground charcoal and store in tight wooden boxes or tin cans. It is well to examine them from time to time and determine their condition by cutting some of them in two with a knife. When properly handled by this method, seeds have been kept in good condition for several months.

\section{THE SEED-BED AND ITS MANAGEMENT}

If only a small number of seedlings is desired, they may be raised in boxes or flats. These should be six to eight inches deep and of any convenient width and length. They should be filled with good virgin soil. The seeds may be sown rather thickly, in rows three inches apart, and when six to eight inches high may be transplanted to the nursery row.

When a large number of seedlings is required, a seed-bed must be provided. It should be located a distance from citrus orchards or old citrus trees, thus reducing the danger of infestation by scale and other insects. A good piece of citrus earth should be selected, either naturally moist enough to insure proper germination of the seed, or made and kept so by irrigating. If deficient in plant-food, it may be enriched by the addition of commercial fertilizer such as is recommended for young trees. This should be applied to the bed and worked into the soil two to three weeks before 
planting the seed, for it is unsafe to apply commercial fertilizer and then plant the seed immediately afterward. The length of time which should elapse between the two operations will depend on the amount of moisture in the soil and the quantity of fertilizer applied. If very dry weather follows the application of fertilizer, a longer time must be allowed to intervene than if there is plenty of rain, unless the land is irrigated.

Sour orange, sweet orange, pomelo, and rough lemon seeds should not be planted until there is no danger of the young seedlings being injured by frost, for if they are frozen they are killed outright. Usually, under favorable conditions four to five weeks may be allowed for the seedlings to get above the ground. Generally the seed may be planted in northern Florida about March 1, or perhaps a week or two earlier. Poncirus trifoliata seed, on the contrary, may be sown in late September or in October, as soon as the fruit is ripe and seed fully matured. If it comes up and is frozen

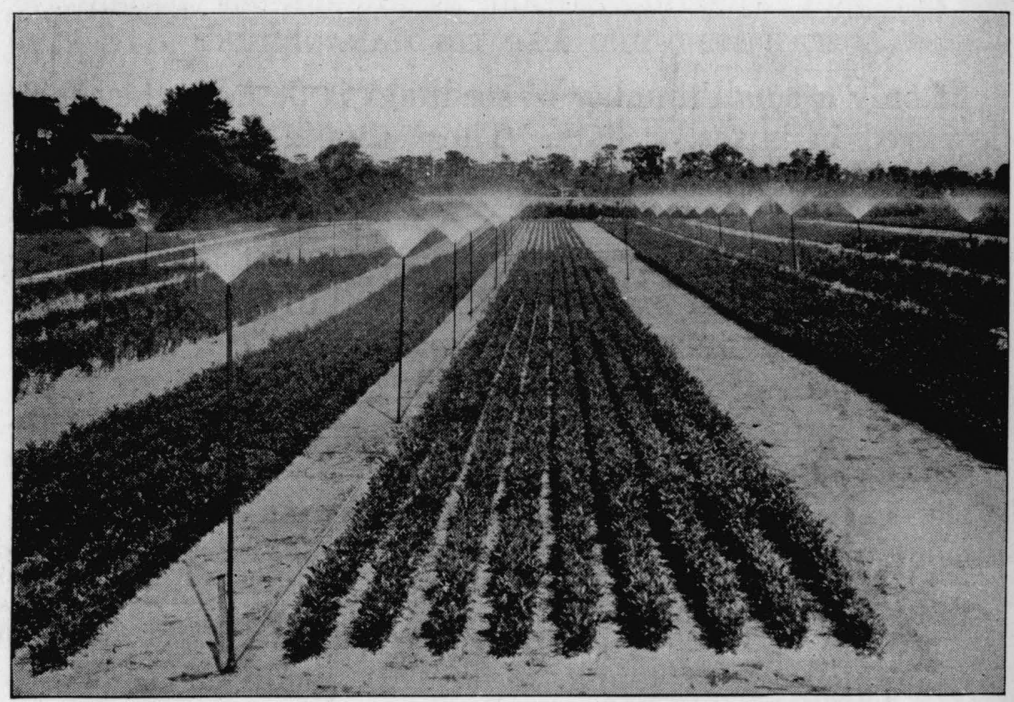

FIG. 99. Citrus seed-bed grown in the open. Irrigated by sprinkling 
above ground, it does not matter; the plantlets are not destroyed and new tops are produced from buds on the tiny stems below ground. The best practice, therefore, is to plant this seed as early in fall as it is ready.

If a comparatively small number of seedlings is required, the rows may be placed close together, but when raised by the thousands hand-labor is too expensive. Cultivating must then be done with a horse or mule, and the space between the rows should be sufficiently great to admit of this - about two and a half to three feet. The seed should be planted thickly, at a depth of three-fourths to one inch, and the ground should be moist at the time of planting, to secure the best results.

The ground should be cultivated thoroughly and frequently throughout the season, and weeds should not be allowed to spring up. In many sections, two or three additional applications of a commercial fertilizer rich in nitrogen should be made during the summer. Care must also be taken that the seedlings do not dry out, and to prevent this it may be necessary to irrigate, but frequent shallow cultivation to preserve an earth-mulch will help materially. Some resort to mulching to prevent the escape of moisture.

"Damping-off," a fungous disease, sometimes gives trouble when the seedlings are young, and the seed-bed should be watched carefully for its appearance. If it shows up, shallow cultivation should be given, to dry the surface of the soil, and a spray with bordeaux mixture. Prompt attention will usually prevent serious damage. Insects should not be allowed to gain access to the seed-bed, and if they do make their appearance, spray frequently and thoroughly. Where citrus scab, also a fungous disease, is prevalent, sour orange and rough lemon seed-beds should be sprayed from time to time with bordeaux mixture.

Some growers deem it necessary to shade the citrus seedbed or to grow the seedlings under a slat shed. About half shade is given, and this is usually secured by placing eight- 
foot posts in ten-foot squares. The height of eight feet gives ample head-room. The tops of the posts are joined with two by four-inch pieces, and slats, usually one by three inches, spaced three inches apart, are nailed, north and south, on these. A more rapid growth of seedlings is thus secured, and they are protected from hot winds, drifting soil or sand, and the full rays of the sun, particularly at that critical time when they are in the "crook" i.e., just coming through the soil. The slat covering also affords some protection against frost.

The shaded seed-bed, however, has its drawbacks. The same piece of land cannot be used for growing many successive crops of seedlings. In fact, in many citrus districts it is not safe to use it more than once. The soil becomes infested with damping-off fungi which in the half shade and moist conditions of the slat shed are almost impossible to control.

The better plan is to provide ample irrigation and grow the seedling in the open, i.e., without shade, and sow the seed late enough to escape frost injury. In Florida, experience has shown that in this way excellent seed-beds may be grown on the same soil for many years, and, if careful attention is given to irrigation when the seedlings are coming through the ground, there is no danger of having the crooked stems injured by sun and wind. It has been found best to water by sprinkling and to keep the soil and plants reasonably moist at and immediately following the germination of the seed. In northern Florida, Poncirus trifoliata seed-beds are commonly grown without irrigation.

Usually the seedlings should be allowed to remain in the seed-bed until they have had one or two season's growth. They may be transplanted to the nursery rows when a quarter of an inch or so in diameter at the ground, but it is usually best to leave the seedlings in the bed until they have reached a good size. It is more expensive to bring them up to size in the nursery rows, and it is poor practice to bud 
them unless they are a half inch or over in diameter. The best time for transplanting is in winter, though the same general laws apply as in transplanting larger trees.

When the seed-bed is irrigated, it should be watered thoroughly just before taking up the seedlings. This will fill the plants with water and make it possible to remove them more easily. In digging the seedlings from the seed-bed the spade should be shoved down beside them to a depth of eight to ten inches to sever the tap-root and loosen the plants in the soil, when they may be lifted out readily. The stocks are bundled in bunches, the tops and roots trimmed back on a block with a hatchet, dipped in a disinfecting solution, packed in boxes with moss or sawdust well wet down, and taken to the nursery field for planting out. This pruning of the tap-root is necessary in securing a well-branched, welldeveloped root system.

\section{THE SEEDLING STOCK NURSERY AND ITS CARE}

The ground for the nursery should be selected carefully, a rather heavy subsoil and light mellow surface soil being the best. A good preparation for the nursery is to sow beggar-weed, velvet beans, or some other soil-improving cover-crop the year previous to planting, and in regular nursery work one of these legumes should always be planted after a block of trees is removed.

Seedlings may be transplanted from the seed-bed to the nursery in November and December. In Florida, seedlings are often planted in summer when rains occur and moisture conditions are satisfactory. In frosty regions, a furrow may be plowed against each side of the row to protect them from frost.

The ground should be cultivated thoroughly before transplanting, and commercial fertilizer applied in rather liberal quantities. One application should be given when the seedlings are set out, a second in June, and a third in August, three to five hundred pounds to the acre at each time. The 
rows should be laid off carefully, perfectly straight, three and a half to four feet apart. This will give plenty of room for cultivation and for the work of budding.

The seedlings should be set in the rows from twelve to fifteen inches apart. When set four feet by one foot, 10,890 seedlings are required for an acre, and at four feet by fifteen

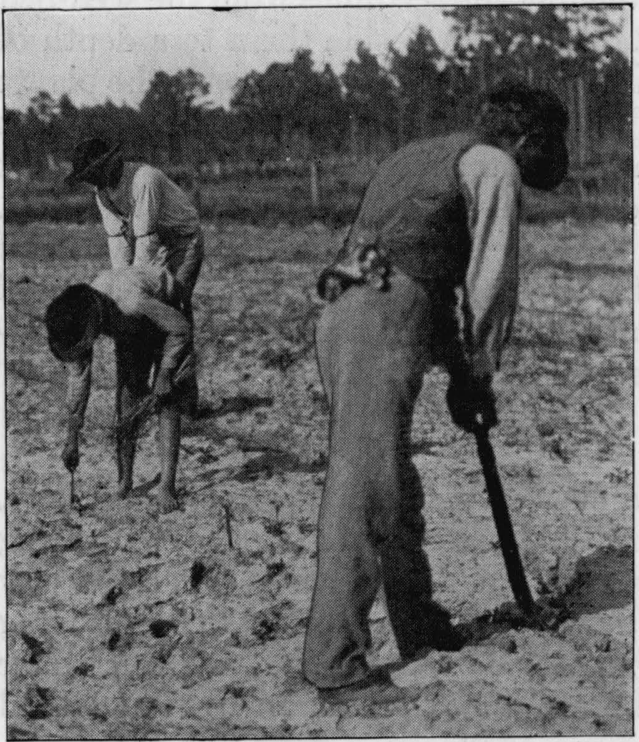

FIg. 100. Planting citrus seedlings in nursery. The man in the foreground is making openings with a spade, while the boy is planting the seedlings. inches, 8,712. As it is necessary to leave passages or roadways through the nursery at frequent intervals, and this is done by omitting a row of seedlings where desired, it is usually estimated that 10,000 and 8,000 seedlings respectively are required to the acre when set at these two distances. If the soil is dry at the time of transplanting, water should be applied. The trees should be firmly placed in the soil, with the earth compacted about them. At time of transplanting, the well-developed vigorous seedlings should be set out together; the smaller ones by themselves, or, better still, discarded entirely. The rows should be laid off with a line stretched across the field, and along this a wheel-marker should be run to space the plants evenly. A nursery spade can be used to make an opening for each seedling, and as it is placed in position, the soil should be packed against it with the foot. (Fig. 100.) Thorough clean culti- 
vation should be the rule. Every effort should be made to keep the little trees growing throughout the season, but cultivation must cease in time to allow the wood to harden up before cold weather. From one to two years after transplanting, the seedlings will be ready for budding, and by this time they should be one-half inch or over in diameter at the crown.

Since the scab fungus attacks sour orange seedlings severely in many regions, and interferes materially with their growth and development, it is good practice to spray them with bordeaux mixture in nursery as well as in the seed-bed. The disease can be kept down by its use, and, as a result, a much better growth will be made during the season.

\section{CUTTINGS}

Many varieties of citrus trees may be propagated from cuttings, and it is possible that the cutting method may have value in the future as a means of propagating stocks of uniform character. The Otaheite orange, used as an ornamental and as a stock for dwarfing large-growing citrus trees, is usually propagated in this way. The citron roots easily, as does also its near relative, the lemon. (Fig. 101.) For these trees, propagation by cuttings seems to give good results. Cuttings of the pomelo and orange are more difficult to root, and, though it may be accomplished, the method for these trees has little to recommend it and is not practicable. Many of the Poncirus trifoliata hybrids can be grown successfully by cuttings.

Cuttings should be made from wellmatured wood of one or two season's growth. Each cutting should have at least three or four well-matured buds and should be about five inches long. Trim off the leaves at the

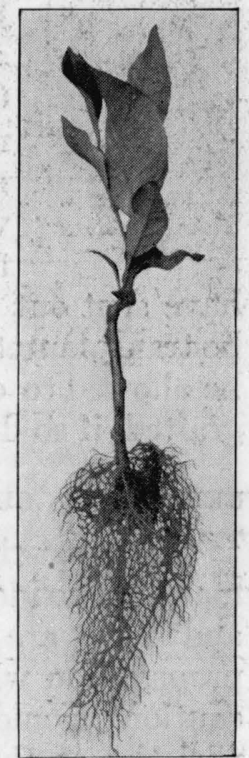

FIG. 101

Rooted citrus cutting 
lower end and cut off about one-half of each leaf-blade of the three or four remaining at the upper end; cut the distal end with a smooth sloping cut just above a bud and cut the proximal end so as to leave a similar surface just below a bud.

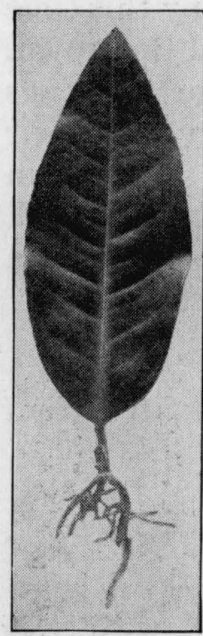

Fig. 102

Rooted lemon leaf

The knife should have a keen sharp edge to insure smoothness of the cut surfaces, as a clean smooth cut greatly facilitates the formation of a callus, which must take place before roots will develop.

Though the cuttings may be rooted in almost any well-drained soil, it is better to plant them in clean washed sand, free from organic substances. Organic matter nearly always contains the organisms of decay, and these may attack the cuttings and cause them to rot. Place the cuttings in rows two to three inches apart and one to two inches apart in the rows. Give sufficient water to keep the cutting-bed moist, and protect it from the direct rays of the sun. If bottom heat can be applied, they will take root more readily. When the cuttings have formed a number of roots, and have sent out shoots bearing two or three leaves, they may be transplanted to two- or three-inch pots. The cuttings may be allowed to develop into trees or they may be budded or grafted, if so desired, after they have attained sufficient size.

SELECTING, CUTTING, AND KEEPING BUDWOOD AND CIONS

The most rigid care should be exercised that no mistake is made in the identity of the tree or trees from which budwood and cions are to be cut. At all places in the process of propagation where it is possible for errors to occur, no precaution should be neglected to guard against mixing of varieties or the accidental substitution of one for another. Careful labeling of varieties, the providing of plantation maps, the employment of capable conscientious men, and 
attention to all details of the work on the part of overseers will, in large establishments, help in preventing the occurrence of mistakes and the consequent origination of supposedly new varieties or the mixing of old ones.

Both budwood and cions should be chosen from well-matured wood of not more than one season's growth. Usually it is best to select from wood of the last one or twogrowths matured just previous to the time of cutting, bearing in mind always that citrus trees generally mature three or more distinct growths each season. In cases in which the variety is especially valuable, almost any bud, small, immature or growing, may be made to grow, but for general propagation work such are not desirable. For ordinary shield-budding, round wood is preferable, and to secure this the older wood must generally be used. All the very new growth is more or less angular; it becomes round only as it grows older. For shield-budding with a right-angled or curved incision, angled wood must be chosen, while for graft cions, either will do, provided it is satisfactory in other respects. No wood should be taken from diseased or unthrifty trees; the parent

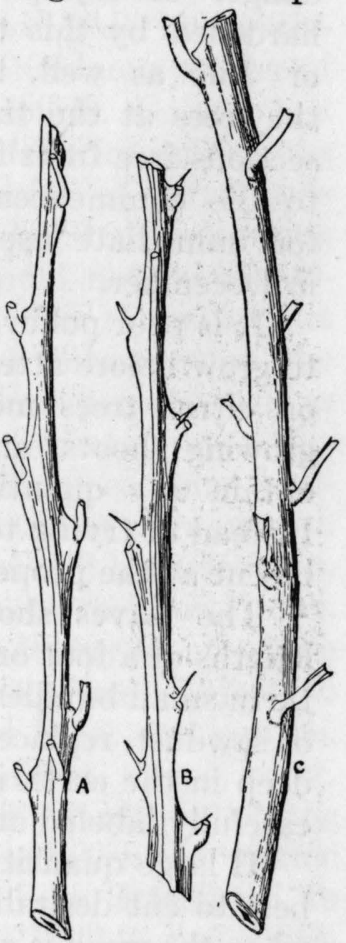

Fig. 103. Citrus budsticks. A, slightly angled; $\mathrm{B}$, too angled for good work; C, round wood. should be healthy and vigorous. Thorny wood should be avoided whenever possible. Thorns are very undesirable on citrus trees, and every effort should be made to eliminate them. Rigid selection, throughout a number of bud generations, of buds or cions from thornless shoots borne on those trees producing the fewest thorns may help in some measure to bring about the desired change in most varieties. 
For work in early spring, the bud-sticks or grafts should be cut from the trees the previous December, if there is danger of injury from frost. The wood is thoroughly hardened by this time and may be kept for use in June or July as well, though material may be secured from the trees at the time of June and dormant-budding. In sections free from frost, the wood may be cut just previous to the commencement of growth in spring, if required for immediate use, but the better plan is to cut the wood in December.

It is poor policy to wait until after the trees have started to grow before attempting to secure budwood and cions, for on citrus trees most of the desirable buds develop into growing shoots, and many of these must be sacrificed to obtain any quantity of wood, and that is very inferior. Instead of trying to secure material out of season, it should be cut at the proper time.

The leaves should be removed and the wood cut in lengths of a foot or so. If only a small quantity is required, tie in small bundles, pack them in a box, in moist sphagnum or sawdust, replace the cover, and bury it six to eight inches deep in the earth in a shady place. The bundles should be carefully labeled and the moss should not be too damp.

If large quantities of budwood are needed in spring, it is best to cut desirable twigs or branches, in suitable lengths, when the wood is well matured, remove the foliage, and pack in large paper-lined boxes in cypress or redwood shingle tow or dust. Place a three- to four-inch layer of damp tow in the bottom of the box, spread out on it a layer of bud-sticks, then fill in a layer of shingle tow, another layer of budwood, and so on until the box is filled. Care must be taken to have the proper amount of moisture in the shingle tow, but no water should run out when it is tightly pressed. The box, or boxes, should be examined from time to time by emptying the contents and repacking. Handled in this way, wellmatured budwood may be kept for months. 


\section{Bud-variations.}

Early citrus writers have noted that buds or grafts taken from certain varieties did not produce trees true to type, and that distinct horticultural varieties arose from bud-variations. Some kinds described in the voluminous works of European writers originated as bud-sports. Gallesio, ${ }^{1}$ a keen observer who exploded numerous fallacies and myths connected with the culture and propagation of citrus, calls attention to very variable kinds best propagated by layering because their peculiar characteristics could not be perpetuated with certainty from a single bud. For the most part those variations which were unusual or bizarre were the ones that attracted attention and were perpetuated as curiosities by citrus propagators of that period.

During the last ten years, investigations covering budvariations in the principal commercial sorts of citrus grown in California, conducted by A. D. Shamel and his associates, have attracted attention in citrus districts the world over. It has been pointed out in California that any or all of the apparent external characters of the tree are subject to variation, and that bud-variations have been, and can be, perpetuated by budding. Differences in size, shape, color, seediness, juiciness, quality, and other characters of the fruit, the habit and growth of the tree, and even the volume and market value of the crop, have been attributed to "sports" or bud-variations.

The conclusions reached in these studies have been questioned by a number of the leading horticulturists of the United States. Serious doubts have been expressed concerning increases in yield from bud-selection, the fixed character of the variations noted, the general deductions, and the broad application of the principles involved. In fairness to both sides of the controversy, it will probably take many years more of experimentation to reach definite basic conclusions on all questions involved.

${ }^{1}$ Traité du Citrus. 1813. 
There can be no question that bud-sports do occur in citrus. By way of example, reference may be made to the color variations, Foster and the two forms of Marsh pomelos which originated in this way. Fruits of the citrus group are very much mixed and of complex origin. This may be the underlying cause of the instability of certain kinds, but what actually causes them to sport is unknown. The answer to the question requires a deeper insight into life functions, life activities, and what life itself is than is possessed at present.

Of greater importance, however, is the frequency with which bud-variations occur and what it is that sets the complex activities of a potentially variable embryonic bud in motion. Perhaps the more artificial the conditions under which citrus fruits are grown, the more prone their buds are to vary. Conditions of soil, climate, and food-supply under which citrus fruits are grown in many districts are indeed very different from those in regions in which they are endemic. Apparently bud-sports are found more frequently in the southwestern than in the southeastern districts of the United States. In the Southeast they are of extremely infrequent occurrence, while in the Southwest they are fairly frequent. This may be due to the influence of environment and it may be in part conditioned on the strains or varieties grown. All kinds of citrus are not likely to produce budsports to the same extent.

Shamel's work has been of great value in emphasizing the need for care in cutting lbuds for citrus propagation. There has been great laxity in this particular and much confusion in the varieties of citrus has resulted. The separation of large numbers of varieties by their fruit characters alone is a problem in pomology that no citrus student has been able to handle with certainty. For this reason, if for no other, the most scrupulous care should be exercised in securing buds. They should be cut only from bearing trees of known origin, high yield and quality. In districts where 
bud-variations are more or less common, great care should be taken to avoid them unless they have value. This safe practice, coupled with rigid selection of stocks and good cultural methods, places the propagator of citrus trees on the safe side of every question concerning the quality of the product. Selected buds are often called "pedigreed buds," but there are no such things as pedigreed buds or trees in this sense and they should not be so designated.

All variations must not be attributed to bud-sports. Many variations in size and shape of fruit, thickness of peel, color, seediness, vigor, and yield, noticeable in whole trees, parts of trees, or single branches, may be brought about by differences in stocks, moisture, soil, food-supply, and many other imperfectly understood environmental factors. These cannot be perpetuated by selective propagation and are to be differentiated from variations due to sporting.

Some propagators have advanced the theory that buds cut from old bearing trees produce individuals that come into bearing at a younger age than when buds are taken from younger trees of the same variety which had not yet come into bearing. This theory has never been substantiated by experimental evidence and it may be safely stated that when the bearing function has once been established in a stable citrus, it is carried from one bud generation to another regardless of the age of the tree from which the buds are taken.

\section{MATERIALS AND TOOLS REQUIRED}

The materials and tools used in budding and grafting are neither numerous nor expensive. While considerable work may be done with a piece of twine and a knife, the following articles should be provided: Grafting-wax, pruning-knife, grafting-iron, shears, small mallet, and labels.

\section{Waxes and cloth.}

The following recipes for grafting-wax have been tried and found satisfactory for the citrus districts: 
(1) Resin, 6 pounds; beeswax, 2 pounds; linseed oil, 1 pint.

(2) Resin, 4 pounds; beeswax, 2 pounds; tallow, 1 pound.

The directions for preparing them are briefly as follows:

Break the resin into small pieces, cut up the beeswax, and place the two together in a suitable iron pot. Pour the linseed oil over them, or, in case recipe No. 2 is used, place the tallow on top. Set the pot over a slow fire and allow the materials to melt. Afterward remove from the fire, pour into cold water, grease the hands, and pull until it is light colored.

If a liquid wax is desired, take 1 pound of resin, 2 ounces of tallow, melt them together and mix thoroughly. Remove from the fire, cool slightly, and add slowly 6 ounces alcohol and 1 ounce spirits turpentine. Keep tightly corked in a wide-mouthed bottle. Apply with a brush.

To make waxed cloth, procure thin bleached muslin and saturate it with wax made according to the following recipe:

Resin, 1 pound; beeswax, 4 pounds; raw pine gum, 3 tablespoonfuls. The raw pine gum makes the cloth stay in place when wrapped around a budded stock. The use of proper wrapping cloth is a large item in the success of budding, for it helps to exclude air and moisture. Prepare the cloth by tearing into strips seven inches wide and winding it in fairly tight rolls not more than two inches thick, or the wax will not penetrate readily to the center. Melt the wax over a slow fire, place the rolls in it, and allow them to remain there until the wax has penetrated the cloth. (Fig. 104.) The wax should not be allowed to become too hot, else there is danger of burning the cloth. It is a safe plan to remove the pot containing the wax and rolls of cloth from the fire, or draw the fire from beneath it and allow the mixture to cool somewhat. Have it just hot enough to keep the wax in a melted condition. As soon as it is saturated, which will take from an hour and a quarter to an hour and a half for two-inch rolls, remove the cloth from the wax and 


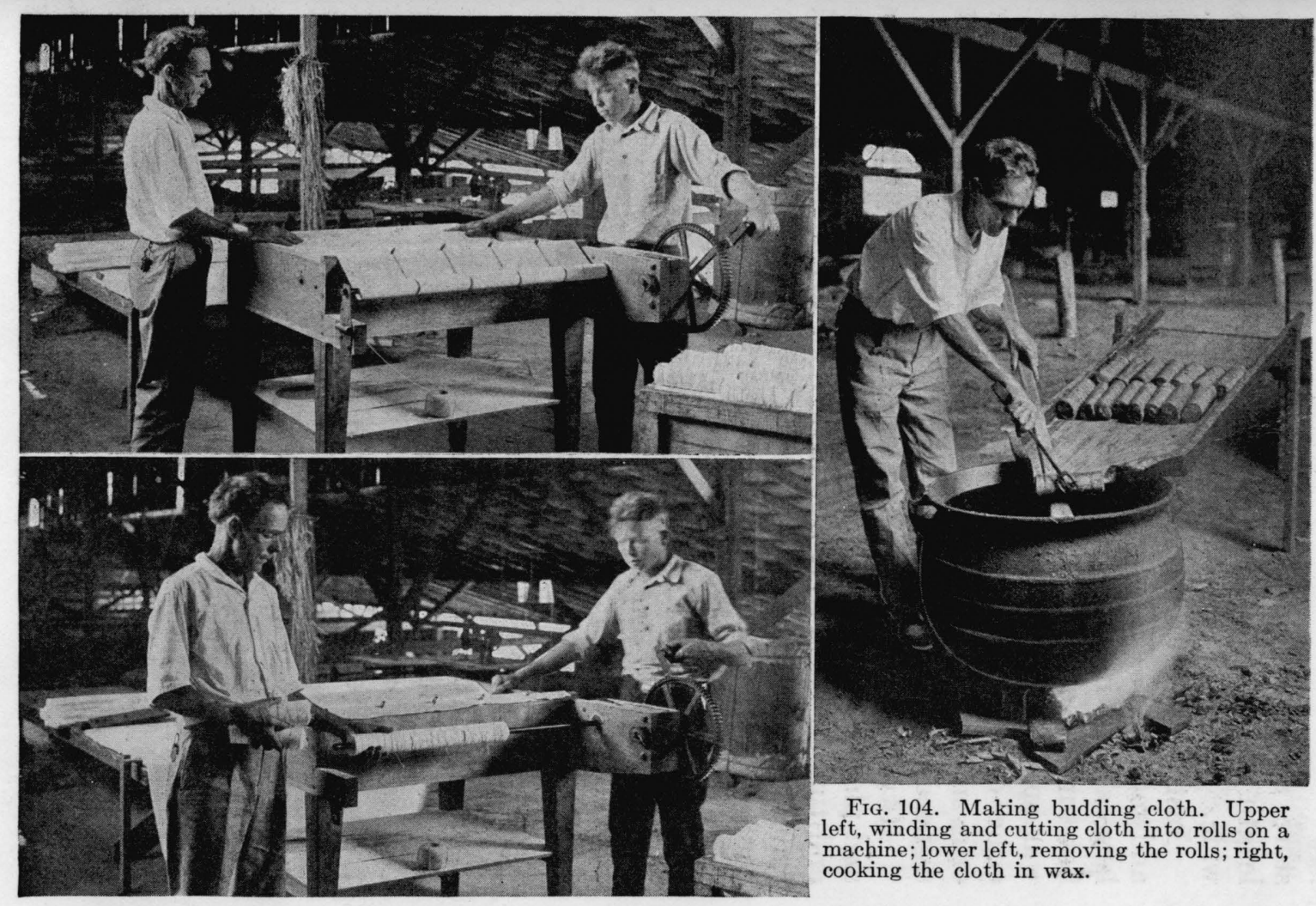


store away. When required for use, unroll the desired length and tear it into strips one-half to three-fourths inch wide.

Instead of tearing the cloth into strips seven inches wide, and making it into rolls, it may be dipped into the wax in large sheets, immediately removed and stretched out on a flat surface; or the cloth may be stretched out and the hot wax applied to its surface with a brush. When prepared by either of these methods, it may be carried to the field in rolls or in small rectangular sheets, from which strips may be torn as needed.

If twine is desired, procure balls of No. 18 knitting cotton and place them in the melted wax, keeping them immersed and turning them over frequently. In the course of five to six minutes, the wax will have penetrated through and through, when they may be removed and set aside. Untreated cloth or twine or raffia may be used instead of the waxed material, but while it possesses sufficient strength, it is more easily broken. It is not necessary to tie the waxed cloth about the stock; it may be drawn tight, whereupon the sticky waxy surface will hold it in place.

Tools.

Good grafting and pruning-knives may be procured from almost any hardware merchant or from dealers in horticultural implements and supplies. The budding-knife should have a thin blade, rounded at the point. A piece of thin bone is inserted in the end of the handle, or the handle itself is thinned down at the end to serve as a spatula. This is intended to be used for lifting the edges of the bark in budding, as explained in the section on Budding, but, as a matter of fact it seldom is, the point of the knife-blade being employed instead.

The best pruning-knives are those with a heavy staghorn handle and straight or somewhat curved blades. These knives are used in propagation work to smooth the cut 
surface of the stock, for splitting the stock, and for removing small branches and thorns which may be in the way of the operator. For the latter purpose, the pruning-shears may also be utilized. (Fig. 105.)

The best shears are the solid steel ones. They are strong and durable; the blades are easily tightened and can be taken apart for sharpening when so desired. Nothing is more unsatisfactory than to work with a poor pair of shears and the best should be secured. See Chapter on Pruning Citrus Trees.

In cleft-grafting, the grafting-iron and mallet come into use. An iron with a concave blade is best. For nursery work, labels made of inch material, two and one-half inches wide and two and a half to three feet long should be provided. These are to be used as labels for rows of varieties, the name being stamped plainly on the upper portion. For block labels, nothing surpasses cypress posts three to four inches in diameter. These are sloped off at the top, leaving a broad

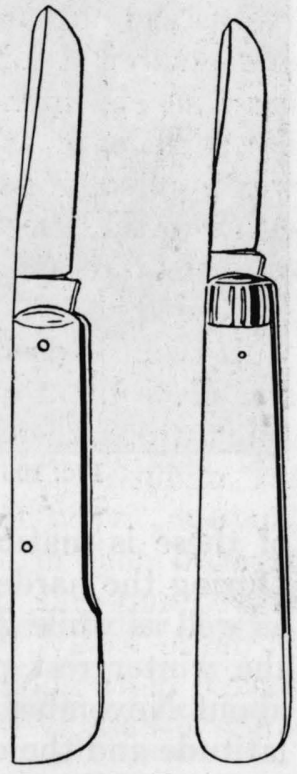

Fig. 105. Two types of budding-knives smooth surface three to four inches long by as much in width. This area is then painted white and the block number placed on it. Wired, wooden or paper tree labels should also be provided.

Time.

\section{BUDDING}

In all citrus-growing districts, nursery trees are propagated almost entirely by budding. Buds may be inserted in stocks any time during the growing period, for the trees are not periodic in their growth as are apples and plums. When well cultivated and fertilized, the stocks will make at least three growths during the spring and summer, and each one 


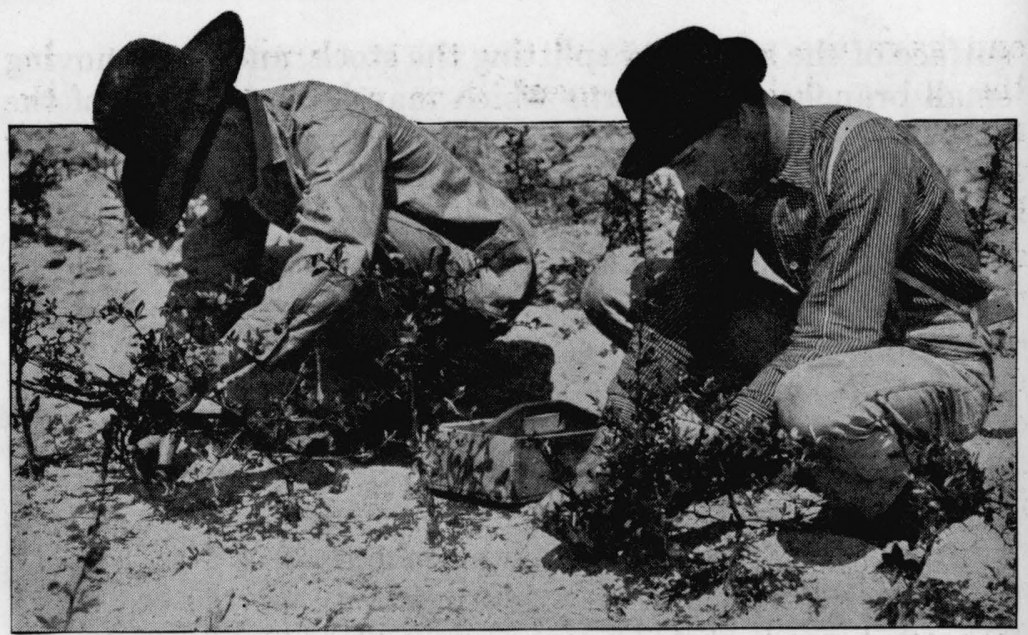

Fig. 106. Budder and tier at work in a nursery row

of these is matured and hardened before the next begins. During the hardening or rest period, the bark does not slip as well as while growth is going on. In most citrus districts the winter rest period, partial or otherwise, extends from about November to February, depending, of course, on the latitude and the climatic conditions throughout the winter.

During this period, buds cannot be inserted to advantage as there is not sufficient sap moving to cause the bark to slip readily. In all American citrus districts, buds may be inserted in March and April. In the Islands, where the winter temperatures are not so low and the winter rest period is of shorter duration, the buds may be inserted much earlier. Budding early in the season is termed spring budding. In June or July, or just before the beginning of the rainy season in Florida, budding may be performed. This is summer budding. Generally, considerable budding is done during September and October, dormant budding. In this case the buds remain dormant until the following spring, when they commence to grow. In nursery practice, dormant budding is given preference, as the buds start early in spring 
and have the advantage of the entire growing season. In the colder districts, dormant buds are protected in the nursery rows during winter by plowing a furrow against them. The tops of the stocks may be frozen back, but no harm results. It merely takes the place of pruning and starts the buds growing soon after the furrow is removed, which should be done during the latter part of March or somewhat earlier. Summer budding is not to be recommended for all sections. In frostless regions, no objection can be urged against the practice, but in sections subject to frost, the growth resulting from buds inserted at this time is often not sufficiently matured to withstand the frosts of early fall and winter. Of course, the point of union with the stock may be covered with earth, as mentioned above, but even then if the growth is soft and succulent, it may be stunted or killed outright.

\section{Methods of budding.}

As soon as the stocks have attained sufficient size, buds may be inserted in them. Occasionally, stocks grown from seed planted in spring may be dormant-budded the following autumn, or they may be spring-budded when one year old, or worked in June or the following September. These are exceptions, however, and usually the stocks are budded when two to three years old. There is no age limit beyond which buds cannot be inserted by some method, provided the stocks are of sufficient size and the bark will slip readily.

One other matter must be considered before taking up the actual discussion of methods, that is, the distance above the ground at which the bud should be inserted. It should be borne in mind that the point of union between the stock and cion is more subject to the effects of cold than any other part of the trunk of a budded tree. Also, if all that part which has developed from the cion perishes in cold weather, rebudding is necessary. This might be prevented by budding well down toward the crown roots, that the earth might afford 
protection or that it might be banked more easily against the point of union during the dangerous season.

On the other hand, on many soils, if the point of union is placed too close to the ground, one would be running the risk of having sweet, mandarin, or lemon trunks attacked by mal-di-goma, or foot-rot, even when worked upon sour orange or other resistant stocks. They are just as liable to attack as though they were seedling varieties of the groups just mentioned. To avoid this, the point of union should be some distance above the ground. In lemon districts, where irrigation, either by furrow or basin methods, is resorted to, as in California, the point of union between stock and cion should be a sufficient distance above the ground to protect the lemon trunk from the moisture provided by irrigation. Likewise, for those regions where gum-disease attacks the trunks of trees, usually near the ground, it is good practice to insert the buds in the stocks well above the ground-level. Unless this is done, the trunks may become diseased. Therefore, a knowledge of the conditions must determine the point at which it would be best to insert the buds.

The commonest method of budding and the one used

+ entirely in nursery work, is shield- or T-budding. In California, the method properly known by this name is practiced, while in Florida and the Gulf States generally the reversed method or inverted T incision is used. The best practice in the Islands is to follow the Florida and Louisiana method. The reason usually assigned for the adoptions of the reversed method is that it excludes water from the cuts, but if waxed cloth is used this explanation has little force. Baltet says that it is employed to avoid the smothering of the bud by the superabundance of sap. This holds good for summer conditions, but is scarcely applicable to autumn or dormant budding. It is, perhaps, true that the reversed method is commonly used as a matter of custom. At any rate, as good results may be secured by one method as by the other.

Figures 107 and 108 show the different steps in the process 


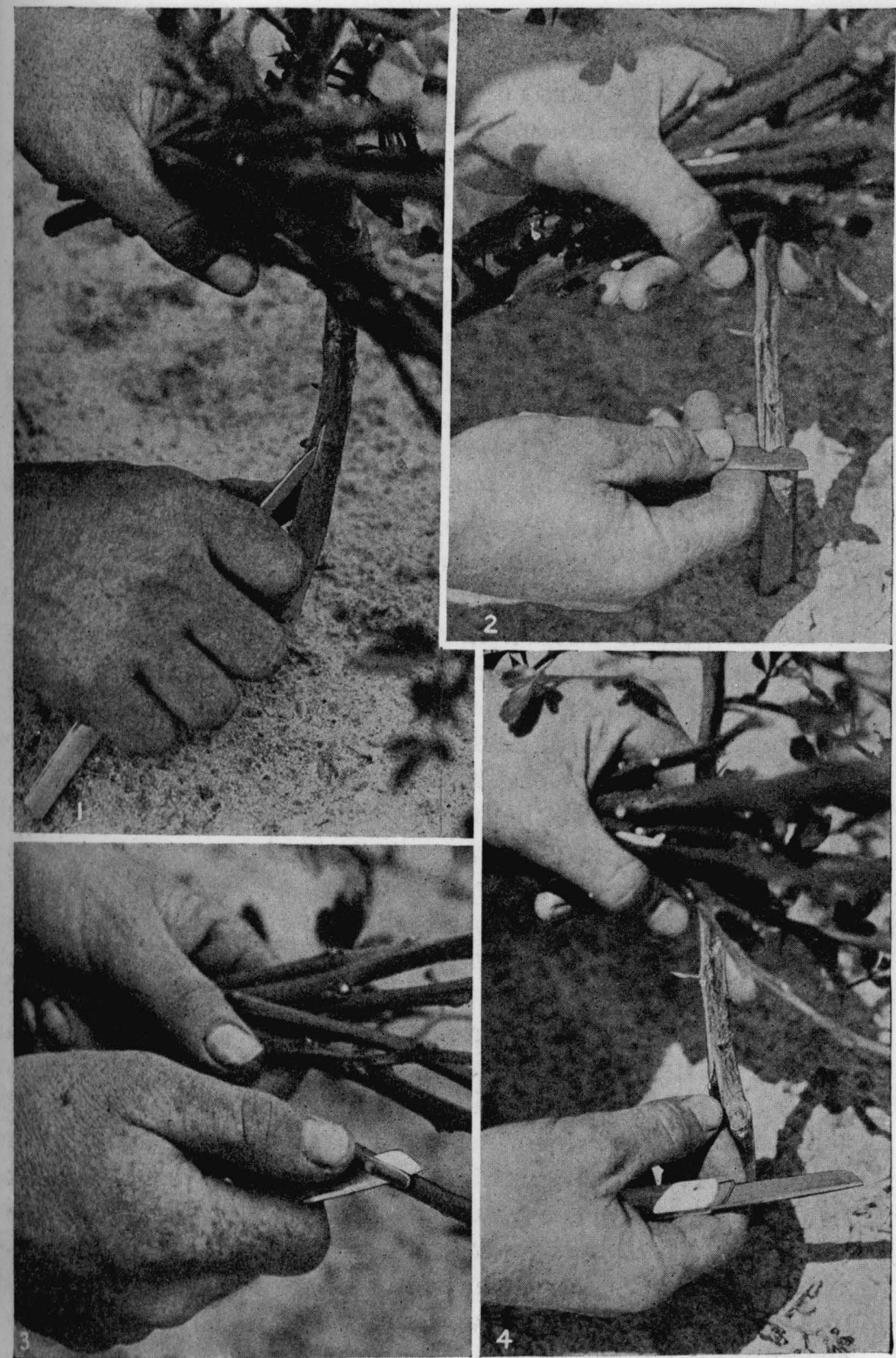

FIG. 107. Budding citrus trees: 1, the downward slit; 2, the cross cut; 3 , cutting a bud; 4 , inserting the bud.

(183) 
of shield-budding citrus trees in Florida. In nursery practice it is best to have stocks prepaied for budding several weeks in advance by removing all thorns, branches, and leaves below, up to and slightly above the point where the buds are to be inserted. When this is done ahead of budding, it saves time and the cut surfaces will have healed over on ordinary-sized stocks. Select the point at which the bud is to be inserted and remove all thorns or branches which may interfere with the work, if this has not already been done. Then a perpendicular slit an inch and a half in length is made on the side of the stock (1) and at its lower end a cross cut with the cutting edge of the blade slanting upward (2). A cut of this kind is preferable, as it makes it easier to insert the bud. Then the corners formed by the intersection of the two cuts are carefully lifted with the point of the knifeblade to permit the entrance of the bud. The bud-stick is grasped in one hand with its proximal end away from the operator. To remove the bud, start the knife in about onehalf inch below it and pass it smoothly along beneath it and finish the cut about one-half inch above the bud (3). The cut is best made from below the bud upward, as there is less likelihood of injury by the upward pressure of the knife against it. After having removed the bud, it is held lightly between the thumb and forefinger and shoved upward in the incision made for its reception (4). Do not invert it in inserting. Generally each bud bears beneath it a leaf-stalk or the scar left where it has dropped or been cut off. When the bud is inserted, this scar should be nearest the ground. Then the wrapping, a strip of waxed cloth, is placed about the stock over the inserted bud to hold the latter snugly in place and closely in contact with the cambium of the stock (6). In all cases the wrapping should be drawn over the intersecting cuts first, and then worked upward in the reversed method or downward in the ordinary one, as followed in California. The men work in pairs, each budder being accompanied by a tier who wraps the buds. A good day's 


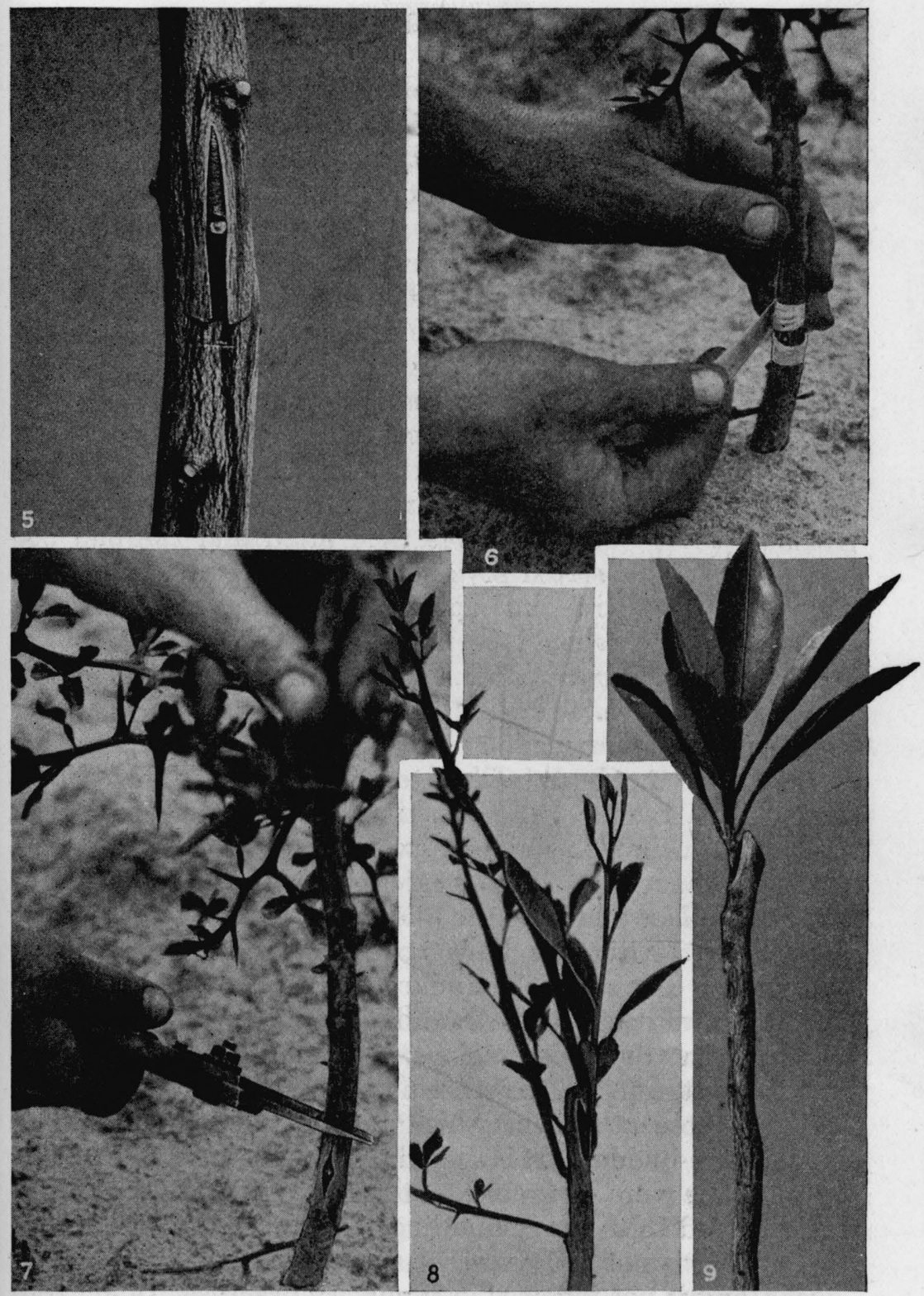

FIG. 108. Budding citrus trees: 5 , the bud inserted; 6 , wrapping a bud; 7 , cutting off the stock top; 8 , bud and sprouts all growing; 9, sprouts trimmed off and bud growing. 
work for a budder and tier is about 1,500 buds, of which more than ninety-five per cent should grow.

Sometimes it is very difficult to secure anything except angled budwood. If a bud is cut from such wood by holding the knife directly under the bud, it is cut off with a shield so narrow as to be undesirable. In such cases the bud should be cut from the side, removing a shield-shaped piece of bark as before, but with the bud at one side of it instead of in the center. Then instead of making an inverted $\mathrm{T}$ incision for

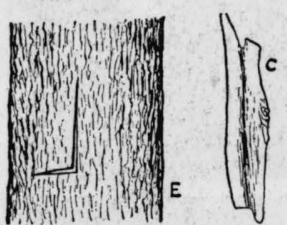

Fig. 109. Right-angled budding its reception, a right-angled incision should be made (Fig. 109) with the lower cut either to the right or left to suit the bud. The angle of the bark at the intersection of the cuts is then lifted and the bud inserted so as to have the bud in position in the upright incision. This method should be known as shield-budding with a right-angled incision. After inserting, the bud is wrapped as directed above.

An examination made ten days or two weeks after the insertion of the buds will determine whether they have united with the stocks. If at that time the buds are still green and a grayish line of new tissue is seen around the edges of the incisions, it may safely be concluded that union has taken place and that the bud will grow, provided it is a perfect one. After the buds are well united, remove the wrappings. The stock should be either lopped, pruned back, or cut entirely off if the budding was done in spring or summer. In the colder regions, if the buds have been inserted in autumn the stocks are not cut off until the following spring. Those stocks in which buds have failed to take should be re-budded. It is a good plan to mark the dead buds by tying the wrap just removed to the top of the stock. This helps to find them for re-budding.

Lopping is not always necessary, particularly with small stocks, and is not followed as a nursery practice. In general 
nursery procedure, the stocks are cut entirely off. However, lopping is the safest plan to follow with stock of large size, and particularly with such vigorous growers as pomelo and rough lemon.

To lop the stocks, cut in with the saw or pruning-shears on the side containing the bud, making the cut about two inches above the bud, and passing about two-thirds through the stock. Then bend the top over, being careful, if it splits, that the line of cleavage runs upward toward the top, not downward toward the root. In lopping trees recently budded in the nursery rows, the tops in

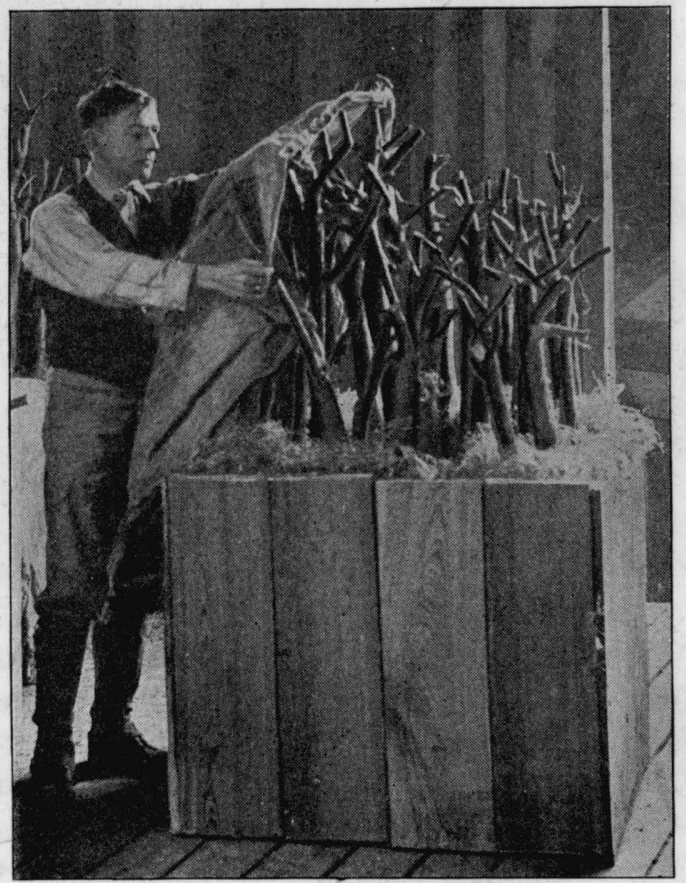

Fig. 110. A box of citrus trees, ready for shipment as soon as the tops are covered with burlap each pair of rows should be turned into the space between them, thus leaving each alternate space free for cultivation. When the buds have pushed out to a distance of a foot or more, the lopped stocks may be removed entirely by cutting off smoothly just above the bud.

Care of the budded nursery.

Before this time, whether or not lopping has been resorted to, each bud should have a stake placed beside it and 


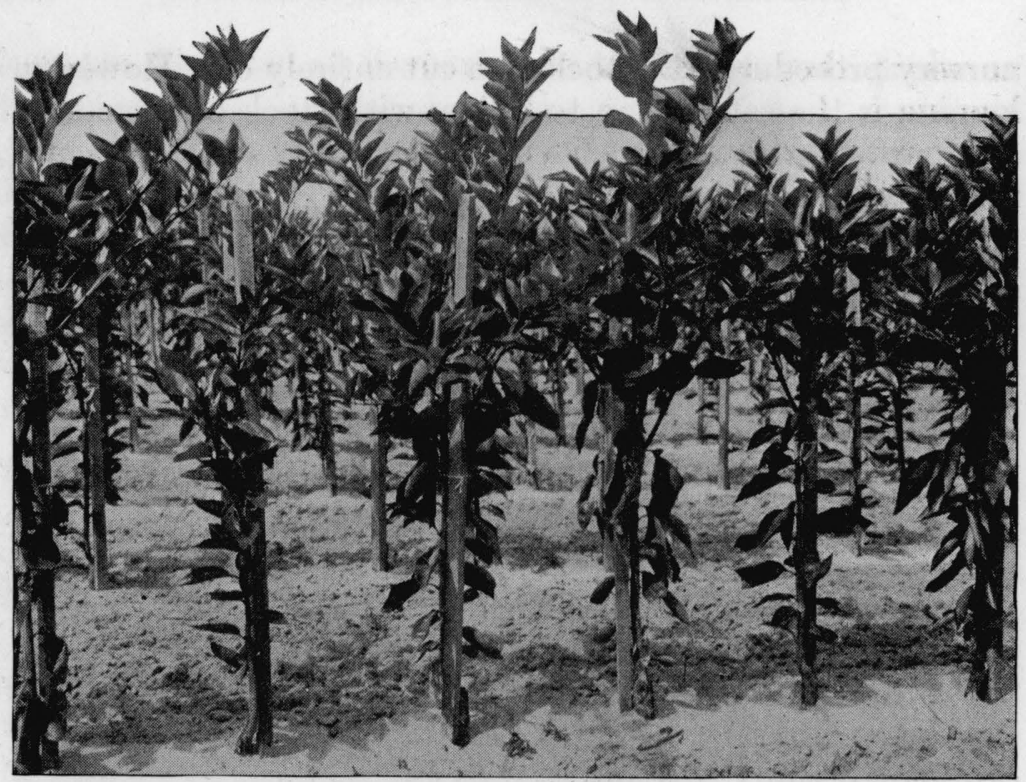

Fig. 111. Stake-trained citrus trees in nursery row

it should be tied to the stake, using cotton twine, raffia, or cotton cloth torn in strips. The stakes may be split or sawed from heartwood of pine or other durable wood, and should be about three-quarters of an inch square and four feet long. As the bud grows upward, it should be tied to the stake to keep it from falling over, making a tie every four to six inches, or as close together as may be necessary to keep the young tree-top straight. From time to time, sprouts develop on the stocks, and these should be rubbed or cut off so that all the root force is given to the new bud.

As soon as the young buds have reached the desired height, they should be topped or cut off and side branches allowed to develop. Recent nursery practice is directed to the production of low-headed trees, and the buds are usually topped at about eighteen to twenty inches. In autumn, by which time the young trees are stiff and straight, the stakes 
to which they were tied are removed to facilitate digging the trees.

Throughout the entire growing season the citrus nursery should be cultivated frequently to keep down weeds and conserve moisture. The spaces between the nursery rows can be taken care of with an ordinary horse cultivator, the hand hoe being used only to care for the spaces between the trees. Cultivation should be discontinued early enough to allow growth to stop before danger of the young trees being injured by the first autumn or winter frosts.

Commercial fertilizers are commonly used in the citrus districts to accelerate the growth of nursery trees. These fertilizers analyze about the same as those employed on young trees set in groves (see Chapter XXII) and are applied at the rate of 500 to 1,500 pounds to an acre. The amount depends on the character of the soil and the general growing conditions. It is unwise and inadvisable to force unduly the growth of the young nursery stock. Good trees cannot be produced by so doing. The first application of fertilizer should be given just before growth starts in the spring. For this dressing the soil should be barred (plowed) away close to the tree, the fertilizer distributed in the furrow and then covered with the cultivator. The second application, given in June, is worked into the soil with the cultivator and the third fertilizing is done about the middle of August. It is well to bear in mind that the earlier applications should be the heavier. More growth can be secured in early spring from a given amount of fertilizer than later in the season; also it is not advisable to prolong growth late into the fall.

Insects may gain a foothold in the nursery. These should be watched for and steps taken at once to eradicate them should they appear. (See Chapter XXVIII.)

Budding old stocks.

If an attempt is made to insert buds in old stems or trunks, it will be difficult by the shield method, with an 
inverted $\mathbf{T}$ incision. The bark may separate readily from the wrod, but even then, when the attempt is made to lift it
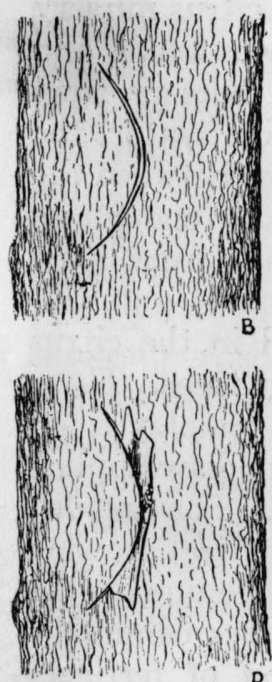

FIg. 112. Budding with curved incision. A, angled budwood; B, curved cut; C, bud partly inserted. away to allow the insertion of the bud, it generally breaks or cracks, being quite thick and brittle. However, buds may be inserted by using a curved incision. Angular budwood, as shown in Fig. 112, should be chosen. Buds are removed from this as already directed, but the stick is held with the bud well to one side so that when it is cut off it is either at the left or the right of the shield instead of being in the center. Then the curved incision is made in the stock to right or left to suit the bud. The bark is carefully lifted and the bud inserted and tied, leaving the bud well out at the side of the curve. This method should be known as shield-budding with a curved incision.

The after-treatment of the buds is the same as in ordinary shield-budding.

\section{GRAFTING}

As already stated, the propagation of nursery trees is accomplished almost entirely by budding. Grafting is objectionable as it cannot be done so rapidly and the whole top of the stock is often wasted, whereas, in budding, if the bud fails to take, a second attempt may be made shortly afterward on the same stock.

Nevertheless, in some special cases, grafting is preferable to budding. Such is often the case in working over old trees which have been frozen back. If they are to be budded, some time must elapse before the buds can be inserted. 
Sometimes it is necessary to wait until sprouts have started and reached sufficient size, but such trees can be crowngrafted at once, thus frequently saving a year's time. Trees girdled or injured by mal-di-goma, or in other ways, frequently may be saved by inarching small trees planted close to the diseased one, or sometimes a number of sprouts around an old stump may have their energies directed to the support of a single top.

The most useful methods are those known as cleft-, whip-, crown-, side-grafting, and inarching. Cleft- and whipgrafting must be performed during the winter dormant season or in very early spring before growth starts. Crownand side-grafting and inarching are best done during those periods when the bark slips or separates readily from the wood. Generally speaking, however, the work should be performed in spring some time before the end of June and the best time is before growth has started to any considerable extent.

\section{Cleft-grafting.}

In some cases it may be desirable to work citrus trees by this method, and it is useful in working large trunks, branches, or old sprouts. The stock is cut off at right angles and the cut surface made perfectly smooth. Then it is split or cleft open, using either a budding-knife (Fig. 105) or the grafting-iron and mallet. Frequently the line of cleavage in orange wood is very irregular, hence it is best to drive the knife or iron in on the side of the stock before splitting it. This will leave a smooth straight surface for the cion. After making the cleft, it may be held open with the wedge end of the grafting-iron, or, if a knife is used, by a wooden wedge prepared for the purpose. The cions should have three or four buds and should be four to five inches in length. Prepare them by trimming the lower end to a wedge (Fig. 113) with the outer edge slightly wider than the inner. The sloping cuts should be about one and a half inches long. 
Slip the cion down into the cleft until the whole of the cut surface is within the cleft (Fig. 113). The thicker edge should be outside, so that the stock may bring the cambium edges more intimately in contact by its pressure against it. If the stock is large, two cions may be inserted, one in each side

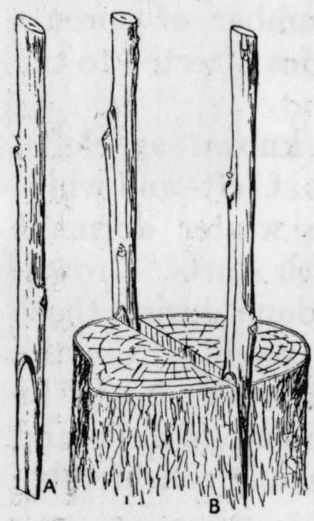

Fig. 113. Cleft-grafting. $A$, cion prepared; $\mathrm{B}$, base of cion; C, stock and cion united ready for tying.

of the cleft. After inserting the cion or cions, the stock should be firmly bound with waxed twine, unless the pressure of the stock is sufficient to hold the cion in place.

Robert T. Morris has successfully used melted paraffin as a covering for cions and graft unions in top-working. This method has been tried out in Florida in grafting citrus and should be tested further. The paraffin is melted, allowed to cool partly, and applied with a small brush while still liquid. Before making application it should be so cool as not to injure the fingers when placed in it.

The cut surface should be covered over with grafting-wax to prevent loss of moisture. If the top of the cion has been cut off it should also be covered with a little of the wax, but if it has been inserted below the ground, the earth should be heaped up around it, covering all except the last bud. No further attention is needed until growth starts, at which time the bandage should be severed, either in the space between the cions where two have been inserted, or, in case only one has been put in, then on the side opposite it. The growing shoot should be tied as directed under Budding.

This method is one of the best in top-working trees, when it is desired to change from one variety to another. In hot dry climates, the removal of a large portion of the sheltering leaves and twigs leaves the trunk and main branches exposed to the hot rays of the sun. This will result in serious injury 
to the exposed parts. A very satisfactory protection can be afforded by a thin coating of whitewash, applied with a spray pump.

\section{Whip-grafting.}

This method may be used on small stocks, three-quarters of an inch or less in diameter. It is best that the stock and cion be of the same size, but if such is not the case, the stock should always be the larger. A sloping cut, an inch and a half long, is made diagonally across the stock (Fig. 114-A). A corresponding cut is made on the cion (Fig. 114-B) and a tongue of wood is raised about the center of each cut with the knife held almost parallel to the sides of the wood. The tongue is raised a little on both stock and cion and the two are gently but firmly shoved together (Fig. 114-C). Then

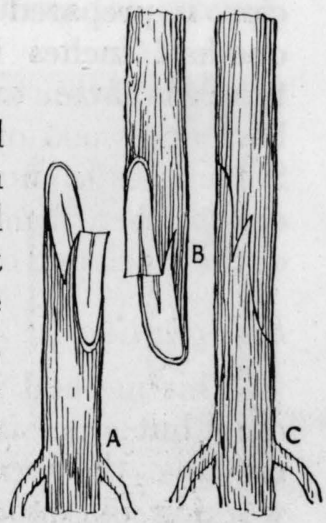

Frg. 114. Wbipgrafting. A, stock prepared; B, base of cion; $\mathrm{C}$, stock and cion united ready for tying. the point of union is securely bound with waxed twine.

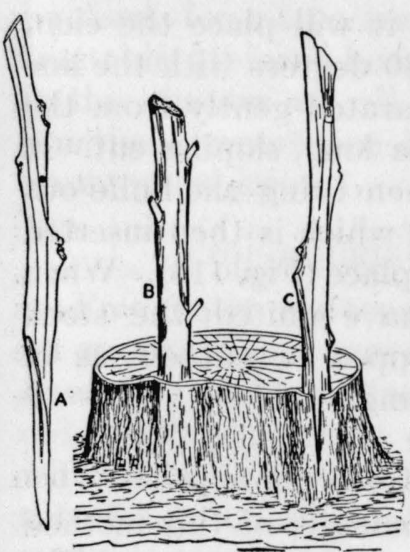

FIg. 115. Crown-grafting. A, cion prepared; $B$, cion inserted without splitting bark; C, with bark on stock split. The after-treatment is the same as for cleft-grafting.

Crown-grafting.

This is one of the best methods for working trees which have been frozen back or for large trunks at the ground. The trunk is cut squarely off at or somewhat below the ground and the cut surface is made smooth with a knife. If the outline of the trunk is irregular, as is frequently the case, concave places should be chosen for inserting the cions. With the point of a budding-knife, gently spring the bark back. In cases in which this 
cannot be done, it may be necessary to slit the bark down a distance of an inch or so and then lift the bark. The cion is prepared by making a single sloping cut one and one-half inches in length at the base, and it should be tapered off thin and smooth. Then it is inserted between the bark and wood of the stock, with cut surface inward. Sometimes a number of cions may be set around the crown, then firmly tied in place and the cut surface of the stock and cion covered with paraffin wax (Fig.115).

Side-grafting.

This method is also known as sprig-budding, but since it is more properly a form of grafting, the former is the better name. For working old stock with thick hard bark, it possesses the same advantages as shield-budding with a curved incision. The method is also useful when small slender twigs are the only ones available for propagating.

An oblique curved cut is made in the side

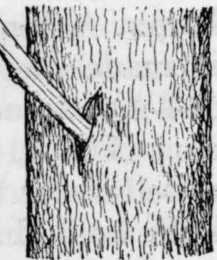

FIg. 116.

$\mathrm{S}$ i d e -grafting showing $\mathrm{c}$ i o $\mathrm{n}$ in serted in stock. of the stock in such a position that it will place the cion, when inserted, at an angle of about 30 degrees with the line of the trunk. The bark is then separated gently from the wood, and the cion is prepared with a long, sloping cut. It is best to cut rather deep at first, then bring the knife out almost straight to the end of the cion which is then inserted

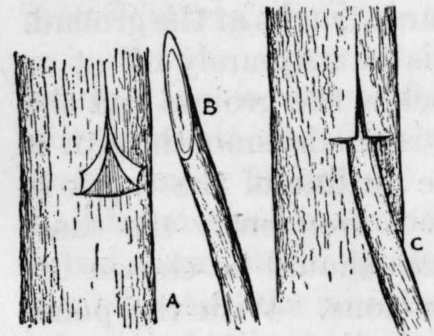

Frg. 117. Inarching. A, stock prepared; B, cion prepared; C, cion inserted in stock. and tied in place (Fig. 116). When the parts have united, the stock must be lopped or cut off, as in shield-budding.

\section{Inarching.}

The advantages of this method have already been pointed out. The work is accomplished thus:

All branches are removed from 
the shoot or small tree and the top is cut off with a sloping cut about two inches in length (Fig. 117-B). Then in the side of the larger tree, at the proper distance above the ground, an inverted $\mathrm{T}$ incision is made (Fig. 117-A), and the corners formed by the intersecting cuts are turned back as in shield-budding. The prepared end of the shoot or tree is inserted in the cut (Fig. 117-C) and firmly tied in place. If it is difficult to tie, it may be nailed with a slim finishing nail, driven in with a punch to prevent bruising. In most cases this method is preferable. All the incisions are then carefully covered with wax. The bandage should not be disturbed until union has taken place and the parts have firmly knitted.

Other methods of working may be used, for citrus trees are very tractable subjects, but those given in this chapter are all that are of practical importance and all the grower need know.

\section{TOP-WORKING}

Frequently new tops are desired

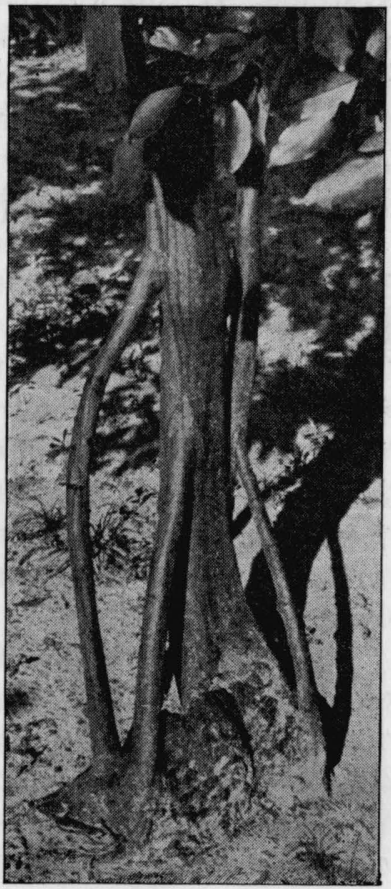

FIg. 118. Tree with three sprouts from base inarched in trunk above. on an established grove of trees; it may be advisable to reduce the number of trees of certain varieties; there may be old seedlings of sweet orange, sour orange, or rough lemon which can be put to better use; or there may be certain diseases to be eliminated. All of these results may be secured by top-working to other species or varieties of fruit. Naturally, it is easier to top-work young trees than old ones, and it is best, therefore, to consider them separately. 


\section{Top-working young trees.}

Usually it is best not to top-work young grove trees until they have been set out long enough to develop good root systems. If top-working is attempted within a year or so after planting, the results may not be entirely satisfactory because the trees are not well enough established. It is best to wait until the trees have been planted two or three years and from then until they are six or seven years old they may be top-worked by budding directly into the branches.

To prepare the trees for top-working, their heads should be pruned out somewhat to make it easier for the budder to insert buds close in toward the trunk on the main branches. Using the ordinary method of budding, three buds are inserted in each of the framework branches, well down toward the trunk. This number is advisable to insure at least one living bud in each branch. The branches at the point of insertion may be an inch and a half to two inches in diameter. Good large buds should be used and wrapped well with waxed cloth.

Immediately following budding, prune out all branches not budded. The cuts should be close and all wounds threequarters of an inch and up should be painted. In two to three weeks the wraps may be removed. If the buds were inserted in autumn before growth ceased for the summer, nothing more is necessary until spring, but if inserted in spring, pruning should be done at once. From the branches in which living buds are established, cut away all side branches and twigs, leaving only a small twig or two toward the tip to keep up sap movement. When the buds have shoved out ten to twelve inches they should be pinched back to prevent their being blown or broken off, causing them to harden up and to branch out with the next flush of growth. After the buds have made their second growth and have been pinched back again, the branches from which they are growing should be cut back to within six to eight inches of the point at which the buds were inserted. In this condition 
the trees may be left until just before growth begins the following spring, when the branch stubs can be cut off close to the buds and the surfaces painted. The angle of cutting should not be too acute. Usually more buds will grow than are needed, and these should be thinned out at this time, leaving nothing but the new top. It is well to mark branches in which buds are inserted with a band of white paint to distinguish them from others which might come out from the original top. It is not necessary to stake the buds if they are pinched or pruned back from time to time. This hardens them, the growth on succeeding flushes is not so rank and vigorous, and they are safeguarded against damage from wind and rain.

Top-working old trees.

Before top-working old trees, they should be examined carefully and those in poor condition from disease or other causes should be dug out. It is much better to replace them with new ones.

While it is possible to insert buds in old bark by the methods described, it is often more convenient to head the trees back and secure young growth in which to place the buds. Either of two plans may be followed. The whole top of an old tree may be cut off at once or the top may be removed in two sections.

Late in winter, after danger of cold is past, but before the trees start into growth, the whole head is cut away. Attention must be given to the making of good wounds and their proper protection. The trees are cut back to stubs of convenient height. To protect them against sunburn, particularly in arid climates, it is best to whitewash them. If there is only a limited number, it may be applied with a brush, but larger numbers may be whitewashed with a spray pump.

During the spring growing season, numerous sprouts develop on the cut-back trees. After they are out two to 
three feet, it is well to pinch them back to harden them and prevent their being broken off. Usually by June the sprouts are large and firm enough for budding, and the buds may either be inserted then or they may be dormant-budded in September or October. Before budding, the sprouts should be thinned out, leaving only the best placed and strongest ones. Two or three buds should be inserted in each to insure a complete stand. In spring (if dormant-budded), or as soon as the buds are set (if spring or early summer budded), the tops of the sprouts should be headed back. When the buds have shoved out ten to twelve inches, they should be treated as described under top-working young trees. This pinching back is a great protection against loss and obviates the necessity for staking.

From time to time the cut surfaces of large stubs must be inspected and the necessary care given to prevent decay.

In partial top removal, only the central branches of the tree, comprising about one-half the top, are lopped, i.e., the branches are cut three-quarters of the way through and then bent over, leaving them partially connected with the tree. Sprouts grow out on the stub portions of these lopped branches, and, when sufficiently mature, in early summer or late fall, buds are inserted in them. When these have grown in place, or in the following spring (if dormant budded), the lopped branches are completely severed and removed. The sprouts are cut back sufficiently to force the buds out and these are then treated as recommended under the other methods.

When the central part of the tree is renewed and established, the side or lower branches are handled in the same way. It takes about two years to top-work trees by this method, but many growers deem it the best plan to follow in the moister regions. 


\section{CHAPTER XV}

\section{CITRUS-TREE STOCKS}

The more important stocks and those most commonly employed in propagating citrus trees are sour orange, rough lemon, trifoliate orange, pomelo, and sweet orange. The Otaheite orange is sometimes used, particularly in the production of dwarf specimens, but for general orchard purposes it has nothing to recommend it. Recently, some interest is being taken in seedlings of the Cleopatra orange for stocks, but its value and its limitations are unknown.

Not all the above stocks are adapted to the same conditions of soil and climate, and it cannot be said that any one of them is best for all conditions. It follows that the prospective planter should be acquainted with their relative merits for different localities, and, at the same time, should be thoroughly informed in regard to the soil, climatic, and other conditions in the region in which he intends to plant.

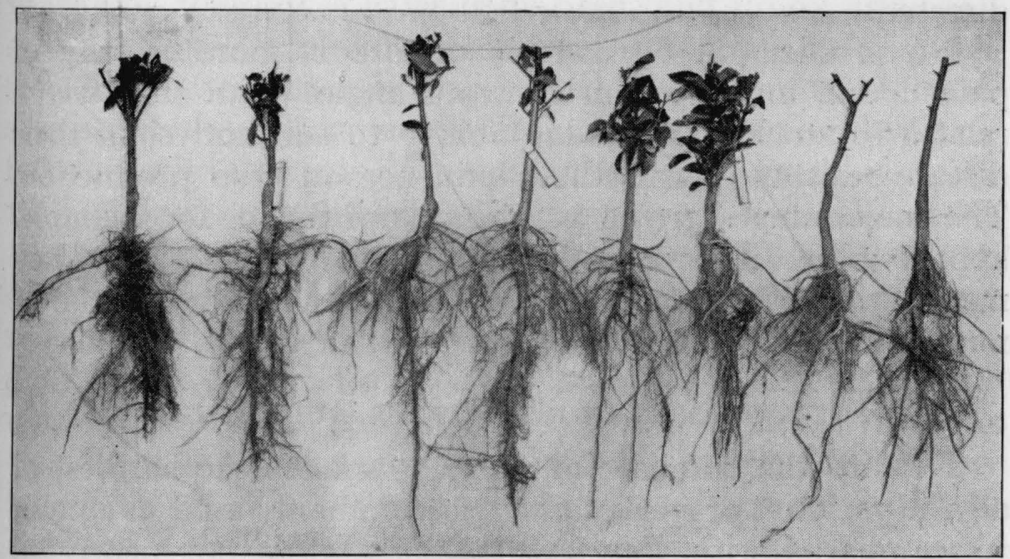

Fig. 119. Citrus-tree stocks. From left to right-two each sour orange, sweet orange, rough lemon, and trifoliate orange

(199) 
Unless this be the case, mistakes may be made which otherwise might be avoided. For example, it would be poor policy to plant sweet stock citrus trees on low ground, where they are likely to be attacked by mal-di-goma, and it would be equally foolish to plant trifoliate orange stock on dry shell ridges. Besides the question of adaptation to certain soil and climatic conditions, the mutual influence of stock and cion must not be entirely overlooked. That such an influence is exerted cannot be doubted, but its extent still remains to be investigated.

Among the influences of stocks, to which attention will be called later, are those affecting the hardiness, the rate of growth, the size and shape of the top, the precocity and prolificness of the tree, the time of ripening and the quality of the fruit, the relative amount of juice and rind in the fruit, and the amount of acid, and, consequently, the flavor. Not all of these effects are noticeable in all varieties and only here and there are they sufficiently marked to attract attention. But if differences sometimes stand out prominently it is not unreasonable to suppose that they exist in some degree in many other cases to which attention has not been directed.

No problem in citrus-fruit culture is more worthy of painstaking investigation from all angles than that which relates to stocks, their adaptability to soil and cion, their disease resistance, and their influence on crop production. The sour oranges grown in orchards of Spain, for example, appear to be different from those known in America. They may be superior as stocks, and this same may be true of numerous varieties and species of citrus fruits.

\section{SOUR ORANGE STOCK (CITRUS AURANTIUM)}

Next to the trifoliate orange, the sour is the hardiest of all the varieties or species of citrus commonly used as stocks. As compared with Poncirus trifoliata, it is not nearly so hardy, but it is considerably hardier than the sweet orange. 
Of course, a very low temperature causes all differences in hardiness between sweet and sour orange trees to disappear, and after such periods of cold no difference can be detected, but the fact remains that a degree of cold which frequently injures the sweet orange has no effect on the sour. Sufficient cold to destroy the young growth and defoliate sweet orange trees does little or no injury to the sour orange. It is impossible to state the relative hardiness in so many degrees, as so much depends on the condition of the trees.

The roots of the sour orange are produced abundantly and penetrate well into the soil. In this respect it possesses an advantage over the sweet stock for some districts because it is not so readily affected by variations in moisture. The roots penetrate sufficiently deep to be in contact with a more or less permanent water-supply. Also it has been observed repeatedly in Florida that both nursery and grove trees on sour-orange stock suffer much less in periods of protracted drought under identical conditions than do those on roughlemon roots.

Sour-orange stock is not subject to the attacks of mal-digoma, and in Europe, where this disease worked great havoc years ago, the groves have again been built up by using this stock. On soils subject to the disease, it is a safe stock to use. The sour orange tree is very much subject to citrus scab, a disease which attacks the fruit, leaves, and young twigs. It is frequently a serious drawback in the production of stocks for budding, as noted in the section on diseases. But such citrus as are not susceptible to the attacks of the disease are in no wise rendered susceptible by being worked on sour stock. The sour orange is very resistant to various forms of gum disease, both in Florida and in California. These diseases attack the trunks of susceptible species, frequently because of soil and moisture conditions. Their attacks may be greatly offset by using sour orange as a stock and inserting the buds well above the ground.

Sour stock sprouts readily, if the top be frozen back, thus 
giving an opportunity for re-budding. It is best adapted to soils containing a liberal supply of moisture, and its natural habitat, if one can judge from its behavior in Florida as an introduced tree, is the shores of lakes and the banks of rivers where the soil is liberally supplied with water and humus. On dry soil, trees worked on sour stock do not grow so rapidly and do not reach the same size as when rough-lemon stock is used. In general, it may be said that it is best adapted to high and low hammock and flatwoods land in Florida, to the low lands of Louisiana, and to all soils where a good supply of moisture is present or to which a liberal amount can be given. Almost from the first cropping, the fruit borne by trees worked on sour stock is of good quality, a statement which is not generally true of trees worked on rough lemon. On matured trees on sour-orange stock, the fruit is of excellent quality, thin-skinned, and juicy. It may be held on the tree to the fullest maturity of the variety without loss of quality and without losing its juice and becoming pithy. In the production of late fruit this has a decided advantage, but always it should be remembered that it must be suited to the soil where planted. During the first years of fruiting, trees on sour-orange stock are not quite so fruitful as those on some other stocks, but this difference disappears as the trees become older. In very old trees worked on sour stock, it will sometimes be noted that the sweet trunk is enlarged above the point of union, having in some measure outgrown the sour root.

It is safe to say that more than seventy-five per cent of the world's output of citrus fruits is produced by trees on sour-orange stocks. Its use in California is on the increase; upward of ninety per cent of all the seeds planted there to produce citrus stocks are sour orange. If possible to use it, it should be given preference. When soil and climatic conditions are suited to its best growth and development, and it is congenial to the variety worked on it, sour orange is a most satisfactory stock to use. Its resistance to cold injury 
and the attacks of foot-rot and gum diseases are strong points in its favor. For some reason not yet explained, it has proved to be a very unsatisfactory stock in the citrus districts of Cape Colony and Rhodesia, South Africa.

As a stock for the Satsuma orange, kumquat, lime, and limequat in Florida, the sour orange is a failure. These citrus fruits make a stunted, unhealthy, unsatisfactory growth on this stock, or refuse to bear. Why this should be so is difficult to say, but for some reason or other the union is decidedly uncongenial. To all appearances the graft union is good, though all the sorts mentioned are slower growers than the sour orange. Perhaps there is a difference in the chemical composition of the sap, or in the nature of the enzymes required by the top and by the root. Florida nurserymen, for the most part, have entirely discontinued the propagation of these fruits on sour-orange stock.

\section{ROUGH LEMON (CITRUS LIMONIA) AS A STOCK}

The rough lemon tree is not so hardy as the sour and the sweet orange and is more liable to injury by cold than the pomelo. Of all the stocks commonly used for citrus trees, it is the most susceptible to damage by cold, and hence cannot be expected to increase the hardiness of the top, but, on the contrary, it is inclined to make it less hardy. In southern Florida it grows wild and appears to be perfectly adapted to its surroundings, but it is not found in the northern parts of the state, being much too tender to stand the climate of the more exposed sections unless protection is afforded.

The main roots of this stock show a wide variation. In all cases the crown-roots extend a considerable distance from the trunk and a strong tap-root is produced, but in some individuals, here and there, the large lateral roots lie rather close to the surface, and most of the feeding-roots are in the top fifteen inches of soil. On the other hand, most trees worked on this stock have the roots well and widely distributed through the soil. A root system is particularly 
desirable for dry soils and for those which need irrigation. Rough lemon is much used on the lower East Coast of Florida and on the high sandy ridges in the interior counties of the state. In South Africa where it is known as Mozoe or Cape lemon it is the most satisfactory stock so far tested.

Rough-lemon stock is capable of inducing a more rapid growth in the kinds top-worked on it than any other now employed in America. For this reason, and because of the great foraging power of its roots, it is an excellent stock for high dry soils, or on those containing a small amount of plantfood, or on soils where the plant-food is not readily obtained because of some undesirable soil-condition. For planting on low ground, sour-orange stock is preferable, and, for various reasons, rough-lemon stock should not be used in such locations.

Rough-lemon stock influences, to some extent, the shape and growth of the variety worked on it. There is a pronounced tendency toward the production of tall upright branches in the center of the top, but this will correct itself after a time, or, if deemed necessary, these upright branches may be cut back somewhat, to assist in the formation of a compact symmetrical head.

Generally, the first crops of fruit produced by trees on rough-lemon stock are thick-skinned, deficient in juice, and of inferior quality compared with fruit grown on trees of the same age on sour-orange stock. This may be attributed largely to the more rapid growth of the young trees, for it must always be remembered that vigorous luxuriant growth and high-quality fruit do not go together. After a number of seasons, when the trees have passed their period of rapid vegetative development, this difference largely disappears. However, fruit cannot be held so late in the season on trees with rough-lemon roots as it can on trees grown on sourorange stock. Oranges are likely to part with their juice at the stem earlier and the seeds in grapefruit sprout earlier when grown on rough-lemon stocks. 
Fruit of the same variety runs somewhat larger in size, and there appears to be an increase in acid and a decrease in sugar in fruit produced on rough-lemon stocks compared with that produced on sour-orange roots. In the winter of 1902, two samples of fruit were picked from adjoining trees of the same variety in the grove of C. T. McCarty, Eldred, Florida, the one worked on rough lemon and the other on sour orange. The difference in acid-content was distinctly appreciable to the taste, and as the fruit was fully matured, it was thought well to have the two samples analyzed. This was undertaken by H. K. Miller, then chemist of the Florida Experiment Station. The specimens on sour-orange stock contained .72 per cent acid and 9.8 per cent sugar determined as dextrose in the juice; those on the rough lemon .91 per cent acid and 7.24 per cent sugar determined as dextrose, a difference of .19 per cent acid and 2.56 per cent sugar. Too much weight must not be laid on these results, as many analyses should be made to establish any difference that may exist.

As a stock for kumquats, rough lemon gives good results under most conditions. Since it can collect large amounts of food material, the kumquat top appears, in some instances, to get more than it can assimilate and use. If one desires to use the rough-lemon stock for the kumquat on rich soils, or those which are heavily fertilized, the best plan would be to adopt the method at one time used quite extensively by $\mathbf{C}$. W. Butler, St. Petersburg, Florida. His practice was to insert kumquat buds in sprouts from rough-lemon roots which already support and feed a sweet or mandarin orange top. A perfectly healthy union was secured in all cases, as most of the material gathered by the roots was used by the larger and more vigorous top. Strange to say, however, the kumquat frequently outstripped the other top, sweet or mandarin orange as the case might be, in growth in height.

For limes and lemons, rough lemon has been found to make commendable stocks. The trees make a satisfactory 
growth and produce fruit of high quality. Since these fruits are gathered before ripening, there is no danger of their parting with their juice before being picked.

Rough-lemon stock, in many sections, is not satisfactory for early varieties of oranges, such as Parson Brown, for example. The fruit is very inferior in quality and is more backward in coloring than usual. Dancy tangerines of high grade may be grown on rough-lemon stock. The great difficulty in growing good tangerines is to produce them large enough, and rough-lemon stock aids to this end. Many growers prefer this stock for both pomelos and tangerines. Excellent Satsuma orange trees may be grown on roughlemon roots, but neither the quality nor quantity of fruit is satisfactory, and its use cannot be recommended.

Rough lemon has marked influence on the fruitfulness of the Bahia navel orange in Florida. This orange is much more prolific on rough-lemon stock, and, with the exception of trifoliata, it is the only stock that can be recommended for the variety in that state. Rough lemon is resistant against the attacks of mal-di-goma, or foot-rot, in this respect almost ranking with the sour orange.

\section{TRIFOLIATE ORANGE (PONCIRUS TRIFOLIATA) AS A STOCK}

Perhaps the first mention of this species as a stock for citrus trees, in occidental literature, was made by Robert Fortune, who, in 1848, said, "The kumquat is propagated by grafting on a prickly, wild species of citrus, which seems of a more hardy nature than the kumquat itself." The citrus species referred to is, undoubtedly, the trifoliate orange. The tree itself was described and illustrated by Kaempfer in his "Amoenitatum Exoticarum" in 1712. No doubt it has been used for ages by the Chinese and Japanese as a stock for citrus trees, but only within recent years has it been so employed in America. It came into use in America about 1895, and by 1905 had received very considerable attention in northern Florida and the sections westward, around the 
coast of the Gulf of Mexico. Now, in 1925, it is extensively used in this same area as a stock for the Satsuma orange.

Of all the stocks for citrus trees, trifoliate is the hardiest and it imparts to the variety worked upon it some of its hardiness and its resistance to heat and to cold. The former is quite as important as the latter, for if the tree responds to heat by starting to grow, it becomes very tender; the measure of a variety's hardiness is frequently its resistance to high temperatures by remaining dormant.

While it should be borne in mind that the place of union between the stock and cion is the one point in the trunk of a citrus tree

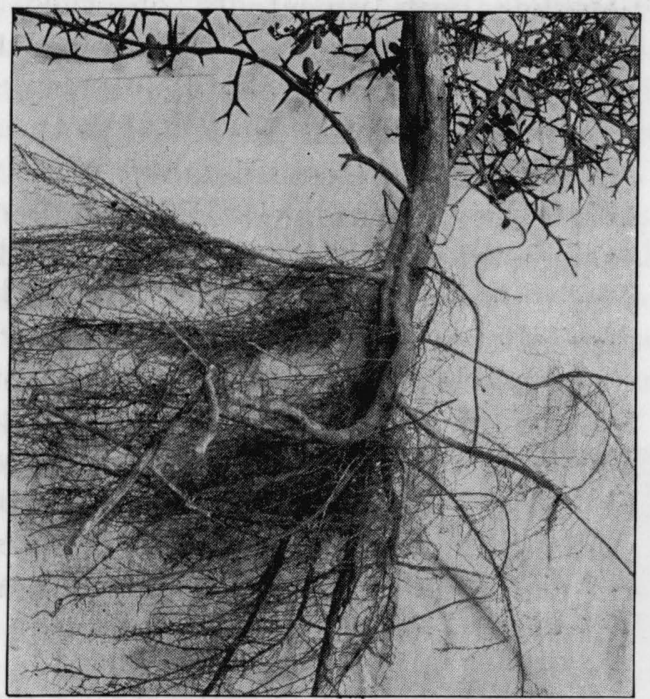

FIG. 120. Root system of trifoliate orange. Note the numerous fibers most sensitive to cold, still this point may be protected and thus a distinct gain is made in ability to withstand low temperatures. Besides imparting to the cion some of its ability to withstand cold, it has a tendency to retard growth in spring. Trifoliata has been known to withstand a temperature below zero. It is also distinctly periodic in its growth, and it is not responsive to sudden changes of temperature during its dormant period.

In the citrus districts it has been noted by some observers that the trees on trifoliate orange roots suffer from cold quite as much as those on other stocks, and they have argued, from this, that the stock was of no value in making trees 
hardier. There is no doubt that the observations were correct, but the deductions were wrong. If the temperature drops low enough, all differences in hardiness disappear, but at temperatures somewhat higher, trees on trifoliata escape while those on other stocks are damaged. This exact condition has been repeatedly observed in northern Florida. Moreover, in a nursery containing trees on rough lemon, sour orange, and trifoliata, following a cold period, every tree on rough lemon was killed to the ground, those on sour orange were hurt considerably, while those on Poncirus trifoliata escaped unhurt. If the temperature had gone low enough, all difference, of course, would have been wiped out. The difference in resistance cannot be stated in so many degrees of temperature, because it is variable, and in no two cold periods or in no two locations would it be the same.

As a general rule, those trees that reach their maximum development in cold or comparatively cold climates cannot be transferred to distinctly tropical or subtropical climates and there grown successfully. On the other hand, since the trifoliate orange succeeds admirably and appears to be well adapted to regions distinctly outside the tropical isotherm, it is doubtful whether it is advisable to use it as a stock in regions removed from all effects of frost. In view of this fact, it would be unsafe to recommend it as a stock in the Islands, or other warm regions. In southern California it is not likely to prove satisfactory, except at comparatively high altitudes, but it succeeds admirably in northern Florida and around the Gulf Coast country as far south as Beeville and Falfurrias, Texas.

The trifoliate orange should not be used as a stock on high, dry, or calcareous soils, for in such situations it is a failure. It grows well and vigorously on good flat woods and hammock lands in Florida, particularly where they are underlaid with clay, and it appears to be well adapted to this class of soils. It is well suited to soils of alluvial formation. Plantings should be made on this stock only on these classes 
of soils or on those correspondingly well supplied with moisture and capable of retaining it. It has not been satisfactory in the Rio Grande Valley citrus district of Texas, where sour-orange stock has been found best to use. The soils are either neutral or slightly alkaline in their reaction and in their natural state do not contain large amounts of vegetable matter. Poncirus trifoliata is best adapted to soils of a different character, and, in particular, to those which contain goodly amounts of moisture and plenty of organic material with a neutral or slightly acid reaction.

So far as known, trifoliata is not subject to mal-di-goma, and in some of the world's citrus districts it is used as a stock resistant to this disease. It is sometimes severely infested with San José scale but this does not interfere with its use as a stock inasmuch as the other species of citrus worked on it are free from this scale.

The root system produced by the trifoliate orange is very good, as the roots penetrate well, and fibrous roots are produced abundantly. When supplied with a vigorous top, the root becomes more vigorous, and, strange to say, not a single case has come under observation where the stock did not outgrow any variety worked on it. The trifoliate root is larger just below the point of union

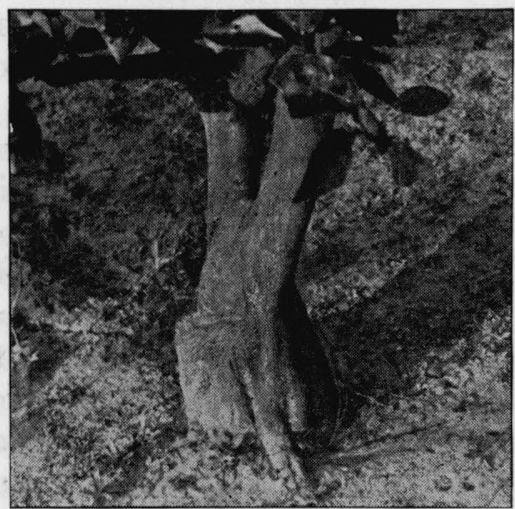

Fig. 121. Union of orange and Poncirus. The Poncirus stock is much larger than the orange above. than is the cion trunk just above (Fig. 121). This goes to show that the stock is influenced by the top and made to grow much more vigorously than might be expected. This may be due to the fact that here is one of the few examples of an evergreen top growing on a deciduous stock. There is 
no question but that food-formation goes on over a much longer period in each year through the effect of the evergreen top. The diameter of worked trifoliate trunks just below the point of union greatly exceeds that of seedling trifoliate trees of equal age at the same distance from the ground.

Many writers on citrus propagation have stated, without reservation, that trifoliate stock dwarfs the top worked upon it. Exception must be taken to the breadth of this statement. It is not always true. Some varieties of citrus appear to grow as rapidly and attain as large size when propagated on trifoliate-orange stock as on sour or sweet.

The most extensive set of experiments to determine the relative merits of $P$. trifoliata and other stocks were those initiated at Glen Saint Mary, Florida, by G. L. Taber in 1899. The early reports of these experiments were reprinted in the author's "Citrus Fruits and Their Culture" in 1904. It was largely due to the interest of $\mathrm{Mr}$. Taber in the trifoliate orange as a stock that the Satsuma orange industry was established. Experimental tests have been made with Poncirus trifoliata and other citrus stocks at Riverside, California, by the California Experiment Station.

The fruit produced on trees grown on trifoliate orange stock usually runs smaller in size than that on other stocks. It is of fine quality, even in the first crops - smooth, thinskinned, juicy, and highly colored. The fruit ripens earlier, and chemical analyses have demonstrated that the sugarcontent is higher early in the season in fruit produced on trifoliata stock than in that on sour-orange stock. Trees of all kinds that do well on trifoliata stock are very precocious and wonderfully prolific. For this reason it is an excellent stock for testing new varieties on suitable soils.

It has been repeatedly demonstrated on a large scale that of all the stocks under discussion it is the only satisfactory one to use for the production of high-grade Satsuma oranges. On all the other stocks this variety does not bear large crops 
or the fruit is practically worthless. It is an excellent stock for the kumquat, limequat, calamondin and Duncan pomelo. The Marsh pomelo is a failure on trifoliate-orange stock, and in California it has not proved satisfactory as a lemon root. Many sweet oranges, as Ruby, Pineapple, Parson Brown, Valencia, and Bahia (Washington Navel), make good growth on trifoliata. It is a good stock for Dancy tangerine. The fruit of the varieties just mentioned, although it runs smaller in size, is of high quality; the trees are very prolific, and this may account in part for the smaller size.

\section{SWEET ORANGE (CITRUS SINENSIS) AS A STOCK}

The sweet orange is not so hardy as the sour and trifoliate oranges. For colder regions, other things being equal, one of the latter two is to be preferred. It has been pointed out that in California sweet stock is not deep-rooted, most of the roots being found in the top eighteen inches of soil. J. W. Mills, on pages 11 and 12 of California Experiment Station Bulletin 138, states the results of his investigation in these words: "In short, the general experience on all kinds of soils and under different methods of cultivation shows that it is the nature of the sweet orange seedling to form a shallow root system"; and further: "To sum this up, the sweet orange is a surface-feeding stock which has few or no deeply penetrating roots." In Florida, investigations have not been carried far enough to prove what the conditions are, but of nursery trees it may be said that the sweet stock is equal in root development to sour stock.

Sweet stock is subject to the attacks of mal-di-goma and therefore should not be employed on soils where this disease is likely to occur. Damp soils, such as are found in the hammocks and flat woods of Florida, should not be planted with trees on sweet stock; even on higher ground they are frequently attacked. On the other hand, it may be pointed out that on light well-drained lands, trees worked on this stock make a good growth and develop into shapely sym- 
metrical trees. The growth of trees on sweet stock is more rapid than on sour or trifoliate orange; and in general it may be said that in rapidity of development it is surpassed only by the rough lemon and pomelo.

When frozen back, sweet stocks sprout readily, and seldom is it necessary to replace them. In some sections it may be advisable to use sweet stock, but the planter should never forget that it is susceptible to the attacks of mal-digoma, and should not use it without counting the risk. In Florida its use as a stock has been discontinued, but in California and other districts, sweet orange is still employed.

\section{POMELO (CITRUS PARADISI) AS A STOCK}

As already pointed out, the pomelo is hardier than the rough lemon but does not equal the sweet orange. It is a strong vigorous grower, and seedling pomelo trees in Florida have attained a size unsurpassed by other citrus species and generally exceeding all others in the amount of fruit.

Within the past few years, attention has been directed toward its use as a stock, most of the trees budded on it being planted on the lower West Coast region of Florida. But outside of this region it has not been used to any considerable extent, and most of the plantings in south Florida are still made on sour-orange and rough-lemon stock. It was thought at one time that it would be used in a large way in Florida, but this has not come about, for too frequently the trees on high pine lands do not make satisfactory growth and show a very strong disposition toward "Frenching" and kindred troubles. In southern California this stock appears to be replacing the sweet-orange stock to some extent and to be superior to it.

The pomelo root system is well developed and distributed in the soil, and, so far as observed in Florida, no cases of mal-di-goma have been authentically reported. In regard to its behavior in California, J. W. Mills, in California Experiment Station Bulletin No. 138, says, "It is resistant; 
to a certain extent, to the form of gum disease that attacks the roots of citrus trees."

\section{SUMMARY OF STOCK ADAPTATIONS}

Sour orange.-Adapted to strong soils, hammock lands, flat woods lands, alluvial soils, and those underlaid with clay close to the surface. Resistant to foot-rot and gum diseases. It is a satisfactory stock for the sweet orange, pomelo, mandarin orange (Satsuma excepted), and lemon, but is not suitable for the Satsuma orange, kumquat, lime and limequat.

Sweet orange. - Should be used only on higher soils where reasonable immunity from mal-di-goma may be expected. Similar to sour orange in root development. It is a good stock for the kumquat, and also for the pomelo and sweet orange so far as growth and fruit production are concerned. The Satsuma orange grows well on it but does not fruit well. In California it is not a satisfactory lemon stock because of brown-rot gum disease.

Rough lemon.-Adapted to high sandy soils, those deficient in plant-food, and to the rocky lands of the Florida East Coast. It is a good stock for the sweet orange, pomelo, mandarin, lime, limequat, and kumquat, but is not satisfactory for some early oranges and Satsuma. As it is subject to certain forms of gum disease it is not satisfactory for lemons in California.

Pomelo.-Adapted to heavy soils rich in vegetable matter and those containing moisture in goodly amounts. Not satisfactory on high pine land. Its exact value as a stock has never been determined, but its soil adaptations appear to be limited. The pomelo and sweet orange do well on it under suitable soil conditions.

Trifoliate orange.-Adapted to flat woods lands, sandy loams underlaid with clay, alluvial soils, and strong lands with good moisture-content. A good stock in colder sections for the Satsuma, kumquat, limequat, Dancy tangerine, Duncan pomelo, and most varieties of sweet oranges. 


\section{CHAPTER XVI}

\section{SOILS FOR CITRUS GROVES}

While citrus trees possess a wide range of soil adaptability, it is true that any and every kind of land cannot be used for their cultivation. Many lands can be planted to citrus trees where certain seedlings would not succeed, if the right stock be chosen on which to work them, and, fortunately, there are a goodly number of stocks with a fairly wide range of adaptability. It is very probable that future investigations may bring into use other citrus stocks of still wider adaptations.

But even with this advantage there are certain classes of soils which should not be used, and, of course, many are more suitable than others. Sticky heavy soils, through which water does not readily percolate, should be avoided and also those which are extremely dry, unless they can be irrigated. Again, damp and wet soils and those underlaid with hardpan should not be chosen for the citrus grove, unless the strata of rock or hard soil can be broken up so as to allow the roots to penetrate deeply.

Citrus trees succeed best on well-drained soils of a rather open nature. If naturally well-drained, so much the better, but if not, artificial drainage must be provided. No stagnant water should stand in the grove; neither should the soil be completely charged with water. Soils of an extremely open porous nature are unsuitable, as they do not hold sufficient moisture; and if they are deficient in plant-food and recourse must be had to commercial fertilizers, these leach readily and the full effects cannot be obtained. If the surface is good tillable earth, with a fair admixture of sand, so as to open it up, and the subsoil is somewhat closer so as to hold moisture and prevent leaching, the ideal conditions have been found. 


\section{FLORIDA SOILS}

The soils of Florida are commonly grouped according to elevation and the growth they support, or have supported, in a virgin state. Those commonly used for citrus culture are high pine land, flat woods, high hammock and low hammock. On all of these citrus fruits are grown successfully.

High pine land, as the term denotes, is well elevated and well drained. In a native state it is covered with a growth of long-leaf pine (Pinus palustris), with little or no undergrowth. Sometimes a few high-ground willow oaks (Quercus cinerea) and other trees are found. Land covered with a mixture of deciduous trees is usually conceded to be somewhat superior to that covered with a clear growth of pine. The surface soil generally contains a fair amount of humus; the subsoil is clay or a rather loamy sand, although frequently the clay is not found until a considerable depth is reached. These soils are not rich, but they respond readily to good treatment and make good citrus soils. They contain about .026 per cent nitrogen, .016 per cent potash, .022 per cent lime, and .05 per cent phosphoric acid.

The flat woods land likewise supports a growth of longleaf pine, but the elevation is considerably less and the ground is flat and level. In the southern part of the state, in the vicinity of Miami and Punta Gorda, for example, and generally south of a line from Cape Canaveral to Tampa Bay, the long-leaf pine is replaced by the Cuban pine (Pinus cubensis). Frequently flat woods land is thickly covered with an undergrowth of saw palmetto (Serenoa serrulata), and gallberry (Ilex glabra), and in many places it approaches the high pine land in elevation. Such lands are usually well adapted to citrus cultivation. On the other hand, much of the land designated as flat woods is low and undrainable, entirely unsuited to the growth of citrus trees. The surface soil contains a considerable amount of humus, while the subsoil may be clay, hardpan, or rock. Those subject to 


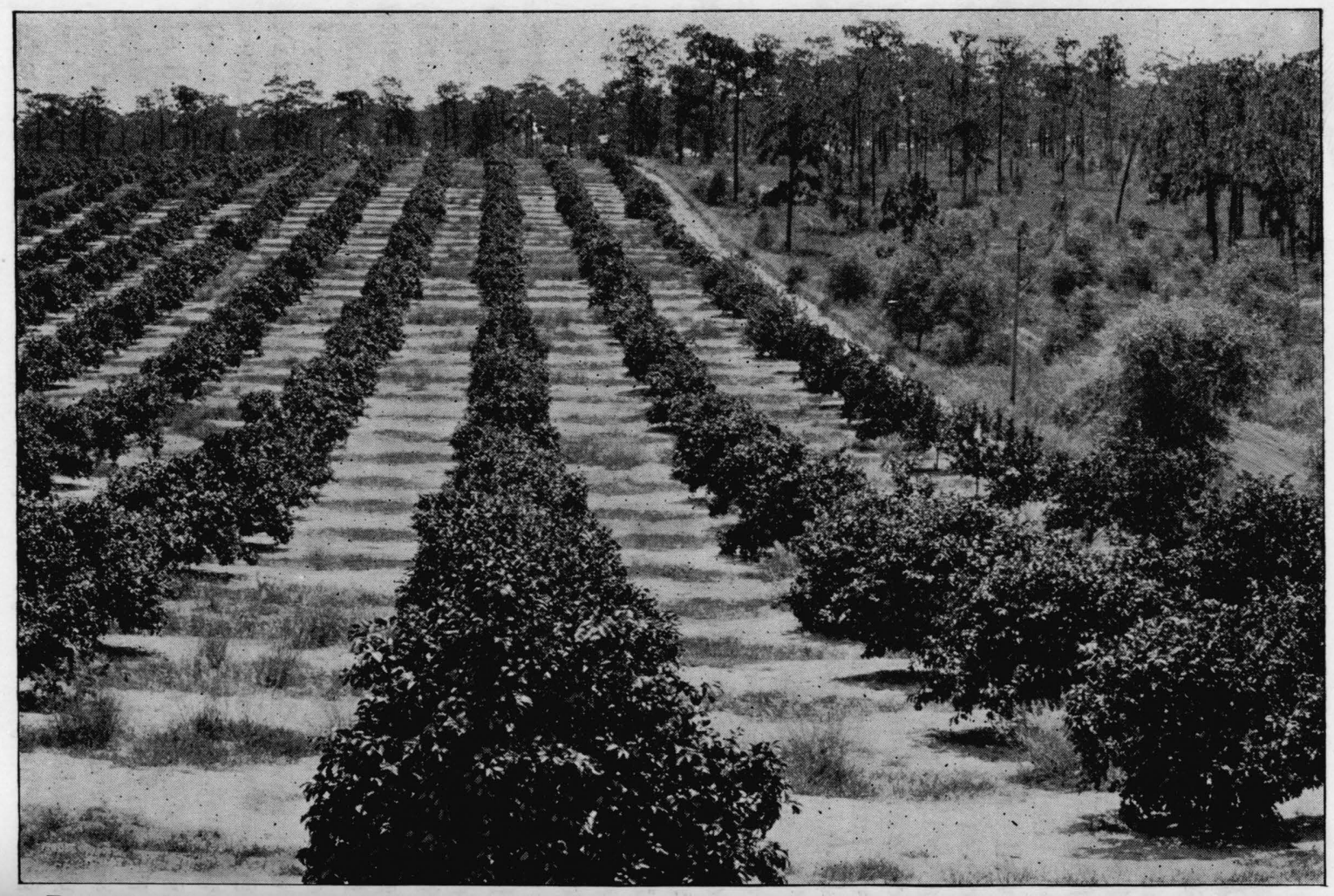

Fig. 122. Citrus grove on high pine land in Florida. The native growth of long-leaf pine and oak is shown at the right 
overflow, not readily drained and which have a hard, compact subsoil, should be avoided. On the other hand, those of intermediate character, as noted above, are among the best Florida citrus lands.

High hammock lands correspond in a large measure to the high pine lands. They are well drained and elevated, but are covered with a native growth of hardwood evergreen and deciduous trees. Among these may be mentioned holly (Ilex opaca), hickory (Carya alba or tomentosa), live-oak (Quercus virginiana), dogwood (Cornus florida), and magnolia (Magnolia grandiflora). Lands of this character are well supplied with humus, have a comparatively deep rich soil, and are well adapted for citrus. The analyses of these soils show about .0658 per cent of nitrogen, .06 per cent of lime, .014 per cent phosphoric acid, and a trace of potash.

The high hammock lands shade off into the low hammocks. The latter are covered with a growth of nearly the same character, but the live-oak is more in evidence and the cabbage palmetto (Sabal Palmetto) is abundant. The surface soils contain a large amount of humus and they are consequently rich in nitrogen. They are generally difficult and costly to clear, but if well drained, or the evil effects of a superabundance of water can be avoided, they are very desirable for citrus fruits. It is on these soils that large numbers of citrus trees have been set and good groves established along the Caloosahatchee River as well as elsewhere in Florida.

In addition to these soils, mention should be made of the hickory or the hickory scrub lands, stretching in broken areas along the shores of the Indian River, from about Cape Canaveral northward. They are covered for the most part with a growth of hickory and the soil is a pure yellow sand with a goodly admixture of humus in the surface layer. In some respects they correspond to the high pine lands of the interior and appear to be well adapted to citrus fruits. The chemical analyses show the following percentage of the 
important plant-foods: .07 per cent nitrogen, .0862 per cent lime, .0431 per cent phosphoric acid and .011 per cent potash.

Other soils are used for citrus culture in the state, but those described above have generally proved most satisfactory.

WESTERN FLORIDA, SOUTHERN ALABAMA AND MISSISSIPPI

In the western part of Florida and the southern, or Gulf sections of Alabama and Mississippi, are large areas adapted to the cultivation of Satsuma oranges on Poncirus trifoliata stock. These are pine lands, now cut over for the most part, formerly supporting a growth of long-leaf or yellow pine. Mostly they are intermediate between the high pine land and Florida flat woods soil types. In many cases they are high and rolling. The surface soil of one to two feet is sandy loam; the subsoil is red clay. In other places the soil is the same, but they are fairly level. The water drainage is good, or can be made so. There are no better Satsuma lands than these. The groves are prolific and they produce fruit of the finest quality. Already numerous plantings have been made, and in the future the developments will undoubtedly continue on a large scale.

\section{LOUISIANA}

In Louisiana, the rich alluvial soils of the Mississippi delta are used for citrus trees. These correspond in some degree to the low hammock soils of Florida, but are much richer and contain more humus. Particular attention must be given to drainage.

\section{TEXAS}

The principal citrus area in Texas is in the lower Rio Grande Valley, in the counties of Hidalgo, Cameron, and Willacy, lying along the northern bank of the Rio Grande River. Arrangements have been made for irrigating about 
400,000 acres, and a large percentage of this is satisfactory for the cultivation of citrus fruits.

The soil, built up by the Rio Grande River in ages past, is composed of silt, sand, and clay. In its native state it bears a growth of mesquite, cactus, ebony, tornillo, and shrubs and trees adapted to semi-arid conditions. With an abundance of irrigation water and good drainage it is an extremely fertile region and a great variety of crops can be grown. The citrus fruits produced-oranges and grapefruit mainly - are of very high quality.

The land lies on different lifts or benches, each of which is fairly level except where the change from one level to another occurs. The higher levels, because of good airdrainage, are best adapted to the cultivation of citrus fruits.

\section{CALIFORNIA}

The best citrus soils in California are on the higher levels and among the foothills. In most parts of the state the actual composition of the soil, whether it be red soil, granite, or sandy loam, does not matter so much as does the drainage and the possibility of supplying water by irrigation.

The soil of the famous Riverside district is of a deep reddish color while the Redlands section takes its name from the color. The mesas are among the best citrus soils of the state, for although the fruit may be produced on other soils, it is not equal in quality to that produced on this class of land and on the foothills. In southern California, the great lemon industry has been built up on the mesas and foothills, lands long untouched, many of them covered with a forbidding growth of cacti, sage-brush, and like vegetation peculiar to such soil and climatic conditions.

In California, lands underlaid with hard pan, alkaline soils, heavy clay soils (adobe), should be avoided. The lower lands, containing larger amounts of humus and moisture, do not produce fruit of as good quality as the uplands. 


\section{CUBA}

In Cuba there are a number of types of soil that may be used for citrus groves. Not all of them are equally adapted, and it will require considerable practical experience to determine which class or classes will be most satisfactory. Not until bearing groves have been grown to considerable age can the question be definitely answered. The health and longevity of the trees, the flavor and quality of the fruit-all are influenced by the character of the soil.

The soils more or less adapted to citrus fruits in Cuba may be divided into three general classes, the sands, red lands, and black lands. Of these, the sandy soils are preferred by many. Soils of this type are easily cultivated, and while some commercial fertilizer will have to be used, other advantages may more than offset this expense. They retain moisture well and, like the sandy soils of Florida, will doubtless produce thin-skinned, juicy fruit of excellent quality.

On the red lands, occurring in large tracts in the provinces of Havana and Matanzas and in smaller areas elsewhere, many old bearing orange trees are to be found. The old groves planted on them have been successful, the chief drawbacks in their management being that they part readily with their moisture, bake and crack in dry weather. They are sticky and pasty in wet weather and, in consequence, are rather hard to till. By incorporating vegetable matter, and perhaps by the use of lime, these conditions can doubtless be considerably improved.

The black lands are likely to produce rank growth in tree and fruit, although by care in fertilizing, when the trees begin to bear, some of this difficulty may be overcome. In choosing the location, attention should be given to drainage, as these soils, particularly when low and flat, are likely to be too wet. 


\section{CHAPTER XVII}

\section{LOCATING THE CITRUS GROVE}

In choosing a location for a grove of citrus trees, a number of points must be carefully considered. The facilities for transportation, susceptibility of the region to frosts, the nature and direction of the prevailing winds, exposure, and the insect problem must all be studied in their relation to the prospective gains, the welfare of the trees, and the quality of the output.

Citrus fruits have a great advantage because they are not perishable in the sense that plums and peaches are, and after being removed from the trees they may be kept for weeks, even with ordinary care. Their ability to withstand the inroads of decay-producing organisms is not dependent upon the resistant power of the inner portion of the fruit, but upon the leathery nature of the cured rind. Their keeping quality has an important bearing on the transportation problem, for with proper care they may be shipped to any of the world's great markets.

The susceptibility of citrus trees to injury from frost decrees that they must be grown in regions far from the effects of rigorous cold, and such areas are far distant from the great markets of the United States in the Northeast and Middle West. Consequently, it is impossible to produce the fruit in proximity to the markets, and this phase of the question may be dismissed.

But in regions where the fruit is grown it is best, other things being equal, to locate the grove in proximity to a railroad station or steamboat landing. Transportation by road is expensive, and a distance of five, ten, or fifteen miles from a shipping point must not be overlooked in the preliminary reckoning of expenditures and returns. Since the development of motor transportation, with which the build- 


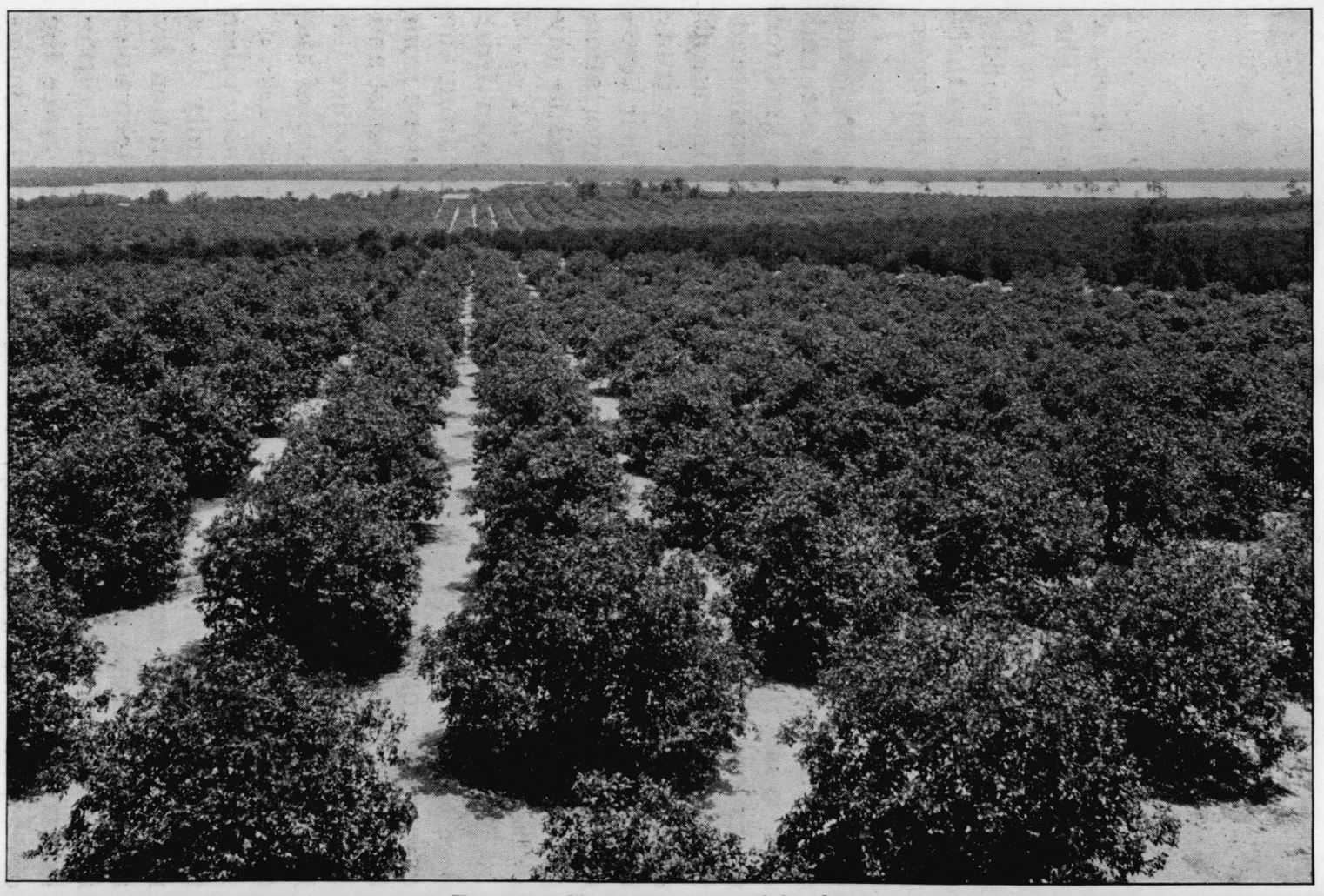

FIG. 123. Citrus groves on a lake shore 
ing of good roads has kept pace, many sections adapted to the cultivation of citrus fruits that formerly were inaccessible have been opened up to the industry. The time from grove to packing-house or depot has been greatly reduced; and from many standpoints the introduction of the automobile and the truck has brought about far-reaching changes in the cultivation of citrus fruits. If the grove can be located conveniently near two railroads, so much the better. Competition sometimes has an influence on freight tariffs and service.

It may be safely said that few districts where citrus fruits are grown within the confines of the mainland of the United States are entirely free from the effects of frost; still some localities are notoriously frosty while others may be considered entirely free, so far as damage to the trees, flowers, or fruit is concerned. Freedom from frosts, or susceptibility to them, is not dependent entirely on either latitude or altitude. A certain situation may not be subject to the baneful effects of frost, while, within a very short distance, another may be repeatedly visited. Even in Florida, where the land is comparatively flat and level, and where one might expect greater uniformity to prevail, isolated spots are visited by frosts while others much farther north escape. The topography of a region, the proximity of bodies of water, the presence of high or mountain barriers, the direction of the prevailing winds, all are factors which largely control the climate of a given region.

It is frequently noted that frosts occur in valleys, hollows, and low areas while the adjacent hillsides or elevated parts are untouched. The cold air drains off into the lower levels and settles there, while the warm air rises to replace it. This interchange of air goes on until frost occurs in the lower area while the higher parts escape. Low ground so situated as to receive the cold air from a higher level should be avoided, a location on the side of the slope or on the top of the elevation being preferable. Even a few feet of rise 
often suffices to protect the trees. Frequently it may be observed that the lower portion of a grove is badly frosted while the remainder, only a few feet higher, escapes. Sometimes the banking of the cold air is materially increased by a wall of timber so placed, adjoin.ng the lower portion, as to prevent air-drainage. This trouble may be obviated by opening up the timber belt sufficiently to allow the cold air to drain through.

It will be seen from the above that if the grove or a part of it is in a depression, air-drainage may be actually injurious, but, on the other hand, it may be turned to good advantage if precaution is taken to choose a proper location. The site for the grove in regions subject to damage by frost should be on sloping or elevated ground, to permit the escape of the cold air.

It is very desirable to locate the grove on the shore of a lake or other body of water, if the body is of some extent. The proximity of such bodies of water have much to do with equalizing the temperature. In many Florida districts there are numbers of lakes and rivers, and in those sections it is best to locate the grove, if possible, either on the east or south side. The freezes that have struck the state have generally come either from the north or northwest. If the lake be of considerable depth, the water does not part with its store of accumulated heat so rapidly as when it is shallow, and the heat slowly given up will raise the temperature in some measure. In prevention of frosts, bodies of water play an important part. The heat which they have accumulated in the day is given off slowly during the night, thus raising the temperature of the air over the adjoining land.

Frosts and freezes must not be confounded. Frosts generally occur in restricted areas on clear still nights. Freezes, on the contrary, usually follow or accompany storms of wind and rain, being associated with meteorological pressureareas which affect great stretches of territory. 
Solid timber areas frequently do much toward staying the progress of freezes and preventing damage. But these areas should be opened up sufficiently to allow movement of air, or a still air-space may be created into which the cold air settles. Moore, in his "Hand-book of Orange Culture," recommends clearing the land and the laying out of the grove in blocks, each block separated from the adjoining ones by a belt of the native timber. The old twenty-acre grove of W. S. Hart, of Hawk's Park, Florida, was laid out in blocks of five acres, separated by belts of native hammock growth fifty feet wide. Ditches were run along these belts to prevent the roots of the native trees from reaching out into the grove. Mr. Hart, on a number of occasions, demonstrated the great advantage of this system of planting. This plan can be unhesitatingly recommended to anyone about to locate where frost protection is necessary. When open fires have to be resorted to, the heat is confined and becomes much more effective. Cutting off the rays of the morning sun is a point of further importance. If trees have been touched by cold, their power to recuperate is greatly increased by the shade provided in such a location.

\section{WINDBREAKS}

The foliage and fruit of citrus trees may be greatly injured by high winds. In coastal regions such winds frequently blow almost steadily and great damage is sometimes wrought. In fact, it is well-nigh impossible to establish and maintain a grove under these conditions unless shelter of some kind is provided. If the native growth is sufficient to afford protection, a belt should be left; if not, a windbreak should be planted or an artificial one constructed. In the famous Indian River district in Florida, windbreaks have to be provided along the shores of the river, to break the force of the whipping wind. These shores are usually fringed with a dense growth of cabbage palmetto and other trees, and this growth has generally been left by planters, but 
occasionally it has been necessary to build a break. An artificial break may be built of slats, sixteen feet long, three inches apart, and nailed to three two-by-four stringers supported by five-inch posts placed ten feet apart. To give additional support, the whole structure is guyed with No. 8 wire every twenty feet on opposite sides.

A slat windbreak may be advisable if land is very expensive, or if it is felt that shelter must be provided without delay. Generally, however, it is best to provide a more substantial one of trees. In California the Monterey cypress, pepper-trees, gums, and silk oak, are most desirable. The cypress is generally planted alone, while the pepper-trees and gums are frequently mixed. The pepper-trees are spreading while the gums are tall and upright, consequently the combination is good. The best trees for windbreaks in Florida are the upland willow oak, willow-leaved oak, and

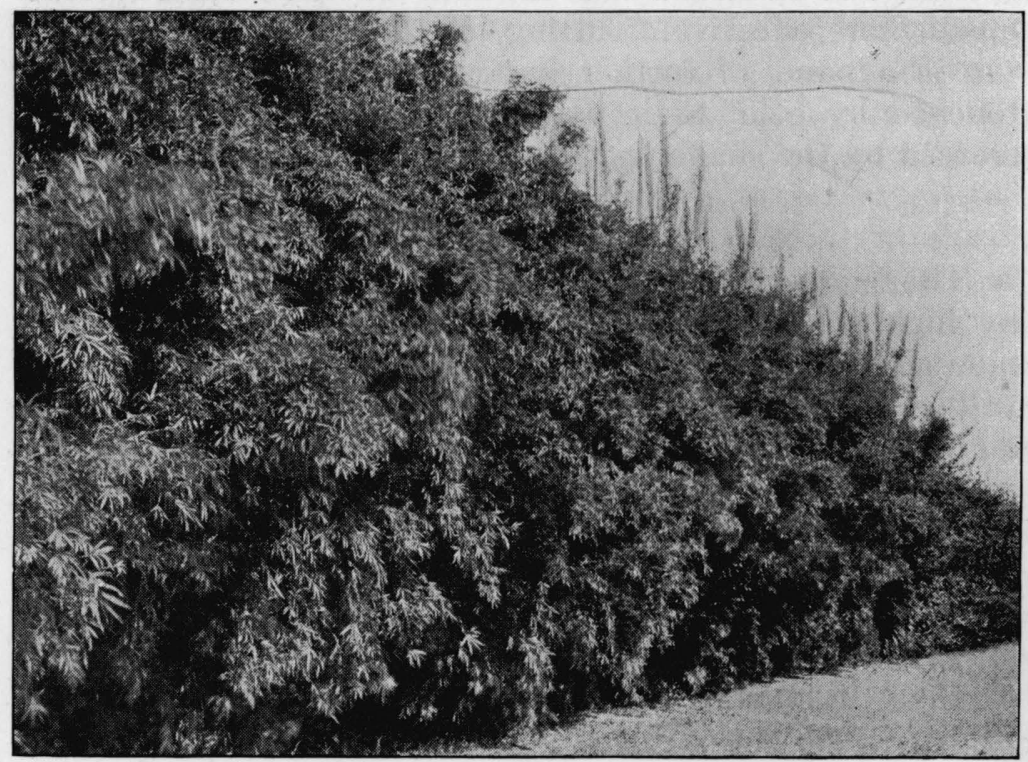

Fig. 124. A windbreak of bamboo 
other native trees, as they are usually exempt from frost injuries. The Australian pine (Casuarina equisetifolia) and camphor-tree are also good. The latter is considerably hardier than most species of Citrus, yet not sufficiently so to render it a very desirable tree to use in the more exposed places. It does not do well on high dry lands. The Australian pine is also subject to frost injury and should be planted only in the southern part of the state. Where frosts do not prevail, the Mexican lime is desirable if planted as a hedge and allowed to attain a height of ten to twelve feet. Bamboos make an excellent windbreak (Fig. 124). Since their roots spread far out from the clumps and occupy about the same depth of soil as the feeding roots of citrus, they should be given ample space in which to grow without encroaching upon the trees they are to protect. Only kinds which grow in clumps should be used. Bambusa argentea and $B$. argentea striata, for example, are good sorts for the purpose.

Preferably, the windbreak should be planted at the same time as the grove. In any case, the ground should be ditched between the line of windbreak and the first tree-row, to prevent the roots of the windbreak from spreading out into the grove and depriving the citrus trees of food and moisture. This ditch may be filled up again after cutting the roots, if so desired, but will need to be opened and the roots cut back again every third or fourth year. It need not be wide; a foot or fifteen inches is enough, with sufficient depth to cut off the surface feeding roots.

Generally speaking, an exposure opening to the south is best for citrus trees, but in frosty districts it is advisable to plant on the south or east side of a lake or other body of water, as already stated, in which case the grove should be set on ground sloping toward the lake.

In irrigated districts, a piece of ground should not be chosen which cannot be watered, and the prospective planter should assure himself that the available supply will 
always be ample for his needs. Many failures have resulted because this caution was not observed. As one writer has expressed it, "find water, then find a piece of ground to put it on."

\section{LOCATION WITH RESPECT TO PESTS}

The insect problem is one to which some consideration may be given. Those affecting citrus fruits are well distributed, and it is perhaps not too much to say that conditions are nearly equalized throughout the country. Regions free from one pest generally have another equally troublesome. No one section can expect long to remain free from their inroads. Still, some climatic conditions appear to be more favorable for the development of some insects than others. The black scale of citrus trees is a great pest in the coast regions of California, while farther inland it is not so troublesome. 


\section{CHAPTER XVIII}

\section{PREPARATIONS FOR PLANTING}

If the piece of land chosen for the grove is covered with timber, one of two plans may be adopted, partial or complete clearing. In all cases the latter is preferable, but the former can be made to give good results.

If it has been decided to plant the trees in a partial clearing, the rows in which the trees are to stand should be cleared out, or the ground should be staked off and a space in the form of a circle cleared for each tree. This row or space should be carefully cleared. No roots of the adjoining standing timber should be left in it, and it should be free of all roots to a depth of fifteen to eighteen inches. It is important that all large roots be taken out to even a greater depth, as these frequently harbor insects and root diseases which may attack the citrus trees later on and cause much trouble. The timber that stood on the ground may be burned and the ashes returned to the soil, or the larger wood may be saved for firing in some cases, or it may be piled and allowed to rot on the ground, while the brush in small quantities may be used as a mulch. All the remainder of the standing timber should be cut out not later than the next winter, and every precaution must be taken to guard against the newly planted trees being deprived of food and moisture by the native growth.

In clearing standing timber, windbreaks should always be allowed to remain. A fifty-foot belt usually suffices, and the plan of planting in small blocks with shelter-belts intervening is advisable, wherever possible. In exposed regions this plan will be a material safeguard against damage from cold.

Having decided to make a complete clearing, it is best to begin operations one year previous to planting. The stand- 
ing timber and all growth should be cut down, and then the stumps should be removed. It is always advisable to use a good stump-puller, and dynamite is often a necessity. The cost of clearing land in the Florida districts, by digging and burning, by means of a stump-puller, or by using dynamite, is practically the same. If time is an object, however, the work can be accomplished more quickly by using dynamite to blow the stumps out, or by employing a stump-puller. Clear thoroughly and either dispose of the wood and brush and plant a cover-crop in summer, or allow the brush, roots, and trunks to shelter the ground in the summer. If the latter course is adopted, the brush should not be piled but allowed to remain spread out over the surface.

Preferably, the site chosen for the citrus grove should be cleared the winter before the trees are planted. After having removed the standing stumps and rubbish, the ground should be plowed, harrowed, and leveled. In the intervening summer season, a cover-crop should be planted. The roots of this crop open the soil, nitrogen is added (if a legume is planted), humus is supplied; on the whole, no better preparation can be given the soil for the future grove than by adopting this plan. If possible, it should always be followed, and if a piece of old ground is to be planted in trees it is the best method of insuring satisfactory results. In the latter case, more than one season may be required to get the ground in shape. As a cover-crop, beggarweed, velvet beans or cowpeas may be planted, and the remarks on these crops in Chapter XXI apply equally well here. Cowpeas generally give excellent results on new ground. W. S. Hart, of Hawks' Park, Florida, a successful grower of many years' experience, makes the following statement regarding this method of preparation: "The quickest profit that I ever realized from an orange grove was where I thoroughly worked the soil and planted it in cowpeas the first year after clearing, and before I set the trees."

Before planting the trees, the ground should be put in 
thorough tilth. It should be loosened up and stirred, but it is not advisable to turn the top soil under unless the subsoil brought to the surface is fertile. The soil should be stirred to a good depth in all cases. If the lower soil is firm and compact, a subsoil plow should be used, to cause the roots to penetrate. After the plowing, use the cultivator or harrow; this, followed by the float or planker, will leave the ground smooth and mellow, in excellent condition both for staking off and for planting.

Dead furrows should be avoided unless it is desired to use them afterward as open ditches. To do this, the plowing should be done from a line down the center of the field, two furrows being first thrown together, then others added on either side until the work is completed.

\section{GROVE PLANS}

A number of different systems may be employed in the planting of citrus groves. The most important of these are triangular, square or rectangular, hexagonal or septuple, quincunx, and double or mixed plantings.

Triangular system.

The triangular system is sometimes referred to as the hexagonal, but the latter is one of equilateral triangles, while the term triangular, as here used, is applied to the method of planting in inequilateral triangles. For example, in Fig. 125, the trees are set in rows thirty feet apart in the rows running east and west. But in every other row the trees are set, not on the

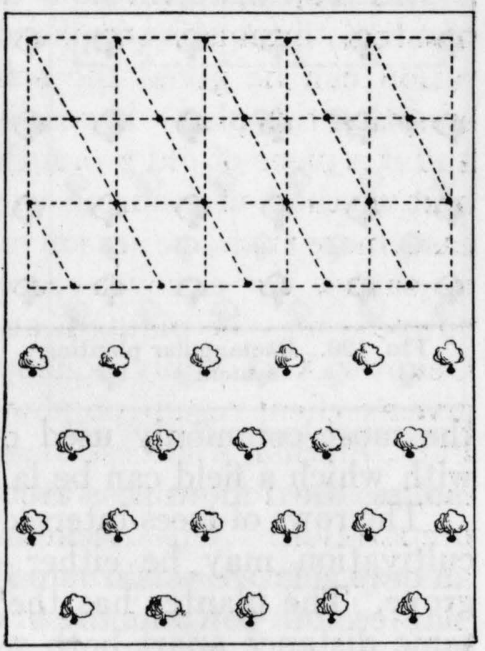

FIG. 125. Triangular system of planting 
corners of the thirty-foot squares, but half-way between the corners, and the distance from tree to tree diagonally across the field, in consequence, is more than thirty feet. In fact, the trees are about thirty-three and a half feet apart. By this method fewer trees are planted to the acre than by the square system. In planting a grove by the triangular method, the field is first laid out in squares, then a line is run diagonally across the field and a tree is planted wherever this line passes through the corners or cuts the side of a square.

There is little to be gained by this system of planting, except that it makes it possible to cultivate readily three

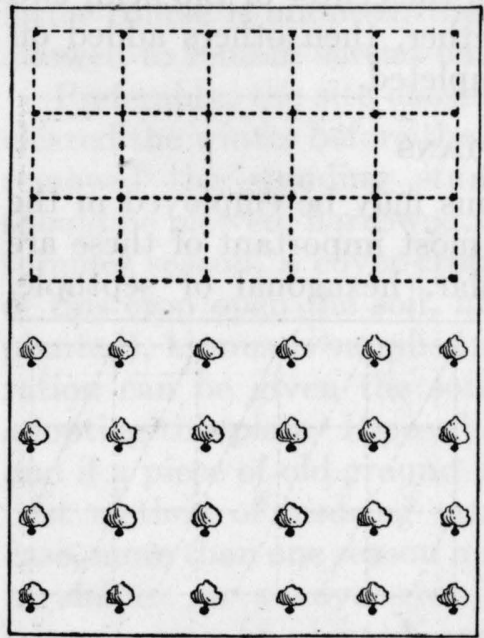

FIG. 126. Rectangular planting system

ways and the trees are given somewhat more space. Planting trees according to the triangular system at thirty-foot distance, for example, is the same as planting in rectangles 30 by $33 \frac{1}{2}$ feet, so far as the number of trees is concerned. Triangles laid out on twentyfoot squares would be the same as planting in rectangles 20 by 22.4 feet.

Square or rectangular system.

In this system is included only the methods of setting trees in rectangles, either square or oblong. It is by far the most commonly used of all the systems, and the ease with which a field can be laid off is greatly in its favor.

The rows of trees intersect each other at right angles, and cultivation may be either crosswise or lengthwise of the grove. The planter has the choice of placing the trees the same distance apart both ways, or of planting them closer together in the rows than the distance between the rows. 
It has been argued that space is not equally divided among the trees, and while this is apparently true, yet, on the other hand, the roots of citrus trees, in most cases, penetrate and permeate all the space allowed in ordinary distances anyway. The roots will certainly secure all the food and moisture there is in the top fifteen inches of soil. When trees are to be planted by this sytem, the stakes must be so set as to be exactly in line, whether viewed from the end or from the side of the field (Fig. 126).

\section{Hexagonal, septuple or equilateral triangle system.}

By this system, six trees are set equidistant from a seventh placed in the center. The basis of the system is not the square but the circle, since the radius of the circle is approximately equal to one-sixth of the circumference of the circle. The name septuple, sometimes applied to this system, refers to the fact that the number of trees in each group-unit is seven. Equilateral triangle system refers to the planting of the trees in triangles of which all sides are equal (Fig. 127).

The hexagonal is the only system in which each tree is equally distant from each of its adjoining neighbors, and the only one that equally divides the

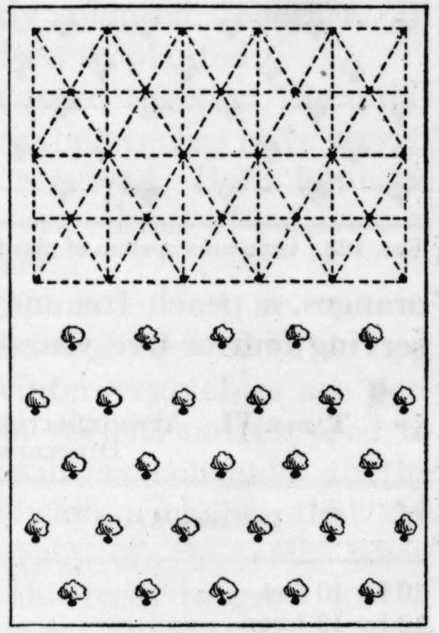

Frg. 127. Planting in hexagons space. By this method, about 15 per cent more trees can be set to the acre than by the rectangular.

For permanent plantings at regular distances, this system and the rectangular should be recommended before the others. Both are well adapted to cultivating through a grove in several directions. 
Quincunx system.

By this system, four trees constitute a square, and a fifth is set in the center. Therefore, the number of rows is greatly

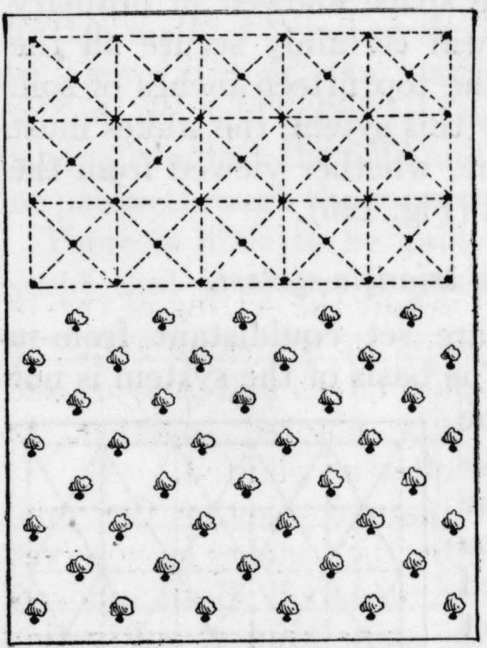

FIg. 128. Quincunx system of planting increased and about 78 per cent more trees can be set to the acre than by the rectangular system. For permanent plantings of varieties of uniform size, it does not possess any particular advantage, but if it is desired to set a tree of some-smaller variety in the center of each square, then the quincunx system is desirable (Fig. 128).

In double plantings, when the intention is to remove some of the trees, this system is to be recommended. If, for example, peaches are set with oranges, a peach tree may be set in each square, and after serving four or five years of usefulness may be cut out.

Table VI. Approximate Number of Trees to the Acre for Different Planting Systems

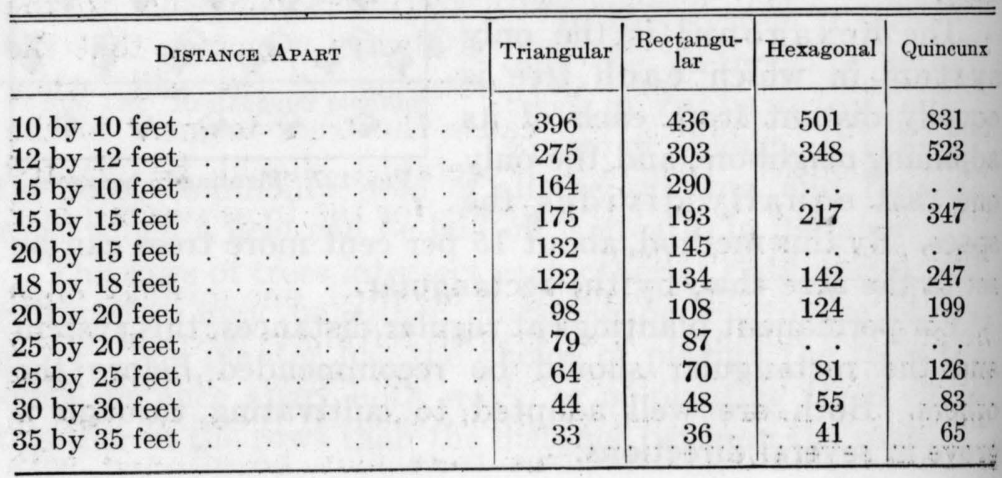




\section{Hedge plantings.}

Some growers have occasionally set the trees to form a dense line one way while a space of twenty feet or so is left between the rows. Large quantities of fruit are obtained from a small area and the system, for a few years at least, works well, but it can scarcely be recommended for general adoption. Eventually the trees crowd each other and many of the branches may die.

Double planting.

By this system of planting is meant the setting of two or more kinds of fruit-trees or plants in the same area. In Florida, citrus trees and pineapples, citrus and guavas, and citrus and peaches are frequently planted together. In Louisiana, citrus and pecans are often so planted.

When peaches and citrus are planted together the quincunx method may be used, and after the peaches have served their term of usefulness they are removed. Both kinds of trees succeed well when given the same kind of cultivation and supplied with the same fertilizer.

Other double plantings may be made, but no tree or plant should be set with citrus trees and allowed to occupy the ground to their detriment. Winter vegetables are permissible in the citrus grove only in regions not exposed to frost, and when supplied with fertilizers congenial to the trees. In frosty regions there is always a chance that the cultivation, fertilizing, and watering of the soil, when planted in vegetables, will cause the trees to grow in the winter months. Generally, vegetables should be planted elsewhere than in the citrus grove, for the trees succeed best when given all the space.

Whenever double-planting is adopted, one mistake must be guarded against. The favorite fertilizers used in many citrus districts for crops other than citrus contain large amounts of organic sources of nitrogen. If these are used in a double planting, the citrus trees may be affected with 
die-back. A fertilizer containing sulfate of ammonia and nitrate of soda as sources of nitrogen, is, in many cases, a safer one to apply.

\section{LEVELING AND SMOOTHING}

Lands on which citrus trees are to be planted are frequently rough. If the ground is left in this condition, it will prove to be a considerable nuisance in after years, as the rough surface will interfere with all kinds of work. Pains should be taken to make the ground level and smooth. Small abrupt elevations or knolls should be removed. Long sweeping slopes are not objectionable, and, if they give the right exposure, are a decided advantage. In the irrigation districts they are necessary for the successful distribution and disposal of water. But in those districts small knolls, two to three feet in height, or less, may act as a barrier over which water cannot be successfully carried. Grading should be very carefully completed before planting, and only after a careful survey of the ground. In fact, the best advice is to turn this part of the work over to a competent surveyor.

Before attempting to grade the ground, it should be plowed. The depth will depend on the nature of the soil and the character of the surface. It may be necessary to use the

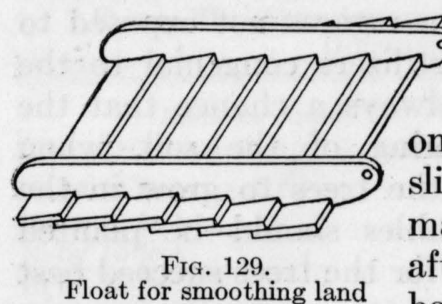
scraper to remove some of the knolls, in which case the plow should be run somewhat deeper on the higher portion. If only very slight inequalities are present, they may be disposed of by harrowing after plowing and then following the harrow with the float or planker shown in Fig. 129 to level the ground.

This float is made of six pieces of eight by two-inch plank, seven feet long for use with horses or mules, and twelve feet or longer for use with the tractor. Two of these pieces are rounded off at each end and a hole is bored in one end of each. 
These two pieces are then notched as shown in the figure. The notches on the two pieces must correspond, and the first notch should be cut about a foot back from the front end. They are two inches deep at the front, and slope out to the edge of the plank six inches back, thus leaving two inches of the plank for overlapping. The six pieces of plank are then laid in the notches and nailed or bolted firmly in place. A chain is run through the holes already provided and to this the whiffletrees or tractor chain are attached. This has proved to be a very satisfactory device for leveling lumps and even for filling up shallow depressions.

\section{DISTANCES FOR PLANTING}

Growers differ greatly regarding the distance apart at which citrus trees should be set. As a matter of fact, no set of distances is best for all conditions. Many things have to be considered in deciding the point. Much depends on the natural moisture-content of the soil, the amount of water that can be secured either by irrigation or from rainfall, the fertility, the kind of stocks, the variety of tree, and whether it is necessary to protect the trees from frost. A canvass of the situation in Florida some years ago showed that sweet oranges are, or have been, planted all the way from 15 by 15 feet to 35 by 35 feet; pomelos the same; mandarins 15 by 15 feet to 25 by 25 feet; lemons 20 by 20 feet to 30 by 40 feet; and limes 15 by 15 feet to 20 by 20 feet.

If the trees are planted in a region subject to frost, and protection by means of open wood fires is to be practiced, it is best so to plant the trees as to leave sufficient space for firing. A plan sometimes adopted is to plant sweet orange trees 15 by 15 feet and omit every third row. It must be remembered also that the effects of frost or freezes is not so severe on densely planted groves as it is when trees are separated by wide avenues through which the wind sweeps unchecked.

The insect problem must be considered as well. If spray- 
ing or fumigating has to be adopted to control insect pests, the trees should stand sufficiently far apart to allow either of these operations to be performed conveniently.

In general it may be said that if trees are planted in rectangles, it is better not to place them in squares but in oblongs, the spaces between the tree-rows being greater than the distance between the trees in the row.

The following distances may be regarded as approximately correct, although much depends on the habit of growth of the different varieties in each group:

Kumquats 10 to 12 feet.

Mandarin oranges

Lemons and sweet oranges 15 to 20 feet.

Pomelos 20 to 25 feet.

Limes 25 to 30 feet. 15 to 20 feet.

LAYING OUT BEFORE PLANTING

The trees should stand in straight rows. They look better and cultivation is easier. Nothing looks worse than zigzag rows of trees, and it is impossible to plow or cultivate straight through the grove.

Laying out squares or rectangles with the plow.

If a good plowman can be secured, satisfactory work can be done with the plow. In some cases, a man is found who needs nothing in the way of a guide except two or three stakes, but with a sufficient number of stakes and a marker attached to the plow, good results can be secured by almost any plowman.

Furrows should be run both lengthwise and crosswise of the field, their intersections marking the place where the trees are to stand. A stake should be set for each tree, ordinary building-laths answering very well for this purpose. It is essential that a true square corner should be secured. This may be accomplished by sighting with an ordinary carpenter's square set upon three posts. 
Laying out in rectangles with a wire.

A wire long enough to reach down one side of the field should be provided. Stretch this straight between two posts and mark on it the distance the trees are to stand apart. At each point marked, firmly twist a piece of small wire about the larger one. These should then be soldered in place. It will not do to let them shift. This wire may be gathered on a roller when not in use.

Measure off along both ends of the field and set small pickets on the tree-rows. Tightly stretch the wire down the first tree-row, attaching it firmly at the ground-level to a pair of good stout posts. Then plant a lath stake at each mark on the wire. Set all of them on the outside of the wire, so as not to interfere with moving it. When this row is completed, lift the end stakes with the wire attached, stretch on the second row, set the stakes as before and repeat the operations until the work is completed.

\section{Laying out in triangles.}

This system can be most easily marked out by using the wire already described. On every other row stretch the wire so that exactly one-half of a tree-space will lie outside the end tree-row, then proceed to set the stakes on the marks on the wire as before.

\section{Laying out in hexagons.}

Stretch the wire down one side of the field and firmly set the stakes, or lay out the base-line by any method, firmly setting a stake for each tree. Then procure two pieces of wire with rings at each end, the length of wire and rings to be exactly the distance between the stakes as set on the baseline. Stretch these wires out toward the side where the next tree-row is to stand. At the point where the rings overlap, set a stake for a tree. Remove wire No. 1 and set it on the third stake in the base line, stretch the two tight and set a 
tree-stake. Repeat as often as necessary. In setting the third row of stakes, use the second as a base-line and so on.

Laying out in quincunx.

By this method the trees are in groups of five, four forming a square, the fifth placed in the center.

The best plan is to lay out with a wire, although the plow may be used. In setting with the wire, each space on the wire should be divided in the center and marked as before. If, for example, to reduce the discussion to a concrete form, we say the trees are to be set in squares of twenty-seven feet, with a fifth in the center, divide the spaces on the wire and mark each one at the thirteen-and-a-half-foot point. On the base-line set the trees at the twenty-seven-foot point. Then stretch the line for the next row, thirteen and a half feet in from the base-line. On this row set the stakes at the thirteenand-a-half-foot marks, thus leaving the stakes twenty-seven feet apart as before. Set the third row to correspond with the base-line, the fourth with the second, and proceed in this way until the work is completed. 


\section{CHAPTER XIX}

\section{PLANTING CITRUS TREES}

The planting of the trees is the actual starting of the grove, and any reasonable amount of time and care taken in the operation is well spent. All the details should be carefully looked after and the work done either under the supervision of a competent foreman or the direction of the owner himself. The varieties must be selected, the trees purchased, the ground laid out, and the trees set. When the earth is placed about the last tree, the surface raked off and left level, or with a basin about the tree to hold water, the work may be considered finished.

\section{SELECTING VARIETIES}

In the colder or more exposed sections it is best to plant the hardier varieties and those which mature early. No citrus fruit will stand the same degree of frost as the tree on which it is produced, and if it is sufficiently mature to pick before cold comes on, it is a decided advantage; the cost of protection will be lessened materially. It should be borne in mind that early-maturing varieties should be planted for early shipments. Green fruit should not be shipped just because the market happens to be good. It is ruinous to the reputation of any section that carries on the practice.

Growers farther south, or in locations free from the effects of frost, should consider late varieties. Either very early or very late fruit usually brings the highest price because the midseason market is abundantly supplied. By growing late varieties, competition with the regions producing early sorts will be obviated.

It is, however, the best policy, when weather conditions permit, to make a selection of such varieties as will give fruit continually from the early shipping season until the 


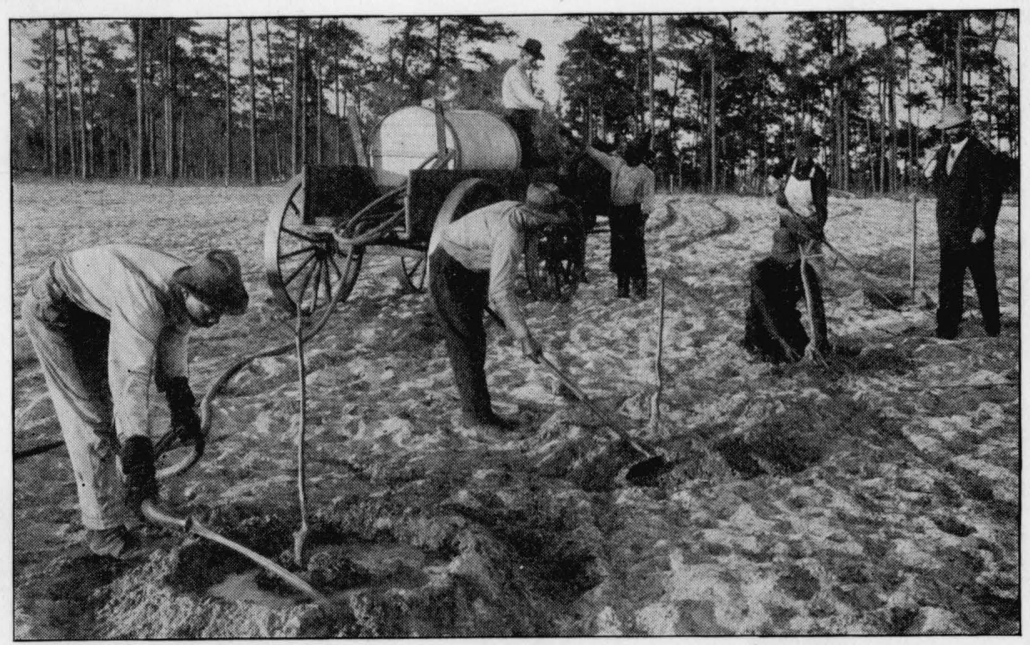

FIG. 130. A planting crew at work. The man farthest back on the tree-row is digging a hole, the next is setting the tree, the third is making a basin, while the one in the foreground is filling the basin with water from the tank wagon.

end. The grower who can do this has his fruit in the market all the time, and, if of good quality and properly handled, his customers can be held for the whole season. Most handlers of fruit prefer a steady supply from a reliable shipper.

The number of varieties chosen should not be large. Only the amateur or the nurseryman who desires a known and reliable source from which to secure budwood or to test the relative merits of varieties, should attempt the planting of any large number. It does not pay in dollars and cents. At most, a sufficient number of varieties should be selected to give a continuous crop of good-sized marketable fruit throughout the shipping season.

Because certain varieties fruit well in some sections and bring fancy prices, planters too frequently jump at the conclusion that the same sorts will thrive in other localities. In California the Bahia is the commercial orange, but it would be folly for a commercial grower in Florida to plant it. 
While it fruits fairly well on rough-lemon and trifoliate-orange stock, even then it is extremely doubtful whether the variety will hold and mature sufficient fruit to make it profitable. The point in question is further illustrated by the action of some California planters immediately following the disastrous freeze in Florida, 1894-95. The demand for pomelos could not be supplied, and the price increased enormously, which led many California growers to plant heavily. In 1900, Wickson said, "The results of these attempts were not satisfactory, and unless some new conditions should arise, it is possible that the California pomelo passion may subside as rapidly as it uprose." Only Florida varieties were planted, and while the growers of pomelos in California have met with some measure of success in the last two decades with the Marsh pomelo, yet the industry as a whole has not developed as in Florida, and Wickson's forecast was entirely correct.

Another problem which frequently arises concerns the relative number of each citrus group that should be planted. In most groves there are pomelos, mandarin oranges, and sweet oranges. How many of each group would it be well to set out? No one can say but the man who is going to set them. He should know best what are his aims and objects. The mandarin orange, or its variety, Dancy tangerine, is of exquisite quality, but it is a fancy fruit; the sweet orange is a staple commodity, always in demand, and never out of season; the pomelo has become a staple and all markets have not been reached yet. It is a new fruit commercially, but it has come to stay. The writer once said, "The sweet orange must, however, be considered the staple product, and it would probably be best to make three-quarters of the planting from this group, leaving the remaining one-fourth to be divided between the pomelos and mandarin oranges." At this time this advice is as good as can be given. For many years, Florida planters set pomelo trees in large numbers. Larger acreages were set than conditions warranted, and had 
it not been that an outlet for grapefruit through canning was found, and other favorable conditions intervened, probably it would have become necessary to top-work many of the trees.

\section{PURCHASING TREES}

Citrus nursery stock matures in autumn and is put on the market during the winter months-November to March. Whether for winter or summer planting, the trees should be purchased early. Nothing is gained by leaving the purchase of required stocks until near the time of setting, and the prospective planter may find himself without trees. "First come, first served" is true in purchasing nursery trees, and he who comes first will be best served. The supply of nursery stock is sometimes inadequate to the demand.

As a general rule, it is best to purchase directly from the nurseryman. A legitimate nursery business may be done through properly accredited agents, but too frequently it is difficult to obtain definite information regarding the kind of stock and where it is grown. Should a mistake occur in dealing with a responsible nurseryman, he will always be willing to rectify it, but with an agent the responsibility is too often shifted.

If possible, the prospective purchaser should visit the nursery, see the conditions under which the trees are grown, make a thorough inspection and choose the trees, become personally acquainted with the nurseryman and buy only from those of good repute. In most cases there are no marks by which the genuineness of a variety may be known, and in the end the only assurance the planter can have that the stock is true to name is the truth and honesty of the man from whom he purchases. Fortunate is the nurseryman whose character warrants a reputation for square honest dealing.

If orders arrive late, the vexed question of substitution of varieties usually arises, but if the orders have been placed 
early this difficulty is not so probable. The planter with welldefined ideas of what he wants should be content with nothing except what he orders. Provided one nurseryman cannot supply the desired trees, he should try elsewhere before changing the list. In some cases, varieties are so nearly alike that substitution is permissible.

The directions for shipment should be plain and explicit, the route given, the time when shipment is to be made, and the address written legibly.

The best citrus tree for setting has a root system about four to five years old, with a stocky, healthy vigorous top of one or two season's growth. Trees should be free from scale and other insect pests and should not show signs of poor stunted growth. Nor, on the other hand, should they show evidence, in long internodes and sappy angular growth, of having been unduly forced to bring them up to size. Some planters have thought to gain time by purchasing large nursery trees, four to five years or even older, but in the end they have generally found that nothing is gained and frequently much is lost. If given particular care and attention, well supplied with water and planted in a favorable season, they sometimes repay the trouble, but such trees are a poor investment for the average planter. No mistake can be made in choosing first-class trees with a caliper of not less than five-eighths of an inch, measured two inches above the point at which the bud was inserted. The very best that can be secured is the cheapest in the end, and poor stock is dear at any price. One should avoid hard stunted stock.

The price of citrus stock is, of course, subject to the laws of supply and demand. The great increase in labor and material costs have in recent years augmented the prices charged for high-grade citrus trees.

For many years citrus nursery trees were graded according to height. Later the basis was changed, giving the diameter of the tree calipered two inches above the point at which the bud was inserted, and the height of the tree as 
well. Since the latter is of no material consequence, and as the common practice is to prune back the trees before packing and shipping, most Florida nurserymen now grade and sell citrus nursery trees by caliper taken two inches above the point of bud insertion, except in the smaller sizes.

The Florida system of grading and the prevailing prices of trees a thousand for $\mathbf{1 9 2 5}$ are as follows:

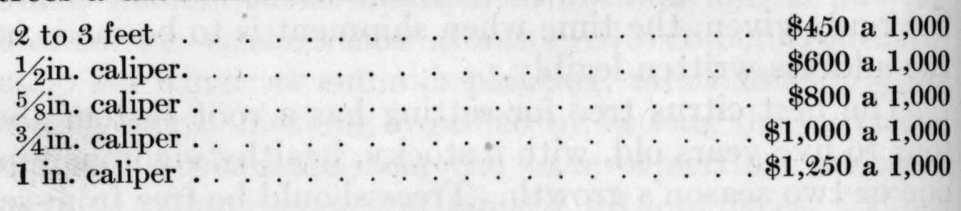

Trees of the mandarin group are priced higher because of their more slender growth. All trees are usually pruned back to stubs 16 to 18 inches long before shipment.

The California system of grading is:

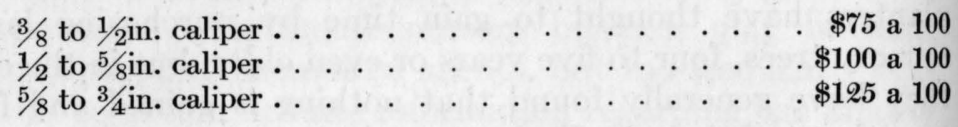

TIME TO PLANT

As already noted, citrus trees are not periodic in their growth. Several growths are made each year, and as long as they are transplanted during their dormant periods, they may be set out at almost any season, so far as the condition of the tree is concerned. Nevertheless, much better results attend the transplanting of the trees at certain periods because of more favorable climatic conditions. The best time for setting citrus trees in California is in spring, just after the completion of the first growth and before the starting of the second.

In Florida and the Islands, trees should be planted during the winter months, or just after the beginning of the rainy season in early summer. Some hesitate to plant in winter in certain sections because of the risk of injury from frost, but, all things considered, it is more satisfactory to set the trees 
then and, if necessary, bank them immediately after planting. Bearing in mind that the dry season in Florida generally begins in March, it is best to set the trees some time between November 15 and February 15. The winter rains settle the soil firmly about the roots, which make some growth, the cut surfaces at least callus, and with the warmer days of spring they start off vigorously. Summer planting is successful, if the trees can be secured in a dormant state and sufficient water is provided, either by irrigation or rainfall. It sometimes happens, however, that summer-planted trees have a tendency to prolong their growth too late in the fall.

\section{PLANTING}

When trees are shipped in boxes or bales, as is most common, they may be unpacked as soon as received and heeled-in in a shady place. Plow out a furrow of sufficient length to accommodate the trees when spread out singly, side by side. With a shovel slope off the furrow at an angle of forty-five degrees, place the roots of the trees in the

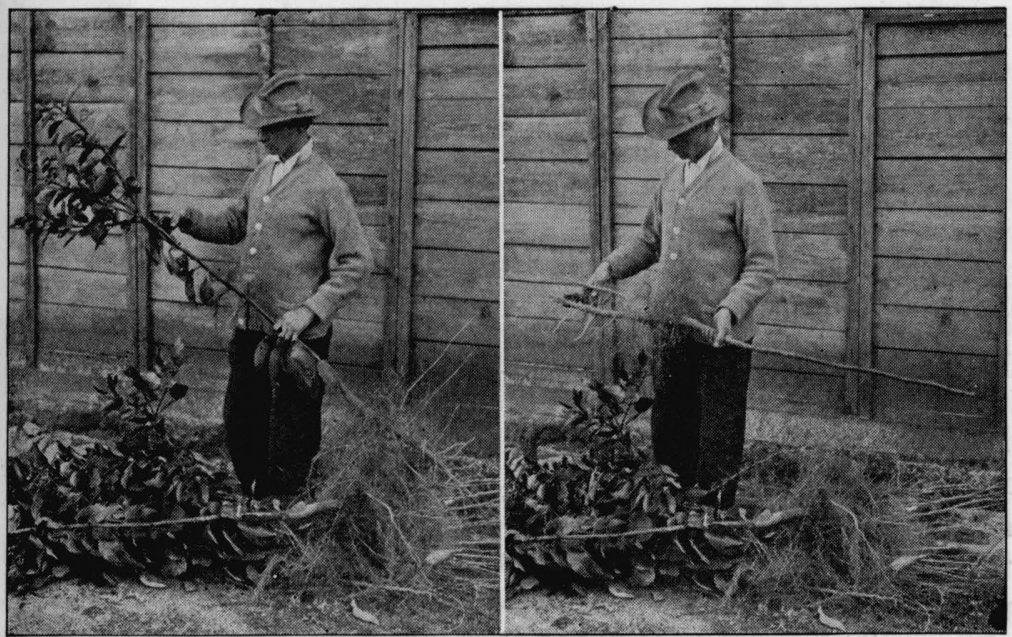

FIG. 131. Pruning roots and tops and defoliating trees before planting 
furrow, spreading them out well, pack the earth about them, and water.

Everything having been arranged for planting, remove the trees from the furrow a few at a time, as needed for setting, trim the roots and wrap them in a damp blanket for carrying to the field. Under no consideration should the strong sunlight or the wind be allowed to strike the roots, for they are extremely susceptible to injury in this way.

In trimming the roots, remove the broken ones, cutting them off smoothly with a sloping cut from the under side. The advantage of a smoothly cut root-end over a torn and ragged one is that it calluses and heals much more readily. From the root, just back of the callus, large numbers of small roots start out which soon take the place and do the work of the portion removed. A part of the small fibrous rootsall if they have become slightly dried-may be removed, and all roots cut back somewhat at the tips. For their food supply from the soil, citrus trees are dependent on the development of large numbers of small fibrous roots. Roothairs are not produced. When a double tap-root is present, it is best to leave one of the parts somewhat longer than the other. Some idea of the root systems of trees as they come from the nursery and the method of trimming may be secured from an examination of Figs. 131, 133, and 134.

In recent years it has become customary to defoliate all trees before shipping or planting. but under some conditions the presence of a few leaves helps the trees to start into growth much more satisfactorily. Usually they are also pruned for planting before being shipped from the nurseries.

If possible so to arrange the work, the holes should not be dug until just before planting. The soil still contains its natural moisture when placed about the trees and in some soils the sides of the holes become so hard and compact as to necessitate being shaved off before setting the tree. The planting-board shown in Fig. 132 is very helpful in keeping the rows of trees straight in the grove. It should be made 


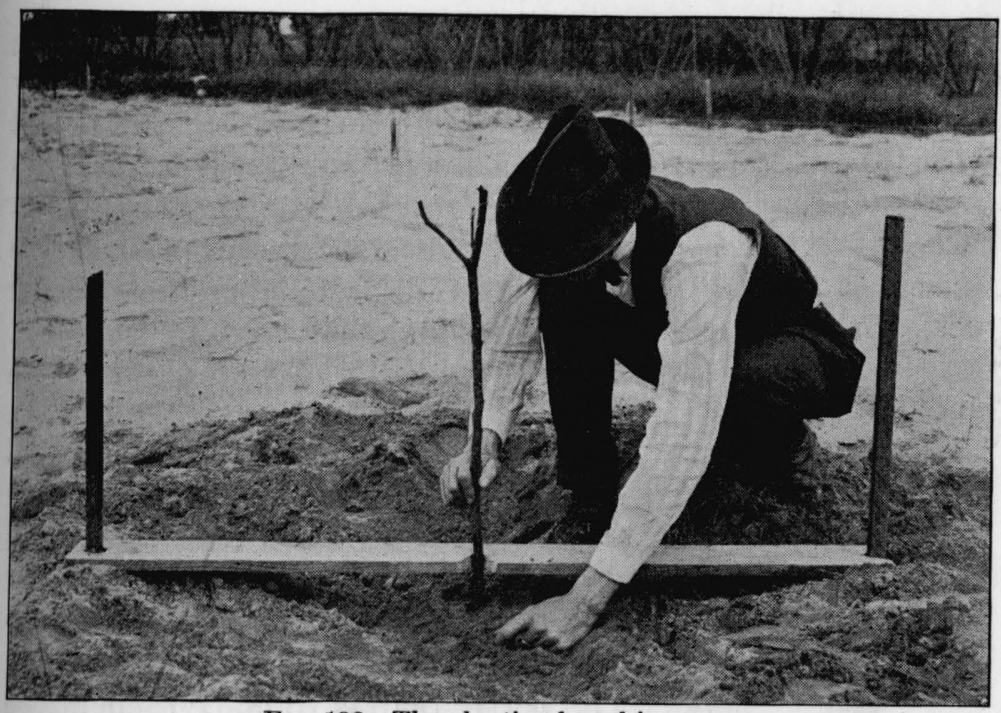

Frg. 132. The planting-board in use

from a piece of inch board, four to five feet long and four inches wide. In each end bore an inch hole and cut a notch in one side at the center. Place the notch against the treestake and shove a pair of small wooden pegs through the holes in the ends. Remove the board and the tree-stake, leaving the pegs in place. Dig the hole, making it large and deep enough to hold the root system without cramping. Place the planting-board in position over the pegs and, holding the tree in the central notch fill in the soil with the hands. A helper may place the earth in the hole in small shovelfuls. Pack the soil well around the roots, spreading and straightening them out at the proper level as the hole is filled. It is best to tramp the soil into place, taking pains, of course, not to injure the roots. Fig. 132 illustrates the best method of planting a tree. Trees set in poor land will be much benefited by thoroughly incorporating a pound of good commercial fertilizer with the soil before placing it about the roots. Raw ground bone is also an excellent fertilizer for this purpose. 
The surface and subsoil should be kept separate, the surface soil to be placed in first in filling up the hole. Water may be applied when the hole is about three-fourths filled, and after planting is completed a liberal supply of water, suff-

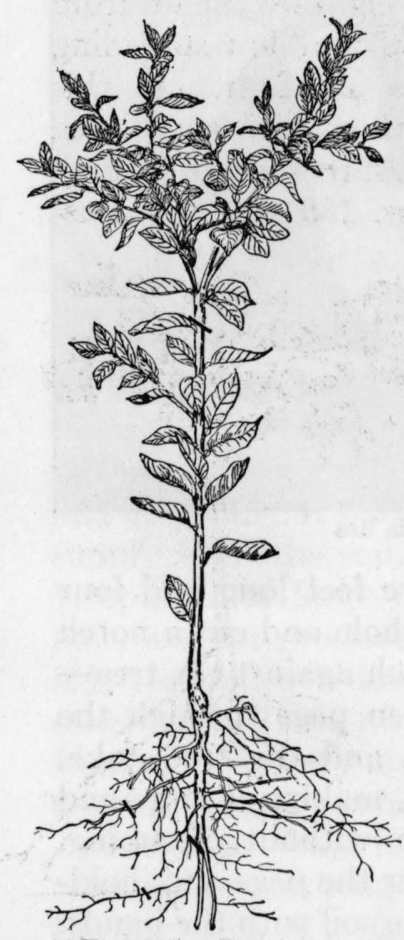

Fig. 133. Pruning roots and tops of a one-year citrus tree for planting. The roots and top should be pruned at the lines and all leaves removed. cient to establish the capillary movement of the soil-moisture, should be given. In California, about half a barrel of water should be used to each tree. Having applied the water, mulch the surface about the tree, with grass, leaves, or dry dust, to prevent evaporation. In the irrigated districts, apply water every ten to fifteen days until the trees are well established.

Trees should never be set deeper than they stood in the nursery row. The better plan is to place them higher rather than lower, to allow for settling. They do not thrive if planted too deep.

In hot dry districts, the trunks of the young trees should be protected from the rays of the sun, to prevent sunburn. Thousands of trees are annually destroyed by this cause and many others are so injured that they never afterward make a satisfactory growth. Lath cylinders, or those made of yucca or paper, serve the purpose well. The trunks may be wrapped in paper, straw, moss, excelsior, or they may be covered with whitewash.

As soon as the trees are set, the tops should be given a final pruning. It is better done at this time than before planting, as more uniform trees can be secured throughout the grove. Most planters retain too much of the top. When the trees are lifted from the nursery row, more than half of 
the root system is left in the ground. The top and leaf area should be reduced proportionately, and all shipped trees cut back and defoliated. If the trees have been grown to a single shoot, without branches, they should be cut off with a sloping cut just above a node, about eighteen inches from the ground. This will start a low top and low-spreading branches. If well-developed branches are found at this height, or perhaps a little higher, trim them into spurs with two or three buds. Should the trees not start promptly, they should be cut back more severely. Figs. 133 and 134 illustrate the methods of pruning the top and reducing the leaf-area of citrus trees, though it is now a more or less common practice to remove all leaves.

The system of lifting the citrus trees with a ball of earth still remaining about their roots, and then encasing this in a sack, is excellent. The trees may be transported long distances and planted out without even wilting the foliage, if the work is carefully done. To lift the trees, a trench is dug along one side of the nursery row, about eighteen inches deep and six to eight inches away from the trees. In digging this trench, the layer of lateral roots is cut off, and the tap-root is severed at the

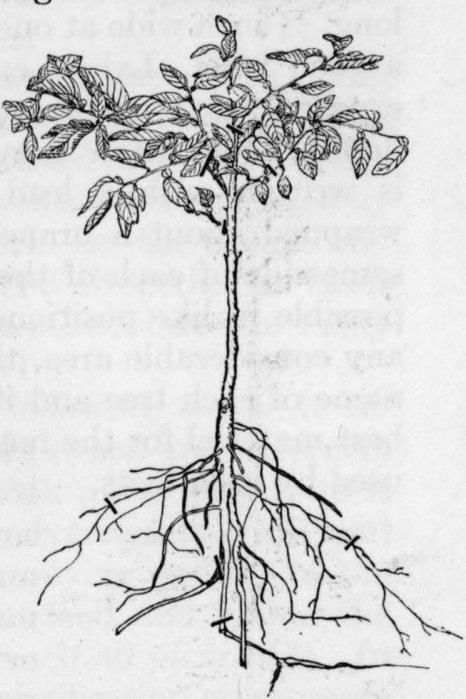

FIG. 134. Pruning indicated by cross lines for a two-year citrus tree. bottom. The top soil is then removed so as barely to expose the crown roots, and a sharp spade is thrust into the soil on the three uncut sides, to sever the remaining laterals. When all the roots have been cut, the tree is carefully lifted from its place. The angles are rounded off and the tree is set on a piece of burlap sufficiently large to cover the ball completely. This burlap is then carefully drawn around and 
tied or sewed about the earth. The size of the ball should correspond with that of the tree: smaller trees have about forty pounds of earth; larger ones about sixty. This method of digging trees cannot be followed on loose sandy soils, but only on those which have sufficient clay to make the ball adhere well about the roots.

\section{LABELS AND MAPS}

After the trees have been planted and pruned, they should be labeled. For this purpose, a piece of zinc, five inches long, $3 / 4$ inch wide at one end, and tapering to a point, makes a good label. Labels embossed on zinc or copper are also excellent, and not only the name of the variety but other detail information may be placed on them. The name is written with a lead pencil and the tapered end then wrapped about a branch. Labels should be placed on the same side of each of the trees and on branches as nearly as possible in like positions. If many varieties are planted on any considerable area, the grove should be mapped and the name of each tree and its position designated thereon. The best material for the map is a piece of glazed muslin such as used by architects. 


\section{CHAPTER XX}

\section{CULTIVATION OF CITRUS GROVES}

There is much difference of opinion concerning the best methods of cultivation for citrus fruits. In the citrus districts of America, the soils are varied in character and in the amount of fertility and moisture which they contain, and the system of cultivation adopted must meet the requirements of the particular soil.

Because of the loose open nature of many citrus lands, it is not difficult to keep them in good condition of tilth. Neither the same amount of time nor hard labor is necessary to maintain citrus groves in good condition as is required by other fruit plantations. Perhaps, herein lies the reason why some persons have neglected cultivation altogether on lands that would be benefited by it, while others have, in many cases, carried the practice too far.

Cultivation is beneficial in the following ways: It increases the water-holding capacity of the soil and conserves moisture, both by allowing rain to sink more freely into it and by checking evaporation. It pulverizes the soil and allows the air to penetrate, thus supplying oxygen to the roots. It assists in setting free plant-food and makes the soil fine, thus enabling the roots to reach all parts of it. In cultivated soils, decomposition and nitrification go on more readily and if the materials are present from which nitrogen can be set free, its liberation takes place more rapidly than if the soil is left uncultivated.

The opening and loosening of the soil permits the rain to penetrate. If the surface of the ground becomes hard and compact, the water will run over the surface or collect in puddles and disappear by evaporation. In either case, the loss will be great, but if the soil is well stirred and loose, the water will enter. 


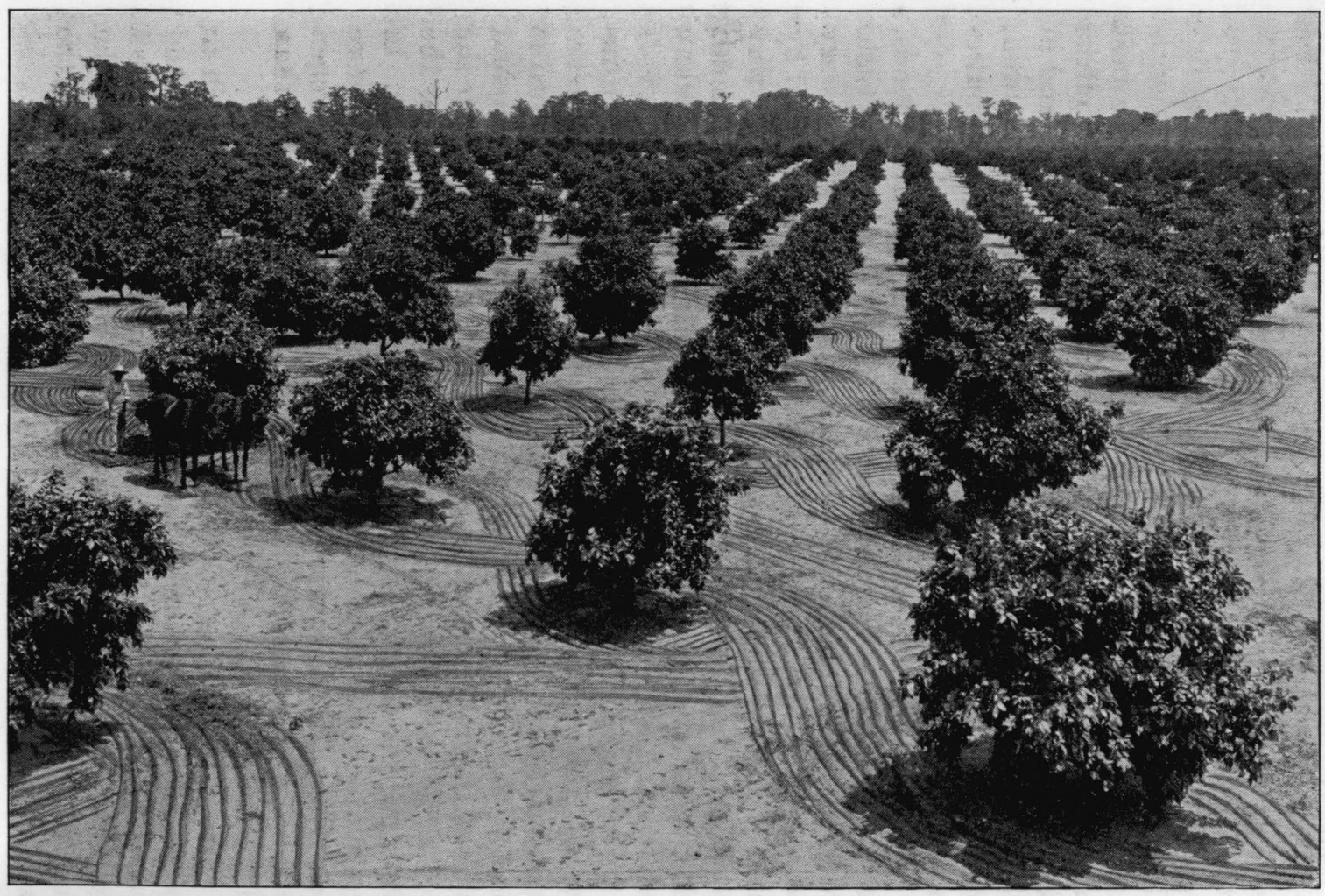

FIG. 135. Zigzag cultivation of a six-year-old orange grove. This method saves much hand labor and may be used until the trees have grown so large that a team cannot pass between them 
Once the water is safely beneath the surface, it is necessary to keep it there; it has gained entrance by a passage through which it should not be allowed to escape. If not prevented, the water will again make its way to the surface by capillary attraction, passing upward through the minute spaces between the particles of soil. If these minute tubes or passages extend to the surface, the water rises to the top, comes out, and is carried away by evaporation. Frequent shallow cultivation will prevent this escape of water by breaking the capillary tubes. If the top inch or two of the earth is stirred, it parts with its moisture becoming dry, and then it acts as a dust blanket, not allowing the great amount of moisture below to reach the surface and be carried away by the moving air above. Thus, moisture is conserved and held for the use of the trees. During the rainy season, it is not necessary to conserve moisture, but often in April, May, and June, in Florida, and sometimes even later, week after week goes by without a shower. The California cultivator is confronted by even worse conditions and must resort to irrigation. In some citrus districts the horse and eultivator are often a most excellent substitute for an irrigation plant.

A hard compact soil, into which air does not enter, is not suitable for the roots of plants. The roots absorb water and food in solution only through their newer parts, and new roots must be formed constantly to carry on this work. For the formation of roots, oxygen is necessary, and if the air cannot enter, oxygen cannot be supplied, and the roots suffer in consequence. The soil should be kept loose and friable during the period of greatest growth so that the roots may be freely supplied with air.

If, in addition, the rootlets can reach and penetrate every portion of the soil, growing here and there at will, they have every opportunity to come in contact with and absorb the plant-food it contains. While food materials in solution may move toward the roots, nevertheless, in general, the roots must search out and procure the plant-food. 
The food materials in any soil are present either in chemical substances or in organic combinations. If fertilizers are applied or added to the soil, they fall into either one or the other of these classes. Most of these materials do not immediately yield up their plant-food, but must be acted on by certain agents before it becomes available, i.e., so that the roots can absorb and the plants use it. A large part, or practically all, of the plant-food in organic substances is liberated through the agency of microscopic plants called bacteria. In order that these may thrive and multiply, plenty of air should be admitted to the soil, and, at the same time, it should be warm and moist. Cultivation aids in making the conditions ideal for the growth and development of soil bacteria. The other class of agents acts chemically. To this group belong the acids and other substances capable of breaking up the food-containing materials in thesoil. Some of these disintegrators are present in the air and are carried to the soil in the rain. Here, again, cultivation helps by admitting the air to the soil and allowing the rain to penetrate.

\section{CLEAN VERSUS NO CULTIVATION}

The practice of keeping the ground on which the orange grove stands perfectly free from herbage and thoroughly cultivated throughout the whole season, year in and year out, has been indulged in by many and is still followed by some. This practice has little to recommend it. A soil so treated soon becomes depleted of its natural fertility and the humus is used up through constant cultivation and the application of various fertilizers. No amount of fertilizer will do the work it should if the soil once loses its natural body and becomes deficient in humus. In spite of every effort in fertilizing, such a soil will become poor and infertile and the trees will soon show the effects in their unhealthy condition. A diseased leaf condition, known as "Frenching" or "mottled leaf," usually makes its appearance. This disorder is 
intimately associated with a deficiency of humus in the soil. "Die-back" or "Exanthema" develops, "wither-tip" becomes prevalent; one disease follows another; the owner becomes discouraged; things go from bad to worse, and the whole grove property becomes unprofitable. The picture is not overdrawn. Clean cultivation and no attention to the vegetable matter content of the soil in the citrus grove inevitably leads to disastrous results.

If clean tillage is adopted, humus must be supplied in some way, and the plan used by a number of successful growers in the citrus districts is to cover the ground with a liberal coating of leaves, leaf-mold from adjoining woods, straw, hay, grass, or similar humus-providing material. By this means, a mulch and the material from which humus may be formed are provided for the soil. It is far easier to maintain the humus-content of soils than to replace it after it has once been worked out, a fact well worth remembering.

Humus, one of, if not the most important ingredient in any fertile soil, is generally present in inadequate amounts in citrus soils, and any system of cultivation which does not tend to increase or maintain a considerable quantity of this substance in the soil is not based on sound principles.

On the other hand, many growers do not cultivate at all, and on some classes of soil this method is really the best. Only on naturally moist soils, low damp hammocks in Florida, for example, should this plan be adopted. On high pine lands, or on those lands naturally deficient in moisture, it is not a safe method to follow. Cultivation conserves soilmoisture and increases its water-holding capacity.

In June, 1902, two samples of soil were taken as representative of cultivated and uncultivated ground. Both were from the horticultural grounds of the Florida Experiment Station, one from soil planted in citrus trees, cultivated frequently from March until that time; the other from a piece of ground which had received no cultivation at all during the season, but which had lain bare and exposed to 
the sun. The samples were weighed, then dried and weighed again. The weights and differences were as follows:

Cultivated soil-

Weight when collected . . . . . . . . . . . 247.8 grams.

Weight after drying .

Loss of moisture in drying . . . . . . . . . 17.3 grams.

Uncultivated soil-

Weight when collected . . . . . . . . 251.4 grams.

Weight after drying . . . . . . . . . . . 240.9 grams.

Loss of moisture in drying $\quad \ldots \quad \ldots . .10 .5$ grams.

Percentage of moisture in sample No. 1-

$17.3 \div 247.8 \times 100=6.97$ per cent

Percentage of moisture in sample No. 2-

$10.5 \div 251.4 \times 100=4.17$ per cent

The cultivated soil contained 6.97 per cent moisture, while the uncultivated soil showed 4.17 per cent - a difference in favor of the former of 2.8 per cent, or, expressed otherwise, cultivation had increased the moisture-content of the soil by 66.5 per cent. While the water-holding capacity of most citrus soils, and particularly those rich in humus, is well up to the average, every effort should be made to hold and conserve the moisture for use during periods of drought. Lands deficient in moisture should be cultivated frequently during the first half of the year, or from the commencement of the growing season until the rainy season begins in districts in which the heaviest rainfall comes in summer.

\section{HUMUS AND ITS VALUE}

Humus is a product of the decay of organic substances. When these undergo decomposition in the soil, humus is the intermediate product formed; that is, just before the resolution of the organic material into its component chemical parts. Probably humus is the most important substance in any fertile soil, and its presence may generally be taken as the index of fertility. The chief difference between a barren and a fertile soil is usually in humuscontent, not in the mineral ingredients. 
Soil changes, which are constantly taking place, may be grouped as physical, chemical and biological. The first relates to movement of water, the size of the particles, and the mechanical changes, such as those produced by the displacement of the soil particles by animals or the roots of plants. In the second is included all changes wrought by the action of acids or other disintegrators of a chemical nature, while the third, in its use here, refers to the changes brought about by soil bacteria. All three of these changes, whether physical, chemical, or biological, are intimately associated with the presence of humus.

In regard to the first, it may be premised that soils rich in humus are not solid and compact, but loose, open, and better aërated than those lacking it, and that the waterholding capacity is materially increased by a fair admixture of it. If the ability of a soil to retain moisture is increased by the presence of humus, it follows that all-plant-food in solution will be held as well; this is an important feature.

Humus contains from three to twelve per cent nitrogen, and soils rich in it are usually well supplied with phosphoric acid and potash.

Reference has already been made to the bacteria which play such an important part in the formation of plant-food, and which are so intimately associated with the work of providing nitrogen for the use of the trees. The bacterial content of the soil other conditions having been met, is dependent entirely on the presence of humus.

It will be seen therefore, that humus is a very valuable soil component and is intimately associated with the lifeactivities of a fertile soil. Growers of citrus fruits in Florida use commercial fertilizer in large quantities, and in all districts the same practice must be followed eventually. Many of the substances applied must undergo certain changes before they can become available. This change from an unavailable to an available state is dependent either on the action of soil bacteria or chemical agents. Humus 
forms the media in which the bacteria work and, furthermore, it holds the plant-food when in solution until the roots have a chance to use it. The best and fullest effects cannot be secured from applications of fertilizers to citrus trees unless the soil is plentifully supplied with humus.

\section{PROBLEMS OF CULTIVATION}

It is always preferable to prepare the ground thoroughly before the trees are planted. The earth should be well stirred and free from roots and stumps. During the first years of the life of the young grove, the ground may be plowed, if deemed advisable, provided always that the plow is not run deep close up to the trees. The tree-rows should be cultivated comparatively shallowly. This treatment will have a tendency to send the roots deeper into the soil as they spread out from the tree. If plowing is resorted to, the depth should be varied from year to year, so that the soil may not become hard and compact at a certain fixed depth, as is likely to be the case if the plow is always run at the same distance from the surface.

\section{Florida.}

When the trees have attained considerable size and the roots have occupied the whole space between the tree-rows, the plowing should be very shallow, or abandoned entirely, the plow giving place to the cultivator. The method followed in the old groves around Orange Lake, Florida, was to give three or four hoeings during the year, all the cultivation the trees received, and results were highly satisfactory. The plow as an implement for continuous cultivation should not be used. If employed at all, plowing should be done only in the dormant period, early in spring or late in autumn. Large numbers of roots are breken or torn by the plow as a result of which new ones are formed rapidly, food is absorbed in great quantities, and in some sections a die-back condition frequently results. 
The fibrous feeding roots in most old groves form a solid mass and extend close to the surface, and in such cases the cultivation should be shallow; but if a proper system has been adopted from the first, the roots will not be too close to the surface. This mat of roots is usually disturbed to some extent, but as commercial fertilizers are used extensively, it is not good policy to cultivate deeply and break them up too much. Shallow cultivation should be the rule, to which there may, of course, be exceptions.

The usual Florida practice is to plow the grove in autumn (October or November), or to cultivate a sufficient number of times with the disc cultivator to incorporate the covercrop in the soil. If the cover-crop is heavy, it is necessary to plow. No ill effects follow this plowing, provided it is shallow and the plow is not run too close up to the trees.

\section{California and Arizona.}

On the heavier soils of California and Arizona the plow can be used to advantage, and, in fact, it is well-nigh indispensable as an implement of cultivation.

Irrigation is an essential part of citrus culture in all western districts and should always be followed by cultivation of the ground. Frequently the mistake has been made of cultivating at exactly the same depth year after year, and the result has been the formation of a hard impervious layer of soil just below the cultivated top layer. This has been termed "hard-pan," "irrigation hard-pan," and "plow-sole." The water cannot penetrate through it, and, as a result, none reaches the lower roots and the trees suffer.

To break up this hard-pan, the subsoil plow has frequently been brought into operation, and while good results have followed in some cases, much damage has been done in others. Frequently the difficulty may be overcome by slightly increasing the depth of cultivation after each irrigation, until the cultivator or plow finally makes its way down through the hard-pan. 
To prevent the formation of this hard-pan, the depth of cultivation should be varied from year to year. Starting at eight inches, the usual depth increases from year to year until thirteen or fourteen inches is reached, then cultivate at eight inches again, gradually increasing to fourteen, and so on.

Frequency of cultivation.

During the period of most active growth, the citrus plantation should be cultivated frequently. The only exception to this is when it is located on damp soil, such as the low hammock lands of Florida, where there is an abundance of moisture.

If the weather is dry, the ground should be cultivated every week or ten days, to prevent the evaporation of moisture. It is an excellent plan to keep the cultivator going all the time. As soon as the work is finished on one side of the area, it should be commenced again on the opposite. A light harrow or weeder should be used. If showers fall during spring, it is wise to cultivate as soon as possible after

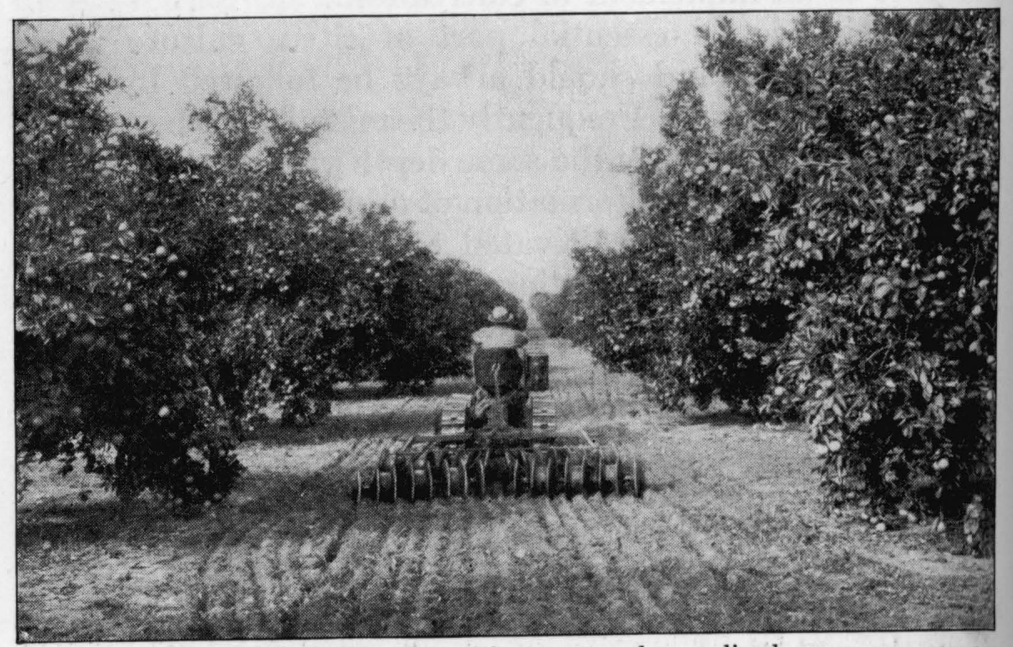

Fig. 136. Cultivating with a tractor-drawn disc harrow 
each one, so that the water which has entered the soil may be retained.

In the irrigation districts the soil should be cultivated after each application of water, just as soon as the surface is dry enough to allow a horse to walk over it. Generally two or three days must elapse before cultivation can be started, depending on the nature of the soil.

Weeds should not be allowed to grow in the grove during the period of cultivation. They pump the water from the soil and in a measure defeat the objects of cultivation. After cultivation has been discontinued for the season, a cover-crop should then be given possession of the ground.

\section{Methods of cultivating young groves.}

Until the young trees are four or five years old, in most regions, they occupy a relatively small portion of the total area on which they are planted. Their roots do not extend far from the trunks and do not take up the amount of space occupied by the roots of old established trees.

During the earlier years, an excellent opportunity for building up a reserve of vegetable matter in the soil is afforded. Cultivation, even early in the season, may be confined to the immediate vicinity of the trees themselves and by far the greater amount of space can be occupied with a leguminous or other cover-crop. Fig. 137 shows this method of handling. A strip along each side of the treerows is cultivated frequently while a broad strip in the middles is taken up by a cover-crop.

When the trees are somewhat older and their roots have reached well out into the middles between the rows, it becomes desirable to cultivate the entire surface for about three months in spring. It is best to keep the immediate vicinity of the trees free from weeds, and this can be done to advantage by cultivating zigzag fashion in and out among the trees. This method is well illustrated in Fig. 135 which shows the work done with an Acme harrow. This greatly 
reduces the amount of hand labor necessary to cultivate close to the trees.

Cultivation in relation to dormancy and frosts.

In regions subject to frost, every effort should be made to have the trees in a perfectly dormant condition during the period when they are likely to occur. Citrus trees are notoriously responsive to slight elevations of temperature during the winter months. In a perfectly dormant condition they will withstand considerable cold, but if the sap is moving a very slight fall of temperature may injure them seriously.

Unfortunately, they cannot be put in a complete state of dormancy, to remain so throughout the winter despite changes in temperature. Still, something may be done. Fertilizers, particularly those rich in nitrogen, which have a tendency to prolong the growth of the tree, should not be applied late in the season. Cultivation should not be continued late into the fall, as the stirring of the soil tends to cause the trees to grow late into the autumn.

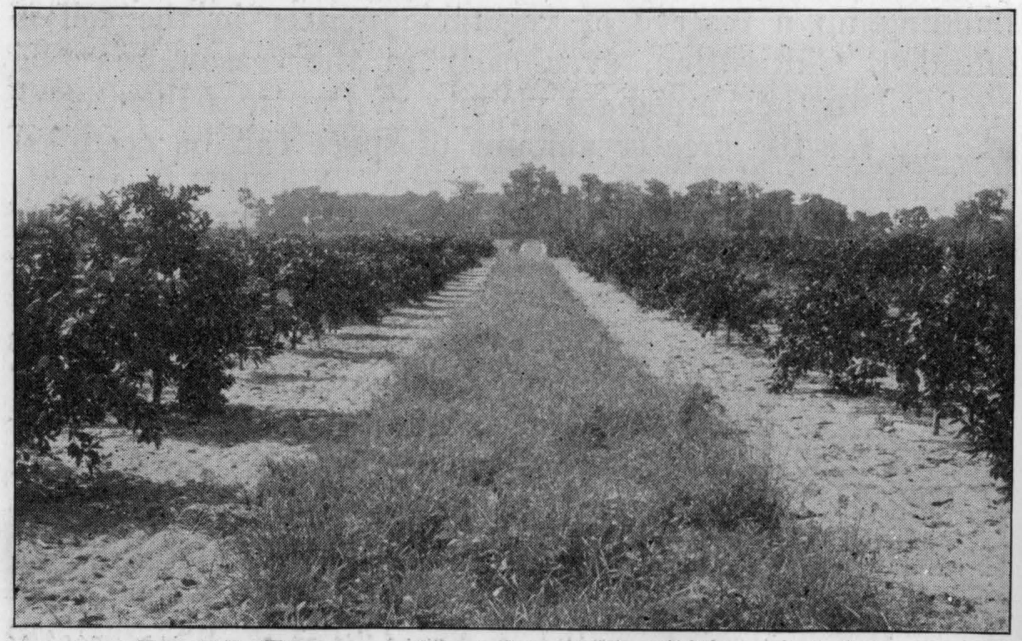

Fig. 137. Tree-rows cultivated, center producing a cover-crop 
All cultivation should be discontinued early. Grass and weeds should not, however, be allowed to remain in the grove during the winter months. If open fires are used to protect the trees, the presence of dry herbage among them is a menace to the safety of the grove. Fire may easily spread through the grove and the trees suffer greatly in consequence. Moreover, it has been observed in Florida that trees standing among dead grass and weeds are much more injuriously affected by frost than are those in clean-cultivated soil. Hence, the best practice is to plow the grove or to cultivate sufficiently to incorporate the dead herbage with the soil about the middle of November and leave the ground exposed and bare throughout the winter months. Cultivation can be resumed the latter part of February.

The die-back problem.

In groves in which trees are affected by die-back, the trouble may be seriously aggravated by continuance of cultivation. Particularly is this the case when the disease has been caused by the use of organic fertilizers or by too much humus incorporated with the soil. When the disease is caused by the presence of hard-pan or by poor drainage, and not by cultural mistakes, the problem is, of course, entirely different.

In the former case, however, much may be accomplished by changing the method of cultivation and fertilizing. Cultivation should be discontinued, thereby restricting the growth of the trees and lessening the amount of available nitrogen in the soil. The fertilizers used should contain no nitrogen, or only a small percentage, and when fertilizers are again applied, organic sources of nitrogen should be rigidly avoided. If beggarweed is growing in the grove, it should be cut frequently and removed. By this line of treatment groves usually can be brought back to their normal condition. The question is discussed further in the chapter on Fungous and Physiological Diseases. 


\section{Rejuvenation of neglected trees.}

Citrus plantings are sometimes neglected or abandoned and allowed to shift for themselves. Trees so situated eke out a miserable existence, but they usually manage to survive and sometimes bear scant crops of fruit. Insects and diseases prey upon them, and the tops of the trees usually contain much dead or dying wood.

The bringing back into fruitfulness of such a planting presents many problems, but if the land is good and the trees are sound in root, trunk, and larger branches, it can be done. Citrus trees are very responsive to good treatment, and worth-while results can be secured, in such cases, in a remarkably short time. Dead and dying wood should be pruned out and the heads reduced to such space as will leave only good wood from which new growth may start. Preferably, this pruning out should be performed in the winter. There should be no thought of a crop of fruit in the following season, but attention should be given only to bringing the tops of the trees back into proper shape and condition. Moss and lichens should be cleaned out. Before pruning, a careful study should be made of the diseases and insect pests, and, on its completion, these should be given proper treatment immediately.

Native trees and shrubs which have become established should be cleared away, and well in advance of the spring growing season the planting should be plowed, fertilized, and cultivated. The fertilizer should be of the same kind and quality as would be applied to young non-bearing trees. If the planting is on low wet ground, and if plenty of mulching is available, it may be generously applied about the trees after fertilizing, instead of cultivation. If the trees are cultivated, it should be continued up until about June 1 in the southeastern districts, when additional fertilizer should be applied and a suitable cover-crop established. From this time the trees should be handled the same as a young grove, and usually they can be brought into satisfactory bearing. 
Implements.

The implements used for cultivating must be adapted to the soil conditions, and each grower should know what will best answer his purposes. Various cultivators can be procured, adapted to shallow or deep cultivation, to light or heavy soils. The equipment necessary for the cultivation of a citrus grove of some size will consist of tractors, moldboard or disc plows, spring-tooth or Planet Jr. cultivators, and disc and Acme harrows. The extension harrow or cultivators used for cultivating close up to low-hanging branches should be provided with guards to prevent injury to twigs, leaves, and fruit. For light sandy soils and steep or hilly lands, a caterpillar tractor will be more satisfactory, while on level lands of ordinary texture,

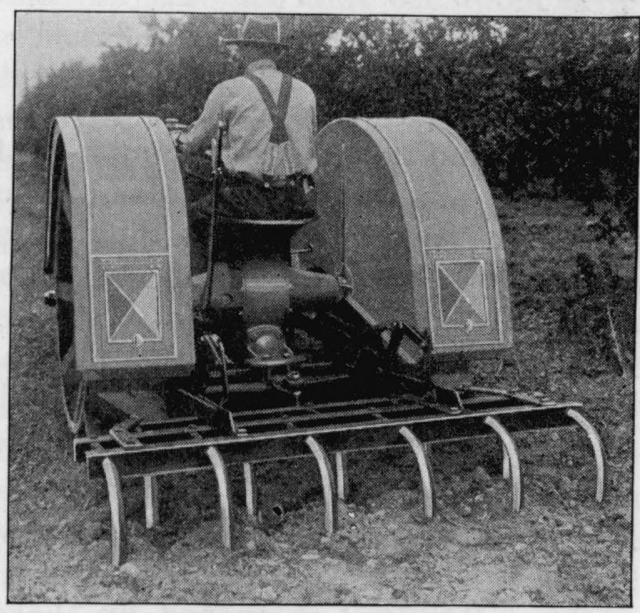

Fig. 138. Spring-tooth harrow and tractor outfit for cultivating wheel tractors will give good results. For cultivating young groves, where only a narrow strip along each side of the trees is kept stirred, mules or horses can be employed to advantage. A corn-or cotton-stalk breaker is frequently useful in disposing of a heavy cover-crop, if a tractor is not used. The introduction of the tractor has made it possible to dispose of heavy cover-crops which, with mules and horses, were exceedingly difficult to dispose of, either by discing with a harrow or by turning under with a plow. With tractors, groves can be cultivated at temperatures and under climatic conditions where mules or horses could not do the work (Figs. 136 and 138). 


\section{CHAPTER XXI}

\section{COVER-CROPS}

In the judicious management of the citrus grove, the use of a cover-crop is frequently an important factor. Not all soils can be treated in the same way. No person knows as much about a given piece of land as the intelligent man who tills it and studies it as he works. He, in the end, should be best able to decide whether clean culture throughout the year, clean culture with a cover-crop, or no culture is best for his conditions. The amount of fertility, of available moisture, the physical qualities of the soil and the climate are the more or less known quantities with which he must work out the equation of citrus-fruit production.

The benefits to be derived from the use of cover-crops in the citrus districts are in part the same as those that obtain in more northern fruit regions, but the problem is in some respects different. The advantages are as follows:

1. Cover-crops affect the physical condition of the soil:

Humus is added and the water-holding capacity increased.

The soil is opened up, hard layers do not form readily; clay soils do not become compacted.

Moisture is removed from the soil in the rainy season in Florida and the Islands.

Surface washing is prevented particularly on hilly or sloping ground in seasons of heavy rainfall.

2. They affect the fertility of the soil:

Prevent leaching of nitrates in the period of excessive rainfall.

Promote nitrification.

Add plant-food (leguminous crops).

Break up the plant-food in the soil and render it available. 
Cover-crops are usually divided into nitrogen-collectors and nitrogen-consumers.

To the first group belong the leguminous plants, such as clover, Japan clover, cowpeas, beans, peas, beggarweed, velvet beans, vetch, lupines, alfalfa, and crotalaria.

In the second group are placed buckwheat, rye, oats, grasses of different kinds, rape, and, in short, all cover-crop plants not belonging to the family Leguminosæ.

The groups are based on the fact that the roots of leguminous plants bear nodules of various shapes and sizes. Usually the shapes are different for each species of plants, and they vary considerably in size. They are formed by the action of bacteria which find entrance to the roots through the root-hairs. These nodules must not be confounded with the irregularly shaped swellings caused by the action of the root-knot produced by the nematode worm, Heterodera radicicola, so common in southern regions.

The nodule bacteria are commonly known as nitrogenfixers, because of their ability to collect and store the free nitrogen of the air in the tubercles. This nitrogen eventually becomes available to the plants. The tubercles are most in evidence in the earlier period of growth of the legumes, while later in the season the greater number of them decay and become shrunken, their nitrogen-contents having been taken up by the plants.

Rye, oats, crab-grass, sand-spurs, and other grasses do not collect nitrogen, but when returned to the soil give back only that which they have withdrawn. However, they add fibre, increase the humus-content, and have a general ameliorating effect.

The benefits derived from cover-crops may be rendered entirely negative unless proper care is exercised in handling them. In the hot climate of the citrus districts, they should not be plowed under while green, but should be allowed to become dry and partially rotted before being incorporated with the soil. Unless this plan is followed, an acid condition 


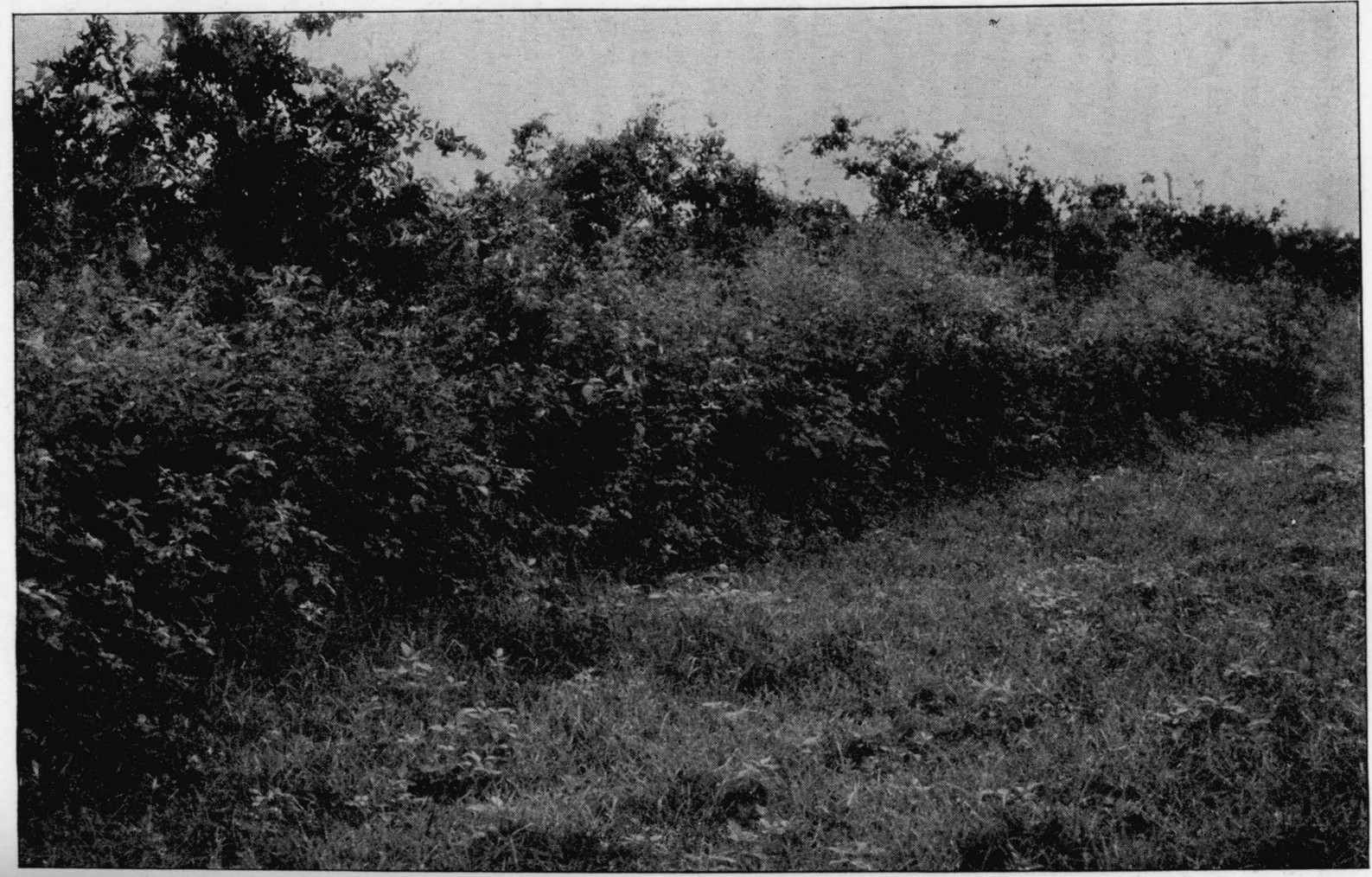

Frg. 139. Beggarweed cover-crop in an orange grove 
inimical to the growth of cover-crops in years following may result. When commercial fertilizers are used, the potash and phosphoric acid content should be increased in proportion to the amount of nitrogen returned by the covercrop. Caution should be exercised in the use of fertilizers containing organic materials. In young or recently planted groves, on light soils, advantage should be taken of the wide spaces to grow good cover-crops and so fill the soil with humus that a liberal reserve will be built up for the future. As the years go by and the trees increase in root and branch area, the space available for cover-crops is reduced until, in many cases, it becomes impossible to grow them. Therefore while the trees are young, cover-crops should be given particular attention. Necessary or desirable leguminous or other vegetable material may be supplied to old groves by growing suitable crops on open ground, cutting them and then applying as a mulch or ground-covering in the grove.

\section{VALUABLE COVER-CROP PLANTS FOR THE SOUTH}

The legumes most serviceable as cover-crops in Florida are beggarweed (Desmodium tortuosum) and velvet bean (species of Stizolobium). The former is a well-known naturalized plant, while the latter was introduced into America, presumably about 1869. The latest additions to the list of Florida cover-crops are Crotalaria striata and C. Retzii, tropical species of heavy growth. Cowpea ${ }^{1}$ (Vigna sinensis) is also sometimes grown, but the presence of the nematode so frequently interferes with its growth that it cannot be recommended for all soils. So far as known this nematode does not attack orange roots, but it is frequently present in the roots of many cultivated plants.

It is generally necessary to get rid of the cover-crop before the picking season. This may be done by cutting it and allowing it to lie on the surface until it decays partially, or it may be harrowed into the soil if dead and dry.

${ }_{1}$ Nematode-resistant cowpea varieties, Iron and Brabham, have been introduced. 


\section{VELVET BEAN}

The velvet bean makes an enormous growth, and, in autumn, after being lightly touched by frost in northern Florida, several inches in depth of dead leaves and vines cover the ground. No other legume will make such a growth in the same length of time. When growing vigorously, it covers the ground to a depth of two to three feet with a tangled mass of vines, individuals of which are frequently upward of seventy-five feet long. Miller has estimated the amount of green material on an acre to be 21,132 pounds, or 5,953 pounds of dry substance. As a cover-crop it is difficult to handle in regions remote from frost, as it continues growing. However, it can be cut with a mowingmachine and drawn aside between the tree-rows, if still green in the autumn, for it is generally advisable to get the cover-crop out of the way before the picking season approaches.

Nitrogen is collected in very large amounts by this covercrop. The following table by H. K. Miller, in Bulletin No. 60 of the Florida Agricultural Experiment Station, shows the results obtained by the Alabama, Louisiana, and Florida experiment stations with velvet beans as a field crop:

Table VII. Results of Velvet Beans as Field-Crop

\begin{tabular}{|c|c|c|c|c|}
\hline & & Alabama & Louisiana & Florida \\
\hline acre & & 10 & 22,919 & 21,132 \\
\hline dried material from an acre & & 8,240 & 7,495 & 5,953 \\
\hline Weight of dried roots from an acre. & $\therefore$ & 1,258 & 191 & 690 \\
\hline Weight of nitrogen in vines from an acre & . & 201.3 & 170 & 131.5 \\
\hline Weight of nitrogen in roots from an acre & . & 12.6 & 2.9 & 9.7 \\
\hline Total nitrogen in crop from one acre & . & 213.9 & 172.9 & 141.2 \\
\hline
\end{tabular}

Such results could not be obtained in the citrus grove, as the whole space cannot be planted, but one hundred pounds of nitrogen to the acre would probably be a conservative estimate.

The root system of the velvet bean spreads out well and 


\section{COVER-CROPS}

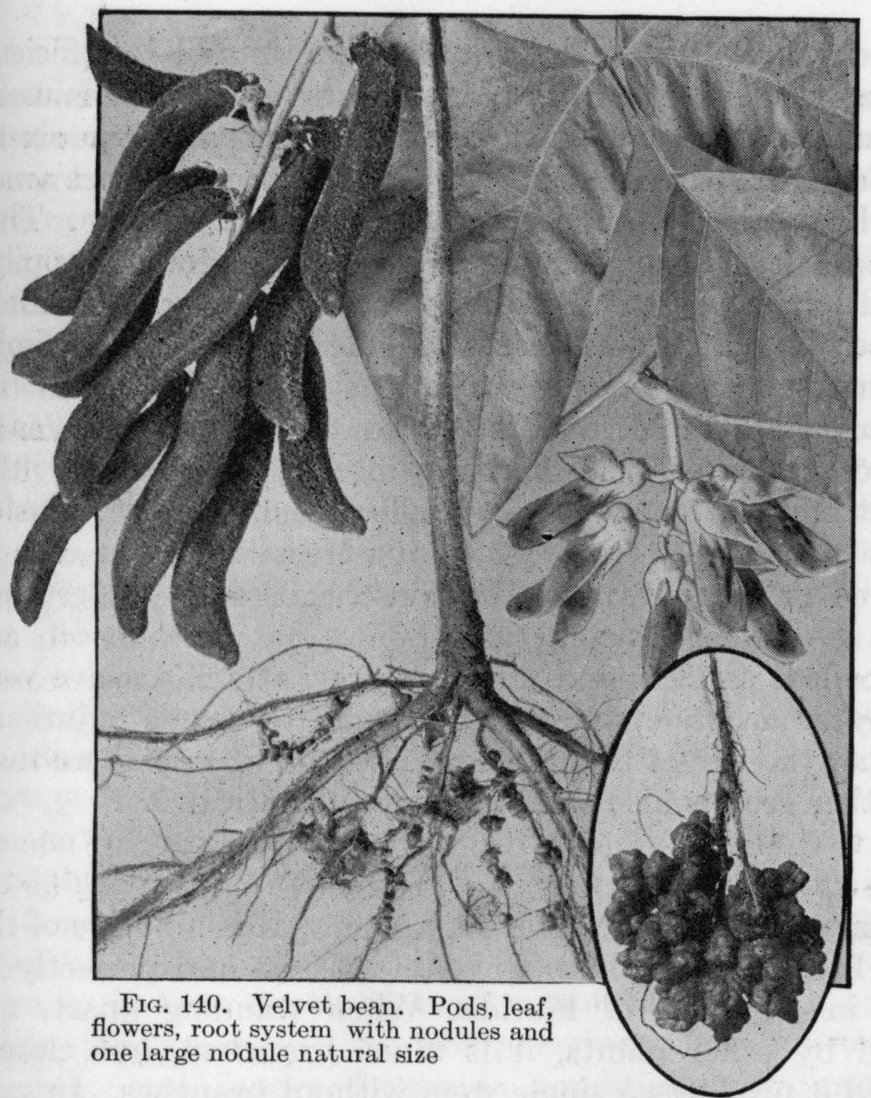

penetrates the soil deeply. The tubercles are very large, frequently an inch and a quarter or more in diameter, black, or brownish black, and covered with projections (Fig. 140).

Velvet beans should be sown not later than the end of May, and earlier, if possible. The crop is benefited by cultivation, as it is somewhat slow in starting, and the weeds should be kept down until it is well established. Tillage may be continued three to four weeks after planting. While the seed may be sown broadcast, it is better to sow in drills, four to five feet apart, or in hills, three or four beans to the hill, 
in checks four to five feet square. One bushel is sufficient seed for four acres. If the old running velvet bean is used, it should not be planted closer to the tree-row than six to eight feet, and care must be exercised to turn the vines away from the trees, else they may cover and smother them. This has happened in the groves of careless cultivators. Happily, several bunch velvet beans have been originated, and these may be planted without fear of damage to trees from climbing vines.

Some growers have objected to the velvet bean as a cover-crop because it harbors insects, particularly the soldier-bug, 'cotton stainer, and allied pests. These transfer their attentions to the fruit on the trees when the crop is removed or dies down, to the consternation of the grower, and much damage is sometimes done. But these insects are more or less periodic and rarely, if ever, attack a grove year after year in numbers great enough to prove injurious. Whether the velvet bean is more likely to attract them than any other crop is also somewhat problematical.

\section{BEGGARWEED}

Beggarweed is a strong erect annual. It is a native of the West Indies but is thoroughly established and perfectly at home in all parts of Florida. When standing apart, unshaded by other plants, it is much branched, but closely planted it produces a single stem without branches. In soils where plenty of tubercles are formed, it frequently grows to a height of six to eight feet, the stem being nearly threequarters of an inch thick at the ground (Fig. 139).

As a cover-crop it is easily managed, and at the end of the season a goodly covering of partially decayed foliage is found on the ground. On many soils it should not be allowed to grow throughout the whole season unchecked, as the stems become hard, woody, and difficult to incorporate with the soil. The crop should be cut once or twice during the season, and if a good length of stubble be left, it will 
stool out, producing another crop. Each cutting may be allowed to decay on the surface, or one or two may be removed for hay, although by this plan the full benefit of the crop cannot be secured. The last cutting should not be so late as to prevent seed formation, for if once well established the crop will reseed itself year after year, if well managed.

The amount of nitrogen collected up to the time of the formation of flower-buds is shown by the following analysis by W. A. Blair, of the Department of Chemistry, in the University of Florida:

Weight in pounds of dried stems and leaves to an acre $3,489.15$

Weight in pounds of dried roots to an acre . . . . 105.85

Weight of nitrogen in stems and leaves to an acre . . . 90.71

Weight of nitrogen in roots to an acre . . . . 10.02

Total nitrogen in roots, stems and leaves to an acre . . 100.73

Only a single cutting is represented in the above analyses. If allowed to grow throughout the whole summer, or if cut once or twice and the crop allowed to return to the soil, the amount of nitrogen collected during the entire season would probably be increased one-half.

Beggarweed has a straight strong tap-root with numerous laterals. These penetrate well into the soil, loosening and opening it to a depth of twelve to fifteen inches, or even more. The nodules are comparatively small, rounded, smooth, and, under favorable conditions, are produced abundantly. The root system is shown in Fig. 141, which also gives a fair idea of how plentifully nodules are formed.

Five to ten pounds of seed are required to the acre, but, as already noted, when once seeded, sowing is not necessary for the next season. The seed should be scattered broadcast on freshly harrowed ground, and a second harrowing then given. If it is deemed necessary to continue cultivation after sowing the seed, it may be undertaken for a time, but this will have to be confined to the tree-rows eventually, tilling 
one way only and allowing the beggarweed free possession of the middles. After having become well established, so as to produce plenty of seed, the whole surface may be tilled from early spring to about the middle of June, after which

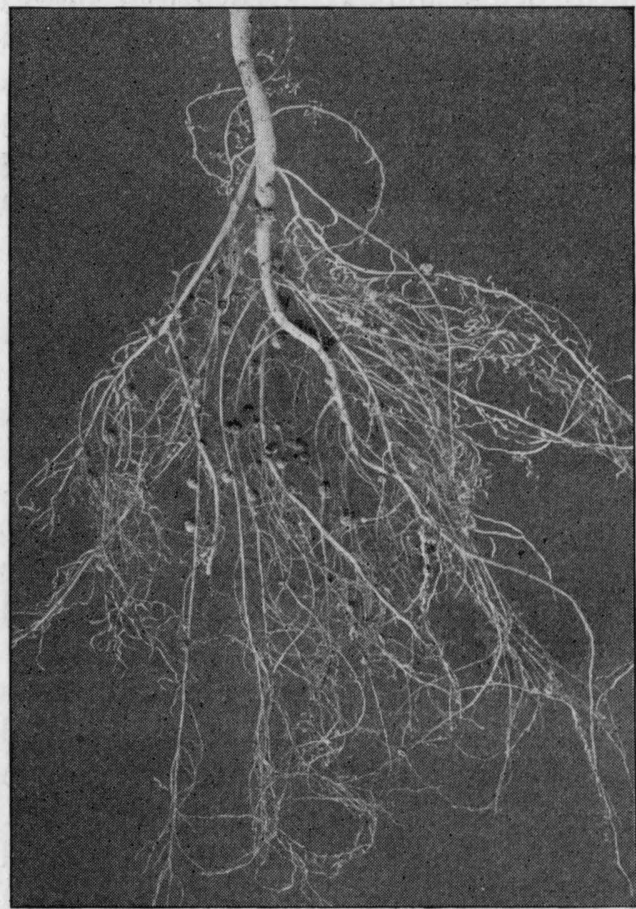

Fig. 141. Root system and nodules of beggarweed the plants will spring up and cover the ground. Beggarweed cannot be grown on very acid soils, and if they become too acid it will disappear, even though once established. Velvet beans and cowpeas can be grown successfully on soils too acid for beggarweed.

A cover-crop of beggarweed can easily be disposed of in autumn by cutting with a mower and allowing it to remain on the surface until it becomes dry and brittle, when it may be worked into the soil. If it has not been cut during the summer and has become dry while still standing, it may be broken down with a corn-stalk smasher. This, followed by a cutaway harrow, will incorporate it fairly well with the earth. Breaking down the beggarweed will not be necessary if the work is performed with a tractor.

If, for any reason, it is deemed advisable to get rid of the beggarweed in a grove, it may be accomplished by cutting frequently to prevent seeding and by prolonging spring 
cultivation well into the rainy season, when the rapid growth of crab-grass and other native plants will choke it out.

\section{CROTALARIAS}

Of the genus Crotalaria, or rattle-box, two or three species are attracting considerable attention in Florida as covercrops. They are strong-growing, perennial, leguminous plants which may be treated as annuals. If the plants are crowded closely, the stems are small but reach a height of six to eight feet. If they are isolated, the stems are stout and woody; they look like shrubs with trunks one inch or more in diameter at the ground. The roots are wide-spreading, strong, deep, and apparently free from nematode attacks. Crotalaria striata has compound trifoliate leaves and yellow flowers, marked with light brown stripes, and borne in terminal spikes (Fig. 143). C. Retzii has large simple leaves and bright

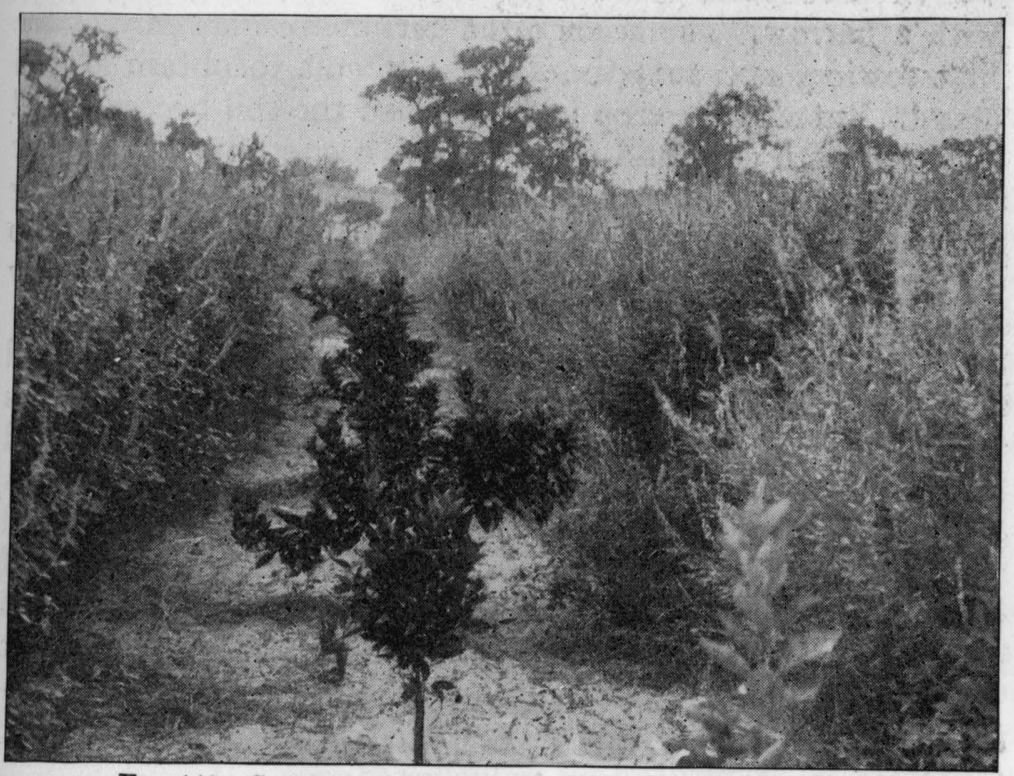

FIg. 142. Crotalaria striata cover-crop in a young orange grove 
yellow flowers. The pods of the latter are also considerably larger than are those of $C$. striata. The leafage of the crotalarias is abundant, and in the stems and foliage a very large amount of green material is produced when the stand is good. The seeds are small and numerous in the inflated pods. When ripe they become detached in the pods and rattle, hence the name crotalaria ( a rattle). Apparently they are well adapted to a wide range of soil conditions and may be grown on almost any soil from well-drained porous sand to heavy moist flat-woods land. Crotalaria is a very large genus, and no doubt contains other desirable cover-crop species.

The crotalarias resow themselves, but they require a long season in which to ripen seed. In the colder districts, seeding should be made just as early as the soil has warmed up sufficiently - early May, or even earlier. Six to eight pounds of seed should be used to the acre, sown after the ground is well prepared, and covered one to one and a half inches deep with a harrow. The seeds often germinate unevenly at the first sowing, and sometimes it is difficult to obtain a good stand. But when a crop is established the soil becomes well supplied with seed and some of it is carried over from year to year. It is then easy to obtain a satisfactory stand after the ground is cultivated in spring. It appears to be easier to secure a stand of $C$. Retzii than of $C$. striata, and consequently the former may meet with more favor.

If a crop of crotalaria is cut after the stems are well developed, it sprouts out again from the stubble, and if this cutting can be made early enough in the season, the second crop will reseed. It is sometimes necessary to cut the plants about midsummer to prevent their becoming too hard and woody. The two crops are credited with a green weight of several tons to the acre. Crotalaria is useless for hay, and there is, consequently, no temptation to cut and remove it from the ground, as is so often done with beggarweed, cowpeas, and volunteer hay crops of crowfoot and crab-grass; this adds to its cover-crop value. 


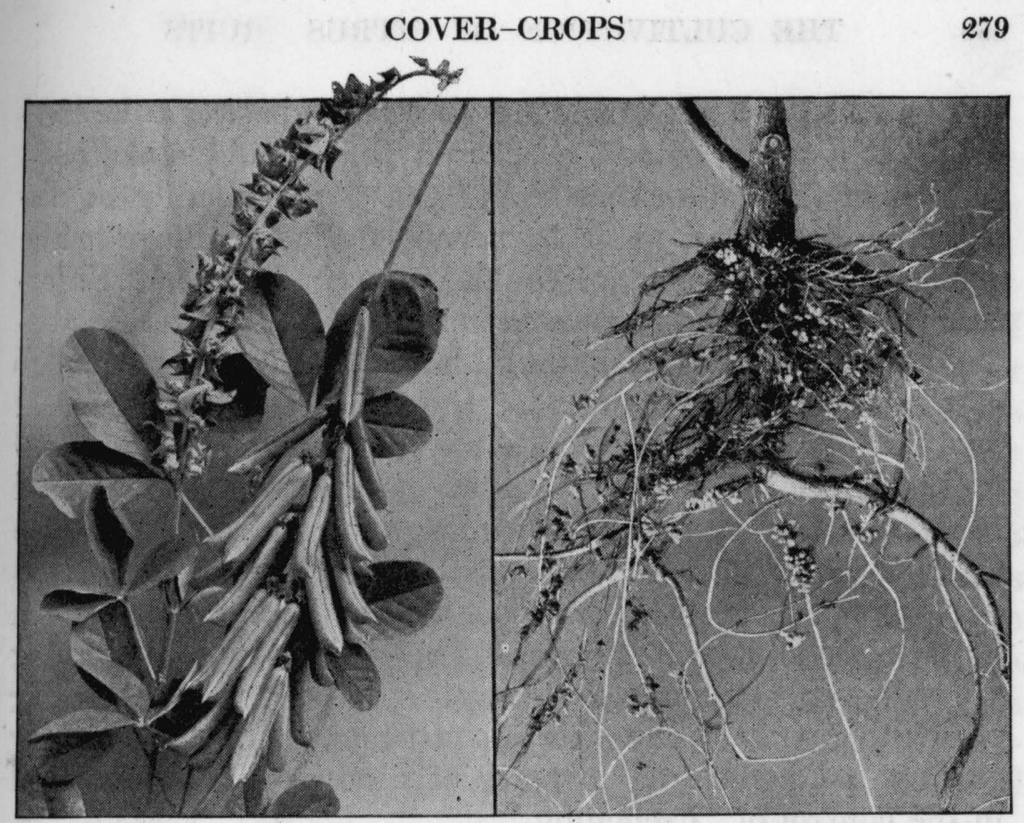

Fig. 143. Flowers, leaves, pods, and root system showing nodules of Crotalaria striata

\section{OTHER COVER-CROPS}

A crop of sand-spurs, crab-grass, and other plants may also be allowed to grow in the grove after cultivation ceases. This plan is adopted by some Florida growers who prefer to apply the nitrogen required, instead of depending upon a leguminous cover-crop for it. Seeding for these crops is not necessary as they spring up spontaneously. Some persons object to such plants as cover-crops, but better by far to have them than bare exposed ground.

\section{COVER-CROPS IN CALIFORNIA}

In California and Arizona, where recourse must be had to irrigation, the growing of cover-crops does not receive the same attention as in the eastern sections. Whether they are planted or not depends largely on the amount of water available. If a supply sufficient for both cover-crop and trees 
can be had, then the latter may be grown between the treerows. If a plant could be secured that would make good growth in the winter season and that could readily be disposed of in spring, so as to permit frequent tillage in the dry summer months, it would be very desirable. Unfortunately, it is too dry, early in autumn, to start a crop satisfactorily without irrigation, and heavy applications of water at this season are not best for the trees. The Canada field pea, bur clover, and vetches have received the most attention as winter cover-crops; cowpeas are sometimes planted in summer. Fortunately, the more retentive nature of the California soils, and their greater store of fertility, has not as yet rendered the growing of a cover-crop of so much importance as it is in Florida. The difficulties of producing a cover-crop on the ground may be overcome by mulching with other vegetable materials. In many cases bean straw or hay has been used in place of a cover-crop and to aid in the control of "Frenching."

In some cases, however, the soils are becoming depleted, and the day is not far distant-in fact has already come in some places-when the cover-crop question will be one of great moment to growers on the Pacific coast. Clean culture cannot produce good results indefinitely and the sooner cover-crops are given attention the better for the future of the citrus industry. 


\section{CHAPTER XXII}

\section{FERTILIZERS AND FERTILIZING}

The problems connected with supplying proper food materials to citrus trees are extremely important. Sooner or later, fertilizers in some form must be used in all citrus districts, for no soil is inexhaustible. Moreover, in many regions they must be used even from the time of planting the trees. In Florida, where the soils are often deficient in plant-food, the kinds, quantities of materials, and the times of their application constitute one of the great questions in citrus culture. The more important problems in California are not use of fertilizers, but the best methods of irrigation and cultivation. As pointed out elsewhere, the soils of California and the arid region generally, are fertile as compared

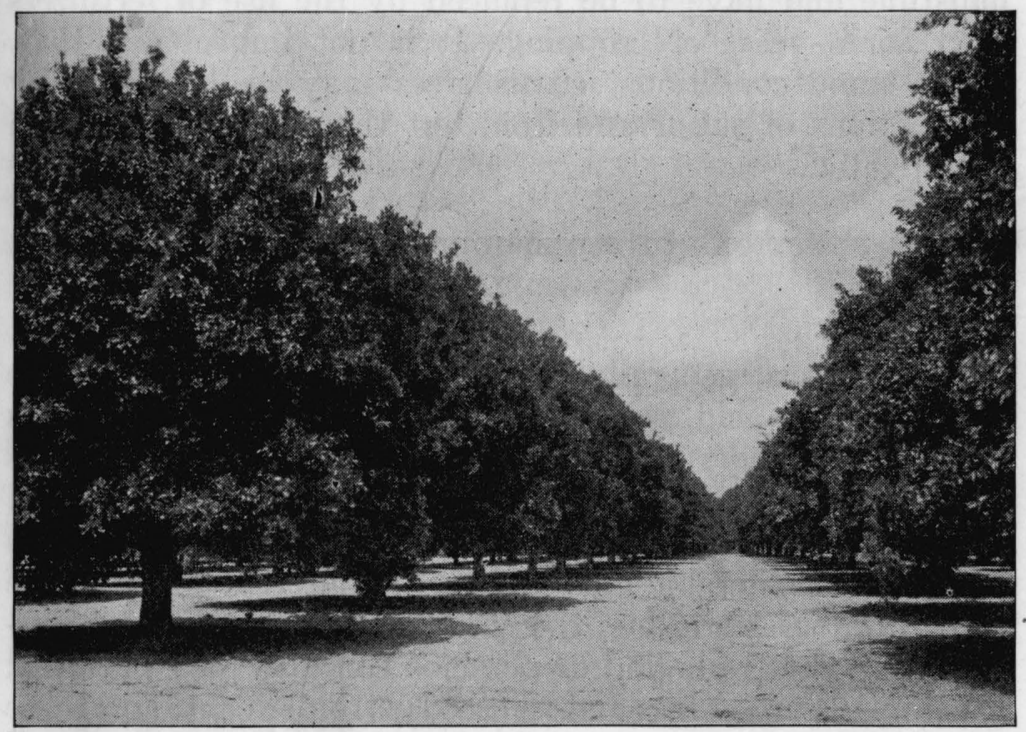

Fig. 144. A well-fertilized citrus grove, showing clean spring cultivation (281) 
with those of Florida, and in some places the need of certain fertilizers has not yet been felt. Most growers in the western districts, however, already realize the importance of keeping up the fertility of the land and make regular applications of nitrogenous fertilizers. The fact should be borne in mind that crops of fruit cannot be harvested year after year from a given area without depleting the soil, decreasing the quantity and impairing the quality of the output, unless some return is made to the soil.

The elements that enter into the composition of citrus trees are carbon, oxygen, nitrogen, hydrogen, potassium, calcium, magnesium, phosphorus, sulfur, iron, and sometimes chlorine, but of those obtained from the soil, all except phosphorus, potash, and nitrogen are usually present in sufficient quantities for the needs of the trees. In some lands even these three may be present in the virgin soil in sufficient quantities to last some time, but they are usually not inexhaustible and have to be replaced by the use of fertilizers after some years of cropping. It is not improbable that, under some conditions, citrus trees may be benefited by applications of sulfur and iron, but this field has not been investigated.

THE FUNCTIONS OF PHOSPHORUS, POTASH, NITROGEN, AND LIME

\section{Phosphorus.}

Phosphorus, generally referred to in the fertilizer trade as phosphoric acid, is a very essential substance and plays an important part in the life activities of plants. It enters into the formation and is a constituent of a certain class of nitrogenous compounds known as proteids. Phosphorus is found in considerable amounts in the different parts of the fruit of citrus trees, but the seeds contain the highest percentage. The fresh rind of pomelos contains .035 per cent; the pulp .044 per cent; and the seeds .315 per cent; and these percentages may be regarded as close approximations for all 
citrus fruits. Unless the requisite amount of phosphoric acid is available, the fruit does not develop normally; and, besides, the maturity of the fruit is somewhat hastened by heavy applications of this material, unless offset by an abundant supply of nitrogen.

Potash.

In the formation of starch, sugar, fruit, and woody parts of the tree, potash plays an active part. By photosynthesis, starch is formed in the leaves as a solid substance, but before it can be transferred to the different parts of the plant it must be dissolved, and potash assists in this process, thus enabling the starch to pass through the cell-walls of the plant. Sugar is probably formed from starch, and various other related compounds in the plant which enter so largely into the composition of the wood and fruit are probably derived from the same source. The great importance of a goodly supply of potash can thus be easily understood.

If large quantities of potash are taken up by the trees it will be found that the rind of the fruit will be much thinner than otherwise and the amount of rag greatly lessened. A plentiful supply of potash in the fruit has an excellent influence on its keeping quality. If too little is present, the fruit is soft and likely to break down shortly after removal from the trees. To increase the keeping and carrying quality of citrus fruits, a large quantity of potash, with a minimum of nitrogen for normal fruit-growth and development, should be used. The influence of potash on the hardening of the wood is worthy of note. Trees plentifully supplied with it are more likely to form firm hard wood, less liable to damage by cold and the attacks of insects, than if a preponderance of nitrogen is applied.

\section{Nitrogen.}

The effects of an abundant supply of nitrogen are much more apparent than those of either potash or phosphoric acid. 
When the leaves have a dark green glossy color they are receiving plenty of nitrogenous food. The effects are further shown in the increased area of individual leaves, strong vigorous sappy growth, and long internodes. Very large quantities of nitrogen impair the fruitfulness of the tree, wood-formation taking place at the expense of fruit. It also has a tendency to retard the maturity of the fruit, and large applications materially increase the amount of rag and the thickness of the rind. On the other hand, when the nitrogen-supply is not sufficient, the leaves become yellow, the trees have a stunted starved appearance and do not make a normal growth of branch and leaf.

\section{Lime.}

The value of lime as a fertilizer may be viewed from two points: its influence on the plant and its effect on the soil. Both of these have a direct bearing on the subject under discussion. In optimum amounts it is beneficial.

In the plant, the presence of lime appears to favor the formation of stronger cell-walls and thus aids in making the trees stronger and more sturdy. Citrus trees planted on soils fairly well supplied with lime have a tendency to mature their fruit somewhat earlier and the fruit is bright and clean.

Much of the fertility of the land depends on the number and activity of soil bacteria, which liberate plant-food and make it available. Soils have a tendency to become too acid, especially in warm climates, and under such conditions the bacteria cannot live. The work of making plant-food available to a large extent ceases when they die out, and even though plant-food is present, the trees receive no benefit from it. Therefore a too acid soil indirectly may be very detrimental.

Most soils in Florida are naturally acid (probably all of them are, except where formations or outcroppings containing lime occur), and under cultivation this acid condition tends to increase from year to year. Contrary to the gen- 
erally prevalent opinion, a moderate content of acid does not appear to interfere with the growth or the quantity and quality of the fruit produced by citrus trees. The amount of acid may become so great as to interfere with the culture of citrus fruits, but, generally speaking, the quantities usually present are not harmful.

Sometimes it is impossible to obtain a good stand of leguminous cover-crops; this is often due to the heavy acidcontent in the soil. It has been observed that cowpeas and velvet beans can be grown on land too acid for beggarweed.

The corrective for acidity is lime. In whatever form applied, whether from burned shells, quick lime, hydrated lime, air-slaked lime, ground limestone, or hardwood ashes, lime must be used with caution. At one time there developed a widespread belief in Florida that lime of any kind and in any amount was beneficial to citrus groves. Because it was cheap and easily obtained, growers applied it in large quantities in the form of ground limestone. The results, in many cases, and particularly on light soils, were far from satisfactory, for the humus-content was greatly reduced, beneficial soil bacteria were destroyed, and plant-food in greater or less amounts was liberated and wasted. The effect on the trees was very unsatisfactory. After a time the foliage became yellow and "Frenched," the leaves dropped, twigs died back at the tips, and the whole appearance of the tops indicated a severe derangement of the vegetative functions. Examination of the smaller roots showed that in many cases they had been killed. It therefore became necessary, in some cases, to counteract the injurious effects of too much lime. The best method for restoring the trees to normal condition consists in applying stable manure, mulching with vegetable material, and establishing good covercrops. The use of fertilizers from organic sources, in such cases, is also indicated.

It is apparent that when lime is applied to citrus plantings it should be used with caution and in moderate amounts. 
Before applying any considerable quantities it is advisable to make sure that the soil is well furnished with humus and vegetable matter. Ground bone, raw or steamed, is a safe and valuable source from which to obtain lime.

\section{CITRUS FRUIT ANALYSES}

The following analyses show the amounts and relative proportions of the three more important fertilizer ingredients -phosphorus $\left(\mathrm{P}_{2} \mathrm{O}_{5}\right)$, potash $\left(\mathrm{K}_{2} \mathrm{O}\right)$, and nitrogen $(\mathrm{N})-$ removed in the fruit of pomelos, mandarin oranges, and kumquats in Florida, as determined by Miller and Blair, of the Department of Chemistry of the University of Florida, and of sweet oranges and Eureka lemon as computed from the data given by Hubert L. Dyer in Bulletin No. 93, University of California Agricultural Experiment Station:

Table ViII. Analyses of the Fruit of Six Varieties of Pomelos (From Bulletin No. 58, Florida Experiment Station)

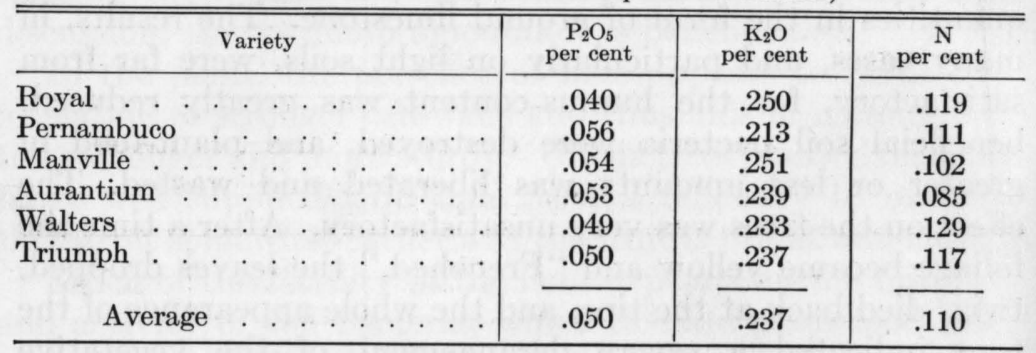

Table IX. Analyses of the Fruit of Six Varieties of Mandarin Oranges (From Bulletin No. 66, Florida Agricultural Experiment Station)

\begin{tabular}{|c|c|c|c|}
\hline Variety & $\begin{array}{c}\mathrm{P}_{2} \mathrm{O}_{5} \\
\text { per cent }\end{array}$ & $\begin{array}{c}\mathrm{K}_{2} \mathrm{O} \\
\text { per cent }\end{array}$ & $\begin{array}{c}\mathrm{N} \\
\text { per cent }\end{array}$ \\
\hline $\begin{array}{l}\text { Satsuma } \\
\text { China } \\
\text { Dancy } \\
\text { Oneco } \\
\text { Cleopatra }\end{array}$ & $\begin{array}{l}.0386 \\
.0758 \\
.0591 \\
.0573 \\
.0529 \\
.0531\end{array}$ & $\begin{array}{l}.2121 \\
.2576 \\
.1903 \\
.2732 \\
.3199 \\
.2791\end{array}$ & $\begin{array}{l}.1661 \\
.1404 \\
.1500 \\
.1653 \\
.1639 \\
.1506\end{array}$ \\
\hline 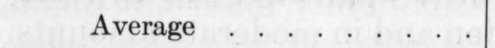 & .0561 & .2570 & .1560 \\
\hline
\end{tabular}


Table X. Analyses of the Fruit of Two Varieties of Kumquats (From Bulletin No. 65, Florida Experiment Station)

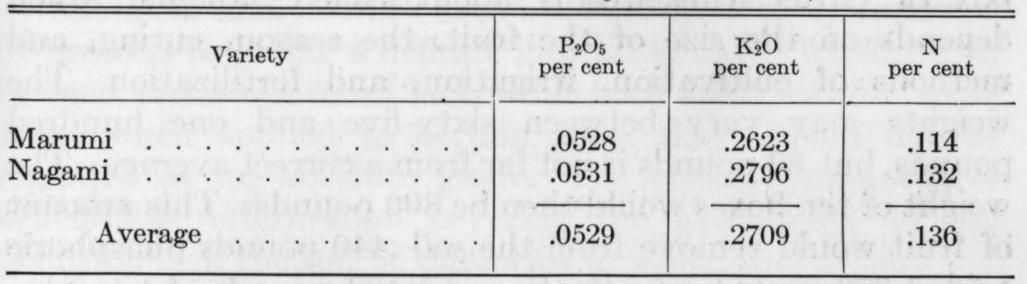

Table XI. Analyses of the Fruit of Four Varieties of Sweet Oranges (Computed from Bulletin No. 93, University of California Agricultural Experiment Station)

\begin{tabular}{|c|c|c|c|c|}
\hline & ariety & $\begin{array}{c}\mathrm{P}_{2} \mathrm{O}_{5} \\
\text { per cent }\end{array}$ & $\begin{array}{c}\underset{\mathrm{K}}{\mathrm{K}_{2} \mathrm{O}} \text { cent }\end{array}$ & $\stackrel{\mathrm{N}}{\text { per cent }}$ \\
\hline $\begin{array}{l}\text { Navel Oranges } \\
\text { Medium Sweet } \\
\text { St. Michael's } \\
\text { Malta Blood }\end{array}$ & 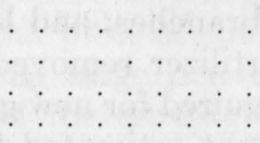 & $\begin{array}{l}.051 \\
.065 \\
.053 \\
.062\end{array}$ & $\begin{array}{l}.215 \\
.225 \\
.216 \\
.221\end{array}$ & $\begin{array}{l}.211 \\
.154 \\
.228 \\
.168\end{array}$ \\
\hline Average &... & .058 & .219 & .190 \\
\hline
\end{tabular}

Table XiI. Analyses of the Fruit of One Variety of Lemon (Computed from Bulletin No. 93, University of California Agricultural Experiment Station)

\begin{tabular}{|c|c|c|c|}
\hline Variety & $\underset{\text { per cent }}{\mathrm{P}_{2} \mathrm{O}_{5}}$ & $\begin{array}{c}\mathrm{K}_{2} \mathrm{O} \\
\text { per cent }\end{array}$ & $\stackrel{N}{N}$ \\
\hline Eureka . . & .058 & .253 & .151 \\
\hline
\end{tabular}

It will be seen from these analyses that the fruit of all kinds of citrus contain practically the same percentage of fertilizer ingredients, and definitely establishes the fact that all the different kinds may be grown with the same fertilizers. The averages of the five tables given above are .055 per cent phosphoric acid $\left(\mathrm{P}_{2} \mathrm{O}_{5}\right), .249$ per cent potash $\left(\mathrm{K}_{2} \mathrm{O}\right)$, and .149 per cent nitrogen $(\mathrm{N})$. Roughly, the proportions are one part phosphoric acid to five parts potash to three parts nitrogen (1-5-3). 
For purposes of computation it may be assumed that a box of citrus fruit weighs about eighty pounds. Much depends on the size of the fruit, the season, curing, and methods of cultivation, irrigation, and fertilization. The weights may vary between sixty-five and one hundred pounds, but 80 pounds is not far from a correct average. The weight of ten boxes would then be 800 pounds. This amount of fruit would remove from the soil .440 pounds phosphoric acid, 1.976 pounds of potash, and 1.192 pounds of nitrogen.

That soil depletion may be prevented, these are the losses which must be made good for each ten boxes of fruit. In addition, provision should be made for a variable and unknown quantity of plant-food that leaches from the soil; and, besides, the tree must have sufficient food-supply to enable it to add new growth in roots, branches, and leaves. A fair approximation, covering the fertilizer removed in the fruit and that lost by leaching and required for new growth, would be two or three times the amount estimated for every ten boxes of fruit.

Fertilizing is more or less a local matter, one which it is well-nigh impossible to reduce to absolute facts and figures, and each grower must determine for himself how much his trees require and how much it is economical to use. It has generally been observed in Florida, where commercial fertilizers are largely used, that the grower who fertilizes liberally with the proper materials generally meets with the best success. This, perhaps, is not only the result of the additional fertilizer, but because a liberal policy along this line leads him to give greater attention to all details connected with the care of the trees. A citrus tree may get along after a fashion and give some returns with poor treatment; it may live and eke out a miserable existence when abused and neglected; but, in all cases, it amply repays good care and attention and will not be profitable unless they are given. The grower who neglects his trees should undertake some other line of work. 


\section{SOIL ANALYSES}

Chemical analyses of citrus soils are frequently regarded by growers as giving a definite indication of the fertilizers to be used. As a matter of fact, while such analyses have some value when applied to certain soils, they should not be regarded as an absolute guide. The chemist cannot give dependable information covering the availability of the plant-foods in the soil or the forms in which they occur.

In Florida, it is hardly worth while having such analyses made. The soils of the state are easily separated into different types by their general appearance, location, and the native growth they support. Large numbers of analyses have already been made, and if the general soil-type is known, a very close approximation of the fertilizer-content of any particular piece of land may be obtained. In Florida, lands containing large percentages of nitrogen are usually either unsuited for citrus-growing, because of drainage or other conditions, or the plant-food is present in unavailable forms. The fertility occurring naturally in most Florida soils may be entirely disregarded in working out a fertilizing program, and from the beginning fertilizers must be used. Some reclaimed muck-lands contain large amounts of nitrogen, but they are deficient in mineral constituents.

\section{SOURCES OF PLANT-FOOD}

The most noteworthy sources from which the required fertilizing elements may be secured are barnyard manure and commercial fertilizers. A good quality of the former, when well rotted, contains about .03 per cent of phosphoric acid, .05 per cent of potash, and .06 per cent of nitrogen, while the latter may be of almost any conceivable composition.

The use of stable manure as a fertilizer for citrus trees in California has produced satisfactory results, but in Florida its application has too frequently been followed by attacks of die-back and other troubles. Whether this be true in all 
cases or not, in the vast majority the benefits to be derived from the use of stable manure are doubtful. It is essentially a nitrogenous fertilizer, and, whenever used, should be accompanied by heavy applications of potash, unless the soil is already rich in this material. Potash is notably deficient in Florida soils. An additional supply of phosphoric acid may also be needed. The greatest difficulty in the use of stable manure is that growers generally fail to realize that, at best, it is a one-sided fertilizer. Stable manure is of great assistance in correcting "Frenching" or "mottled leaf" conditions, and in putting new growth in starved and neglected trees.

Sources of phosphoric acid.

The principal sources of phosphoric acid are bone and phosphatic rock. The bone is sold either as ground bone, steamed bone, or dissolved bone-black; the other as superphosphate (acid phosphate), and double super-phosphate. Ground raw bone contains about 22 to 26 per cent phosphoric acid; steamed bone about the same; dissolved boneblack, 16 to 19 per cent; super-phosphate, 13 to 15 per cent available; a high-grade super-phosphate, 16 to 19 per cent available; and double super-phosphate, 45 to 57 per cent available.

The readiness with which the phosphoric acid may be obtained from bone depends largely on its fineness of division, and the finer it is ground, the more readily the roots can take it up. As it must undergo decomposition before yielding up its phosphoric acid, it is not well to use it when quick results are desired. It is an excellent substance to increase the phosphoric acid-content of the soil, supplying a store from which the tree may draw gradually. All the phosphoric acid that bone contains will eventually become available to the trees unless this plant-food becomes locked up in insoluble compounds when liberated from the bone. It is usually safe to assume that 50 per cent of the phosphoric 
acid in finely ground bone becomes available within twelve months. Bone is also an excellent material from which to obtain lime without the injurious effects which follow the use of ground lime rock and slacked lime on many soils. At the time of planting citrus trees, a pound or two incorporated with the soil before placing it about the roots is an excellent practice, and is highly recommended.

Phosphoric acid fertilizers derived from phosphate rock are of two kinds: super-phosphate, known to the trade as acid phosphate or high-grade acid phosphate, and double super-phosphate. The latter is not applied to any great extent. It has been said that it is best to use bone as a source of phosphoric acid, and yet acid phosphate has been employed in some groves in Florida continually for years with uniformly satisfactory results. Each year the crops have been all that could be desired. In the face of results obtained from the use of either bone or acid phosphate, it is probably safe to say that one is as good as the other as a source of phosphoric acid.

Sources of potash.

The forms in which potash may be supplied to citrus trees are three: high-grade potash, containing about 51 per cent available potash; low-grade sulfate of potash, containing about 26 per cent; muriate of potash, containing about 50 per cent. The raw salt, Kainit, is also used sometimes, but the bulk to the unit of potash is so great that cost of handling and freight charges make it too expensive to recommend. It is generally regarded as a satisfactory material. Wood-ashes are also sometimes applied and with gratifying results, particularly on heavy soils. Their potashcontent, compared with other materials, is usually very low.

Of all the materials, the sulfates are the safest and best. It is an established fact that it is not well to use muriate of potash on some crops, for their quality is impaired. This is true of tobacco, the Irish potato, the sugar-beet, and, perhaps 
other crops. The deterioration is ascribed to the presence of chlorine, which interferes with the accumulation of starch as a stored product. There is a general impression that muriate of potash is not a good substance to use on orange trees, and while its deleterious effects have never been properly elucidated, the impression is probably well grounded. It may be that chlorine interferes with sugar formation, and starch and sugar are very closely related compounds. High-grade sulfate of potash is usually preferable to low-grade, as the cost of freight and handling is less to the unit of potash, but either may be employed.

\section{Sources of nitrogen.}

Nitrogen may be obtained as nitrate of soda, sulfate of ammonia, dried blood, cottonseed meal, and castor pomace. Tankage, sometimes sold in the markets as blood and bone, is another source of supply. Nitrate of soda contains approximately 16 per cent nitrogen; sulfate of ammonia, 21 per cent; dried blood, 14 per cent; cottonseed meal, 6.5 per cent; castor pomace, 6 per cent; low-grade tankage, 6 per cent. The last three also contain some phosphoric acid. These six substances may be divided into two groups, the first two being designated as chemical sources of nitrogen, the last four as organic sources, vegetable or animal.

In Florida the use of the chemical sources is often advised, owing to the fact that applications of cottonseed meal and blood, and other organic sources, or of mixed fertilizers containing these materials, have been followed by "die-back." This has happened so repeatedly that any organic source of nitrogen is always, and justly, regarded with suspicion. Their use in large quantities is always attended with considerable risk, and it often happens that all the growth added may be lost, owing to the disturbance of the functions of the tree. In sections where "die-back" does not follow their use, organic sources are good, if used with discretion, but heavy applications may impair the quality of the fruit. 
The nitrogen in nitrate of soda is available as soon as it is dissolved in the soil. Most of the nitrogen taken up by plants is in the form of nitrate, which explains why the trees respond so readily to applications of nitrate of soda. It must be used with discretion, preferably in the dry season, else a considerable part may be leached from the soil, and it is better applied in a number of separate dressings of one to two hundred pounds to the acre. The effect of nitrate of soda on acid soils is to decrease soil acidity. As the nitrogen is used up, a soda residue remains which combines with the soil acid.

Sulfate of ammonia is of such physical character as to be readily distributed through the soil. The form of the nitrogen has to be changed to nitrate through the process of nitrification before it can be utilized by plants, hence it does not act so quickly as nitrate of soda. It is an excellent form of nitrogen for citrus groves, particularly among bearing trees. Sulfate of ammonia, if applied continuously, increases soil acidity, and while citrus trees apparently are not injuriously affected by soil acid, it is usually good practice to alternate this ammonia compound with nitrate of soda. This helps to decrease soil acidity. These two materials may be combined in the same fertilizer mixture to good advantage.

\section{CAUTIONS IN APPLICATION OF FERTILIZERS}

Some persons have said, and perhaps on good grounds so far as some crops are concerned, that it does not matter from what source the three important plant-foods are derived. While this may apply to some crops and some fruits, it is not true of citrus. They reflect the food-supply. They may be thin-skinned, heavy, and juicy through the use of the proper materials, and the very flavor may be influenced by the fertilizers used. On the other hand, they may be thickskinned, full of rag, insipid, and lacking in character, owing to the use of poorly balanced fertilizers. The tree itself may 
come to an untimely end through the persistent use of rank organic sources of nitrogen. Under Florida conditions there is reason to think that ammonia derived from inorganic sources gives best results, although other ammoniates may be used at times.

It is a difficult matter to mix fertilizers derived from mineral sources only. If acid phosphate, sulfate of potash, and nitrate of soda are combined in a fertilizer, for example, without other materials, the resulting mixture is likely to part with some of its ammonia and to become caked and hard. This makes it very difficult to handle. To overcome this trouble, it is usual to add such materials as ground tobacco, ground bone, or some of the organic sources of nitrogen in sufficient amounts to keep the fertilizer in good mechanical condition.

\section{LEACHING OF FERTILIZERS}

Not all the fertilizer used in citrus groves accomplishes the purpose for which it was applied. In periods of excessive rainfall, certain plant-foods in fertilizers may be leached from the land or carried out of reach of the roots. The amount and rapidity of this loss is influenced-increased or retarded-by certain factors, such as the character of the soil, the amount of humus, the age and size of the trees, climatic variations, and the character of the fertilizer materials themselves. The conditions best suited to obtaining maximum results from fertilizers should be carefully studied, that losses from leaching and from other causes may be reduced to the smallest possible amount.

Losses by leaching are greater in porous sandy lands and subsoils than in those more compact and containing clay in the surface and subsoils. Lands with clay subsoil are much more retentive of plant-food and soil-moisture than those composed entirely, or almost entirely, of sand. Clay soils have the power to hold both ammonia and potash in much larger quantities than sandy soils. A high humus-content is 
also very desirable, and losses of plant-food are very greatly reduced by maintaining a liberal supply of it. The waterholding capacity of humus is great and plant-food is also held in solution. This factor is largely under the control of the grower; it is good practice to maintain the vegetable matter and humus-content of the land at a relatively high point. The combination of a soil containing some clay and well supplied with humus is most desirable.

In young plantings, the volume of soil occupied by roots is limited, while in old groves the surface soil is filled with a network of root fibers. Fertilizer, as it passes into the proper form for the roots to use, is taken up more rapidly in the older groves. But when applied to plantings of young trees, it may pass through the soil without coming in contact with their root systems. It is wise, therefore, to make frequent small applications of fertilizers to young trees and to apply it well within reach of their feeding roots. In old groves, planted at ordinary distances, the soil is completely filled with a mass of fibrous roots, and fertilizers may be applied over almost the whole surface of the land without getting outside the root-zone.

The rainfall in many citrus regions is very heavy in certain parts of the year. The Florida rainy season comes in the summer months, while in California the season of heaviest rainfall is in winter. Caution should be exercised in applying fertilizers in rainy periods. It may be wise to go so far as to withold it for some time until rains cease, or the fertilizer may be applied in small amounts and more frequently to avoid losses. If an application of fertilizer is followed shortly afterward by a very heavy downpour, it may be well worth while to apply more of it as soon as conditions are favorable. Since the loss of nitrogen is likely to be much greater than that of phosphoric acid and potash, it may be advisable to apply nitrogen only in such cases.

The plant-food in fertilizers of many kinds becomes available much more rapidly in warm weather than in periods of 
low temperature. Heavier applications, therefore, can usually be made in early spring without loss than in summer months. Fluctuations in soil temperatures, nevertheless, have an important influence on the rapidity with which plant-food becomes available. Damp weather, high temperatures, and tillage are important factors in increasing the activity of the soil bacteria and the rapidity of chemical changes. Plant-foods become soluble and available very rapidly under such a combination of circumstances.

Nitrogen is lost in much larger quantities by leaching than either phosphoric acid or potash. Its nature, the chemical combinations into which it enters, and the ways in which materials carrying it are acted upon by different kinds of soil bacteria, all contribute to its rapid disappearance from the land. The more easily and quickly the nitrogen in the applied fertilizer becomes available for the trees' use, the more readily it may be lost unless taken up immediately by the roots. The nitrogen in the organic ammoniates, such as dried blood, tankage, cottonseed meal, and castor pomace, is not available until it is acted upon by certain soil bacteria which change it to nitrate. This requires time, and opportunity is afforded the roots to make use of it over a longer period. As soon as the nitrogen is changed, it is subject to the same losses by leaching as though derived from any other source. The ammonia in sulfate of ammonia is held in part in the soil and soil-water. It is acted on by soil bacteria and changed to nitrate. Because this change takes place, the nitrogen it contains is not so easily lost as is that in nitrate of soda.

Phosphoric acid is held in the soil in such a way that little leaches out. For this reason it is not necessary that the same caution be exercised as in applying nitrogen. It is also possible to build up reserves of phosphoric acid, but some of it passes into insoluble compounds and is lost to the trees. This is particularly true when it unites with iron and aluminum, from which combinations it is particularly diff- 
cult to liberate it. When it combines with lime, however, the resulting compound is readily broken up, again freeing the phosphoric acid and making it available to the roots.

The loss of potash from leaching is not so great as of nitrogen, but much more than of phosphoric acid. Clay soils, particularly, have considerable power to retain soluble potash, while sandy soils have only limited retentive power. Hence, caution must be exercised in the use of potash on sandy lands. It is possible, however, to build up some reserve. For many years, potash was used by Florida growers in larger amounts, probably, than were necessary. There seems to be little doubt that a reserve supply was stored which, during the World War, was of great value in carrying trees and fruit in good condition through the period of potash shortage.

To give a rough idea of the relative difference in loss from leaching of the three plant-foods, the phosphoric acid loss may be represented by 0 , the potash by 7 and the nitrogen by $25(0-7-25)$. Experiments in Florida have shown that over a period of two years 41 per cent of the sulfate of ammonia, 72.5 per cent of the nitrate of soda, and 38.3 per cent of the dried blood were leached from the soil. Of the potash applied over a period of four years, 30 per cent was lost. A loss of only .05 per cent of the phosphoric acid applied in four years was leached out. The fertilizer materials were applied to young trees, the root systems of which were not developed and did not fill the soil. Losses in old groves would be much less. The results indicate that caution must be used in applying fertilizers, particularly nitrogen, if losses from leaching are to be avoided.

\section{FORMULAS; AMOUNTS REQUIRED}

In discussing fertilizer formulas for citrus trees, great emphasis is usually placed on the relative proportions of phosphoric acid, potash, and nitrogen. This has gone so far that manufacturers emphasize the value of fractional per- 
centages, $1 / 4$ or $1 / 2$ of 1 per cent, for example. Calling attention to these small amounts is only a selling argument, and all fertilizers properly made up carry some excess of the analyses indicated. Nothing that may be said here should be construed as reflecting on the value of the right analysis of a citrus fertilizer, but too frequently no particular emphasis is placed on the quantity to be used. It will not matter much, so far as the trees and the fruit crop are concerned, whether a fertilizer contains 10 or 12 per cent of potash, but it does matter greatly if a tree which should have 40 pounds of fertilizer at an application, or for the year, receives only 20 pounds.

Young and old trees differ in their fertilizer requirements. Young trees use their food-supply in the formation of wood and leaves. For the first four or five seasons they grow vigorously. When the bearing period is reached, a gradual change comes about; the trees do not grow so rapidly and a large portion of the food-supply is diverted to fruit-formation. The demands on the trees being different, the food supplied should be different in character. Young trees require a large amount of nitrogen, while bearing trees require less nitrogen, relatively, and more phosphoric acid and potash.

For young trees, the fertilizer should contain about 6 per cent phosphoric acid, 5 per cent potash, and 4 per cent ammonia, while one containing 8 per cent phosphoric acid, 10 per cent potash, and 3 per cent ammonia should be applied to the grove of bearing trees.

In the earlier days of the use of commercial fertilizers, the materials were commonly purchased separately and mixed by the grower. This is still undertaken by some, but the practice has almost disappeared. Labor, as related to the citrus industry, is not so abundant as it once was, and there is little difference between prices charged by fertilizer manufacturers for mixing and sacking and the cost of mixing at the grove. It is also a fact that fertilizers can be mixed much 
more thoroughly by machinery at the factories than by hand. Some growers have machines for mixing. A cement mixer may be used for the purpose.

The amounts of fertilizer required depend on the age, size of crop, the amount of fertility already in the soil, and the amount of nitrogen supplied by the cover-crop, if one be grown.

On poor soils, a half pound of fertilizer for each young tree should be incorporated with the soil at the time of planting; if the trees are set in winter, an additional pound should be given in June and one-half to three-fourths pound in early September. The second year, the amount should be increased. Each succeeding year the quantity must be augmented, never allowing the trees to become stunted or to assume a starved appearance. It is better to anticipate their needs than to wait until they are injured. It is usually better to estimate the amount of fertilizer on the basis of so many pounds for each tree, rather than to figure requirements on acreage basis. The number of trees to the acre varies.

When a leguminous cover-crop is grown, the amount of nitrogen may be lessened. On all soils rich in certain plantfood, those materials that are present in sufficient quantities should be omitted in the fertilizer. If it is noted that the trees are growing too vigorously, the nitrogen should be decreased. In case of "die-back," nitrogen should not be applied, and the actual amount of potash and phosphoric acid may be increased to good advantage.

When the trees begin to fruit, the formula should be changed to one for fruit; and the formula for growth may be re-applied whenever it is seen that the trees are not adding sufficient new wood. Trees in Florida producing ten boxes of fruit should receive about thirty to fifty pounds each. This same proportion may be preserved for each additional ten boxes of fruit. It may be noted that the pomelo is an exceedingly vigorous grower and can use more fertilizer to advantage than some other kinds of citrus. 
In the southwestern districts there appears to be enough of both potash and phosphoric acid to maintain citrus groves in good condition. At all events, the addition of these materials does not appear to increase either the quantity or the quality of the fruit, and no noteworthy results follow their use. The situation, as related to nitrogen or ammonia in California groves, shows they are benefited by its addition as a fertilizer. It may be derived from any of the sources already mentioned, except nitrate of soda, and an application of two to three pounds to the bearing tree per annum will generally prove profitable. Younger trees must be watched to see that they do not suffer for lack of this necessary material. It may become depleted, without the effect being noted, until the trees have suffered for want of it. It is always easier to maintain trees in good condition than it is to re-condition them after they have been starved.

In cases where organic matter has become deficient and cannot be successfully returned to the soil by growing covercrops, the use of such materials as bean or pea-straw and alfalfa hay proves beneficial. These bulky materials have an ameliorating effect on heavy soils. They add nitrogen and vegetable matter. If humus cannot be supplied in sufficient quantity by growing it on the soil as a cover-crop, then it must be added, in bulky material, from outside sources.

\section{APPLYING FERTILIZER}

Fertilizers should be evenly distributed on the ground occupied by the feeding roots of the trees. The root-feeding zone on young trees is, for the most part, just within and outside the tips of the branches. The branch-spread is therefore about the center of a circular band some feet wide on which the fertilizer should be spread. In groves eight to ten years old and over, the feeding roots will have extended to occupy all the space between the trees, and the fertilizer is usually scattered over the entire surface. 


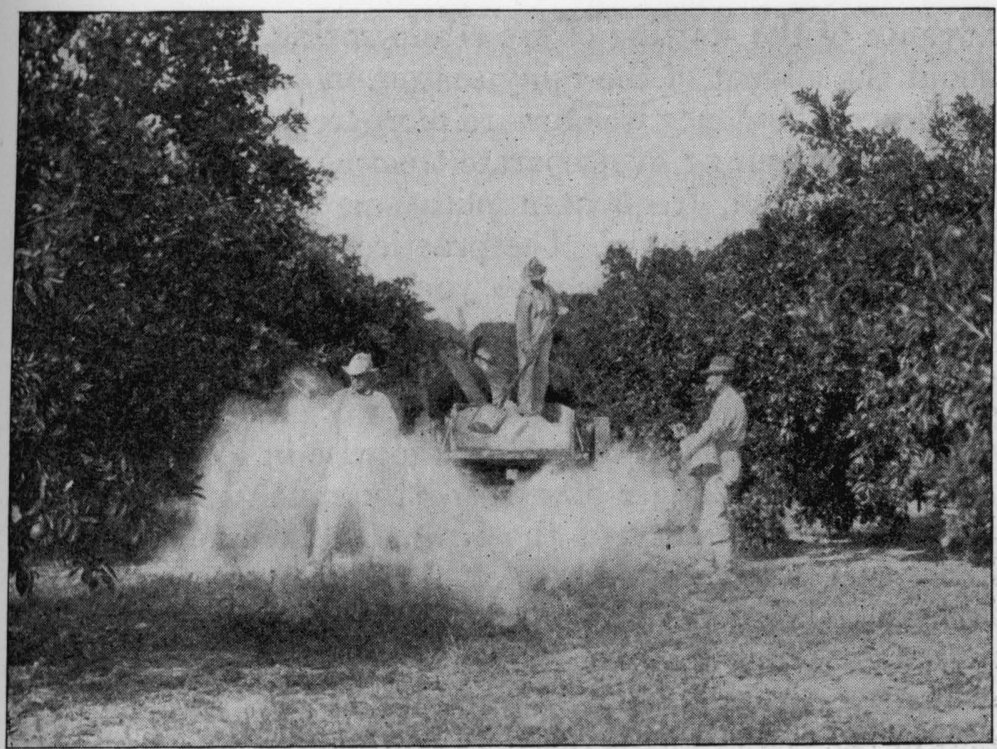

Frg. 145. Distributing fertilizer by hand

After applying the fertilizer, the ground should have shallow tillage. Young trees may be hoed, or a small cultivator employed. In large plantings of young trees, the cultivator may be run parallel with the tree-row, in and out among the trees, thus covering practically the entire surface close up to the trunks (Fig. 135). This plan reduces hand cultivation to a minimum. Groves of large trees may be tilled in two directions and the ground very completely covered with extension cultivators.

Fertilizers are distributed either by hand or with a distributor. If the trees are variable in size, a more satisfactory distribution may be made by hand, as it is easier to reduce the amounts applied to the smaller trees. In bearing groves, the quantity of fruit carried by the trees should be observed and allowance made for this factor.

The old Florida practice in fertilizing citrus trees was to make two applications a year, the first some little time in 
advance of the starting of growth in spring, and the second about the advent of the rainy season, in early June. Later, the general tendency was toward more frequent applications, as many as four or five separate treatments in a year. It is true that small, frequent applications reduce losses from leaching to a minimum. The practice of applying fertilizer three or four times yearly to young trees is still the best method to follow.

However, it is questionable whether numerous applications of fertilizers, particularly those carrying a large or even a fair amount of ammonia, are wise in feeding bearing trees. There is danger of securing too much growth and of impairing the quality of the fruit. The old plan of fertilizing well in early spring, to start the crop on its way, and in June to bring the fruit up to size and carry it through to maturity, had something to recommend it. All things considered, two, or at most, three applications are sufficient, and in the colder citrus districts two only are best unless it may be advisable, in certain cases, to make an early fall application with nitrogen omitted entirely or reduced to a very small amount. Some fertilizer may be wasted by leaching, but this is offset by better quality fruit and by having the trees go into the winter season in the best possible condition to withstand the effects of adverse climate.

It may be pointed out that no rule-of-thumb method for fertilizing citrus trees should be followed. To state definitely that fertilizer should be applied in certain amounts at certain times of the year, and then to apply these quantities without regard to the condition of the trees, weather, and other factors, is not good practice. It is a common practice to increase the amount of ammonia in the earlier applications, and to reduce it and increase the potash in the fall fertilizings. This appears to be sound practice, both from the standpoint of the fruit crop and for the trees, as related to their winter condition. One point should not be overlooked: a tree that is well fertilized and in the best of condi- 
tion will resist more cold and go through the winter in better shape than one that is starved.

When fertilizing for growth in young or old trees, greater results may be obtained from a given amount of fertilizer applied so as to take effect in early spring than that given at a much later time. The winter dormant period is usually of considerable extent; root-action is more or less active during the period; there is an accumulation of reserve food in the tree, and if this reserve can be increased, the spring flush of growth produces greater results than if fertilizer is applied later in the season. As a grower once put it, referring to making growth, "An application of one pound of fertilizer before July 1 is worth two applied thereafter."

The carrying of a crop of fruit through the fall and winter months is a heavy drain on vitality. Some persons think that when the crop is grown and begins to color it is no further burden on the tree. This is not the case. It still requires plant-food to keep it in good condition. In this period the trees must also prepare for and produce another crop of bloom and the double burden must be provided for by fertilizing. Nitrogen particularly is needed; it is often good policy to apply, late in August, two to three pounds of nitrate of soda to each tree carrying ten or more boxes of fruit, if the weather conditions are right. Often this plan is of great assistance in securing uniformly heavy crops from year to year. After all, the wise grower watches his grove and crops closely and gives fertilizer or withholds it as the condition of the trees may indicate. One of the compensations in growing citrus fruits on poorer lands is that the growth of the trees and the quality of the fruit are more definitely under the control of the grower than if the land is well supplied with plant-food. It is true of citrus fruits that they reflect in their character and quality the wisdom and care of him who produces them. 


\section{CHAPTER XXIII}

\section{THE IRRIGATION OF CITRUS GROVES}

It is useless to attempt the cultivation of citrus fruits where an adequate supply of water cannot be secured, either as rainfall or by irrigation. When only an inadequate quantity is available, the trees do not make normal growth, the leaves curl and drop, the young fruit falls, and such as is brought to maturity is deficient in juice and inferior in quality. Under such conditions, the trees become fit subjects for attacks of fungous parasites and scale insects. The combination of unthriftiness and the inroads of different enemies soon bring about the death of the trees or the abandonment of the grove by the owner.

Therefore, in choosing a site it is necessary to be assured that sufficient water will always be available. Citrus trees require more water than deciduous trees of equal size and age, for transpiration is greatly reduced in the winter season or dormant period in such trees as peaches, plums, and pears. The leaf-area of citrus trees is the same winter and summer, and much water is required by them in the winter dormant season and still larger quantities in the period of more active growth in summer. If climatic conditions are practically the same the year round, then there is no seasonal difference in the water required. Citrus trees are more or less active all the time, and transpiration goes on to a greater or less degree during the entire year.

The minimum quantity of water necessary annually is difficult to state in exact figures. It is directly related to the character and depth of soil, the distance to shallow underground waters, the kind, age, and bearing capacity of the trees, the kind of stock, direction and force of prevailing winds, humidity of the atmosphere, presence of fogs, temperatures, clouds, and sunshine. 
In California, where irrigation of citrus fruits is practiced on an extensive scale, and where intelligent care is exercised in the conservation of moisture, the total water provided by rainfall and irrigation is usually between thirty-five and forty-five inches annually. If rainfall provides one-third to one-half of this quantity, the remaining one-half to twothirds has to be provided by irrigation at an annual average cost of around $\$ 20$ to the acre. In seasons of extreme drought and scarcity, even less than two feet has sufficed to carry the trees through, but if the attempt were made to make this quantity do year after year, failure would inevitably result.

In relation to irrigation, the areas in which citrus fruits are grown in the United States may be divided into two sections. The first embraces California, Arizona, and the Texas Rio Grande area, in which a part of the water must be supplied artificially. The second comprises the citrus sections of Florida, Alabama, and the Gulf Coast region, where irrigation is the exception, but where it is occasionally resorted to as a supplement to copious but sometimes irregular rainfall.

\section{RAINFALL IN FLORIDA}

The annual rainfall in Florida, as shown in the accompanying table, is ample for the development of citrus fruits. In fact, viewed in the light of the amounts used in California, it might be deemed excessive. But even with such a heavy precipitation, it sometimes happens that the groves suffer to a considerable extent, and they would at times be benefited by an additional supply. If the heavy rainfall were divided into a large number of equal portions, and these distributed at intervals as needed, citrus trees would certainly never suffer from lack of moisture. But frequently the total rainfall for a month is precipitated in a few hours, most of it runs off, and the full benefit is not secured from it. 
Table XiII. Annual Precipitation in Florida

\begin{tabular}{|c|c|c|c|c|c|}
\hline & 1920 & 1921 & 1922 & 1923 & 1924 \\
\hline Fort Myers . . . . . . & 53.28 & 52.04 & 77.35 & 44.52 & 61.61 \\
\hline Tampa . . . . . . & 49.42 & 49.65 & 47.93 & 37.08 & 55.40 \\
\hline Orlando & 60.13 & 47.63 & 51.20 & 51.60 & 66.23 \\
\hline Gainesville . & 63.71 & 36.10 & 51.33 & 41.72 & 61.96 \\
\hline Tallahassee . & 62.55 & 39.19 & 59.35 & 44.70 & 75.59 \\
\hline Jacksonville & 59.20 & 40.62 & 57.19 & 39.99 & 56.83 \\
\hline DeLand . . . . . . . . . . & 54.75 & 40.16 & 56.06 & 53.61 & 84.03 \\
\hline Jupiter & & 55.61 & & 46.67 & 70.22 \\
\hline Miami . . . . . & 47.61 & 44.37 & 67.57 & 41.85 & 65.54 \\
\hline State average & 57.79 & 45.24 & 57.53 & 50.17 & 61.62 \\
\hline
\end{tabular}

The period during which rainfall is most uncertain, and in which the groves are most likely to suffer, is between the first of March and the middle of June. Frequently, weeks pass without a shower, while at other times an amount of water sufficient for the whole period falls within a few hours. It is during this time that groves often would be benefited by irrigation, and the seasonal occurrence of these conditions with more or less regularity has led many growers, even on comparatively moist soils, to make provision for applying water artificially. The period from June to October is usually designated as the "rainy season," in which showers are of daily occurrence and in which irrigation is usually needless.

One of the irrigation difficulties in moist climates is that after making an application, a downpour may follow before the irrigation water has been dissipated. If the drainage is not good, damage may result, and, at any rate, plant-food in available forms may be washed or leached away.

\section{IRRIGATION IN RIO GRANDE AREA, TEXAS}

The annual rainfall in this area of Texas is variable, but usually sufficient water is not forthcoming for the successful culture of citrus trees. The precipitation at Brownsville, in 1917, was 12.15 inches, and the annual mean precipitation 
over a period of years was 26.75 inches. Farther up the valley the average is somewhat less, about twenty to twentythree inches. Irrigation water is secured from the Rio Grande River by pumping. On the higher ground, in the upper or western part of the area, two or three lifts of about thirty feet each are necessary to put the water on the land.

THE SOUTHWESTERN AREA

Water for irrigation in the citrus districts of the California-Arizona region is secured from a number of different sources. Some of it comes from mountain streams, some of it from deep wells, and some from artesian wells. All the water from these sources is supplied from the adjoining mountains. The areas in cultivation in citrus fruits are often determined or limited by the possibility of putting water on them. The higher elevations are usually freer from frost, but frequently such locations are not available because water cannot be raised to them economically. Electricity generated by water-power has made it possible in recent years to handle water at much less expense than formerly.

\section{SOURCES OF FLORIDA IRRIGATION WATER}

In Florida there are no irrigation projects comparable with those in the Southwest, as it has no large areas in which citrus-fruit culture depends on water brought from a welldefined source. But water for irrigation is available in Florida almost wherever needed, and it can be secured in some one of several different ways. The principal sources of supply are lakes, rivers, springs, and shallow and deep wells. From deep wells water either flows naturally (artesian wells), or it is pumped.

Surface water is abundant in Florida. The streams and lakes are well distributed, and in some parts, as in Lake and Polk counties, the lakes are very numerous. It is said that within a radius of five miles from Winter Haven, in Polk County, there are one hundred and fifteen lakes. An 
airplane view of this area gives the impression that onehalf of the country is occupied by them. There are also many springs, some of them of enormous capacity. The water is usually of the highest quality.

Shallow underground waters are available and very abundant. Wells, yielding plentifully, when sunk to a depth of twenty to thirty feet, supply all the water needed throughout large districts. The close proximity of this water to the surface no doubt has a considerable influence on the moisture conditions in the upper layers of soil, and it may be obtained for irrigation purposes by means of driven wells. One-and-one-half or two-inch pipes, with perforated wellpoints, are driven into the ground. Several of the wells are spaced over an area of a few hundred square feet. At the top they are all connected with a single large pipe which leads to the pump, and when pumping is under way, water is drawn from each of the several wells. In most of the flat-woods areas of Florida, water of good quality can be obtained in this way. Internal combustion engines are used for power.

Deep wells are usually of much larger diameter-six, eight, or even ten inches - and either cased for part of the depth or all the way down. In the higher areas of the state, although the water rises to a level of considerable height it does not flow out on top, and has to be brought to the surface by pumping. At lower levels, artesian or flowing wells can be secured, but their force is variable. In some cases it is barely sufficient to bring the water out of the ground, but in other locations a head of as much as thirty-five to forty feet is secured. These wells vary in depth, depending on location. Sometimes a good supply is close to the surface, and in other cases wells have to be drilled several hundred feet.

Along the Atlantic and Gulf coasts there is a belt of varying width in which the elevations above sea-level are fifty feet or less, and it is in this lower area that the great 
artesian belt is located. It includes much of Nassau and Duval counties, nearly all of St. Johns, and from there south along the coast and through the valley of the St. Johns River to its headwaters. On the Gulf Coast, the area, so far as located, begins in Lee County and follows up the coast as far north as St. Petersburg and Tampa. Inland there are artesian areas along the Kissimmee and Peace rivers, and in western Florida along the Gulf Coast at or near sea-level from Franklin County westward. Here and there in other parts of the state, artesian wells are also secured at suitable levels. Of the three important artesian areas in Florida, from the standpoint of development and use, the most valuable are around Hastings, Sanford, and Bradenton.

The water which makes these artesian wells possible comes from points mostly within the state, and not many miles distant from where the wells are located. In the western part of the state, the area of supply embraces parts of Alabama and Georgia. While the surface of much of Florida appears very flat to the eye, yet there is considerable variation in the topography. Besides the low areas along the coast, the central-southern portion, embraced in the Everglades area and territory adjacent to it, is low and flat. Further north, beginning some little distance west of the St. Johns River and extending westward and northward, the land is rolling and much higher, as well as in western Florida. In the peninsular part, the higher elevations run from one hundred and fifty to two hundred and fifty feet above sealevel, while in western Florida heights of two hundred to two hundred and fifty feet are reached. So far as known, the highest points in the state are at Mount Pleasant and Hardaway, Gadsden County-three hundred and one and three hundred and three feet, respectively. For the sake of comparison, it may be pointed out that the elevation at Hastings is eight feet above sea-level, and at Sanford six feet. Such differences in elevations are what make artesian wells flow within the state. 
Artesian wells are made possible by the collection of water in an inclined pervious layer of rock that lies between two impervious layers. Water collects in this layer under pressure and rushes upward, when wells are drilled into it, reaching nearly the same level as the plane at which it entered. It is not improbable that the lakes in the higher sections of Florida are the source of many artesian wells. Numbers of these lakes are not drained by rivers or streams

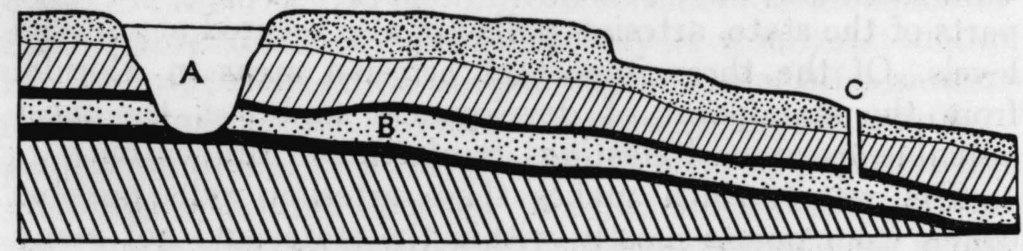

Frg. 146. Diagram showing origin of artesian wells. A, lake; $\mathrm{B}$, pervious layer of rock; $\mathrm{C}$, artesian well

and have no visible outlet, but in some cases they have been entirely emptied for a time by the disappearance of the water through an opening in the bottom. This is brought about by the gradual wearing away and breaking down of the limestone strata on which the lake rests. It is probable that water sometimes escapes constantly through a pervious stratum in the bottom or side. Fig. 146 shows how this might be. Opening into the lake, A, is a pervious layer, B, between two impervious layers, into which the water passes. The water following the dip in the strata flows downward, and if a well is bored at $\mathrm{C}$, the water rises above the surface. The Florida wells are usually between forty and two hundred and fifty feet deep, although some are much deeper.

Artesian water is not always suitable for irrigation. In the southern part of Florida, salt water only is secured, and this, of course, is injurious to plant-life. While most of the artesian well waters are suitable for irrigation purposes, it is always best to have a new well analyzed chemically or tested out on small areas before using it in large quantities. 


\section{DISTRIBUTION OF WATER}

However secured, water is taken to the grove in a number of ways. There has been much improvement in the matter of conveyors, but the older types still remain in use. Water is now delivered to citrus trees in open ditches, wooden flumes, concrete-lined ditches, iron, and concrete pipes. The concrete conveyors are the newer ones and have certain advantages: Obstructions to the free movement of water are eliminated and there is no loss by leakage, seepage, or evaporation. Iron pipe is used if the pressure is high, but concrete is satisfactory for low pressure, and more durable.

From the main source, water is emptied into underground pipes or open flumes of concrete. The number and location of these depend on the contour of the land, the size of the planting, and the character of the soil. They may be as close together as two to three hundred feet, or as far apart as seven hundred or eight hundred feet; the run of water covers the space, or spaces, between. The shorter distances are preferable because they make possible more even distribution of water. These pipes are provided with hydrants and flumes with gates through which water for irrigation is delivered directly to the soil. After the water is distributed to different points in the grove, it is usually delivered to the trees by the "furrow" system.

\section{The furrow system.}

When citrus trees are irrigated by this system, several furrows for carrying water are made down the middle spaces between the tree-rows. The number to each interspace varies with the size of the trees as well as their age. In irrigating small trees, fewer furrows are made, while in groves of large trees, set twenty to thirty feet apart, from five to nine furrows are run. Sometimes short offset furrows are run out between the trees. The water is not turned into all the furrows of the grove at once, but is supplied to a small number at one time (Fig. 147). 


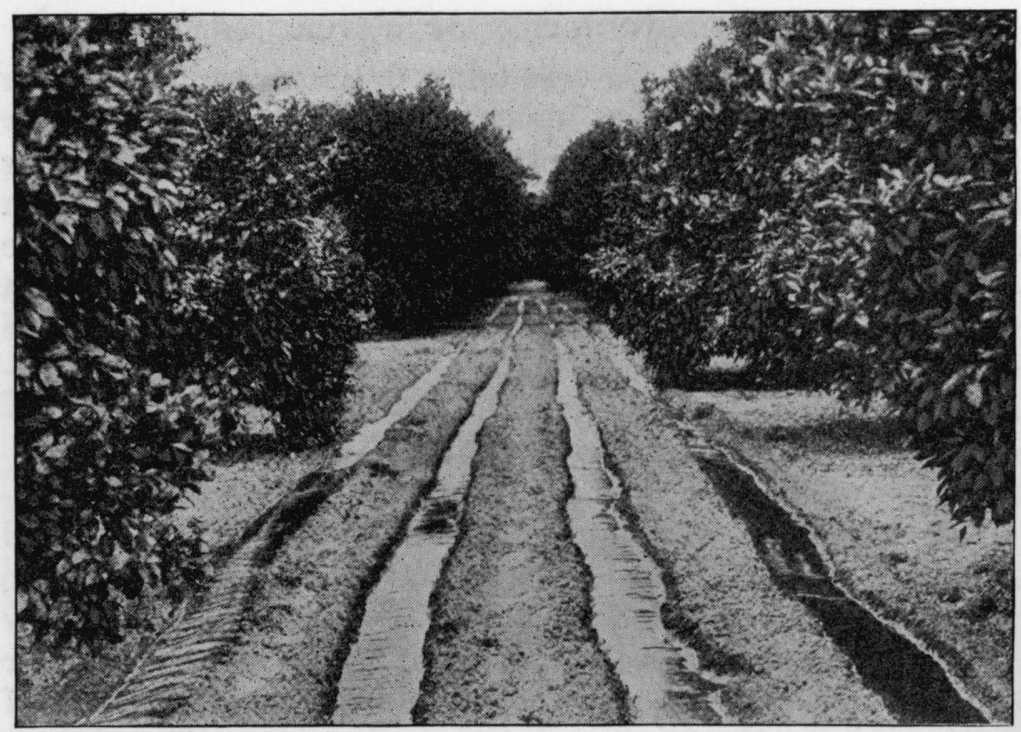

Fig. 147. Distributing water in furrows

In distributing the water, it should be allowed to flow gradually and sink in well. Application over a period of about forty-eight hours gives satisfactory results in most cases. The flow of water should be so regulated as to control its very gradual seepage into the sides and bottom of the furrow. By this plan, better results are obtained with the same amount of water than by applying it in a shorter space of time.

Following the application of water, the soil should be tilled as soon as its condition will permit. Shallow tillage at this time prevents the formation of a hard crust and the consequent loss of moisture by capillary movement and evaporation.

The continued application of water at the same depth frequently brings about the formation of what has been termed "irrigation hard-pan." The soil on a level with the bottom furrows becomes hard and compact and prevents 
the water from entering. This can be broken up by using a subsoil plow. It is best to vary the depth of tillage and also the depth of the irrigation furrows.

For a long time it was deemed impossible to irrigate citrus plantings on light porous soils in Florida. It was thought that sufficient run of the irrigation water could not be secured. However, experimental work and the operation of several irrigating plants in the state have demonstrated that groves on light soils can be satisfactorily and economically irrigated by the furrow method. When sandy soils are very dry, they hold water on the surface for a long time. It is under these conditions that the furrow system can be operated satisfactorily, and three or four furrows are usually sufficient. Water should be applied for a period of approximately one hour in runs of two hundred and fifty or three hundred feet. Either terra-cotta, concrete, or iron pipe may be used for conveyors.

Check system of irrigation.

Irrigation by the check method, when thoroughly done, leaves little to be desired. The checks contain one or more trees, and each time the land is irrigated a basin must be formed by inclosing the space about them with a ridge sufficiently high and well made to retain the water applied. It entails much hard labor in preparing the surface to receive the water, in distributing it, and in getting the soil leveled and in tillable condition after the work of irrigation is completed (Fig. 148). Generally, the method gives better results on porous soils than the furrow system. It is described as follows by Sydmer Ross, of Fullerton, California, in Bulletin No. 108, United States Department of Agriculture, Office of Experiment Stations:

The ground must be cultivated, say, about five inches deep, so as to have plenty of loose soil with which to throw up a high ridge. Then a fouror six-horse 'ridger' should be run once each way between the rows, if it is a citrus or deciduous orchard, or twice should the trees be walnuts, because these trees are grown about forty feet apart. After this is done the 
ridger should be run entirely around the outside of the piece to be irrigated, so as to have as perfect a ridge as possible on the outside. One man will ridge about fifteen acres in a day. The ridger should be built with a steel plate extending along the bottom of both sides, bolted to the inside and projecting about two inches, so as to take a good hold of the ground. Then with one horse attached to what is locally known as a "jump scraper," one side of the checks should be closed up, for the ridger in making the cross ridges breaks down the first ridge at its intersection. These repairs were first made with a shovel, but the "jump scraper," also locally called the "horse-shovel," closes up the gaps very quickly. The practice generally followed is to close up the high side of the checks if the land does not cut by running water, but if it cuts, close up the lower side.

After closing up the checks the ditches are plowed out and then the V-shaped "crowder" is run through them. On lands inclined to cut, it is advisable that the length of the rows to be irrigated should not be over 250 feet, but in heavy land this distance can be considerably increased, if necessary, without danger of cutting the ridges by too long a run of water.

If the checks have been closed up on the low side of the ridge, it is better to run the water to the ends of the ditch and water the last row first; but if the high side has been closed up, it is best to water first the row nearest the gate or the main ditch, as the case may be, as in each instance dry earth will thus be available, if necessary, to close up the checks. The

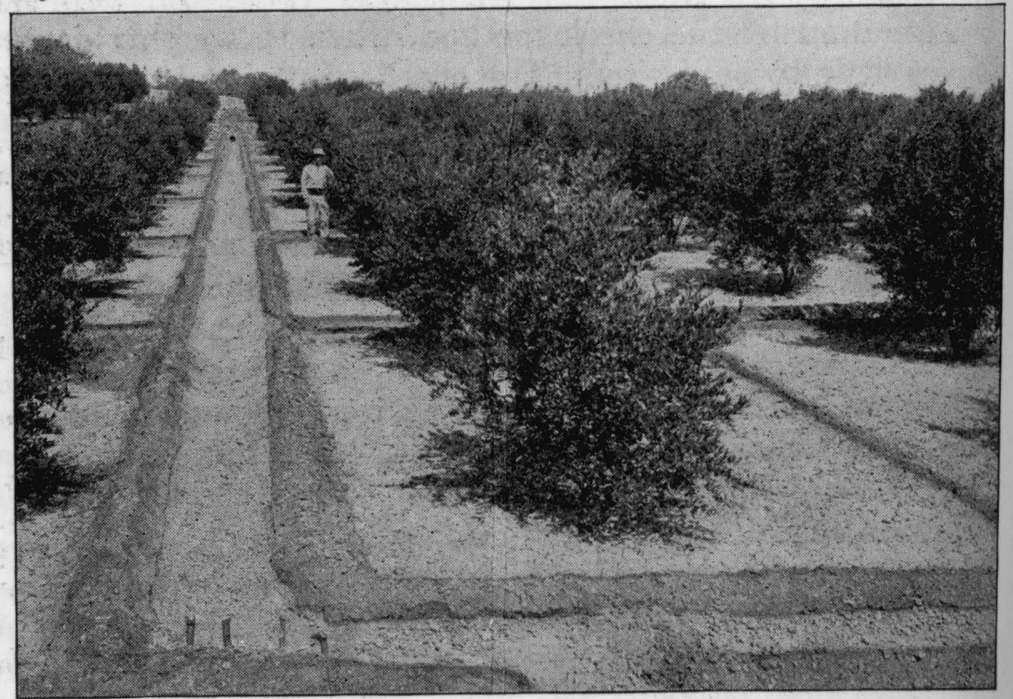

FIg. 148. The check system of irrigation, two trees in a check 
water is run down the row to the end tree, and as soon as the last check is filled it is closed up, and so on till all are filled and closed, when water is turned down the next row.

To do good work, it is usual to allow three men for every fifty inches of water, but in our own practice we have had much better results by dividing up our water and running from 35 to 40 inches to a ditch and allowing two men for such streams. In doing this we get better work and find it much easier for the men. If everything is well in hand, each man will irrigate about thirty acres in a day.

For turning the water from the ditches into the checks, metal dams or tappoons are used. The gate is not a great success, as the water is apt soon to cut its way under the tappoon, but it may be much improved by having a shelf for the water to drop on after it passes through the opening. The common practice for dividing water is to throw a tappoon partly across the ditch, putting a gunny-sack on the opposite side to prevent cutting by the water. This is, on the whole, fully as satisfactory as using the tappoon with a gate.

All who follow this system should get ready for the water before it comes. A great many seem to think that if they ridge up their land, close up the checks and plow out their ditches, everything necessary has been done. Such is not the case, as ditches that are liable to cut should be fixed in the weak places with brush or burlaps. Old gunny-sacks cut open and spread out are excellent for this purpose. Occasionally there are places where it is impossible to get a perfect ridge. These should be looked up and fixed with a shovel. The jump scraper will not entirely close up a check; it generally requires a shovelful or two to complete it. It is usual after the water is turned down one row to fix up the next one, but it is an excellent plan to have a few rows ahead, for there come times when breaks occur and there is not time to make the necessary repairs, and when water once gets the start there is apt to be much trouble and hard work before it can be put under control, besides doing poor work.

After the ground is dry enough to work, the ridges are split with a listing plow or a furrower attached to a cultivator. Then the ground should be run over with a harrow, setting the teeth to go well in, so as to pulverize the surface thoroughly. By using the harrow the ground can be worked about one day earlier than with the cultivator, and it also prevents the ground from baking till such times as it can be worked with the latter implement, besides doing far better work than with the cultivator alone, especially when there is much land to go over, as some of it is certain to get too dry before it can be reached, and then it will not pulverize well. All trees should be worked around by hand with either a fork or a hoe as soon after irrigation as the ground becomes dry enough and before it becomes hard. 


\section{DRAINAGE IN RELATION TO IRRIGATION}

It has been pointed out repeatedly that alkali is injurious to citrus trees. Some species or varieties, and some stocks, are more tolerant than others, but it may be premised that for satisfactory cultural results the soil must be neutral or acid in its reaction, preferably the latter. In some localities in the southwestern districts, small amounts of alkaline materials, such as common salt (sodium chloride), black alkali (sodium carbonate), and glauber salts are carried in the irrigation waters. While the amount is small, after a time so much of these substances accumulate in the soil as to affect the trees injuriously. The worst of these is common salt. How much of such mineral matters can be allowed in the irrigation water without injury is difficult to say. Something depends on the character of the soil, the drainage, and other factors outside the condition of the trees themselves. Hilgard has stated that forty grains of mineral matter to the gallon of water is probably a maximum; and if this matter is common salt, then a less amount might preclude its use over a period of time.

When trees have been injured by alkali, a change to pure water should be made and the drainage carefully examined. If possible, any conditions that prevent the injurious material from being carried downward and away from the roots should be removed. Good drainage helps in this connection, and if pure water is available it is probably best to apply it in generous quantities, so as to dilute the alkali and wash the soil as rapidly as possible. The incorporation of large amounts of organic material in the form of stable manure, bean-straw, or alfalfa hay also proves helpful in many cases.

\section{THE IRRIGATION SEASON}

As already mentioned, irrigation is not commonly practiced in Florida and the Gulf Coast districts. Probably something over ninety-nine per cent of all the citrus fruits is grown without artificial watering, but there are seasons 
when irrigation would pay in increased yields, larger fruits, and improved quality. The period when moisture is most likely to be needed extends from late February, when the trees are in bloom and putting on their spring flush of growth, through into June. Irrigation in this season would help to insure a good setting of fruit and carry it through the danger period of its early development. The number of times water should be applied will, of course, vary greatly. The moisture condition of the soil and trees is the best indication.

In the Southwest there is generally enough moisture accumulated in the grove to last thirty to forty days after the last good winter rain. Irrigation is usually given then, and thereafter at intervals of thirty days or so until the winter rains set in again. The number of irrigations varies from about five to nine, depending on location, weather conditions, and the kind of fruit, and some sections need even more at times. From three- to five-acre inches are given at each application. Lemons require much larger quantities of water than oranges, because of their habit of fruiting and growth and the amount of the crop. While no figures are available, grapefruit trees probably require more water than orange trees. 


\section{CHAPTER XXIV}

\section{FROST CONSIDERATIONS}

Few, if any, regions in which citrus fruits are grown commercially in the United States are safe from cold waves of sufficient severity to injure the fruit or trees, or both. Some citrus fruits, the more acid ones particularly, may be grown to perfection in frostless regions. Good limes and grapefruit, for example, are produced within the tropics, but oranges appear not to reach their highest quality except in countries where frosts occur. It is not far from being true that the farther north oranges can be grown and brought to full maturity, the better the quality, and it is extremely doubtful whether the orange-consuming public could ever have been induced to use them in the present quantities if the fruit had been the sweet insipid product of the tropics. Always, therefore, the citrus-grower must have in mind the possibility of injury to his trees and their crops from frosts and freezes.

As far back as historical records go, citrus-growing regions in America have been visited, from time to time, by cold waves. A very severe freeze occurred in Florida in 1835 , and all the groves in the important citrus sections at that time were destroyed. There were considerable plantings at Mandarin and St. Augustine, and these were killed to the ground. In 1886 there was another, and the freezes of 1894-95 were very destructive (Fig. 149). The estimated crop for $1894-95$ was $6,000,000$ boxes, but so badly damaged were the trees that in 1895-96 only 75,000 boxes of fruit were shipped. This was brought about by the defoliation of the trees in December, 1894, followed by warm weather which brought them into growth, then the freeze of February 6, 1895, killed them. The cold wave of February 13, 1899, was probably the most severe that Florida has ever experienced. A temperature of 10 degrees Fahr. was recorded 


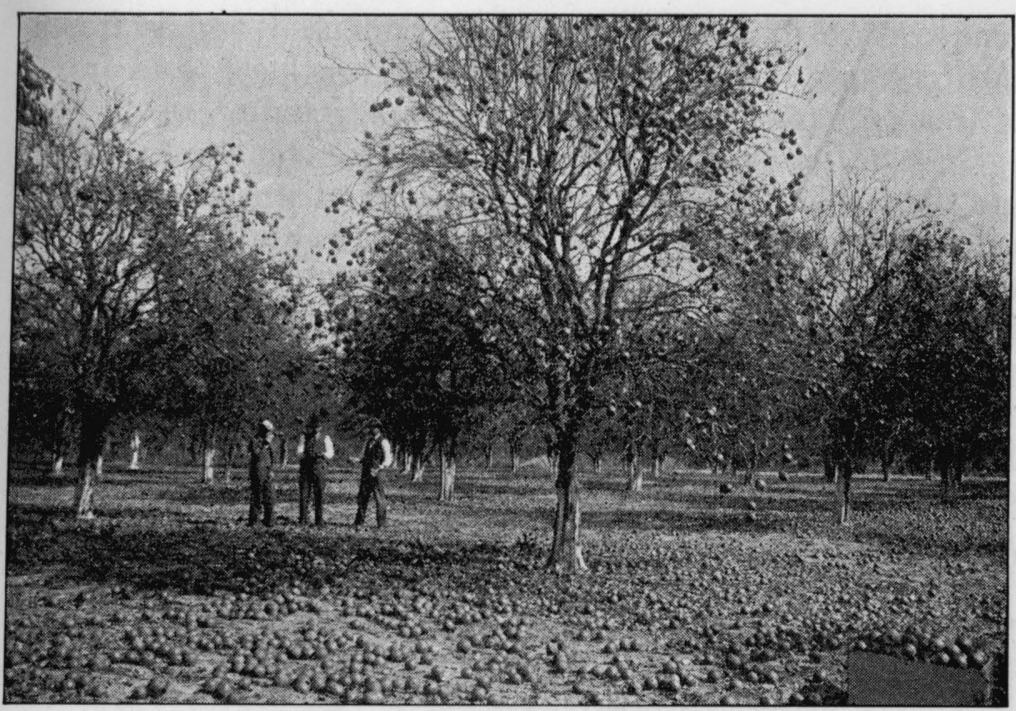

Fig. 149. Disastrous results from a freeze; trees defoliated, killed back, and crop destroyed. This was taken in Florida in February, 1895

by the Weather Bureau at Jacksonville. The last freeze of any consequence was in February of 1917, although all of that winter was cold.

California has experienced several freezes within the past fifty years, which is about as far back as records go. Damaging frosts have occurred in the years 1882, 1888, 1891, 1895, $1899,1911,1913,1919,1921$, and 1925. That of 1913 was the most severe ever recorded in the state. Usually the severest cold experienced in California comes in early January, while in Florida the first half of February is the period in which severe weather is most likely to occur.

Any drop in temperature to or below the freezing-point of water, 32 degrees Fahr., is, in the wider sense of the word, a "frost." But among citrus-growers, the term "frost" is usually applied to the formation of ice crystals on the earth's surface. Frosts of this kind occur on still clear nights when the air close to the earth contains water vapor. As the 
temperature drops, this vapor is condensed and is frozen into crystals. Often these conditions are local, and frosts of this type may take place in very restricted areas.

Freezes, or "cold waves," as they are sometimes called, are the result of widespread atmospheric disturbances. As a rule, they are accompanied by high winds and usually hoar or white frost is not formed. In the South, areas of low barometric pressure develop. These vary in depth, and usually the farther south their path the more severe the cold wave. Areas of high pressure of great size and spread are formed in high latitudes. The movement of air from areas of high to areas of low pressure draws down the cold from the north and a freeze or cold wave, preceded by rain, is the result. The path or direction of the cold storm depends on the location of the area of high pressure, and the speed with which it moves governs, to an extent, its intensity.

Between the southeastern citrus districts and the arctic circle there is no mountain range. Florida is slightly protected by the Appalachian barrier, and the cold waves that reach the state, swing round, and come in out of the northwest. When the wind shifts to due north and then to northeast, the crest of the wave has passed. Usually it takes about three nights and two days for the disturbance to subside, and on the second and third nights white frost is sometimes formed.

The cold waves that affect the remainder of the southern districts come directly out of the north. Those by which southern California has been affected usually come through El Cajon Pass, but the freeze of 1913 came directly over the crest of the Sierra Madre range. The prevailing winds are from the north and northeast.

\section{HOW FROSTS FORM}

The earth receives its heat from the sun by radiation, and it is estimated that, under the most favorable conditions of bright clear weather, about 65 per cent of the earth's 
proportion of the sun's heat reaches the surface of the earth. Part of this is absorbed by the soil and its temperature is raised thereby. This heat is, in turn, radiated from the earth and lost to the cold air surrounding it. Moisture on the earth's surface is converted into water vapor and this is added to the air envelope surrounding the earth. Radiation goes on to a greater or less degree at all times, but its rate is checked by water vapor in the air and by clouds. These are important factors in frost prevention at times.

As the soil is warmed by radiated heat from the sun during the day, a thin layer of air in contact with it becomes heated by conduction. When this happens, the air expands, rises, and is replaced by colder air. This process goes on until a considerable blanket of air is warmed up and it rises to a point at which the temperature of the warmed air and the colder air above becomes uniform. During the night the process is reversed. After sunset, the earth loses heat rapidly and in turn takes heat from the air in contact with it. This results in the formation of a cold blanket of air close to the earth, which, because of its density, remains. If this process goes on long enough, the water vapor in the air is condensed and deposited as dew, and if it still continues, frost results.

The temperature at which dew forms is called the "dewpoint." This is a variable point, governed by the amount of water vapor in the air and the general atmospheric conditions. When dew and frost are formed, heat is released, and this may be sufficient to check the downward trend of temperature. Moreover, in some cases, a heavy coating of ice crystals affords some measure of protection.

Frosts are most likely to take place on bright clear nights when there is a very slow movement of air from an area of high to an area of low pressure. If clouds cover the sky, radiation of heat from the earth is checked and frost is prevented. Fogs from adjacent bodies of water, rain, and the amount of water vapor in the air are also controlling factors. 


\section{FOREWARNINGS}

One of the most necessary and essential considerations in frost-fighting is that the grower should have some means of knowing when frosts are to be expected. If forewarned, everything will be in readiness for firing, and he will be on the alert. The United States Weather Bureau stations are always willing to keep growers advised concerning weather conditions and what may be expected in given localities. Usually, warnings are given through the newspapers and by telegrams placed in the post offices or in other conspicuous places. Either individually or in groups, growers should keep closely in touch with their local station when general forecasts of an approaching cold wave have been sent out. Nevertheless, the grower should not be entirely dependent on someone else for his knowledge of what is to be expected. Occasionally the Weather Bureau fails to report the full extent of an approaching cold wave, or local conditions may cause frost to be much more severe in a given locality than in another nearby. The citrus-grower must rely upon himself to a considerable extent.

Good thermometers, properly placed, are of great assistance in determining exact conditions of prevailing temperature. The thermometers used by the U. S. Weather Bureau are good, although ordinary thermometers at less cost are serviceable. Before using them they should be carefully tested with a standard instrument to be certain whether they are correct. If there is a deviation from correct readings, and this deviation is constant, the thermometer may still be used with satisfactory results. But when it is placed in position there should be put with it a card showing what the variation from the correct temperature is, so that a correct reading may be secured when desired. Every grower should have one or more thermometers which are absolutely dependable.

Thermometers should be placed in a number of different locations if the area being watched is of large extent. Due 
consideration should be given to lower or more exposed parts of a citrus planting, and it may be advisable to have as many as a half-dozen or more thermometers at strategic points. In placing the thermometers, each should be so located as to give an accurate indication of the temperature condition at its particular point. They should be set away from trees and buildings, shaded from direct sunlight, and not exposed to the open sky. Free circulation of air around the places where these instruments are placed should be essentially maintained. The type of thermometer shelters used by the Weather Bureau can scarcely be improved. It is an excellent plan to have a set of maximum and minimum thermometers located in one of these shelters at several different points throughout the district.

A sling psychrometer, with necessary tables for making calculations, is also a valuable instrument. It is used for determining the temperature of the dewpoint. In its simplest form it consists of two thermometers mounted side by side on a strip of material to which is attached a handle for whirling (Fig. 150). One of the thermometers is placed a little lower than the other and its bulb is covered with a piece of muslin. To make a reading, the muslin is moistened and the instrument is immediately whirled rapidly in the open air. A reading is then quickly taken on both thermometers. As soon as a note is made of the readings, or shortly afterward, the instrument is used again in the same way and a second reading taken. Several readings are made, until one is finally secured in which the two thermometers are very nearly the same, or until the temperature of the thermometer with the wet-bulb begins to rise. The point aimed at is to

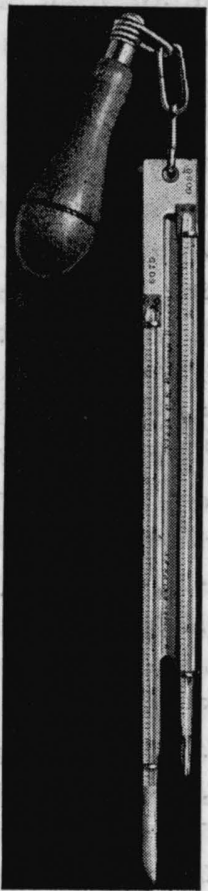

Frg. 150.

The sling psychrometer 
get a reading of the wet-bulb thermometer at the lowest temperature it will reach. After the readings have been completed, the temperature of the dewpoint is determined by noting the difference between the two, and referring to special tables provided with the instrument. A very close forecast of the lowest temperature for the night may be made with this instrument.

\section{TREE FACTORS AFFECTING COLD RESISTANCE}

Citrus trees, under certain circumstances, are more resistant to frost than under others. Disease conditions, starvation, the presence of insects, and the degree of dormancy, all bear an important relation to the amount of cold a tree can successfully withstand.

\section{Diseases.}

Diseased conditions, brought about by die-back, foot-rot, or other disturbing factors, either of a physiological or a fungous nature, reduce the resistant power of the tree as much as do attacks of insects. The trees must be kept in a healthy growing condition.

\section{Food.}

Citrus trees are in much better condition to withstand cold when well supplied with food, so that they form healthy vigorous shoots and well-developed leaves, than when they are starved or only poorly fed. Nitrogen sufficient to give a healthy dark green color is essential. The trees must not be over-stimulated, however, else the sappy immature wood suffers severely; but enough well-balanced food should be available to keep the trees healthy. A starved condition is analogous to a diseased state. Nitrogen must not be supplied in excess of other elements, but it will prove to be poor policy so to reduce the amount, in the hope of keeping the tree dormant, as to interfere with the normal development of the branches and leaves. 
Insects.

It has been noticed, in many instances, that trees affected by white-fly or scale insects suffer to a far greater degree in a cold period than those free from these pests. A rough estimate of the difference in favor of trees free from insects would be four to five degrees; it may be more; it certainly is not less. The insects suck the sap from the tree, devitalize it, and in consequence it is in poor condition to withstand cold. In view of this, every precaution should be exercised to keep the trees free from insects.

\section{Dormancy.}

Unfortunately, the citrus tree is not distinctly periodic in its growth. It responds readily to short periods of warm weather; the sap starts to flow; the buds begin to swell. In this condition it may be severely injured by a comparatively high temperature. How many degrees more of cold a tree will stand when dormant than when not dormant cannot be definitely stated, but the difference is appreciable. Practices or treatment of the trees having a tendency to start growth during the danger period should be promptly discontinued. Among these may be mentioned severe pruning, heavy fertilizing, and tilling the soil too early.

Heavy applications of nitrogenous fertilizers, followed by tillage, have a tendency to start growth. As a general rule, cultivation should not be begun in spring until all danger of frost injury is passed. It is preferable that the bulk of the nitrogen applied in the fertilizer should be given early in spring and that the amounts be gradually lessened in each successive application as the season progresses.

Cultivation should not be continued late in the season, as it has a tendency to prolong the period of growth. Cutting the surface soil with a cutaway harrow, or a shallow plowing after the cessation of growth, will not affect the trees to any appreciable extent, but it must not be carried too far.

Liberal amounts of potash have a decided effect on hard- 
ening and maturing the new growth, and this feature should not be overlooked, particularly in the southeastern districts where the soil is deficient in this mineral element.

Stocks.

That there exists a mutual interrelation between the stock and cion cannot be doubted. In many cases, a hardy stock has a marked influence on the power of the cion to withstand cold without injury.

As pointed out in the chapter on stocks, they vary considerably in resistance to cold. In order of frost-resistance they may be arranged as follows: trifoliate orange, sour (Bigarade) orange, sweet orange, pomelo, rough lemon. It is probably not too much to say that, other things being equal, the hardiness of the tops of the same species worked on these stocks will stand in the same order.

The gain in many cases may be scarcely appreciable, but in others it is well marked. In colder regions, the distinct superiority of sour (Bigarade) orange over rough lemon is quite noticeable, even on young trees, while the trifoliate orange imparts its hardiness to the top worked on it to such an extent as to make a decided difference.

Some investigators havecontended, after carefully examining trees on various stocks following a severe cold, that there is no variation in the damage to different trees which might be correlated with the influence of the stock. No doubt their observations were correct, but the fact remains that the stock of an orange tree has an influence on the hardiness of the tree budded on it. If the temperature drops low enough, all differences are wiped out, of course; but in the southeastern districts it has repeatedly been observed that trifoliata, sour orange, and rough lemon stand in this order in their ability to impart enough hardiness to their tops to make a very noticeable and noteworthy dissimilarity. Many times trees on Poncirus trifoliata pass through a certain temperature untouched, while trees on sour-orange stock are partially 
or wholly defoliated, and those on rough lemon were killed to the ground. At Glen Saint Mary, Florida, in the winter of 1909, a temperature of 15 degrees (Fahr.) was reached. Satsuma oranges on Poncirus trifoliata lost less than twentyfive per cent of their leaves. The trees bloomed the following spring and bore one of the heaviest crops of fruit the plantings ever gave. Adjacent groves on sweet-orange stock lost more than seventy-five per cent of their foliage and did not bloom the following spring and produced no fruit. There was no variation in the handling or general treatment of these plantings, and no factor to which the difference could be attributed, except to the diversity in the hardiness of the stocks.

In cold regions, where soil conditions are suitable, the hardier stocks should always be given the preference. A slight gain in hardiness, due to the influence of the stock on the cion, may frequently be as effective as a decided rise in temperature.

\section{Varieties in relation to frost injury.}

If varieties of edible citrus fruits equally as hardy as the stock could be obtained, total immunity from frost would be secured throughout the whole of the citrus regions. The attempt to obtain such a variety has been made by the United States Department of Agriculture, and some measure of success has been attained and further results may be expected. But while we may look to the final outcome of these investigations with some degree of hope, we must not lose sight of the fact that for many years to come the citrusgrowers must depend on varieties now in existence for the continued prosperity of the industry.

It is always difficult to determine the relative hardiness of different species and horticultural varieties of citrus. What may be learned concerning them in one freeze may be upset in another, and only after there has been opportunity for a wide range of observations under many different condi- 
tions can dependable conclusions be reached. The fact is, however, that some citrus fruits are hardier than others. This is due, in some cases, to inherent differences but in others to growth habit.

First in point of hardiness must be placed the trifoliate orange which grows and fruits as far north as Washington. What its limit of resistance is has not been determined, but it is somewhere below zero. Its hybrids are also very hardy. No information on plants belonging to the genera Microcitrus and Eremocitrus, which may rightly be classed as citrus fruits, is available. There is every indication, however, that they are extremely hardy. Citrus ichangensis is supposed to be very hardy, but it has not been tested sufficiently in America to make it possible to place it. Satsuma is the hardiest of the Mandarin group, and the hardiest large-fruited edible citrus grown in America at this time. With it stand the kumquats and the calamondin orange in hardiness, closely followed by the Eustis limequat. The Dancy tangerine orange is fairly hardy, and, after Satsuma, is the hardiest commercial variety in its class. The sour oranges are usually hardier than the sweet, and are probably hardier than the Mandarin oranges, those of the Satsuma group excepted. Among sweet oranges, Lue Gim Gong is the hardiest in tree that has come under the writer's observation, but its fruit, which ripens late, is no hardier than that of other oranges. Duncan is the hardiest pomelo that has so far come under observation, while Triumph is one of the most tender. Among lemons, Lisbon is regarded as somewhat hardier than some of the other varieties. Citron, lime, and shaddock are all very tender.

If the different kinds commonly in cultivation are arranged in order of hardiness, the sequence would be about as follows: (1) Trifoliate orange, (2) Satsuma, (2) kumquat, (2) calamondin, (3) sour orange, (4) tangerine, (5) sweet orange, (6) grapefruit, (7) lemon, (8) lime, (8) citron and (8) shaddock. 
Soil conditions and frost.

In the southeastern districts it has been repeatedly observed that trees suffer more from cold if the preceding period has been dry. This added injury may be brought about in several ways. The resistance of the trees themselves may be lowered by a reduction in the moisture their cells contain. If the soil is dry, there is a reduction in the water vapor in the air immediately above it. This vapor checks heat radiation and also yields heat when it is condensed. These factors may account for the greater amount of damage done to citrus trees in a freeze if the soil is dry.

\section{Fall cultivation.}

Before the season when cold weather may be expected, but after the completion of all summer growth, groves in the southeastern districts should be plowed or harrowed, so that all cover-crop growth is either covered up or incorporated in the soil. The bare surface of the earth should be exposed during the winter months, and there should be nothing on the ground to prevent the sun's heat reaching the soil. More moisture is thus evaporated from the bare soil, adding to the humid condition of the air in the grove, and more heat will be taken up during the day. When cold comes with night, heat is liberated from the air moisture as it condenses, and that stored from the sun in the daytime is given off by conduction at night. Frequently the simple precaution of cleaning up the grove in autumn is sufficient to protect it from considerable injury.

\section{INJURIOUS TEMPERATURES}

The question arises as to how much cold a citrus tree will stand. The danger point is influenced by many factors, principally, however, by the state of dormancy of the tree, the variety, soil and moisture conditions, duration of the cold, and the weather conditions immediately preceding the cold snap. If the tree has already been partially or wholly de- 
foliated by cold, the danger of injury to the branches and twigs is materially increased.

The temperature at which fruit will freeze is affected by the degree of maturity it has reached and the length of time the temperature is endured. Green fruit freezes at a higher temperature than fully ripe fruit. It has been determined that Bahia (Washington) navel oranges have a freezing point of 28 degrees Fahr., with a variation of 26 to 28.9 degrees; Valencia oranges 28.3 degrees, and a variation of 26.5 to 28.9 degrees; pineapple 27.7 degrees; Temple 28.6 degrees; lemons 28.3 degrees, with a variation of 26.9 and 29.5 degrees; grapefruit 28.3 degrees. In the southeastern districts the freezing-point of full ripe oranges is usually placed at $\mathbf{2 6}$ degrees. Grapefruit withstands a low temperature for a longer period because of the greater thickness of the rind.

Dormant sweet orange trees have been known to stand a temperature of 18 to 20 degrees Fahr. for a short time, with no injury beyond the loss of a few leaves. This approaches the limit. Owari Satsuma orange trees on trifoliata stock have withstood a temperature of 15 degrees Fahr., with the loss of not more than 25 per cent of their foliage and no damage to twig growth. They were completely dormant at the time. On the other hand, when the sap is moving they may be severely injured or killed to the ground, even at much higher temperatures. One of the most critical periods is when the trees are in bloom, but, fortunately, cold weather does not occur frequently at that stage of growth.

\section{EFFECTS OF COLD ON CITRUS TREES}

The first effect of cold on the leaves is to give them a dark greasy appearance. This may be noted only in spots on parts of a leaf, or the whole leaf may be affected. The same peculiar discoloration may also be noted on young twigs and green fruit. If not chilled too far, they regain their normal condition and remain on the tree, apparently unhurt. 
Whether such leaves will perform their normal functions as long as those not affected is not known. If the cold becomes slightly more severe, they curl to such an extent as to indicate that they are suffering from the lack of moisture. If still further frosted, they are curled and, in the course of a few days, drop from the trees. Usually the upper leaves fall before the lower, some of the latter frequently remaining, even when the upper portion of the tree is practically defoliated. These trees are in great danger of severe injury from a second cold wave, as the blanket of thick foliage serves as a material protection to the branches.

It often happens that the injury is to leafage only and the twigs even remain uninjured. Such trees, however, bear no fruit the following season.

Cold sufficiently intense to defoliate the tree may injure, to some extent, the young tender growth without severe damage to the larger branches. Much depends, of course, on the degree of dormancy, for the twigs resist a considerable degree of cold if sufficiently dormant. It may be stated that, as a rule, the resistant power of a branch becomes less and less as it decreases in size, or, in other words, varies directly with the diameter. Large branches are injured only by intense cold, and the top of a tree may be very decidedly cut back by frost before the large branches are affected. The exact degree of injury to the twigs cannot be determined until some time after the frost occurs.

No part of the tree can withstand lower temperatures than the trunk. When severely frozen, however, it is killed to the ground, and may frequently be split open if the cold is intense. As with the branches, its resistant power is in direct ratio to the diameter. It would not seem that there should be much difference in ability to withstand cold between a trunk four inches in diameter and one eight inches, but such is the case, nevertheless. Possibly, larger trees become more dormant than smaller ones, and their sap does not respond so readily to elevations of temperature. 
The weakest spot in the whole anatomy of a budded or grafted citrus tree is the point of union of stock and cion. This should be protected by placing about it a mound of earth, and the union should be as close to the ground as possible.

Protection afforded the trunk by a dense mass of foliage, twigs, and branches is frequently not fully appreciated. The warm air is held to some extent and the cold is prevented from penetrating to the framework of the tree. Low-headed trees are preferable to high-headed ones, because the branches serve as a protection to the trunk. The latter should not be grown in exposed regions. Branches and foliage also shade the inner portions of a tree from the sun. This is very beneficial following a freeze.

When citrus trees are frozen to the ground, the roots are seldom killed. The tops on sour orange and rough lemon may be frozen back many times, yet their vitality or resistance is such that the roots continue to send up sprouts for years afterward. This is not true of trees on trifoliate orange stocks, however. When the good-sized trees on this stock are severely frozen to the ground, or nearly so, they are generally killed-root, trunk and branch. This may not be apparent at first for the trees may look as though they will come back, but they very seldom do.

As to the fruit, no statement has been made as yet whether any one variety of citrus is more resistant to cold than others. It is probable that no appreciable difference exists, or, if so, it is too slight to be of any practical value.

Hesperidin crystals, small whitish specks $1 / 2$ millimeter in diameter, appear in the tissues of the fruit after it has been slightly touched by frost (Fig. 151). These are due to chemical changes and are present in all kinds of citrus fruits when frozen. They have been noted in lemons, sweet oranges, mandarin oranges, kumquats, and pomelos. Their presence may be regarded as an indication that the fruit has been frosted, as they are not known to be caused in any other way. 
Injury to citrus fruit from freezing may range all the way from a slight spotting of the rind to complete destruction of the tissue, the latter occurring when the fruit is frozen almost or entirely solid. Slight spotting may be due in part at least to the presence of drops of moisture on the rind. The injury to the skin shows as discolored, somewhat shrunken, irregular spots (Fig. 152) and spoils the exterior appearance of the fruit, even though it may not be injured seriously inside. Usually, however, spotted fruit deteriorates. Some species and varieties of citrus fruits show

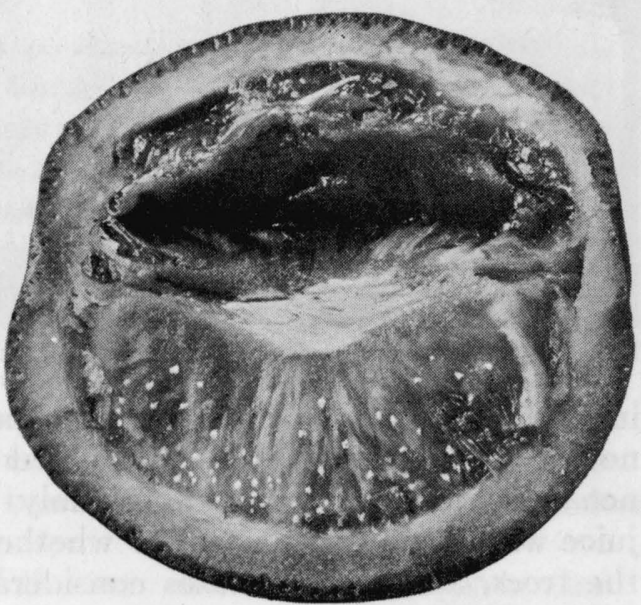

FIG. 151. Section of frozen orange showing hesperidin crystals, as white specks, in lower half of pulp much less frostspotting than others. Light-colored fruits-the pomelo, limequat, and lemon - are very subject to it, oranges are affected to a less degree, and Dancy tangerine not at all. Spotted fruit is often attacked by blue-mold which very quickly destroys the fruit.

Frequently, citrus fruit may not be sufficiently injured to show on the outside, and yet the rind may be damaged or its nature changed in such a way as to permit the evaporation of the juice. After a time, nothing is left in the fruit except a chaffy mass of juice-sacs. This drying out frequently causes separation of the pulp segments (Fig. 152). The fruit may appear all right on the surface, yet it may have so deteriorated as to be worthless.

Growers cannot be too careful in the handling and market- 


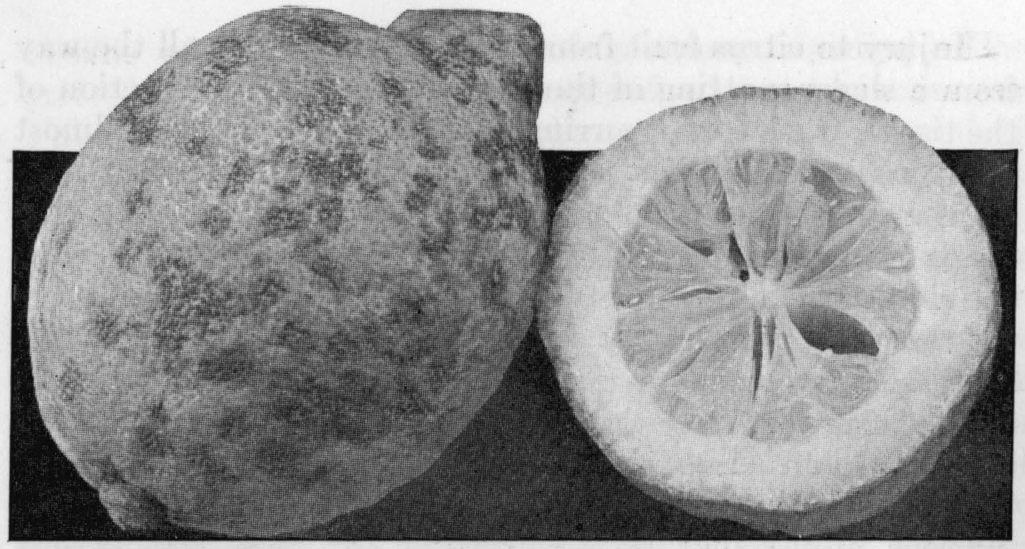

FIG. 152. Spotting of lemon rind and breaking down of interior following freezing

ing of frosted fruit. If frosting is suspected, the fruit should not be shipped until it is determined positively that it has not been injured. Even when only slightly affected, the juice will disappear, no matter whether the fruit is on or off the trees, and in such cases considerable time must elapse before the actual extent of the frost injury can be determined. When severely frosted, the fruit falls. This is the inevitable consequence of severe injury to twigs and branches.

\section{PROTECTION AGAINST FROST DAMAGES}

The question of frost-protection has been forcibly brought to the attention of citrus-growers, in nearly all districts in the United States, and, as a result, many different plans have been devised. Some of these have stood the test of many trials while others have been discarded. In no region has the growing of citrus fruits been abandoned entirely because of the effects of cold, and considerable success has rewarded the efforts to maintain groves in exposed regions. No matter what means of protection may be adopted, the principal factor in the success of any one of them is the individual himself. Provision must be made beforehand; everything must be in readiness. 
The principal worth-while means for protecting citrus trees are wrapping, banking, and heating.

\section{Wrapping.}

It is always much more difficult to protect young or small trees by fires than to safeguard large ones. They offer no obstruction to free air movement and the heat is carried away rapidly. Fortunately, young trees can be protected by wrapping the trunks from the ground upward with newspapers. Several thicknesses should be used, and the wrapping well done and securely tied in place. The paper may cover the entire trunk. Particular care must be taken that protection at the bottom is complete; any bare surface at that point may be protected by banking after the wrap is tied. For trunks of one- to four-year-old trees, it is a practicable method of considerable value. Wrapping can also be combined with banking, both means of protection being provided in November.

After a cold night, if the sun rises bright and clear, the damage from frost may be augmented by rapid thawing. Part of the value of wrapping is in the shade it affords.

\section{Banking with earth for frost-protection.}

No method of protecting the trunks of citrus trees from cold is more efficacious than banking. Never, in any of the citrus districts, has the temperature fallen low enough to injure the trunk of a tree through a mound of earth.

If the trees have been headed as low as they should have been, not only the trunk but a large part of the main branches can be protected with earth (Fig. 153).

The trees should be banked early in November, for in northern Florida severe frost is likely to occur as early as the middle of the month. If the trunks have been slightly touched by frost before the banks are placed about them, unsatisfactory results are obtained. The bark rots during the winter if it has been slightly frosted and the trees are 


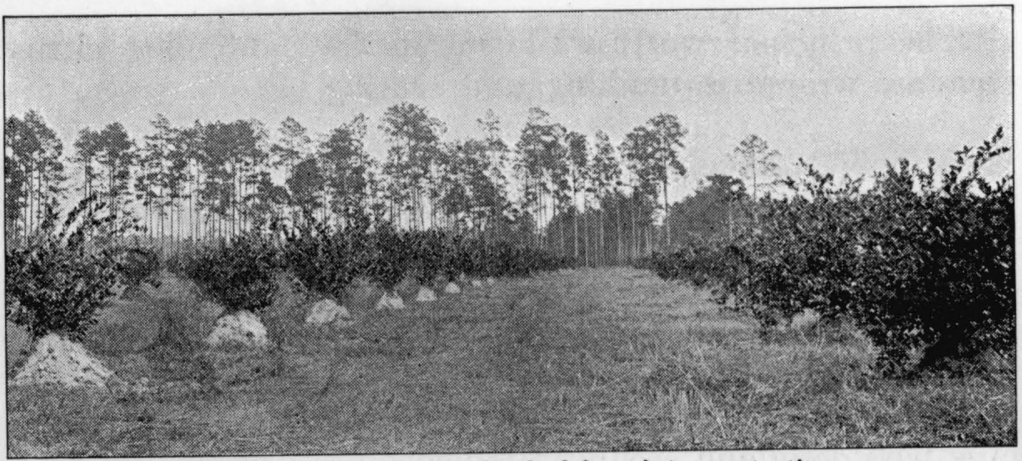

FIG. 153. Orange trees banked for winter protection

frequently killed outright in consequence, when they might otherwise survive, provided, of course, that the remainder of the winter is mild. The best plan is to place the banks about the trees about the beginning of the second week in November.

The earth should be heaped well up about the trunk of old trees, but young ones should have a considerable portion left exposed. If they are banked too high, respiration will be prevented and death of the trunk and branches will follow. The part most susceptible to the effects of cold is the point of union between stock and cion, which should be close to the ground, as already stated, and the earth well banked about it. After the trees have been banked, the earth usually settles somewhat or is washed down by the rain. For this reason, it is usually best, three to four weeks afterward, to place more earth about the tree. The banks are not likely to remain in good condition without attention from time to time.

All grass and weeds should be cleaned away from the trees, and nothing but fresh clean soil should be used in banking. If weeds and grass are placed in contact with the trunks, wood-lice too frequently cause considerable damage. They begin work first in the decaying vegetation and then transfer their attentions to the trunk. One of the best ways 
to secure fresh clean earth, free from organic matter, is to remove the weeds and four to five inches of surface soil from an area of two square feet or so, then dig a hole deep enough to supply sufficient earth for the tree. In spring the earth may be thrown back into the hole and the surface leveled before cult vation begins.

The banks should be removed in spring, usually about the end of March, or as soon as danger of damage from cold is past. They should never be left about the trees throughout the summer, as mal-di-goma may attack the trunk above the point of union of stock and cion.

Protecting by fires.

When citrus trees and their crops are to be protected by firing, enough heat must be generated actually to raise the temperature. Nothing is to be gained from smudging or from trying to cover the planting with a blanket of smoke and water vapor. This may have some value in giving shade after a night of frost, but as a protection against frost it is useless.

The fuel will depend on the convenience and expense involved. In the southwestern districts, crude oil is the favorite fuel, while the southeastern region uses wood, coke, and crude oil. No storage facilities are required for wood and coke, but it requires much labor to supply and to keep the fires going with wood.

Whatever the material, a sufficient amount of fuel for not less than twenty-four hours of continual burning should be close at hand, and additional supplies available to replace it when exhausted.

There is no use in undertaking protection by firing unless the grower is sufficiently prepared to carry it through with a very reasonable chance of success. Every factor must be carefully considered and provision made to protect against minimum temperatures and maximum duration of a cold wave. 


\section{Wood-fires.}

In many of the southeastern citrus sections, wood of some sort can still be had for firing citrus groves. Anything that will burn may be used. When cut-over pine land is cleared for planting, stumps, roots, parts of tree-tops and logs, useless for lumber, become available. Too frequently this material is destroyed in clearing. Stumps are removed by burning them out, when they can, just as cheaply, be removed by digging or by blasting with dynamite. When taken out by either of these methods, the wood is excellent for grove-heating. Being filled with resin or gum, this wood does not decay readily and will keep in good condition for years (Fig. 154).

Wood for firing should be piled between the tree-rows, and sufficient quantities provided to make the necessary fires for at least one season. On the approach of winter, after the grove has been plowed or disced to remove all vegetable matter, the piles of wood are torn down in part and smaller piles laid ready for firing. Kindling should be provided and everything placed in readiness for immediate lighting. One of the best materials for starting the fires is

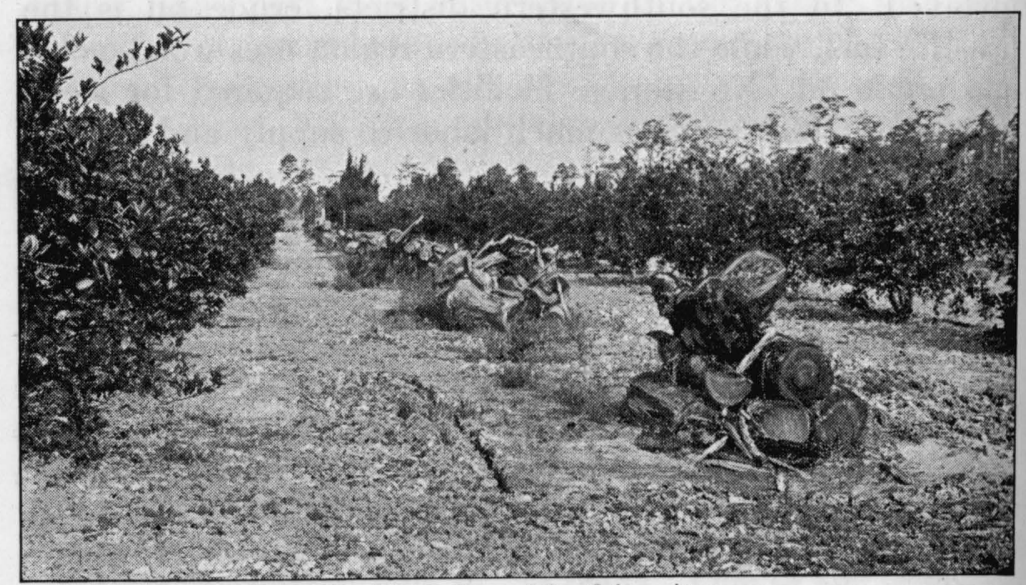

Fig. 154. Piles of wood for firing citrus grove 
"dross" from the turpentine stills. It consists of chips, pieces of bark, and the like, coated with resin. Kerosene or crude oil is also helpful in starting wood-fires if the cold is accompanied by high winds and rain. The same torch used for lighting heaters may also be used for starting wood-fires.

The firing-wood should be laid on the northwest side of each tree, and on the north and west sides of the grove a double line of fires should be provided. It is best to have a large number of small fires, because large ones create air currents which may carry away the heat. When the fires are started, every other pile should be lighted and the remainder brought into use only as needed. The torchman who lights wood-fires should be closely followed by one or more to see that they are well started. A plentiful reserve of wood and kindling must be on hand and a sufficient number of men to handle them. Since firing must go on at times continuously for several nights and days, the men have to work in shifts.

In former years, many citrus groves in different parts of Florida were successfully protected against frost by woodfires. The cost of materials, if secured from clearing the land, is relatively small, but the labor is great. It is a method that should be given careful consideration wherever a supply of wood is available.

Oil-heaters for frost-protection.

Since the first oil-heaters were tried out in citrus groves in the early 1890's, many types have been introduced. Most of them have disappeared. Difficulties arose because of incomplete combustion. In part this was due to the quality of oil, but it was also the result, in a measure, of insufficient draft. Many heaters of too small capacity were used at first. They burned out too soon and left the grove unprotected unless refilled very quickly, which was often difficult. The work was not well organized.

For two reasons, the capacity of a heater must be ample. (1) There is often a residue of asphaltum which will not burn, 
and this accumulates as the heater is used, thus reducing its capacity. The fewer times a heater has to be filled, the better. (2) The size should be sufficient to burn with good draft through at least one night, and for this time the heater should hold not less than nine or ten gallons of fuel oil.

The favorite type of oil-heater in use at present, commonly referred to as high-stack heater, consists of a covered, flat-bottomed, sheet-iron pot in which the oil is burned by a down draft, regulated through an opening in the top. In this heater, the stack, from three to five feet high, may be shortened or lengthened by removing or adding a joint of pipe. To give additional draft, the base of the stack is perforated for some distance up. The oil is lit in the pot, and the heat is sufficient to convert it into gas which is burned in the stack. Much radiant heat is given off, and after the heater has been burning for some time and is well warmed up, smoke and soot are largely consumed in the stack (Figs. 155, 157).

Can-heaters are also used to some extent. They are cheaper to install but combustion is not nearly so complete as in the high-stack heaters. Too frequently their capacity is not great enough, necessitating refilling at critical times. If they are emFIG. 155. A highstack oil-heater ployed, the number should be greatly increased so that some of them, unlighted, may always be in reserve (Fig. 156).

At least one oil-heater should be provided for every tree. This requires at least seventy to eighty heaters to the acre, depending on the planting distance. In addition, when placing them, the number should be doubled on the side of the grove from which the cold wind usually comes. Two, or even three, heaters should be placed near each tree, to warm the air before it starts into the grove. 
With the approach of the cold season, the heaters should be made ready, placed in position and filled with oil. When the danger period is over, they should be collected, cleaned, and stored. The asphaltum is very difficult to remove, except by burning it out with distillate.

In the southeastern district they should be brushed clean, greased or painted, and stored under cover. Where the humidity and moisture are less, they are sometimes stored outdoors or beneath the trees. It is more economical to give heaters the care necessary to make them

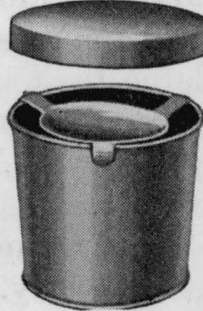

FIG. 156.

The can-heater last a long time than to purchase new ones frequently.

Fuel-oil is stored in cement or steel tanks, elevated or placed on a hillside that the oil may be emptied by gravity. These should be of sufficient capacity to furnish oil for a season's protection, unless the grove is so located that addi-

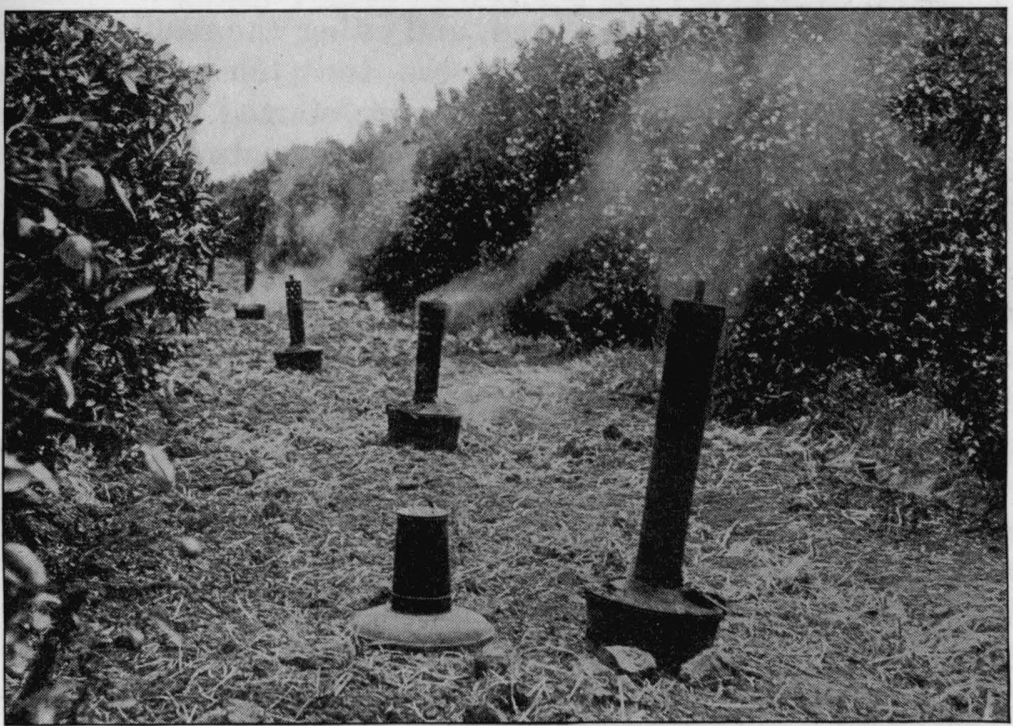

FIG. 157. Protecting citrus trees with high-stack heaters in California 
tional supplies can be obtained quickly. In the latter case, however, the tanks should be refilled as soon as the fuel is lowered, unless the season is so far advanced as to render this unnecessary. If the grove is of great extent, a single large tank may be used and the oil piped from it to convenient points in the grove. From the tank or from the pipe-stands, the heaters are filled by means of a tank wagon.

Sometimes results from firing groves have been far from satisfactory. A number of unfortunate causes contribute to this result. Most often the trouble has been underestimating the equipment necessary and the labor involved. In some cases, too small pots were used; these burned out quickly and facilities for refilling were not provided. Then, too, sometimes the number of pots is insufficient. Poor fuel has also been a serious drawback, and at times there was too

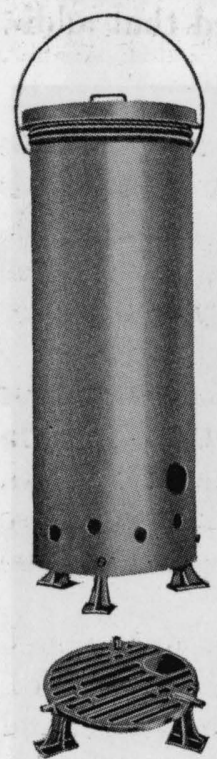

Fig. 158. The Skinner coke-heater much asphalt in it, and it did not burn readily. Frequently the thermometers were incorrect or improperly placed, and either the readings were not correct, or a too low temperature was reached before fires were started. It requires capable painstaking labor to heat a citrus grove properly, and there should be sufficient men to attend to every detail. The job of firing must be done right or it might as well not be attempted.

In the southeastern districts, freezing generally occurs at night, the coldest point usually being reached just before sunrise. The temperature then rises during the day and drops again the following night and usually for three nights.

\section{Coke-heaters.}

Coke-heaters have been tried in the southeastern citrus districts with excellent satisfaction. Such a heater consists of a sheet-metal cylinder, with holes near the base for draft, set 


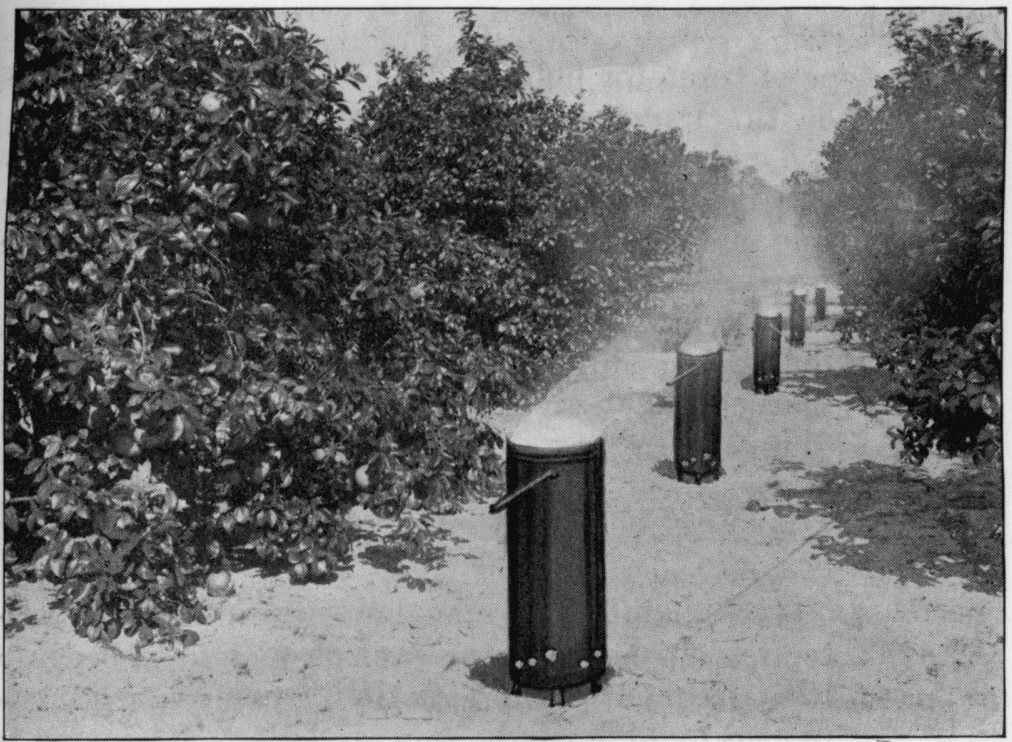

Fig. 159. Coke-heaters in use in a Florida citrus planting

on a cast-iron grate, elevated a short distance from the ground on three feet to give additional draft. A small cup is cast in the grate, to hold oil for lighting. This heater holds thirty-three pounds of coke, sufficient to burn seven to nine hours. The rate of burning is controlled with the cover of the heater (Figs. 158 and 159).

Charging the coke-heater for use is accomplished by first filling the grate-cup with oil-waste, placing kindling wood in small pieces crosswise over it, and then filling the heater with coke. The best grade is what is known as "forked gashouse coke" in hen-egg size. Distribution and handling is the same as for oil-heaters.

Coke may be stored in any convenient place, in the open or under cover. It does not deteriorate. For convenience in using, it may be placed in piles throughout the grove, and enough to charge the heaters a second time placed beside them in vegetable hampers or baskets. 


\section{Lighting torch.}

One type of torch for lighting oil- or coke-heaters is illustrated herewith. It consists of a can with a long spout, in

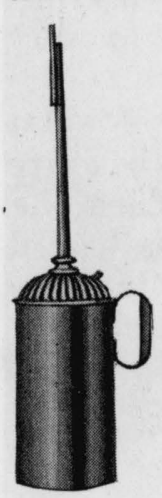
the end of which an asbestos wick is placed. This can is filled with a mixture of sixty per cent gasoline and forty per cent kerosene. The torch is ignited and as it is tipped over a small quantity of the burning gasoline-kerosene mixture is poured out, thus insuring certain and rapid lighting. One man can light several hundred heaters in an hour. (Fig. 160.)

\section{WALLS, WINDBREAKS, AND WATER FOR FROST-PROTECTION}

Great difficulty may be encountered in proFig. 160. tecting citrus trees by means of open fires, because
Torch for lighting it so frequently happens that freezes are accomfires panied by high winds, rain, and sleet. The wind is often so strong as to extinguish the fires and the heat is blown away. It has been noted, too, that while the temperature was sufficiently high on the side of the tree nearest the fire, on the opposite side the thermometer registered several degrees below freezing.

To overcome this undesirable condition, triangular or circular walls have been used in many cases, with excellent results. Sometimes these are movable; at other times they are built stationary on the north and west sides of the trees. The wind frequently shifts its direction, making the movable ones somewhat more desirable. A fire may be placed on the opposite side from the triangle with effective results. Wood, oil, or coke may be used.

Windbreaks and water protection have been discussed in a former chapter. In many respects, the windbreak, either artificial or natural, may serve the same purpose as a wall on the northwest sides of the trees. The windbreak stops the force of the driving wind and prevents the dissemination 
of the heat. In many cases, growers, in Florida, finding that covered sheds which they had built previously to protect their groves were not satisfactory, removed the covering, and left the walls standing. These have acted as very efficient checks to the wind.

The ameliorating influence of adjoining bodies of water should not be overlooked, and, whenever possible, the grove should be so located as to receive the beneficial influence of the heat slowly given off by them. The water is heated during the day. It parts with its heat more slowly than the land during the night, and its influence is considerable. 


\section{CHAPTER XXV}

\section{PRUNING CITRUS TREES}

As a whole, no fruit-trees require less pruning than the citrus group, after they are once established in the grove. In many cases, most of the pruning is given only at the time of planting. With the possible exception of the lemon, systematic annual pruning, such as is given peaches, is not practiced. Fine old specimens of citrus trees, to which the pruning shears are entirely unknown, may be found throughout the citrus districts. Nevertheless, pruning has a place as a part of good grove practice, although it must be done carefully and not carried to excess.

High vs. low-headed trees.

When the citrus industry was young, it was the invariable rule to grow high-headed trees with trunks bare four to six feet from the ground. Then practice changed in the extreme opposite direction in favor of low-headed trees, with

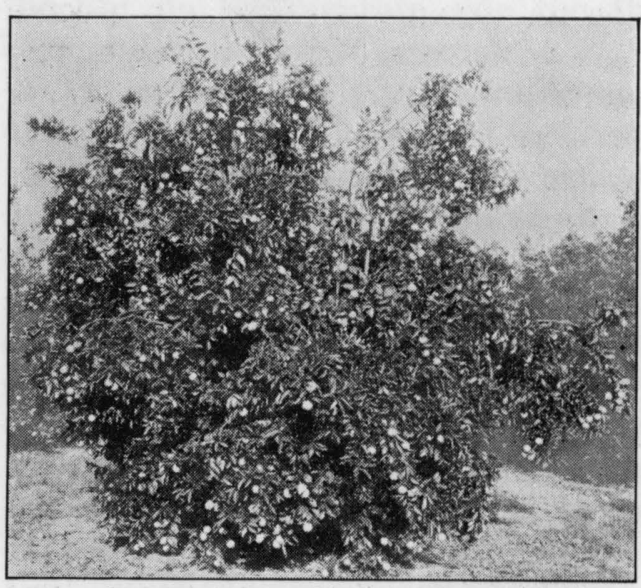

FIg. 161. A low-headed citrus tree branches sweeping the ground. While the latter style of tree is much preferable, yet it is objectionable to have fruit-laden branches rest on the ground. Good fruit cannot be produced on branches so low as to bring it in contact with the earth. These low branches, too, are subject to

(346) 
damage by the cultivator and are difficult to spray or dust and keep free from injurious insects (Fig. 161).

The best plan in heading trees is to have the lowest branches close to the earth, but without actually resting on it when in fruit. Properly placed supports, however, can be employed to advantage in keeping fruit off the ground, and there should be no return to the old system of high-headed trees.

Low-headed trees have several distinct advantages over the other type. The trunk is protected by the dense foliage from the heat of the sun and from the cold. Few persons realize the degree of protection afforded the trunk and large branches by the mass of leaves. The fruit is more easily and economically removed from low-headed trees than from highheaded ones, and they are not so liable to injury by windstorms. Air does not circulate through a grove of low-headed trees so rapidly as through plantings of high-heads, consequently protection by fires of any kind can be installed to better advantage. Low-headed trees shade the ground beneath them and prevent the rapid evaporation of moisture, while the low-hanging branches serve many of the purposes of a mulch. However, on soils inclined to bake and become hard, it may be necessary to have the lower branches sufficiently elevated to permit of tillage, but usually this is unnecessary. The expense of spraying and fumigating is lessened considerably by heading the trees low.

\section{Pruning newly-planted and young trees.}

To secure low-headed trees, they should be cut back severely at the time of planting, leaving not more than eighteen to twenty-four inches of trunk, and, if not already pruned at the nursery, should be cut back to this height when planted. The branches which form the strong framework should be allowed to develop four or five buds along the trunk, near the top. The exact number and placement of these is not so essential as in deciduous fruit-trees. The 
connection between trunk and branch in citrus trees is very strong, capable of bearing heavy strains, and branches are not often split away.

The subsequent pruning of young trees, particularly the first season or two after planting, frequently puzzles the

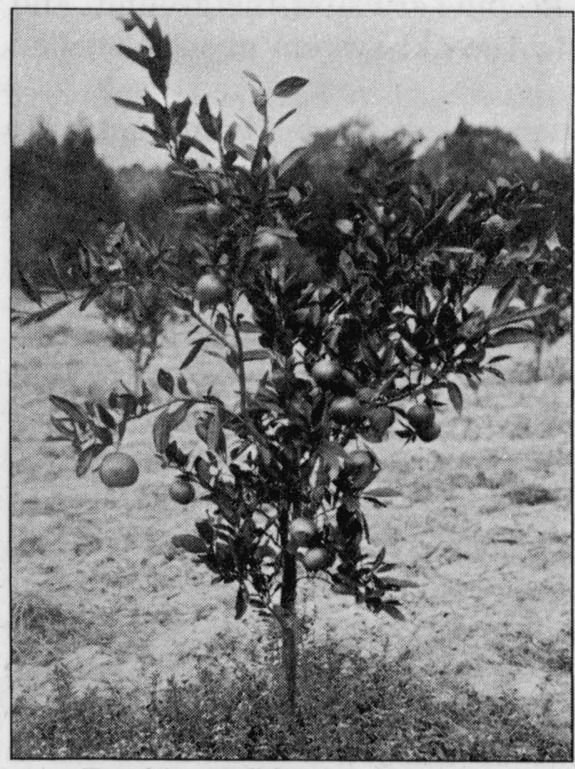

Fig. 162. Well-headed young tree planter, especially if he is a novice in handling citrus trees. The usual disposition is to give them more attention than they really need, for they require very little pruning until at least a year after setting.

When trees are taken from the nursery rows with bare roots and planted out, they put forth every effort to establish themselves. Every living bud receives a growth impulse, and many of them develop into growing shoots. These may be scattered along the stem all the way from the ground to the top of the stem or trunk. Those that develop below the bud union should be rubbed out or cut off, but it is best to leave all buds above it, for they assist greatly in increasing the diameter of the young tree. They also do an important work in helping the young trees to become established, shading the trunk, and the more shoots and leaves, the better. Allow these shoots to remain one or two seasons, depending on the vigor and growth of the tree, then thin out, leaving four or five properly placed branches to form the main framework of the head of the tree. This method of handling 
newly planted trees has been in use for many years, with excellent results.

In the early years of the young tree's life, sufficient attention should be given to make a well-balanced shapely head. Sometimes it may be wise to take out a branch or to cut one back here and there, but orange and grapefruit trees have a way of balancing themselves, and it is a mistake to remove branches, seemingly out of proportion, when the next flush of growth will do the work of making a symmetrical head much better than the pruner could have accomplished it. Under normal growth conditions, citrus trees will develop shapely beautiful heads. It is their habit.

\section{Pruning older trees.}

It is extremely doubtful whether attempts at what might

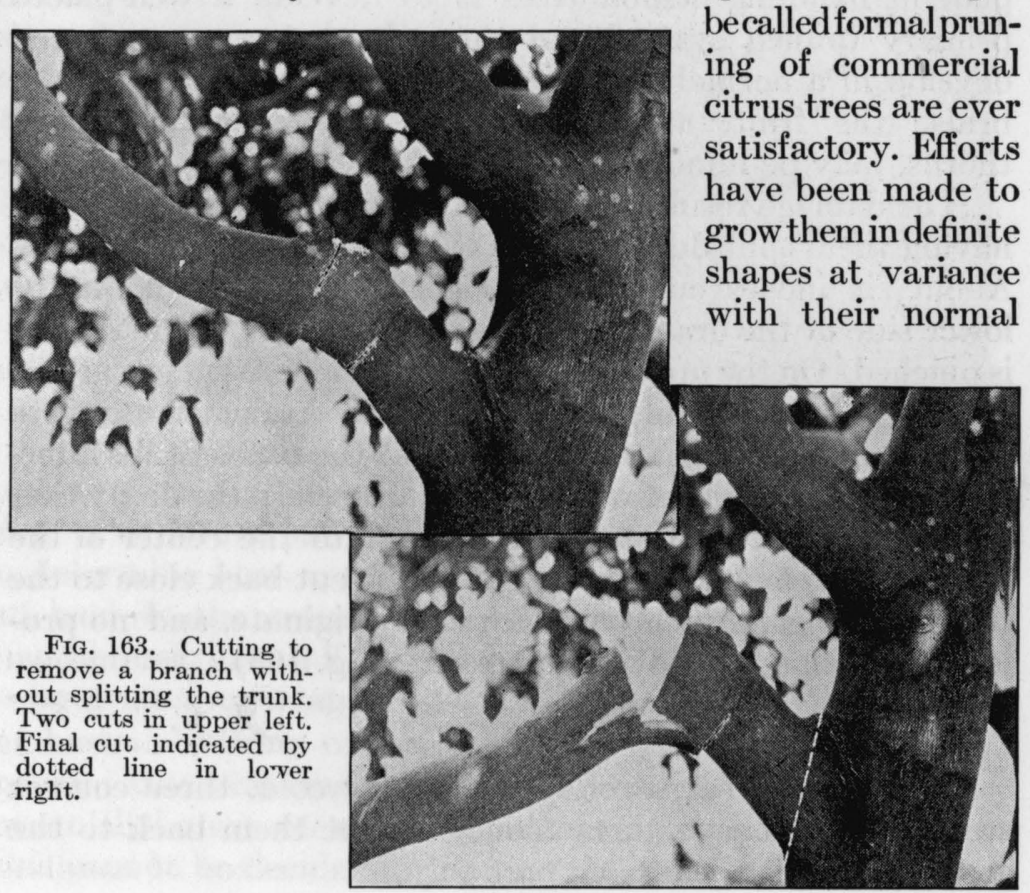


habit, but while they will stand much abuse in the form of pruning, it is uncertain whether these various practices have ever brought satisfactory results when compared with trees grown in a normal way. It is best that any system of pruning should work toward developing the tree along natural lines. If good trees are planted and kept in healthy condition, they need very little attention on the part of the pruner, unless misfortune overcomes them. Severe pruning interferes with the normal growth and development of trees and may actually bring on diseased conditions. Dead branches should be removed, and if limbs rub against one another, it is usually best to cut some of them out entirely.

The formal kind of pruning has been attempted oftener with lemons than with other species of citrus. The best plan in handling lemon trees is to develop a well-placed primary branch system and then let the trees grow and develop in a normal way. Branches so placed as to scar or bruise the fruit, and particularly those carrying many thorns, may be removed.

The damage resulting from cutting off large branches and having them split downward on the trunks is easily avoided. About six inches out from the trunk, make a cut on the lower side of the branch to be removed, cutting until the saw is pinched. On the upper side of the branch, two inches farther out, cut downward until the weight of the branch causes it to drop off. Then cut the stub off clean at the base. Stubs interfere with the healing of wounds, and, when left, the decay that eventually destroys them is extended into the center of the trunk. All removed branches should be cut back close to the trunk or other branch on which they originate, and no projecting portion be allowed to remain (Fig. 163).

\section{Pruning frozen trees.}

In treating trees severely injured by cold, three courses are open: (1) Leave them alone; (2) cut them back to the ground; (3) cut them back part way. 


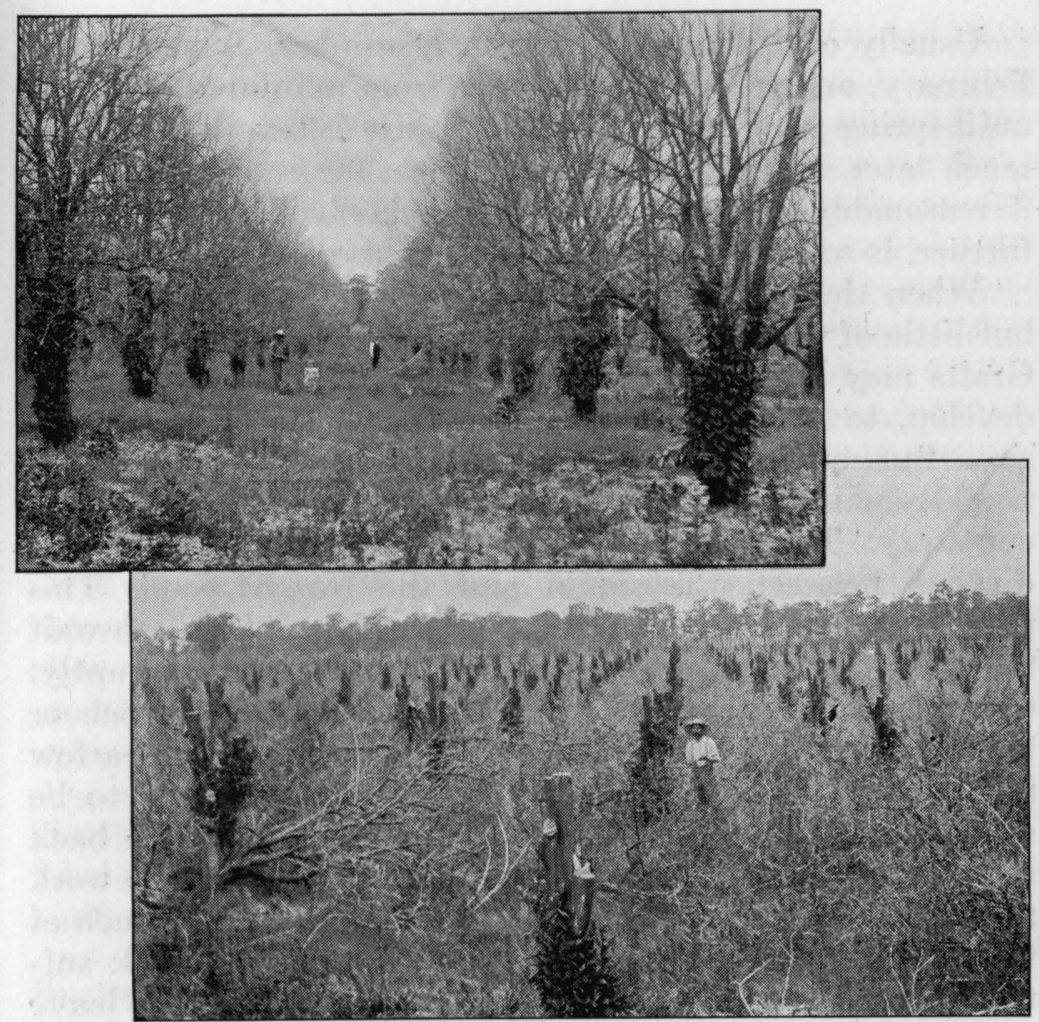

Fig. 164. A frozen orange grove. Sprouts grown out in upper picture. Tops removed afterward in lower

Everything considered, leaving them alone is the best plan. For some time following frost-injury it is impossible to determine how much pruning should be undertaken. If cut back to the ground, more of the tops may be removed than necessary, and if headed back part way they may have to be pruned over again at a later date. There is no need for haste. Nothing can save trees or parts that have been frozen. Much expense and labor may be prevented by waiting until the exact extent of the injury can be determined. This cannot be decided until growth starts. (Fig. 164.) 
Usually cold damage occurs in December, January, and February, and sprouts do not arise from uninjured branches until spring growth begins; if the injury is severe it may be much later. When shoots have grown far enough to make it reasonably certain that the branches will not die back further, is soon enough to start the pruning.

When the tree has been so severely injured as to leave but little of the trunk, it is best to cut it off at the ground. Grafts may be inserted in it, or sprouts may be allowed to develop, to be budded when they have attained sufficient size. But, on the other hand, if a considerable part of the trunk remains uninjured, the upper portion only should be cut away. The best place to cut is well below the line of division between the sound and the frozen wood. This point is not easily determined, and the best plan is to wait until sprouts have grown out, then start work promptly. Cut back below the uppermost sprouts on each branch or trunk where they are healthy, strong, and vigorous - a few inches more or less does not matter. What appears to be sound uninjured wood may develop shoots which die back later in the season, making it necessary to go over the work a second, or even a third time, which is expensive. Much of this additional labor can be avoided by cutting back sufficiently at the first pruning. The usual tendency is to leave too much old wood; the heartwood rots away, leaving nothing but a shell, frequently so thin and weak that the branches that develop on it break down when loaded with fruit. Wiring must be undertaken to support them, and even this is not always successful.

When sprouts are slow in starting, the removal of the earth from about the crown and crown-roots will hasten them. Good tillage, loosening and opening the soil, also assists in bringing them forward.

It has been repeatedly demonstrated, as elsewhere explained, that there is a distinct relation between the size of the trunk and its resistance to cold. Small trees suffer much 
more severely than large ones. For this reason, in working with badly frozen trees, a single trunk from each root is desirable. If all the growth-force is put into a single shoot instead of several, greater size can be secured in a given time. At most, no more than two or three sprouts should be allowed to develop. Thin them out after they have grown sufficiently to make it possible to choose the more vigorous ones. A good plan is to allow one good strong sprout to develop into the trunk, and inarch a number of others into it.

The bark of frozen trees is frequently split and killed. These patches should be carefully cut away to healthy tissue and the wounds treated with an antiseptic solution and covered with paint.

If citrus trees are affected by any of the gum diseases before being frozen they should be given careful and thorough treatment when they are pruned back. The removal of the tops and most of the branches permits this work to be done thoroughly. All diseased spots must be carefully cleaned out, the diseased bark and wood removed back to healthy tissue, and then thoroughly disinfected (Formulas Nos. 14, 16). As soon as the disinfectant has dried in, a good application of paint should be given the injured spots.

\section{Wiring sprouts from frozen trees.}

Supporting sprouts by one or more wires, drawn tightly around them to hold then together, is probably the best means of preventing their breaking away. Telegraph wire is best. Some growers have taken infinite pains to bore a small hole through each branch, through which to pass the wire, thinking that if it were simply tied about them it would gradually cut into the branch and destroy it. Observation has shown that when the wire is tied around the branches it cuts into them, but the wood grows over and unites on the outside, leaving the wire firmly imbedded in them. Branches wired in this way in 1896 were examined in 1904. They were three to five inches in diameter, and 
the wires passed directly through their centers, with the wood firmly united about them. The flow of sap and the growth and development of the branches were not hindered. If the sprouts start from the ground, a wire should be placed about them at a height of three and a half to four feet.

\section{Pruning neglected trees.}

In some of the citrus districts it sometimes happens that groves are neglected and left to themselves for a considerable length of time. If the trees were young when abandoned, it is usually best to start over again and replant the ground with new vigorous stock, but if they were of some age and of good size before the period of neglect began, they can usually be brought into good bearing condition by cautious pruning.

The plantation should be gone over carefully and irreparably injured trees removed, replacing them with new ones. Those that remain should be pruned carefully, each tree being treated according to its condition. All dead branches should be removed and also all those in poor condition. If there are a sufficient number of good branches to make a new top, the removal of dead and unhealthy parts may be all that is required. However, if the top is in bad condition, with few healthy vigorous branches remaining, it is best to cut them all back severely, leaving only the trunk and short stubs of the main branches.

Following the pruning of the whole grove, the trees should be thoroughly sprayed, first with bordeaux mixture to remove lichens, if in a moist climate, and then with a miscible oil to destroy insects. Spots on the trunks or branches injured by gum disease must be cleaned out and treated. The grove should then be thoroughly tilled and fertilized, treating it for the two or three seasons following as though the trees were young. All efforts should be centered on bringing the trees back into good vigorous growth.

It sometimes happens that trees in bearing for a con- 
siderable length of time begin to deteriorate, the growth becoming stunted and the crops lighter from year to year. In such cases, the trees may be brought back into good condition by cutting them back severely and growing new tops on them. In arid and semi-arid climates, it is good practice to whitewash trees that have been cut back, to protect the exposed trunks and branches from sunburn.

Old high-headed trees may often be improved by building the head downward. Frequently, suckers spring from the large branches and shove their way up through the top of the tree. Many growers call them water-sprouts, think they will never bear, and remove them as soon as they appear, but this is not good policy. They may be thinned out if too numerous, but some of them should be allowed to remain. After rising above the surrounding top, they branch and bear fruit. Unless they are needed to fill out a space in the top, or if they crowd or interfere with branches already developed, they may be carefully drawn down out of the tree, below the lowest branches, and bent out to one side, there to grow into large strong branches, thus bringing the head of the tree closer to the ground.

\section{Pruning for insect treatment and sun-protection.}

It is sometimes necessary to remove some of the interior branches so that spray materials may be thoroughly and easily applied. This pruning must not be too severe, however, and no more of the center branches should be sacrificed than is absolutely necessary. Heavy pruning is too frequently followed by a vigorous growth of sprouts, and unless these are promptly checked, the interior of the head will become as dense as before.

The sprouts are favorite places for some species of whiteflies and aphids to lay their eggs. On no condition should so many branches be removed as to allow the sun to penetrate and strike the remaining ones, for it is essential that the trunk and larger branches be protected by a mass of leafy 
twigs. Dead dry branches, the result of the strong rays of the sun, clearly show this necessity. Deciduous trees should be so pruned as to admit the strong sunlight to all parts of the head, but not so with citrus trees. A head the shape of a hollow cone is a good form, but the outer band or zone of foliage must be sufficiently dense to exclude the strong and injurious sun rays.

\section{Pruning in relation to die-back.}

In Florida it has frequently been observed that die-back follows the freezing back of the tops of citrus trees. The roots, as a rule, remain uninjured, and large amounts of materials in solution are collected. The enzyme which probably produces die-back enters the trunk in large quantities, and the disease becomes manifest. Exactly the same condition may result from severe pruning. This is the reason for the advice so often given: "Keep the pruning shears away from the trees and let them develop as they will"-advice which it is usually best for the Florida grower to keep in mind.

When trees are affected with die-back, much may be done toward effecting a cure, on most soils, by root-pruning. The amount of pruning required depends on the severity of the attack, the size of the tree, and the nature of the soil. Roots may be pruned by cutting a circle around the tree with a sharp spade, thrusting it well into the earth so as to sever a large number of roots. The balance of the tree is restored by this method, and a complete recovery frequently follows. It should be borne in mind, however, that in addition to this treatment, the cause of the disorder in the tree should be sought and the conditions favoring the development of dieback removed if possible.

\section{Pruning for other diseases.}

No dead wood or fungous-infested twigs should be allowed to remain in a citrus tree. It may seem a large undertaking to remove all of these twigs, however small, but 
the nearer the owner can come to this result, the freer the grove will be from a long list of diseases and fruit blemishes. After the trees are once thoroughly cleared out, and spraying, tilling, and fertilizing are properly furthered to maintain the trees in thrifty condition, it is not difficult to keep them free of such additional dead and sickly twigs as may appear. They should be gone over frequently. Spraying without pruning and pruning without spraying are not effective means of disease control, and the removal of dead and diseased wood as a part of citrus grove routine is sound practice.

\section{Wound-protection.}

The natural protective covering of the trunk and branches is bark, and when this is broken or so injured as to lay bare the wood, the exposed surfaces should be protected to prevent entrance of the germs of decay. Within four to five minutes of the removal of a branch, the edge of the wound, where bark and wood meet, should be coated with shellac, and when this has dried the whole cut surface should be coated with good paint or some other protective covering. The shellac should always be put on the bark, also as a narrow band around the wound. Wounds smaller than threequarters of an inch in healthy trees do not require protective covering, but all over that diameter should be treated. Normal wood tissue grows from the outer rim of the wound toward its center and eventually covers it.

As a wound-covering, many citrus-growers use nothing but good white-lead paint. If so desired, enough coloring material may be added to match the color of the bark. An excellent coating may be made from asphalt by reducing it to the proper consistency with benzine. Melt the asphalt over the fire, then remove it to a safe distance and allow it to cool slightly. Stir in enough benzine to bring it to the working thinness of good paint.

Liquid or melted grafting-wax and paraffin are sometimes 
recommended for covering wounds, but they are not permanent enough to be effective in southern climates. The materials previously recommended are usually cheaper and

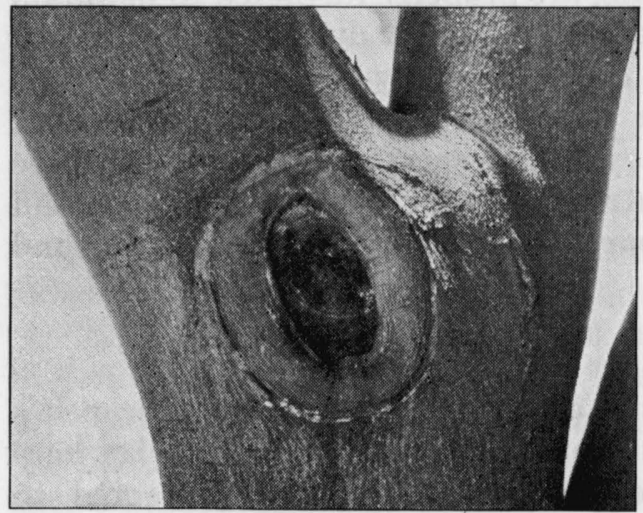

FIG. 165. The healing of a well-made wound on a citrus tree

better. At least once annually, after the first painting of the wounds and until they have healed over, they should be examined and an additional covering given if required.

A disinfectant and protective covering should be used following pruning, chiseling, and scraping for the removal of diseased branches, roots, wood, or bark. After all the infected material has been cut away, the exposed surface should be treated. For this purpose a number of materials may be used. The principal ones are creosote, protexol (carbolineum), crude carbolic acid, bichloride of mercury, and bordeaux paste (Formula No. 14). The three materials first mentioned are closely related compounds and are effective disinfectants. Crude carbolic acid should be used half strength by mixing it with water in which laundry soap has been dissolved, one pound to a gallon. The material formerly known as carbolineum avenarias has, in recent years, been placed on the market under the name of protexol. Only the genuine material should be procured. It has been widely tried and gives satisfactory results. Creosote should be used with care in treating large areas of exposed wood, and its application should be limited to such surfaces only. The best material for covering gum wounds after they have been disinfected is asphalt. If gum diseases are present, 
it is best to treat all wounds with protexol solution or bordeaux paste (Formulas No. 12 or 14) as an additional safeguard before painting; and even the smaller wounds should be treated.

\section{When to prune.}

Citrus trees may be pruned at any time, but it is better to avoid those periods when the trees are in active growth. They grow by putting out a flush of new twigs and leaves, then resting for a period and starting again. Of course, the winter dormant period is the longest one, and following this the trees burst into bloom. The other flushes of growth are somewhat variable, depending on the age of the trees, the treatment they have received, their general condition, and the amount of crop. Frequently the June flush brings with it additional bloom, and following this there may be one or two more flushes before the cool weather of autumn checks the trees.

If the varieties to be pruned are early, and the fruit has gone out early in the season, the period between the shipping of the fruit and the starting of new growth is a good time to give a thorough pruning. It is not easy to prune trees when they are carrying a full crop of fruit without damaging it in some measure. If possible, pruning should be begun after the crop is gone and before the spring growth starts. . In the case of late varieties, however, this is impossible, and perhaps the best time to take care of them is after the fruit has set and attained a size of about three-fourths of an inch for oranges and an inch for grapefruit. By this time the spring growth has matured and they are in dormant condition.

Pruning tools.

For pruning citrus trees, several kinds of tools should be provided. The equipment will include: (1) a pair of sevenor eight-inch hand pruning shears; (2) a pair of pruning shears with handles about twenty-four inches long; (3) a 
pair of pole pruning shears; (4) a pruning saw of the California type, with a fourteen-inch blade; (5) a pruning saw with a curved blade; (6) a pruning knife with a curved blade;

(7) a grafting or budding

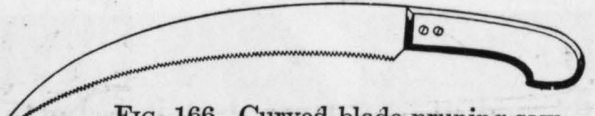

knife with a straight blade; (8) a whetstone FrG. 166. Curved blade pruning saw for keeping the tools in condition; (9) a pair of heavy leather gauntlets to protect the hands and arms from thorn-pricks; (10) a good step-ladder, or one of some other type.

To keep the pruning tools together, it is best to provide a suitable box with handle attached for carrying. In obtaining tools for pruning, special attention should be given to the quality of the materials. Cutting edges, at all times, should be keen and sharp, and if the temper of the steel is good, much time will be saved in sharpening and otherwise keeping them in condition.

Many kinds of pruning shears have been placed on the market, and it is an unfortunate comment on American shears to say that imported ones are nearly always superior. Sometimes hand pruning shears are

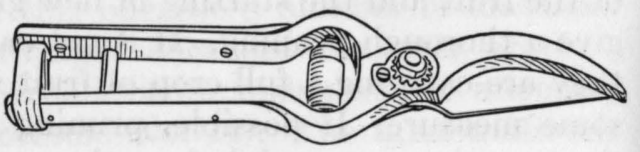
made with flat springs,

FIG. 167. The best type of hand pruning skears one riveted to each handle and meeting near the bolt. This is not the best type of spring; it weakens under continued use and it is a job for a blacksmith to put new pieces in place. The best shears is one with a flat coil or volute spring. When a spring of this type becomes weakened, a new one can be slipped in place without delay, and new springs should always be on hand for replacement. The best type of longhandled pruning shears is one with double cutting blades. The pole pruning shears will be found very useful.' With them it is possible to cut branches otherwise out of reach. 
The California saw is very convenient. The blade can be turned at an angle, making it possible to cut in close crotches where an ordinary saw cannot be used (Fig. 168). A pruning saw with a curved blade and teeth set to cut on the back stroke enables the

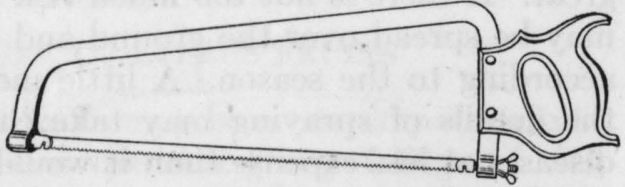

Fig. 168. The California pruning saw operator to work in close places with less risk of injuring the hands. For very heavy work, it may be necessary to add an ordinary carpenter's cross-cut hand saw, with large well-set teeth.

\section{Disposal of prunings.}

There are three ways in which branches and twigs may be disposed of: (1) They may be hauled outside of the grove, piled, and burned; (2) they may be piled about and under the trees and used as a sort of mulch; (3) they may be scattered over the ground, cut up with disc harrows, and incorporated with the soil.

It is best to eliminate the second plan because the branches piled about the trees are constantly in the way of the different grove operations, and as it takes a considerable length of time for them to decay, the prunings are a very considerable nuisance in the meantime.

The first method has much to commend it, and in smaller plantings of a few acres it appears, on the whole, to be the best one to follow. In any case, the larger branches have to be taken out and burned. If diseases are presentand usually they are in greater or less degree - there is always a chance of a considerable amount of re-infestation if the prunings are left in the groves, particularly of such diseases as scaly bark, melanose, diplodia, and brown rot.

In plantings of thousands, or even hundreds of acres it is a considerable task to remove all the material at times. 
Of course, if the trees are carefully pruned from year to year, neither the quantity nor the size of the material will be great. If there is not too much risk from diseases, prunings may be spread over the ground and plowed or harrowed in, according to the season. A little more careful attention to the details of spraying may take care of any danger from diseases at less expense than it would take to haul the twigs and branches out of the grove and burn them. Yet this, of course, must be practiced with pieces an inch or so in diameter and more. 


\section{CHAPTER XXVI}

\section{POT CULTURE OF CITRUS FRUITS}

All varieties of citrus fruits may be grown in pots or tubs. The perfumed flowers and the rich glossy foliage of wellkept specimens make them exceedingly desirable for the greenhouse or house conservatory. Fruit can be secured in greenhouses if care is exercised, but when grown in an ordinary living-room, the chances for fruit-production are not so good. Pomelos have been grown in tubs, and have produced a box of fruit, juicy and of good quality, from a single tree.

Specimens for planting in pots usually can be secured from nurserymen in the citrus-growing districts. They should be of small or medium size, with well-developed root systems. Plants may be propagated, if so desired. Cuttings may be made, rooted, and afterward either budded or allowed to retain their own tops. Specimens raised from cuttings are quite satisfactory. It is possible to raise the Otaheite orange, lemons, and citrons from cuttings, but it is not practicable to root cuttings of sweet orange, pomelo, and lime without special facilities. If desired, citrus seeds may be procured and sowed in flats. When they have germinated and reached a height of three to four inches, they should be transferred to pots, and as soon as they are as thick as a lead pencil, or a little larger, they may be budded. Buds can be secured from citrus nurserymen.

Perhaps the most desirable stock for potted plants is Poncirus trifoliata, but the Otaheite orange is also good. Either of these will make the potted plant more precocious and prolific. However, good results can be obtained with almost any stock. Although there is no more rapid-growing stock than the rough lemon, it has proved satisfactory. The confinement of the roots by the pot or tub reduces all stocks 
to nearly the same level so far as inducing fruitfulness is concerned.

In dealing with potted plants, the soil is under the control of the grower. A number of different soils give good results.

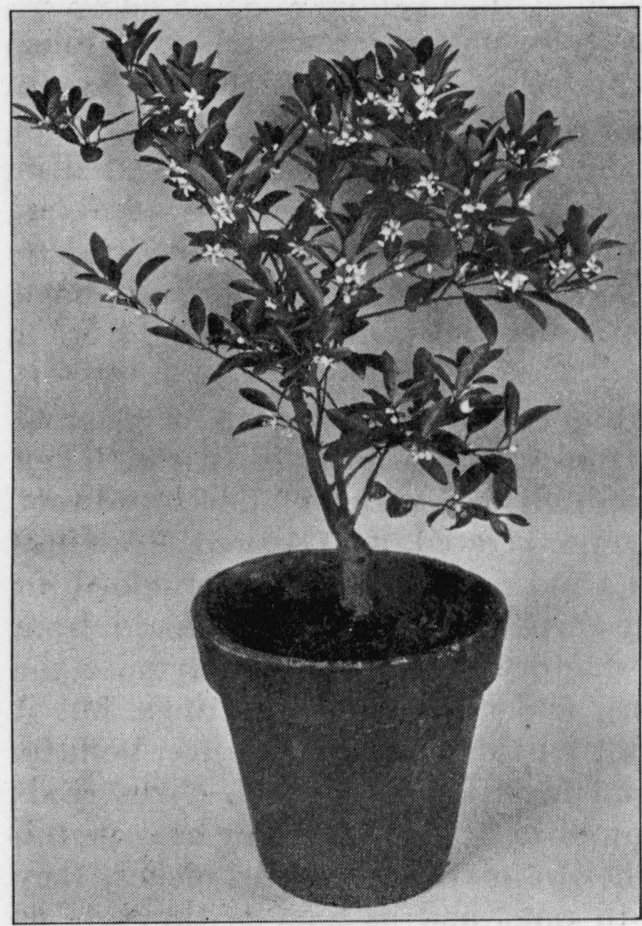

Fig. 169. Pot-grown kumquat in flower

One composed of equal parts of virgin soil from the woods, sand, and well-rotted cowmanure has proved satisfactory. When the materials can be obtained easily, a soil made up of onequarter good garden soil, one-quarter sand, one-quarter leaf-mold and onequarter thoroughly rotted cow-manure is probably best. The composition may be varied greatly, but in all cases a sticky pasty soil, too retentive of moisture, should be avoided.

Careful attention must be given to the size of the pot. As the trees grow, they should be transferred from one size to another as they become pot-bound. Older trees should be placed in large tubs, but, in general, it is not advisable to increase the size of the tub beyond a diameter of three feet. Perfect drainage should be provided, a point too frequently overlooked. This may be secured by boring holes in the bottom of the tub, and filling in to a depth of two to 
three inches with large pieces of broken pottery. In potting, the soil should be well packed about the roots. The large tubs should be filled only to within four to five inches of the top with soil. Afterward, when the plant has become established and the soil somewhat depleted, this space can be filled in with potting soil containing a half or so of wellrotted cow-manure. Repotting may be obviated by digging out the top layer of soil to a depth of three to four inches and replacing with fresh material from time to time. Another very satisfactory plan is to "plug" the pots or tubs. This is done by inserting a sharp iron rod nearly to the bottom and twisting it about so as to make a funnel-shaped hole. Three or four holes should be made around each tree. These holes can then be filled with suitable fertilizer or with rich soil and fertilizer combined.

Dwarf varieties, such as Otaheite (useless for its fruit), the kumquat, and the myrtle-leaved orange ${ }^{1}$ (Citrus myrtifolia) make excellent pot plants. They do not need large pots and do not require repotting as frequently as the large varieties. Their flowers are rather small, but are borne in profusion, and fruit may easily be secured. If flowers are desired, no variety surpasses Satsuma, which produces its blossoms densely packed along the branches. The sweet lemon bears a profusion of sweet-scented flowers, purple on the outside of the corollas. Of the sweet oranges, it is best to choose those which can be dwarfed by growing on trifoliate orange, if that stock is used. The following varieties are recommended:

Sweet oranges-Parson Brown, Pineapple, Ruby, and Valencia.

Pomelos-Duncan, McCarty, and Triumph.

Lemons - Villafranca, Genoa, and Ponderosa.

Limes - Tahiti.

Kumquats-Marumi, Nagami, and Meiwa.

${ }^{1}$ The myrtle-leaved orange has been referred to $C$. Aurantium by some writers. 
Mandarins-Satsuma, Dancy, and China.

Miscellaneous-Otaheite and myrtle-leaved oranges, calamondin, Eustis limequat.

It is not advisable to grow seedling specimens in pots, as they seldom bloom or fruit.

\section{PRUNING POT PLANTS}

From time to time it is necessary to prune the tops of pot plants. Small immature branches accumulate and should be removed before they die. Every five or six years it may be necessary to head-in the tops to keep them within bounds and to favor the production of new vigorous wood. All the large or medium-sized branches should be cut back, leaving three or four good buds on each one, and the smaller branches should be removed entirely. As a result of this treatment, no fruit will be borne for at least two seasons, but a healthy vigorous top will be secured. If standards with rounded heads are desired, it is better to pinch back the young shoots from time to time, rather than to prune severely.

\section{FERTILIZING AND WATERING}

Fertilizers may be given in the form of liquid manure and top dressings of bone-meal, sulfate of potash, or of a good citrus commercial fertilizer. The sulfate should be used with caution, else injury to the roots may result. It should be given only in numerous small applications. Good results have also been obtained from dried blood and bone-meal in combination with sulfate of potash. Plants should not be allowed to become starved. This condition is readily shown by the yellowing of the foliage and by poor wood development.

Water must be supplied in sufficient quantities. If an insufficient amount is given, the leaves curl and drop, fruit, if present, also falls, and the smaller twigs die back. On the other hand, if too much water is applied, the leaves become yellow and fall, and the whole plant assumes a sickly ap- 
pearance. The remedy for the first condition is to give water, and if the plant has been exposed to strong sunlight, it should be shaded or transferred to a shaded place. If the plant is suffering from a superabundance of water, it should be turned out of the pot or tub immediately, a large portion of the wet soil removed, and repotted. A moist atmospheric condition is beneficial to citrus trees.

A period of rest is necessary for citrus trees as for ordinary deciduous fruittrees. For about two months in the winter season, the full amount of water should not be given and the temperature

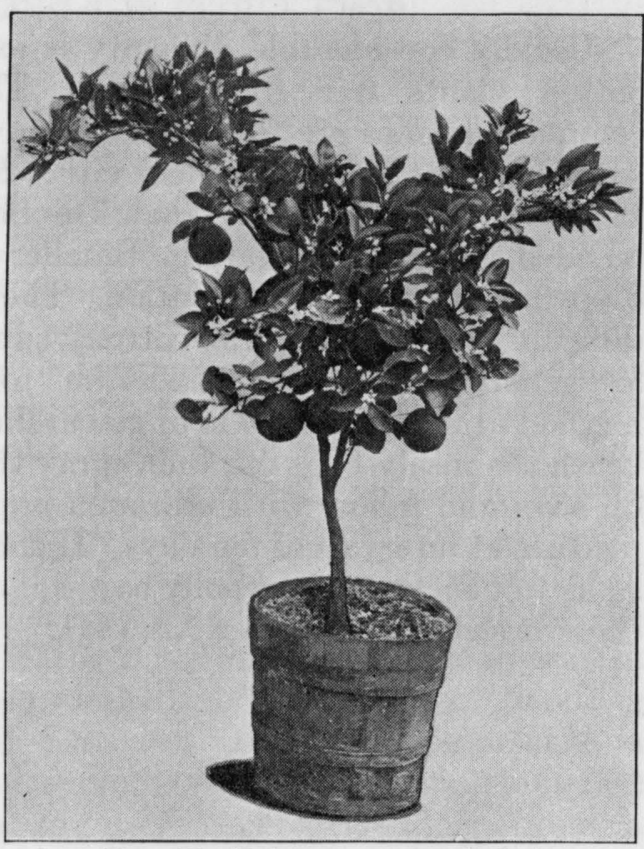

Fig. 170. Tub-grown orange in fruit should be reduced to 40 or 50 degrees. Water should, of course, be provided but not in sufficient quantities to excite growth (though this would hardly occur at so low a temperature), only enough to make good the loss through the leaves and prevent their falling.

This treatment will cause the wood to harden and prepare it for blooming. Following this rest period, a higher temperature, (75 degrees or more) should be given, water should be given in the usual amounts, fertilizer applied, and the plants placed in a well-lighted airy place. Plants of sufficient age treated in this way will bloom during the spring or 
summer months. In summer the potted plants may be set out-of-doors.

\section{TREATMENT OF INSECTS}

Usually considerable difficulty is experienced in keeping potted plants free from insects. The worst and most common enemies are the scale insects and mealy-bug. The scales can best be held in check either by spraying, for which purpose Good's Potash Whale-Oil Soap No. 3 is recommended, or by fumigating. Smaller pot plants may be dipped in a tub of soap solution. The mealy-bugs are more difficult to deal with. The cottony substance by which they are generally covered is impervious to sprays, and the only method at all efficacious is to go carefully over the trees and brush the mealy-bugs off, then spray thoroughly with whaleoil soap and follow with thorough applications of the same mixture at intervals of ten days. It should be worked in well so as to penetrate the woolly covering. For further notes on these insects, see Chapter XXVIII. 


\section{CHAPTER XXVII}

\section{HANDLING THE CITRUS CROP}

No portion of the history of citrus fruit culture is more interesting than the evolution of present systems of preparing the fruit for market. When the first oranges were shipped to nearby points from the Florida districts, boxes and barrels of various sorts and sizes were used. The picking of the fruit and its preparation and packing for market were not understood, and it was not handled as carefully as at present. As a natural consequence of the rough methods and carelessness in handling, heavy losses between the groves and markets were the usual result. For the most part, the fruit was of good quality, but no one knew exactly how to market it in good condition.

The late E. Bean, of Jacksonville, was the originator of the present package used for citrus fruits in Florida, and the influence of his work has been felt in every citrus district in America. The rational methods of packing and handling introduced by him have been of paramount importance in the success of the industry and have had a molding influence on the methods of handling every other tree-fruit in America. The following letter from his pen, giving the interesting details of his early experience, appeared in the Florida Agriculturist, November 7, 1900:

In compliance with your request for some reminiscences of the origin of the systematic handling of Florida oranges, I will say that I arrived in Florida on Thursday evening, early in November of 1875 , and on the following Monday, accompanied by my brother-in-law, P. P. Bishop, went to Fernandina to attend a meeting of the Fruit Growers' Convention. During the meeting I introduced a resolution making the $12 \times 12 \times 27$ box the standard package of the state. The resolution was adopted and the package has been used since. I opened a packing-house at Palatka and commenced the use of them at once, having them cut from cypress at Mr. Boyd's mill. The next year, as there were no veneer mills in Florida, we ordered a cargo from Maine. After securing the box it was necessary 
to learn how to pack it so as to fill and make a solid pack. This we found to be a difficult problem. We spent much time in experimenting, sizing and learning how to place the oranges in the box, eventually developing the $225,200,176,146,128,96,80$ sizes, which, with slight variations, have been used since.

It might interest your readers to know why the $12 \times 12 \times 27$ box was decided upon.

Before coming South I canvassed the cities of Buffalo, Rochester, Syracuse, Utica, Albany, and New York, soliciting orders for Florida oranges. I found that the few that had reached those markets were packed in soap-boxes, meat-boxes, dry-goods boxes, and old flour-barrels, unwrapped, and arriving in very bad order. I secured a few small orders in Buffalo and Rochester, but could not sell an orange in New York, although I canvassed faithfully. I was met in every case with the statement that the oranges were no good, that they would not bear transportation. They jeered me when I said that I was going down to engage in the business of handling them. One prominent dealer said that he thought that I would simply illustrate the proverb that a fool and his money would soon part company. In the course of the canvass I was seeking information, not only as to the best package to use, but also to learn all that I could about the manipulation of oranges in older countries. I called on several Italian packers, who kindly gave me a full description of their methods of handling and packing and showed me photographs of their packing-houses. From all the information that $\mathbf{I}$ could gather I reached the conclusion that a square box that would give a multiple of 3 inches would be the best. After reaching here and conferring with $\mathrm{Mr}$. Bishop, going into a storehouse where there was a quantity of loose oranges, piling them up, comparing the $12 \times 12$ space with the $10 \times 14$ of the foreign box, we decided that the $12 \times 12$ was far preferable and that size was agreed upon. (Fig. 171.)

I might add in conclusion that the results of my shipments from $\mathrm{Pa}$ latka during the winter $1875-76$ were satisfactory, as they demonstrated that with a suitable package and careful handling and manipulation, oranges could be transported and sold; for when we closed the packinghouse in the spring, we had standing orders from New York alone for about 200 boxes per week. In my canvass among the dealers and packers in New York I came to the conclusion that the success or failure of the enterprise would to a great extent depend upon the care in handling and the proper classification of the fruit, and that only perfect fruit should be put in the box. We, therefore, from the start, rejected creased, plugged, thorned, and all imperfect oranges. As the result of this care, we had but one complaint of fruit arriving in bad order. We had a considerable quantity of very fine oranges from the Lee grove, Leesburg. One lot 


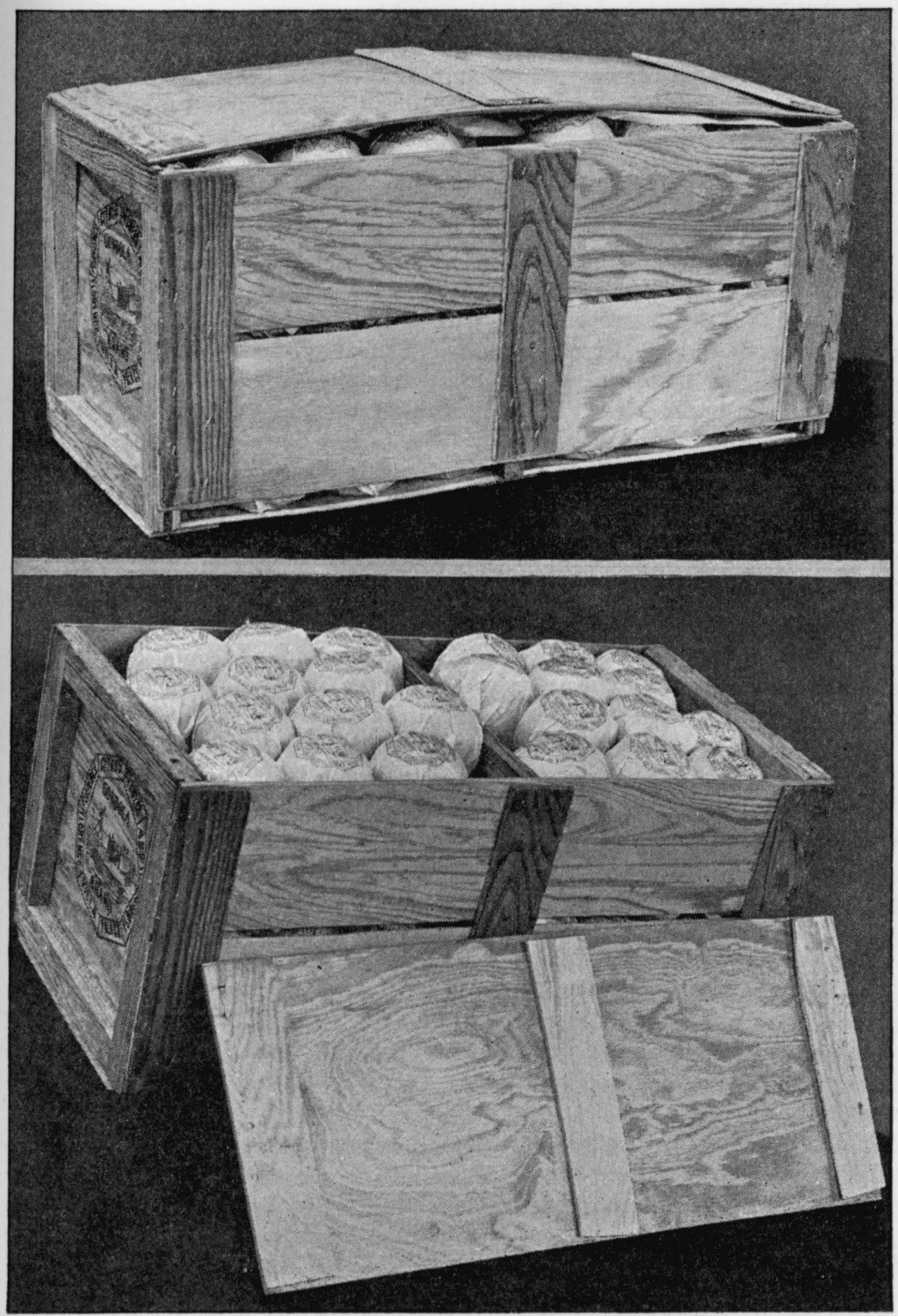

FIG. 171. The Florida citrus box, bulge packed, with grapefruit

(371) 
came in a little soft. We shipped twenty boxes of it to Mills \& Everals, New York, billing them at $\$ 6$ per box, f. o. b. Palatka. They complained they were not quite up to standard in condition, and asked for a reduction of $\$ 1$ per box, which we, of course, conceded. This close assorting left a considerable quantity of cull fruit. A laughable incident in connection with it is worth relating:

Judge Gillis, a prominent lawyer of Palatka, came into the packinghouse one day to see what we were doing. Looking about he saw quite a pile of culls in one corner, and asked what we intended to do with them. I replied that we expected to sell them in Palatka, but if we failed, we should dump them. He expressed some surprise, and soon left. Meeting a friend on the street he said to him that he had been down to see that Yankee who had come to show them how to pack oranges; that he was shown quite a pile of nice-looking fruit in one corner and was told that unless it could be sold in Palatka it would be dumped into the river. $\mathrm{He}$ guessed that Yankee would not last long.

We did get more culls than we could sell in Palatka. Selecting the best of them, we packed and shipped them to parties in New York who were very pronounced in their expressions of the opinion that the Florida oranges would not stand transportation. They reached them in good order and sold for satisfactory prices, and we continued to ship them during the winter. The house was so much pleased with the result that they sent a man down in the spring to negotiate for an interest in the business.

The most of the oranges handled at Palatka were pulled from the trees and as a consequence many of the stems were pulled out and the skin broken, and, besides, many were bruised by rough handling, and had to be put in the cull pile. We, therefore, concluded that in the future we must buy the oranges on the trees, have the stems cut, and provide for careful handling in the various stages of the work. This policy was inaugurated for the next season's business, and as most of the fruit came from the St. Johns and Ocklawaha Rivers, a packing-house was built at San Mateo, as being the most convenient point for concentration. Contracts were made for most of the oranges in sight, but the severe cold of December 1, 1876, destroyed all the fruit north of Lake Munroe, and we practically lost the season's business. In 1877-78 there was a considerable quantity of fruit.

Carrying out the policies outlined above, we were fairly successful and did a satisfactory business.

As our system required tight packages, we found that the fruit must be held until the skin softened and became flexible, for if packed when it was hard and crisp the cells would be broken and more or less decay would follow. We therefore held them for several days after they were taken from the trees before assorting, which enabled us to detect the bruised, 
injured, and thorned fruit. Our assorting and classification was very carefully done; each orange was taken up separately and carefully examined and placed in the class where it belonged.

We made three grades of bright oranges and two of the russets, putting them under separate brands. I put my name on the first class, which was supposed to be absolutely perfect, and will relate a little incident that occurred in relation to it. I was making a trip through the West, and, being detained several hours at a junction point, strolled up into the town, a place of two or three thousand inhabitants. Passing up the main street, and happening to look up, I found that $I$ was standing directly under a sign, "Headquarters for E. Bean's Oranges." I went in and inquired what there was about $\mathbf{E}$. Bean's oranges that justified so prominent a notice. The proprietor replied that when they saw that name on a box of oranges, they knew that it meant that they were perfect.

I have written the above, which I think is about what you asked for. It is largely personal, but this could not be avoided, as there was apparently no one else who had the courage to undertake such an enterprise. Later on many dealers and growers became packers, using substantially the same methods.

F. G. Sampson, of Boardman, Florida, under date of August 2, 1903, wrote the following interesting letter to the author, giving his early experiences in marketing citrus fruits. Many others went through much the same trials before they discovered the secrets of packing and marketing.

When we came to Florida, in 1874, oranges were poured into secondhand barrels, shaken down, headed up, and rather roughly handled all the way through. After two or three years the supply of barrels was not enough for the increasing crops, and boxes were brought in from Maine. They were of different sizes and we found a great deal of trouble in filling them, often having to take the fruit out and repack so as to make the box right on top.

I should think it was in $\mathbf{1 8 7 6}$ that Mr. E. Bean (who lately died at Jacksonville) bought a number of crops of oranges on Orange Lake at Citra, and he, with Messrs. Harris and Bishop-I think they were the chief ones-decided that the square box, $12 \times 12 \times 27$, was the most convenient size. They figured up the size of orange for each pack and practically the present style of packing and number per box as generally packed now. We sized the fruit by holes cut in a piece of thin wood, handling each orange and placing it in the box, but H. B. Stevens, then with Bishop \& Co. (now manager for J. B. Stetson, DeLand), got up a sizer which did much better work and saved an immense amount of labor. 
It was the second year of our shipping that we got a bit of experience which showed us the need of careful handling. Our fruit had to be hauled twenty miles to the railroad and the time those railroads made was very slow, so that, although our crops were being sold in South Carolina, we often had complaints of rot. We had a visitor who urged us to ship a few barrels to a friend of his in the commission business in New York, and we made a shipment of six barrels. The reports said that half were rotten. The remainder sold for $\$ 11$ per barrel for the three barrels of sound fruit. Before we got those returns six barrels more were on the way. That trip the steamer picked up a disabled steamer and, bringing her back to port, made a very long passage for our fruit. The report came "seventy sound oranges only. Please remit balance on freight." That seemed to settle the matter, as a neighbor said, "It is as I told you, you can't ship oranges to New York," and told of his experience the year before.

I was not satisfied, however, that fruit which would remain sound on the trees for months could not be put in New York sound. I knew the fruit was not being handled decently anyhow, so I said I would make one more shipment. Captain Keep said he wanted to join in, so he took three of the barrels to his house (first being more careful in picking and handling fruit), and he packed them; first a layer of black moss, then a layer of oranges, and so on, and marked the number of oranges on each barrel outside. I packed one barrel, first a layer of oranges, then a sheet of newspaper, second barrel papered each orange, and third barrel no paper (same as all shipments before), and marking the number of fruit in each barrel. We requested an exact report on each barrel by number. The report came: "Not a rotten orange in any barrel," and they sold at $\$ 16$ per barrel. That seemed to tell the story and from that day my brand has had the reputation of standing up. An orange does not show a bruise, but it is likely to be there all the same, and the only safe way is to handle, not pour the fruit. If fruit drops the shortest distance, it should not go in the regular shipment.

\section{GREEN FRUIT SHIPMENTS}

Ever since oranges and grapefruit have been grown and marketed on a commercial scale, the problem of restricting the handling of green or immature fruit has been before the growers, shippers, and consumers each year. During part, or all, of the months of September, October, and November, citrus fruits are scarce in the markets and high prices generally prevail. There has always been a strong temptation to take advantage of this situation. Much fruit, unfit for 
consumption, has gone into the markets early in the season. As a result, a demoralized condition of the citrus-fruit market has followed the early shipments, and it has been late in every shipping season before the markets recovered and a normal demand prevailed for good fruit at satisfactory prices.

When certain fruits have grown to full size, the ripening process continues after harvesting until eventually it matures and becomes in every way as good, and, in some cases, better than if it had been tree-ripened. Green apples may be used satisfactorily for culinary purposes, and pears picked when matured, but still hard and inedible, will ripen into very delicious fruit. Some kinds of citrus fruits may be picked while green and used to good advantage, but green oranges have no culinary use and they do not ripen after picking. They do not better their acid-or sugar-content. They are never any better than when taken from the tree. Indeed, if picked while too green, the flavor of the fruit becomes very disagreeable if held for a time. By many food and health authorities, citrus fruits in this stage have been considered unfit for use, and occasionally considerable amounts have been destroyed by boards or commissions having authority in such matters.

Many attempts have been made to check the shipping of immature citrus fruits, a practice more or less common to all the large producing districts. In Florida, the matter was taken up in the state legislature, and the first Florida Green Fruit Law was passed during the session of 1911. The shipping of citrus fruits which were immature and unfit for consumption was declared unlawful, but no standard or method was set by which maturity or immaturity was to be determined. A committee was appointed by the Commissioner of Agriculture to set a standard. This committee reported to a convention of citrus-growers, August 15, 1912, that:

"If the chemical analysis shows tree percentage by 
weight of total sugar, as invert sugar, to be seven times or more than the total acid, as citric acid, the fruit shall be deemed mature."

This became known as the Florida standard and with only slight modification was generally adopted by officials and health officers throughout the country.

Then followed a series of long legal battles in Florida, instituted by those interested in the shipment of green fruit. The legislature of 1913, seeking to clarify the situation, established a dual standard by which maturity was to be judged. A chemical standard was set, but the law stipulated that fruit showing an average of one-half color on the trees should be deemed mature. Really this was equivalent to removing all restrictions on shipments of green fruit. Practically no good came from these earlier efforts beyond awakening an interest on the part of the general public. The Florida legislature, in the spring of 1925, enacted a new law which was approved by the governor, May 20, 1925. Those persons who have the best interests of the citrus industry at heart are very hopeful that the enforcement of this law will put an end to the shipment of immature citrus fruits from Florida.

FLORIDA CITRUS FRUIT LAW, 1925

Section 1. That, as used in this Act, the word "person" shall extend to and include persons, partnerships, associations and corporations; and that the word "box" refers to the standard size containers now in common use in this state in the packing and shipment of citrus fruit; and the words "citrus fruit" shall extend to and include only the fruits of Citrus grandis, Osbeck, commonly and hereinafter called grapefruit or pomelo, and Citrus sinensis, Osbeck, commonly called sweet or round oranges, and hereinafter called oranges; the word "packing-house" shall extend to and include any structure or place prepared for and used for packing or otherwise preparing citrus fruit for market or transportation.

Section 2. It shall be unlawful for any person to sell or offer for sale, transport, prepare, receive, or deliver for transportation or market any citrus fruit between the 31st day of August and the 26th day of November in any year, unless such fruit is accompanied by a certificate of inspection and maturity thereof as defined by this Act, issued by a duly authorized 
Citrus Fruit Inspector, or State Chemist, an Assistant State Chemist; an Inspector of the Chemical Division of the Department of Agriculture of this State or a duly authorized Inspector of the United States Bureau of Agricultural Economics.

The certificates of inspection and maturity mentioned in this Act shall be of such number, form, size and character, and shall be used in such manner to identify the fruit to which they relate, as the Commissioner of Agriculture of this state may by rule or regulation prescribe. All inspections shall be made at the packing-house. Provided, that it shall be unlawful during the remaining period from November 26 to August 31 following in each year, when inspection is not required by this Act for any person to sell, offer for sale, transport, deliver or prepare for sale or transportation any citrus fruit which is immature or otherwise unfit for consumption, or for any person to receive any such fruits under a contract of sale, or for the purpose of sale, offering for sale, transportation, or delivery for transportation thereof. Provided, further, that the provisions of this Act shall not apply to sales of citrus fruit "on the trees," nor to common carriers or their agents when the fruit accepted for transportation or transported by such common carrier is accompanied by a proper certificate of maturity of such fruits, as hereinafter provided, or when accepted by them for transportation between the 25th day of November in any year and the 1st day of September next thereafter, or transportation of fruit from grove to packing-house located within this State.

Section 3A. That within the purpose and meaning of this Aet, pomelos (grapefruit) shall be deemed to be mature only when the total soluble solids of the juice is not less than 8.5 per cent, and when the ratio of total soluble solids of the juice thereof to the anhydrous acid is as follows:

$a$. When the total soluble solids of the juice is not less than eight and one-half (8.5) per cent, the minimum ratio of total soluble solids to anhydrous citric acid shall be seven to one ( 7 to 1$)$.

$b$. When the total soluble solids of the juice is not less than nine (9) per cent, the minimum ratio of total soluble solids to anhydrous citric acid shall be six and one-half to one (6.5 to 1$)$.

$c$. When the total soluble solids of the juice is not less than ten (10) per cent, the minimum ratio of total soluble solids to anhydrous citric acid shall be six to one (6 to 1 ).

$d$. When the total soluble solids of the juice is not less than eleven (11) per cent, the minimum ratio of total soluble solids to anhydrous citric acid shall be five and one-half to one (5.5 to 1$)$.

$e$. When the total soluble solids of the juice is not less than twelve (12) per cent, the minimum ratio of total soluble solids to anhydrous citric acid shall be five to one ( 5 to 1 ). 
Section 3B. That oranges shall be deemed to be mature only when the juice thereof contains not less than eight (8) per centum of total soluble solids to each part of anhydrous citric acid.

The remaining sections of the Act deal with its enforcement.

Sometimes attempts have been made to disguise the immaturity of citrus fruits by coloring them artificially. This practice has been declared illegal by the United States Department of Agriculture, in so far as interstate shipments are concerned. Food Inspection Decision 133 is as follows:

\section{UNITED STATES DEPARTMENT OF AGRICULTURE OFFICE OF THE SECRETARY}

FOOD INSPECTION DECISION 133

\section{The Coloring of Green Citrus Fruits}

The attention of the Board of Food and Drug Inspection has been directed to the shipment in interstate commerce of green, immature citrus fruits, particularly oranges, which have been artificially colored by holding in a warm, moist atmosphere for a short period of time after removal from the tree. Evidence is adduced showing that such oranges do not change in sugar or acid content after removal from the tree. Evidence further shows that the same oranges remaining on the tree increase markedly in sugar content and decrease in acid content. Further, there is evidence to show that the consumption of such immature oranges, especially by children, is apt to be attended by serious disturbances of the digestive system.

Under the Food and Drugs Act of June 30, 1906, an article of food is adulterated "if it be mixed, colored, powdered, coated, or stained in a manner whereby damage or inferiority is concealed." It is the opinion of the Board that oranges treated as mentioned above are colored in a manner whereby inferiority is concealed and are, therefore, adulterated.

The Board recognizes the fact that certain varieties of oranges attain maturity as to size, sweetness, and acidity before the color changes from green to yellow, and this decision is not intended to interfere with the marketing of such oranges.

Approved:

JAMES Wilson

Secretary of Agriculture.

Washington, D. C., March 28, 1911.
H. W. WILEY

F. L. Dunlap

Geo. P. McCabe

Board of Food and Drug Inspection. 


\section{THE CITRUS CROP SEASON}

Oranges, grapefruit, lemons, and limes are in the markets the year around, but the great crop movements take place during the winter and early spring months. In California, the season for navel oranges usually covers the months from November to May, inclusive, while Valencias are harvested from June to October, inclusive. The Gulf Coast Satsuma crop comes in during October, November, and early December. Florida's crop of round oranges and grapefruit is marketed from October 15 to July 1, and little or none of it is available during the three or four months of July, August, September, and October. The quantity of matured fruit in October is relatively very small. Lemons are picked nearly every month in the year, the heaviest crop coming in February, March, and April, and the lightest pickings in August, September, and October. Limes are available in largest quantities during the summer months, and kumquats are shipped most largely from November to February, inclusive.

Every citrus fruit should reach its best maturity before it is picked, and the shipping season should be covered by planting and growing a succession of varieties. Too often a variety is made to do duty over a longer period than its season warrants, either by shipping before it is fully matured or by holding it on the trees until it becomes passé. The most generally planted early orange in Florida, for many years, has been Parson Brown, and hundreds of cars of fruit have been shipped and sold under that name that never grew on a Parson Brown tree.

If oranges and pomelos are removed from the trees before they are matured, they assume a light yellow color and an exterior appearance which may deceive one into believing they are ripe, but they never acquire the rich delicate flavor of the fruit ripened on the trees. They generally have such a decidedly disagreeable bitter flavor that, after the first fruit is eaten, there is no wish or desire to sample another. The 
real test of whether an orange is mature may be summed up by saying, "If after eating one orange, there is a desire to eat a dozen, the fruit is ripe."

The early varieties of oranges, such as Early Oblong, Parson Brown, and Boone, should be picked just as soon as matured. Few of the early oranges equal the late varieties in quality and flavor, and they become very flat and insipid if allowed to remain on the trees after they reach maturity. The best rule is to pick them as soon as they have acquired their best flavor. This, unfortunately, is often a little before they are fully colored.

Midseason and late oranges have a longer period during which they are in good condition, and there is much less danger of deterioration in quality because of over-ripeness. The period during which they are in good marketable condition may extend over a number of weeks, and the grower has an opportunity to market his fruit to better advantage. Midseason and late varieties should not, however, be picked until fully ripened. The sugar-content and quality gradually increase up to the time of full maturity. On the other hand, if held on the trees too long, oranges may become deficient in juice and a considerable amount of fruit may drop.

Though most of the Florida pomelos are shipped before the first of January, few varieties reach their highest perfection until February or March, or even later. To secure the finest quality, the fruit should not be picked until then.

Lemons and limes must be picked while green, but they should be well grown before they are taken from the trees. The rule for lemons is to pick them when they will pass through a 21/4-inch ring. Any variety of lemon which is not well grown at that diameter is not desirable. If allowed to ripen on the trees, lemons become overgrown and do not develop the strong clear acid that characterizes the wellcured fruit.

Kumquats should be picked as soon as well matured and colored. 


\section{PICKING CITRUS FRUITS}

Reliable pickers only should be engaged, or picking crews culled out until only such remain. They must be careful men who can be trusted to handle fruit properly. Instructions should be given that fruit must not be dropped, roughly handled, or bruised in any way. Slight bruises cannot be seen, but they may be there, nevertheless, and will eventually show up in the form of soft rotten spots. Any picker who handles fruit carelessly and who will not mend his ways should be dismissed promptly. Each picking crew should be in charge of a competent foreman. The size of the crew will depend on the kind of picking, their experience, and the number the foreman can supervise properly. Five to eight men in a crew are sufficient. The foreman should not pick any fruit himself. It should be his duty carefully to supervise the work of every man, giving particular attention to clipper cuts, long stems, and rough handling.

Nearly all picking is paid for at so much a box. It has been argued that day work would result in better picking, but if careful and necessary supervision is given this is not the case, and piece work usually means faster labor. Pickers may, therefore, be engaged by the day, week, or month, or the picking may be paid for by the box. In the latter case, some system of checking must be employed. The fruit picked by each individual may be designated by a number on the end of the field-box. This makes it possible to check the fruit picked by any member of the crew.

\section{Picking equipment.}

The equipment used in harvesting citrus fruits consists of clippers, picking-bags or baskets, ladders, field-boxes, wagons, and trucks.

Clippers.- Several different types of citrus fruit clippers are in use. Some are shown in Fig. 172. The favored clipper today is shown on the right, known as the Tuttle. It will be noted that the blades are very short, curved, 


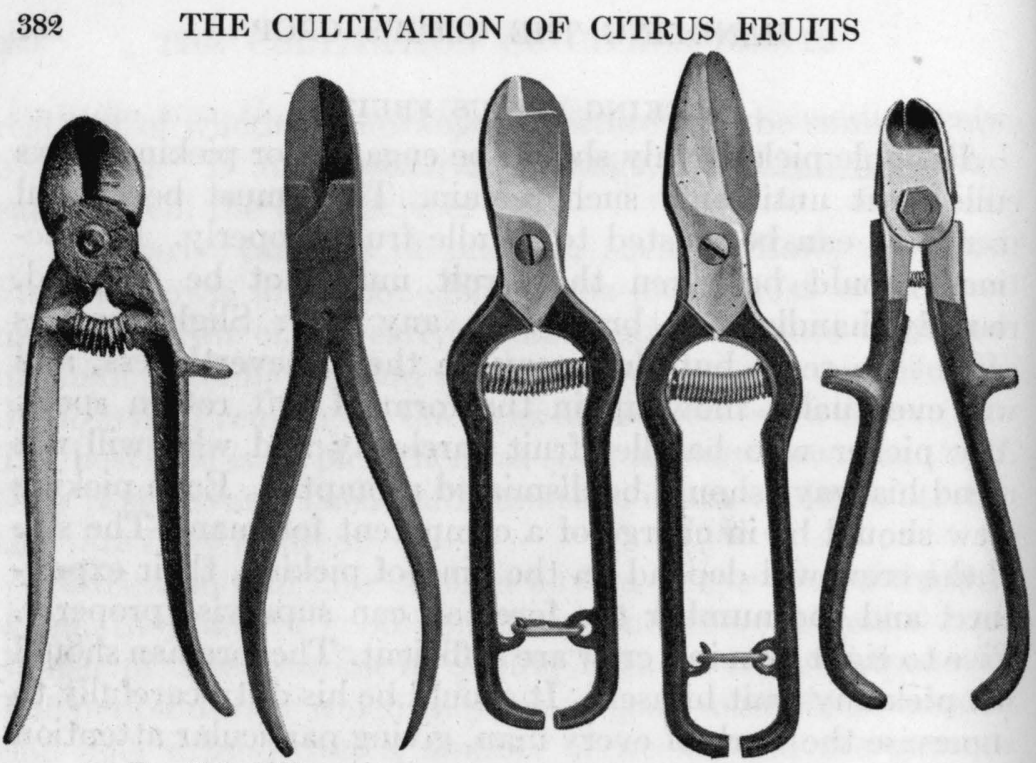

Fig. 172. Different types of clippers. From left to right, Hart, Spanish, Weiss, Weiss, and Tuttle

cupped, and the cutting end small enough to make it a very serviceable tool. Sometimes the Weiss type clipper is used, and it is very serviceable in picking grapefruit from clusters as the blades are thin and long. The fourth clipper from the right is commonly employed in picking oranges in Spain. It is without springs, and therefore unhandy. The fifth clipper is the Hart, used for a considerable time in the Florida districts but now superseded by the Weiss and Tuttle types. Clippers should be kept in good repair and there should be no looseness at the bolt, or screw, which holds the parts together.

Picking-baskets and bags.-For many years the favorite receptacle in the southeastern districts was a rattan basket, flat on one side, rounded on the other, with a wooden bottom and lined with heavy duck. By means of a stout broad strap it was slung across the shoulder. Inside it measured $301 / 2$ by $15 \frac{1}{2}$ by $73 / 4$ inches and was so constructed as to afford protection to the fruit from bruising 
when rubbed against ladders or branches. It was emptied by lifting the fruit from the basket to the field-boxes with the hands. Occasionally one sees these baskets in use still, but they have almost entirely given way to picking-bags. The latter, holding not more than a halfbox, are made of heavy canvas, open at the top, with a flap bottom fastened by hooks, by means of which they can be emptied. The better types are so constructed that their depth may be

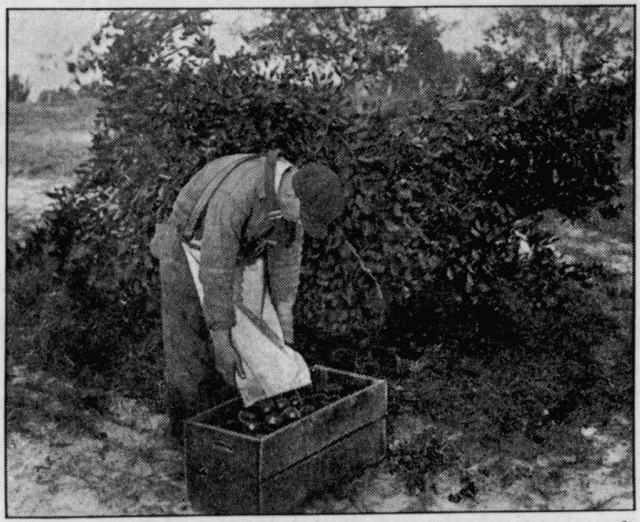

Fig. 173. The proper way to empty a picking-sack changed by lifting or lowering the bottom. In emptying these bags, the bottom is lowered until it is at the point where it is emptied, the flap is unfastened, and the fruit allowed to roll out (Fig. 173). In using picking-bags, care must be exercised to prevent bruising by swinging them against any hard object, such as tree branches, ladders, wagons, and picking-boxes.

Ladders. - In picking citrus fruits, some sort of ladder is generally a necessity, but it may not be in much demand if the trees are low and compactly headed. For removing the fruit from the outside branches, a light strong ladder of suitable length, with the sides spread apart at the upper end, is best, and it should have sufficient breadth at the base to prevent its tipping when laid flat against the branches. It is difficult to place an ordinary ladder in the center of a tree when removing the fruit from the inside branches, and for this purpose, a ladder in which the uprights are united at the top is not so likely to catch in the branches and is, there- 
fore, much more easily handled. Stepladders of the ordinary type are somewhat difficult to manage. They will not stand securely unless the ground is perfectly level, and the lower branches frequently interfere with the double supports in placing the ladder straight against the tree. A stepladder with a single support is preferable, more easily placed in position, and as secure and substantial.

Field-boxes.-The standard field-box in the southeastern districts holds a little more than a packed box of fruit. The usual dimensions are about 28 inches long, 12 inches wide, and $13 \frac{1}{2}$ inches deep, with or without a central partition. It came into use as a rough means of crop measurement. After culling, this box is supposed to hold a packed box of marketable fruit. The chief objections are its large size and unwieldiness. When filled with fruit it is difficult to handle gently. On this account, some growers use a different and smaller style of field-box. They should be well made, free from sharp or cutting edges, splinters, or projecting nails, and must be frequently inspected and always kept in good repair.

Field-wagons.-A low truck is best for hauling fruit from the trees to the loading point. The height to which the fruit must be lifted in loading is much less and the low wheels are not so likely to interfere with the branches in passing through the grove. Wagons for hauling fruit should be provided with good springs. The best type for use in the grove is one with a double reach. In turning sharp corners the rear wheels will then track with the front. These take the fruit from the trees to the roadside where it is stacked on loading platforms. Wagons for hauling from grove to packing-house should be provided with good springs, front and back. The best type is a double one which fits on both sides of and parallel with the wagon bunks. Motor trucks have almost entirely taken the place of mules and wagons, except for short hauls and in the rush of the season. The fruit should not be exposed to the sun after it is removed 
from the trees. When filled, the field-boxes should be set on the shady side of the tree. Neither should the packed boxes be exposed to the strong rays of the sun. To protect the fruit, either in hauling from the grove to the packinghouse, or from the packing-house to the shipping point, a duck or canvas cover should be thrown over it.

\section{Injuries to fruit due to picking.}

Since citrus fruits have been handled commercially, there has been trouble with decay caused by blue or green mold. As long ago as 1178, Han Yen-Chih, in his monograph on the oranges of Wen-Chou, Chekiang, China, wrote on "Gathering the Fruit":

Those fruits gathered in the Chung Yang festival time (about the ninth day of the ninth month), before they have turned to yellow, are called "chai ch'ing" (literally: "gathered while green"). The boats carry loads of these fruits throughout Kiangsu and Chekiang provinces. Of course it is these green oranges that persons like to obtain but only occasionally do the shrewd merchants have fruit picked before ripening. After two or three evenings of frost all the fruit should be clipped off with scissors. This should be done on a clear sunny day. Small scissors should be used for removing the fruit from the branches, cutting them off even with the surface of the skin and carefully placing them in a basket. To protect them from injury one must be very careful not to cut the skins, thus causing the volatile oil to escape, when the fruit will easily spoil. The oranges with which this oil come in contact will likewise be affected. The fruit should be kept away from liquor fumes. All pickers must not drink liquor during the whole day.

The appearance of citrus fruits gives an erroneous impression of their ability to withstand rough handling. Perhaps this is responsible, in some measure, for the frequent lack of care exercised when gathering the crop and preparing it for market. Few fruits will keep longer than citrus if handled carefully. They will actually harden and shrivel up until they are mummified without decaying; but no fruit will break down much quicker if the rind is injured and decay-producing organisms gain entrance. Spores of citrus molds are almost everywhere in grove and packing-houses, 
on pickers' clothes, on wagons, trucks, and utensils, in spite of most painstaking efforts to eliminate them. Safety, therefore, consists in so handling the fruit that it goes to the consumer absolutely uninjured.

So much difficulty was encountered in the handling of lemons, oranges, and grapefruit, both in California and in Florida, that careful investigations were conducted over a period of several years to determine the causes of decay. The conclusions reached, as the result of exhaustive study of the situation, amply confirmed Han Yen-Chih's statement that the skin should not be cut and that the fruit should be handled carefully if decay is to be avoided.

Too much stress cannot be laid on the proper manner of handling the fruit during picking. When it is removed from the trees, the rind is turgid with moisture, particularly early in the season, and the greatest care must be exercised in handling it. Early oranges are exceedingly difficult to handle. The least bruise on a fruit will send it to the cull pile, and this is particularly true if the fruit is artificially colored before shipment.

If all the crop is to be removed from a tree at one time, the fruit, which may be reached easily from the ground, should be picked first. Then ladders should be used and the top fruit removed. In this way danger of injury to the fruit on the lower branches from ladders and pickers, as they move about, is eliminated.

It is essential that no projecting stems be left on the fruit. They must be clipped off carefully, just above the calyx or button, as long stems are a prolific source of punctures while fruit is being handled. To eliminate them entirely it is usually best to make a double cut, one to remove the fruit from the tree with a stem a half inch or so in length, and a second to trim off the stem close and smooth to the button.

Kumquats are commonly picked in bunches with twigs and leaves. Sometimes the branches may be a foot or more in length. These are used principally for decorations during 
the holiday season. Most of the kumquat crop that finds its way into the markets, however, is picked by cutting the fruits singly, with a short piece of stem and two or three leaves attached. They are packed in quart baskets, such as used for strawberries. The bottom fruits are placed in irregularly, but the top layer is faced with green leaves sticking up between the fruits. Sometimes damage is done to the fruit by the projecting twigs, but if carefully handled it usually goes through to market in good condition.

Among the principal sources of injury to fruit in picking, and the manner of correcting or removing them, are the following:

1. Finger-nails of the pickers. They should be trimmed closely and the pickers should wear cotton gloves.

2. Sand, twigs, trash, gravel, or other foreign material in picking-bags and field-boxes. Anything of the sort should be kept away from the fruit and field-boxes closely inspected before being filled.

3. Bruises. Frequently fruit is bruised in dropping or by being swung against ladders or branches while in the pickingbags. Fruit should not be poured, or allowed to drop any distance when emptying picking-sacks. The bottom of the sack should rest easily on the surface where the fruit is to be emptied and then the fruit allowed to roll out gently. A fall which will break an egg will injure an orange.

4. Splinters, nail-points, and the like. Field-boxes and picking receptacles must be free from splinters, sharp edges, exposed nail-ends, or anything that may injure or puncture the rind.

5. Fruit stems. Long stems are a prolific source of trouble and a single one may puncture and destroy many fruits between grove and car.

6. Cuts. Clipper cuts are responsible for much damage. The rind of the fruit is frequently rough or corrugated about the calyx, or the calyx may be set in a depression. In the effort to clip close when the fruit is cut from the tree, a tiny 
bit of rind is sliced off. This must be guarded against rigidly, for a cut or punctured rind generally results in a decayed fruit.

Filling the field-boxes.

As the picking-bags are filled, they are emptied into the field-boxes. These should be placed on the level in the shade. The fruit is emptied by lowering the picking-bag into the field-box, unfastening the flap bottom, and allowing it to roll out. It must not be dropped or bruising may result.

Field-boxes are stacked in tiers on hauling trucks and in the packing-houses to economize space. They must be filled so as to leave the fruit entirely free from the bottom of the upper box when they are stacked up. Serious damage to fruit may result from filling them too full.

\section{Hauling.}

Drivers should be checked from time to time to see that due caution is exercised over rough pieces of road. There must be no unnecessary jolting or bumping of loaded fruit. In unloading at the packing-house, the boxes should not be dropped. A drop of a few inches may injure fruit in the bottom of the field-boxes.

\section{Weather conditions.}

Temperature and moisture conditions, both before and during harvesting, have a definite bearing on the condition of the fruit. If wet weather has prevailed for some time, the fruit is likely to be more turgid, the rind more easily injured, and blue mold is much more active in its growth than in dry weather. Consequently, during periods of high humidity even greater care must be exercised in handling the crop. Sometimes it is possible to delay pieking until weather conditions are more favorable, that is, dry and the atmosphere free from fog or excess moisture. Bright clear dry weather, with a temperature of about seventy degrees, is ideal. 


\section{PACKING THE FRUIT}

Since 1900, the handling of citrus fruits in the southeastern districts has undergone very important and farreaching changes. The small individual packing-house has disappeared entirely. Formerly nearly every grower picked and packed his own fruit, and there were as many different systems of handling, grading, and packing as there were growers. There was no uniformity of method and much variation existed in the product marketed.

Now the fruit from large areas is brought together and packed in a single large packing-house. This has resulted in uniformity in handling, packing, and in the product as placed on the markets. Gathering the crop and preparing it for market has been standardized in every particular. (Fig. 174.)

The old plan of sweating or curing oranges and grapefruit has been abandoned. It had some advantages, but now the fruit from tree to consumer is handled as rapidly as possible, with little or no pause in the several steps which prepare it for shipment. The only curing the fruit now receives is during a temporary stop in the packing-house or when it is in transit. The bulge pack has been evolved, to make good any slackness from curing shrinkage after packing.

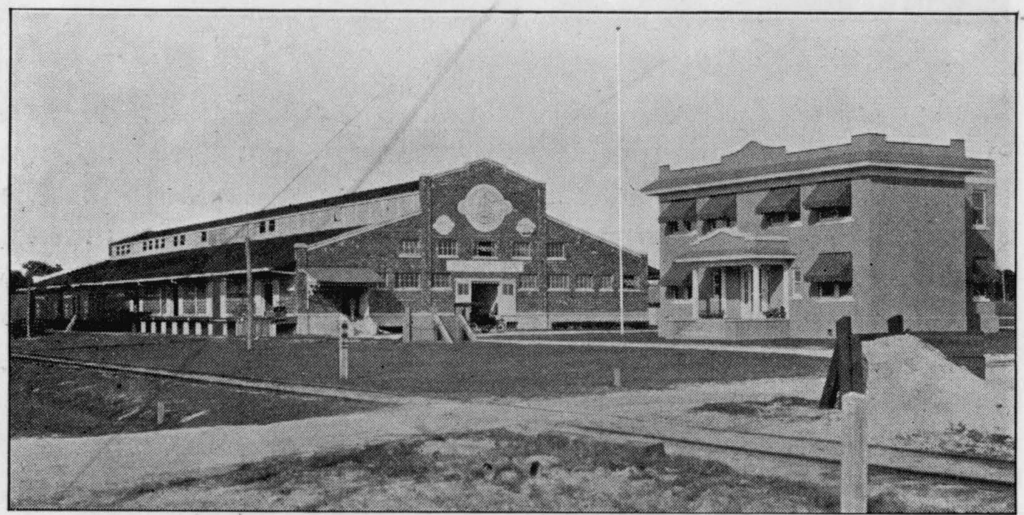

FIG. 174. A modern citrus packing-house with executive office at right 


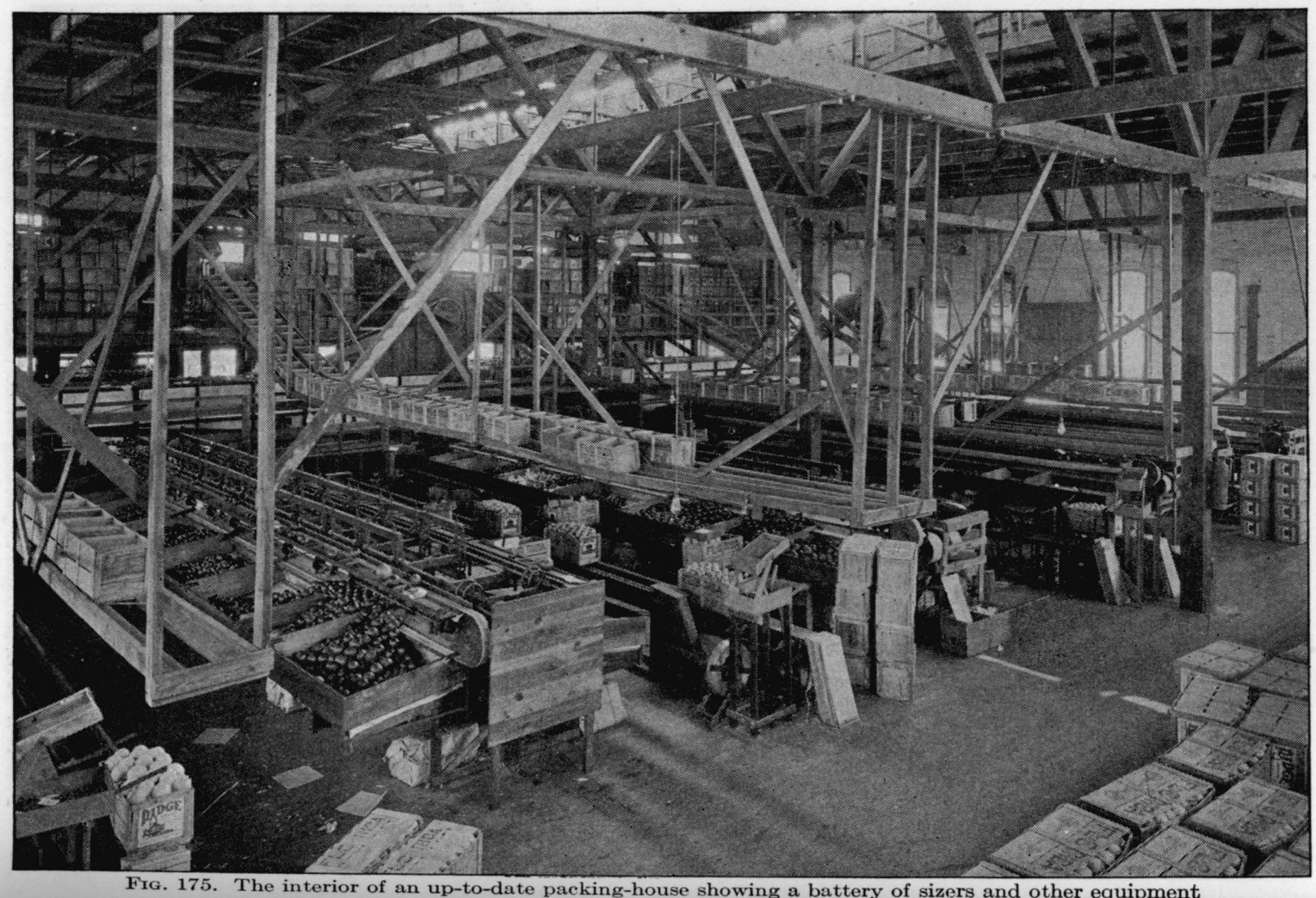




\section{Packing-houses.}

The packing-house should be located where it may conveniently take care of the fruit from large areas. It should be either on the side of the railroad, or a switch track should be run from the main line to the packing-house, with ample track facilities for handling empty and loaded cars. The size of the packing-house will depend on the quantity of fruit to be handled. In sections in which an increase in output is to be expected in future years, the house is sometimes so planned as to make enlargement easy.

Modern packing-houses are constructed of different materials, but the better and larger ones are made with steel frames, tile, brick, or concrete walls, tile roofs, and are practically fireproof. They should be well lighted and plenty of space provided for packing supplies (boxes, paper, and the like), for fruit, machinery, and for packing. (Fig. 175.)

The interior of an up-to-date citrus packing-house bears little or no resemblance to one of former days. Gone are the old-time sizers and more or less crude home-made equipment, and in their place is an array of machinery, conveyors, and labor-saving devices that makes the interior resemble a manufacturing plant. At a glance one wonders how a citrus fruit can be sent through them and come out sound, but the constant aim has been to safeguard the fruit at every stage.

If possible, the packing-house should be at least two stories high. The basement, or lower floor, is used for receiving and washing fruit, for storing box materials, making and storing boxes; the second floor is given over to grading, sizing, packing, nailing up, and stenciling. Here, also, are the offices, storage-room for paper and other materials used in packing, and rest-rooms for workers. A sufficient space for temporary storage of packed fruit should also be provided, and when available, a third story is devoted entirely to storage and box-making.

To secure satisfactory results in handling fruit, the packing-house must be in the hands of a competent manager. 
He must be acquainted with every detail connected with the handling of citrus fruits and the operation of packing-house machinery, should also be a good manager of labor, in order to secure their whole-hearted cooperation. Since his contact with the patrons of the packing-house is intimate, he must handle his work in such manner as to gain and hold their confidence. The labor must be intelligent, conscientious, and interested in building up and maintaining the reputation of the house for putting up a high-grade uniform pack. Everything in and about the packing-house should be kept scrupulously neat, clean, and free from decaying or rotten fruit.

\section{Delivery of fruit.}

Fruit is delivered at the packing-house by unloading the field-boxes onto a gravity roller conveyor. The outer end is placed at a convenient height for handling the fruit from motor truck or wagon, and the boxes of fruit are carried downward into the basement of the building by their own weight. There they are stacked up to await their turn or sent directly to the washer.

\section{Washing.}

Nearly all citrus fruit comes to the packing-house in such condition that it must be washed before being packed. Sometimes washing is necessary to remove dust or soot, or the fruit is coated with sooty mold, or scale insects are on the rind. Often it is so dirty that it must be soaked in a tank of water before being washed. When dirty fruit comes from the washer, its appearance at least is much improved. Unfortunately, it is very difficult to wash citrus fruit without injury. Nails, splinters, worn brushes, and pieces of trash often damage the fruit. The washing machine must be given very close supervision by a careful watchful man to keep it in proper working condition (Fig. 176).

From the field-boxes the fruit is emptied into the washer 


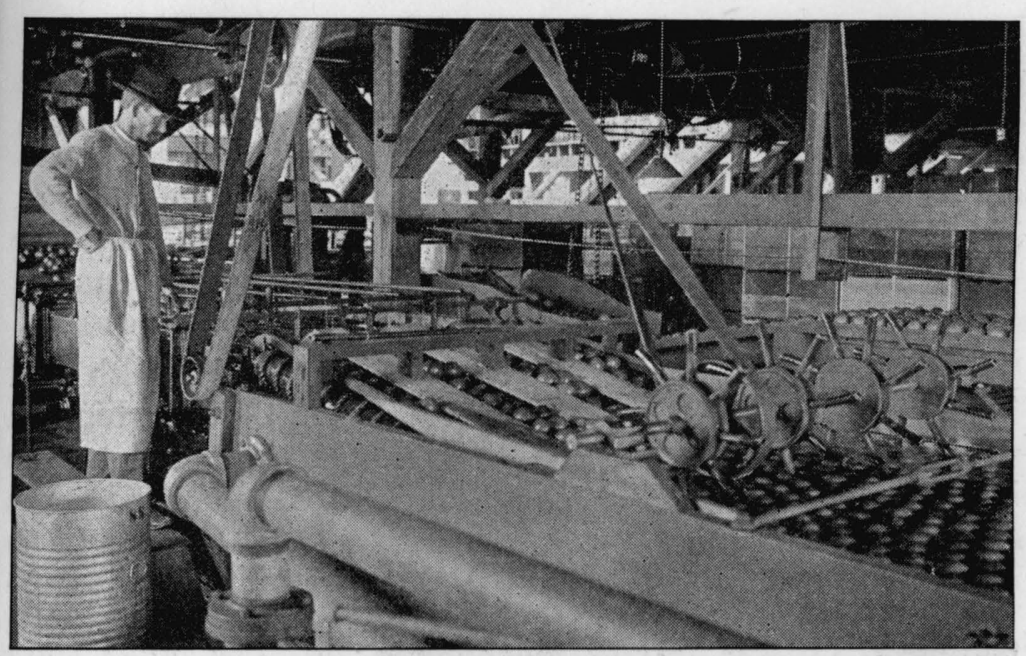

Frg. 176. A citrus fruit-washing machine

and the empty boxes are carried outside by conveyor. In the washer, the fruit passes between revolving brushes, either under or at the surface of the water. It is turned over and over, and gently but firmly brushed as it passes to the opposite end of the washer.

\section{Drying.}

From the washer the fruit is conveyed to the dryer. Sometimes fruit can be dried by air alone, but often it is necessary to heat the air. The dryer is a long closed box through which the fruit is carried on a conveyor. As it passes through, hot dry air is blown over and around it, through several openings with fans, and by the time it reaches the end of the dryer it is entirely dry, unless conditions are very unfavorable.

\section{Grading.}

On leaving the dryer, the fruit is carried before the graders on broad slowly moving canvas belts. Several graders sit at the side of these belts and carefully examine 
each fruit as it passes. Culls are taken out on one section of the grading belt and the remaining fruit is separated into as many classes and grades as desired. Each is carried on the belts to the sizers. (Fig. 17\%.)

Grading belts must be well lighted and grading must be very careful and uniform. On the quality and uniformity of the pack depends the reputation of the house, and rigid standards should be adhered to.

It means much to any citrus region to establish and maintain a reputation for the production of fruit high in eating and keeping quality, that can be delivered to the consumer in first-class condition. No reasonable effort

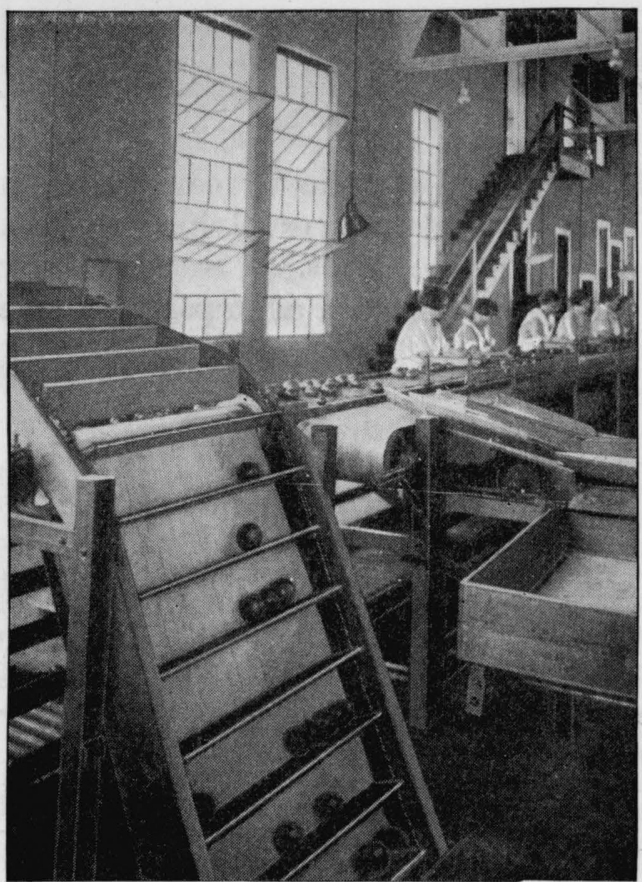

Fig. 177. Grading-belt and graders at work. The elevator which brings fruit from the drier is shown in the foreground should be spared to secure such recognition, as it makes the marketing of the crop and the securing of satisfactory returns so much easier. In this connection, nothing is of more importance than careful uniform grading and standardization of all fruit shipped. Such standards should not vary from season to season or from year to year unless in the direction of improvement, and any improvement made should be kept up. 
The Bureau of Agricultural Economics, United States Department of Agriculture, has suggested grades and standards for handling the Florida citrus crop which have been accepted by many packing-houses. These and the proposed grading rules for California fruit will be of great assistance in securing uniformity of product and in holding the confidence of markets if followed. (Fig.178.)

\section{UNITED STATES DEPARTMENT OF AGRICULTURE \\ BUREAU OF AGRICULTURAL ECONOMICS}

\section{TENTATIVE U. S. GRADES FOR CITRUS FRUITS (FLORIDA)}

\section{U. S. Fancy Bright.}

U. S. Fancy Bright shall consist of citrus fruits of similar varietal characteristics (1) which are firm, mature, well-formed, smooth, thinskinned, free from decay, cuts and bruises, and from damage (2) caused by dirt or other foreign materials, dryness, limb-rubs, thorn-scratches, scars, scale, scab, insects or mechanical or other means.

Fruit of this grade shall be free from all discoloration apparent in the process of proper grading.

U. S. Fancy Golden.

U. S. Fancy Golden shall consist of citrus fruits of similar varietal characteristics (1) which are firm, mature, well-formed, smooth, thinskinned, free from decay, cuts and bruises, and from damage (2) caused by dirt or other foreign materials, dryness, limb-rubs, thorn-scratches, scars, scale, scab, insects or mechanical or other means.

Fruit of this grade may show not more than 75 per cent light discoloration.

\section{U.S. No. 1 Bright.}

U. S. No. 1 Bright shall consist of citrus fruits of similar varietal characteristics (1) which are firm, mature, well-formed, fairly smooth, fairly thin-skinned, free from decay, cuts and bruises, and from damage (2) caused by dirt or other foreign materials, dryness, limb-rubs, thornscratches, scars, scale, scab, insects or mechanical or other means.

Fruit of this grade may show not more than 20 per cent light discoloration.

\section{U. S. No. 1 Golden.}

U. S. No. 1 Golden shall consist of citrus fruits of similar varietal characteristics (1) which are firm, mature, well-formed, fairly smooth, 


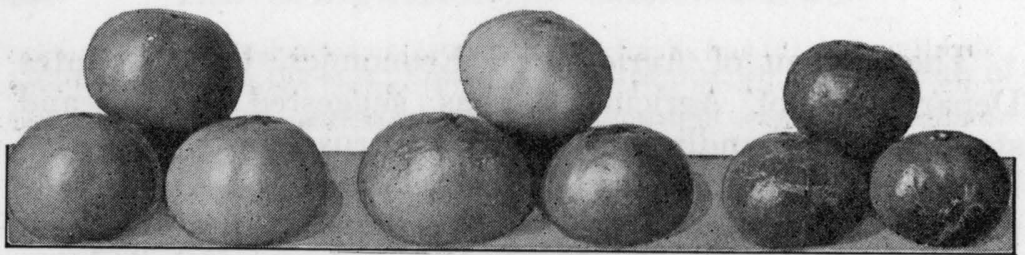

Fig. 178. United States grades for Florida citrus. From left to right, Fancy Bright, No. 1 Bright, and No. 2 Bright. Tangerines illustrated

fairly thin-skinned, free from decay, cuts and bruises, and from damage (2) caused by dirt or other foreign materials, dryness, limb-rubs, thornscratches, scars, scale, scab, insects or mechanical or other means.

Fruit of this grade may show not more than 75 per cent light discoloration.

\section{U.S. No. 1 Russet.}

U. S. No. 1 Russet shall consist of citrus fruits of similar varietal characteristics (1) which are firm, mature, well-formed, fairly smooth, fairly thin-skinned, free from decay, cuts, and bruises, and from damage (2) caused by dirt or other foreign materials, dryness, limb-rubs, thornscratches, scars, scale, scab, insects or mechanical or other means.

Fruit of this grade shall show no black or unsightly russeting.

U. S. No. 2 (Choice) Bright.

U. S. No. 2 (Choice) Bright shall consist of citrus fruits of similar varietal characteristics (1) which are firm and mature, which may be slightly rough (6) and slightly misshapen (5) but which are free from decay, cuts, bruises and from serious damage (4) caused by dirt or other foreign materials, dryness, limb-rubs, thorn-scratches, scars, scale, scab, insects or mechanical or other means.

Fruit of this grade may show not more than 20 per cent light discoloration.

U. S. No. 2 (Choice) Golden.

U. S. No. 2 (Choice) Golden shall consist of citrus fruits of similar varietal characteristics (1) which are firm and mature, which may be slightly rough (6) and slightly misshapen (5) but which are free from decay, cuts, bruises and from serious damage (4) caused by dirt or other foreign materials, dryness, limb-rubs, thorn-scratches, scars, scale, scab, insects or mechanical or other means.

Fruit of this grade may show not more than 75 per cent light discoloration.

U. S. No. 2 (Choice) Russet.

U. S. No. 2 (Choice) Russet shall consist of citrus fruits of similar varietal characteristics (1) which are firm and mature, which may be 
slightly rough (6) and slightly misshapen (5) but which are free from decay, cuts, bruises and from serious damage (4) caused by dirt or other foreign materials, dryness, limb-rubs, thorn-scratches, scars, scale, scab, insects or mechanical or other means.

Fruit of this grade shall show no black or unsightly russeting.

U.S. No. 3 .

U. S. No. 3 shall consist of citrus fruits which are free from decay and which do not meet the requirements of any of the foregoing grades.

\section{TOLERANCE}

In order to allow for variations incident to proper grading and handling in each of the foregoing grades not more than 10 per cent, by count, of any lot may be below the requirements of this grade, but no part of this tolerance shall be allowed for decay at point of origin, nor more than 3 per cent of the lot at destination.

\section{DEFINITION OF GRADE TERMS}

As used in these grades:

1. "Similar varietal characteristics" means that the fruits in any container are similar in color and shape.

2. "Free from damage" means that any injury from causes mentioned shall not materially affect the appearance of the fruit.

3. "Russeting" means that the skin of the fruit is roughened and shows a reddish brown, reddish yellow, or gray color.

4. "Serious damage" means that any damage from the causes mentioned shall not seriously affect the appearance or edible quality of the fruit.

5. "Slightly misshapen" means that the fruit is not of characteristic shape but is not decidedly pearshaped, elongated, or sharply pointed.

6. "Slightly rough" means that the skin is not of smooth texture but is not creased or wrinkled.

Revised November 18, 1924. U. S. Fancy Golden added December $11,1924$.

\section{ORANGES}

Proposed Grading Rules on California Citrus Fruit for American Fruit and Vegetable Shippers Association

Fancy Grade: Shall consist of mature, hand-picked oranges of one variety which are of smooth texture, of good color, normal form and shape, clean and free from dirt or scale (except that a slight amount of dirt or scale may be permitted within the basin of the stem or navel), and free from fruit which is rough, coarse, misshapen, scarred, sunburned, puffed, thrip-marked, scaly, split, cut, or bruised. 
In order to allow for variations incident to commercial grading and handling, 10 per cent of the fruit by numerical count may be below the foregoing requirements; and an additional 5 per cent may show thripmarks of not exceeding one-quarter inch in area.

Choice Grade: Shall consist of mature, hand-picked oranges of one variety which are of fair texture, fair color, of normal shape and form, and free from fruit which is misshapen, badly puffed, split, cut, or bruised. In order to allow for variations incident to commercial grading and handling, 10 per cent of the fruit by numerical count may be below the foregoing requirements.

Extra-Choice Grade: When all oranges that otherwise comply with both Fancy and Choice grades are packed together, this grade may be designated as Extra Choice, provided, however, that none of the higher grades of oranges from any lot shall have been sorted out. In order to allow for variations incident to commercial grading and handling, 10 per cent of this grade may be below the foregoing requirements of Choice Grade but at least 30 per cent of the fruit-shall meet the requirements of Fancy Grade.

Standard Grade: Shall consist of mature, hand-picked oranges of one variety which are not up to the specifications of a Choice grade as regards color, texture, blemishes, deformities, but which are edible and merchantable fruit, practically free from bruising or broken skin.

Orchard Run Grade: When any two or more of the above grades are packed together, boxes must be marked "Orchard Run" but "Orchard Run" oranges must not contain any fruit that will not meet the requirements of the Standard Grade. None of the higher grade oranges shall be sorted out of any lot and the remainder packed as "Orchard Run."

Color Requirements: All oranges shall conform to the California State Law on color and sugar content.

Frost: All oranges shall conform to the California State Law.

\section{Sizers.}

Citrus fruits of round or oblate form can be accurately sized by machinery. Lemons and limes must be sized by the eye, either before or at the time of packing.

A good sizer must possess the following points: It must size all fruit accurately, whether round or flat, passing the fruit through on its greatest diameter. It should be easily adjusted and of sufficient capacity to handle its requirements. It must not injure the fruit.

In large packing-houses, several sizers are usually in- 
stalled, to facilitate the handling of different classes and grades of fruit. Each sizer is equipped with bins for receiving the fruit after it is sized. These should be so placed as to prevent a drop between sizer and bin. It is usual to pad the inside of the bins. The sizes at which these machines should be set are given with the packing diagrams (Fig. 181).

Citrus packages.

In the United States, several boxes are recognized as standards for citrus fruits. In addition, Italian lemons, which find their way into American markets, are packed in a box of different size from that used for domestic shipments. The inside dimensions of these several boxes are as follows:

Table XIV. Sizes of Citrus Packages

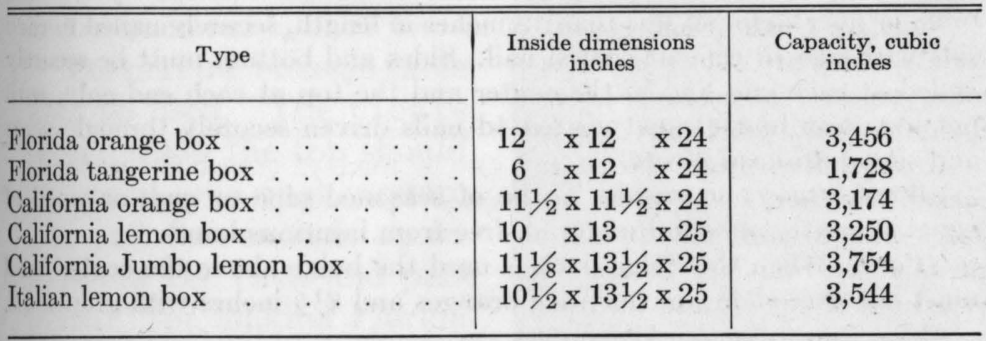

The twenty-four-quart carrier, such as is used for strawberries, is most generally adopted for kumquats, and the six four-quart basket carrier is sometimes employed for limes.

\section{MATERIAL SPECIFICATIONS FOR FLORIDA ORANGE AND GRAPE- FRUIT BOXES}

Dimensions. $12 \times 12 \times 24$ inches, inside measurements.

Capacity. 3,456 cubic inches.

Heads. Three heads not less than $\frac{13}{16}$ inch thick, made of one or two pieces, stapled together or made of head sticks not less than $\frac{13}{16}$ inch thick, $1 \frac{1}{4}$ inches wide.

Panels. Two end and two center panels made of one piece not less than $\frac{3}{16}$ inch thick, securely nailed to head sticks with not less than four No. 16 gauge $7 / 8$ inch wire nails top and bottom and not less than three 
No. 16 gauge $7 / 8$ inch wire nails across the sides (total 14 nails). The veneer may be stapled on with eight double pointed staples $7 / 8$ inch long made from No. 18 gauge wire.

Sides. One or two pieces not less than $\frac{3}{16}$ inch thick, $11 \frac{1}{4}$ inches wide, if in one piece, not less than $51 / 4$ inches wide if in two pieces and 27 inches long.

Top. Same as sides, except when bulge pack is used, to be not less than $271 / 4$ inches long and not to exceed $273 / 8$ inches and nailed flush with head-pieces.

Bottom. Same as sides, except may consist of one to four pieces cleated together.

Cleats. Three hoops of birch, metal, or fiber secured at each end and center head, or three cleats of veneer not less than $\frac{3}{16}$ inch thick and $1 \frac{1}{4}$ inches wide fastened with staples of not less than No. 20 gauge wire driven through veneer and securely clinched, not less than three long or six short staples to each end and center cleat. Center cleat on top is optional.

Making up. The top must be fastened around center by a metal, birch or fiber strip not less than 19 inches in length, securely nailed to each side with one $4 \mathrm{~d}$ cement-coated nail. Sides and bottom must be securely nailed at each end and in the center and the top at each end only, with not less than four cement coated 4d nails driven securely through cleats and slats into head pieces.

Wood, veneer, or sawed. To be of seasoned pine or gum or wood of equal strength, of sound material, free from injurious knots.

Pack. When the bulge pack is used the bulge above the center head must not exceed $1 \frac{1}{4}$ inches with oranges and $21 / 2$ inches with grapefruit.

\section{TANGERINE CRATE}

Construction to be as in specifications for the standard size box except that dimensions should be $12 \times 6 \times 24$ inches inside measurements.

When oranges and pomelos were packed flat, birch hoops were formerly nailed around the ends and middle of each box, but these are no longer used, and for bulge-packed boxes, thin narrow metal strips are nailed about the ends only, or covers with three cross cleats are used (Fig. 171).

All materials which enter into the construction of packages for citrus fruits should be bright, clean, and well seasoned, and all similar parts should be of uniform size. Yellow pine is commonly employed in Florida. Though both 
solid and paneled heads are in use, the latter are more common in Florida, while in California the solid heads are at present adopted almost entirely. The solid heads are preferred because of the greater solidity of the box, but when expressmen and others have once handled boxes with the paneled heads, they dislike solid-headed boxes.

It is essential that boxes for shipping citrus fruits should be strong and well made. The fruit is heavy and the box must therefore be capable of standing a considerable amount of strain. Cement-coated wire nails should be used. All stained or discolored pieces should be discarded, so that all boxes, when completed, may be bright, clean, and attractive.

For making boxes, a table may be used. The cleats tacked upon the top should be about one inch square and just far enough apart to admit the ends and partition. For making Florida standard orange boxes, with one-inch heads, the distance from center to center of the grooves between the cleats should be exactly thirteen inches. Variations in the thickness of the heads or the

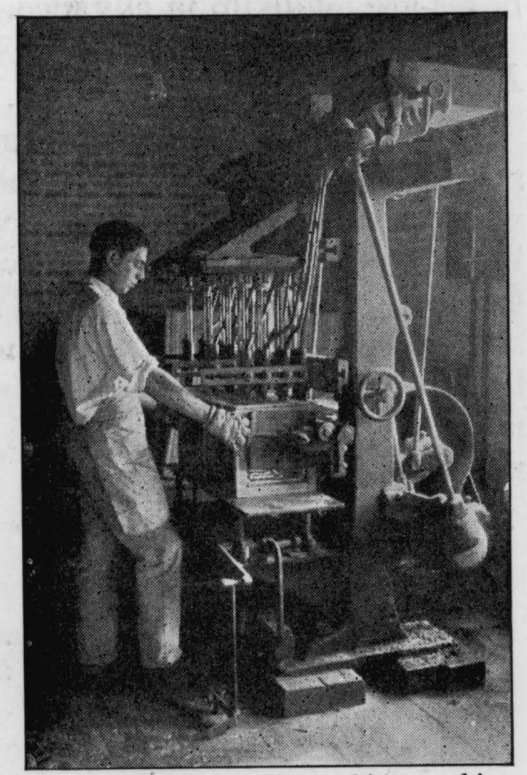

Fı́̆. 179. A citrus box-making machine in operation size of the compartments will render it necessary to change the position of the cleats, but they must always be so adjusted that the finished box will have two compartments of exactly the same dimensions. The slightest variation increases the difficulties of packing. Instead of using cleats, grooves may be cut in the table top. 
Box-making machines have been introduced (Fig. 179). All the operator does is to feed nails and box material to the machine, turn the boxes over and remove them when finished. The machine drives all the nails on one side of the box at the pressure of a foot lever. It does the work quickly, but, unfortunately, it gets jammed or stuck at times. Packing-houses often find it necessary to have a number of good box-makers in their employ to help out during rush periods or in cases of emergency. Usually large numbers of boxes are made up in advance.

Paper for wrapping fruits.

The paper for wrapping citrus fruits should be thin and strong. Frequently the wrappers supplied are so thin and weak that the fruit cannot be wrapped and packed without breaking them. The paper serves as a protection and should surround the fruit intact when snugly placed in the box.

The size should be varied according to the diameter of the fruit, but must be sufficiently large to allow enough margin for a good twist. The following sizes are approximately correct:

Fruts to a Box
$36-46$

Wrappers printed with a suitable design and the name and address of the grower are more expensive than fancy paper, but fruit so wrapped presents a much more attractive appearance than if plain paper is used. Colored and fringed paper is also sometimes employed to advantage, and the Italian lemons shipped to this country are usually so wrapped. 
Packing conveniences.

The fruit runs out from the sizer, each size into its own bin. By the side of the bin, so that the packer can readily reach the fruit, the box is placed on a table of convenient height, with a revolving top. When the end of the box nearest the bin is packed, the box ends are reversed to bring the empty half next the bin.

Small trays should be provided for holding the wrapping paper and the bottom of these should be made from a piece of board slightly larger than the paper. The back should be of one-half-inch board, two inches high, and the sides of the same material, and sloping off in front. The paper can be placed in these trays and the backs and sides will prevent, in some measure, its being blown about by the wind.

Packing the fruit.

After accurately sizing the fruit, previous to which it has been properly culled and graded, it is ready for packing. The packer grasps a piece of paper with the tips of his fingers,

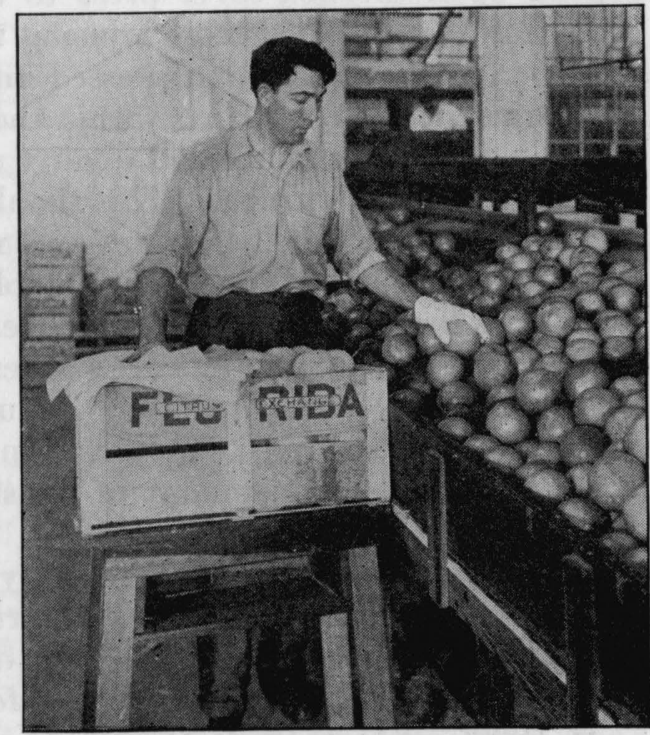

FIg. 180. Citrus fruit-packer at work leaving it spread out on his hand, and with the right hand he places a fruit on the paper in the palm of his left hand; then, with the right hand draws the edges together, giving them a dexterous twist to hold it in place. It is then put in position in the box. (Fig. 180.) 
The first two layers of fruit in the bottom of the box should have the twists on the paper upward, afterwards they should be turned down. Each layer should be snugly packed and each fruit gently but firmly placed in position. If a system of packing diagrams is used, and the boxes are properly made, each individual fruit has its own special place in the box into which it should fit snug and tight.

When packing is completed, the fruit should stand onehalf to three-quarters of an inch above the box at the ends and about an inch higher in the middle. Mandarin oranges should project less rather than more. It will not do to depend upon the box-cover press to tighten the fruit into place, for there is danger of injuring the fruit. Each layer must be tightly packed and pressed into place so that there may be no chance of shifting within the box.

If linings are used, a good quality of shelf paper should be secured for the purpose. This should be cut into 11-inch lengths, about $8 \frac{1}{2}$ inches wide, and may be glued to the inner edges of the box, or it may be folded about two and a half inches back from the straight edge. It should be placed so that the first layer of oranges will rest upon it and hold it in position. Colored paper may be used, but pure white paper is very neat and attractive. An objection to colored paper is that a slight amount of moisture causes the color to run.

In order that the fruit may exactly fill the box, it must not only be sized properly, but each fruit must be placed in position in the box according to a definite arrangement. These arrangements are commonly referred to as diagrams. Each layer contains a certain number of fruit placed in position. The fruit in the next layer above should never rest directly upon the individual fruits in the layer below, but should be so placed as to come between two or more fruits with a tendency to spread them. When the spaces or joints are broken, the contents of the box are solidly packed and yet retain a certain amount of elasticity. 
SWEET

ORANGES

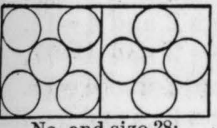

No, and size 28 .

Dia. $51 / 4$ in.; Layers 3

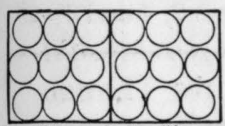

No. and size 54;

Dia. $41 \frac{1}{2}$ in.; Layers 3

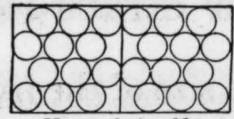

No. and size 96 ; Dia. $31 / 2$ in.; Layers 4

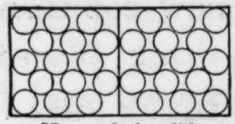

No. and size 150

Dia. $3 \frac{1}{16}$ in.; Layers 5

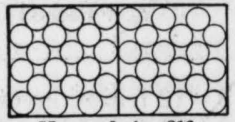

No, and size 216;

Dia. $2 \frac{11}{16}$ in.; Layers 6

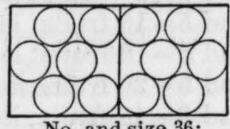

No. and size 36 ;

Dia. 5 in.: Layers 3

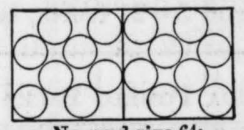

No. and size 64 ;

Dia. $4 \frac{1}{4}$ in.; Layers 4

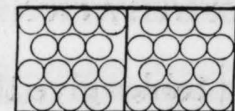

No. and size 112;

Dia. $3 \frac{1}{4}$ in.; Layers 4

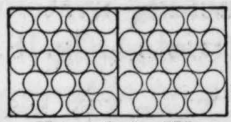

No. and size 176;

Dia. $2 \frac{25}{16}$ in.; Layers 5

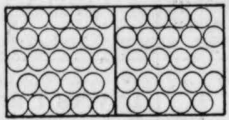

No. and size 226 ;

Dia. $2 \frac{9}{16}$ in.; Layers 5

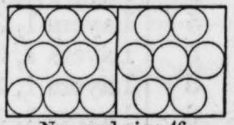

No. and size 46;

Dia. $4 \frac{3}{4}$ in.; Layers 3

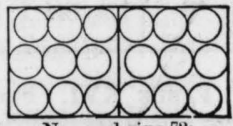

No. and size 72;

Dia. $4 \frac{1}{6} 8$ in.; Layers 4

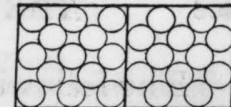

No, and size 126 :

Dia. $31 \%$ in.; Layers 5

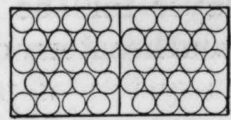

No and size 200

Dia. $2 \frac{3}{16}$ in.; Layers 5

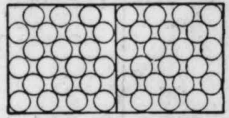

No. and size 252 ; Dia. $2 \frac{7}{16}$ in.: Layers 6

\section{POMELOS}

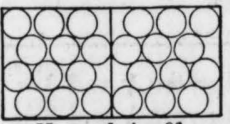

No and size 96;

No. and size 80 ;

Dia. 4 in.; Layers 4

Dia. 35 in.; Layers 4

MANDARIN

ORANGES

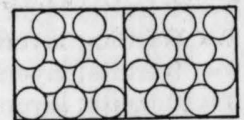

No. and size 60;

Dia. 31/2 in.; Layers 3

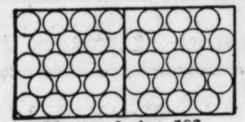

No. and size 106 Dia. $2 \%$ in.; Layers 3

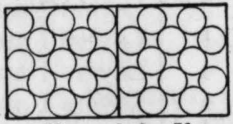

No and size 76 ; Dia. $3 \frac{1}{4}$ in.; Layers 3

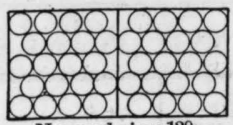

No and size 120; Dia. $2 \frac{1}{2}$ in.; Layers 3

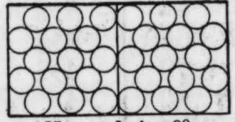

No. and size 90;

Dia. 3 in.; Layers 3

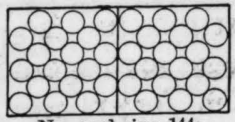

No. and size 144; Dia. $2 \frac{1}{4}$ in., Layers 4

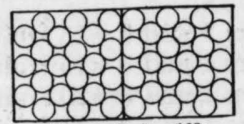

No. and size 168: Dia. $2 \frac{1}{2}$ in.; Layers 4

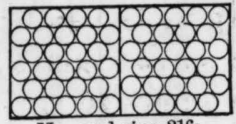

No and size 216;

Dia. $2 \frac{1}{4}$ in.; Layers 4

Fig. 181. Florida citrus fruit-packing diagrams 
The following tables give the size of the fruit, the number of layers, their arrangement, and the number of fruits in each layer for the packing systems now commonly used in the southeastern districts (Fig.181).

Table XV. Sweet Orange Packs

\begin{tabular}{r|c|c|c}
\hline \hline $\begin{array}{c}\text { No. and } \\
\text { Size }\end{array}$ & $\begin{array}{c}\text { Diameter } \\
\text { of Fruit }\end{array}$ & $\begin{array}{c}\text { No. of } \\
\text { Layers }\end{array}$ & How Packed \\
\cline { 2 - 4 } 96 & $31 / 2$ & 4 & Layers 1 and $3=12$ fruits; layers 2 and $4=12$. \\
112 & $31 / 4$ & 4 & Layers 1 and $3=14$ fruits; layers 2 and $4=14$. \\
126 & $31 / 8$ & 5 & Layers 1, 3 and $5=13$ fruits; layers 2 and $4=12$. \\
150 & $3 \frac{1}{16}$ & 5 & Layers 1, 3 and $5=15$ fruits; layers 2 and $4=15$. \\
176 & $2 \frac{15}{16}$ & 5 & Layers 1, 3 and $5=18$ fruits; layers 2 and $4=17$. \\
200 & $2 \frac{13}{16}$ & 5 & Layers 1, 3 and $5=20$ fruits; layers 2 and $4=20$. \\
216 & $2 \frac{11}{16}$ & 6 & Layers 1, 3 and $5=18$ fruits; layers 2, 4 and $6=18$. \\
226 & $2 \frac{9}{16}$ & 5 & Layers 1, 3 and $5=23$ fruits; layers 2 and $4=22$. \\
252 & $2 \frac{7}{16}$ & 6 & Layers 1, 3 and $5=21$ fruits; layers 2, 4 and $6=21$ \\
\hline
\end{tabular}

Table XVI. Florida Pomelo Packs

\begin{tabular}{|c|c|c|c|}
\hline$\underset{\text { Size }}{\text { No. and }}$ & $\begin{array}{l}\text { Diameter } \\
\text { of Fruit }\end{array}$ & $\begin{array}{l}\text { No. of } \\
\text { Layers }\end{array}$ & How Packed \\
\hline 28 & $51 / 4$ & 3 & Layers 1 and $3=5$ fruits; layer $2=4$. \\
\hline 36 & 5 & 3 & Layers 1 and $3=6$ fruits; layer $2=6$. \\
\hline 46 & $43 / 4$ & 3 & Layers 1 and $3=8$ fruits; layer $2=7$. \\
\hline 54 & $41 / 2$ & 3 & Layers 1 and $3=9$ fruits; layer $2=9$ \\
\hline 64 & $41 / 4$ & 4 & Layers 1 and $3=8$ fruits; layers 2 and $4=8$. \\
\hline 72 & $41 / 8$ & 4 & Layers 1 and $3=9$ fruits; layers 2 and $4=9$. \\
\hline 80 & 4 & 4 & Layers 1 and $3=10$ fruits; layers 2 and $4=10$. \\
\hline 96 & $3 \frac{5}{8}$ & 4 & Layers 1 and $3=12$ fruits; layers 2 and $4=12$. \\
\hline
\end{tabular}

Table XVII. Florida Satsuma Mandarin Packs

\begin{tabular}{|c|c|c|c|}
\hline $\begin{array}{l}\text { No. and } \\
\text { Size }\end{array}$ & $\begin{array}{l}\text { Diameter } \\
\text { of Fruit }\end{array}$ & $\begin{array}{l}\text { No. of } \\
\text { Layers }\end{array}$ & How Packed \\
\hline 76 & $31 / 4$ & 3 & Layers 1 and $3=13$ fruits; layer $2=12$. \\
\hline 90 & 3 & 3 & Layers 1 and $3=15$ fruits; layer $2=15$. \\
\hline 120 & $23 / 4$ & 3 & Layers 1 and $3=20$ fruits; layer $2=20$. \\
\hline 168 & $21 / 2$ & 4 & Layers 1 and $3=21$ fruits; layers 2 and $4=21$. \\
\hline 216 & $21 / 4$ & 4 & Layers 1 and $3=27$ fruits; layers 2 and $4=27$. \\
\hline
\end{tabular}


Table XVIII. Florida Mandarin Orange Packs

\begin{tabular}{|c|c|c|c|}
\hline $\begin{array}{l}\text { No. and } \\
\text { Size }\end{array}$ & $\begin{array}{l}\text { Diameter } \\
\text { of Fruit }\end{array}$ & $\begin{array}{l}\text { No. of } \\
\text { Layers }\end{array}$ & How Packed \\
\hline 60 & $31 / 2$ & 3 & Layers 1 and $3=10$ fruits; layer $2=10$. \\
\hline 76 & $31 / 4$ & 3 & Layers 1 and $3=13$ fruits; layer $2=12$. \\
\hline 90 & 3 & 3 & Layers 1 and $3=15$ fruits; layer $2=15$. \\
\hline 106 & $23 / 4$ & 3 & Layers 1 and $3=18$ fruits; layer $2=17$. \\
\hline 120 & $21 / 2$ & 3 & Layers 1 and $3=20$ fruits; layer $2=20$. \\
\hline 136 & $23 / 8$ & 3 & Layers 1 and $3=23$ fruits; layer $2=22$ \\
\hline 144 & $21 / 4$ & 4 & Layers 1 and $3=18$ fruits; layers 2 and $4=18$. \\
\hline
\end{tabular}

Table XIX. Lemons and Limes

\begin{tabular}{|c|c|c|c|}
\hline $\begin{array}{l}\text { No. and } \\
\text { Size }\end{array}$ & $\begin{array}{l}\text { Diameter } \\
\text { of Fruit }\end{array}$ & $\begin{array}{l}\text { No. of } \\
\text { Layers }\end{array}$ & How Packed \\
\hline 210 & $23 / 4$ & 5 & Each layer, 21 fruits. \\
\hline 250 & $25 / 8$ & 5 & Each layer, 25 fruits. \\
\hline 270 & $21 / 2$ & 5 & Each layer, 27 fruits. \\
\hline 300 & $23 \%$ & 5 & Each layer, 25 fruits. \\
\hline 360 & $21 / 4$ & 6 & Each layer, 30 fruits. \\
\hline 420 & $2-21 / 8$ & 6 & Each layer, 35 fruits. \\
\hline
\end{tabular}

Formerly, boxes of oranges and grapefruit were packed level, or with the fruit projecting about one-half to threefourths inch above the edges of the boxes. As the fruit was cured, this extra height was easily pressed down into the box when the head was put on, leaving it level with the top. After curing was discontinued, it became necessary to allow for shrinkage, and the bulge-pack came into use (Fig. 182). In packing boxes in this way, the larger fruits are selected and worked toward the center of the box. There is a slight variation in sizing the fruit, and this is taken advantage of to bring the center of the box to a greater height. When finished, the fruit in a well-packed box is practically level at the ends, but at the center it is sometimes up one to one and one-half inches above the sides of the box. Some packers even go to a greater extreme and pack it as high as two and one-half inches. It is best, however, to adhere to a reasonable 


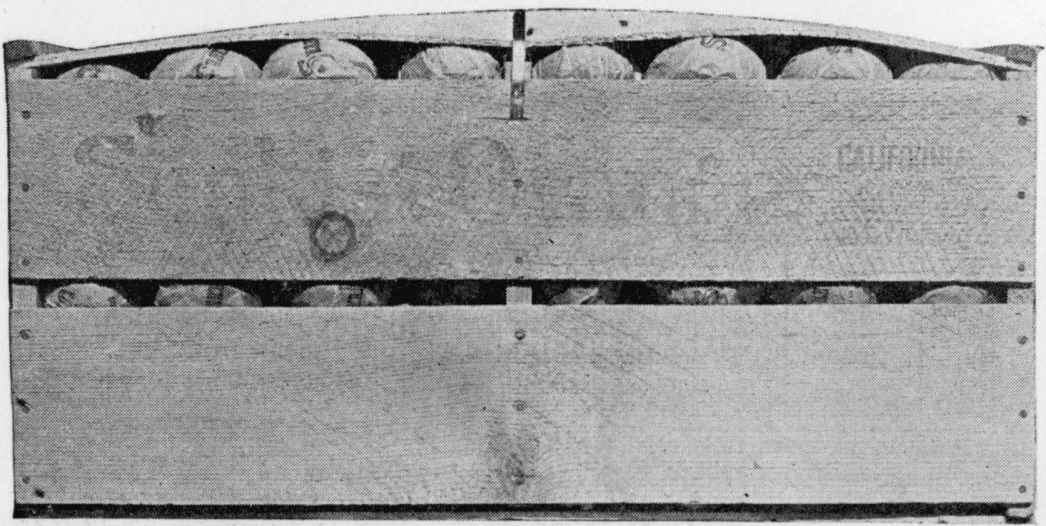

Fig. 182. Well-packed box of California oranges, showing amount of bulge

height. Much damage may be done to the fruit by exerting too much pressure to get the cover on. Sometimes the fruit is actually burst and it cannot, of course, arrive at the markets in any but a decayed condition.

As soon as the boxes come from the hands of the packers they go to the heading machine, or press. The cover is placed in position and the lever of the press brought down. In this way the ends of the cover are pressed into place and the operator nails them to the heads. Metal strips are bound around the box to keep the sides from being torn off in transit. (Fig. 183.)

Marking the boxes.

Each orange box is marked with the number of fruits, the grade, and the contents in bushels. The Florida box contains one and three-fifths bushels. The marking of the contents of the box is in accordance with the requirements of "Food Inspection Decision No. 157" issued July 25, 1924, which reads as follows:

Marking packages of citrus fruit under net-weight amendment.

DEAR SIR: In the enforcement of the net-weight amendment, this department is concerned with the quantity of the contents in a package 
and cannot undertake to advise a manufacturer of containers as to the labeling thereof, inasmuch as the containers may be used for a wide variety of products and under conditions over which the manufacturer of the containers has no control.

The statement of the quantity of the contents in the case of citrus fruits may be expressed in terms of dry measure as provided by paragraph $(e)$ of Food Inspection Decision 154. If the declaration is made in accordance with paragraph $(g)$, the statement of the number of oranges, or other fruit, which a given crate or box contains must be qualified by a

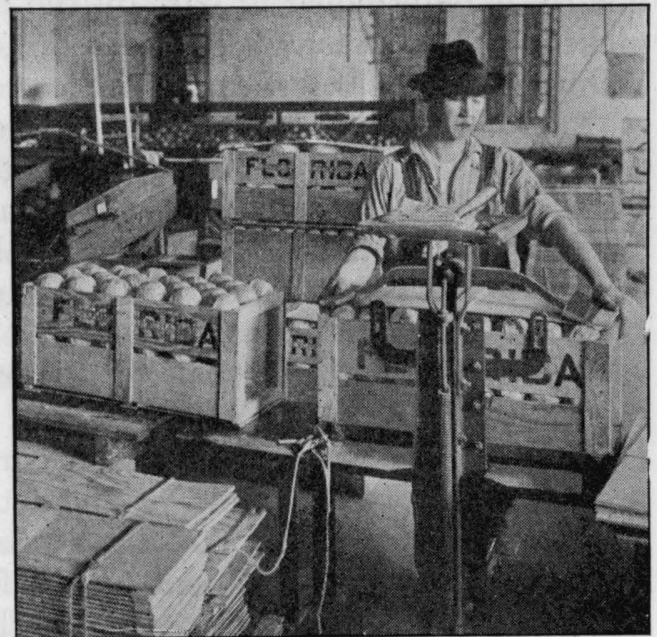

FIG. 183. Heading machine or press in use statement of the size of the fruit. This should be given in terms of the average diameter in inches, which it is believed may be easily determined by means of the "sizer" in accordance with the usual trade custom. A statement of the cubical capacity of a box as 3,456 cubic inches is not a statement of the quantity of the contents, neither is it in the terms of weight, measure, or numerical count as provided by the regulations.

Respectfully, C. F. Marvin, Acting Secretary of Agriculture.

On the ends of the boxes, labels, printed in several bright colors, are pasted. They indicate the grade, give the name of the packing-house, and where located.

\section{Grading and packing lemons. ${ }^{1}$}

The handling of lemons in the packing-house is a longer and more involved process than is necessary for oranges. Lemons are delivered at the packing-house in field-boxes and are washed shortly afterward. The fruit of each grower is

1 Mackay, A.W., U. S. Dept. of Agr. Department Bull. No. 1261, pp. 12-14. 
weighed as it is received and is stacked. After it is washed, the fruit is separated according to color. The keeping quality is determined in part by the color at the time it is picked, and color is also an indication of the length of time it must be cured before shipment.

The most desirable fruit is dark green when picked; but light green lemons may be of equally good quality, although they cannot be stored for as long a period. "Tree-ripe" lemons have attained a deep yellow color on the tree. Fruit of this grade must be shipped within two or three weeks after it is harvested.

Light green fruit is usually cured for about a month but may be held for two months without great danger of loss. Dark green fruit is generally well cured in six weeks, and present practice is to ship it at about the end of this period. However, dark green lemons have been held in the curingroom as long as five to six months, and formerly three months was not an exceptional period. At the end of the curing period, lemons that were light or dark green when first stored are a light yellow color, the skin has become thin and flexible, and the juice-content of the fruit has increased greatly.

Lemons are placed loosely in packing-boxes after they are washed and are transferred with hand trucks to the curing-rooms. Often the fruit is cured in the basement, but sometimes a portion of the main floor of the packing-house is also used as a curing-space. The identity of each lot of fruit is maintained during the curing process.

In the grading-room the fruit is sorted, after curing, into shallow wooden trays and separated into the various grades which the association ships. The fruit is again weighed and loses its identity at this point. Each grower is paid on the basis of the weight here recorded. The trays are trucked, or in some instances moved by conveyors, to the packing-room.

Mechanical sizers for lemons have been only indifferently successful on account of the irregular shape of the fruit, and lemons are almost universally sized by hand labor. More 
skill and time are required to pack a box of lemons than a box of oranges on account of the irregular shape of the lemon, the fact that the fruit is uniformly smaller, and because the packer must select the fruit according to size. Labor costs for this operation average 11 cents a box, compared with $51 / 2$ cents for packing oranges. Lemon sizes range from 270 to the box, sometimes larger, to 442,490 , or smaller. The socalled standard sizes, 300 and 360 , comprise the larger proportion of the fruit shipped. The 270 size is fairly common, and a small percentage in a shipment is not objectionable on many markets. Because lemons are sized roughly when they are picked, there are comparatively few commercial sizes.

\section{Coloring citrus fruits.}

The color of ripe fruit is valuable. All citrus fruits can be sold to best advantage when the skin shows its normal ripe color-lemon-yellow, pomelo-yellow, tangerine-red, or orange, as the case may be. Green color, suggesting immaturity, is decidedly against satisfactory merchandizing, and this is more particularly true in recent years or since an active campaign against green fruit was inaugurated. As the fruit reaches full size, large numbers of minute yellow-, orange- or red-colored bodies develop in the outer cells of the rind. At first these are masked by the green of the chlorophyll present, but as the ripening and coloring process advances, the chlorophyll loses its green color and the yellow- or orange-colored pigment in the rind shows up. Under natural conditions, these changes seemingly are hastened by the cool weather of early fall. It is commonly stated by growers that cold weather aids in ripening the fruit, but this does not help very much the coloring of early fruit.

Unfortunately, certain early or very early varieties of oranges are satisfactory and desirable for food when their skins are only slightly colored or still green; in short, they 
are ripe inside and green outside. Sometimes, if left on the trees to become tree-ripe and fully colored, their eating quality is not so good as though they had been picked and used at an earlier date. They are then insipid because the proportion of acid becomes too low. This often applies to such varieties as Boone, Parson Brown, and Satsuma. Late fruit also may be partly green, although mature. The best grade of lemons must always be picked while still green. Tree-ripened fruit is thick-skinned and not so juicy. Growers avoid the larger and less juicy lemon fruit by picking frequently, the trees usually being gone over at intervals of a month.

Before being marketed, lemons have always been handled so as to develop normal yellow color. Formerly this was accomplished by placing the fruit in canvas-inclosed spaces within the packing-house, and a period of several weeks was required. It was believed that heat and moisture played an important part in the coloring process, and, at times, oldfashioned kerosene oil-stoves with incomplete combustion were used to raise the temperature. These stoves greatly accelerated the coloring. Later it was determined by Sievers and True $^{1}$ that the pungent gases generated by the stoves were the real factor in coloring lemons and not the heat. Since this discovery, the curing and coloring of lemons have been so perfected as to bring the whole process practically under control. The time can be shortened at will from several weeks to a few days. The same processes are now successfully applied to the coloring of early oranges, and it has been found that exhaust gases from gasoline engines may be used instead of those generated by kerosene stoves.

Preferably, the coloring-room should be of brick, concrete, or stone, gas-tight, and built a distance from the

1 A Preliminary Study of the Forced Curing of Lemons as Practiced in California. Bull. No. 232, Bureau Plant Industry, U. S. Dept. Agr., Washington, D. C., Feb. 13, 1912. 
packing-house as a safeguard against fire. The doors should either be double or of the refrigerator type. An unloading platform along one side is essential. Provision should be made for quickly and thoroughly ventilating the room. This can be done best by providing ventilators through the ceiling and roof and openings spaced at intervals just at the floor. The floor should be on the same level as the packinghouse and connected with it by an elevated platform for convenience in handling fruit. This passage may be constructed so that it can be taken down or put in place at will. The stove-room, if stoves are used, should be separate from the fruit-room, or built with concrete walls and ceiling within it. From the stove-room the gases are forced through a large conduit into the fruit-room with a blower. A fruitcoloring room should be of sufficient size to hold a car of fruit in the field-boxes, with enough space added for handling the fruit and for gas circulation. Thirty-five hundred cubic feet capacity is about right, and as many rooms should be built as are necessary for the crop.

Fruit, to color well, should have reached a certain degree of maturity. If it is too green it will not develop normal color. Oranges do not improve in quality during the process; coloring adds nothing to them except color, hence they must be good to eat before picking. In any case, fruit must be ripe enough to meet state and national maturity tests. More than usual care must be taken in harvesting. Oil liberated from the rind may spot the fruit. The least abrasion or bruise shows up as a green or greenish area, and the fruit comes from the curing-room spotted and unsightly. If the fruit at the time of ripening is in several stages or degrees of color on the trees, it should be graded as to color in picking and handled separately. Fruit which is partially colored will require much less time to color than that which is still entirely green. Depending on the degree of maturity of the fruit, it can be fully colored in three to four and up to fifteen days. Fruit 50 per cent colored at time of picking 
will require the shorter time, while green fruit will require a longer period. To develop desirable color on greener fruit, it should be processed slowly, and it may be advisable to resort to fractional treatment, the fruit being gassed two to three hours forenoon and afternoon for several days. It is also advisable, in many cases, to gas the fruit only during the day and open up and ventilate the coloring-room during the night. Fruit can be taken directly from the grove to the coloring-room in field boxes and stacked five or six tiers high.

The amount of gas required is not great. Two or three burners of the cook-stove size are sufficient for one room. The ventilation and draft of the burners should be cut off or reduced with a perforated sheet-metal disk placed close down to the flame. This increases the amount of gas generated because of incomplete combustion. A temperature of $75^{\circ}$ Fahr. is regarded as the optimum, with a variation of $5^{\circ}$ above and $4^{\circ}$ below permitted. Humidity, bearing a relation to shrinking or shriveling of the fruit, and apparently to the dropping of the stems or "buttons," should be maintained at about 80 per cent. In dry weather, moisture may be added to the air in the coloring-room by sprinkling the floor, hanging up wet burlap sacks, or using a humidifier. ${ }^{1}$ This latter consists of a sheet-metal box in which cloths, acting as wicks, are suspended in water. These cloths are inclosed in a tin box and air is driven through and between them with a blower. The moisture-laden air is thus distributed through the curing-room.

Experience gained by actual work in coloring is the most reliable guide in handling fruit. Each separate lot may require somewhat different treatment and great care must be exercised. Unless carefully and intelligently done, the coloring of fruit by gassing may cause much loss. It should be picked and handled with more than usual care.

${ }^{1}$ Shamel, A. D. A Humidifier for Lemon Curing-Rooms. Bull. No. 494, Bureau Plant Industry, U. S. Dept. Agr., Washington, D. C., Jan. 16, 1917. 


\section{Pre-cooling and refrigeration.}

It has been learned that decay in transit is greatly lessened if the fruit is cooled and the car in which it is shipped is cold before loading.

A great part of the orange and grapefruit crop is shipped under refrigeration. Cars are iced in advance of loading, to lower the inside temperature. The bunkers of a refrigerator car hold from two to two and one-half tons of ice. Twentyfour to forty-eight hours are usually required to bring the temperature down to the proper point.

In addition, the fruit should also be cooled. This can be done by placing it in a refrigerator or cold room a sufficient length of time to lower its temperature to the necessary point for shipment. Sometimes this cooling of the fruit and of the inside of the car is accomplished by conducting cold air from a refrigeration room into the car for a sufficient period to lower the temperature to the required degree. Practically all citrus fruit is shipped in refrigerator cars. These are a great safeguard against fluctuations in temperature. If the outside temperature is high, cars should be iced before loading or before leaving the packing plant, and additional ice put in the bunkers while the car is in transit. During the cold season it is usual not to ice the cars, and the ventilators are left open until they reach a section in which there is danger of freezing. Lemons are neither pre-cooled nor shipped under refrigeration.

\section{Loading.}

The fruit is taken on trucks from the packing-house to the car, a stack of four boxes being handled at one time. (Fig. 184.) In the car the boxes are placed on end, six boxes crosswise of the car, and two tiers deep. A forty-foot car will hold 384 boxes; in a car thirty-three feet long, 360 boxes is the usual load. Heavier loading has been attempted at times by placing a third row of boxes flat-wise on top, but 
the results have been unsatisfactory and the practice is not advised. (Figs. 185, 186.)

Each tier of boxes is fastened in place with thin strips of

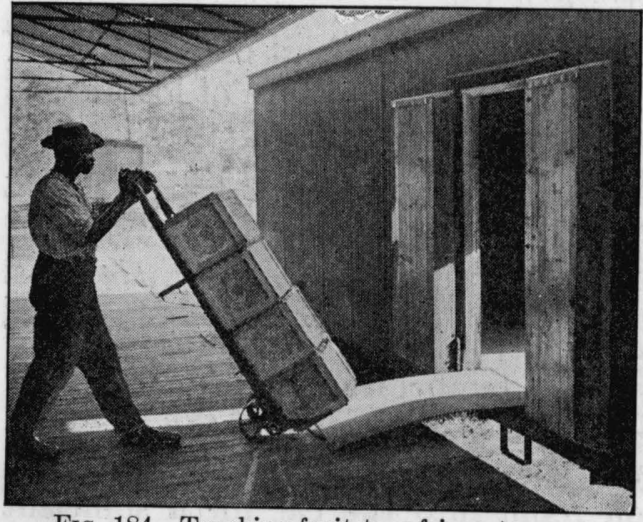

FIG. 184. Trucking fruit to refrigerator car wood, commonly referred to as car-strips, extending cross-wise of the car and nailed to the ends of the boxes. To do this properly two strips should be placed across each tier. A car "squeeze" is used to tighten the boxes into place and to take up the slack space.

\section{MARKETING CITRUS FRUITS}

More attention has been given to production than to marketing. When crops were smaller than the demand, all went well, but when their volume increased so that it equaled or exceeded demand, trouble began. The real reason for growing citrus fruits is to secure a livelihood and to make a profit, but too frequently there has been loss instead of gain. The marketing system has been largely at fault.

On the other hand, the grower has been to blame in some cases. Frequently the fruit has not been of such quality as to command a good or even a fair price. Good fruit stimulates demand. If the quality is good and the appearance fine, more can be sold to advantage than if it is inferior stock. All over the citrus districts it is incumbent on growers to put forth every effort to produce a high-grade product. Well grown is well sold.

There have been several crises in the marketing of citrus 


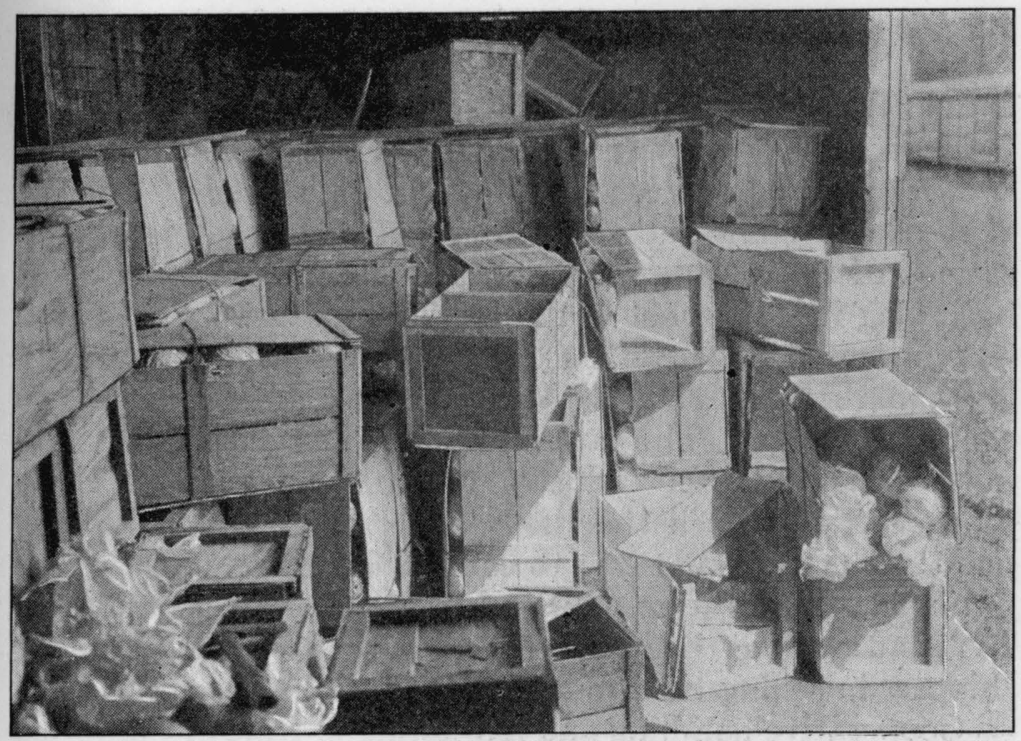

Fig. 185. Condition of improperly loaded and braced car on arrival in market

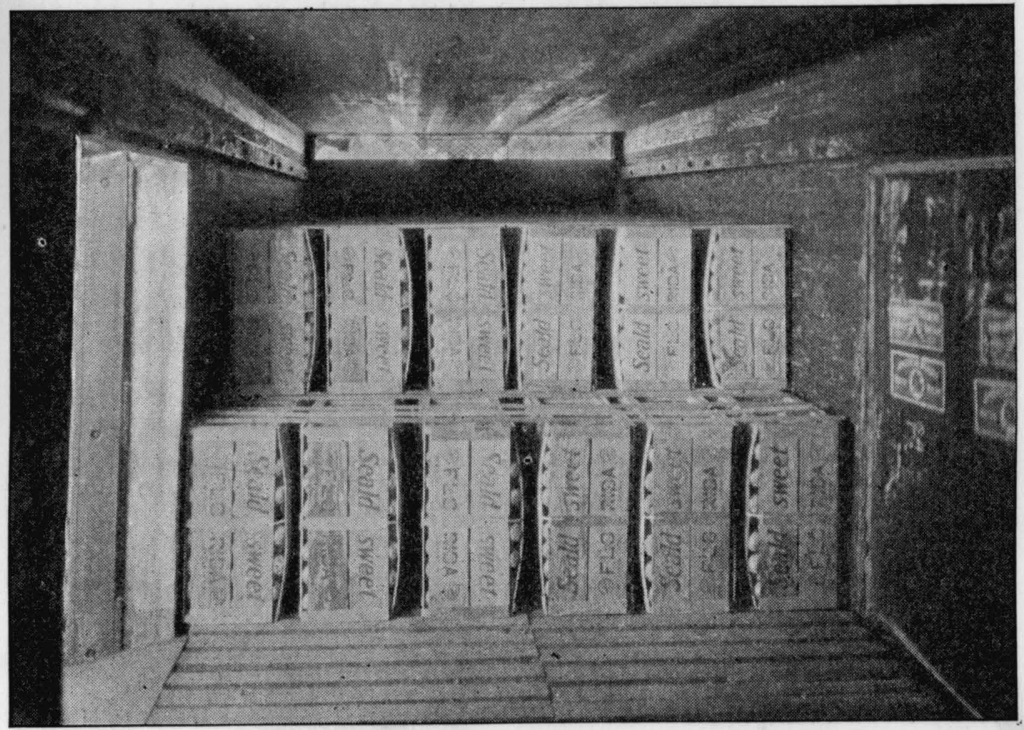

Fig. 186. Interior of well-loaded car on arrival at destination

(417) 
fruits. One of these brought about the organization of the California Fruit Growers' Exchange. Today, controlling as it does about 75 per cent of the California output, it is one of the outstanding successful cooperative marketing organizations of the world. Commercial fruit production had its beginning in California in the early 80's. In 1883, the crop was estimated at a little over 200,000 boxes. As the industry grew, marketing difficulties were encountered. There was no concerted action. The large markets were far distant and in the early 90's the industry became unprofitable. Some growers tried to sell their fruit for cash, f. o. b. shipping point; some of it went east to commission merchants on consignment; many crops brought the producers nothing. Distribution was bad and there was competition among shippers in selling the product.

Cooperative handling and marketing of fruit in California began with the organization of the Claremont California Fruit Growers' Association, which first operated in the season of 1892-93. Two or three other associations were organized about the same time, but it was the first to undertake the packing, shipping, and marketing of citrus fruit. During the summer of 1893, the Southern California Fruit Exchange was organized and began operations the following season (1893-94).

In 1903, the Southern California Fruit Exchange and a commercial shippers' association, known as the California Citrus Union, were combined into a single selling organization known as the California Fruit Agency. This combination did not work well, and it was discontinued September 1, 1904. The Southern California Fruit Exchange continued to operate. In 1905, the name California Fruit Growers' Exchange was adopted as more in keeping with the development of the industry.

The California Fruit Growers' Exchange consists at this time of twenty district exchanges and one hundred and ninety-two local exchanges. Most of the latter are co- 
operative associations controlled by a board of five to seven directors elected annually by the membership. This board of directors manages the affairs of the local exchange, picks and packs the fruit, operates the packing-house, hires the manager, and attends to all necessary local details of preparing the fruit for market. The packing-houses are built and equipped by the local exchange members, the expense usually being distributed over a considerable length of time. In addition to these cooperatively organized local exchanges, certain large corporations and individuals who own and operate their own packing-houses and handle their own fruit, are affiliated with the exchange on the same basis as the local associations.

The district exchanges are organized from the local exchanges, and the number of the latter represented in a district exchange is variable. About ten is the average number, though there may be as few as two and as many as twenty. The affairs of the district exchange are managed by a board of directors, each member of which has been elected by and represents a local exchange, and are in charge of a manager, under the direction of the board of directors. The district manager is the fruit sales agent for the local exchanges under his jurisdiction, and in cooperation with the central exchange performs all the duties incident to that office.

One director elected from each of the district exchanges forms the board of directors of the California Fruit Growers' Exchange. They elect the president, general manager, sales manager, and other officers. Thus it will be seen that the entire structure of the exchange is in the hands of the growers themselves. The expenses of the whole organization are met by a levy of so much a box on the fruit handled.

In the Exchange there are several departments, each in charge of a head or manager. The principal ones are sales, advertising, legal, accounting, field, and service. Each of 
these has a definite field of work to handle, both for the present and future good of the Exchange.

The traffic department looks after all details pertaining to transportation and keeps the district and local exchanges advised on freight rates, embargoes, routing, car supply, and the like. All claims for loss and damage are handled by it, in conjunction with the legal department.

The advertising department has charge of all advertising, preparing copy and placing it in newspapers and magazines. It also prepares posters for use in sales campaigns in different cities, and it has aided greatly in securing wider distribution and increased consumption. In 1921, the sum of $\$ 855,798$ was spent in advertising. This would have been impossible under any other system of marketing. If the handling of the crop had been in the hands of brokers and packers, this fund probably would never have been used and the demand would not have been sufficient to take care of the crop. The usual annual average amount is about $\$ 800,000$, and the whole advertising plan centers about the Exchange brands "Sunkist" and "Red Ball."

The legal department takes care of all legal matters that arise in connection with the work of the Exchange. Many details are involved in the making of contracts, conforming to different laws, and defending suits which may be brought against the Exchange.

The accounting department manages the business affairs of the Exchange. It also prepares data on the expenses of all fruit-handling transactions.

The field department has in charge all details pertaining to the production of better fruit and picking, grading, and packing it for shipment.

Because citrus fruit-growers felt they were not receiving satisfactory returns for their fruit, the Florida Citrus Exchange was organized under a charter granted by the state July 20, 1909. This was largely brought about by the late Dr. W. F. Inman who headed a party of Florida growers on 
a visit to California to investigate the workings of the California Exchange. The Florida Citrus Exchange is modeled along the same lines as the California organization and operates on the same general plan. There are twelve sub or district exchanges in the organization at this time (1925).

The Florida Citrus Exchange has met with much competition in handling fruit, in many cases directed toward getting fruit to ship and not at securing higher prices for the crop. This does not mean that there are not privately operated marketing concerns of high standing in Florida, but there has been too much competition within the state in the marketing of the citrus crop. The Florida Citrus Exchange has never controlled so large a percentage of the crop as has its model in California. When the shipping season of 1923-24 opened, with the largest crop the state had ever produced, there were said to have been about one hundred and forty marketing agencies, big and little, handling Florida fruit. The competition was disastrous and the result chaos. The Exchange itself was in some measure to blame, because it had not made adequate preparations for its share of the crop that was coming. Some markets were glutted with Florida fruit; some were bare. There had not been any state-wide preparation for handling the crop, and a very large percentage of the growers got no returns. Too many agencies were in the field and no concerted action in the interest of the industry. The number has since been

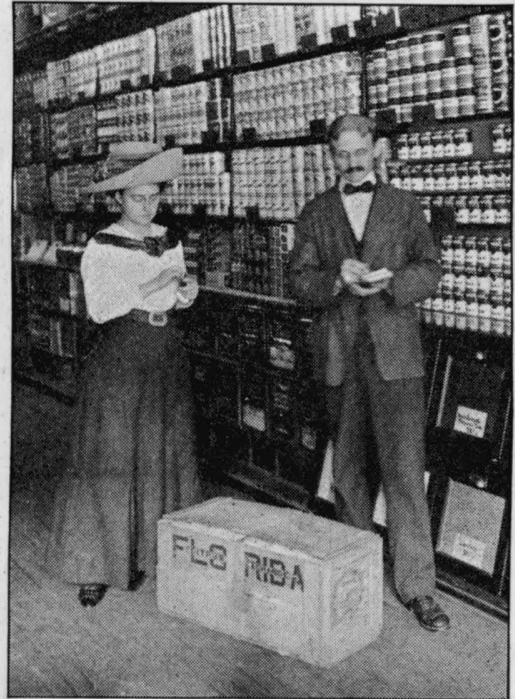

FIG. 187. Selling citrus fruit by box from grocery 
reduced and in the season 1924-25 the Florida Citrus Exchange handled sixty per cent of the fruit shipped. There is still too much competition among selling agencies.

Through organizations such as the Florida Citrus Exchange and the California Fruit Growers' Exchange it is possible carefully and widely to distribute the fruit, collect information on markets, market conditions, and ruling prices in all the markets, advertise the fruit and secure for it a wider distribution and greater consumption. Many growers acting through a single marketing agency can secure results in selling fruit which would not be possible if acting as individuals.

Methods of selling.

The citrus fruit crop is sold in a number of different ways. (1) It is sometimes sold on the tree to packers or speculators at a fixed price a box or for a lump sum for the crop in a

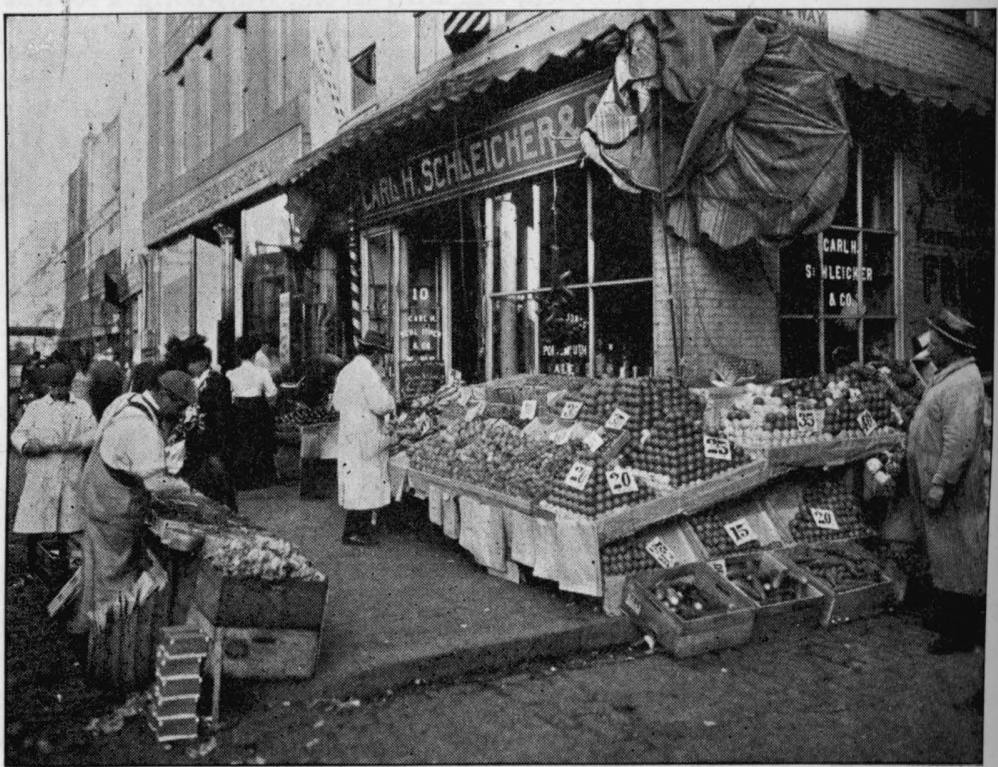

FIG. 188. The street-corner fruit-stand 
grove. (2) It is consigned to commission merchants in different cities. (3) It is sold f. o. b. shipping point to wholesale dealers in fruit. (4) It is sold in small lots of one box or more to a private trade. (5) It is handled by cooperative marketing agencies such as the California Fruit Growers' Exchange and the Florida Citrus Exchange.

The Exchanges maintain selling organizations in the larger centers of population and work through brokers or jobbers in smaller ones. For example, the California Fruit Growers' Exchange, for the season 1923-24, had fifty-two sales offices in the United States and Canada, besides jobbers in the smaller centers. It is the duty of these sales offices to look after distribution and to see that each center of consumption receives its proper quota of fruit daily and weekly throughout the entire season. They check the condition of the fruit on arrival, oversee the sales end of Exchange activities, and are constantly on the alert in increasing fruit consumption in every legitimate way.

The wholesale handling of fruit in the markets is in the hands of fruit-brokers, commission-men, and auction houses. It is from them that the local retail dealers secure their supplies daily. From these same sources distribution is made from the larger centers to outlying towns and villages.

Auction houses are operated in some of the larger cities, and fruit is shipped to these and sold to the highest bidder. Sample boxes from different car lots are opened and placed on display in the show-room, for in-

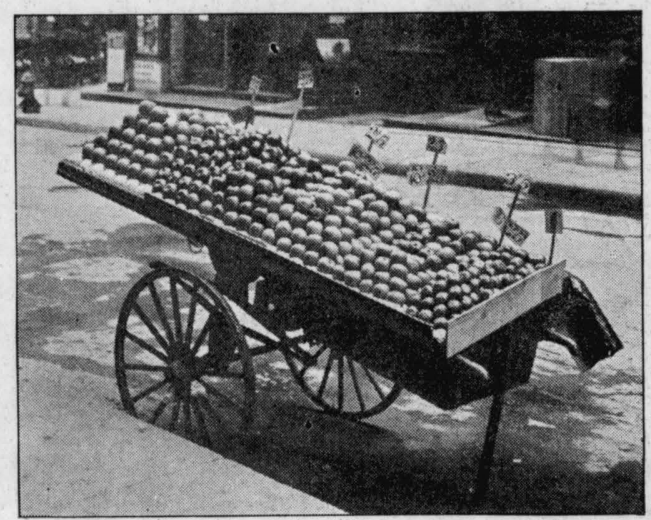

FIG. 189. The push-cart market 
spection by prospective buyers, and each lot is numbered. At a certain hour each day the market is opened and the fruit on hand is sold, either in car lots or in smaller lots. If the market is short, competition among bidders is keen and high prices prevail; if fruit is plentiful, the bidding is slack and the price drops.

Final distribution of citrus fruits is handled by fruitstores, grocers, street fruit-stands, and push-cart dealers. (Figs. 187-189.) Each reaches a certain more or less distinct kind of trade, and through these channels the fruit goes out to every class of people. It is handled by the box, by the dozen, or by the single fruit, and each dealer calls for a certain grade or for fruit which may be sold at a certain price. There was a time, not so many years ago, when oranges were seen only during the holiday season, at Thanksgiving and Christmas, but now they are to be had the year round. So, also, are lemons, while grapefruit and limes are absent from the markets for short periods only. No doubt, the increased consumption of these fruits has been a worthwhile factor in improving the health of the nation. 


\section{CHAPTER XXVIII}

\section{INSECTS INJURIOUS TO CITRUS TREES}

Insects attacking citrus trees may conveniently be grouped as biting and sucking. The first group, including the grasshoppers, orange-dog, and a few other insects of less importance, injure the trees by eating the foliage and other tender parts. Sucking insects, however, obtain their food from the trees by sucking the juices out of the cells. Many of them also inject poison into the tissues which assists in destroying the cells. The members of this second group are far more numerous than those of the first; in fact, the most dreaded insect enemies of citrus trees belong here. This group may be further divided into scale insects and insects other than scales, the latter embracing the whitefly and different kinds of mites. The scale insects may be divided into armored or protected scales and unarmored or unprotected scales. Armored scales have a protective covering and are unable to move about after having once settled themselves in a certain position. The unarmored scales have no hard covering and are motile during the greater part of their existence, moving freely while young but in a very limited way when mature. A graphic outline of the groups of more important citrus insects described is:

I. Biting Insects: (a) Grasshoppers, (b) katydids, (c)

II. Sucking Insects:

$$
\text { orange-dog, }(d) \text { ants. }
$$

(1) Scales- $(e)$ armored scales, $(f)$ unarmored scales.

(2) Insects other than scales- $(g)$ whiteflies, aphids,

(h) citrus mites, thrips, (i) pumpkin bugs.

Those insects which feed by biting off and chewing portions of the plant can be destroyed by putting a poisonous substance on the part attacked; not so with those which 
obtain their nourishment by sucking the juices of the plant. These can only be destroyed by spraying over them some penetrating or sticky substance, such as oil emulsion, whale-

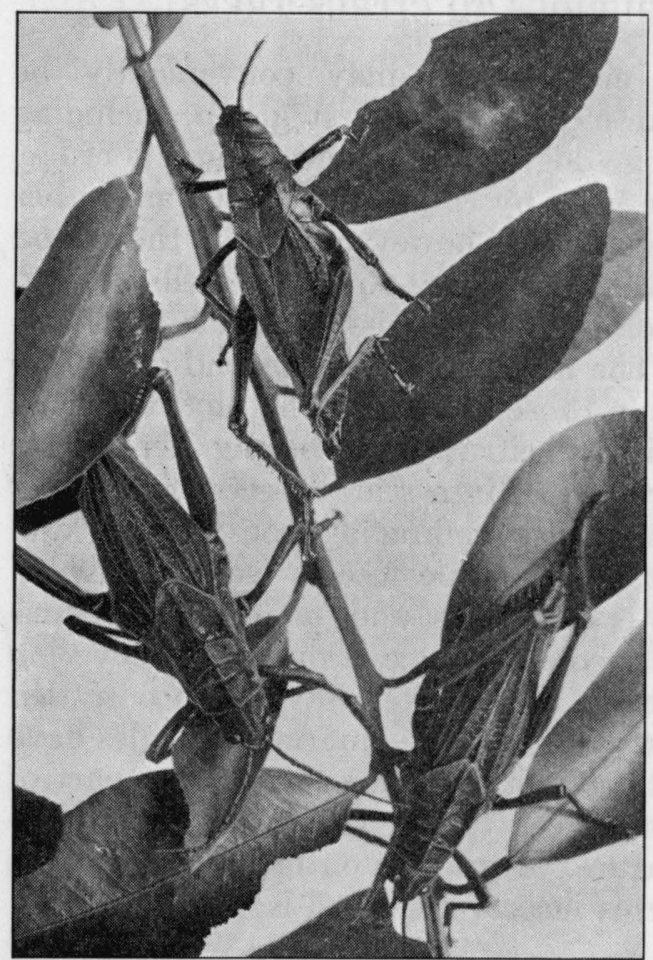

FIG. 190. The lubberly grasshopper eating citrus leaves

oil soap, or kerosene emulsion which will enter their bodies through the walls or close out the air by plastering them under.

Poisonous gases, liberated under tents over the trees, suffocate them, and fine powders, such as pyrethrum, prevent their breathing by stopping up their spiracles.

BITING INSECTS

Grasshoppers and katydids.

(Figs. 190-192.)

Grasshoppers are often responsible for considerable injury to citrus trees. In the southeastern districts three species do most of the damage. These are the lubberly grasshopper (Dictyophorus reticulatus), the bird grasshopper (Schistocerca seralis), and the yellow-lined grasshopper (Schistocerca aleutacea). If grass- or pasture-lands adjoin the grove, grasshoppers frequently start there, but finding citrus trees more to their liking, they often attack the adjacent outside row of trees and gradually spread throughout the planting. 
Very serious injury may be done, particularly to young trees and to nursery stock. The foliage and tender twigs are eaten first, but small trees may be entirely stripped of their leaves. If they attack bearing trees when the fruit is young, considerable damage may result. Pieces are bitten out of the side of the fruit and as it increases in size, large, depressed scurfy spots are formed. These render the fruit unsalable or reduce its grade. Some of the young fruits drop off when injured. Flower-buds are also eaten.

Katydids, closely related to grasshoppers, injure citrus trees in much the same way. They eat the flowers, foliage, and tender twigs, and scar the fruit so as to render it unsalable. At times they have caused the loss of much fruit, in some cases as

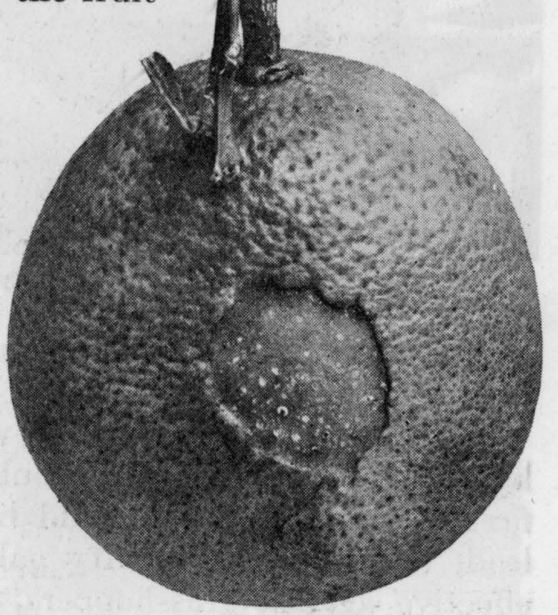

FIg. 191. Katydid injury to an orange much as 57 per cent. Over considerable areas in California the loss has amounted to 8 or 10 per cent of the crop. In Florida, the damage, though considerable, is not so great, perhaps because of the greater amounts of other food materials available. The species mainly concerned in injury to citrus are the forked-tailed katydid (Scudderia furcata) and, to a much lesser extent, the angular-winged katydid (Microcentrum rhombifolium). In Florida districts, the broad-winged katydid (Crytophyllus concavus) and another angular-winged species (Microcentrum retinerve) are fairly common. All these insects are green in color, closely resembling the leaves in shade, and, consequently, difficult to see. The eggs are laid either on the edges of the leaves (C. concavus) or on twigs in two or three rows $(M$. retinerve 


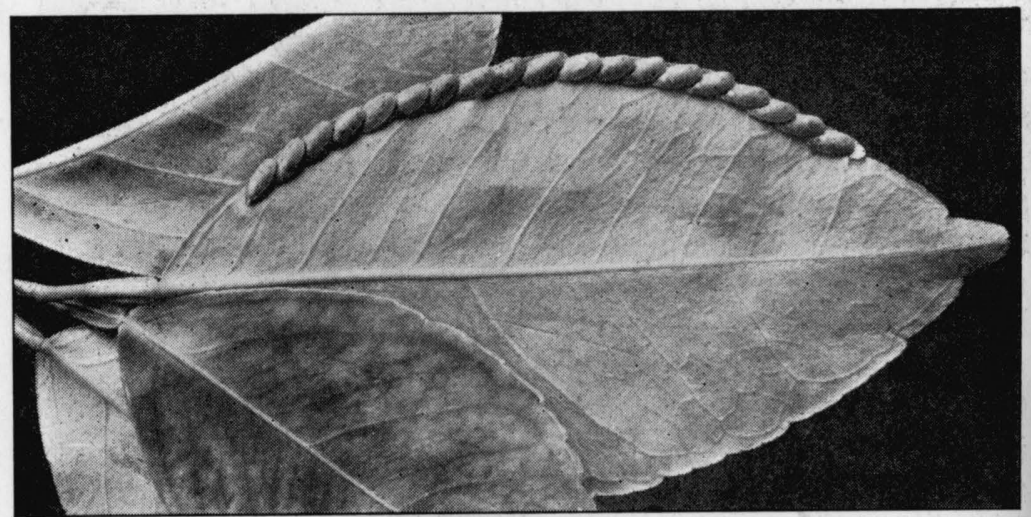

FIG. 192. Eggs of the broad-winged katydid on the margin of an orange leaf

and $M$. rhombifolium) or within the tissue at the edge between the two surfaces of the leaf (S. furcata).

Treatment.-In sections in which groves are subject to katydid injury, the trees should be watched carefully. At first appearance they should be sprayed with arsenate of lead, three pounds to fifty gallons of water. This is also effective against grasshoppers, though they may be killed with poisoned bait (Formula No. 12). This should be placed on lands or in grass where they are present. The bait should be scattered early in the morning, so as to be ready for the grasshoppers when they begin feeding.

The orange-dog (Papilio cresphontes Cramer).

Frequently a large disagreeable-looking caterpillar, $21 / 2$ inches or slightly more in length, may be observed feeding on the leaves of citrus trees. It is dark brownish black in color and marked with large blotches of a dirty white color on the posterior end, the sixth and seventh segments and the sides of the head. The anterior end is much enlarged and when at rest the mouth-parts are drawn in under it, as shown in Fig. 193. When irritated or disturbed, the insect protrudes a pair of golden colored horn-like feelers, emitting 


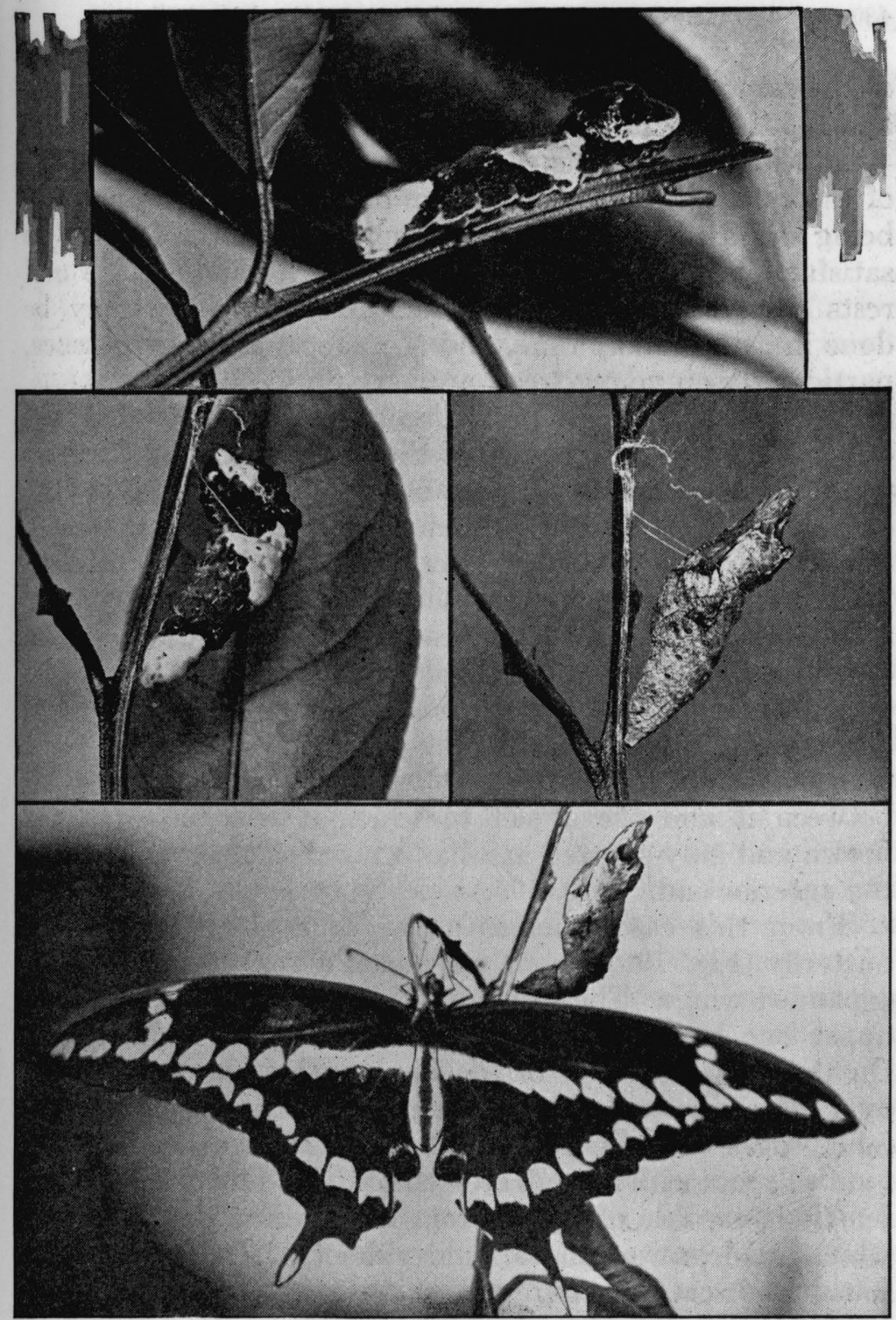

FIG. 193. The orange-dog; larva, larva preparing to pupate, pupa, the butterfly which has just issued from the pupa case above it 
at the same time a liquid having an exceedingly disagreeable and repellant odor.

It is in the larval stage that damage is done. The appetite of the caterpillar is enormous, an ordinary sized orange leaf being disposed of in about five minutes. After feeding to satisfaction, the caterpillar retreats to a shady place and rests until its next feeding-time. Much damage may be done in a very short time, and the effects of their presence, particularly on young trees, are very noticeable.

The larva, when full grown, seeks out some secluded spot on the side of a limb or leaves the tree entirely, making its way to an adjacent tree, stake, or fence. There it enters the chrysalis stage. First an attachment is made by means of a matted web joining the posterior end to the chosen place. Then a strand of silk is attached to the support, passed around the body, and with head upward and the body inclining outward at an angle of about 45 degrees, it spends its period of pupation, lasting from twelve to seventeen days, depending somewhat on weather conditions. The chrysalis is inconspicuous on account of the strong similarity in color between it and the object to which it is attached. It is brown and gray-spotted and has a number of projections on the anterior end. (Fig. 193.)

From this case emerges a gorgeous black and yellow butterfly (Fig. 193), about six inches across the tips of the expanded wings. The yellow markings form two bands, the upper one crescent-shaped, the lower almost semicircular. On the projecting tips of the hinder wings are two yellow oval spots surrounded by a margin of black, and at the rear inner edges of the same pair of wings are two brownish or reddish spots with a small crescent of blue dots above. Each female is capable of laying from four to five hundred eggs, which are deposited on the tender shoots. There are usually four broods each season.

Treatment.-Hand-picking of eggs and caterpillars may be practiced. Formula No. 11 or paris green, at the rate of 
four ounces to fifty gallons of water, may be sprayed on the foliage when the larvæ are present. Hubbard recommends shooting the butterflies. Besides citrus trees, the caterpillar feeds on zanthoxylum, ptelea, and some other trees.

Ants.

Different species of ants are often responsible for insect troubles in orange groves. When ants are active in citrus trees, running up and down the trunks and out along the branches, the trees should be examined carefully for insects, such as soft scales and mealy-bugs.

Ants feed on the honey-dew (it contains a large percentage of sugar) excreted by the mealy-bugs and related pests. They protect them from enemies and move them from one place to another. Some ants cut tender shoots and leaves and carry away the pieces. In this way they do material damage, particularly to newly planted and young trees.

When ants are present they should be destroyed if possible. If their nests can be found, it is comparatively simple. With a sharp stick make several holes in the nest (the number will depend on its size), and into each of these pour a few tablespoonfuls of carbon bisulfide or calcium cyanide dust; cover or fill the holes with soil and pack with the feet. Care must be taken with both these materials not to use in quantity close up to the trunks of small or young trees for fear of damaging them. Constant vigilance and attention are required to keep ants in check.

Ants may also be poisoned by using a poison bait, Formula No. 13. Place a tablespoonful of the liquid in a tin can, such as a baking-powder tin, to protect it from rain; punch two holes in the top to allow the ants to go in and out and place the can where the ants can easily reach its contents. They carry the poison bait to their nests and feed their young upon it and in this way the whole nest or colony can be exterminated completely. 


\section{ARMORED SCALES}

The purple scale (Lepidosophes beckii Newm.).

This is one of the commonest and most conspicuous citrus scales in Florida. The insect is widely known wherever the orange is grown, either in America, or abroad. Hubbard observed, in 1885, that the purple scale was more abundant in the northern than in the southern portions of the orange belt. The freezes since that time have reversed this order of distribution.

The scale of this species is one of the largest in the genus, that of mature females sometimes reaching a length of 0.12

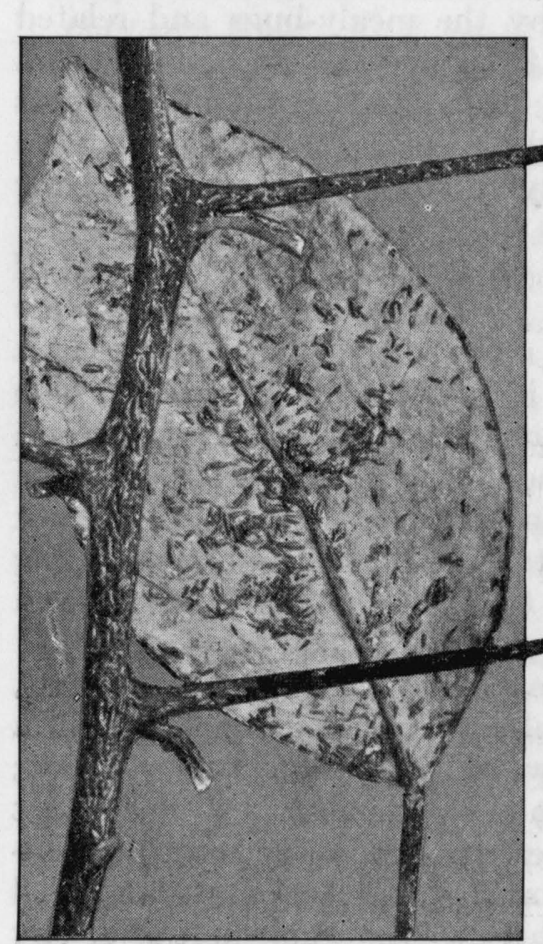

Fig. 194. The purple scale on citrus twig and leaf of an inch (3 mm.), and that of the male 0.05 of an inch (1.4 mm.). The name "oyster-shell bark-louse" has been applied to a closely related scale insect, Mytilaspis pomorum, a common apple pest, because the general outline of the scale, together with its ridgings and markings, are suggestive of an oyster-shell in miniature; the purple scale, $L$. beckii, and in lesser degree, the long scale, $L$. gloverii, share this resemblance, and it is not uncommon to hear "oystershell bark-louse," applied to any one of them by the general public. The form may be described as broadly trumpet-shaped, increasing 
in width behind, often curved like an oyster-shell, but rarely or never with the sides parallel. The surface is glossy and smooth and from a light to a dark red-brown-purple color. The male scales, being less than half the length of the females, of a more linear shape and straight outline, may suggest some other species of insect on superficial examination. However, the identity cannot be confused with any other species than the long scale, L. gloverii, the female of which is twice as long as the male, L. beckii, the male of which is shorter and rather more slender, both absolutely and relatively. The characteristic purple color which the male gives to a mass of scales belongs to no other species. (Fig. 194.)

The eggs are pearly white, very minute, elongate-oval, and are usually laid in four rows, but sometimes promiscuously. Each female deposits from twenty-five to seventy eggs.

The newly hatched larva is irregularly oval in shape, 0.12 of an inch long, of a transparent white color, and with fiery red eyes which have been likened to grains of cayenne pepper. This young insect wanders about a very short time and then settles upon the bark or leaves, preferably along the midrib, and is soon covered with a white film of wax threads, some of which stand out from the remainder. If not carried away by the wind, the larvæ accumulate and form cottony tufts or tangles.

The shedding of the larval skin or first molt occurs about three weeks after hatching, and the formation of the true scale is begun. A second molt of the female takes place three to four weeks later and egg-laying begins when nine to ten weeks old, the eggs being laid beneath the scale. The young issue in about a week after the eggs are deposited, unless retarded by cold weather.

The male goes through its second molt several days earlier than the female, and changes into a pupa from which it emerges as a winged fly, and is ready for mating at the time the females are passing through their first molts. 
There are three or four generations a year, but the separation into distinct broods is often more or less confused, one generation overlapping the succeeding one, so that all stages of the insect may be found at almost any season of the year upon infested trees. Generally speaking, the greatest numbers of migrating young are present in one of three periods, namely: in the spring, usually in March and sometimes extending into April; in June or July; and in September or October. In mild winters a fourth brood commences in January and straggles through into February.

Treatment.-In the southeastern citrus districts, both purple and long scale are held in check to a very large extent in certain districts by parasitic fungi (see Chapter XXXI), and these should be given every opportunity to exercise control. Thorough spraying with oil emulsion (Formula No. 5), particularly when the young are moving, will prove very effective. Formula No. 9 is also excellent. If neither is available, No. 6 may be applied. Treatment for these scales and for whiteflies can be combined. In the southwestern sections fumigation gives satisfactory results.

The long scale (Lepidosophes gloverii Pack.).

This scale is of a more linear shape than the purple, with which it is so often associated, and the body is not so often curved as is that variety.

The female scale is brownish, about 0.11 of an inch $(3 \mathrm{~mm}$.) in length and less than one-fourth as wide. When crowded, the scales adjust themselves to their surroundings by taking all sorts of shapes, and many will be dwarfed and malformed almost beyond recognition, except by microscopic examination. The young insects themselves are of a translucent waxy white, with the outer edge of the last joint yellowish. As they grow older they incline to purple, which becomes deeper as the insects increase in age. The adult female is about 0.05 of an inch $(1.3 \mathrm{~mm}$.) in length, with the sucking proboscis longer than the body. 
The scale of the male is smaller than that of the female, about 0.04 of an inch $(1 \mathrm{~mm}$.) in length, and usually straight. The color varies from shades of brown to yellow when young, becoming darker with age, and reaching a dark brown in the older females. Usually, densely clustered colonies, including both sexes, have a reddish hue. The male insect is a minute two-winged fly, 0.01 of an inch in length. Its body is pale pink in color, and about one-fourth as wide as long. The eggs are elongate-oval in shape, passing from a light to a purple color before hatching.

The life history is so nearly parallel with that of the purple scale that it is unnecessary to enter into details. It has practically the same number of broods, which occur at about the same time. Sometimes the broods of the one species precede or follow those of the other by a few days, but they are often simultaneous. The treatment and times of application, therefore, are

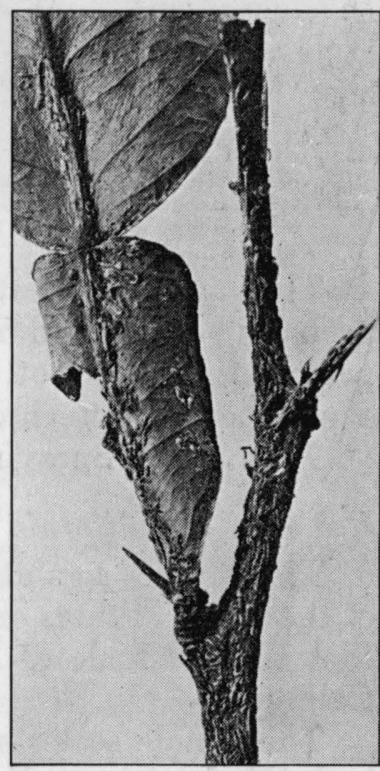

Fig. 195. Long scale infested leaf and twig the same as for the purple scale. The parasites of the two species are, likewise, similar.

Treatment.-The life history of the long scale parallels that of the purple scale and the same means of control give satisfactory results. It is by no means so common or so troublesome as the purple scale.

Red scale of Florida (Chrysomphalus aonidum L.).

The female is circular, dark reddish brown to black in color, and $2 \mathrm{~mm}$. in diameter. The scale of the male is smaller, being about one-fourth the size of that of the female. 


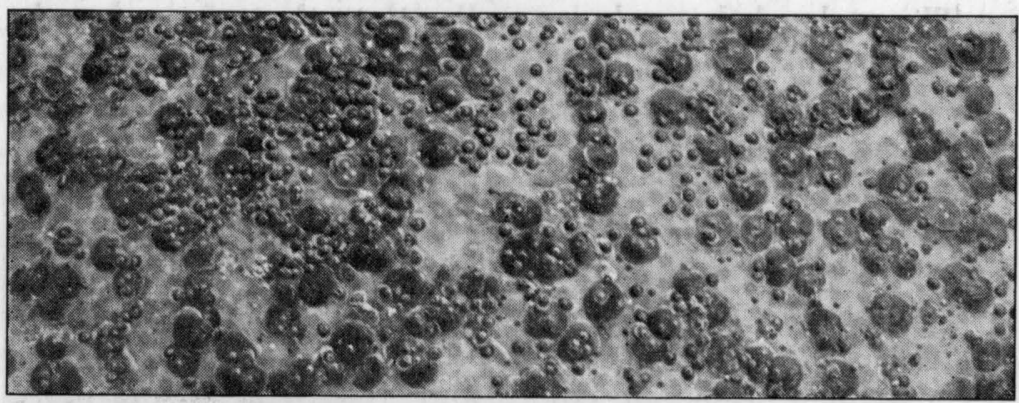

FIG. 196. The Florida red scale (enlarged)

This species infests leaves and fruit mostly. It was probably introduced into Florida from Cuba, but at the present time it is not very widely distributed and does not cause nearly so much damage as the purple and long scales.

Treatment.- Spraying with Formulas 5, 6, or 9.

\section{Red scale of California (Chrysomphalus aurantii Mask.).}

This species has attracted attention within the confines of the United States only in California. It is worthy of note that the red scale of Florida has not gained a foothold in California.

The female scales are light grey in color, but the brown body of the insect showing through gives a reddish brown cast. The male scale is one-fourth as large as that of the female, and the posterior end is a projecting flap.

Like its close relative, the Florida red scale, it infests the trunk and branches slightly, but is most common on leaves and fruit. It has proved a very troublesome pest in California, and since no predaceous enemies have been secured to control it, the grower must rely on his own efforts.

Treatment.-Fumigation, spraying with Formulas 5, 6, or 9.

\section{Chaff scale (Parlatoria pergandii Comstock).}

The female scale of this species is 1.4 to $1.6 \mathrm{~mm}$. long. It is thin, light straw-colored, and more or less circular in 
outline. The body of the insect showing through the scale imparts to it a somewhat greenish cast. Several faintly marked ridges radiate from the point of origin of the scale. The male scale is smaller than the female, being $1 \mathrm{~mm}$. in length. It is thin, white and almost oblong in outline.

This scale is most common on the trunk and larger branches of citrus trees, spreading to the fruit and leaves only when it becomes very abundant. Frequently its presence is overlooked, owing to its resembling the bark in color, and the trees frequently suffer severely before the grower finds out where the trouble lies.

Treatment.-Same as for purple scale.

The orange snow scale or orange Chionaspis (Chionaspis citri Comstock).

The female scale is flat or very slightly convex and the more recently shed skins are toward the narrow end. The male scales are smaller, white, and marked with three parallel ridges. When clustered on

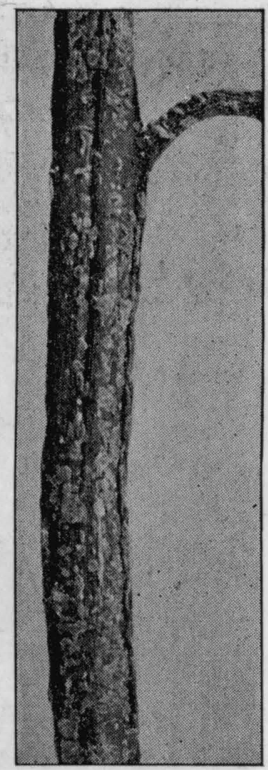

Fig. 197. Chaff scale on citrus twig the twigs or leaves of the citrus plants, the males are very conspicuous (Fig. 198). This scale is rarely found in Florida, but is abundant in Louisiana, Bermuda, and Cuba.

Treatment.-Same as for purple scale, Formulas 5, 6, or 9.

\section{UNARMORED SCALES}

The turtle-back scale (Coccus hesperidum L.).

The turtle-back scale, with others described in the following pages, belongs to a subfamily of naked or waxy scales, known as Lecaninæ, and are not covered with a true scale. Insects of the genus Coccus are unprotected by any covering, except their skins, which becomes toughened with age so as to resemble parchment. 
The full-grown insect is from 0.12 to 0.16 of an inch (3 to $4 \mathrm{~mm}$.) long, broadly oval, more or less swollen and convex

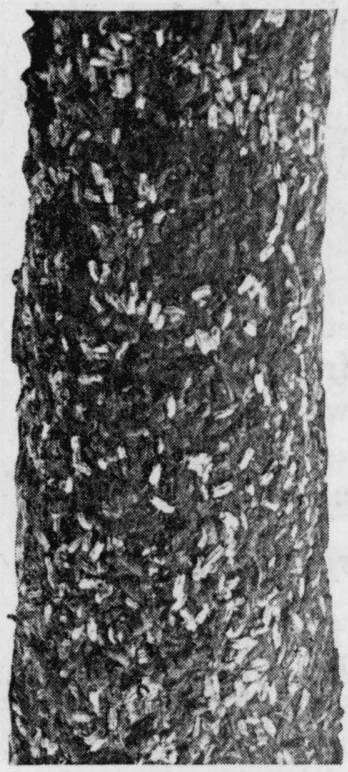

FIG. 198. A heavy infestation of orange snow scale upon the disk, surrounded by a thin flat margin which is notched on the sides and behind. This shape, with the brownish color, gives it its popular name. The legs are concealed beneath the body.

The young insect is of a yellowish color and always settles upon the bark and leaves of tender growth. The adult insects appear unable to pierce the bark of the trunk or older branches, always being found upon wood of newest growth.

In the spring and early summer, when new growth is forming, the increase of the insect is most rapid, especially during the month of June. Later in the season the colonies disappear, only a few gravid females remaining to restock the plants at the next favorable opportunity. The young, hatching in the latter part of the season, often starve, because they are unable to reach tender twigs upon which to feed.

Treatment.-Spraying with Formulas No. 5, 6, or 9.

The black scale (Saissetia olece Bern.).

This scale is nearly black in color, approaching hemispherical in form, and longer than broad; length from 0.16 to 0.20 of an inch (4 to $5 \mathrm{~mm}$.), height about 0.12 of an inch (3 mm.). The middle of the back carries an elevated keel which is crossed at right angles by two elevated ridges, the latter dividing the body into three nearly equal parts. The body is slightly margined, the outer part of the disk being 
marked with many small ridges which extend from the margin half way up to the center of the back.

The eggs are long, oval in shape, about .0012 of an inch in length and of a yellowish color.

The young larvæ prefer the smaller twigs of the plants which they infest, and usually settle upon the leaves. The development of the species is slow, so there is probably not more than one brood a year. It lives on all citrus plants, olive, pear, apricot; plum, pomegranate, apple, eacalyptus, rose, cape jessamine, live oak, holly, oleander and some other plants.

Treatment.-Fumigate, or spray with Formulas 5, 6, or 9.

The hemispherical scale (Saissetia hemispherica Targ.).

This scale is of a more rounded form than the other common species, approaching hemispherical, about 0.14 inch $(3.5 \mathrm{~mm}$.) in length, 0.12 inch $(3 \mathrm{~mm}$.) in width, 0.08 inch $(2 \mathrm{~mm}$.) in height. The color varies from a light almost reddish brown when young to a dark brown slightly tinged with red when old. The insects found on twigs are usually more elongate than those on leaves.

The egg is of an ellipsoidal shape, about 0.006 inch $(0.15 \mathrm{~mm}$.) in length, and of a whitish color inclining to yellow.

Treatment.-Spraying with Formulas No. 5, 6, or 9.

The wax or white scale (Ceroplastes floridensis Comstock).

This beautiful insect is 0.08 to 0.12 inch ( 2 to $3 \mathrm{~mm}$.) in length, of an oval form, convex above and concave beneath. The upper surface presents a rounded protuberance in the center, around which are arranged six or eight smaller prominences or lobes, which are separated by a groove from the central projection. The white covering consists of soft wax, similar to the commercial article. The color in clean specimens inclines to a beautiful flesh-tinted white (Fig. 199), the pinkish tinge being given by the reflection of the light 
through the wax from the red insect beneath. The insect itself bears on its upper surface six tubercles, three on each side, and shows a short anal tube, the end of which is seen projecting from the posterior extremity of the waxy covering

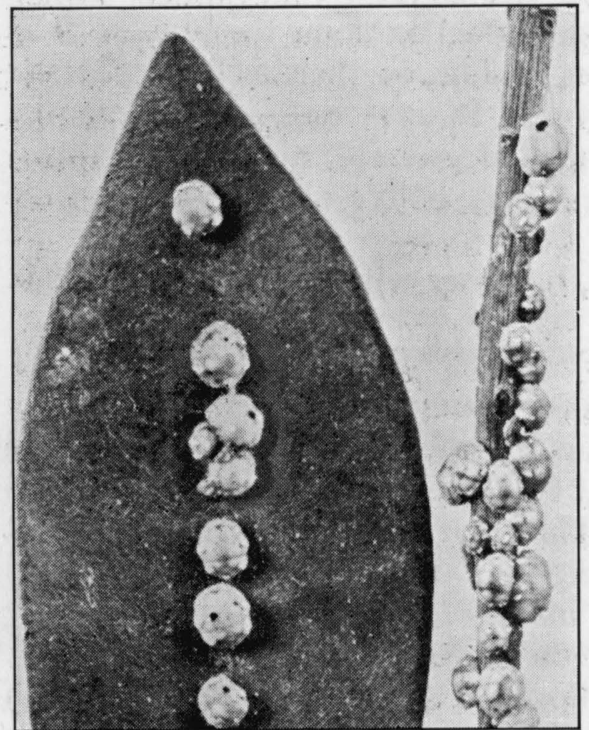

FIg. 199. The wax scale (enlarged) at the bottom of a deep pit. The walls of the body are very thin and inclose liquids or eggs of a dark red color. The egg is 0.01 inch $(0.25$ $\mathrm{mm}$.) long and of ellipsoidal form.

The eggs, 71 to 100 in number, are extruded from the body and hatched beneath the waxy scale, from which they escape and attach themselves by their beaks to the surfaces of the leaves, chiefly along the midribs and veins. As they approach maturity they go to the bark of the twigs and smaller branches. The exudations of wax first form in ridges, the marginal ones uniting around the central one.

About a dozen or fifteen similar tufts of wax arise around the center, and the young louse, when about a week old, has been compared to an oval white star upon the leaf. At this stage it has some superficial resemblance to some of the stages of insects belonging in the Aleyrodidæ. The adult insect is covered with six large plates, three on each side, and three smaller plates, located one at each end and one in the center. As it ages, the wax becomes covered with dust and dirt and takes on a very different appearance. 
There are about three broods, each extending over three to four months. The first brood occurs in April and May, the second in July and August, and the third in October and November. This insect is native to Florida and is very numerous on the gallberry. It also occurs on quince, apple, pear, the citrus fruits, ferns, figs, myrtles, guavas, and a number of other plants. As the insects become aged, many of them fall to the ground and perish, being unable to reascend the plants from which they fell. They do not often become numerous on orchard or grove trees, but sometimes get thick enough to cause some alarm.

Treatment.-It is not often that the wax scales require particular attention, but reports indicate that they may inflict considerable damage during a short period. If fully developed, they will probably lose their hold and fall to the ground in a short time, so are not worthy of much attention while in this stage. When the growing larvæ become numerous they can be checked by spraying with Formulas No. 5,6 , or 9 .

The barnacle scale (Ceroplastes cirripediformis Comstock).

This insect is similar to the preceding species in possessing a white waxy covering but is differently marked. The average length is 0.20 inch $(5 \mathrm{~mm}$.), width 0.16 inch (4 $\mathrm{mm}$.), and height 0.16 inch $(4 \mathrm{~mm})$. The naked insect is dark reddish brown in color, of subglobular shape, and with a strong spine-like projection at the posterior end of the body. Shades of grayish or light brown often mottle the general white color, but the boundary lines of the plates remain apparent, even at an advanced age. A convex dorsal plate covers the back, and this is met on each side by six lateral ones, each of which is marked by a radiating nucleus in the center. The posterior plate is larger than the others, possessing two nuclei, thus indicating that two plates are joined together. The eggs are 0.014 inch $(0.35 \mathrm{~mm}$.) in length, and of a light reddish brown color. 
The newly hatched larvæ are dark brown in color and follow practically the same course of development as wax scale.

Treatment.-Same as for wax scale.

The cottony cushion scale (Icerya purchasi Maskell).

Immediately after the molt by which the female insect passes into the adult stage, it is free from waxy excretion and presents a broadly oval form with two prominent raised surfaces on the second and third thoracic segments. Its

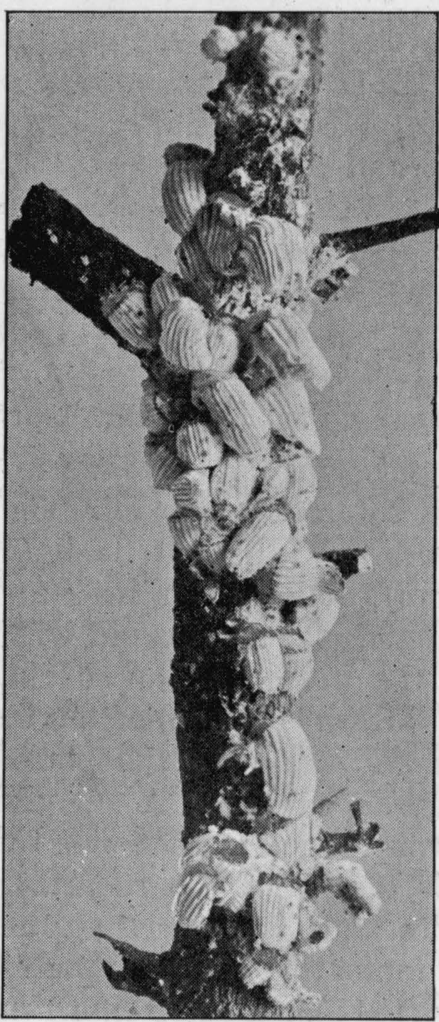

FIG. 200. A colony of cottony cushion scale color is still reddish brown, with several dark spots along the front sides and the posterior part of the body, while the antennæ and legs are black. Just after the insect in any stage has withdrawn from its old shell in molting, the legs are perhaps the most transparent and whitish parts of the body, but they begin to darken in about a half hour and within two hours are black and as dark as they become in the preceding stages. The antennæ are eleven-jointed, the club being one and one-half times as long as the tenth joint. The whole body is furnished with tufts of short black hairs, which are gathered into a parallel row around the edge of the body. The secretory pores occur in enormous numbers beneath the sides of the body and are scattered more sparsely over the 
back. On the back, the inner row of tufts is broken at its anal point by a depression in which is situated a very large pore from which the insect occasionally ejects a globule of semi-liquid honey-dew. This depression is surrounded by an irregular ring of hairs which are yellowish in color instead of black. The glassy filaments described in the last stage are now very long and radiate from the body in almost every direction. They break off very easily, yet they often reach a length double that of the insect and the egg-sac together.

Just as the body of the female begins to swell from the eggs forming inside, the beginning of the egg-sac is made. The insect lies flat on the bark. The edges of the body turn slightly upward, and the waxy material of which the sac is composed begins to issue from numberless pores on the under side of the body, but more especially along the sides below. As the secretion advances the body is raised, the head end still being attached, until the insect is apparently standing on its head nearly at right angles to the surface to which it is fastened. The egg-laying commences as soon as the thin layer of secretion has begun on the inner side of the abdomen, and it continues during the formation of the sac. Around the edge of the abdomen there soon appears a narrow ring of white felt-like wax which is divided into a number of flutings. These flutings grow in length and a mass of eggs and wax under them increases, forcing the female upward until the sac is completed. When complete it is from two to two and one-half times the length of the female's body and is of a snow-white color. The outside is covered with fifteen of these longitudinal ridgings or flutings of about equal size, except that the middle one is smaller than the others. The upper part of the sac is firm in texture, but the lower is looser and thinner and from the inner side the young make their escape after hatching. The size of the sac and length of time required for its growth depend, leaving the weather and the health of the food-plant out of con- 
sideration, on the number of eggs which the female deposits. The excretion of the egg-sac continues as long as oviposition lasts. (Fig. 200.)

It probably requires from sixty to ninety days to complete the egg-sac from its beginning. The length of time depends largely on the health of the tree on which the insect is located and also on the number of insects infesting it. Development is much more rapid on vigorous than sickly trees.

The adult male is a winged insect with dark red body, grayish wings, and of very slender fragile structure. Its antennæ are dark colored and have two whorls of light hairs extending from each joint except the first. When the insect is at rest, the wings lie flat upon the back. It is readily found in situations where the male larvæ have pupated, under boards, beneath cracks, and in the general litter of the grove.

Treatment. - It was against the cottony cushion scale that fumigation was first practiced. Although the insect was held in check to some extent, neither fumigation nor spraying availed much against its inroads. The entire citrus industry of California was threatened, and it was not until the Australian lady-bug was introduced that its ravages were checked. By this predaceous enemy, Novius cardinalis, the cottony cushion scale was brought under absolute control. In Florida the same method was likewise entirely successful. Hence, when the cottony cushion scale gains a foothold, its enemy, the Australian lady-bug, should be introduced at once. While waiting temporarily for the arrival of the lady-bugs, oil emulsion or kerosene emulsion may be used.

\section{The mealy-bug (Pseudococcus citri Risso).}

This insect, with other closely allied species, is fairly common in Florida. The adult female is about 0.14 to 0.16 inch (3.5 to $4 \mathrm{~mm}$.) in length, 0.08 inch in width, and very 
flat. The color is dull brownish yellow, the legs and antennæ agreeing with the body in color. There are seventeen appendages on each side, and most parts of the body are more or less powdered with particles lighter than the groundcolor. The egg is about .01 inch in length, of long ellipsoidal form and light yellow color. (Fig. 201.)

The eggs are laid in a large cottony mass at the posterior extremity of the abdomen, and require considerable time to hatch. After hatching, the larvæ exhibit a marked tendency to settle along the midribs and veins on the under side of the leaves or upon the younger twigs, especially in the forks. Ants are very industrious agents in scattering them. The honey-dew excreted

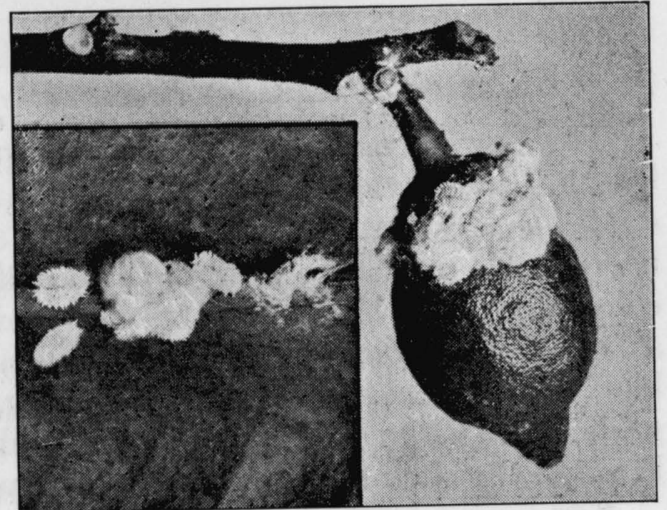

Frg. 201. Mealy-bug on lemon fruit and leaf by the mealy-bugs forms the attraction for the ants which care for them in a way that has been compared to the attention man gives to his domestic animals. Free use of carbon bisulfide or scalding water in the nests of the ants often furnishes the best means of controlling the mealy-bug.

Treatment.-In American citrus districts, mealy-bugs are thoroughly held in check by parasitic fungi and predaceous insects. A lady beetle (Cryptolomus montrouzieri) controls them in California, while in Florida a fungous disease (Entomopthora fumosa) destroys them. For further details see Chapter XXXI. However, it is sometimes necessary to combat this pest by spraying. A powerful force pump and penetrating insecticide, such as kerosene emulsion, 
should be used on mature insects. Thoroughness and frequency of application will govern the degree of success achieved in fighting this insect. Repeated applications of whale-oil soap, one pound in two or three gallons of water, made while the insects are young, will give most successful results. Badly infested limbs should be painted with insecticide with a brush or they may sometimes be pruned out altogether. Formulas No. 5, 6, or 9 .

\section{SUCKING INSECTS OTHER THAN SCALES}

\section{The common citrus whitefly (Dialeurodes citri R. \& H.).}

The egg is very minute, about $\frac{1}{125}$ inch $(0.2 \mathrm{~mm}$.) in length, being attached to the leaf by a slender stem or footstalk. It is about four times as long as thick, widest just beyond the middle toward the free end, and pale yellow in color, when first laid, tinged with greenish, becoming darker as the embryo develops, some specimens dark steel-gray or blue. The surface is smooth and shiny, often with clinging particles of white wax. Red eyes of embryo are conspicuous through the shell as it approaches maturity.

Egg-laying begins within eighteen to thirty hours after the adults issue, when the weather is warm (65 to 75 degrees), but with damp cool weather, several days may elapse before they are deposited. Egg-deposition occurs upon the under surface of the leaves, preferably on new ones, especially those of water-sprouts, but old leaves may also be well covered. They are usually scattered over the surface of the leaf without much order of arrangement, but sometimes are laid in the arc of a circle. From four to ten eggs may be observed in such an arc and are so placed by the female, using her beak as a pivot around which the body is swung during the oviposition.

By mathematical computation, a leaf from young orange, five inches long and two and one-half inches wide in the middle, collected at Myers, June 22, 1901, had upon it 


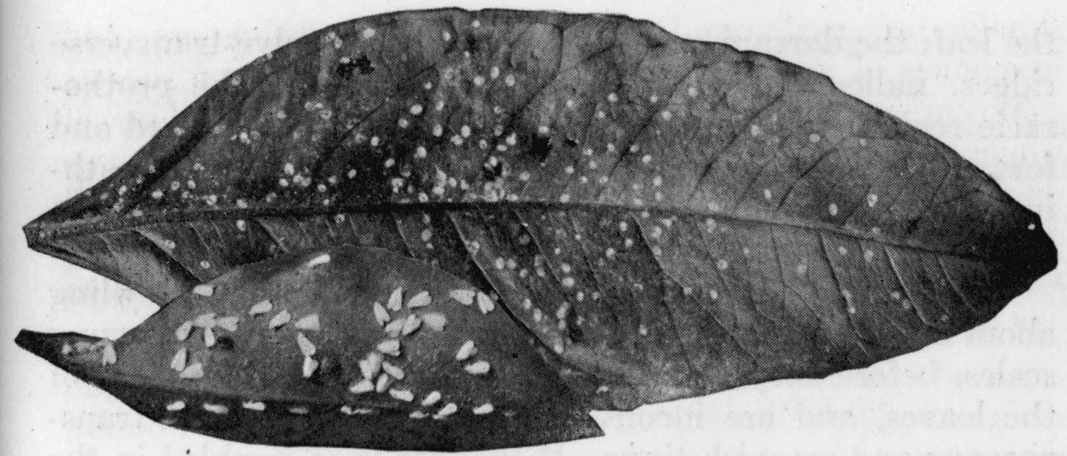

FIG. 202. Whitefly adults below (natural size) and pupa above on under side of citrus leaf

upward of 20,000 eggs. While so many eggs in such a space is beyond the average, it is by no means rare, and sometimes this number is exceeded. Hatching occurs in three to twenty days, according to the weather.

The larva passes through four molts before reaching the pupa stage. When first hatched the insect is about $\frac{1}{80}$ inch in length $(0.3 \mathrm{~mm}$.), of a pale greenish yellow color, with two darker yellow spots on the back of the abdomen. There are four conspicuously long bristles at the posterior part of the body and six long ones on the anterior end, with minute ones along the sides, each arising from a tubercle; antennæ three- or four-jointed; four dark reddish eyes; legs short, six in number; mouth-parts consist of a long sucking tube. On the dorsal side of the last abdominal segment is a subovate brown-colored opening, the vasiform orifice. Appearance in second and third stage is not markedly different from the first, except in size and minute microscopical characters. In the fourth stage, the length has increased to about .06 inch (1.5 mm.), the width to .04 inch $(1 \mathrm{~mm}$.), and the conspicuous bristles have vanished. A pair of persistent minute bristles is found on the anterior border, one on each side, and another pair, also minute, is disposed one on each side of the anal cleft. The insect is very flat and close pressed to 
the leaf; the dorsum or back is crossed by twelve transverse ridges, indicating the segments. Arising from the prothoracic region on each side, extending obliquely outward and forward to the margin, is a distinct ridge or fold, the breathing-fold. The outline of the developing wings of the embryo can be seen distinctly from the first.

The young larvæ of the whitefly are motile, crawling about over the leaves and twigs for several hours, like young scales, before they attach themselves to the under sides of the leaves, and are inconspicuous, because of their transparency and greenish tinge. If the leaf is so doubled in the hand that air is admitted beneath the insect, it at once becomes readily seen and is translucent, whitish green, spotted with orange.

The pupa, to an ordinary observer, is similar to the fourth larval stage, but more plump and of thicker body, broadly oval; measurements about as in fourth stage, slightly narrower (Fig. 202). A broad deep orange or coral-red spot is present on the back near the anterior end of abdomen; eyes purplish; vasiform opening and ring brown; transverse ridges on abdomen shorter and less distinct than in last larval stage.

The adult female is slightly over $\frac{1}{20}$ inch $(1.4 \mathrm{~mm}$.) in length, the wing expanse being about twice the length of the body $(2.8 \mathrm{~mm}$.). The color is light orange, with the rostrum or beak tipped with black; wings are colorless when newly hatched, but within two or three hours become covered with a fine white wax, hence the name, "mealy-wing" sometimes given to the insect. More or less wax also covers the body, but its ground color is not wholly obscured. The tarsi are two-jointed. The eyes, reddish brown in color, are each divided into two parts by a curved ridge projecting from the cheek, the upper divisions being the smaller. The ovipositor is short and retractile.

The male resembles the female, but is smaller, with the head and abdomen having heavier tufts of adhering wax; 
abdomen is more slender and has at its termination a pair of claspers slightly curved upward.

Treatment.-Whitefly is difficult to control. Little can be done when the insects are flying about, and all remedial work must be undertaken during the larval and pupal stages, when they are at rest on the under sides of the leaves. Fumigation or spraying at this time is effective. The best time for fumigating is from the middle of December to the end of February. Spraying may be done during the same period or in the summer. When the insects are pupating use Formulas 5,6 , or 9 . Strong effort should be made to introduce such beneficial fungi as the red Aschersonia and the brown fungus. This may be accomplished successfully in a number of ways. Worthless seedling citrus trees, usually uncared for, serve as whitefly hosts and should be destroyed. In the southeastern districts, chinaberry and umbrella trees, on which whiteflies multiply, should be destroyed and new ones should not be planted.

\section{Cloudy-winged whitefly (Dialeurodes citrifolii Morgan).}

For many years only one species of whitefly was recognized as an important enemy of citrus trees in the Southeast. However, in 1910, E. W. Berger pointed out another species, differing from the common citrus whitefly in its black eggs covered with a network of ridges, its thinner larval skin, and in having a darkened area in the middle of each wing. In summer it takes about two weeks longer to cover the different stages of development from egg to adult insect. The cloudy-winged species shows a marked preference for the tender succulent foliage found on so-called water-sprouts.

So closely does its life history parallel that of Dialeurodes citri R. \& H., the common whitefly, that the same methods of control have been satisfactory against the cloudy-winged species. It is essential that the water-sprouts be removed, and if only the cloudy-winged species is present in a planting, the periods for spraying will be three to four weeks 
later. The cloudy-winged whitefly is attacked by the yellow Aschersonia, and so closely does this fungus confine its work to this species that its presence may be regarded as positive proof that the cloudy-winged whitefly is present in trees where Aschersonia flavo-citrina is found.

Treatment.-Same as for the common whitefly. Formulas 5,6 , or 9 .

\section{Woolly whitefly (Aleurothrixus howardii Quaintance).}

The differences between this species of whitefly and the two just described have been noted by J. R. Watson ${ }^{1}$ :

"The woolly whitefly differs more from the two other species than they do from each other. The name is derived from curled waxy filaments which completely cover the pupa and have the appearance of wool. The empty pupal cases of this species are very persistent and remain on the leaves for many months after the adults have emerged.

"The eggs are brown in color and curved in shape, somewhat like a short sausage. They are laid mostly in circles. This results from the habits of the female during egg-laying. She inserts her beak into the tissue of the leaf and, on that as a pivot, rotates her body. The female does not choose the very youngest and most tender leaves on which to lay eggs, as do those of the other species, but leaves more nearly mature, and often lays on the leaf on which she herself was raised.

"The first-stage larvæ are light green, with well-defined legs and antennæ. The other stages are dark brown in color, black if parasitized, and widely fringed with a corona of shining white waxy plates. The larvæ give off honey-dew copiously, and there is usually a drop clinging to them during their entire life. In the third stage the woolly covering develops.

"The adults are distinctly more yellow than those of the two preceding species and do not hold their wings so high.

${ }^{1}$ Insects of a Citrus Grove. Bull. 148, Univ. Fla. Exp. Sta., June, 1918. 


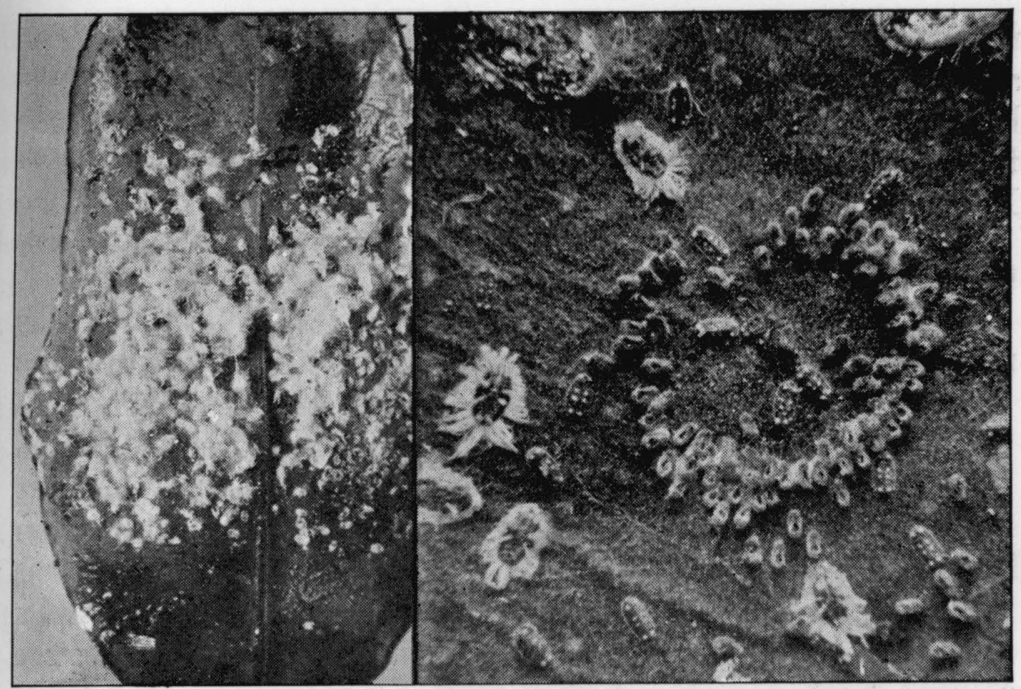

FIG. 203. Eggs (in circle) and larvæ, in two stages, of the woolly whitefly (enlarged)

They are very sluggish, seldom taking to wing and then flying only short distances. On the other hand, they will cling tenaciously to one's clothing and doubtless are thus carried long distances.

"There are four distinct broods a year, with adults flying from December to February, the last of May, the last of July, and the first of September."

Treatment.-The woolly whitefly is held in check by the same natural enemies as the other whiteflies, but in addition a small wasp-like insect, Eretmocerus haldemanii, lays its eggs in the larvæ. The minute grub feeds on the interior of the whitefly larvæ and destroys them. This parasite effectively controls the woolly whitefly, and frequently no particular harm has resulted from its appearance in a grove. Occasionally, however, when its parasitic enemy was not present it has caused considerable damage for a few months. If the Eretmocerus is not present, steps should be taken to introduce it, and in the meantime oil sprays recom- 
mended for the other species should be used. Spraying should be done before the larvæ are too advanced in growth, because in their later stages they are protected very effectively by the woolly, felt-like, waxy covering. Formulas No. 5 or 9 .

\section{Citrus aphis (Aphis spircecola Patch).}

For many years the common aphis (Aphis gossypii) has been noticed in citrus groves in Florida, but at no time has

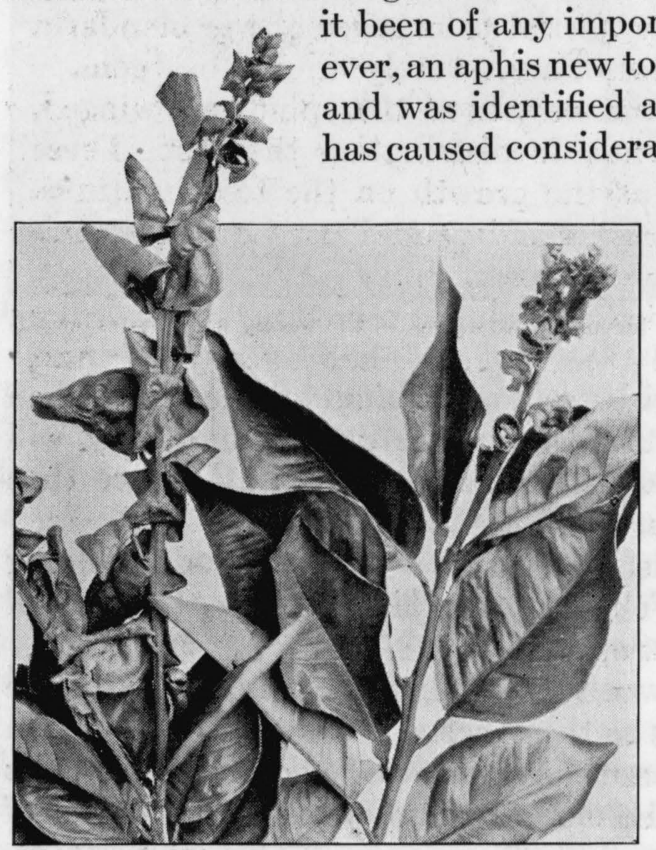

FIG. 204. Aphis injury to orange leaves and twigs of the Florida citrus districts, though its virulence in some sections seems to be abating. It is likely to give growers of citrus fruits in Florida considerable trouble from time to time.

The aphis attacks the young parts of citrus trees, such as leaves, twigs, buds, blossoms, and fruit. When severe, the injury completely prevents the growth of young twigs, but if the twigs have made some start before the attack begins, the growth will extend out some distance. When the leaves are very badly curled twigs never reach normal size, and, if the injury is severe enough, the leaves and ends of the twigs are eventually destroyed. (Fig. 204.) Bloom- 
buds, when attacked, fail to develop and when they have opened previously do not form fruit. If the infestation is heavy, the prospective crop of fruit may be entirely destroyed. If the fruit has reached some size before injury, it becomes distorted and misshapen. The aphis is unable to feed on leaves after they are two-thirds grown and on twigs after they have somewhat hardened. It is only on new growth that aphis makes headway.

Grapefruit appears almost immune to attacks of aphis, but the insects are very partial to oranges of the mandarin group. Sweet oranges, also, are severely injured by them.

Under some conditions, certain of the aphids are winged, and these are instrumental in distributing the pest. These winged forms develop as the growth on the trees matures. They multiply with great rapidity and consequently their capacity for damage is very great.

Several insect enemies are helpful in holding the aphid in check, and it is hoped that through their agency the pest eventually may be controlled. Those noted feeding upon the new citrus aphis are the larvæ of surface flies, lacewinged flies, and lady-beetles, particularly the blood-red and convergent. The Australian lady-beetle, hitherto known to eat nothing except cottony cushion scales and one another, have been reported as feeding on aphis.

Treatment.-The citrus aphis is easily destroyed if it can be touched with spray or dust. However, as the insects are covered and protected by the curled and twisted leaves, it is very difficult and often impossible to reach them. Hence it is important that particular attention be given to cleaning up small infestations early in the season. These are the foci from which the insects multiply and spread, and their destruction will be more effective than control measures. As a spray, use Formula 10 or dust with Formula 18, with nicotine dust added. Dusting is more effective than spraying. Careful attention should be given to cultural details that the development of new growth at irregular intervals may be avoided. 
Orange rust mite and lemon silver mite (Eriophes oleivorus Ash.).

This mite is minute, being $0.14 \mathrm{~mm}$. in length. In outline its body is rather wedge-shaped, widest near the head and tapering gradually to the posterior end, which is provided with a pair of appendages. The abdomen is divided into about thirty segments, and the legs are four in number, placed close together on the anterior portion.

The young insects are bright yellow in color, becoming darker as they grow older. Spherical, transparent, yellow eggs are deposited by the adult singly or in clusters on the leaves.

Rust mites occur in great numbers on the leaves and fruit, as many as 4,568 having been found on a square inch of leaf surface in winter by the late H. G. Hubbard. During warm weather, when not too dry, these insects multiply rapidly. They attack both the leaves and the fruit. The leaves lose their glossy color and become covered with brownish spots, but it is on the fruit that the effects are most noticeable. Through the punctures which they make to feed on the

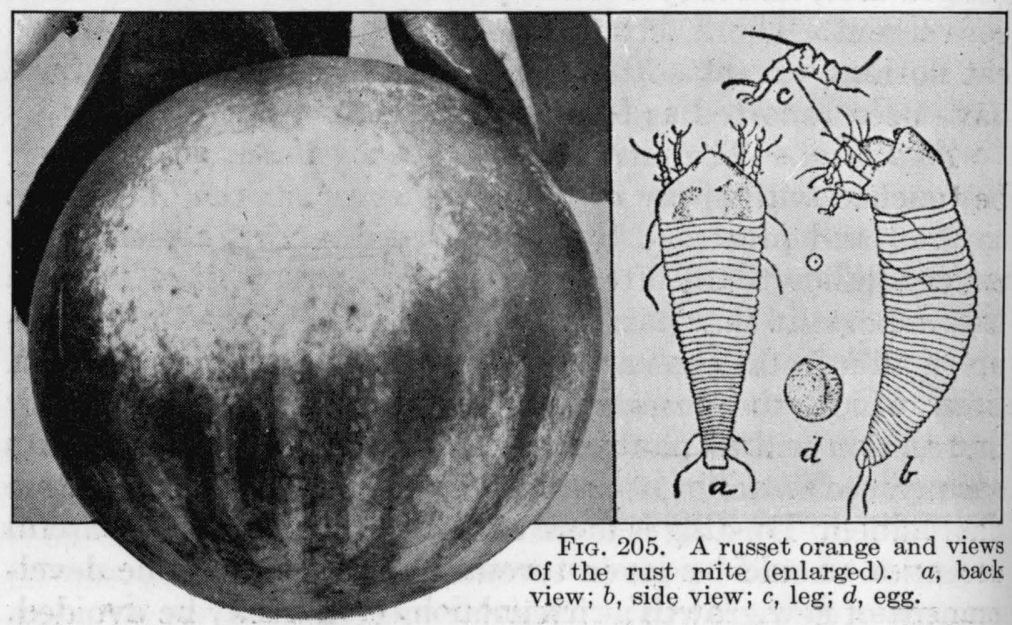


essential oil of the rind, the air comes in contact with the oil, bringing about a change in color. On the lemon, the coloration is somewhat silvery, hence the common name, silver mite, applied to the insect by Marlatt. Fruit when attacked does not develop normally but remains undersized. The insects prefer and seek the shade, hence the under side of the fruit, not exposed to the sun, becomes "rusty," while the upper portion in the strong light is not affected. (Fig. 205.)

The cost of handling the citrus crop is increased materially because of this mite, as two classes of fruit have to be distinguished. As a matter of fact, the russet fruit is supposed to be sweeter than the bright, but usually brings somewhat less money, the markets generally preferring a smooth bright fruit.

Treatment.-Spray with Formulas 7 or 8, or dust with sulfur and lime (Formula 18) every two weeks. A more adhesive solution, Formula 4, may be used if so desired, and this will destroy the scales as well. If this solution is employed, the intervals of application may be lengthened to about a month with fairly good results.

The six-spotted mite (Tetranychus sex-maculatus Riley).

The length of full-grown specimens is $0.3 \mathrm{~mm}$., or about .012 inch. This is slightly smaller than most members of its family. The six-spotted mite is of oval shape, being widest just back of the eyes, and its general color is pale greenish yellow, the abdomen in mature specimens being marked with six or less small dusky spots, arranged in two lateral rows of three in each row on the back. Most of the younger mites are without these spots or have only part of them present. Some of the mature specimens have fewer than six spots, and these are often quite indistinct. There are two eyes on each side, the anterior one of each pair being blood-red and the pigment so disposed as to give the appearance of two red eyes on each side; the posterior eyes are colorless and transparent. A lateral constriction just back of the eyes 
divides the body in two more or less distinct regions. The terminal joint of the legs is longest. The thumb of the palpus is quite stout and bears on its tip three fingers, of which the middle one is the largest. The young mites have only three pairs of feet. The eggs, which are globular in shape and either colorless or of a pale greenish yellow, are loosely attached to the delicate web which is found chiefly along the under sides of the leaves. With warm dry weather the life cycle from egg to adult is not more than ten days.

The insects are carried from tree to tree upon the feathers of birds, by becoming attached to the feet of lady-bugs, on fallen leaves driven before the wind, and similar agencies. They can travel about two inches in one minute upon a leaf surface, or ten feet in an hour, and therefore they may spread quickly from any point where they have become newly established.

A yellowing of the leaves, showing as streaks and spots along the midrib on the upper surface and as blotches of yellowish rusty brown on the lower sides, indicates the presence of the six-spotted mite. The excrements show as minute black spots and the cast skins, when aggregated together, constitute whitish silvery patches. After a few weeks the leaves curl, shrivel and fall, more than one-half often coming down and from one-third to two-thirds of the immature fruit. In 1899 one grove in Citra, Florida, reported a crop of only about ten thousand boxes from the heaviest bloom the grove had ever put forth, whereas it had yielded twenty-four thousand boxes the preceding year, the whole shrinkage of product being attributed to the sixspotted mite.

The rainy season of June and July causes the mites practically to disappear and they remain in such small numbers during the latter part of the year that they are rarely noticed at all. Vigorous trees, especially those grown on high hammock land or low moist soil, are not likely to be injured, and when irrigation or artificial watering is practiced 
damage is slight. Drenching the trees with water from a hose, when the water supply is abundant, as in the case of some irrigated groves, meets every demand.

Treatment.-Same as for rust mite, but not necessary to spray or dust so many times or during moist weather.

Purple mite or red-spider (Tetranychus citri McGregor).

The red-spider seems identical with the insect known throughout Florida as the purple mite, which is quite small, yet distinctly visible to the naked eye. During the summer months, red-spiders frequently appear in large numbers and effect great damage by causing the fruit to drop and injuring the leaves so that they do not perform their functions properly. The leaves become spotted and lose their natural glossy green color.

The females are considerably larger than the males, and both are covered with a number of stiff hairs which act as a protection. These insects are purplish or reddish purple in the old adults. The younger ones are lighter, the newlyhatched individuals being almost colorless or straw-colored.

The eggs are bright red and are deposited mostly on the under side of the leaves in proximity to the midrib. They are attached to the leaf by a number of silken threads joined to a stalk fastened to the egg at right angles on the upper surface. Eggs hatch rather irregularly, but generally take from one to two weeks. As soon as the young are out of the shell, they begin to suck the juices of the plant and continue feeding throughout their whole existence.

Treatment.-Red-spider disappears in Florida with the coming of the rainy season, but much damage is wrought in most citrus districts during dry weather. Spray with Formulas 4,7 , or 8 , every two or three weeks until damage ceases.

\section{Thrips (Franiliniella bispinosus projectus Watson).}

Often a peculiar type of blemish is found on the surface of citrus fruits. The markings may cover so much of the fruit 
as to make it unsightly and unsalable and in some cases as much as 5 to 10 per cent of the total crop is damaged. The remainder of the fruit on the trees attacked may be slightly affected and its market value lowered. The scars are

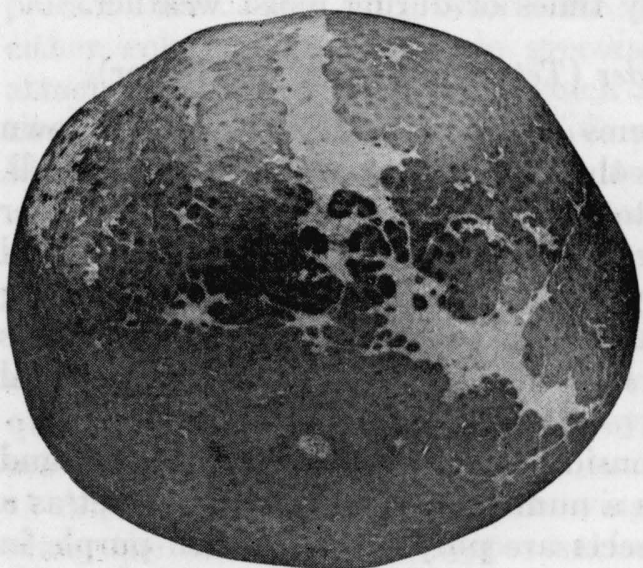

Fig. 206. Scars of irregular shape caused by thrips smooth, brownish, sunken areas, and they may be either in streaks, blotches, or circles. These markings are caused by the flower thrips, a common insect which attacks many different kinds of flowers. They are often numerous in citrus flowers when they are open, and are very small, light yellow in color, and active. Thrips feed by sucking the juices from petals, stamens, and ovaries, and, when feeding, injure the surfaces of the miniature fruit by rasping or scarring it. The marks they leave on the tiny fruits are very small, of course, but as they develop, the injured spots also increase in size and a very small mark may become very large on the mature fruit. (Fig. 206.)

Treatment.-Thrips can be controlled by spraying and dusting when the trees are in bloom. Since the blooming period often covers a considerable length of time, it is usually necessary to treat the trees twice so as to reach all the blooms. In spraying it is necessary to use high pressure and to direct the spraying in such a way that it goes straight into the blooms. For these applications use No. 4. The grove and its immediate vicinity should be kept free from weeds on which the pest lives and breeds. 


\section{Pumpkin-bug (Nezara viridula L.).}

Pumpkin-bugs and related species sometimes injure the new growth on young trees and damage much fruit in bearing groves. At times, in some Florida sections, the losses caused by these native insects have been very heavy, and in some groves as much as 50 per cent of the crop has either been destroyed outright or rendered unfit for shipment.

Insects of this group secure their food by sucking the sap from juicy succulent plants. When they attack the new growth on vigorous young trees, they take out so much sap as to cause it to wilt, die, and dry up. They damage oranges by inserting their sucking-tubes through the rind and extracting the juice from the sections. If large enough quantities of juice are removed, the fruit drops. Even though the orange still hangs on the tree, injury is done to the rind by the punctures, and sections or portions of sections are sucked out, leaving them dry and pithy. Such fruit at maturity is not marketable. Pumpkin-bugs are especially injurious to mandarin oranges. The finer the fruit the more susceptible to injury, because the skin is thin.

Pumpkin-bugs, known as green soldier-bugs and stinkbugs, are so well known as to need little description. The adults are flat oval-winged insects about $1 / 2$ inch long and about $\frac{5}{16}$ inch in width, bright green in color. The nymphs, as the young are termed, are bluish in color and marked with red. When disturbed or injured, they give off a very strong disagreeable smell.

The eggs are laid on velvet beans, beggarweed, cowpeas, and other juicy crops which constitute their favorite food plants. Pumpkin-bugs multiply and feed upon these covercrops, and when the latter die down in autumn, they migrate to the orange trees.

Treatment.-When the pumpkin-bugs are young and wingless, they are unable to move far. Consequently, if the crop on which they are feeding is cut down early enough in the season (before September 15), the bugs perish. Since 
they can crawl from plant to plant, and so reach the trees, the destruction of the cover-crop should be thorough. This practice is recommended if pumpkin-bugs are present in numbers large enough to cause material damage. In the young stages they also may be destroyed by spraying with oil emulsion, but this treatment is useless against the adults. After the bugs have started work on the trees, the most satisfactory method of control is to shake them off into a net. Using a circular muslin net, three to four feet in diameter and of nearly equal depth, two men can go through a grove very quickly and destroy the insects. One man holds the net beneath a branch, the other shakes it, and the insects drop off into the net. From time to time they are collected and destroyed in kerosene. It is best to do the work in early morning, as the insects are not likely to take to wing when it is cool. If the destruction is carefully performed over a period of a few days, the damage from these pests can be reduced to a minimum. Larger nets can be used on larger trees, with three or four men to handle them. 


\section{CHAPTER XXIX}

\section{CITRUS DISEASES}

The number of diseases affecting citrus is not so large as in many other groups of fruits, but it is of sufficient importance to attract serious attention. These diseases at times make it impossible for the grower to realize a profit on his crop. Some conditions of location are conducive to certain diseases and should be avoided. It is extremely difficult to overcome fundamental drawbacks of soil, drainage, and climate. Too frequently these are given no consideration when selecting a location, and the grower does not realize his handicap until after he has planted his trees. Some diseases are brought on by negligence or maltreatment; others are intimately associated with methods of cultivation and fertilizing. In certain cases they may appear in groves where the best and most intelligent care is given. Generally citrus diseases have a small start and, if neglected, make gradual headway from year to year, so prompt attention to small infestations is essential. A knowledge of the life histories, the ways in which the diseases are spread, and methods for combating them is an essential part of a grower's equipment for the successful culture of citrus fruit crops. Within recent years, Webber, Rolfs, Fawcett, Stevens, Smith, and Winston have added greatly to the knowledge of citrus diseases and the control measures to be used against them.

\section{FUNGOUS DISEASES}

Many citrus diseases are due to the attacks of fungi. These injure different parts of the plants - the roots, stems, branches, or leaves - and interfere with their functions, eventually bringing about the death of the part, and, in some cases, the whole tree succumbs. Others attack the 
fruit and either destroy it, reduce its grade, or make it unsalable. Fungi are spread mostly by means of spores which bear the same relation to the fungus that seed does to the higher plants. The spores are scattered by the wind or rain, and under favorable conditions of heat and moisture grow and enter the tissues of the plant. Slender fungal threads, the mycelium, penetrate the tissues until they have obtained enough food and have grown sufficiently to produce spores again. These are again scattered, and so the life circle is completed. In some cases fungous diseases are spread by pieces of the vegetative parts of the fungus being scattered or spread about. For the most part, it is in the young tender tissues that fungous diseases gain a foothold.

\section{Foot-rot or mal-di-goma.}

So far as known, this disease occurs in nearly every citrus district in the world, and no American center is free from it entirely. Its history in Europe extends back to about 1845, and foot-rot worked destruction in the groves of the Azores some years previous to that time, in fact, seems first to have been noted there. In Florida, it has been responsible for the destruction of many trees and for the disappearance of many of the old sweet seedling groves.

Mal-di-goma occurs in California in groves in which sweet-orange stock was very largely used in establishing the citrus industry. Few citrus districts are exempt from it, unless sour-orange stock was utilized for the first plantings, and the trees budded high enough to prevent contact between the earth and the trunk above the union of bud and stock.

Foot-rot is confined to the crown and main roots of the tree, extending a foot or so above the ground and downward along the roots (Fig, 207). Its presence is first indicated by an exudation of gum, which forms in drops on the bark covering the diseased spot. Further examination at this time reveals a brownish coloration of the outer cortex and a de- 


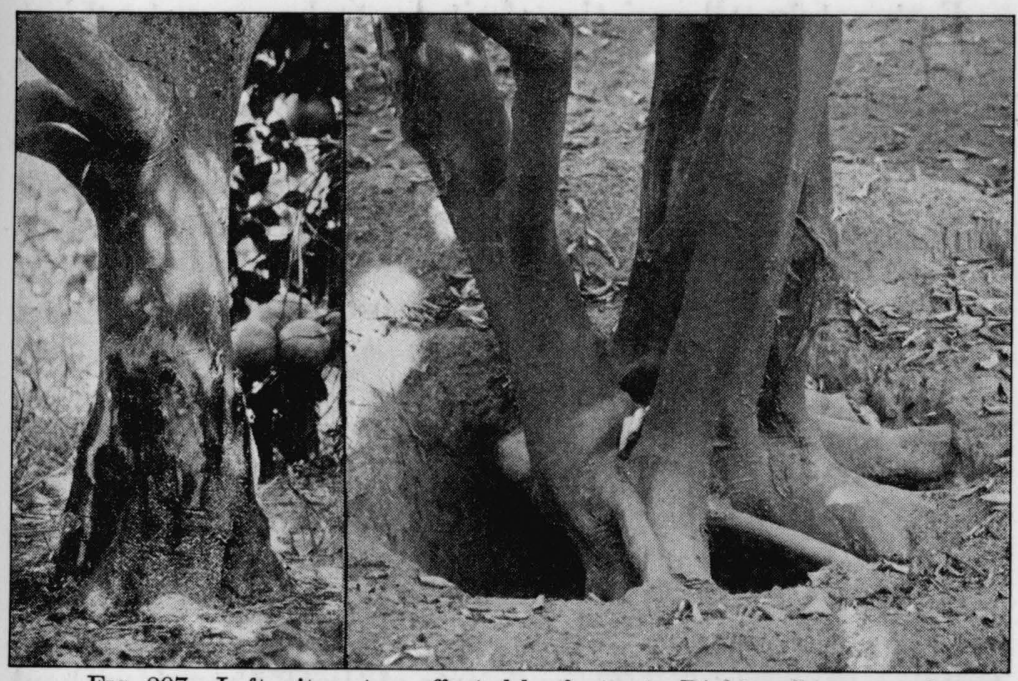

Fig. 207. Left, citrus tree affected by foot-rot. Right, soil excavated for treatment and aëration

cayed condition of the inner. The affected areas emit a fetid odor similar to that from a decaying orange. All plants, when attacked by a disease, strive to overcome it, and the trees attempt this by cutting off the affected portion by a wall of new tissues similar to that formed around an ordinary wound. Following this, the bark covering the spot dries up, breaks away from the adjoining parts, and drops off. The wood is then found to be decayed for a short distance beneath. The disease continues to spread until the trunk is girdled.

Though the tree still continues to bear fruit, its appearance is far from healthy; the leaves become yellow, the twigs and young branches die, and the whole tree assumes an unthrifty appearance. When the affected individual can be seen from a distance, it stands out in marked contrast to its neighbors. Unless the disease is checked in some way, the tree attacked eventually succumbs and has to be removed. 
Fortunately, all varieties of citrus stocks are not subject in the same degree to this dreaded disease. In order of footrot resistance they stand about as follows: Sour orange, rough lemon, trifoliate orange, grapefruit, and sweet orange. The sour orange is generally credited with entire immunity to the attacks of the disease. Under favorable conditions, even in districts where foot-rot is prevalent, seedling sweet orange trees or those budded on susceptible stocks may escape injury. Sanitary conditions surrounding the trees have a very important influence on the prevalence and virulence of the disease.

Cattle-penning, deep setting, a wet soggy soil condition, the use of rank organic nitrogenous fertilizers, planting in localities underlaid with hard-pan, faulty drainage, a shaded condition of the soil, and many similar circumstances and practices have been given as the causes of foot-rot. The disorder, however, is not due to any of these, though without doubt they have a deleterious effect on the general health of the tree and favor the development of the disease.

While foot-rot was long regarded as a parasitic disease caused by some fungus or bacteria, the exact causative agent remained unknown for many years. In 1916, Stevens succeeded in isolating a fungus, Phytophthora terrestria Sherb., from an active case of foot-rot in Florida, and there appears little doubt that the disease in the Florida citrus districts is caused by it. Probably it is also the cause of foot-rot in other regions, though this has not been definitely proven at this time. Diplodia natalensis is frequently associated with the disease and is doubtless an agent contributing to the progress of foot-rot.

As already indicated, many conditions bear an important relation to foot-rot, and a brief discussion will not be out of place. (a) Cattle-penning and pasturing, so often resorted to for the purpose of fertilizing the groves in years past, is a questionable practice. The sharp hoofs of the animals cut and bruise the bark on the crown roots, and thus this 
parasitic disease may be carried more rapidly from affected to unaffected trees. Also, the rank manure may act injuriously, and there are better means for supplying the requisite plant-food; the best orange is produced by the judicious use of commercial fertilizers. (b) Close planting is often practiced as a means for shading the ground. A moist or damp condition of the soil is produced about the tree, which, in the warm citrus climates, is exactly suited to the development of disease. It would be decidedly better to provide a surface mulch, either by the growing of leguminous crops or by a mulch of leaves and leaf-mold. Then air could be freely admitted, and the sunlight, one of the best germicides, allowed to reach the soil. (c) The piling of rubbish, old tin cans, palmetto roots, and the like, about the trunks of trees is strongly condemned. When a mulch of leaves or grass is placed close to the trunks, it should, from time to

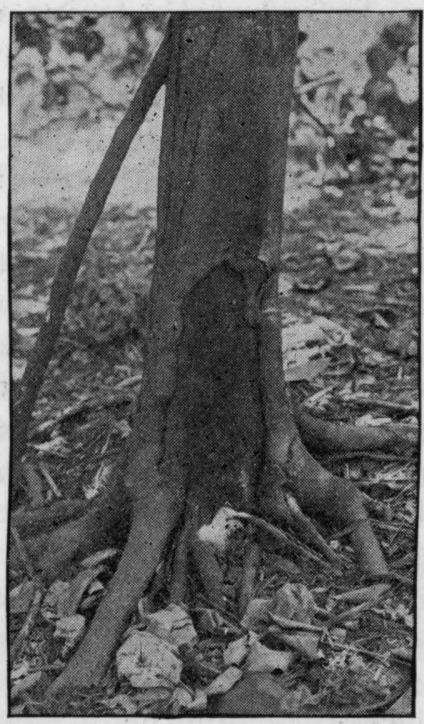

Fig. 208. Citrus tree attacked by foot-rot. An inarched sprout at the left. time, if the disease is present, be removed to allow the soil to dry out on the surface. If trees have been banked with earth to protect them from frost, these banks should be removed promptly in spring. $(d)$ Strict attention should be paid to drainage, so that no stagnant water is allowed among the trees. A soggy ill-drained soil is not conducive to the health of an orange tree. (e) When the basin method of irrigation is used, a cone of earth should be banked against the trees to keep the water from the trunks. This bank should be removed shortly after irrigating. (f) New groves should be set only on resistant stocks, and, where injury from frost is not 
feared, they should be worked a considerable distance above the ground. The disease may attack the trunk above the point of union, particularly if it is close to the ground.

Treatment.-Consists in removing, as far as possible, the detrimental conditions to which reference have just been made, and particular attention should be paid to everything conducive to the health of the grove. Plantings in which the disease is present should be examined carefully and frequently for small infections. The disease spreads rapidly, and a tree may be girdled before remedial measures are applied. The earth should be removed carefully from about the tree, avoiding injury to the healthy roots. This may be done with spade and trowel, and a stream of water from a power spray pump will also assist materially. With a sharp strong knife, or mallet and chisel, cut out all the diseased tissue down to the healthy wood; burn the material removed, and with a brush paint the freshly cut wood with Formulas No. 14, 15, or 16. The earth should not be replaced, or, if so, it is best to fill in with fresh porous soil. In closely planted groves a sufficient number of trees should be removed to let the light reach the ground. These can be set out in another plot of ground. Cultivators, plows, and harrows should be disinfected with carbolic acid after use in diseased groves and before employing them among healthy trees. As a preventive measure, use resistant stocks, as already indicated, and where trees have died out reset with others budded on sour orange, or rough lemon, as the soil conditions render necessary. Frequently, trees may be made to serve some years of usefulness by planting a number of small resistant stocks around the affected tree and inarching them above the injured parts (Fig. 208).

Scaly bark (Cladosporium herbarum var. citricolum Fawcett).

This citrus disease was first noted by the author early in 1904 on orange twigs from the Pinellas Peninsula, Florida. Since then it has appeared in a few other citrus districts in 
the state. While it is not so serious as some of the other diseases, nevertheless care should be taken to prevent wider distribution. The fungus causing the disease was isolated, identified, and named by H. S. Fawcett, in 1911.

Primarily scaly bark is a disease of the sweet orange. It has also been found on sour-orange and rough-lemon stocks. Grapefruit and oranges of the mandarin group are so resistant to scaly bark as to be almost immune. Usually it is a bark disease on twigs, branches, and trunks of trees. The fruit is also attacked but the disease is rare on the leaves.

On young branches, the fungus produces characteristic spots. In the early stages, the diseased areas appear on the green surfaces of the branches in the form of oily greenish yellow blotches. Later these crack and break open, showing the edges of the dead yellowish brittle bark. These diseased spots are well-defined, round, oval, or slightly irregular in outline. They are about one-fourth to one-half inch in

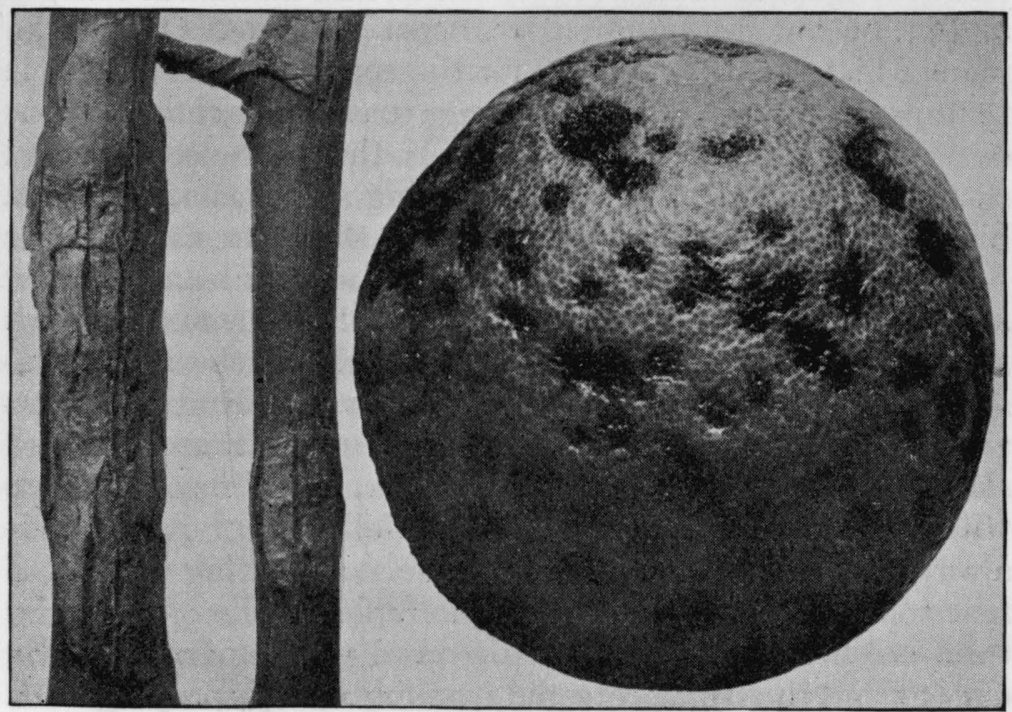

Fig. 209. Scaly bark on orange twigs and fruit 
diameter, rusty yellow in color, and elevated above the surrounding parts. Often the spots are so close together that they connect and form large areas of rusty scabby bark. As the disease progresses, the older branches and trunks become covered with rough scaly bark, and from this condition the disease derives its name. (Fig. 209.)

On the fruit, the disease forms depressed areas which may be isolated or so close together that they join. Sometimes the areas are in the form of ringed spots, with the rings depressed and the center remaining at its normal elevation. The fruits are rendered unsightly and unfit for market.

The disease takes about four months from the time of infection until it shows on the fruit, and it may continue to make its appearance until the fruit is ripe. On the younger twigs and branches, it takes about six months for the disease to develop after infection takes place.

Treatment. - As already noted, scaly bark is more severe on sweet oranges than on other citrus, and mandarin oranges and grapefruit are apparently almost immune. One of the plans which may be adopted for the control of the disease is to top-work infected sweet orange trees and change them over to tangerines or grapefruit. If this is done, the trees should be cut back severely, removing all twigs and smaller branches. The remaining portions of the trees should then be scraped thoroughly to remove all loose bark from diseased areas, and then thoroughly sprayed with bordeaux mixture, standard strength. Later the trunks and branches should be sprayed again and as many as four or five applications given throughout the year. All material pruned from the trees should be destroyed by burning. The plan of heading back without top-working may also be followed, but there is always greater danger of the disease reappearing than if a new top of grapefruit or tangerine replaces the old. If the trees are not severely attacked, the diseased parts may be cut out and the fruit protected from injury by spraying with bordeaux mixture, once in January, a second time before 
blooming, a third when the fruit is about three-fourths of an inch in diameter, and a fourth the first of August. It is preferable that bordeaux-oil solution be used for one of the applications to check scale insects. If this is not done the trees should receive separately an application of oil emulsion.

Gum diseases (Figs. 210, 211).

In addition to foot-rot and scaly bark, which have been discussed, a number of somewhat similar diseases cause gumming of the trunk, branches, and sometimes twigs. The more important are brown rot, Botrytis, Psorosis and Diplodia.

Brown rot causes the most damage to lemon trees in California. It produces a gum disease on the trunks of the trees and brown rot of the fruit, sometimes destroying much fruit while curing and after packing. The rot is due to a fungus, Phytopthora citrophthora.

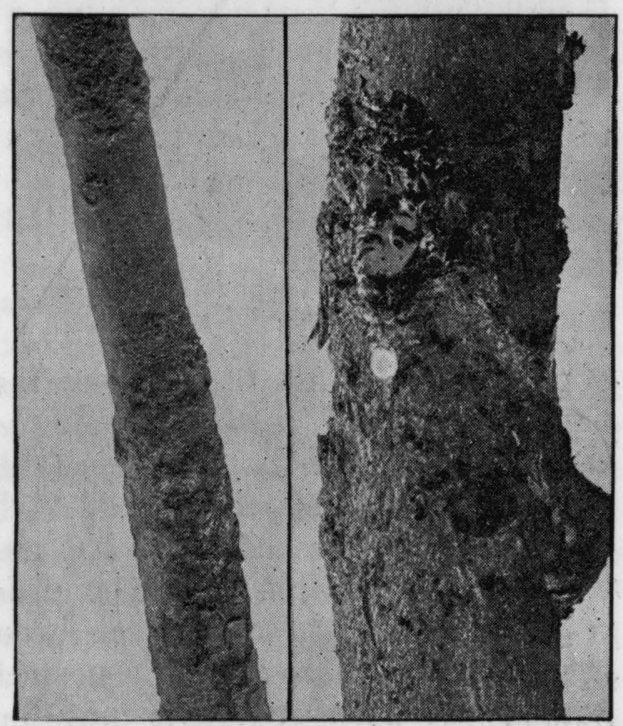

Fig. 210. Citrus branches affected by gum disease Botrytis, or gray gummosis, perhaps caused by Botrytis cinerea, is a gum bark disease of lemons in California. Psorosis is a scaly gum bark disease present in both California and Florida, principally on orange, tangerine, and grapefruit trees. Diplodia is common in both states on citrus trees. It is caused by Diplodia natalensis, and this fungus also is responsible at times for the rotting of citrus fruits-a form of stem-end rot: 
As has been noted, the causative agents of some of these diseases have been isolated and identified, but those of others are unknown. Generally, gum diseases are found on the

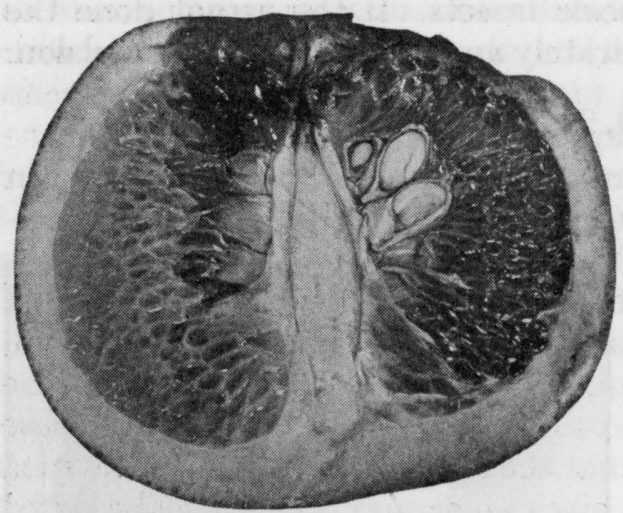

FIG. 211. Grapefruit decayed by Diplodia trunks and on the larger branches, trees of considerable size and age being attacked. Usually, diseases of this group are easily recognized by the following symptoms: The bark covering diseased parts is scaly or gum-soaked, or both. The dead bark areas are discolored and usually longer up and down the tree than they are wide. Drops of gum ooze from the bark. These may be liquid or they may have become hardened. In some cases, gum is plastered on the outside of the diseased areas, like varnish, or the outer bark may have dropped off and left the roughened inner bark exposed. The tree attacked has an unhealthy appearance.

Treatment.- Often certain conditions are in some measure responsible for these diseases becoming established, and these should be avoided or corrected so far as possible. Among predisposing causes may be mentioned mechanical injuries to the bark, deep planting, poor drainage, excessive irrigation, and poor soil aëration. The use of sour-orange stock is recommended whenever possible, as it is very resistant to gum diseases. Sometimes, also, high budding on this stock is advantageous, thereby removing the susceptible top a distance from the ground. This also allows free air circulation beneath the branches and permits the sun to reach a larger part of the exposed soil. The diseases themselves may be treated by cutting or scraping away the injured 
parts until nothing but clean healthy bark and wood tissue is left. The clean surface should then be painted with bordeaux paste or protexol solution (Formulas No. 14 or 16). It should be applied liberally and near-by areas covered as well. When it has dried, the wound should be painted with good paint. The trees should be inspected from time to time to detect any indication of the reappearance of the trouble.

\section{Damping-off (Fusarium, Rhizoctonia, and Sclerotium).}

Citrus seed-beds are sometimes injured by a number of fungi which attack the seedlings at the surface of the ground, girdle and kill them. Usually the first indication of the fungi is the dying and yellowing of the little plants. Close examination will show that the stems are dead and blackened at the ground, and the black color may sometimes be noted in advance of the destruction of the top.

Treatment.-When damping-off appears in the seed-bed, prompt measures should be taken to prevent spread. Dead plants should be removed and also those adjoining them for some distance along the rows. If a space of six to eight inches shows diseased individuals, then the plants on either side of them should be removed for a distance of a foot or more. Following this, the ground should be thoroughly soaked with bordeaux mixture. Seed-beds are usually grown under irrigation. When the plants are young, just as little water should be used as will keep them in good condition. They should be watered thoroughly once a week or so, and in the intervals the surface of the ground should be scratched and kept finely pulverized and dry. Any crust which may form on the surface of the soil among or adjacent to the young plants should be broken up. Sometimes it is advisable to remove the soil from the stems of the young plants to a depth of an inch or more, exposing their crowns, and to spray them thoroughly with bordeaux mixture. Usually these precautions will protect the seedlings while 
they are tender, and as soon as they have attained some size the tissues become hard enough to resist the disease.

Wither-tip, anthracnose, bloom-blight, leaf-spot (Colletotrichum gloeosporioides Penz.).

This disease of citrus trees is widely distributed. It occurs in all the Florida districts, in California, particularly in the coastal sections, and is generally present in all American citrus regions. Its attacks are worst in the moister climates or in years of greatest moisture, and its inroads are checked by dry conditions of soil and climate. It is known by a number of names, depending on the part of the tree injured. Besides affecting branches, twigs, leaves, and large fruit, it is responsible for some of the dropping of young fruits and the shedding of flowers before and after opening. All of the latter, however, must not be charged to this disease, because young fruits and flowers may drop from other causes. So far as known, no species of citrus is exempt from its attacks, although a similar disease on limes is attributed to a different fungus, Gloeosporium limetticolum Clausen. It may attack trees from seedlings to old age. Well-grown nursery

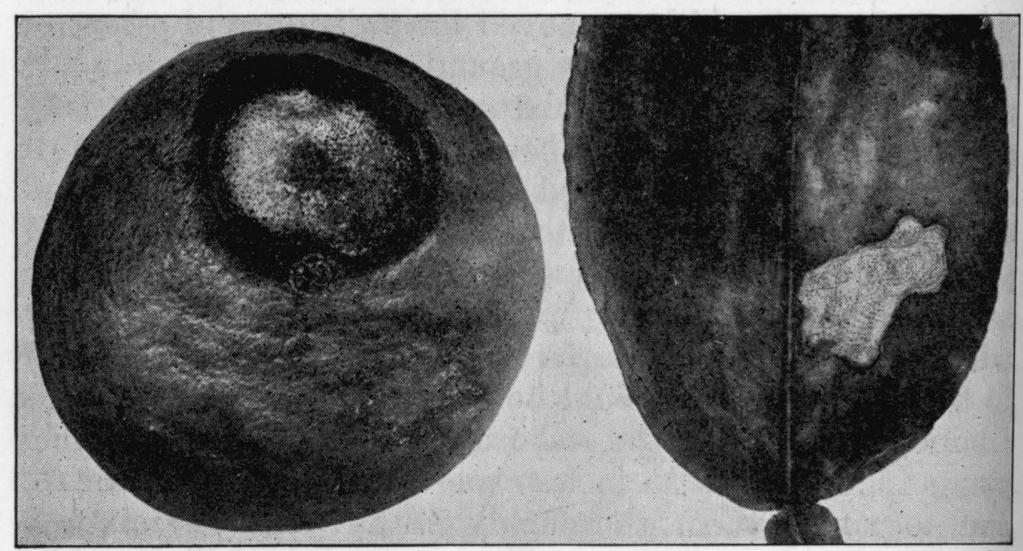

FIg. 212. Anthracnose on pomelo fruit and leaf 
trees are usually free from it because of their healthy vigorous growth.

The fungus is not an active virulent parasite, but when trees are weakened or injured by other causes, such as overcropping, starvation, dry weather, frost, mistakes in spraying or fumigating, attacks of insects and other diseases, it affects the weakened parts and adds greatly to the unhealthy condition of the trees. When firmly established, it progresses rapidly and does much damage to different parts of the tree, interfering with its fruitfulness and often destroying much of such fruit as is produced. If trees are kept in healthy vigorous condition at all times, it is difficult for the disease to get started.

Wither-tip on the twigs.-This phase of the disease affects twigs and branches or tips of twigs. When attacked, they soon wither and die. They may have suffered some mechanical injury or may have been injured, devitalized, or partly killed back by some of the causes already enumerated. The leaves wither or turn yellow and drop. Larger branches are attacked and killed directly by the fungus or by poisonous substances produced during its growth. The disease progresses, making its way from the outer and smaller twigs and branches to larger ones nearer the center and eventually large portions of the tree top are either killed outright or so weakened and injured as to be useless. Such fruit as may start to develop drops before maturity. Trees severely infested can scarcely recover without help, but if only slightly affected they may throw off the disease if in vigorous condition. A wither-tip diseased tree is marked by numbers of dead twigs and branches, yellowed leaves, stunted growth, a general out-of-condition appearance and leaves in large numbers on the ground beneath it.

On the fruit.-Anthracnose is the name given to the disease when it causes spotting of the fruit. In size the spots may vary from a quarter of an inch to those several inches in diameter. When first noted, they are reddish or 
reddish brown in color, but when fully developed they are black or dark brown, owing to the large number of fruiting bodies, circular or nearly so, and depressed below the general level of the surface. When the disease has progressed far enough, the skin of the fruit is destroyed and decay results. Sometimes the spots appear as numerous minute reddish specks on the fruit. These often enlarge, join together, and cover larger areas of the surface. The injury by the anthracnose form of wither-tip is most likely to develop on matured or nearly matured fruit. (Fig. 212.)

On the flowers, bloom-blight.-Flower-buds and flowers of citrus may be attacked by the wither-tip fungus. If unusual numbers of unopened flowers drop during development, and the disease is present in the tree-top, it may be suspected that it is responsible, though this dropping may be due to thrips or brought about by other causes. If wither-tip has caused the dropping, careful examination of the flowers and buds will show the presence of numerous small red specks, in marked contrast to the normal white color. On infected trees, the falling of the flowers may be followed by dropping of the developing fruit in its younger stages. The attacks of the fungus on the flower-buds, flowers, and small fruits may result in greatly reducing the crop.

On the leaves, leaf-spot.-Often healthy leaves suffer mechanical injuries or spots may develop as a result of sunburn and frost. Insect attacks also may leave weakened spots in the leaf tissue. In these weakened or injured areas the wither-tip fungus grows and invades the surrounding tissue. The spots formed are somewhat circular, yellowish gray in color. As the disease develops, minute dark specks are noted over these areas. (Fig. 212.)

Wither-tip and the manifestations described are attributed to Colletotrichum gloeosporioides Penz. It is an open question whether the name $C$. gloeosporioides does not cover a group of fungi, rather than a single species. If a single species, then the variation within it is very great. 
Burger, ${ }^{1}$ after very careful investigation of the morphology of the fungus, states that it is a polymorphic species, made up of a number of different strains, and that mutations occur in cultures.

As already stated, when the fungus has grown for a sufficient length of time in the diseased tissues of the host, small black pustules may be noted on the affected areas. These contain the spores of the fungus, and under favorable conditions they are forced out of the pustules in pinkcolored masses. The spores are spread in various ways by the wind, by birds, insects, and other agents. They find lodgment on parts of the tree and under suitable conditions grow and repeat the damage done by the fungus which produced them. From year to year the pest is carried over on diseased parts of the tree.

Treatment.-(1) Keep the trees in vigorous healthy growth. The disease cannot make headway in stronggrowing trees. Fertilize and cultivate well. (2) Watch for weakened growth or branches and dead twigs in the treetops. Prune them out, removing even the very small pieces. The work should be done thoroughly and well; no stubs or dead parts should be left. Prune during dormant periods, preferably in winter. Do not prune when new growth is developing as it is so easy to injure and infect the young shoots and leaves. (3) Spraying in connection with pruning is very helpful. Use bordeaux-oil mixture (4-4-50), with 1 per cent oil as emulsion, following the winter dormant season pruning. Spray the trees when in fruit with ammoniacal solution if the disease appears. If the blossoms are attacked, spray at once with bordeaux mixture (3-3-50), and oil. This may cause some of the bloom and young fruit to drop, but some injury from this source is preferable to heavier losses from the disease. Usually, these attacks on the flowers can be warded off by timely advance pruning and spraying.

1 Burger, O. F. Variations in Colletotrichum gloeosporioides. Journal of Agricultural Research, Vol. XX, No. 9. Washington, D. C., Feb. 1, 1921. 
Citrus scab (Sphaceloma fawcettii Jenkins).

The fungus causing citrus scab was long classified as Cladosporium citri Massee, but it has now been identified as Sphaceloma fawcettii Jenkins, a new species. This disease may attack, to a greater or less extent, the leaves, twigs, and fruit of many kinds of citrus fruits. Within a given species, certain varieties may be very susceptible to the disease and others practically immune. Of the whole group, the sour orange is probably the most severely attacked, and there appears to be no difference between the sour orange and bitter sweet in this particular. In America the sour orange is not cultivated except as a nursery plant, and the damage caused by the disease is in the stunting of nursery stocks used in the propagation of other species. The lemon is severely attacked, and when lemon culture is undertaken in sections where the disease occurs, scab is a serious drawback in the growing of marketable fruit. The greatest commercial injury caused by scab is to the pomelo crop, in those regions where its cultivation has reached large proportions. All varieties of grapefruit are not attacked to the same degree. Hall is the most susceptible sort while Marsh is the least.

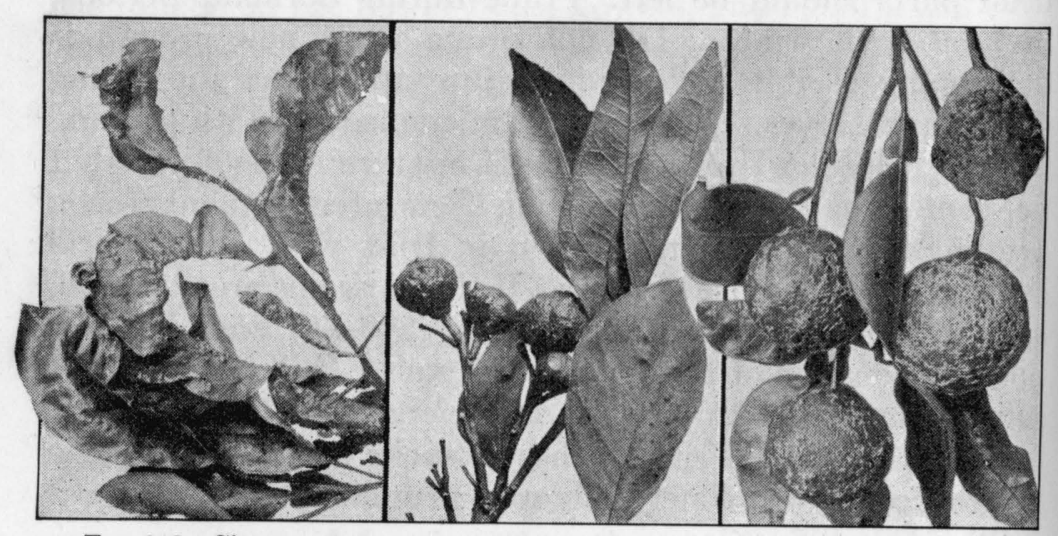

FIG. 213. Citrus scab on sour orange leaves and twigs (left), Satsuma fruit (center), and pomelo fruit and leaves (right) 
Duncan, Walters, and Foster are less affected than Hall. Triumph appears to be entirely resistant. Satsuma oranges are susceptible to the disease. The other mandarin or kidglove oranges are attacked but not often severely. The Clementine orange (a cross between tangerine and sour orange) is very severely affected. Among the minor citrus fruits, the Rangpur lime, the Otaheite orange, and the tangelos are much injured by scab. Citrus mitis, represented by the calamondin, is susceptible and may be severely attacked. Citrus scab occurs on the shaddock and Poncirus trifoliata is sometimes slightly infested. Hybrids of the latter are also susceptible. Sweet oranges, though the disease sometimes attacks the fruit slightly, may be considered immune and the same is true of the kumquats.

Citrus scab was probably introduced into America from the Orient on Satsuma orange trees, which it usually attacks only very slightly though occasionally with some severity. It has become established in the Gulf Coast country, in the West Indies, Central America, South America, and in the Orient from India to Japan. The disease is definitely limited in its spread by certain climatic conditions. It has become most troublesome in regions of heavy dews and rainfall and high humidity. Scab is not a disease of dry climates. It is not known in California, where it has doubtless been introduced many times. In those regions where scab occurs, its virulence may vary greatly from year to year, depending on the climatic conditions prevailing during the stage of growth when the trees are susceptible to attack.

Scab has attracted more attention in recent years than formerly in Florida, owing to the large increase in grapefruit plantings. It was feared that the causal fungus was increasing in virulence and adapting its growth to species and varieties of citrus previously immune. According to Winston, who made a thorough investigation of the disease, this is not the case.

Scab attacks the growing parts of the tree-top while very 
tender and before the tissues become developed and hardened. It appears unable to attack the older parts; in fact, after the leaves are about one-half inch wide and the fruit about three-quarters of an inch in diameter, they are immune. (Fig. 213.)

As the leaves are unfolding, the fungus gains entrance and forms small, pale orange, usually somewhat circular elevated spots. As growth develops these infections become well-marked warts or excrescences on one side of the leaf, often with a conical depression on the opposite side. The centers or tops of these warts become covered with a scabby corky tissue which though at first pale yellowish orange in color later become pink, then olive-drab and finally grayish black. Badly infested leaves become very much twisted and distorted, having little resemblance to normal foliage. The infected spots run together and cover large areas with corky, scabby growth. Grapefruit leaves generally are not so heavily infested as those of the sour orange. On the twigs, the characteristic effects of the disease are the development of small masses of the same corky growth on their surfaces. The small centers of infection may remain entirely separate or they may run together to form larger somewhat elevated ones. Twigs when severely attacked, as on the sour orange, are sometimes malformed, but owing to the thicker woody under tissue the distortions are not often seen. In severe cases the twigs are frequently killed. Grapefruit twigs usually show very limited infection. When the fruit is attacked, its beginning is marked by the same small spots where the fungus starts. These become cream-colored passing to olive-drab and grayish black. This change in color is accelerated by saprophytic fungi gaining entrance and growing in the dead or injured scabby tissue. The fruit is often distorted and misshapen; if severely infested it may drop. Citrus scab is one of the factors in premature fruit dropping. On grapefruit, the infected areas flatten out and the fruit which reaches maturity shows these as splotches of 
considerable extent. Fruit when badly injured is unfit for market while slight attacks lower the grade. From both these causes the damage is large. On sour orange and lemon fruit the scab areas are elevated above the normal skin and covered with the dark gray corky tissue. The entire surface of the fruit is covered in severe cases. (Fig. 213.)

The fungus causing scab gains entrance to the tissues of susceptible species of citrus when very young and tender. It is carried over from year to year in infected leaves and twigs and probably spreads by means of diseased fragments and parts of the mycelium which break up into spore-like parts that serve the same purpose. It does not live over from season to season in ripe fruit. The optimum conditions for the spread of the disease are proper growth in the host plant, a plentiful supply of moisture, and a temperature around 68 degrees Fahr. It has been thought that the growth of the fungus was affected materially by high temperatures, and that periods of rather cold damp weather were more conducive to its attacks. It is doubtless true that cool weather causes a slower development of tender growth on the host plant, and this growth is susceptible to attacks over a longer period, but the synchronizing of favorable growth and moisture conditions is the real factor in bringing about heavy infestations. Dry weather during those periods when new flushes of growth are developing provides a definite check to the spread of the disease and the virulence of its attacks.

Treatment.-(1) The removal of those sources of infection not connected with fruit production in a grove. Very frequently in a grove trees of rough lemon and sour orange are present; these usually carry the disease and act as foci of infection. They should either be removed or worked over to commercial citrus varieties. Rough lemon and sour orange sprouts from the stocks on which the planting was propagated should be eut out and burned whenever they appear. (2) In groves where scab has become firmly estab- 
lished, it is difficult to check without pruning out the old sources of infection. This should be done in advance of spring growth, going thoroughly over the trees and pruning away the diseased branch tips and leaves. This rubbish should be destroyed by burning. (3) Since scab attacks and gains entrance into the tissues and tender growth, it is necessary to spray very early if the fruit is to be protected. If the infestation has been serious in previous years, it may be well to spray thoroughly with bordeaux mixture (3-3-50), before the growth starts. Generally, however, commercial control of the disease can be secured with one thorough spraying at the time the petals drop. Since this spraying is mainly for the protection of the young growth, it is very important that it be well done. (4) Seed-bed and other nursery stock before budding can be kept almost entirely free from scab with considerable gain in size by watching for the new flushes of growth and spraying with bordeaux mixture. When dormant, budded with grapefruit buds, the stocks should be cut off in spring well in advance of growth and the stock tops should be burned.

\section{Melanose, stem-end rot (Phomopsis citri Fawcett).}

This citrus disease, found in Florida, is apparently unknown in California. It has been reported from Australia, Jamaica, Porto Rico, and elsewhere in the West Indies. In Florida it is more prevalent in the northern and central portions than in the southern. Perhaps climatic conditions affect its distribution.

The term melanose was applied to that form of the disease which manifests itself in small crust-like yellow to darkbrown or black dots. These dots measure $\frac{1}{100}$ to $\frac{1}{16}$ inch in diameter and consist of elevated areas in which the plantcells are filled with dark gum. Stem-end rot refers to a soft decay of the fruit, which begins at the stem end and quickly brings about its complete destruction. It is best to discuss these two manifestations separately. 
In infested trees the fungus, Phomopsis citri, which causes melanose, is carried over from year to year in dead twigs and branches. From these the spores which produce the disease are given off in large numbers. Under favorable moisture conditions the spores germinate and the disease starts in any of the young tender growing parts. Twigs and leaves are susceptible to its attacks over a period of about six to eight weeks from the beginning of growth, while fruit may be attacked over a considerably greater length of time, amounting to as much as four to five months after blooming.

Melanose.-In this form the disease is present on twigs, leaves, and fruit. It is not found on older branches because as the bark grows and sloughs off on the outside, the marks of the disease disappear. Twigs attacked show characteristic dotting or spotting, with the small elevated dots already referred to. These marks are dark and dull in color. If the infestation is heavy, the twigs are destroyed, the fungus continues to grow in them and gives off its spores for a long time after the twigs themselves are killed. The dots on the leaves are similar to those on the twigs. When the leaves and twigs are badly affected the leaves drop off. Very frequently the dots or spots on the leaves, as will be noted later on the fruit, form patterns or markings in rings, curves, and straight lines, which are due to the spores being washed down by water and covering certain areas. It is to the surface of the fruit that melanose does the greatest damage. The marks cannot be washed off and if scraped away the underlying tissues are injured. Much of the fruit is made unsightly and its grade is either reduced or rendered unfit for sale. The surface of the fruit may be spotted all over or the dark dots may be arranged in streaks, rings, bands, and irregular groups (Fig. 214). In heavy infestations the whole surface may be covered so that cracks or splits occur around certain areas, and the exterior of the fruit becomes very unsightly.

Stem-end rot.-Whenever the characteristic markings of 
melanose appear on twigs, leaves, and the exterior of the fruit, stem-end rot may be expected to develop. It may affect green fruit early in the season, or it may not appear until the fruit has reached maturity, and often not until the fruit has been picked, packed, and is on its way to market. It is believed to gain entrance into the fruit through the stem or button. It may be present in the latter when the fruit is gathered, and conditions in the packing-house may favor its further and rapid development. This form of the disease manifests itself on the fruit by a softening at the stem end (Fig. 214). From the infection around the calyx the decay progresses rapidly downward, and when about onethird to one-half of the fruit has been destroyed, fingerlike projections usually protrude downward toward the stem end, following along the lines of division between the pulp sections. Before the fruit shows decay all the way down, a soft spot usually develops on the stylar end, the disease having progressed through the pith.

Treatment.-Melanose, in the form in which it appears on leaves, twigs, and the outside of the fruit, is fairly easy to combat, but often the control

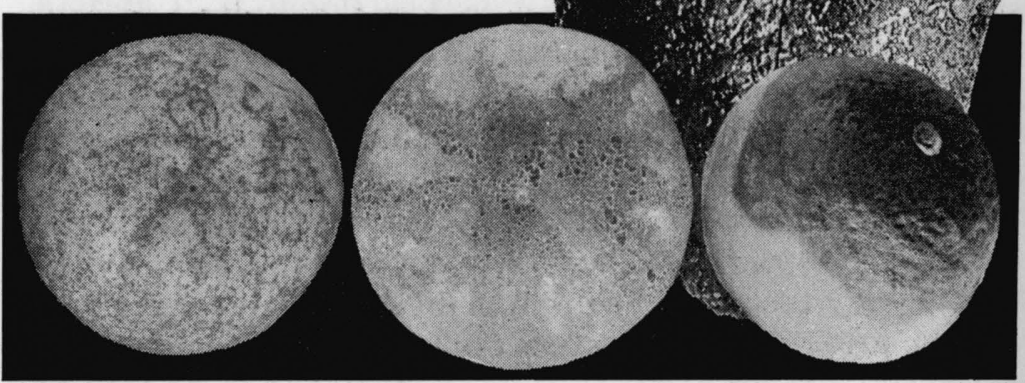

FIG. 214. Two fruits at left showing melanose spotting. Fruit at right with melanose stem-end rot. Above, leaf attacked by melanose 
of stem-end rot is more difficult. While the value of careful and thorough pruning out of all the dead wood has been questioned, it is of considerable assistance. In spring, between April 1 and 10, in most parts of Florida, the trees should be sprayed thoroughly with bordeaux mixture (3-3-50), with one per cent oil, as oil emulsion. This spraying should be timed as nearly as possible to a date shortly after the blooms have dropped. Generally this will give good commercial control. If the disease has gained a strong foothold, it may be wise to make a second application between May 1 and 10. This schedule, if carefully followed for a few seasons, should reduce the disease to a point at which it will give very little trouble, even though there may have been a severe attack.

The removal of the buttons from fruit by gassing, after it has been gathered for market, as has been shown by Winston, Fulton, and Bowman, very materially reduces the losses from stem-end rot. The handling of the fruit at low temperatures is also of material assistance, and pre-cooling and shipment under refrigeration will still further eliminate losses from this cause.

Ripe fruit rots - green-mold (Penicillium digitatum Sacc.) and blue-mold (Penicillium italicum Weh.).

During the process of picking and preparing for market, citrus fruits are sometimes injured slightly. The cell structure of the rind is broken into and the blue and green molds gain entrance. Usually one or the other, or both, are present in every packing-house and grove in the citrus districts. Weather and growth conditions add to the difficulties. Sometimes they may gain entrance through thorn-pricks or branch injuries before the fruit is gathered.

During the last quarter of a century or more, attempts have been made to reduce the damage to fruit by ripe rots. The favorite plan has been to wash or immerse the fruit in a solution containing some substance that would destroy the spores of the rot and kill the mycelium, if not too deep in the 
fruit tissues. Copper sulfate, iron sulfate, permanganate of potash, formalin, and potassium alum have been used with some measures of success. On the whole, the results have not been satisfactory enough to bring about the general use of any of these substances. Practically all citrus fruits are washed before packing, and the addition to the wash-water of any substance which will reduce damage by ripe rots is simple. No change in packing-house procedure would be required.

More recently, Barger and Hawkins ${ }^{1}$ have secured results which indicate that blue-mold may be controlled largely and economically by immersing citrus fruits in a $\mathbf{2 . 5}$ per cent borax solution before packing. Further experiments may justify the use of borax in a large way. The protection of fruit against some decay-causing spores between packing and consumption is entirely feasible. Under no conditions, however, can immersion in a fungicidal solution be expected to take the place of careful handling of fruit during picking and packing.

${ }^{1}$ Barger, W. R., and Hawkins, L. A. Borax as a Disinfectant for Citrus Fruits. Journal of Agricultural Research, Vol. XXX, No. 2, pp. 189192. Washington,D.C., Jan. 15, 1925.

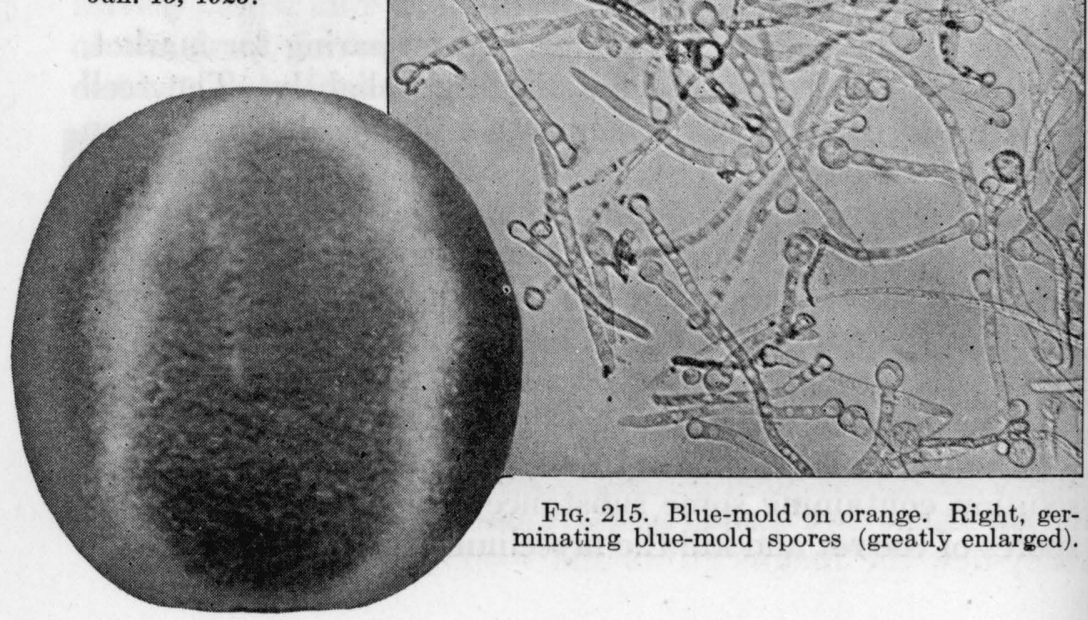


Sooty-mold (Meliola camellice Catt. Sacc.).

Sooty-mold is widely distributed throughout the sections where citrus fruits are grown. It occurs as a sooty-black covering on the leaves, fruits, and twigs of many plants, and is intimately associated with various insects belonging to the families Aleyrodidæ, Coccidæ, and Aphididæ. In Florida it follows Saissetia olece on Nerium Oleander and Persea carolinensis; Aphis gossypii on the orange, eggplant, and many other herbs, shrubs and trees; Coccus hesperidium, Ceroplastes floridensis, Icerya purchasi, Dialeurodes citri, and other insects on citrus trees. In short, it is found with all the scale and allied insects which exude honeydew in any considerable quantities.

The fungus is a saprophyte and is dependent on this honey-dew for its sustenance. The insects already referred to are gregarious in their habits, consequently the honey-dew accumulates in considerable quantities on various parts of the plant, and in this substance the fungus lives. The black covering is composed of its vegetative threads. A number of different kinds of reproductive bodies are produced, and, through the agency of the wind, are carried about from tree to tree. Wherever suitable food material is found, there the fungus develops. (Fig. 216.)

When sooty-mold follows the attacks of the whitefly or allied insects occurring in enormous numbers on citrus trees, much damage results. The whitefly spends a great portion of its life on the under sides of the leaves. The honey-dew exuded by it falls upon the upper sides of the leaves beneath and upon the twigs and the stem ends of the fruit. In this honey-dew the fungus grows and soon covers the trees with 
a thick, black, sooty covering, so that from a distance they appear covered with a liberal application of stove-black.

Sunlight is necessary to the leaves and the black screen of fungal threads prevents the light from reaching them. Their natural functions are interferred with, and the tendency is to keep the tree in an unhealthy condition. Often the yield of bearing trees is greatly lessened as a direct consequence.

Undoubtedly, the quality of the fruit is impaired and the normal development of sugar, acids, and solids affected. The uniform ripening and coloring of the fruit is interfered with, for where covered by the sooty fungus, the skin remains green while the parts free from it color normally, the result being a mottled green and orange fruit.

Treatment.- The insects with which the fungus of sootymold is associated should be controlled, for when they are destroyed the fungus disappears. The sprays usually employed against whiteflies and other insects, particularly miscible oil and fish-oil soap, are effective in loosening and breaking up the black covering so that it falls away from the leaves, fruit, twigs, and branches.

\section{BACTERIAL DISEASES}

Very few diseases of bacterial origin affect citrus. Up to 1925 only one disease of primary and one of secondary or minor importance have been reported in the citrus districts of the United States. These are citrus canker and black-pit. The former is a very serious disease and at one time threatened the complete destruction of the citrus industry of Florida, while the second, occurring in California on citrus fruits, is not important. Other diseases of this same group are doubtless present on citrus trees elsewhere in the world, and every reasonable effort should be taken to prevent their gaining a foothold in American citrus regions. Since 1915 some safeguards against their entrance have been afforded through federal and state quarantine regulations and their enforcement. 
Citrus canker (Pseudomonas citri Hasse).

About 1910 or 1911, this serious disease was brought to the United States on citrus trees from the Orient. It gained a foothold at about the same time in a number of the Gulf Coast and Florida citrus sections. Before the malignant nature of canker was known, or the fact that it was an unidentified citrus disease new to America, many foci of infection were established and the industry in these districts was threatened. At an early date it was observed to be extremely virulent and infectious, indeed, long before the bacterium which causes it was isolated and identified as new to science. It was further noted to be unsafe to touch or handle diseased trees, and it was soon learned that canker could be spread or carried by any agent or means which might come in contact with virile germs on an infected tree. Fortunately, early in its American history, the usual diseasecontrol methods, such as pruning and spraying, were recognized as futile, and the only plan of handling the pest which gave hope of success was to stamp it out by completely destroying infected trees by burning where they stood. This was accomplished by spraying kerosene with a pump, setting fire to the spray as it issued from the nozzle and using the flame as a torch.

The practical stamping out of canker is one of the most interesting chapters in disease control. The names of Byrd, Krome, Tenny, Sterling, and Rolfs are associated with the early campaign against citrus canker, and the results secured in this initial work are a tribute to their ingenuity, foresight, and determination. In Florida, it was not until the passage of the State Plant Act of 1915 placed the work under the State Plant Board that the general campaign of freeing the state from the disease was undertaken on a farreaching, systematic basis. Wilmon Newell was called to take charge of the program and probably for the first time in history a pernicious disease was mastered. Florida owes an everlasting debt of gratitude to the man. The disease may 
appear again, but the citrus industry is safe. Between 1913 and 1923 more than two million dollars of private, state, and federal funds were spent in the fight in Florida alone. In the other Gulf States the history of the war waged against citrus canker was much the same.

The disease is well described by H. E. Stevens ${ }^{1}$ as follows:

"The distinguishing feature of citrus canker as observed in the field is the characteristic spotting produced on the fruit and foliage. As usually seen, the infection appears as small, light brown spots, from less than $\frac{1}{16}$ to $1 / 4$ of an inch in diameter. The spots are usually round and may occur singly, or several may run together, forming an irregular area. This last condition usually occurs on fruits. The spots are raised above the surrounding healthy tissue, and are composed of a spongy mass of dead cells, covered by a thin white or grayish membrane. The membrane finally ruptures and turns outward, forming a lacerated or ragged margin around the spot. (Fig. 21\%.)

"On the leaves.- Infections first appear as small, watery dots, with raised convex surfaces. These dots are usually of a darker green than the surrounding tissue. Sometimes, however, the surface of the spots is broken as soon as they appear. Spots may appear on either surface of the leaf, but they do not at first penetrate through the leaf tissue. They gradually increase in size, change to a light brown and become visible on both sides of the leaf. In the older spots one or both surfaces may be bulged or raised, and such spots are commonly surrounded by a narrow, yellowish band or zone. In the more advanced stages the surface of the spots becomes white or grayish, and finally ruptures, exposing a light brown spongy central mass. Old spots soon become overgrown by saprophytic fungi, and may appear pink or black on account of these fungous growths. (Fig. 21\%.)

"On the fruits. - The spots are very similar to those

\footnotetext{
${ }^{1}$ Stevens, H. E. Florida Citrus Diseases. Bull. 150., Fla. Exp. Sta., pp. 6268. Aug., 1915,
} 


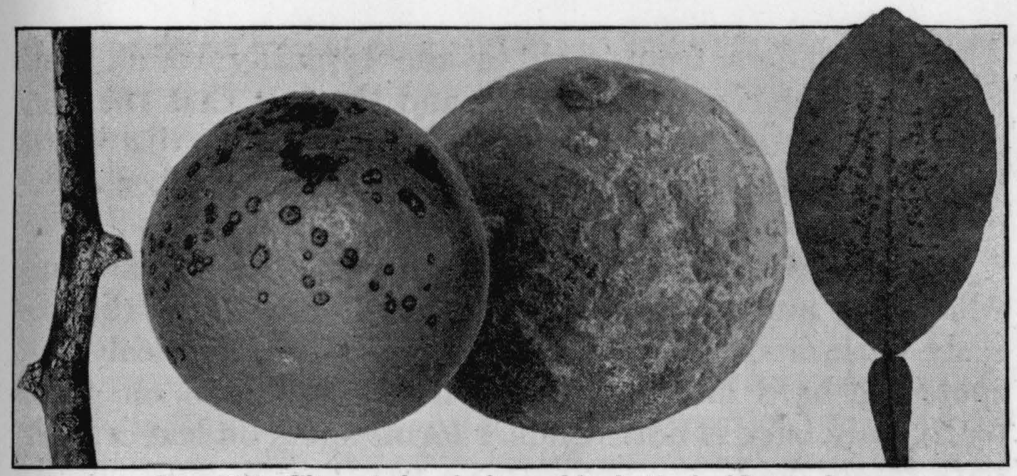

FIG. 217. Citrus twigs, fruits and leaf attacked by canker

formed on the leaves. They project, and retain a circular outline. They do not penetrate far into the rind. They may be scattered over the surface, or several may occur together, forming an irregular mass. Gumming is sometimes associated with the spots formed on the fruits. Canker apparently does not cause a rot of the fruits directly, but opens the way for other fungi to enter and cause infected fruits to rot. (Fig. 217.)

"The spots on young twigs are like those on the leaves and fruit. On the older twigs they are more prominent, and more or less irregular in shape. This is especially true of old spots. They show the same spongy tissue as is found in the spots on the leaves, but assume a cankerous appearance and the surface membrane completely disappears. These spots or cankers are formed in the outer layers of the bark tissues, and do not penetrate into or kill the wood. The spots once formed in the bark are persistent and are not readily sloughed off. They may remain for a long time, and form centers from which infections may readily spread.

"Canker distinguished from other diseases.-Other citrus diseases with which canker may be confused are scab, scalybark and, possibly, anthracnose. It can, however, be readily distinguished from any of these by noting the following points: 
"1. It differs from scab in the typically round spots produced, the size of the spots, and the fact that the spots penetrate through the leaf tissue. It does not distort the leaves. There are no wart-like projections. Canker occurs on older wood; scab does not

"2. Canker differs from scaly bark in the size of the spots, which are much smaller and more circular than those of scaly bark, and the spongy nature of the spots; scaly-bark spots are hard and glazed. Canker is common on grapefruit; scaly bark is not. Canker forms spots on leaves; scaly bark rarely does.

"3. Canker differs materially from anthracnose in the size of the spots, which are much smaller than those of anthracnose. Canker spots are raised; anthracnose spots are sunken. Canker has spots of a spongy character; those of anthracnose are hard. Canker occurs on young shoots and older twigs; anthracnose does not.

"Cause.-Citrus canker is a bacterial disease. It is caused by Pseudomonas citri, a short rod-shaped, motile organism that can be seen only with a compound microscope. These bacteria are found in countless numbers in the canker spots and they are exuded in masses whenever the spots become moistened by rain or dew. Drops of water contaminated with bacteria spread the disease and when the organisms come in contact with citrus tissue, especially the tender foliage, twigs and fruit, new canker spots are rapidly formed. In the older bark on the branches and trunks of trees the bacteria probably gain entrance through small wounds or cracks.

"The disease may be spread some distance by the wind and beating rains, or any agent coming in contact with the moistened foliage of an infected tree is apt to spread the disease to other trees.

"Citrus canker attacks all varieties of citrus trees of commercial importance in Florida, except the kumquat. Any part of the tree above ground may become infected. 
Grapefruit is apparently most severely attacked, the infections occurring on leaves, twigs, branches, and fruits, and occasionally in the bark of exposed roots. Poncirus trifoliata is probably next in susceptibility and then follow some of the varieties of sweet orange. According to E. W. Berger, whose statement is based on field observations, the different varieties of citrus are susceptible to the disease about in the order named: Pomelo (grapefruit), Poncirus trifoliata, Key lime, navel orange, Satsuma, tangerine, mandarin, King orange, and lemon. The writer has observed infections on all parts of $P$. trifoliata above ground, except on the fruits. The disease has been observed on leaves, twigs, and fruits of the navel and some other varieties of sweet orange. Scanty infections have been found on the leaves and twigs of the Satsuma, tangerine, and lime. The rough lemon seems to be quite susceptible. Almost any of the varieties of citrus may be severely attacked by canker, if all the conditions are favorable for the development of the disease. Inoculations made on sweet orange, $P$. trifoliata, rough lemon, and grapefruit trees indicate that these varieties show about the same degree of susceptibility to infection, where growth and moisture conditions are the same. The young growth is more readily attacked by canker, but tissue of any age may become infected. Canker has been observed to develop in the bark of grapefruit branches that were two or three years old."

Treatment.-The only safe treatment for canker is to destroy the infected trees with fire and disinfect the soil where they stood and for some distance around with formaldehyde. This should be done only by state or government authorities and all canker infections should be referred to them.

Black-pit, citrus blast (Bacterium citriputeale Smith).

In 1913, Clayton O. Smith described a disease of lemon fruit in southern California to which the common name 
black-pit was applied. While fairly widely distributed at that time, its attacks were rather limited. Black-pit is due to bacteria described and named by Smith, Bacterium citriputeale. In 1916, J. Elliot Coit called attention to a new disease affecting citrus leaves and twigs to which he gave the common name citrus blast, and in $1917 \mathrm{H}$. Atherton Lee determined that this was due to a bacterium which he described and named Bacterium citrarefaciens. Later, H. S. Fawcett and his associates proved that black-pit and citrus blast were different manifestations of the same disease caused by Bacterium citriputeale Smith. Black-pit, in one form or another, is widely spread in California.

A disease of citrus fruits in South Africa, very similar in general appearance, has been fully described by Ethel M. Doidge, and a new species, Bacillus citrimaculans Doidge, named as the causative agent.

On leaves and twigs. - Citrus leaves are usually attacked on the petiole, the petiole-wings, and near the base of the blade, though occasionally diseased places are found near the tips. Discolored black areas of irregular shape develop, the whole petiole may be killed, and, generally, the articulation of blade and leaf is destroyed. The leaf then droops and shrivels. From the leaves the disease spreads downward to the twigs. In some cases, considerable lengths of these are killed, while in others diseased or dead patches are formed about the nodes. As the season advances, these patches become soaked with gum and form scab-like spots. The crusted gum covering drops off with the continued growth of the twigs, but scars may persist for several years. In these spots on the twigs the germs which cause the disease are carried over for a considerable length of time. Trees in which black-pit is present on twigs and leaves present a a ragged unkempt appearance. The loss of much new growth and foliage interferes seriously with the development of the tree and the crops of fruit borne.

On the fruit.- The most serious injury has been done to 
lemon fruit. The disease appears in the form of dark brown or black, roundish, irregular areas. These are firm and depressed. They extend through the glandular part of the rind and for some distance into the white inner portion. Attacked fruit may remain in good condition for some time, but the lesions lay it open to attacks of blue-mold, besides making it unsalable because of the spotting. The bacteria gain entrance to the fruit and twigs through mechanical injuries which may be caused in various ways. Thornpricks, tears, scratches, bruises, and insect attacks are largely responsible. High winds in thorny trees cause many breaks in the foliage. The activity of the bacteria is greatly influenced or definitely limited by climatic conditions. It does most damage where a combination of fog, heavy rains, high winds, and rather cool weather prevail at certain seasons of the year, particularly in spring, when the growth is young and tender. It makes little headway during bright warm weather. The most favorable temperature for the development of citrus blast is about 68 degrees Fahr.

Treatment.-As far as possible, trees should be protected from the prevailing spring winds by windbreaks to reduce wind injury to a minimum. In early fall, about October 15 to November 1, the trees should be sprayed with bordeaux mixture $(5-5-50)$. To prevent staining of the fruit, ammoniacal solution of copper carbonate may be used instead.

\section{PHYSIOLOGICAL DISEASES}

Under this heading are included a few diseases of obscure origin and their exact cause is not known definitely. The manifestations of these troubles are usually plain enough, but what brings them about is by no means clear. They may be caused by certain poisonous materials in the soil, may be associated in some measure with insect attacks or with the ordinary grove practices of cultivation. In any case, they are intimately connected with cell development and the life functions of the plants. 
Die-back or exanthema.

Die-back or exanthema is a gum disease of citrus fruits widely distributed in Florida. It also occurs in California and has been reported from some other citrus districts. In Florida it is more prevalent and injurious than elsewhere and is responsible for considerable damage to twigs, leaves, and fruit. It is a disease of the younger growing parts of the trees, of growth and not of dormancy, the older portions not being subject to it, or at least not showing it. So far as known, no species or variety of citrus is exempt from its attacks. Die-back manifests itself in a number of ways, depending on the severity and duration of its attack on a given tree. Its course is progressive, all the symptoms being developed only after several months of growth.

On the twigs and branches. - One of the earliest symptoms of die-back is the development of gum pockets on young growing branches. These appear before the woody tissue is fully hardened. The blisters, located near the nodes, are elevated and the cavity beneath the elevation, between the

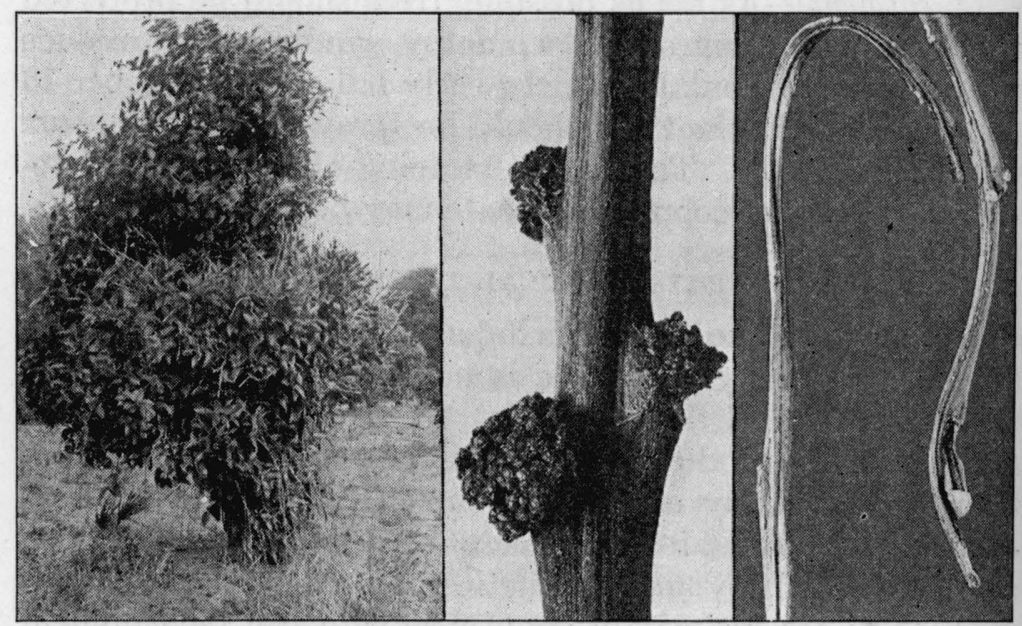

Frg. 218. Diseased tree (left), multiple buds (center), and distorted twigs caused by die-back 
bark and the wood, is filled with a clear amber-colored gum. Usually these gum pockets occur on angular growth and as the branches grow and become rounded out they disappear or are covered up. As the disease progresses, the young shoots become stained and their tissues filled with hardened gum. Excrescences or outbreaks frequently appear in the form of longitudinal streaks of encrusted hardened resinous gum. This exudate often forms drops in the leaf-axils. If trees are in vigorous growth, the twigs are often very angular, distorted, and misshapen. The distortion frequently takes the form of the letter S. Affected twigs are devitalized and are readily attacked by wither-tip and other fungi. In consequence, badly diseased trees soon become marked by the large number of small dead branches. Adventitious buds accompanied by hardened gum are frequently developed in leaf-axils. Normally, only one or two are present but this number may be increased greatly by the disease. If numbers of these buds develop into branches, a bushy appearance of the tree-top results. (Fig. 218.)

On the leaves of die-back trees the same characteristic gum staining occurs as on the young twigs, the cells become filled with gum, and brownish hardened areas result. This appears principally on the petioles and along the midribs. The leaves of affected trees have a characteristic dark green shade, owing to the deepening of the color of the chlorophyl. Often they are very large and show symptoms of overvigorous growth such as normally comes from the use of an abundance of nitrogenous fertilizer. In aggravated cases, the leaves are very coarse and abnormally long.

On the fruit.-The exterior of the fruit shows much the same stained resinous areas as are found on the twigs and leaves. These are irregular in shape, and, while more common on the side or about the stem end, may occur on any part of the fruit. Badly affected specimens may be practically covered with these discolored areas. The stained parts are roughened and checked. Frequently the rind 
splits, exposing the pulp within. These are referred to as die-back splits, to distinguish from those induced by other causes. Such fruit is worthless. The rind is thick and coarse, the quality poor and deficient in sugar and acid. Die-back fruit is usually referred to as ammoniated. In the interior, about the seeds, a quantity of gum, similar to that in the gum pockets, is frequently present. A very large percentage of die-back injured fruit drops before maturity and the disease is a noteworthy cause of dropping. Very often fruit will show the disease before it is noted on other parts of the tree, indicating that it is perhaps more easily affected. (Fig. 219.)

Probably die-back is one of those obscure plant troubles intimately associated with the life functions of the tree. From some cause the character of the sap is changed, a poisonous substance, not sufficiently potent to destroy the cells, is introduced, and the nutrition and growth of the tree is disturbed. The development of this substance is associated with certain soil conditions or with the food taken up by the roots. The external symptoms are indicative of an internal deranged condition, but it is entirely possible that tree functions may be disturbed so slightly by die-back as to present no external symptoms and this disturbance may be responsible for certain phenomena in the behavior of citrus trees not now understood. When the trouble is manifested in growth, the disease has made considerable advance. It appears not to be a fungous disease and no living organism has been found responsible for it.

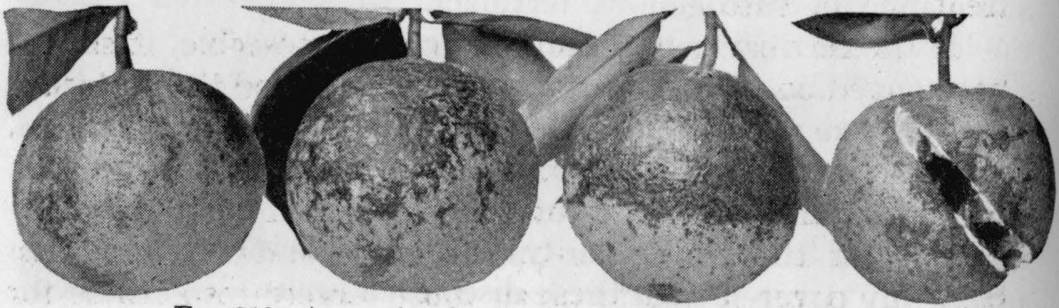

FIG. 219. Ammoniated and split oranges caused by die-back. The dark areas are gum-soaked 
Die-back is associated with a number of soil conditions, with the environment and with the treatment given the tree. All are apparently conducive to the same end, the development of a substance inimical to normal sap and cell formation. If die-back appears in a grove, the problem should be studied carefully to learn the predisposing causes. When these are determined, they should either be corrected or removed. If drainage is at fault, the land should be drained. If hardpan is present and the soil is good or fairly so beneath, it should be broken up. Dynamite may be employed to advantage. If the soil beneath the hardpan is poor white sand, nothing is gained by breaking it up unless it will aid drainage. In such circumstances, the condition may be helped by discontinuing cultivation and increasing the moisture-retaining power of the soil by mulching. Under some conditions it may be wise to consider seriously abandonment of the planting. If too heavy cover-crops are suspected, they may be cut from time to time during their growing season and allowed to die and dry on the surface. Since too much or too deep cultivation is sometimes at fault, the practice should be changed, giving less frequent cultivation and using implements of shallow tillage such as the Acme and disc harrows. If the plant-food is out of balance, owing to an over-supply of organic ammonia already present in the soil from sources previously indicated, ammonia should be eliminated from the fertilizer and an increased amount of potash given. Potash appears of considerable value in treating the disease.

If the fertilizing program has been responsible, it should be changed both in relation to the amounts and the materials used. It may be advisable to withhold fertilizer for a time, almost to the point of starvation. This should not be carried to an extreme, however, as the tree may be placed in a condition favoring wither-tip, melanose, and other troubles. Since ammonia is the fertilizer most largely responsible for growth, it should be reduced or left out entirely. Organic 
sources should be avoided and the ammonia for die-back trees, particularly on soils well supplied with vegetable matter, should be secured from such materials as nitrate of soda, sulfate of ammonia, and nitrate of potash. These materials, so far as known, are not conducive to die-back. It requires some time for trees to take on the condition known as die-back, and a considerable interval to outgrow it when started on the way to recovery.

Bordeaux mixture is of great assistance in bringing dieback trees back to normal condition. They should be sprayed during winter before the spring flush of growth develops or in summer before one of the flushes of growth comes on. It has a biochemic effect in stimulating cell activity that is of material assistance to the tree in throwing off the disease. A strength of $4-4-50$ is as effective as a stronger mixture. It must be followed up with a good insecticide to destroy scale and other insects which gain headway when their fungous enemies are checked or destroyed by bordeaux spray.

Finely pulverized copper sulfate (blue stone), at the rate of two to three pounds for trees ten to twenty years old, is also a good preventive and curative. It should be distributed on the ground about the trees and cultivated into the soil. Greater or lesser amounts should be used, depending on the size of the trees. Care must be exercised in the use of blue stone as an excess may injure the trees.

It is known that die-back develops under certain soil conditions, and is likely to occur on poorly drained soils, seepage areas and "sand-soaked" spots, poorly aërated soils, and those underlaid with organic hardpan. Trees planted on spruce-pine, and similar soils are likely to develop the disease. Citrus trees on clay soils or those underlaid with clay with fair or good drainage are seldom attacked. Trees near poultry-yards, stables, closets, cesspools, or where the roots have access to rank organic and nitrogenous material, frequently show the symptoms of die-back. It is 
also associated with the turning under of too large masses of organic cover-crop material. Heavy frosts and freezes have an influence in accentuating the disease. Following winters when trees are so injured it shows up to a much greater extent in sections in which it is prevalent. The tops of the trees are cut back and the root systems are greatly in excess of requirements. The whole structure is thrown out of place and under favorable conditions the disease shows up in marked degree. Deep plowing or deep cultivation, causing the breaking of many roots in the soil, may be another assisting cause. When the roots are broken up, new ones are formed in larger numbers than usual and perhaps more food is taken up than would otherwise be the case.

Die-back may be brought on by the use of organic sources of ammonia in the fertilizer. Limited quantities of such materials are not usually injurious but on some soils and under certain conditions the application of large amounts is likely to be followed by an outbreak. They must at all times be used with caution. When trees are planted on soils formerly devoted to vegetables, or when crops, fertilized with organic ammoniates, are grown between the rows of trees, die-back with its attendant ills is likely to develop. Die-back has been produced under experimental conditions from the use of fertilizers from organic sources.

Treatment.-Care should be taken in selecting citrus lands to avoid, as far as possible, those conditions known to favor the disease. There is no use in inviting trouble if it can be avoided and on certain types of soil diseased conditions may be expected to develop. It is always difficult to overcome the bad effects of unsuitable soils and environment. On soils known to be favorable to the disease, the management and care given the trees from the very beginning should be directed along lines known to offset die-back tendencies. Cultivation, cover-crops, and fertilizers should be carefully studied and handled in their die-back relationships. It is always better to prevent than to cure. 
Frenching, or mottled leaf.

This condition of citrus trees is present both in Florida, where it is known as "frenching," and in California where it is called "mottled leaf." It also occurs in many other citrus districts of the world.

While frenching is rather widely distributed in Florida, it is not a serious disorder and usually attracts very little attention. In California it is classed as one of the most serious citrus troubles, and the area in which trees are attacked appears to be extending. The symptoms are more aggravated in California than elsewhere, and there may be some question whether the disease is due to a single cause or whether it is brought about by several different causes or conditions.

The most pronounced symptom of frenching is a characteristic mottling of the leaves. The young foliage is affected from its first appearance and normal green leaves are never developed. The variations in color become more definitely marked as the leaves expand. Light-colored or yellow areas are present between the main veins. (Fig. 220). If badly affected, the yellow areas may be continuous on the leaf surface near the margins. The veins retain a darker green shade, giving the leaf a variegated appearance. Leaves

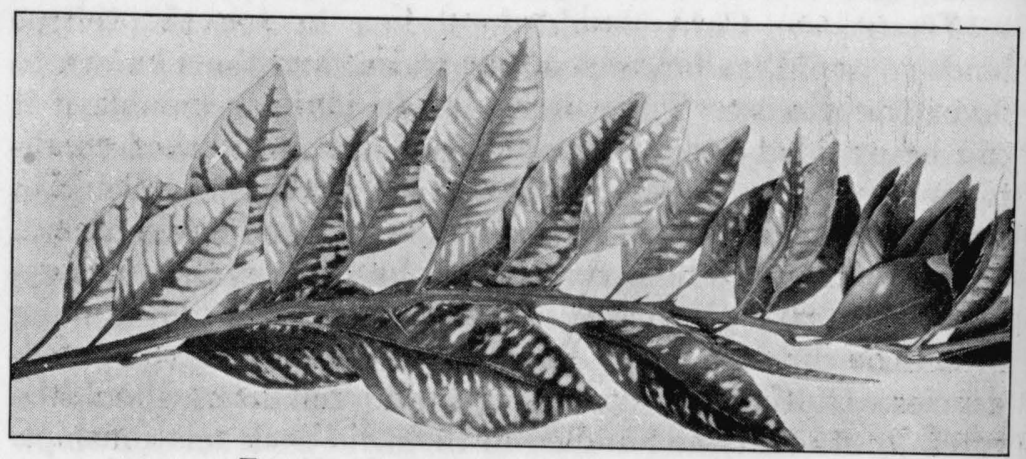

FIG. 220. Frenched or mottled orange leaves 
which develop with normal color do not revert to the mottled or variegated condition, and whatever it is that affects them exerts its influence on the embryonic leaf. The frenched leaves are smaller than normal and the twigs are weak, small, and attenuated.

A whole tree-top may be affected, but more often frenching shows here and there in a grove on a single branch, a cluster of twigs, or a portion of the top. It appears without apparent cause, and, seemingly, with no change in the handling of the trees. Often frenching disappears without corrective measures being applied. While present it may interfere seriously with the growth and development of the tree and the production of fruit.

The cause of frenching is not known with certainty. It has been attributed to some of the same causes as bring on die-back. In Florida, frenching is sometimes associated with die-back, but this is probably only a coincidence. Frenching has been attributed to the attacks of nematodes on the roots. This may be a contributing cause, but it is not the only one for the disease occurs where there are no nematodes.

Perhaps the most constant condition with which the disease is associated in Florida is a deficiency of humus and organic matter in the soil. There has been discussion about acid conditions in citrus soils, which do not appear at all injurious to the trees, and ground lime rock and other forms of lime were liberally applied. Frequently their use was followed by severe outbreaks of frenching. In former years, when continuous clean cultivation was practiced, frenching in the trees was commonly associated with it. If lands were cropped in nursery stock too continuously, the disease appeared. Nursery stock is always grown with continuous clean cultivation.

Treatment.-Many cures for frenching have been effected in Florida on light well-drained soils by applying a liberal dressing of stable manure and following this up by a good cover-crop year after year. At this time the only line of 
corrective handling that can be suggested is to give the trees such treatment as will tend to put them in good normal growth. The condition and the amount of vegetable matter in the soil should be investigated carefully. If there is a deficiency of this material, as there is likely to be, heavy mulching with nitrogenous materials and the use of stable manure experimentally are recommended. A cover-crop should be grown.

\section{DISEASE RESISTANCE OF CITRUS}

All species or varieties of citrus are not susceptible to diseases in the same degree. Their reaction may vary from extreme susceptibility to practically complete immunity, and, whenever possible, this power of resistance should be used in the grower's favor. If a disease is more or less prevalent in a certain section, varieties not subject to its attacks should be given preference in planting a grove. Also much may be gained by using those kinds of citrus ' stocks most resistant to disease. Disease resistance may be used to the advantage of the industry in breeding new varieties. Fortunately, the disease resistance and susceptibility of most sorts is fairly well known and may be summed up as follows:

The sour orange is very resistant to foot-rot and various forms of gum disease. It is severely attacked by scab.

Pomelos and tangerines appear to resist scaly-bark or nail-head rust infection in a very decided degree.

Kumquats are not readily attacked by citrus canker or by citrus scab.

Sweet oranges are not affected by scab while the lemon is very readily attacked. Grapefruit and Satsuma orange are injured in less degree than the lemon. Royal and Triumph grapefruits are not subject to it and the Mexican lime appears to be immune. 


\section{CHAPTER XXX}

\section{SPRAYING, DUSTING, FUMIGATING}

For control of the more injurious insects and related pests by direct means, resort must usually be made to either spraying, fumigation, or dusting. Under certain conditions each method has its advantages. The eastern citrus districts have given more attention to spraying than to fumigation. Fumigation is preferred for some insects in the western districts, particularly in California. Dusting is practiced both east and west for the control of some pests but is not used to the same extent as the other methods.

The equipment for fumigating, consisting of tents, wagons, and hoisting apparatus, is much more expensive than for spraying; for this reason the former method of control is not likely to come into favor with owners of small groves unless undertaken on a cooperative basis. On the other hand, fumigating is more efficient against many insects, as one fumigation will prove as satisfactory as two or three sprayings. A single fumigation under some circumstances may take care of insect problems for two or three years. It has been estimated that the cost of one fumigation and three sprayings is about equal after leaving out of consideration the cost of the tents and the wear and tear on the apparatus. Whenever the expense of fumigating seems justifiable this method should be adopted if the conditions are favorable. The cost does not, however, justify its use except in more or less isolated communities where reinfestation cannot take place from adjoining unfumigated properties.

The methods followed depend on climatic conditions, the stage of growth in the trees, and the pest to be destroyed. Generally, fumigation has given better results in drier climates where the planted areas are circumscribed. Heavy 
dews, rains, and temperatures too high or too low interfere materially with success from fumigation. The work is generally done at night to secure more uniform conditions and more satisfactory results. Trees in active succulent growth under unfavorable conditions will not stand the usual fumigation dosage necessary to destroy the pests, and the work must be performed at such seasons as growth and climatic conditions indicate to be suitable. In all districts, mites, spiders, and thrips are controlled by spraying or dusting, as fumigation is not satisfactory against them. These pests must be fought when they are troublesome, regardless of tree growth and climatic conditions. In many localities it is necessary to control fungous diseases. Fumigation will not accomplish this, and spraying must be practiced. The control of both diseases and insects frequently can be combined in the one spraying operation. Fumigation control has been thoroughly tried out in Florida. It is not now used and is not likely to be unless some new developments arise.

The choice of methods must in some degree be governed by the shape and density of the tops of the trees. It is impracticable thoroughly to spray trees with dense thick heads; these must be pruned out. The heads must be formed like a hollow cone with a leaf zone covering the framework of branches. Trees with low flat heads, such as are formed by some systems of lemon pruning, are well adapted to spraying. All dead wood should be pruned before spraying is commenced. For further details see Chapter XXV.

\section{SPRAYING}

The twenty years between 1900 and 1920 have seen some noteworthy improvements in spraying machinery. In 1900 , spraying outfits were designed to take care of small numbers of trees. Since then, in those districts in which spraying is the favored method of insect and disease control, the areas 
in single plantings have greatly increased in size, and it is not uncommon for a planting to embrace a thousand acres or more. It became necessary to meet an entirely new set of conditions if spraying was to be prompt and effective. This has been accomplished by increasing tank capacity, engine power, the distribution area of nozzles, and reducing the distance between the point of mixing and the place of application. Formerly, a pressure of fifty to seventy-five pounds at the nozzle was considered excellent, while now a force of two hundred and fifty to three hundred pounds at the nozzle is commonly used. This increased pressure and the improvements in nozzle design have made it possible to reach the tops of the highest trees and to do the work with a thoroughness that a few years ago was quite impossible. New types of spraying outfits have been designed to meet special needs.

Within the same period, noteworthy changes have developed in spraying mixtures and materials. Arsenate of lead has largely taken the place of paris green. Lime-sulfur, a combined fungicide and contact insecticide, and miscible oil spray have come into general use, replacing the less effective mixtures of twenty years ago. Both of these have made possible great improvements in grove sanitation. Resin wash, often more injurious to the trees than the insects it was used to control, has disappeared. No material superior to bordeaux mixture as a fungicide has been found. It remains today the most efficient weapon against fungous diseases, even as it has been ever since its introduction in 1878.

To secure satisfactory results from spraying, certain conditions must be met. The sprayer must know something of the nature or life history of the insect or disease he seeks to control. At certain stages of development these pests may be attacked to advantage; at other periods spraying will have little effect. The sprayer may waste time, effort, and money and not secure the results desired. 


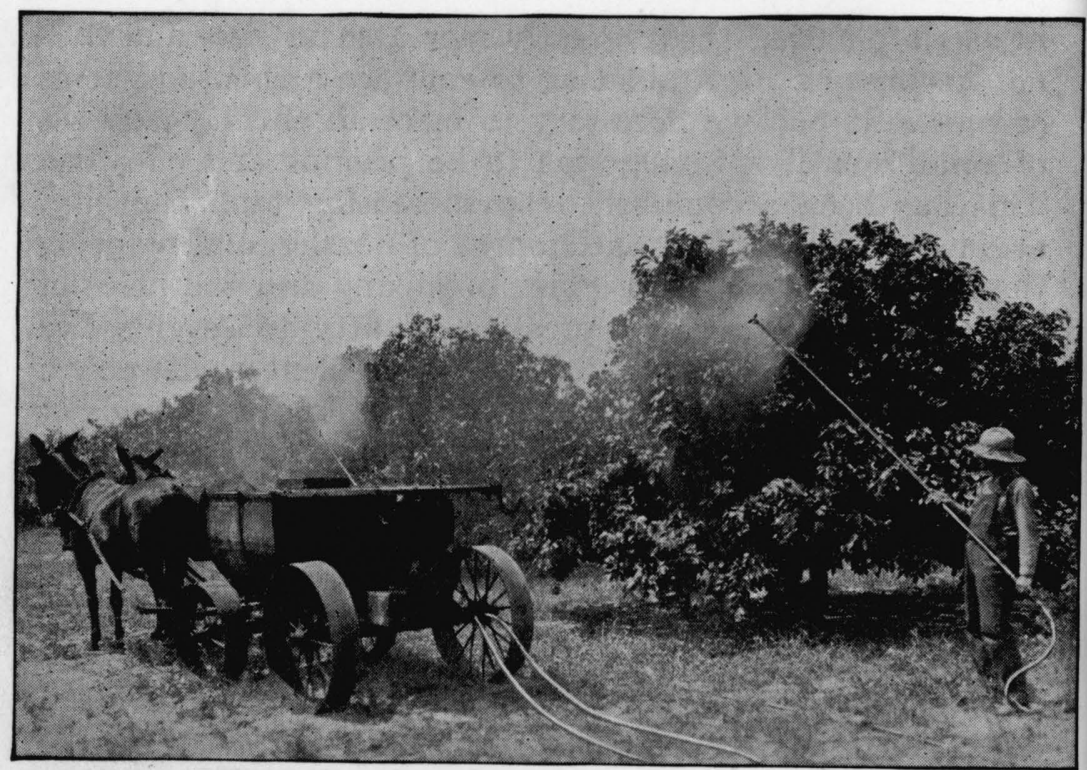

FIG. 221. Power spraying outfit at work in a citrus grove

It is necessary to perform the work at the proper moment and on time. In fact, it is often as important that it be done on time as that it be done at all. The effective period to destroy whiteflies, for example, is when the adults, which fly about, are dead or present only in limited numbers and the young are at rest on the under sides of the leaves in the pupal or larval stages. Fungous diseases cannot be cured. They may be destroyed by cutting away and burning or they may be controlled. It is well to remember that most of them are more likely to gain entrance to tender growing parts (fruit, twigs, and leaves) than to attack the older and more resistant tissues. Fungicides are effective because they prevent fungi from obtaining a foothold and should be applied to make a protective covering.

When citrus insects are held in control by parasitic fungi, there is a very material increase in their numbers 
when the trees are sprayed with fungicides. It is, therefore, necessary to follow with an insecticide spray, unless the two can be combined in a single application. The insecticide should be applied within six weeks after the fungicide. Conditions should then be watched carefully and additional applications made if necessary.

Spraying should be done thoroughly. The spray can be effective only when it strikes the insect or the young shoot or foliage to be protected. It should be applied as a fine mist and should cover all parts completely. A poor job of spraying is expensive at best and may be entirely worthless. Ten to fifteen gallons will be required for trees from fifteen to twenty feet high, while those from twenty-five to thirtyfive feet will require about half a barrel. Attention should be given to the condition of the tree at the time of application. Sometimes fruit, leaves, and twigs are burned and injured by the spray. By advancing or delaying the time of spraying this damage can be avoided.

Often the effectiveness of a spray is reduced because the foliage and branches are wet from recent rain or dew. Sprays should be applied to the trees only when they are dry and should not be started in the morning until the dew has dried off, nor until a sufficient time has elapsed to allow drying off after a rain. It is also necessary, to be effective, that the spray remain in contact with the different parts of the plant and the insects thereon for some time after application. If rain falls within thirty minutes to an hour after spraying, it is in most cases well to make another application.

The spraying equipment should be suited to its task. For a limited number or for small trees a smaller outfit will be needed than for a large grove of large trees. For the smaller place a hand pump may be used while the larger planting will require a number of spraying units of large size with powerful gasoline pumps and engines.

The spraying machinery should be kept in first-class condition, ready for use on a moment's notice. As soon as a 
job of spraying is finished, the outfit should be thoroughly overhauled and cleaned. Worn or broken parts should be repaired or replaced. Likewise, those spraying materials which may be kept without deterioration should be on hand and those which cannot be stored should be procured at the exact time needed. Hose deteriorates when not in use; only the best should be purchased and it should be inspected to see that it is still in good condition. Only by such precautions can exasperating and costly delays be avoided.

Spraying must be done by competent and intelligent labor. Nothing is gained by purchasing efficient spraying

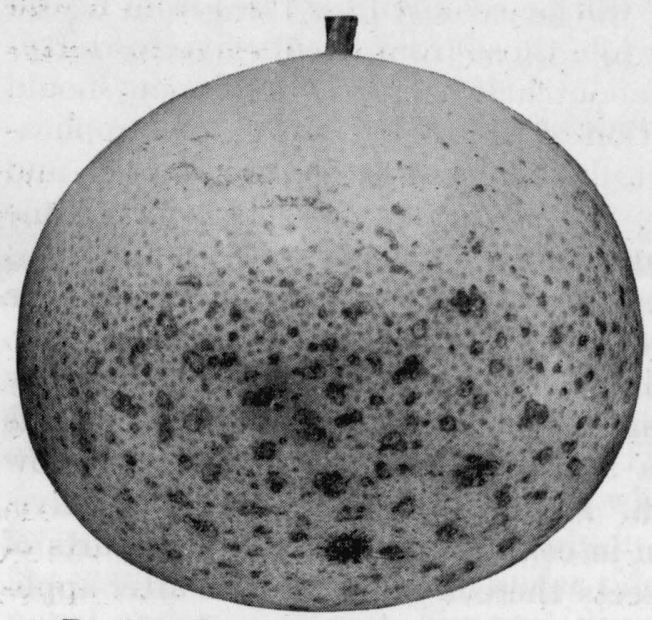

FIG. 222. Orange fruit injured by spraying with too strong a mixture equipment and good materials, and then allowing the machinery to be badly handled and spraying materials improperly made up and badly applied. The person responsible for the spraying must have some knowledge of insect life, of the machinery and its operation, and of the methods for making up the mixtures employed against particular insects or diseases. Great care should be exercised in making up and applying spraying mixtures. It is very easy to damage fruit, twigs, and leaves with improperly mixed sprays. Sometimes strong mixtures can be applied with safety under certain conditions, while if the same spray combinations are used under other circumstances severe damage to the trees might result. The more dormant the trees, the less danger there is of injury. 
In large plantings, water or spray-mixing depots should be established at convenient points, to save long hauls for filling the spray tanks. Sometimes it is economical to have two outfits operated by one spraying crew; while one tank is in use, the one just emptied can be refilled by the man in charge of the spray depot.

To hold most insects in check, one or two winter and one or two summer sprayings and several dustings will be necessary. As a general rule, the armored scales must be sprayed during the immature stages, as they are not easily destroyed when their hard covering is fully developed. Whiteflies are best attacked during the larval and pupal stages, in winter, while the mites must be sprayed or dusted whenever active.

\section{Spray calendars or schedules.}

The grower who attempts to control citrus insects and diseases by spraying, without considering them in their relations to each other, undertakes the impossible. It is necessary to know something of their life histories and the time when they may be attacked most effectively. Spray mixtures must be compounded or their application timed to control more than one pest, and spraying must be done at the proper moment.

It is well to bear in mind that trees, insects, and diseases synchronize in their growth activities. They are advanced or retarded each season by the same factors - temperature, moisture, and food-supply. There is considerable variation in the time when trees begin to grow in spring, when they bloom, when leaves and fruit reach a certain size and pass beyond the point when they are susceptible to attacks from pests. So there is also a corresponding variation in the seasonal development of the insects and fungous diseases which attack the new growth. Hence no exact date can be set for spraying in each year. The grower must make careful note of growth conditions from time to time and he must watch carefully the development of the enemies he desires 
to control, if spraying is to be effective. He who tries to grow citrus fruit profitably by rule of thumb will make a dismal failure of the undertaking.

As a general guide in spraying, several schedules have been worked out. The ones here given are by Winston, ${ }^{1}$ Bowman and Yothers. Remembering that seasonal variations in growth occur and that trees are later in starting in northern than in southern districts, these schedules will be very helpful. Also, the routine of all grove work should be carefully planned and scheduled. The working plan should cover not only insect and disease control but it should include all other cultural details. Only by carefully checking operations from year to year, ordering necessary supplies well in advance and working on a definite program can work be done at the most opportune time.

Table XX. Spray Schedule for Grapefrutt

\begin{tabular}{|c|c|c|c|c|}
\hline $\begin{array}{l}\text { Appli- } \\
\text { cation }\end{array}$ & $\begin{array}{l}\text { Time of } \\
\text { Application }\end{array}$ & Material & Enemy & Remarks \\
\hline A. & March 15-25. . & $\begin{array}{l}3-3-50 \text { bor- } \\
\text { deaux mixture } \\
\text { plus } 1 / 2 \text { per cent } \\
\text { oil as emulsion. }\end{array}$ & \begin{tabular}{lr}
\multicolumn{1}{|c}{ Scab, } & early \\
melanose, & scale \\
crawlers, & and \\
whitefly. &
\end{tabular} & $\begin{array}{l}\text { Only partially effec- } \\
\text { tive against severe scab } \\
\text { outbreaks, but a good } \\
\text { time to spray for scab } \\
\text { control if grower can } \\
\text { make but one appli- } \\
\text { cation for scab. }\end{array}$ \\
\hline A. & March 15-25. & $\begin{array}{l}\text { Lime-sulf ur } \\
\text { solution, } 21 / 2 \text { to } \\
3 \text { gallons in } 100 .\end{array}$ & $\begin{array}{l}\text { Scab, red-spi- } \\
\text { ders, rust-mites, } \\
\text { scale crawlers. }\end{array}$ & $\begin{array}{l}\text { Has but little effect } \\
\text { against scab, but is de- } \\
\text { sirable against insect } \\
\text { pests. }\end{array}$ \\
\hline & April 5-15... & $\begin{array}{r}\text { Lime-sulfur } \\
\text { solution, } 11 / 2 \text { to } \\
2 \text { gallons in } 100 \text {. }\end{array}$ & $\begin{array}{l}\text { Rust-mites, } \\
\text { shark-skin,tear- } \\
\text { stain, and scale } \\
\text { crawlers. }\end{array}$ & $\begin{array}{l}\text { Probably not nec- } \\
\text { essary if lime-sulfur is } \\
\text { used in application A. }\end{array}$ \\
\hline $\mathbf{C}$ & April 25-May 5 & $\begin{array}{l}\text { 3-3-50 bor- } \\
\text { deaux mixture } \\
\text { plus } 1 \text { per cent } \\
\text { oil as emulsion. }\end{array}$ & $\begin{array}{l}\text { Melanose, } \\
\text { whitefly and } \\
\text { scale insects. }\end{array}$ & $\begin{array}{l}\text { Usually quite effec- } \\
\text { tive against melanose. }\end{array}$ \\
\hline & June 25-July 5 & $\begin{array}{l}1 \text { per cent oil } \\
\text { as emulsion plus } \\
\text { dry soda-sulfur, } \\
21 / 2 \text { pounds in } \\
100 \text { gallons. }\end{array}$ & $\begin{array}{r}\text { Rust-mites } \\
\text { andscaleinsects. }\end{array}$ & $\begin{array}{l}\text { Very important if } \\
\text { copper sprays have been } \\
\text { applied during the } \\
\text { season. }\end{array}$ \\
\hline & Sept. 1-Feb. 1. & $\begin{array}{l}1 \text { per cent oil } \\
\text { as emulsion plus } \\
\text { dry soda-sulfur, } \\
21 / 2 \text { pounds in } \\
100 \text { gallons. }\end{array}$ & $\begin{array}{l}\text { Scale insects, } \\
\text { whitefly, sooty- } \\
\text { mold, and rust- } \\
\text { mites. }\end{array}$ & $\begin{array}{l}\text { Not always neces- } \\
\text { sary. }\end{array}$ \\
\hline
\end{tabular}

${ }^{1}$ U. S. Dept. Agr. Dept. Circ. 259, pp. 6 and 7. March, 1923. 
Table XXI. Spray Schedule for Oranges

\begin{tabular}{|c|c|c|c|c|}
\hline $\begin{array}{l}\text { Appli- } \\
\text { cation }\end{array}$ & $\begin{array}{l}\text { Time of } \\
\text { Application }\end{array}$ & Material & Enemy & Remarks \\
\hline B... & April 20-May 5 & $\begin{array}{l}\quad 3-3-50 \text { bor- } \\
\text { deaux mixture } \\
\text { plus } 1 \text { per cent } \\
\text { oil as emulsion. } \\
\\
\text { Lime-sulf ur } \\
\text { solution, } 11 / 2 \text { to } \\
2 \text { gallons in } 100 .\end{array}$ & $\begin{array}{l}\text { Mela nose, } \\
\text { whitefly, and } \\
\text { scale insects. }\end{array}$ & $\begin{array}{l}\text { Usually effective } \\
\text { against melanose; prob- } \\
\text { ably not necessary on } \\
\text { rather young trees } \\
\text { where these enemies do } \\
\text { not appear. } \\
\text { The critical rust-mite } \\
\text { application. }\end{array}$ \\
\hline & June 25-July 5. & $\begin{array}{l}1 \text { per cent oil } \\
\text { as emulsion. }\end{array}$ & Scale insects. & $\begin{array}{l}\text { Very important if } \\
\text { application A was used. }\end{array}$ \\
\hline D. & Sept. 1-Feb. 1. & $\begin{array}{l}1 \text { per cent oil } \\
\text { as emulsion plus } \\
\text { dry soda-sulfur, } \\
21 / 3 \text { pounds in } \\
100 \text { gallons. }\end{array}$ & $\begin{array}{l}\text { Scale insects, } \\
\text { whitefly, sooty- } \\
\text { mold, and rust- } \\
\text { mites. }\end{array}$ & $\begin{array}{l}\text { Not always neces- } \\
\text { sary. }\end{array}$ \\
\hline
\end{tabular}

\section{FUNGICIDAL SPRAYS}

Bordeaux Mixture. Formula 1.

Copper sulfate . . . . . . . . . . . . . . . 5 pounds

Unslaked lime . . . . . . . . . . . . . . . . . . . . . 5 pounds

Water . . . . . . . . 50 gallons

Place the copper sulfate in a coarse sack and suspend it in a barrel containing 25 gallons of water. Hang it from a stick laid across the barrel, so that it is just covered by the water. In this way, the copper sulfate will dissolve much more readily than if simply thrown into the barrel. Slack the lime in a wooden bucket by adding water, a little at a time, and reduce the whole to a thin paste. Then place the paste in a second barrel in 25 gallons of water. Allow sufficient time to cool, then agitate thoroughly before attempting to mix the two solutions. In pouring the copper sulfate and lime solutions together into the barrel of the spray pump, dip out a bucketful from each and pour them together in a united stream, at the same time thoroughly agitating the mixture in the pump barrel. This method will secure a mixture of the finest quality.

If a large amount of spraying is to be done, stock solutions of copper sulfate should be prepared. In a barrel holding 50 gallons of water, suspend a sack containing 100 pounds of copper sulfate. After the sulfate has dissolved, fill up the barrel to the 50-gallon mark. When thoroughly stirred, each gallon will contain 2 pounds of copper sulfate.

Carefully slake 100 pounds of good fresh lime, place it in a second barrel and add water to make 50 gallons. This solution will contain 2 pounds of lime to each gallon, when thoroughly agitated.

In making up the spraying mixture from these stock solutions, stir 
well, then dip out $2 \frac{1}{2}$ gallons of the copper sulfate solution and dilute to 25 gallons with water in one barrel and place $2 \frac{1}{2}$ gallons of the lime solution in a second barrel and dilute to 25 gallons. Then pour these together in the barrel of the spray pump as already directed.

If sufficient lime is not put into the mixture, there is danger of injuring the foliage. To obviate this, the mixture should be tested before using and if deficient in lime more should be added. One of three tests may be used. Dip out a small quantity in a shallow dish, hold it up between the eye and the light and blow the breath gently into it. If a thin pellicle forms on the surface, there is sufficient lime present, but if this pellicle is not seen lime must be added until it becomes visible. Second, dip a clean steel blade into the solution and hold it there for a minute or more. If a thin film of copper forms on the blade, more lime must be added. Third, prepare a solution of ferrocyanide of potash by dissolving an ounce of the substance in four to five ounces of water. Dip out a portion of the bordeaux mixture into a shallow white porcelain dish and allow a drop or two of the ferrocyanide of potash solution to fall into it. If a brownish red coloration is noted, lime must be added until no color is seen.

Strain all solutions into the spray pump to prevent clogging and use only wooden vessels in preparing the mixture.

\section{Bordeaux Oil Emulsion. Formula 2.}

Prepare bordeaux mixture (3-3-50) in the usual way. The following plan is suggested for 200-gallon outfits: (a) Prepare a stock solution of blue stone by suspending fifty pounds in a sack at the top of a 50 -gallon barrel of water; (b) slake fifty pounds of quick-lime into a thick paste and make up to 50 gallons; (c) measure out 12 gallons (carrying 12 pounds of lime) of the stock solution of lime (after thorough stirring) and pour it through a strainer into the spray tank about three-fourths full of water; (d) after stirring, pour 12 gallons of the stock solution of blue stone (carrying 12 pounds of blue stone) into the tank while the agitator is running; (e) add the oil emulsion while the bordeaux mixture is being agitated. Completely fill the tank with water. Of the oil emulsion 3 gallons in 200 gallons of bordeaux mixture gives 1 per cent of oil. Run the agitator while spraying. Make oil emulsion according to Formula No. 5.

Ammoniacal Solution of Copper Carbonate. Formula 3.

Copper carbonate
Strong ammonia $\left(26^{\circ}\right.$ Baumé)
Water

Use only earthenware or wooden vessels. Dilute the ammonia with 2 gallons of water. Reduce the copper carbonate to a thin paste, using a 
small quantity of water-about $1 \frac{1}{2}$ pints is sufficient. Add the copper carbonate paste to the diluted ammonia. Allow the solution to stand for an hour or a little more and during this interval stir from time to time. The resulting solution is a deep blue liquid. For use in spraying add enough water to bring up to 50 gallons.

If so desired, the stock solution of copper carbonate, made as directed above, may be kept in a tightly corked glass bottle or stone jug and diluted in the proportion given in the formula when desired for use. Where staining of fruit or trees is objectionable, this fungicide may be used.

\section{INSECTICIDAL SPRAYS}

Lime-Sulfur Solution. Formula 4. For Fungi, Mites, Spiders, Thrips.

Lime-sulfur solution is valuable both as a fungicide and an insecticide. Its exact value as a fungicide for citrus trees has not been determined, but it is an effective spray against red-spider, rust-mite, and thrips.

Commercial lime-sulfur is a standard solution which may be secured from dealers in spraying supplies. If so desired lime-sulfur solution may be manufactured at home and directions for making may be secured from the experiment stations.

The commercial material is usually furnished in barrels, though it may be purchased in smaller quantities. It usually tests 32 degrees Baumé, though it is wise for the user to have his own lime-sulfur hydrometer and test each lot. For spraying the usual strength is one part of lime-sulfur testing 32 degrees Baumé to 50 to 75 gallons of water. It must be used with discretion and weaker solutions may have to be applied in spraying trees with very tender leaves and shoots to avoid injury.

For the control of thrips, a spray composed of

Lime-sulfur solution $32^{\circ}$ Baumé . . . . . . . . . . 11/2 gallons

Black-Leaf 40 (nicotine) . . . . . . . . . . 1 pint

Water ... . . . 100 gallons

has proved very effective both in California and Florida.

Boiled Oil Emulsion. ${ }^{1}$ Formula 5.

Paraffin oil . . . . . . . . . . . . . . . . . 2 gallons

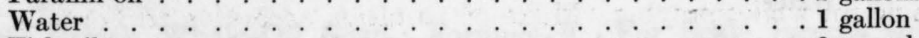

Fish-oil soap . . . . . . . . . . . . . . . . 2 pounds or

Hard soap . . . . . . . . . . . . . . . . . . . . . . . . . . . 1 pound

To the making of miscible oil sprays W. W. Yothers of the Bureau of Entomology, United States Department of Agriculture, has given much time and attention, and the formula ${ }^{1}$ here given was worked out by him.

${ }^{1}$ U. S. Dept. Agr., Farmers' Bull. No. 933. 
For making this spray, any pot or vessel in which the mixture may be boiled is satisfactory. Place the materials in the vessel and boil thoroughly for a few minutes. While still hot mix it thoroughly by pumping with a small hand pump back and forth several times from one vessel to another until the whole is thoroughly emulsified. For use dilute with 200 gallons of water.

If large quantities of the material are to be employed, larger vessels for boiling should be provided, and it may be heated directly over the fire, or by using live steam from a boiler. As before, as soon as the emulsion is cooked and while it is still hot it should be pumped back and forth twice. It may be mixed by pumping from the vessel in which it has been made up into the tank of the spray pump and then from the tank back into the vessel in which it was boiled, merely by using the spray pump and then reversing the action.

In making the emulsion it is always best to use soft water from lake or river, but if hard water from wells must be utilized it should be softened. Caustic soda at the rate of 1 pound and soap at 3 to 6 pounds to 100 gallons of water, depending on its hardness, are excellent for this purpose. Dissolve the caustic soda in the whole quantity of water, then dissolve the soap in 3 to 6 gallons of water and add it to the diluted soda solution. Stir thoroughly. After the water is softened the desired quantity of the oil emulsion, made according to the above formula, is poured in, mixed, and the solution is ready for use.

It has also been found that weak bordeaux mixture, made with a half-pound each of copper sulfate and rock lime to 50 gallons of water, is an excellent softener. The oil emulsion may be added to this weak mixture as soon as it has been made up, whereupon the whole is ready for use.

Miscible oil spray may be secured from dealers in spraying materials, and these mixtures, carrying about 1 per cent of oil, are generally very satisfactory.

Kerosene Emulsion. Formula 6. For Scale Insects and Whitefly.

Kerosene oil . . . . . . . . . . . . . . . . . . . . 2 gallons Soft whale-oil soap . . . . . . . . . . . . . . . . 1 quart Water

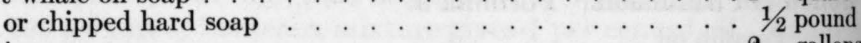

Dissolve the soap by boiling in 2 gallons of water and while still boiling hot pour out into another vessel, removed from the fire. Then add the kerosene and churn steadily for fifteen to twenty minutes or until a good stable emulsion is formed. The best implement for the necessary churning is a force pump, the liquid being pumped back into itself until the emulsion is formed. Make good the amount of water lost in boiling by adding sufficient warm water to bring solution up to $4 \frac{1}{4}$ gallons. 
For use during winter months, dilute each gallon with 10 of water, and for summer months dilute at the rate of $\mathbf{1}$ gallon of the mixture to 15 of water. Never use kerosene emulsion on citrus trees or seedlings growing under slat sheds. Kerosene emulsion is not now employed to the same extent as formerly, having been replaced by miscible oil. It is included here, however, because it is often possible to make and use it when other sprays are not readily or quickly available.

Soda-Sulfur Solution. Formula 7. For Red-Spider, Six-Spotted and RustMites.

Sulfur

20 pounds

Caustic soda $(98$ per cent) $\quad \ldots \quad 10$ pounds

Water . . . . . . . . . . 20 gallons

To make the stock solution, mix the sulfur to a medium-thick paste with cold water in a barrel. Then add the caustic soda so that it may boil the sulfur after the same manner as lime boils when slacking. Have at hand 20 gallons of water and as the boiling process progresses, add it to prevent burning.

For use take $1 / 2$ gallon of the stock solution and dilute with 40 gallons of water. Strain well.

Soda-Sulfur Solution. Formula 8. For Purple-Mite, Red-Spider, and Rust-Mites.

Sulfur

Caustic soda (98 per cent)

Water

30 pounds

20 pounds

To make stock solution, place the sulfur in a half-barrel and reduce it to a thick paste with the 3 gallons of water. Then add the caustic soda and mix it well with the sulfur paste. As the mixture becomes warm, gradually add water to prevent burning. Stir thoroughly, adding water until 20 gallons of solution are obtained. Drain off into a keg and use as desired.

For use, take 1 to 2 quarts of this stock solution to 50 gallons for rustmite and double strength for six-spotted mite.

Caustic Potash Whale-Oil Soap. Formula 9. For Scale Insects and Whiteflies.

Soap 12 to 15 gallons

Water 50 gallons

Whale-oil soap makes a very efficient spraying solution against scale insects and whitefly. It appears to have a beneficial effect on the trees aside from its insecticidal value. 
Whale-Oil Soap and Nicotine Sulfate. Formula 10. For Mites, Spiders, Thrips, Plant-Lice, Scale Insects, and Whiteflies.

Soap
Nicotine sulfate (Black-Leaf 40$)$
Water

Water 50 gallons

The efficiency of the soap is increased materially by adding the nicotine sulfate to the solution.

Arsenate of Lead Solution. Formula 11. For Biting Insects.

Lead arsenate . . . . . . . . . . . . . . . . . $21 / 2$ pounds

Rock lime . . . . . . . . . . . . . . . $21 \frac{1}{2}$ pounds

Water . . . . . . . . . . . . . . 50 gallons

Reduce the lead arsenate to paste form with a little water. Slake the lime and make it into lime-milk. Mix thoroughly with the water. The lime is added to prevent injury to the foliage. Arsenate of lead may be added to bordeaux mixture.

\section{POISON BAITS}

Kansas Grasshopper Bait. Formula 12. For Katydids and Grasshoppers.

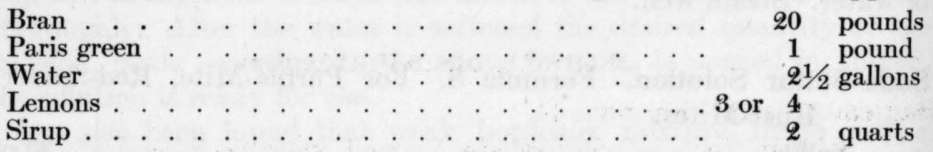

Mix the bran and paris green together thoroughly while dry. Grate or chop the lemons into fine pieces and mix with the water. Moisten the bran and paris green part of the mixture with water, using sufficient to make a good crumbly mass. Then add the sirup and mix well. Distribute by scattering in crumbs over the land infested by grasshoppers. It is best applied early in the morning before the insects begin to feed.

Ant Sirup. Formula 13.

Water ........................ 11 pints

Tartaric acid (crystallized) _. . . . . . . . . . 7 grams

Benzoate of soda. . . . . . . . . . . . . . . 9 grams

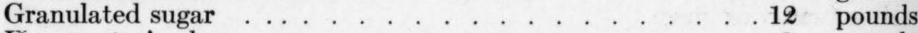

Honey, strained $\ldots . .20 .2$ pounds

Sodium arsenite, C. P. . . . . . . . . . . . 3/4 ounce

Total sirup $21 / 2$ gallons, costing about 50 cents a gallon.

Put 10 pints of water in a clean vessel over a low fire. When tepid, add tartaric acid, then benzoate of soda, and then the sugar, slowly, while stirring to prevent burning. Measure the depth of the liquid with a stick. Slowly bring it to a boil and allow it to simmer for thirty to 
forty minutes. Remove from the stove and add water to compensate for evaporation. Stir in the honey before the mixture cools. Then add sodium arsenite which has been dissolved in one pint of hot water and partially cooled before being poured into the sirup. Stir thoroughly. Great care must be used in the selection of the materials as well as in the preparation of the sirup. The sodium arsenite should be chemically pure. The honey should be strained and free from comb. The sodium arsenite preferably should be dissolved in distilled water to avoid the precipitation which sometimes occurs if very hard water is employed. Vessels should be thoroughly cleaned before being used for the preparation of ant sirup, and it is desirable that they be utilized for this purpose only. The stability of the sirup depends very much on the way it is boiled. If brought to a boil within a few minutes and boiled vigorously for thirty minutes, the stability appears to be much less than if brought to a boil very slowly and then merely allowed to simmer for thirty or forty minutes. Where several times the amount given in the formula is made in a large vessel, the sirup appears to "stand up" best. This seems to be due to the fact that the sirup does not come to a boil for an hour or longer, which probably results in greater inversion. The sirup should be used when fresh. Clean glass bottles are best if the sirup is to be stored.

\section{WOUND DISINFECTANTS}

\section{Bordeaux Paste. Formula 14.}

Solution No. 1.-Copper sulfate, 1 pound; water, $1 / 2$ gallon.

Solution No. 2.-Quick-lime, 2 pounds; water, 1 gallon.

Thoroughly dissolve and mix each solution separately. Then pour the two together slowly and mix well. It should be used while fresh. This paste has given good results in California in the treatment of gum diseases. In Florida it should be used with caution particularly on living wood, because it induces a flow of gum from the trees under some conditions.

Crude Carbolic Acid Solution. Formula 15. For Foot-Rot.

Mix together crude carbolic acid and water in equal parts and apply with a brush or mop.

Protexol. Formula 16.

Protexol ... . . . . . . . . . . . . . . . 1 gallon

Water $1 . .1$ gallon

Soap . . . . . . . . . 1 pound

Dissolve the soap in the water and add the Protexol. Protexol is the trade name for the material formerly sold as Carbolineum avenarius. 
Bichloride of Mercury. Formula 17.

Bichloride of mercury is used at the rate of 1 part to 1,000 of water. It can be purchased in tablets and makes a very valuable disinfectant. After it has dried into the surface to which it is applied, another and more permanent covering, such as paint, should be put on. It should not be left about carelessly as it is a very strong poison.

\section{DUSTING}

While dusting has not been employed in the control of citrus pests to such an extent as have spraying and fumigating, nevertheless the method is worth the careful attention of citrus-growers, particularly against mites and spiders, and during recent years has come into rather general use against these pests. They multiply rapidly, sometimes make their appearance unexpectedly or ahead of their usual season, making it necessary to act quickly. It is possible to treat many more trees in a given length of time by dusting than by spraying.

In the control of mites on citrus trees, including both rust mites and red-spider, it was very early recognized in Florida that satisfactory results could be secured from the use of powdered sulfur. In the early days the chief difficulty encountered was in applying the material quickly, uniformly, and economically. During the last decade, highpower dusting machines have been perfected and it is now possible to cover thirty acres of ten-year-old orange grove in a single day with one dusting machine. No means of insect control is so satisfactory as dusting, if the dust is effective. (Fig. 223.) With a good dusting machine it is possible so thoroughly to dust orange trees that practically every part of the tree-top, including fruit, leaves and twigs, is well covered with the dust. Formerly it was deemed necessary to apply the dust early in the morning while the trees were wet with dew, but this is no longer considered essential, and since much of the effect of sulfur is caused by the fumes it is now realized that dusting in the dry hot part of the day is quite as effective as early in the morning. 


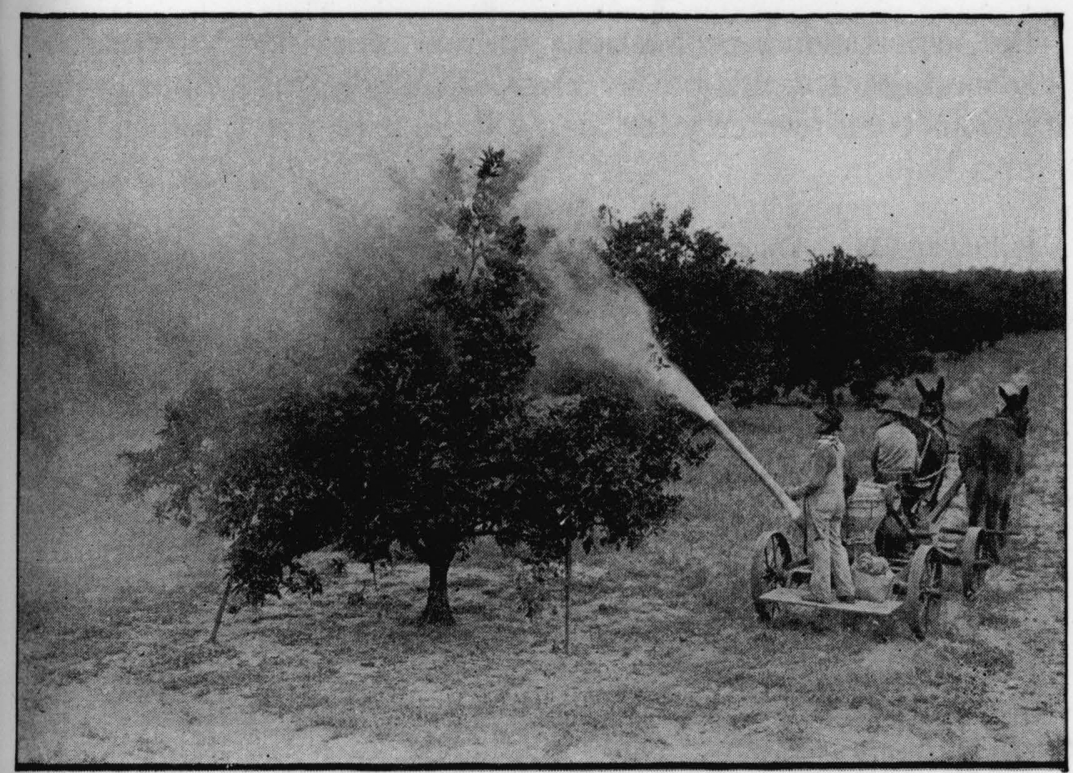

FIG. 223. Power dusting for rust mite. Note how completely the tree is enveloped in dust

Finely ground tobacco is also a good insecticide and recently a concentrated material with greater killing effect and lasting properties has been placed on the market.

Arsenic can be applied as a powder either in the form of arsenate of lead or as calcium arsenate. Hydrated lime may be used as a carrier to reduce the strength of any of the above materials and it is possible to combine them with one another in many ways.

Dusting machinery has been greatly improved. Hand machines of very considerable power and covering capacity are now available. Machines operated by internal combustion engines make it possible to take care of large areas. Application of dust poisons to some kinds of trees by airplane has been successful. Further developments along this line are quite possible. The worst enemies to food crops are insects and allied pests and the fight against them takes on 
the aspects and proportions of real warfare. No possible advantage should be overlooked. The problem is more serious than formerly for man's stake is so much larger than ever before.

Sulfur and Lime Dust. Formula 18. For Mites and Spiders.

Hydrated lime . . . . . . . . . . . . . . . . 121/2 pounds Sulfur, dry, powdered . . . . . . . . . . . . . . . 37 $1 \frac{1}{2}$ pounds

Mix the two very thoroughly. If desired, Black-Leaf 40 (nicotine sulfate) powder may be added to the above.

\section{FUMIGATING}

The fumigation of citrus trees with hydrocyanic-acid gas for the destruction of insects was first tried out by the late D. W. Coquillet, in California, in 1886. From the first, the method of treatment was very successful. Since that time fumigation has come into very large use and today it is the chief means of controlling insects in many districts. The gas is a deadly poison and consequently destroys all insect life exposed to it under confined conditions.

The work is accomplished by covering the trees with a gas-proof or nearly gas-proof tent, and liberating the gas

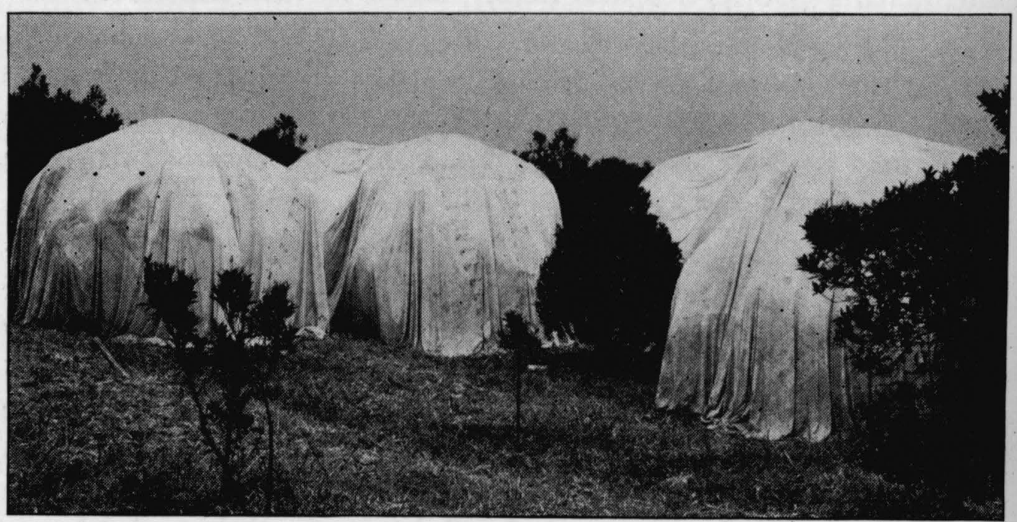

FIG. 224. Citrus trees covered with tents for fumigation 
under it. This is allowed to remain for a certain length of time, usually about one hour. The general plan of fumigation has not undergone any change since the work was first undertaken, though methods of handling the tents and using the dose of gas have been greatly improved in recent years.

Fumigation has its limitations. It is very effective against whiteflies and armored scales, but not against mealybugs. The soft scales, both in the mature and egg stages, are very resistant. The only satisfactory time to fumigate armored scales is during the younger period of their development.

Fumigation is now the chief means of citrus-insect control in California, and it appears the most satisfactory method for the control of many insects in arid and semi-arid climates. Fumigation is generally performed in the night, and in arid districts dews do not interfere with its effectiveness. Moreover, the host plants (other than citrus) of these insects are not present in large numbers, and the cultivated areas are circumscribed.

In Florida, fumigation has been attempted many times and has been carefully worked out experimentally. At present there is probably not a single fumigation outfit in operation in that state. The reason is that fumigation has been tried for the most part against whiteflies. Properties which were cleaned up by fumigation were very quickly reinfested from adjoining unfumigated groves. Fumigation was not general enough. Many citrus insects, whiteflies in particular, have numerous host plants and in Florida many of these are close to the citrus groves. From these foci, reinfestation quickly took place. Moisture conditions, also, interfered with efficient work under all conditions. Spraying remains the principal method for the control of citrus insects, and it does not now appear that it will ever be replaced by fumigation in Florida.

In those districts in which fumigation is the chief means 
for controlling citrus insects, the actual work is handled in a number of different ways:

1. By private corporations or individuals. If the grove holdings are sufficiently large, the owners often do their own fumigating. Since the necessary equipment entails the investment of considerable money, the private individual is not justified in purchasing his own equipment unless the acreage is large.

2. By contract. Individuals or companies with all necessary equipment contract to do the fumigating at a certain price a tree. Sometimes the chemicals are purchased by the grove owner and sometimes supplied by the contracting firm.

3. By associations. In the larger citrus districts, associations are formed, in the interest of the growers, for marketing, for purchasing supplies, or for controlling citrus pests of different sorts. Such organizations sometimes take care of fumigation for their members.

The outfit for fumigating consists of tents, poles or derricks, tackle for placing the tents over the trees, equipment for generating hydrocyanic-acid gas, and chemicals for making it.

Tents.

Several sizes of tents are required, depending on the trees to be fumigated. They should last for four to five years, and, when purchased, allowance should be made for the increase in height and width of the trees from year to year. The table below will serve as a guide to the sizes required. For larger trees two or more tents may be lapped over one another. The number will depend on the size of the organization handling the outfit.

Table XXII. Sizes of Tents for Different Sizes of Trees Height of Tree

6 to 10 feet

11 to 15 feet

16 to 20 feet

Size of Tent

21 to 25 feet 36 to 41 feet

26 to 30 feet 41 to 45 feet 45 to 52 feet 55 to 72 feet 80 to 85 feet 


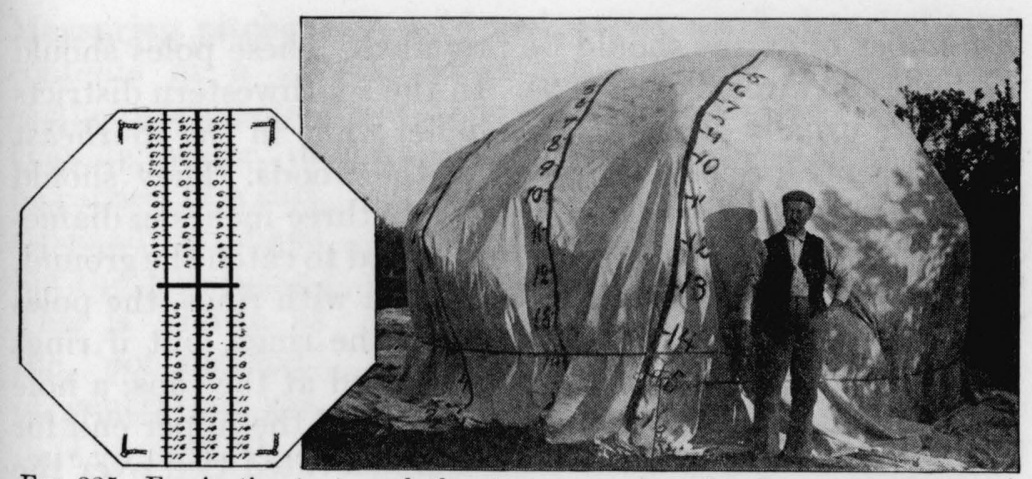

Fig. 225. Fumigation tent marked, a tent over a tree showing marks, and tapemeasure drawn around tent for calculating dosage

Fumigation tents are flat and octagonal in shape. The best material to use is eight-ounce United States Army duck or its equivalent. It is very closely woven and holds gas well. Preferably, the duck should be shrunk before being made up, and it will add to the period of usefulness if the tents are dipped in a solution of hot oak tannin, mixed in the proportion of 40 pounds of extract to 100 gallons of water. This is the best mildew-proof treatment. When not in use the tents should be thoroughly dried and carefully stored, off the ground, in a warm dry place.

If the tents are plainly marked by the Morrill system in such a way as to show the size of the tree over which they are to be placed, it will eliminate guesswork and save time in actual labor. Numbers, one foot apart, beginning at center of tent and numbering outward are marked on them in three parallel lines, three feet apart. On larger sized tents, the parallel lines of numbers are separated five feet. A paint made of turpentine, lampblack, and printer's ink will be very satisfactory for numbering.

Poles, derricks, and tackle.

For elevating tents of the smaller sizes, two poles are required, but for fear of breakage, and so delaying the work, 
a number of extras should be provided. These poles should be light and strong (Fig. 229). In the southwestern districts they are usually made of hard pine, while in the southeast the poles are peeled cypress from the woods. They should be fourteen to sixteen feet long, two to three inches in diameter, and sharpened sufficiently on one end to catch the ground. If the corners of the tents are provided with rings, the poles should be shouldered so as to catch the rings, but if rings are not used the poles should be rounded at the tops, a hole bored through a short distance back from the upper end for the hoisting rope, and the tent to be elevated tied over the poles at the corners with a half hitch. To the upper end of each pole a piece of half-inch to five-eighths-inch rope is fastened, and this rope should be about a yard longer than the pole. For handling very large tents, it is necessary to

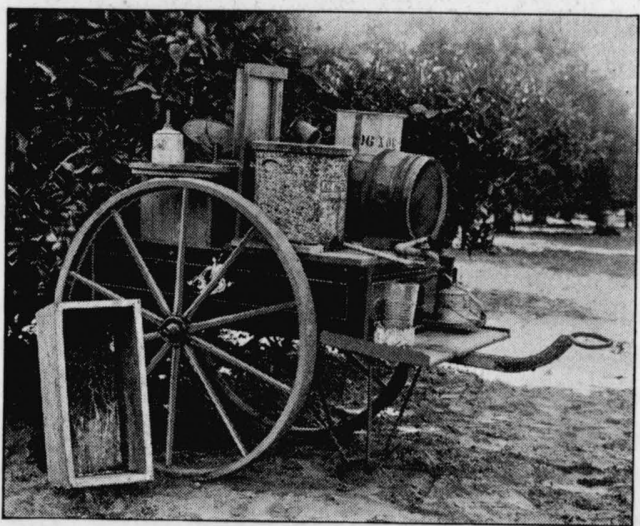

Frg. 226. Cart outfit for handling cyanide, acid and water used in generating gas by the "pot ware vessels, and for small jobs of fumigating these are still used. The vessel, containing the necessary quantity of water and sulfuric acid, is placed beneath the tent after it is in position, inclosing the tree, the required amount of cyanide dropped into it, and the tent closed quickly. provide a derrick for ners of the tent, fitted with block and tackle. With this equipment the tent is elevated to the full height of the tree before being pulled over (Fig. 230).

\section{Gas generators.}

The old plan was to generate the gas in glazed earthen(n) each of the two cor-

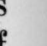


Measuring pitchers for acid and water, marked to indicate contents at a glance, scales for weighing cyanide, and earthenware pots for generating, are required. The acid, cyanide, water, utensils, and all necessary equipment can be carried in a cart especially arranged for the purpose. This is known as the "pot method" of generating gas.

The second or machine method is to generate the gas outside the tent. The cyanide and acid solutions are carried in separate tanks on a cart. The solutions in proper proportions are emptied first in to a graduated measure attached to the tanks and

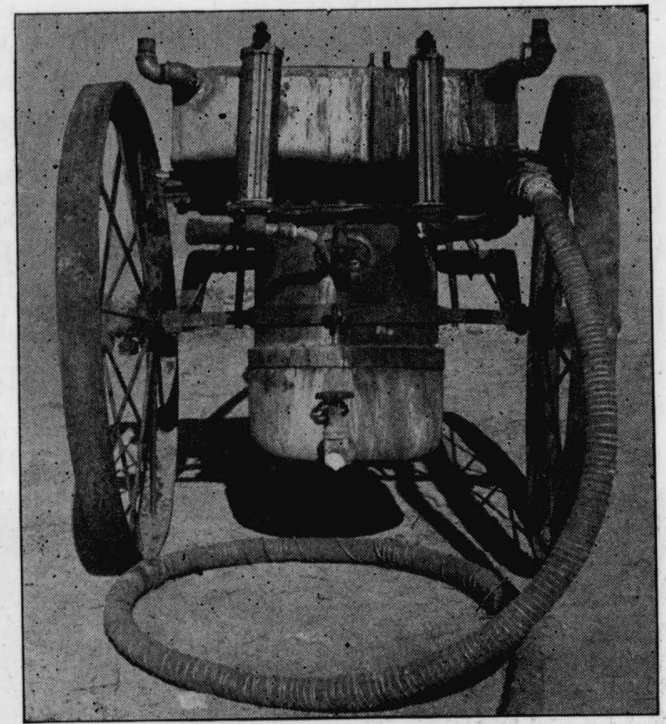

FIG. 227. Machine for generating hydrecyanic-acid gas then simultaneously into a third tank where the gas is generated. From there it is conducted under the tent through a hose.

The cyanide solution is made in the proportion of 1 ounce, by weight, of sodium cyanide to 2 fluid ounces of water. To this the sulfuric acid, full strength, at the rate of $1 \frac{1}{4}$ ounces to $21 / 2$ of the cyanide solution, is added.

The cyanide, 100 or 200 pounds at a time, can be dissolved in a strong leakage-free iron tank, at the rate of 4 pounds to 1 gallon of water. At this concentration it has a specific gravity of 1.173 at 80 degrees Fahr. The best plan is to suspend the cyanide in the water, as this permits it to dissolve more quickly. 
Care must be exercised that the first doses used after starting the machine are effective. Sometimes the gas is diluted too much with air contained in the generator. This difficulty can be overcome by increasing the dosage mixed for the first several trees.

For large-scale operations the machine method has almost entirely taken the place of the pot method. The latter is being replaced in turn by a more recent one, the liquid hydrocyanic-acid gas method. Gas is first generated and then condensed to liquid form under pressure. This can only be done at a factory or plant equipped for the purpose. After the liquid gas is manufactured it must be kept at a low temperature by the use of ice or cold water surrounding or applied to the containers. It is carried to the grove in steel cylinders or drums covered with damp sacks to keep

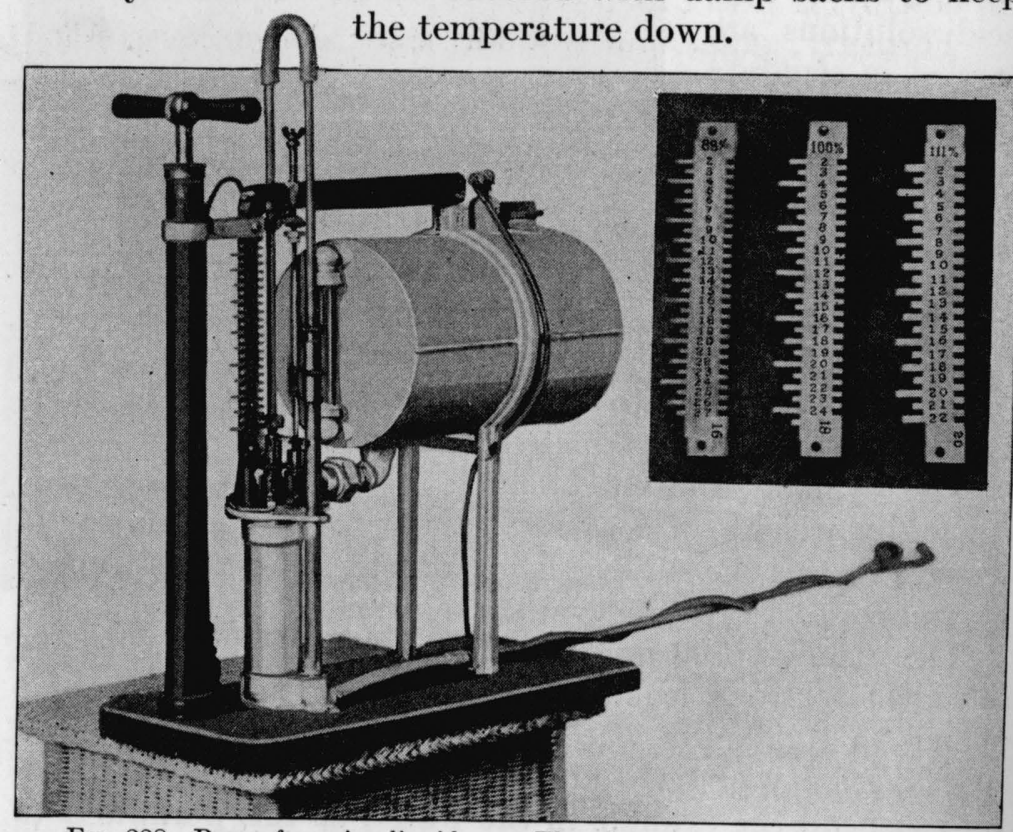

Fig. 228. Pump for using liquid gas. The plates or gauges for regulating or changing the dosage are shown on the right 
The method of using liquid gas is very simple. The correct dosage is drawn out into a pump and discharged from it into the tent through a small pipe, fitted with a nozzle to give a fine misty spray. The machine and liquid gas methods have advantages over the pot system. Acid burns in tents are reduced or eliminated and the danger to operators is greatly reduced. Fumigation can be performed in daylight with liquid gas if the air is dry and warm.

The materials used in generating hydrocyanic-acid gas are potassium or sodium cyanide, sulfuric acid, and water. Only the best chemicals should be used, and they should be of uniform strength. All fumigation practice is standardized on the basis of pure chemicals. In no other way can an even strength of gas be secured and satisfactory results obtained in destroying insect life.

Formerly, potassium cyanide was used entirely, but it has been replaced by sodium cyanide. The latter costs less and is even more satisfactory. It should have a purity test of 96 to 99 per cent and contain 51.3 per cent cyanogen, or more. Cyanide is usually made up in lumps about the size and shape of a hen egg and packed in tin boxes weighing 50, 100 , or 200 pounds.

Sulfuric acid should test 66 degrees Baumé, or 93 per cent or more pure. In small quantities it is usually secured in 10-gallon carboys. Large amounts are purchased in steel drums of about 2,000 pounds capacity.

The usual combination is to use the chemicals in the proportion of 1 ounce of cyanide, $1 \frac{1}{2}$ ounces of sulfuric acid (liquid measure), and 2 ounces of water. This is known as the $1-1 \frac{1}{2}-2$ formula.

\section{Dosage tables.}

The dosage is calculated on two measurements, one over the tent from the earth on one side to the earth on the other, and the distance measured at three feet above the ground around the tent, after it is in place. The first measurement 
is ascertained from the marks on the tent, while the second is taken for each tree with a tape measure.

Since fumigation of citrus trees with hydrocyanic-acid gas was first practiced, there has been a constant effort to reduce the calculation of required dosage for different sized trees to an easily workable basis. The marking of the tents so that the distance over the tree or tent could be easily secured was a great help. The making of simple workable dosage tables was a further step in the same direction.

Dosage tables, from which the required amounts of cyanide can be determined almost at a glance, are now available. These make it possible to work with greater speed

TABLe XXIII

DISTANCE AROUND IN FEET

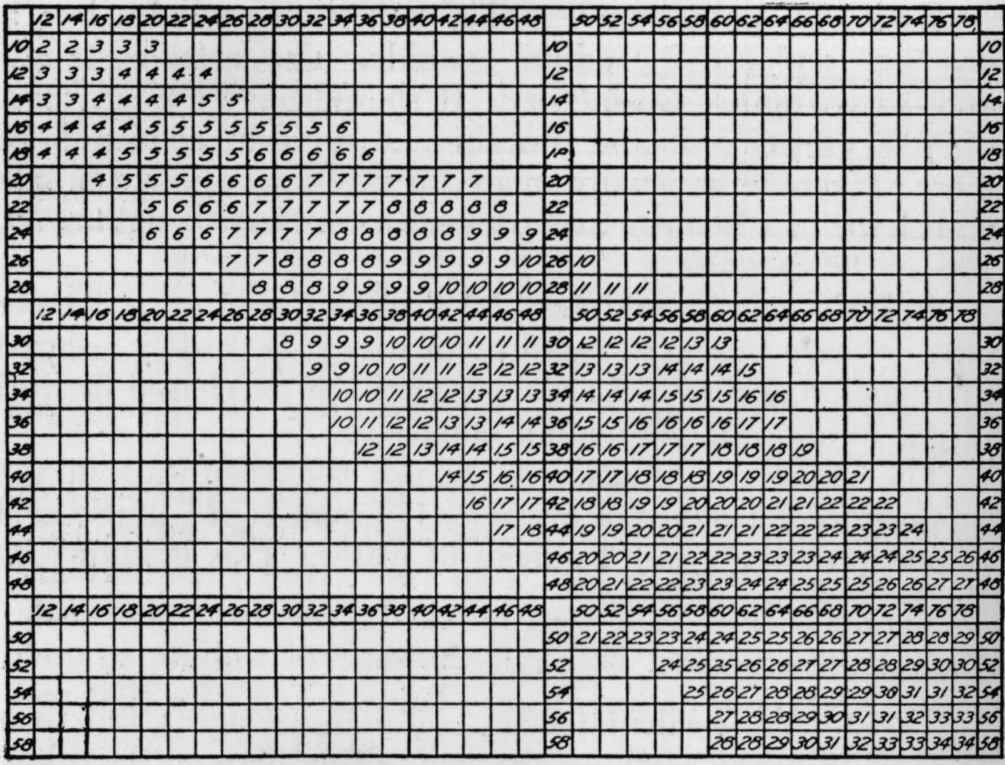

Dosage schedule ${ }^{1}$ No. 1 (100 per cent) for pot or fumigating machine, for sodium cyanide 96 to 99 per cent (containing not less than 51.3 per cent cyanogen). Dosages are in ounces.

1 Woglum, R. S., U. S. Dept. Agr., Farmers Bull. No. 1321. 


\section{TABLE XXIV}

DISTANCE AROUND IN FEET

\begin{tabular}{|c|c|c|c|c|c|c|c|c|c|c|c|c|c|c|c|c|c|c|c|c|c|c|c|c|}
\hline & 14 & 4]1 & & & & & & $\sqrt{3}$ & 32 & \begin{tabular}{|l|l|}
4 & 36 \\
\end{tabular} & 38 & \begin{tabular}{|l|l|l|l|}
40 & 42 & 44 \\
\end{tabular} & \begin{tabular}{l|l|l|}
446 & 4
\end{tabular} & & & 5052 & $\begin{array}{ll}545 \\
5\end{array}$ & \begin{tabular}{|l|l|}
5658 \\
\end{tabular} & $\begin{array}{lll}600 & 62 \\
\end{array}$ & 264 & \begin{tabular}{|l|l|}
66 & 68 \\
\end{tabular} & $\begin{array}{l}7072 \\
7\end{array}$ & \begin{tabular}{|l|l|}
7476 \\
\end{tabular} & \\
\hline 10 & 22 & 3 & 3 & 3 & & & & & & & & & & & 10 & & & & & & & & & 10 \\
\hline 12 & \begin{tabular}{l|l}
3 & 3 \\
\end{tabular} & 3 & 4 & 44 & 4 & & & & & & & & & & 12 & & & & & & & & & 12 \\
\hline 14 & \begin{tabular}{|l|l}
3 & 3 \\
\end{tabular} & 4 & 4 & 44 & 5 & 5 & & & & & & & & & 14 & & & & & & & & & 14 \\
\hline 16 & \begin{tabular}{l|l}
4 & 4 \\
\end{tabular} & 4 & 4 & \begin{tabular}{l|l}
5 & 5 \\
\end{tabular} & 5 & 5 & 5 & 5 & & & & & & & 16 & & & & & & & & & 16 \\
\hline 18 & \begin{tabular}{l|l|}
4 & 4 \\
\end{tabular} & 4 & 5 & $\begin{array}{l}55 \\
\end{array}$ & 5 & 5 & 6 & \begin{tabular}{l|l}
6 & 6 \\
\end{tabular} & \begin{tabular}{l|l}
6 & 6 \\
\end{tabular} & \begin{tabular}{|l|l|}
6 & 6 \\
\end{tabular} & & & & & 18 & & & & & & & & & 18 \\
\hline & & & & & 224 & 26 & & $\begin{array}{ll}30 & 32 \\
\end{array}$ & 3234 & 3436 & & \begin{tabular}{|l|l|l|}
40 & 42 \\
\end{tabular} & 4446 & 48 & & 052 & \begin{tabular}{|l|l|}
54 & 5 \\
\end{tabular} & \begin{tabular}{|l|l|}
56 & 58 \\
\end{tabular} & 606 & & \begin{tabular}{|l|l|}
66 & 68 \\
\end{tabular} & \begin{tabular}{|l|l|}
70 & 72 \\
\end{tabular} & \begin{tabular}{|l|l|l|}
74 & 76 \\
\end{tabular} & \\
\hline 20 & & & & 5.5 & 6 & 6 & 6 & 6 & 67 & 77 & 7 & \begin{tabular}{|l|l|}
7 & 7 \\
\end{tabular} & & & 20 & & & & & & & & & 20 \\
\hline 22 & & & & $5-6$ & 6 & $\overline{6}$ & 6 & 7 & 77 & 77 & 7 & $\begin{array}{lll}7 & 7 \\
\end{array}$ & \begin{tabular}{|l|l|}
8 & 8 \\
\end{tabular} & & 22 & & & & & & & & & 22 \\
\hline 24 & & & & 6 & 6 & 6 & 7 & 7 & $7 \longdiv { 7 }$ & 78 & 8 & $\begin{array}{lll}8 & 8 & 9 \\
\end{array}$ & 99 & & 24. & & & & 7 & & & & & 24 \\
\hline 26 & & & & & & 7 & 7 & 7 & 78 & 88 & 9 & $\begin{array}{ll}9 & 10 \\
\end{array}$ & 1010 & & \begin{tabular}{|l|l}
26 & 1 \\
\end{tabular} & & & & & & & & & 26 \\
\hline 28 & & & & & & & 7 & 7 & & & & \begin{tabular}{|lll}
10 & 10 & 11 \\
\end{tabular} & 1111 & & \begin{tabular}{|l|l}
28 & 11 \\
\end{tabular} & & & & & & & & & 28 \\
\hline & & & & & & & & 303 & 3234 & 3436 & & \begin{tabular}{|l|l|l|}
40 & 42 & 44 \\
\end{tabular} & 1446 & & & 5052 & 545 & \begin{tabular}{|l|l|}
5658 \\
\end{tabular} & $8 \longdiv { 6 0 6 }$ & 6264 & 6668 & 87072 & 747678 & \\
\hline 30 & & & & & & & & 8 & 89 & \begin{tabular}{l|l|}
9 & 10 \\
\end{tabular} & & \begin{tabular}{|l|l|l|}
11 & 11 & 12
\end{tabular} & 1212 & & \begin{tabular}{l|l}
30 & 1 \\
30
\end{tabular} & \begin{tabular}{l|l|}
13 & 13 \\
\end{tabular} & \begin{tabular}{|l|l}
14 & 1 \\
\end{tabular} & \begin{tabular}{|l|l|}
14 & 14 \\
\end{tabular} & & & & & & 30 \\
\hline 32 & & & & & & & & & & 10. & & $\begin{array}{lll}12 & 13 \\
\end{array}$ & 13 & 14 & 321 & 1415 & 151 & \begin{tabular}{l|l}
15 & 16 \\
\end{tabular} & 5 & & & & & 32 \\
\hline 34 & & & & & & & & & & 1011 & & \begin{tabular}{|l|l|l}
13 & 13 & 14 \\
\end{tabular} & 1414 & & $34 / 1$ & 1516 & 171 & \begin{tabular}{|l|l}
17 & 17 \\
\end{tabular} & 181 & 18. & & & & 34 \\
\hline 36 & & & & & & & & & & 11 11. & & $1414 \quad 15$ & 515 & 16 & \begin{tabular}{l|l}
36 & 1
\end{tabular} & 1717 & 181 & \begin{tabular}{l|l}
18 & 19 \\
\end{tabular} & 192 & & & & & 36 \\
\hline 38 & & & & & & & & & & & & $\begin{array}{lll}14 & 1516 \\
\end{array}$ & 617 & 17 & \begin{tabular}{|l|l}
38 &
\end{tabular} & 1818 & 192 & $\begin{array}{ll}20 & 20 \\
\end{array}$ & $\begin{array}{ll}021 & 2 \\
\end{array}$ & 2122 & 22 & & & 38 \\
\hline & & & & & & & & & & & & \begin{tabular}{|l|l|l}
40 & 42 & 4 \\
\end{tabular} & 1446 & & & & 545 & \begin{tabular}{|l|l|}
5658 \\
\end{tabular} & $\begin{array}{l}8606 \\
8\end{array}$ & 6264 & $\begin{array}{ll}66 & 68 \\
\end{array}$ & \begin{tabular}{l|l|l|}
8 & 70 & 72 \\
\end{tabular} & 244678 & 8 \\
\hline 40 & & & & & & & & & & & & \begin{tabular}{|l|l}
16 & 17 \\
\end{tabular} & 1718 & & 40 & 1920 & 212 & 2122 & 2 & 2324 & 2425 & 5 & & 40 \\
\hline 42 & & & & & & & & & & & & & 18 & & 42 & 2121 & 22 & 23 & & & 262 & \begin{tabular}{|l|l|}
6 & 27 \\
6
\end{tabular} & & 42 \\
\hline & & & & & & & & & & & & & 20 & & 44 & & 23 & 2425 & & $2 7 \longdiv { 2 7 }$ & & \begin{tabular}{l|l|l|l|}
88 & 29 &
\end{tabular} & 30 & 44 \\
\hline$\frac{44}{46}$ & & & & & & & & & & & & & & & 46 & $2 3 \longdiv { 2 4 }$ & 25 & 2627 & 727 & 28 & & \begin{tabular}{|l|l|}
30 & 31 \\
\end{tabular} & 32 & 46 \\
\hline 48 & & & & & & & & & & & & & & & \begin{tabular}{l|l}
48 & 2 \\
\end{tabular} & $24 \quad 25$ & 26 & \begin{tabular}{|l|}
27 \\
28
\end{tabular} & & 3031 & & \begin{tabular}{|l|l|l|l|}
32 & 33 & 34
\end{tabular} & \begin{tabular}{ll|l|l|}
34 & 35 \\
\end{tabular} & 64 \\
\hline & & & & & & & & & & & & & & & & $5 0 \longdiv { 5 2 }$ & 54 & 565 & & \begin{tabular}{l|l}
62 & 64 \\
\end{tabular} & & \begin{tabular}{l|l|l|}
68 & 70 & 72 \\
\end{tabular} & \begin{tabular}{|l|l|l|}
274 & 76 & 7 \\
\end{tabular} & \\
\hline so & & & & & & & & & & & & & & & 50 & 2526 & 27 & $\begin{array}{ll}283 & 30 \\
\end{array}$ & 1030 & \begin{tabular}{l|l}
31 & 32 \\
\end{tabular} & \begin{tabular}{|l|l}
233 & 3 \\
2
\end{tabular} & 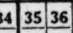 & 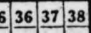 & 850 \\
\hline & & & & & & & & & & & & & & & 52 & & & 303 & 1132 & 33 & 435 & \begin{tabular}{l|l}
36 & 37 \\
37
\end{tabular} & $\begin{array}{lll}38 & 39 & 40 \\
\end{array}$ & 52 \\
\hline 54 & & & & & & & & & & & & & & & 54 & & & 32 & 2233 & 3536 & $\begin{array}{ll}637 & 3 \\
\end{array}$ & \begin{tabular}{l|l}
38 & 39 \\
40
\end{tabular} & $\begin{array}{lll}0 & 41 & 42 \\
\end{array}$ & 254 \\
\hline 56 & & & & & & & & & & & & & & & 56 & & & & 35 & 3638 & $\begin{array}{ll}89 \\
\end{array}$ & $4 0 \longdiv { 4 1 / 4 2 }$ & \begin{tabular}{ll|l|l|l|}
42 & 43 & 44 \\
\end{tabular} & 45 \\
\hline & & & & & & & & & & & & & & & 58 & & & & 36 & $\begin{array}{ll}38 & 39 \\
39\end{array}$ & & \begin{tabular}{l|l}
41 & 42 \\
42
\end{tabular} & \begin{tabular}{l|l|l|}
47 & 45
\end{tabular} & 78 \\
\hline
\end{tabular}

$100 \%$ DOSAGE UNIT $=18$ CUBIC CENTIMETERS

A dosage schedule ${ }^{1}$ for citrus-tree fumigation with liquid hydrocyanic acid 95 to 98 per cent pure

and accuracy than formerly. Two of these tables are given, one for "pot" or machine and the other for liquid gas fumigation.

The tables or charts are divided into small squares. These are formed by the intersections of lines representing the distance around in feet from the top of the chart and the distance over the tent-inclosed tree from the side. Where these intersect is found the dose of sodium cyanide (Table XXIII) or of liquid gas (Table XXIV) for that particular size of tree. For example, if the distance around the tent is $\mathbf{4 0}$ feet and over the tent is 34 feet, 12 ounces of sodium cyanide will be required. With this amount of

1 Woglum, R. S., loc. cit. 
cyanide, 18 ounces of sulfuric acid and 24 ounces of water will be necessary to fumigate the tree.

Large and varied experience in fumigation has demonstrated that the standard dose of cyanide may be varied for different insects with satisfactory results. When advisable, the dosage given in the accompanying tables may be modified to meet special conditions. Weaker or stronger doses may be prepared from these in fractional amounts as one-third, one-half, or three-quarters or one and oneeighth, one and one-fourth, or one and one-half. Some scales appear to have developed resistance to fumigation and, in consequence, heavier dosages have become necessary. For black, purple, and citricola scales, doses of as high as 110 per cent are often used. In summer it is usual to start with a three-quarter dose and gradually increase it as the season advances and the trees are able to stand more without injury.

\section{How to measure the trees. ${ }^{1}$}

"The dosage for a tented tree is based on the distance over the top and around the bottom. The distance over the top of a tree is measured easily with a tape-line, but a much better and quicker method is to mark the tent as described previously. When such a marked tent is centered over a tree, the distance over the top is obtained by adding the two numbers that show where the line over the top of the tree touches the ground on opposite sides.

"In tenting trees, especially small ones, the center of the tent frequently will fall to one side of the center of the tree, and in such instances one of the auxiliary lines is used. To avoid confusion, the center line should be heavier than the other two. The distance around the tent is taken by means of a tape-line, and can be measured by one man if the tape is provided with a catch for attachment to the tent. This measurement should be taken about three feet above the ground. Never guess the distance around by pacing."

${ }^{1}$ Woglum, in U. S. Dept. Agr., Farmers' Bull. No. 1321. July, 1923. 
Strength of gas. ${ }^{1}$

"The lemon tree is much more resistant to injury from fumigation than is the orange or grapefruit and seldom suffers appreciable damage when treated under normal conditions with either schedule or the three-fourths schedule. Some varieties of oranges are injured more easily than others. Of the varieties of commercial importance in California, the Navel and Valencia are the least susceptible to injury from gas treatment. The seedling is almost equally hardy, while the tangerine (Mandarin) stands the gas quite well. Mediterranean Sweet is not quite so resistant to the gas as are the preceding varieties, and Homosassa and St. Michael are easily injured by fumigation. It is inviting damage to fumigate the last two varieties with schedule No. 1, and injury might result with the three-quarter schedule unless prevailing conditions were favorable. Fortunately, the Navel, the Valencia and seedlings comprise the bulk of the oranges grown in this state (California).

"In general, a strength of gas up to the three-fourths schedule, and in some districts schedule No. 1, can be used on citrus trees with a minimum amount of injury if care be exercised. In Tulare County a 110 per cent schedule is safely used, except at the start of the season. This same schedule is sometimes used in the interior valleys of southern California toward the close of the season. In recent years, with increased resistance of some scales, dosages of 125 per cent strength have come into practice. Such high dosages have been found unsafe on oranges during the growing season unless the exposure is shortened.

"As fruit on the tree matures, its resistance to gas injury increases. Fruit in transport or in storage appears to be more resistant to gas injury than fruit on the tree."

After making a normal growth and having become entirely dormant, trees are in the best possible condition to stand maximum doses of gas.

${ }^{1}$ Woglum, R. S. Fumigation of Citrus Trees for Control of Insect Pests. U. S. Dept. Agr., Farmers' Bull. No. 1321. July, 1923. 
Fumigation practice.

When using the pot method of fumigation, thirty tents operated by five men formerly constituted a unit for ordinary sized trees, but the more recent field practice has been greatly to increase the number of tents, add two men to the crew, and speed up the work. If the gas is generated in a machine, four men can operate the smaller outfit.

When the work starts, the tents are taken to the grove and spread out on the ground along the first row of trees at one corner of the planting. Each tent is "squared" in position for the tree it is to cover, with the seams running toward the tree to protect them in pulling.

Poles for elevating are attached to the corners by bringing the tent over the rounded end of the pole and throwing a half hitch with the pulling-rope to hold it there. The lower ends of the poles are placed in line with the trunk, well spread to keep the tent taut. Two operators, handling the ropes, brace the lower end of the pole with one foot and
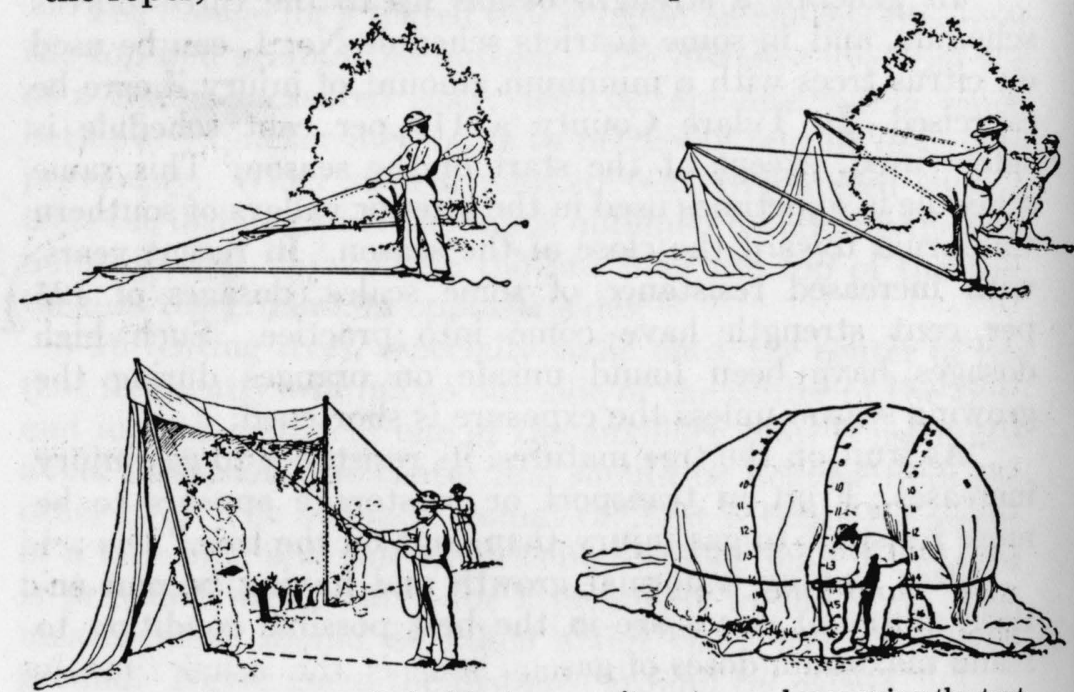

Fig. 229. Placing a small-sized tent over a citrus tree and measuring the tent for dosage 
pull steadily to bring them upright, then over until the tent covers the tree (Fig. 229). If large trees are fumigated, two derricks are placed in position on opposite sides of the specimen, two additional men hoist the tent to their tops with block and tackle, and it is then pulled over the tree. The pullers then move on to another tent (Fig. 230).

The dosage man next measures the distance around the tent, three feet from the ground, with a tape measure, kicks the tent in around the bottom to make it gastight, takes the reading over the top, and computes the dose of cyanide, acid, and water. Then the cyanide is weighed out by the cyanide man and water and acid are measured and placed in the pot by the acid man. The pot is placed under the tent, but well away from it, and the side of the tent is raised a little, the cyanide placed in the

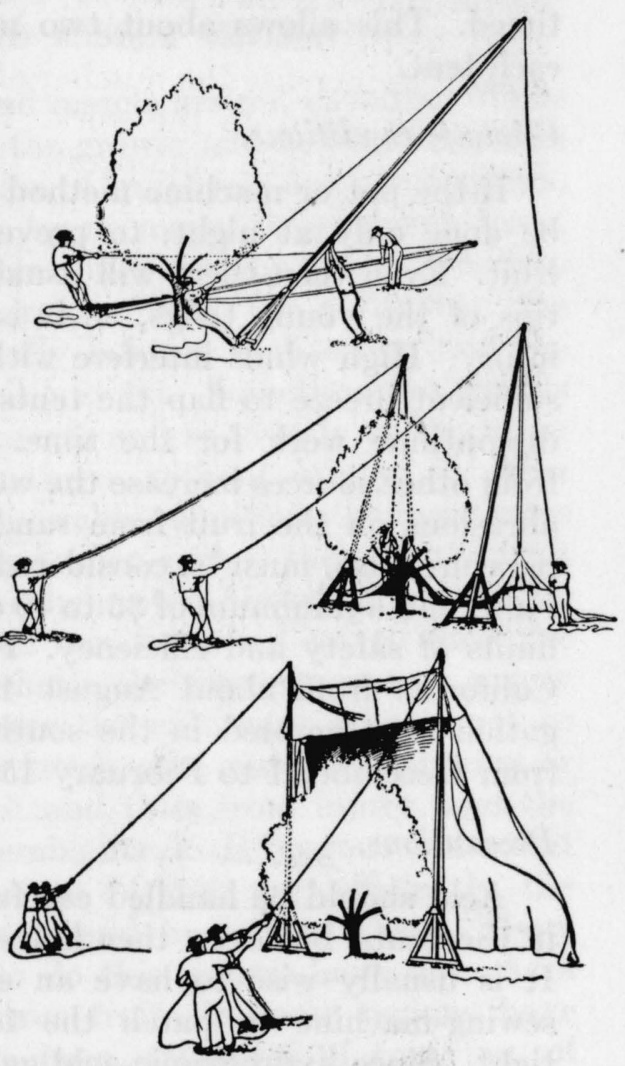

FIg. 230. Covering a large citrus tree with a tent by means of derricks pot, and the tent edge dropped quickly into place. The acid man should not touch the tent. Both cyanide and acid should be handled with rubber gloves.

Forty-five minutes to one hour is the usual time for gassing a tree. As soon as the interval is up, the tents are 
pulled over onto the next tree, and so on through the grove. When the last tent in the outfit is pulled over its tree in the row, the first tent is ready to be moved, if the work is properly timed. This allows about two minutes or less for placing each tent.

\section{Climatic conditions.}

If the pot or machine method is used, fumigation should be done only at night, to prevent burning of foliage and fruit. Even then there will usually be some burning of the tips of the young twigs, as it is not possible to avoid all injury. High winds interfere with efficiency, and if there is sufficient breeze to flap the tents when placed, it is best to discontinue work for the time. Heavy dews or moisture from other sources increase the weight of the tents and cause abrasions on the fruit from sand adhering to them. Temperature, also, must be considered; a maximum of 70 degrees Fahr. and a minimum of 35 to 40 degrees Fahr. are about the limits of safety and efficiency. Fumigation is performed in California from about August 1 to February 1. If fumigation is attempted in the southeastern states, the season from December 1 to February 15 is recommended.

\section{Precautions.}

Acid should be handled carefully to avoid burning holes in the tents, but even then holes are made in various ways. It is usually wise to have an extra man with a suitable sewing-machine to patch the tents and keep them gastight. Since hydrocyanic-acid gas is a very deadly poison, it must be handled with care. Fumigation must be well done if satisfactory results are to follow. One should not spray with bordeaux mixture and then follow with fumigation. If this is done, the trees are likely to be defoliated. 


\section{CHAPTER XXXI}

\section{FUNGOUS AND INSECT FRIENDS}

Fortunately all fungi and insects are not enemies. While many are arrayed against the grower and at times interfere seriously with the cultivation of fruit-trees and other plants, a considerable number, a by no means insignificant force, wage war against the insects which destroy crops. The two forces, one working in harmony with the cultivator, the other against him, frequently balance each other, and the injury to the trees and fruit is slight. Sometimes his friends overcome the injurious insects and so greatly reduce their numbers that the crop matures without injury; at other times his enemies, under favorable conditions, increase more rapidly than his friends, and when such is the case the fruit crop suffers severely unless the grower himself intervenes.

When fungi and insects can be relied on to hold the enemies of citrus trees in check, the grower possesses a very considerable advantage over the cultivator who is not so fortunately situated. The latter must resort to spraying or fumigating to protect fruit and trees from injury, and the added expense is a considerable item. If fungous and insect friends can be depended on to do their part efficiently, the control of insect enemies should be left to them. Many growers have been able to do this, others have not. As a result, the growers of citrus fruits in some regions have separated and there have been advocates of spraying, of non-spraying, and a mixture of the two practices. The lastmentioned combines all the bad effects of the other two practices and none of the good. Enough spraying is done to destroy or drive away the friends and too little to destroy foes. It should be understood that there is no intermediate ground. The citrus fruit-grower must either spray thoroughly and systematically, just as he would cultivate, fertilize, or 
irrigate, or he must depend entirely on certain fungi and insects to control the foes which attack his trees and fruit, and do everything in his power to foster and assist them. Which plan is the best to adopt no one but the grower can determine, and then only after having obtained a thorough knowledge of his own conditions.

Before spraying mixtures, machinery, and methods were brought to present-day perfection, parasitic fungi and insects were of untold and often unnoticed assistance in controlling many citrus pests. Had it not been for their intervention, the growing of citrus fruits in the earlier years of the industry in many districts would have been a difficult undertaking. When insects new to American groves appeared, as they did from time to time in earlier days, it was the friendly fungi and insects that finally checked them. This was true of every insect up until 1900 or later. Spraying technique has advanced to such an extent that these fungi are relatively not so important as formerly, but they are still a worth-while factor in insect control and their value should not be overlooked.

To control insects successfully by natural agents, certain conditions are necessary. The insects must be gregarious and sufficiently numerous, in the beginning at least, to enable the controlling agent to become thoroughly established. Thereafter the host insect must always remain in sufficient quantities to supply food for the existence of the friendly insect or fungus. Lacking this, the grower must see that a sufficient number of the injurious insects are kept to insure the perpetuation and multiplication, to a considerable extent, of their fungous and insect enemies. In short, the latter must be bred and kept for use in case of outbreaks.

Some fungi parasitic upon insects can be grown on artificial media and kept on hand at all times ready to be sent out and disseminated when and where insects controlled by them threaten serious damage. The work of cultivating these beneficial agents can be done best by experiment 
stations, plant boards, or similar institutions. For many years, the Florida State Plant Board has performed a noteworthy service in cultivating parasitic entomogenous fungi and making the cultures available for combating citrus insects.

Insect friends of many kinds are grown in cages by the State Board of Horticulture in California and kept on hand for distribution as needed. Many insect enemies of citrus in the Southwest have been completely controlled through the efforts of this Board.

\section{THE ENTOMOGENOUS FUNGI}

Fungi can be used successfully to check the ravages of insects only in those regions having a moist climate and a warm season sufficiently long to permit their full development. In Florida, the Gulf Coast, and the Islands, fungi may be depended on, to a certain extent, to control injurious insects, but they would fail utterly in the arid or semi-arid climate of Arizona and southern California. These regions must rely on predaceous and parasitic insects as controlling agents if natural enemies are employed. In some cases a combination of fungous and insect control has been satisfactorily established in the humid areas.

In Florida, the control of the more injurious citrus insects, the scales and their relatives, by means of their fungous enemies has received more attention than in any other portion of the world. None of these fungi, so far as known, is an introduced species.

The principal fungous enemies of citrus scale insects in Florida are the red fungus (Sphorostilbe coccophila Tul.), well known through the work of P. H. Rolfs, the gray fungus (Ophionectria coccicola E. \& E.), and the black fungus (Myriangium duriaei Mont.). Of these probably the most effective and abundant is the gray fungus. Its efficiency in checking purple and long scale in Florida has attracted general attention among growers and investigators. 
Preying on the whiteflies (Dialeurodes citri, D. nubifera) are the red Aschersonia (Aschersonia aleyrodes Webber), yellow Aschersonia, (Aschersonia flavo-citrina P. Henning), and the brown fungus (Egerita webberi Fawcett). Sometimes whiteflies in the pupal stage are attacked by the same fungi that are so effective against scale insects.

Mealy-bugs in Florida are almost completely held in check by a fungus, Entomopthora fumosa Speare. Several other species of parasitic fungi also are helpful in controlling insect pests. Among these may be mentioned the cinnamon fungus (Verticellium heteroclodum), on citrus scales, and the pink fungus (Microcera fujikuroi) on red scale. It is probable that all or nearly all the more important insects attacking citrus trees in Florida are held in check in some measure by entomogenous fungi, and that several unknown and undescribed species are at work.

The red fungus (Spharostilbe coccophila Tul.).

When attacked by red fungus the body of the scale becomes filled with a mass of fungal threads (mycelium) and shortly after the time of attack, the insect is dead. By the time the fruit stage of the fungus is reached, the body of the insect has been destroyed; the scale covering alone remains.

Following this period of growth in the body of the insect, one or more orange-colored knob-like bodies are produced. Sometimes these actually break through the scale; at other times they emerge from the sides. These knob-shaped bodies contain the spores which are microscopical in size. By means of them the disease spreads to other insects; the spores light upon or near other scales. A delicate mycelial tube is produced which penetrates the body of the scale and its death is brought about as before.

The red fungus can be spread by taking twigs about four to six inches long, on which scale insects are infested with the disease, and fastening them to the upper side of shaded twigs 
or branches on which plenty of living scales are present. The spores will then be protected from the direct sunlight, and dews and rains will carry them down onto the healthy scales. Red fungus has also been established successfully by collecting the red knob-like fruiting bodies, mixing them in water, and spraying them over the living scales.

The gray fungus (Ophionectria coccicola E. \& E.).

This is probably the most widely distributed fungous enemy of the citrus scale insects in Florida. In the early stages, the disease attacks the scale much as does the red fungus. A mycelium is produced which grows and develops in the body of the insect.

Two kinds of spores are created: The first are borne in rather conical knobs (Fig. 231A). These knobs are composed of spores (conidia) borne upon a very short stalk, called the conidiophore. When clustered together over the dead scales, these conidiophores give a pebbled appearance to the part. They are gray in color. The spores (Fig. 231B) are

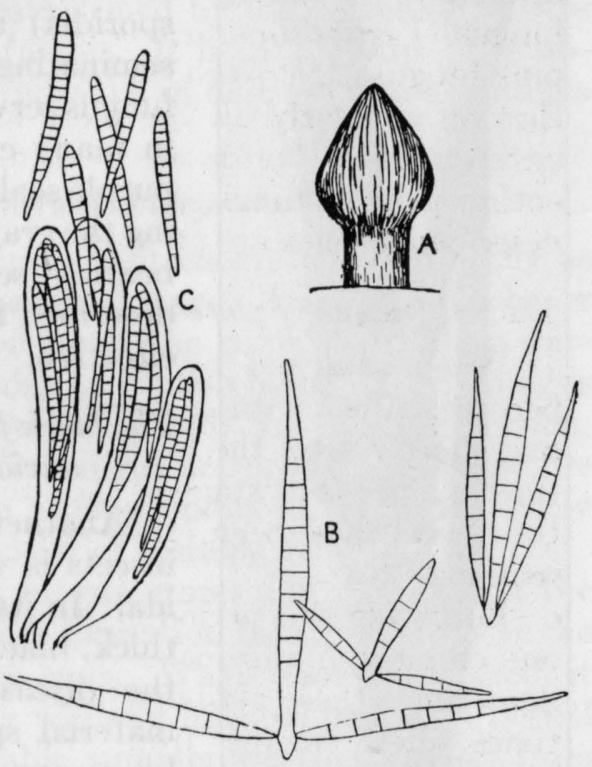

FIG. 231. The gray fungus (greatly enlarged). A, head-like conidiophore; B, conidia; C, asci or spore-cases and spores. divided into three parts, trident-shaped, the central one being the largest. Each side projection has from five to eight cells, while well-developed central ones have about fifteen. After having dried for a time, these trident-shaped conidia spread apart on the application of moisture and thus are set free 
from the conidiophore. If placed under the microscope and a drop of water added, they move like animate objects.

The other kind of spores (sporidia) are twelve- to fifteencelled, club-shaped, and borne eight together, in a spore-case

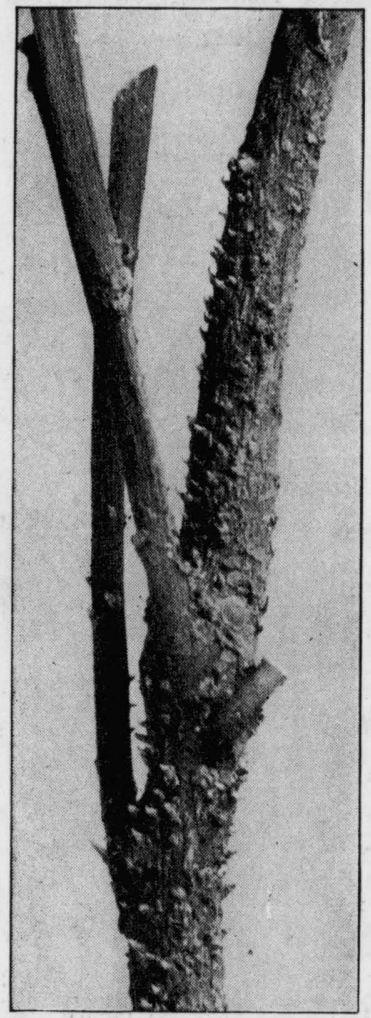

Frg. 232. Fruiting bodies of gray fungus on purple scale on orange twig.

(Fig. 231C). In this stage the fungus assumes a dirty gray buff color. These spores are specially provided to carry the fungus through periods unsuitable to its growth.

Both kinds of spores (conidia and sporidia) are instrumental in disseminating the disease. The gray fungus serves as a very efficient check in many cases against the long and purple scales. The method of spreading the gray fungus by means of twigs bearing scales infested with it, as described for the red fungus, is very effective.

\section{The black fungus (Myriangium duriai Mont.).}

Another fungus parasitic on scale insects is widely distributed in Florida. In its fruiting form it makes a thick, black, elevated crust covering the diseased scale. In this black material spores are developed and by means of these the black fungus spreads. Often the scales attacked are difficult to identify because the black fungus so thoroughly covers and destroys them. The disease has been found, however, on a large number of species and does not seem particular as to the kind it attacks. The Chionaspis citri, purple scale, long scale, and many others are destroyed. When scales are 


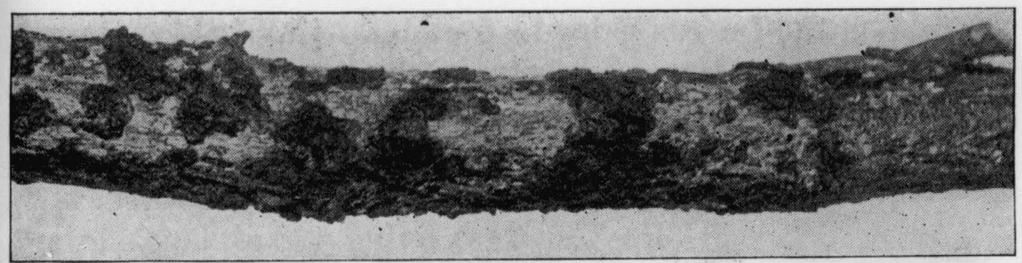

Fig. 233. Crust-like bodies of the black fungus on chaff scale

attacked by black fungus on citrus fruit, it is often difficult to remove the black encrustations.

Black fungus can be established by using pieces of twigs as described for the red fungus. It is rather slow in establishing itself, but is very thorough in destroying scale insects when once started.

\section{The red Aschersonia (Aschersonia aleyrodes Webber).}

This is an extremely important enemy of the whitefly as it attacks the insect in the pupal stage. An elevated ruby or pinkish pustule is formed upon the pupa and this is surrounded by a little yellowish or whitish band. As the fungus matures, the color becomes deep red. In this red portion, the spores (sporules) of the fungus are produced. These are borne in pits. They are narrow, pointed, and frequently curved. Usually they consist of a single cell.

The mycelium of the fungus grows and develops in the body of the pupa, the spore formation taking place after the insect is dead as in other cases. When once established, it spreads rapidly through a whitefly infested grove. A period of a few weeks in favorable summer weather elapses from "sowing" of the spores until the fruiting bodies appear. In three seasons the whiteflies are killed off, the disease disappears, and the insect infestation starts over again.

Several methods have been worked out for successfully introducing the Aschersonias. The first was to move small trees, on the leaves of which the fungous fruiting bodies were present on whitefly pupæ, and set them close to other trees, 
whereupon the fungus gained a foothold in favorable summer weather. E. W. Berger undertook a series of experiments in spreading the fungus. His first step was to collect citrus leaves bearing Aschersonia pustules on the whitefly pupæ

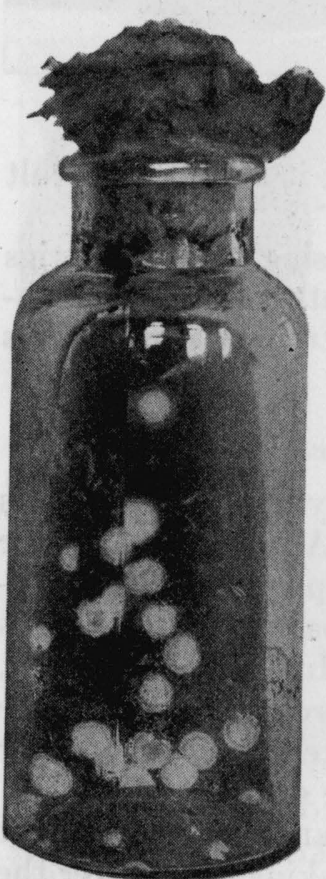

Fig. 234. A culture of red Aschersonia grown in a bottle of sterilized sweet potato. and pin these in close contact with leaves having living pupæ. This method was quite successful, but necessarily it did not establish the disease widely and quickly. It was then found that the Aschersonias could be started quickly and thoroughly by soaking pustule-bearing foliage in water, using about a dozen well-infested leaves to a gallon, straining through cheesecloth to remove all trash, and with a thoroughly clean pump spraying the water over whitefly-infested trees at the proper time. The results were satisfactory. It was recognized, however, that other diseases, some injurious to the citrus trees themselves, might be spread by this same method. Finally, in the year 1907, H. S. Fawcett succeeded in growing and fruiting pure cultures of red Aschersonia and the brown fungus on artificial media in the laboratory. Blocks of sweet potato were found satisfactory for the purpose. These were broken up in water and in that way the disease was spread successfully. The State Plant Board of Florida now produces large quantities of Aschersonia fungi for distribution by the spraying method.

The brown fungus.

This fungus was first brought to notice by H. J. Webber. At first only its sterile form was known, but later H. S. 
Fawcett discovered the fruiting bodies. It was determined a new species and named Egerita webberi Fawcett. It is probably the most effective fungous enemy of the whitefly.

The fungus forms hard brown pustules on the larvæ and pupæ of the insects on the under sides of the leaves. Having once gained a foothold, brown fungus spreads by means of minute fungal threads which grow out from the edges of the diseased insects. When these threads reach other pupæ, they penetrate them and so every insect on the leaf is finally destroyed. The
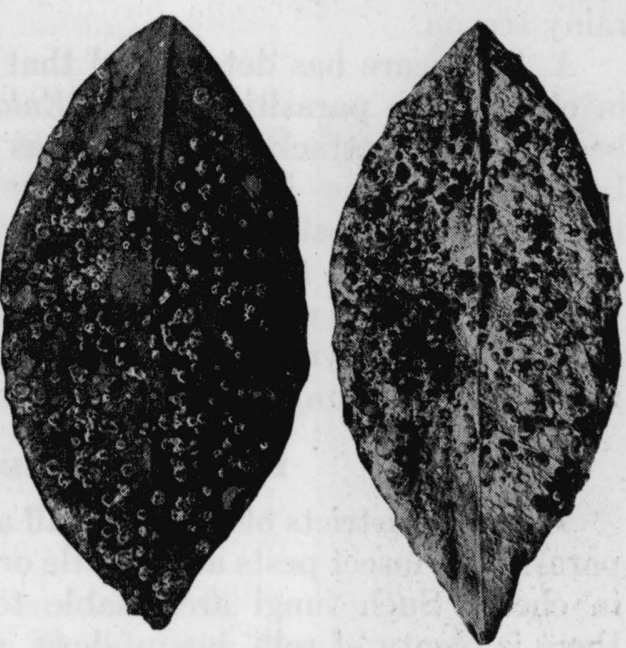

Fig. 235. Red Aschersonia (left) and brown fungus (right) on whitefly pupæ on under side of citrus leaf.

fungous filaments also grow along the edges and over onto the upper sides of the leaf. Spores, formed on the upper surfaces of the leaves, are borne on short side branches of the filaments and when abundant look like reddish brown dust. When examined microscopically they are seen to be in bunches or clusters with filaments attached. These spores are blown about and under favorable moisture conditions spread the disease.

\section{The Entomopthora fungus (Entomopthora fumosa Speare).}

In the citrus groves of Florida, the mealy-bug (Pseudococcus citri Risso) is more or less widely distributed but has never made much headway, even though growers have seldom instituted remedial measures against it. When it has gained a foothold, here and there, it has multiplied for a 
time and then has gradually become scarcer until finally it has disappeared. The reduction in numbers and the disappearance of the pest has usually been coincident with the rainy season.

A. T. Speare has determined that the mealy-bug is held in check by a parasitic fungus, Entomopthora fumosa, and because of its attacks the insect has never become particularly troublesome in Florida. The fungus grows in the bodies of the mealy-bugs, at maturity spores are formed, and these, under favorable conditions, spread the disease rapidly. They may be carried about by ants and other insects, by the wind, and perhaps by water. Against the mealy-bug this fungus gives almost complete control.

\section{BENEFICIAL INSECTS}

In citrus districts of light rainfall and dry air, the fungous parasites of insect pests are of little or no use in holding them in check. Such fungi are unable to spread except where there is plenty of rain, heavy dews, and moisture-laden air. In arid and semi-arid regions the more useful natural controlling agents are predaceous and parasitic insects, and to them much attention has been given. So successful has been this line of entomological work that many species of insects which at one time threatened the very life of the citrus industry have been reduced to a place of no importance. Insectaries are maintained where insect friends are raised in large numbers to be sent out whenever citrus insect enemies, finding their natural checks lacking, increase rapidly. In regions of heavy rainfall and more abundant natural moisture, many of these friends have also proven of great assistance in checking the increase of insect pests.

The greatest triumph of modern economic entomology was the control of the cottony cushion scale (Icherya purchasi) by the imported Australian ladybug (Novius cardina$l i s)$. This scale secured a strong foothold in California, and threatened to destroy the whole citrus industry. 
Spraying and fumigating were attempted with indifferent success, when the happy suggestion was made by Alexander Craw to send someone to Australia to find and introduce the natural enemies of the pest. This was accomplished through the cooperation of the United States Department of Agriculture and Frank McCoppin, of San Francisco, United States Commissioner to the Melbourne (Australia) Exposition. Albert Koebele was selected to do the work. The task was successfully accomplished. He found the natural enemy, Novius cardinalis. It was sent to California, thrived in its new home, and speedily destroyed the dreaded Icherya purchasi.

When the cottony cushion scale became established in Florida, the late H. A. Gossard, then of the Florida Experiment Station, was instrumental in introducing the ladybug from California, and the ravages of the insect were again checked.

A number of other ladybeetles are of material assistance in holding injurious insects in check. In Florida the two-spotted ladybeetle (Chilocorus

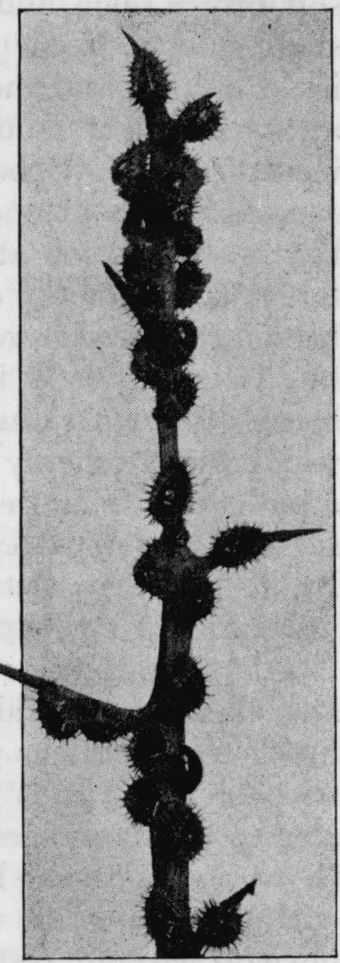

Frg. 236. Pupa cases of the two-spotted ladybeetle on dead orange twig. bivulnerus) is an effective enemy of several scale insects. Both the larvæ and the mature insects feed upon scales and, fortunately, this beetle is very common throughout the state. The blood-red ladybeetle (Cycloneda munda) and the convergent ladybeetle (Hippodamia convergens) feed on aphids, particularly Aphis gossypii, and sometimes arrest this pest completely. The California whitefly-eating ladybeetle, Delphastus cataline, is a worth-while enemy of whiteflies. 
Parasitic wasps of many kinds lay their eggs in the bodies of scales and other citrus pests. The hemispherical scale, soft brown scale, and wax scale are often controlled by these small insects. Sometimes they also lay their eggs in the bodies of aphids, and the young larvæ completely destroy them, after having eaten out their interiors. In California numerous insect friends have been brought into use, following the signal success which attended the introduction of the Australian ladybeetle. Much attention has been given to insects of different kinds for the control of pests, and many species have been introduced from various parts of the world. The mealybug is largely held in check by a parasite, one of the ladybeetles (Cryptolamus montrouzieri), and the black scale has a very effective enemy in Rhizobius ventralis. Sautellista cyanea, a parasite, the larvæ of which feed on the eggs of the black scale, is a very important factor in the control of this pest. In all American districts syrphus flies and other predaceous insects are very helpful in controlling injurious insects.

All operations, such as pruning, spraying, fumigating, and dusting, should be conducted in such a way as to interfere as little as possible with the life activities of insect friends. Often it is possible to save these friends from destruction by advancing or delaying the work. It is difficult to overestimate the help they give; this cannot be measured entirely until some misfortune overtakes them, when pests develop without restriction and work great harm.

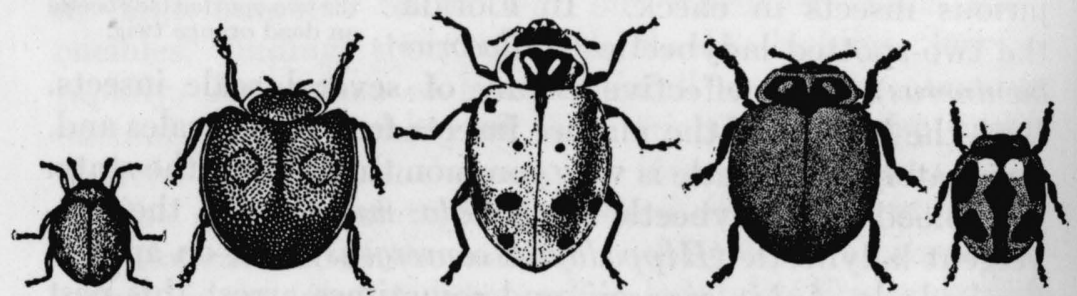

Frg. 237. Five ladybeetle friends (greatly enlarged). From left to right: California whitefly-eating ladybeetle, D. catalinæ; two-spotted ladybeetle, C. bivulnerus; convergent ladybeetle, $H$. convergens; blood-red ladybeetle, C. munda; Australian ladybeetle, $N$. cardinalis. 


\section{N D E X}

Acme orange, 57.

Acosta, 49.

Acreage in citrus fruits, 4.

Adobe, 219.

Adventitious buds, 495 .

Egerita webberi, 538, 543.

Egle Marmelos, 29.

sepiaria, 35.

Eglopsis Chevalieri, 29.

Air drainage, 222.

Alabama citrus area, 9.

Alfalfa, 269.

Alkali injury, 316.

Ammoniacal solution of copper carbonate, 512 .

Ammoniated fruit, 496.

Amyris, 25.

Analyses of beggarweed, 275 .

kumquats, 287.

lemon, 287.

mandarins, 286.

oranges, $286,287$.

pomelos, 282, 286.

velvet bean, 272 .

Angular budwood, 190.

Angular-winged katydid, 427.

Ant injury, 431. sirup, 516.

Anther, 144.

Anthracnose, 472, 473.

Ants, 431.

treatment for, 431.

Aphids, 545.

Aphis, 452.

gossypii, 452, 545.

spiræcola, 452.

treatment for, 453.

Appalachian barrier, 320 .

Application of fertilizer, 293.

Applying fertilizers, 189, 300.

Arcadia orange, 57.

Areas of high pressure, 320 .

Arizona citrus areas, 9. citrus in, 5 .

Armored scales, 428, 432.

Armory, Charles, 54.

Arsenate of lead, 505, 516.

Artesian water, 308.
Aschersonia, 449.

aleyrodes, 538, 541.

flavo-citrina, 538.

Ashes, 285.

Asphalt paint, 357.

Asphaltum in oil, 339, 341.

Atalantia citrioides, 32 .

Auction houses, 423.

Auctioning fruit, 424.

Aurantium pomelo, 99.

Australian desert kumquat, 32.

finger-lime, 33.

lady-bug, 444, 453, 544 .

lime, 33.

orange, 71 .

pine, 227.

Baccillus citrimaculans, 492.

Bacterial diseases, 486.

Bacterium citrarefaciens, 492. citriputeale, 491, 492.

Bael fruit, 29.

Bahia navel, 55. orange, 71 .

Balled trees, 251.

Balsamocitrus Dawei, 29. gabonensis, 29. paniculata, 29.

Bamboo windbreak, 227.

Banking trees, 335.

Barger, W. R., 484.

Barnacle scale, 441.

Barrel packages, 373.

Bean, E. quoted, 369.

Beans, 269.

Bearss lime, 138.

Beauty mandarin, 81 .

Beggarweed, 269, 271, 274.

Beneficial insects, 544.

Benefits from cultivation, 253.

Bessie orange, 62.

Best trees to plant, 245.

Bichloride of mercury, 518.

Bigarade orange, 21, 43.

in Spain, 45, 46.

Biological soil changes, 259.

Birch hoops, 404.

Bird grasshopper, 426. 
Bishop-Hoyt grove, 45.

Biting insects, 425, 426.

Bitter sweet orange, 46.

Black alkali, 316 .

fungus, 537, 540 .

-pit, 486, 491.

scale, 438.

Blood oranges, 51 .

Bloom-blight, 472, 474.

Blue mold, 385, 483.

stone, 498.

Boiled oil emulsion, 513.

Bonavia, 77.

Bone-black, 290.

Bone meal, 286.

Boone orange, 57.

Bordeaux mixture, 505.

and die-back, 498.

formula, 511 .

oil emulsion formula, 512 .

paste, $358,517$.

Botanical classification, 14 .

Botany of Citrus, 10.

Botrytis cinerea, 469.

Box capacity, 399.

cleats, 400.

heads, 399.

labels, 409.

-making machine, 402.

Boxes to car, 415.

field, 384 .

Bright fruit, 395.

Broad-winged katydid, 427.

Brown fungus, 449, 538, 542. rot, 469.

Browne, D. J., 55.

Bruises, 387.

Buckwheat, 269.

Bud sports, occurrence of, 174 .

storage of, 172.

time to cut, 172 .

-union, 332.

variations, 173.

Budded nursery, 187.

Budding illustrated, 183, 185. in thick bark, 190.

knives, 179.

methods, 181.

old stocks, 189.

time, 179.

with curved incision, 190 .

Budwood, 171.

Bulge pack, 389, 407.

Bur clover, 280.
Bureau Agricultural Economics, 593.

Burger, O. F., 475.

Butler, C. W., 205.

Calamondin, 24, 133, 328.

Calcium cyanide, 431.

Calendars for spraying, 509 .

California citrus acreage, 4 . citrus areas, 8.

Experiment Station, 210.

Fruit Exchange, 5.

Fruit Growers Exchange, 419.

fruit season, 379 .

grades, 397.

judging scales, 154 .

lemon crop, 4.

lemon scale, 156.

orange box, 399 .

pomelo scale, 157.

pruning saw, 361 .

red scale, 436 .

soils, 219 .

State Board of Horticulture 537.

Calyx, 143.

Can-heater, 340.

Canker, 486.

Captain Shaddock, 93.

Carbolic acid, 358.

Carbolineum, 358, 517.

Carbon bisulfide, 431, 445.

Carload of fruit, 416 .

Car-squeeze, 416.

Car-strips, 416.

Carya alba, 217.

Castor pomace, 292.

Cattle-penning, 464.

Causes of fruit injuries, 386.

Caustic potash whale-oil soap, 515 .

Cement-coated nails, 401.

Centennial orange, 62 .

Ceroplastes cirripediformis, 441. floridensis, 439.

Chaddock, 91.

Chadec, 91.

Chætospermum glutinosa, 29.

Chaff scale, 436.

Chalcas exotica, 27.

Check system, 313 .

Chemical soil changes, 259.

Cheng Lei pen t s'ao, 34 .

Chilocorus bivulnerus, 545 .

China mandarin, 81 .

Chinaberry tree, 449 .

Chionaspis citri, 437. 
Choice grade, 398.

Chrysomphalus aonidum, 435. aurantii, 436.

Cinnamon fungus, 538.

Circassian orange, 63.

Citrange, 37.

Colman, 39.

Morton, 40.

Rusk, 40.

Savage, 40.

Citrangequat, 38, 39.

Sinton, 40.

Telfair, 41.

Thomasville, 42.

Citric acid, 125.

Citron, 18, 119, 328.

Etrog, 121.

Lemon, 121.

Lyman, 122.

orange, 122.

peel, imports of, 121.

Citropsis gabonensis, 32 .

Preussi, 32.

Schweinfurthi, 32 .

Citrus, 14.

acreage, 4.

aphis, 452 .

areas, 6.

aurantifolia, 20, 131.

Aurantium, 21, 43, 47, 48, 74.

Aurantium var. sinensis, 48 .

Bigaradia, 43.

blast, 491 .

botany, 10 .

canker, 486-491, 502.

classification, 11 .

crops, 2, 6.

decumana, 90.

diseases, 461.

exchanges, 5 .

florida, 43.

fruit judging, 151.

fruits, 13,14 .

Fruits and Their Culture, 210. grandis, 108.

ichangensis, 24, 328.

in Georgia, 9.

Limonia, 19.

locations, 221.

maxima, 20, 90, 108.

medica, 18, 119.

mitis, 24, 133, 477.

myrtifolia, 365 .

nobilis, 23, 74-77.
Citrus nobilis var. deliciosa, 23.

nobilis var. Unshiu, 23.

packages, 399.

paradisi, 21, 90 .

relatives, 25 .

scab, 45, 476-479.

seed-bed, 163.

seedling trees, 159 .

seeds, 160,162 .

sinensis, 22, 47, 48, 74 .

soils, 214 .

species, 14.

stocks, 199, 363.

trifoliata, 15, 34.

vulgaris, 43.

whitefly, 446.

Cladosporium citri, 476.

Claremont fruit growers association, 418.

Classification of oranges, 51 .

Claucena, 27.

Clay soils, 294.

Clean cultivation, 256.

Clearing land, 229.

Cleft-grafting, 191.

Clementine orange, 477.

Cleopatra mandarin, 82. stock, 199.

Climate, effect of, on fumigation, 534 .

Clipper cuts, 387.

Clippers, 381.

Cloudy-winged whitefly, 449 .

Clover, 269.

Coccus hesperidum, 437.

Coke, 343.

Coke-heaters, 342.

Cold, 1876, 372 .

forewarnings, 322 .

resistance, 324 .

waves, 318 .

Colletotrichum glœosporioides, 472, 474.

Colman citrange, 38,39 .

Coloring green fruit, 382 . citrus fruits, 411 .

Commirsion merchants, 422.

Composition of citrus trees, 282. of soil, 216-218.

Concrete irrigation pipe, 311 .

Cooling before loading, 415 .

Coöperative marketing, 418.

Copper carbonate, 512. sulfate for die-back, 498.

Coquillet, D. W., 520.

Cordoba, 45. 
Corn-stalk smasher, 276.

Corolla, 143.

Cotton gloves, 387 .

seed meal, 292.

stainer, 274.

Cottony cushion scale, 442 .

Cover-crops, 268.

in California, 279.

Cowpeas, 230, 269, 271.

Craw, Alexander, 545.

Creosote, 358.

Crop season, 379.

Cross, 142. pollination, 142, 145.

Crotalaria, 269, 277.

Retzi, 271, 277.

striata, 271, 277.

Crowder, 314 .

Crown-grafting, 193.

Crude carbolic acid, 517.

Crystals of hesperidin, 332 .

Cryptolæmus montrouzieri, 445, 546.

Crytophyllus concavus, 427.

Cuban soils, 220.

Cultivation, 301.

after irrigating, 312.

and cold, 325 .

implements, 267.

in Arizona, 261.

in Florida, 260, 261.

methods, 260 .

of citrus groves, 263.

of nursery trees, 189.

of young groves, 263 .

Curing, 389.

Curved blade saw, 361 .

Cutaway harrow, 276.

Cuts, 387.

Cutting buds, 174.

Cuttings, 169.

Cyanide, calcium, 431. solution, 525.

Cycloneda munda, 545.

Cypress, 226.

Damping-off, 165, 477.

Dancy mandarin, 84 . tangerine, 328 .

DeCandolle, 34 .

Decay investigations, 386 .

Deep setting, 250 . wells, 308 .

Deliciosa, 74.

Delivery of fruit to packing-house, 392.
Delphastus catalinæ, 546.

Depletion of soils, 288.

Desmodium tortuosum, 271.

De Soto pomelo, 100.

De Tussac, Chevalier, quoted, 91.

Dew point, 321.

Diagrams, 404-407.

Dialeurodes citri, 446. citrifolii, 449.

Dictyophorus reticulatus, 426.

Die-back, 257, 265, 494, 495. and fertilizers, 497. and pruning, 356 .

Digging holes, 248. seedlings, 167.

Diplodia natalensis, 464,469 .

Diseases and cold, 324.

caused by bacteria, 486 . caused by fungi, 461 . of Citrus, 461. resistance of Citrus, 502. resistance of sour orange, 201.

Disposal of prunings, 361 .

Distances and spraying, 238. for planting, 237 .

Distributing fertilizer, 301. water, 311.

District exchanges, 419.

Doidge, Ethel M., 492.

Don, George, quoted, 96.

Don Phillippe, 95.

Dormancy, 264, 325.

Dormant budding, 180.

Dosage tables for fumigating, 527-529.

Double Navel orange, 72 . plantings, 235.

Downing, A. J., quoted, 113. Charles, 97.

Drainage, 316.

Dried blood, 292.

Dryers, 393.

Drying, 393.

Dummitt orange, 57.

Duncan pomelo, 100, 328.

Du Roi orange, 63.

Dust mulch, 255.

Dusting, 503, 518.

Early Oblong orange, 58 . orange seasons, 380 . varieties, 241.

Effects of cold, 330 .

Egyptian orange, 72.

El Cajon Pass, 320. 
Elevating tents, 532.

Emasculation, 147.

Emptying picking bags, 382 .

Enterprise orange, 58.

Entomogenous fungi, 537.

Entomopthora fumosa, 445, 538, 543, 544 .

Eremocitrus, 328. glauca, 32 .

Eretmocerus haldemanii, 451.

Eriophes oleivorus, 454.

Essential organs, 145.

Etrog, 121, 134.

Eureka lemon, 126.

Eustis limequat, 26, 134, 328.

Everbearing lemon, 126. orange, 63 .

Everglade lime, 132.

Exanthema, 254, 494.

Excelsior pomelo, 101.

Exchange departments, 420.

Exchanges, 418.

Experiments of G. L. Taber, 210.

Exquisite orange, 63.

Extension cultivators, 267.

Extracting seed, 162.

Fall cultivation, 329 . fertilizing, 303 .

Fawcett, H. S., 467, 492.

Fecundation, 145.

Feronia Limonia, 27.

Ferrari, 48, 56.

Fertilizer, 281.

amounts, 297.

and cold, 325 .

distributor, 301.

formulas, 297.

in planting, 249.

removed in crop, 288.

Fertilizing, 281.

for fruit, 299 .

in California, 300.

neglected trees, 266 .

old trees, 295, 299.

policy, 288 .

pot plants, 366 .

young trees, 295, 298.

Field-boxes, 384 .

peas, 280 .

-wagons, 384.

Filament, 144.

Filling field-boxes, 388.

Finger lime, 33.

Finger-nails, 387.
Fires, 337.

danger, 265.

Flat woods land, 216.

Float for smoothing land, 236.

Flora Japonica, 34 .

of India, 26.

Florida Agriculturist, 369.

artesian areas, 308.

citrus acreage, 4 .

citrus areas, 7 .

citrus box, 370, 399 .

Citrus Exchange, 6, 421.

fruit season, 379 .

grades, 395 .

green fruit laws, $375,376$.

judging rules, 151.

orange box, 399 .

pomelo scale, 153.

rainfall, 306.

red scale, 435 .

soils, 216.

State Plant Act, 487.

State Plant Board, 537.

Flower parts, 143.

Flumes, 311.

Food inspection decision, 378, 412.

Foot-rot, 462, 502.

Forbidden Fruit, 91, 93.

Forked-tailed katydid, 427.

Formulas, 297, 511.

Fortune, Robert, 12, 15, 113, 206.

Fortunella, 13-15, 113.

crassifolia, 17.

Hindsii, 17.

japonica, 16.

margarita, 16.

Foster orange, 58 . pomelo, 101.

Franciscans, 50.

Franilinella bispinosus projectus, 457.

Freedom from frost, 222.

Freezes, 224, 318.

in California, 319.

in Florida, 318.

Frenched, 285.

Frenching, 212, 256, 280, 290, 500.

Frequency of cultivation, 262.

Frosts, 224, 264, 319.

and citrus, 318 .

considerations, 318 .

formation, 320 .

protection, 334 .

spotting, 333 .

Frozen trees, 350 . 
Fruit growers exchange, 418. packing, 403. -rots, 481. stands, 424 .

Fruiting formulas, 299.

Fuel-oil, 341.

Fumigating, 503.

Fumigation, 520 . cart, 525.

equipment, 503. formula, 527 . in California, 521. in Florida, 521. injury, 531. practice, 532. reactions, 534 . tents, 522 . time, 533 .

Fungi attacking insects, 537.

Fungicidal sprays, 511.

Fungous diseases, 461. friends, 535 .

Furrow system, 311.

Fusarium, 471.

Gallesio, 48, 54, 173.

Garroway's finger-lime, 33.

Gas generators, 524.

Gathering citrus fruits, 386.

Generators for gas, 524 .

Genoa lemon, 127.

Glauber salts, 316 .

Gloosporium limetticolum, 472.

Gloves, 387.

Golden fruit, 395.

Gossard, H. A., 545.

Grades, 393, 395, 398.

Grading, 236, 393.

belts, 393 .

lemons, 409.

terms, 397.

Grafting, 190. at the crown, 193. -iron, 179, 191. knives, 178. wax, 175,357 .

Graft-union, 332.

Grapefruit, 21. acreage, 4 .

for planting, 140 .

in California, 243.

origin of, 93, 94 .

origin of name, 91.

Grass cover-crops, 269.
Grasshopper, 426.

bait, 516 .

injury, 427.

Gray fungus, 537, 539. gummosis, 469.

Green fruit, 241, 374 . fruit laws, 375,376 . mold, 385,483 .

Ground bone, 290. limestone, 285. tobacco, 519.

Grove plans, 231.

Growing citrus in pots, 363.

Gum-diseases, 469.

Hall pomelo, 101, 476.

Hamlin orange, 64 .

Handling citrus fruits, 369.

Han-Yen Chih, 385.

Hardiness of poncirus stock, 207. of sour orange, 200.

Hard layers in soil, 268.

Hardpan, 216, 219, 311.

Hardy varieties, 327.

Hart, E. H., 55, 75, 91. W. S., 225, 230.

Hart's late orange, 67. Tardiff orange, 67.

Hauling, 388.

Hawkins, L. A., 484.

Heading press, 408.

Heating failures, 342 .

Hedge plantings, 235.

Hemispherical scale, 439.

Hesperethusa crenulata, 30.

Hesperidin crystals, 332 .

Heterodera radicicola, 269.

Hexagonal planting, 233.

Hick orange, 59.

High-hammock land, 217. -headed trees, 346. pine land, 216. stack heater, 340 .

Hilgard, 316.

Hippodamia convergens, 545.

Homosassa orange, 59.

Honey-dew, 431, 485.

Hongkong kumquat, 17, 116.

Hooker, 26.

Hop-tree, 25.

Horse-shovel, 314.

How often to eultivate, 262. to know good trees, 245.

Hubbard, H. G., 432, 454. 
Hughes, Griffiths, 93.

Humus, 257, 258.

Hybrid, 142.

Hydrated lime, 285.

Icherya purchasi, 442, 544, 545 .

Icing, 415.

Ilex glabra, 216. opaca, 217.

Implements, 267.

Inarching, 191, 194.

Indian River, 217. oranges, 50,59 . pomelo, 104.

Injurious temperatures, 329.

Injury from ants, 431. from grasshoppers, 427. from katydids, 427 . from orange-dog, 430 . to fruit, 386.

Inman, W. F., 420 .

Insecticidal sprays, 513 .

Insects, 425.

and cold, 325 .

classified, 425.

control by natural enemies, 536 .

friends, 535 .

on pot plants, 368 .

Iron irrigation pipe, 311.

Irrigation, 304.

areas, 305 .

in California, 305.

in Florida, 305.

in Texas, 306.

runs, 313.

season, 316 .

Italian lemon box, 399 .

Jaffa orange, 64 .

Jamaica, 43.

Japan clover, 269.

Johnson, John, 56.

Josselyn pomelo, 101.

Judging citrus fruits, 151.

Jump scraper, 315.

Kaempfer, 34.

Kainit, 291.

Kansas grasshopper bait, 516.

Katydids, 426, 427.

Kerosene emulsion, 514.

Kid-glove oranges, 75 .

Kinds of grafting, 191. of stock, 199.
King mandarin, 84 . orange, 23,74 .

Kingsley, Z., 55.

Kin Kan, 112.

Kinneola mandarin, 85.

Kino Kuni mandarin, 86.

Keobele, Albert, 545.

Kou Chu, 34.

Kumquat, 15, 112, 328.

analyses, 287.

Australian desert, 32.

for planting, 140 .

fruit season, 380 .

hardiness of, 115.

Hong Kong, 116.

introduction of, 113.

Latin names of, 113.

Marumi, 117.

Meiwa, 117.

Nagami, 117.

oblong, 117.

packing, 386.

round, 117.

uses of, 116.

Kusaie lime, 135.

Labels, 179, 252, 409 .

Ladders, 383.

Lady-beetles, 545 .

Lady-bug, Australian, 544.

Lakeland limequat, 135.

Late varieties, 241.

Lavanga scandens, 30 .

Laying out in hexagons, 239. in quincunx, 240.

in squares, 238.

in triangles, 239.

with a wire, 239.

Leaching, 294.

of nitrates, 268 .

Leaf-spot, 72, 474.

Lee, H. Atherton, 492.

Legumes, 269.

Lelong, M. B., 55.

quoted, 50.

Lemon, 19, 123.

acreage, 4 .

analyses, 287.

box, 399 .

citron, 121.

crops, 4.

Eureka, 126.

Everbearing, 126.

for planting, 140 . 
Lemon fruit season, $379,380$.

Genoa, 127.

in California, 124.

in Florida, 123.

Lisbon, 127.

Mozoe, 127.

Otaheite, 128.

Ponderosa, 128.

Rough, 128.

scale for judging, 156.

Sicily, 129.

sizes, 411 .

stocks, 205.

Sweet, 129.

uses of, 125.

Villafranca, 130.

Leonardy pomelo, 102.

Lepidosophes beckii, 432. gloverii, 432, 434.

Leveling land, 236.

Lighting-torch, 344.

Lime, 20, 131, 282.

Australian Finger, 33.

Bearss, 138.

-berry, 30.

Calamondin, 133.

for planting, 140 .

fruit season, 380 .

Kusaie, 135.

Mexican, 135.

Persian, 138.

Rangpur, 136.

stocks, 205.

Tahiti, 138.

Limequat, 134.

Eustis, 134.

Lime-sulfur, 505, 513.

Limonia, 35.

Linnæus, 34, 48.

Liquid gas pump, 526.

hydrocyanic-acid gas, 526 .

Lisbon lemon, 127, 328.

Live-oak, 217.

Loading, 415. strips, 416.

Locating the citrus grove, 221.

Locations and pests, 228.

Long scale, 434 . stems, 386, 387.

Loose-skinned oranges, 74 .

Lopping, 186, 187.

Losses by leaching, 294, 295, 297. of nitrogen, 296.

of phosphoric acid, 296.
Losses of potash, 297.

Louisiana citrus areas, 9. soils, 218.

Low-headed trees, $188,346$.

Lubberly grasshopper, 426.

Lue Gim Gong orange, 64, 328.

Lunan, John, quoted, 91.

Lupines, 269.

Lyman citron, 122.

Macfayden, 43.

Machine method of fumigating, 525 .

MacKay, A. W., 409.

Madame Vinous orange, 59.

Magnolia grandiflora, 217.

Magnum Bonum orange, 60.

Majorca orange, 65 .

Making boxes, 401 . waxed eloth, 176.

Mal-di-goma, 462.

Maltese orange, 69. oval orange, 65 .

Mammoth shaddock, 110 .

Mandarin oranges, 328 .

Beauty, 81.

China, 81.

Cleopatra, 82.

Dancy, 84 .

for planting, 140 .

importance of, 79.

introduction of, 77,78 .

King, 84 .

Kinneola, 85.

Kino Kuni, 86.

Mikado, 86.

Oneco, 86.

Owari, 87.

Satsuma, 87.

Tangerona, 88.

Temple, 89.

Manville pomelo, 102.

Maps, 252.

Marketing agencies, 422 . citrus fruits, 369, 416.

experiences, 369 .

Marking boxes, 408 . tents, 523.

Marquis orange, 65 .

Marsh pomelo, 102, 476.

Marumi kumquat, 117.

May orange, 60. pomelo, 103.

McCarty pomelo, 104.

McCoppin, Frank, 545. 
McKinley pomelo, 104.

Mealy-bug, 444.

Measuring trees for fumigating, 530 .

Mediterranean oranges, 51, 52 .

Meiwa kumquat, 117.

Melanose, 480, 481.

Meliola camelliæ, 485.

Melitensis orange, 72 .

Melon-apple, 90.

Metal dams, 315 . strips, 400.

Methods of budding, 181. of grafting, 190. of selling, 422 . of top-working, 195.

Mexican lime, 135.

Microcentrum retinerve, 427. rhombifolium, 427.

Microcera fujikuroi, 538.

Microcitrus, 328. australasica, 33 .

australasica var. sanguinea, 33 . australis, 33 .

Garrowayi, 33.

inodora, 33.

virgata, 33.

Mikado mandarin, 86.

Mildew proofing tents, 523 .

Miscible oil, 505, 514.

Mission gardens, 50.

Mississippi citrus area, 9. soils, 218.

Mite, 454, 455. injury, 456.

Mixing fertilizers, 294, 298.

Mold, 385. sooty, 485.

Monterey cypress, 226.

Moore, Rev. T. W., 97.

Morris, Robert T., 192.

Morton eitrange, 38-40.

Motor transportation, 221. trucks, 384 .

Mottled leaf, 256, 500.

Mozoe lemon, 127.

Mulching, 271.

Muriate of potash, 291.

Murraea exotica, 27.

Mycelium, 462.

Myriangium duriæi, 537, 540.

Myrtle-leaved orange, 365 .

Nagani kumquat, 16, 117.

Nail-points, 387.
Navel markings, 55. orange, early reference to, 55,56 . orange season, 379 . oranges, 51,54 .

Nezara viridula, 459.

Neglected trees, 266.

Nematodes, 269, 271.

Newell, Wilmon, 487.

Nicotine sulfate, 516 .

Nitrate of soda, 292.

Nitrification, 253.

Nitrogen, 282, 283. in velvet bean, 272 .

Nocatee tangelo, 106.

Nodules, 269, 274.

Nonpareil orange, 60 .

Novius cardinalis, 444, 544, 545 .

Number of buds inserted, 186. of trees to an acre, 234 . of varieties, 242 .

Nursery cultivation, 189 . fertilizers, 189. insects, 189.

tree grades, 246.

Oats, 269.

Oblong kumquat, 117.

Oil-heaters, 339 . storage, 341.

Old Vine orange, 61 .

Oneco mandarin, 86.

Ophionectria coccicola, 537, 539.

Orange, Acme, 57. acreage, 4 . analyses, 286, 287.

Arcadia, 57.

Australian, 71.

Bahia, 71.

Bessie, 62.

Bigarade, 43, 44.

Bitter Sweet, 46.

Boone, 57.

boxes, 399 .

Centennial, 62 .

Circassian, 63.

Citron, 122.

classification, 51 .

-dog, 428-430.

Double Navel, 72.

Dummitt, 57.

DuRoi, 63.

Early Oblong, 58 .

Egyptian, 72.

Enterprise, 58. 
Orange, Everbearing, 63 .

Exquisite, 63.

for planting, 140 .

Foster, 58.

Hamlin, 64.

Hart's Late, 67.

Hart's Tardiff, 67.

Hick, 59.

Homosassa, 59.

Indian River, 59.

introduction, 49, 50 .

Jaffa, 64 .

Jessamine, 27.

Lue Gim Gong, 64.

Madame Vinous, 59.

Magnum Bonum, 60.

Majorca, 65.

Maltese, 69.

Maltese Oval, 65.

Marquis, 65.

May, 60.

Meletensis, 72.

Nonpareil, 60.

Old Vine, 61.

Osceola, 61.

Paper Rind, 66.

Parson, 73.

Parson Brown, 61.

Pineapple, 66.

Prata-Riverside Navel, 71.

Ruby, 69.

rust mite, 454 .

St. Michael, 70.

Sanford Blood, 69.

Saul Blood, 70.

scale for judging, 151, 154 .

seasons, 379 .

Seville, 43.

snow scale, 437 .

sour, $43,47$.

spray schedule, 511 .

Star Calyx, 67.

Starke, 62.

Surprise, 73.

Sustain, 73.

trifoiiate, 15.

Valencia, 67.

Valencia Late, 67.

Washington Navel, 71.

White, 68.

Whitaker, 62.

Orangeade, 46.

Orchard run grade, 398.

Order of hardiness, 328.
Originating new varieties, 141.

Origin of artesian wells, 310 .

Osbeck, 48.

Osceola orange, 61 .

Otaheite, $125,365,477$.

lemon, 128.

stock, 199.

Oval kumquat, 16.

Ovary, 144.

Ovules, 144.

Owari mandarin, 87.

Oyster-shell bark-louse, 432.

Packing citrus fruits, 369 .

conveniences, 403.

diagrams, 404-407.

fruit, 389,403 .

-house, area served by, $389,391$.

-house manager, 391 .

lemons, 409.

table, 403.

Paint, 357.

Palmetto lime, 132.

Paper for wrapping, 402.

linings, 404.

rind orange, 66 .

trays, 403.

Papilio cresphontes, 428.

Paraffin, 357. in grafting, 192.

Paramignya monophylla, 30.

Parasitic fungi, 506. wasps, 546.

Parlatoria pergandii, 436.

Parson orange, 73.

Brown orange, 61 .

Partial clearing of land, 229. cultivation, 263.

top-working, 198.

Peas, 269.

Pedigreed buds, 175 .

Penicillium digitatum, 483. italicum, 483.

Pepper trees, 226.

Pernambuco pomelo, 104.

Persian lime, 138.

Petal, 143.

Phomopsis citri, 480.

Phosphoric acid, 290.

Phosphorus, 282, 283.

Physical soil changes, 259.

Physiological diseases, 493.

Phytopthora citropthora, 469. terrestria, 464. 
Pickers, 381.

Picking, 381.

bags, 382 .

baskets, 382 .

crews, 381 .

equipment, 381 .

foreman, 381 .

fruit, 386 .

ladders, 383.

weather, 388 .

Pineapple orange, 66.

Pink fungus, 538.

shaddock, 110.

Pinus cubensis, 216. palustris, 216.

Piso, 49.

Pistil, 144.

Plan of packing-house, 390.

Plant-food, 289. and cold, 324 .

Planting, 247.

board, 248 .

citrus seeds, 163, 241.

distances, 237.

in hexagons, 233.

in squares, 232.

in triangles, 233.

seedlings, 168.

time, 246.

Plowing before planting, 231.

Plunkenet, 108.

Poison baits, 516 .

Poisoning ants, 431.

Pollination, 145.

Polyembryony, 143, 149, 150.

Pomelo, 21, 90.

analyses, 286.

Aurantium, 99.

De Soto, 100.

Duncan, 100.

early shipments of, 97 .

Excelsior, 101.

Foster, 101.

Hall, 101.

hybrids, 90 .

in California, 98.

Indian River, 104.

in Florida, 98.

introduction into Florida, 95.

Josselyn, 101.

Leonardy, 102.

Manville, 102.

Marsh, 102.

May, 103.
Pomelo, McCarty, 104.

McKinley, 104.

old trees of, 95 .

origin of, 93, 94 .

Pernambuco, 104.

root system, 212.

Royal, 105.

seale for judging, 157.

seeds, 160.

Silver Cluster, 101.

stock, 212.

Triumph, 105.

value of, 95 .

varieties of, 99 .

Walters, 105.

Pompelmoes, 90.

Pompelmous, 20.

Poncire, 14.

Poncirus, 13, 14, 26.

erossing, 36 .

hybrids, 38,39 .

seed, 34 .

stock, 206, 326.

trifoliata, 15, 35, 477.

Ponderosa lemon, 128.

Porto Rico, 43.

Potash, 282, 283. and cold, 325 .

Pot culture, 363. method of fumigating, 525 .

Potting soils, 364 .

Power duster, 518, 519.

Prata-Riverside navel orange, 71 .

Precautions in fumigating, 534.

Precipitation in Florida, 306.

Pre-cooling, 415.

Preparations for planting, 229.

Press, 408.

Prevention of evaporation, 255. of hard pan, 262.

Prices of citrus trees, 246.

Prickly ash, 25.

Problems of cultivation, 260.

Propagation of eitrus, 159. tools, 175, 178.

Proportions to plant, 243.

Protecting against frost, 334 . by fires, 337 .

pollinated flowers, 148 .

wounds, 357.

young trees, 250 .

Proteids, 282.

Protexol, 358, 517.

Pruning, 361, 471. 
Pruning citrus trees, 346.

frozen trees, 350 .

knife, $178,360$.

neglected trees, 266, 354 .

newly planted trees, 250 .

old trees, 349 .

potted citrus, 366 .

saws, 360 .

shears, 179,360 .

time, 359 .

tools, 359 .

young trees, 347,348 .

Pseudægle, 35.

Pseudococcus citri, 444.

Pseudomonas citri, 487, 490.

Psorosis, 469.

Psychrometer, 323.

Ptelea, 25.

Pummelo, 20.

Pumpkin bug, 459.

Purchasing trees, 244.

Purple scale, 432.

Push-cart market, 424.

Pyrethrum, 426.

Quarantine, 486.

Quercus virginiana, 217.

Quick lime, 285.

Quincunx planting system, 234.

Radiated heat, 321 .

Radiation, 321.

Rag, 293.

Rainfall in California, 305.

in Florida, 305.

in Texas, 306.

Rainy season, 306.

Rangpur lime, 136.

Rape, 269.

Rattle-box, 269.

Re-budding, 186.

Recipes for wax, 176.

Rectangular planting system, 232.

Red Aschersonia, 449, 538, 541.

Ball, 420.

fungus, 537,538 .

scale, $435,436$.

Refrigeration, 415.

Rejuvenating neglected trees, 266.

Removing banks, 337.

Resin wash, 505.

Rhizobius ventralis, 546.

Rhizoctonia, 471.

Right-angled budding, 186.
Rio Grande Valley, 218.

Ripe fruit-rots, 483.

Robinson, T. Ralph, 103.

Root-hairs, 269.

Rooted cuttings, 169.

Root-knot, 269.

Root nodules, 269.

Roots of beggarweed, 275 .

pruning of, 248.

system of pomelo, 212.

system of rough lemon, 203.

system of sweet orange, 211 .

system of trifoliate orange, 209.

Ross, Sydmer, quoted, 313.

Rough handling, 385.

lemon, 128, 161.

lemon stock, 203.

Round-fruited Australian lime, 33.

Round kumquat, 16, 117.

Royal pomelo, 105.

Ruby orange, 69.

Rusk, 38-40.

Russell River lime, 33.

Russet fruit, 396.

Rust mite, 454 .

Rustic, 38.

Rutaceæ, 14, 25.

Rye, 269.

Sabal palmetto, 217.

St. Michael orange, 70 .

Saissetia hemispherica, 439. olex, 438.

Salt, $310,316$.

Sampson, F. G., 373. tangelo, 107.

Sand-spurs, 269.

Sanford, General, 54.

Blood orange, 69 .

Satsuma lands, 218. mandarin, 87. orange, $24,79,81,210$.

season, 379 .

Saul Blood orange, 70.

Saunders, William, 35.

Sautellista cyanea, 546.

Savage citrange, 38-40.

E. M., 36.

Frank M., 36.

Saw palmetto, 216.

Saws, 361 .

Scab, 45, 476, 502.

Scales, 425, 432, 437.

Scaly bark, 466, 502 . 
Schedules for spraying, 509.

Schistocera aleutacea, 426. seralis, 426.

Scissor (clipper) cuts, 385 .

Sclerotium, 471.

Scudderia furcata, 427.

Season for citrus fruits, 379 .

Seed-bed, 163.

diseases, 471.

Seed, extracting, 162.

in citrus fruits, 140.

of pomelo, 160 .

planting time, 164.

to a bushel, 162 .

Seedless citrus fruits, 140 .

Selecting buds, 170.

varieties, 241.

Selling methods, 422 .

Sepal, 144.

Septuple planting, 233.

Serenoa serrulata, 216.

Serra, Junipero, 50.

Setting too deep, 250.

Seville, 45. orange, $21,43$.

Shaddock, 20, 91, 108, 328. introduction of, 93, 108.

Mammoth, 110.

Pink, 110.

Tresca, 111.

use of, 108.

Shaded seed-beds, 166 .

Shallow cultivation, 261 .

Shamel, A. D., 102, 172, 414.

Shears, 179.

Sicily lemon, 129.

Side-grafting, 194.

Sierra Madre, 320.

Sievers and True, 412.

Silk oak, 226.

Silver cluster pomelo, 101. mite, 454 .

Sinton citrangequat, 39,40 .

Six-spotted mite, 455.

Sizers, 398.

Sizes, 373.

of citrus packages, 399 .

of lemons, 411.

Sizing lemons, 398, 410.

Sling psychrometer, 323 .

Sloane, Hans, 93, 108.

Smith, Clayton O., 491.

Smoothing land, 236.

Snow scale, 437.
Soda-sulfur solution, 515 .

Sodium carbonate, 316 .

chloride, 316.

cyanide, 527.

Soil acidity, 284.

analyses, 289.

bacteria, 259 .

depletion, 288.

fertility, 281 .

for sweet-orange stock, 211.

for trifoliate orange, 208 .

improvement, 230.

moisture, 329 .

to be avoided, 214 .

Soldier-bug, 274, 459 .

Sooty-mold, 485.

Sources of lime, 285.

of nitrogen, 292.

of phosphoric acid, 290 .

of plant-food, 289.

of potash, 291.

of water, $307,308$.

Sour orange, $21,43,161,472$.

root system, 201.

seed, 161.

soils, 202.

stock, 200.

stock in Africa, 203.

Southern Alabama soils, 218.

California Fruit Exchange, 418.

Sowing beggarweed, 275 .

crotalarias, 278.

velvet bean, 272 .

Spalding, William A., 97.

Spanish oranges, $51,52,57$.

Species Plantarum, 48.

Sphaceloma fawcettii, 476.

Sphærostilbe cocophila, 537, 538.

Splitting of fruit, 350 .

prevention of, 350 .

Spores, 462.

Sports, 173.

Spotting, 333.

Spray injury, 508. pressure, 505 . schedules, 509-511.

Spraying, 503, 504.

equipment, 504.

time, 509.

Sprig-budding, 194.

Spring budding, 180.

Sprouting nursery trees, 188.

Square systems of planting, 232.

Squeeze, 416. 
Stable manure, 289.

Stacking field-boxes, 388 .

Stagnant water, 214.

Staking nursery trees, 187.

Stamens, 144.

Standard grade, 398.

Star Calyx orange, 67.

Starch, 283.

Starke orange, 62 .

State Boards, 537.

Steamed bone, 290 .

Steerbeck's Citricultura, 76 .

Stem-end rot, $469,480,481$.

Stevens, H. B., 373.

H. E., quoted, 488.

Stizolobium, 271.

Stocks, 199.

adaptation, 213.

and dormancy, 326.

and freezes, 326 .

for kumquats, 205.

heater, 340 .

influences, 200, 204.

union of trifoliate orange, 209. values, 213.

Storing buds, 172.

Street fruit-stands, 424.

Strips for loading, 416.

Style, 144.

Suckers, 355 .

Sucking insects, $425,446$.

Sugar, 283.

Suitability of artesian water, 310 .

Sulfate of ammonia, 292. of potash, 291.

Sulfur and lime dust, 520 .

Sulfuric acid, 527.

Summer budding, 180. planting, 247.

Sunkist, 420.

Suntaras, 138.

Supplying humus, 257.

Super-phosphate, 290.

Surface washing, 268.

Surprise orange, 73.

Sustain orange, 73 .

Sweating, 389.

Sweet lemon, 129.

orange, $22,48,161$.

orange analyses, 287.

orange stock, 211.

Swingle, Walter T., 12, 13, 26, 35, 41, 74.

Swingle and Robinson, 42.

Syrphus flies, 546 .

Systems for planting, 231.

Table for packing, 402.

Tabog, 29.

Tackle for tents, 523 .

Tahiti lime, 133, 138.

Tangelos, 90, 106.

Nocatee, 106.

Sampson, 107.

Thornton, 107.

Tangerine box, 399, 400 .

Tangerona mandarin, 88.

Tankage, 292.

Tappoons, 315 .

Tavares limequat, 135.

Telfair citrangequat, 39-41.

Temple mandarin, 89.

Tent derricks, 523.

for fumigating, 522 . poles, 523.

Terms used in grading, 397.

Tetranychus sex-maculatus, 455.

Texas citrus areas, 8.

citrus in, 5 .

rainfall, 306.

soils, 218.

Thermometers, 322 .

Thomasville citrangequat, 42 .

Thornton tangelo, 107.

Thrips, 457.

Thunberg, 34 .

Timber belts, 225, 229.

Time to plant, 246.

to fertilize, 301, 302.

to prune, 359 .

Tobacco dust, 519.

Tools for pollinating, 147 .

Topping nursery trees, 188.

Top-working, 195.

by grafting, 192 .

old trees, 197.

young trees, 196.

Torch, 344 .

wood, 25.

Tractors, 267.

Transplanting seedlings, 167.

Trash in field-boxes, 387.

Trays for paper, 403 .

Treatment for grasshoppers, 428 . for katydids, 428 .

Trees for windbreaks, 226.

of America, Brown, 55.

resistance to fumigation, 531 . stakes, 188. 
Trees to an acre, 234.

with balls of earth, 251 .

Tresca shaddock, 111.

Triangular system of planting, 231, 233.

Trifoliate orange, $15,34,39,160$.

introduction of, 35 ,

seed, 160.

stock, 206.

stock experiments, 210.

union, 209.

Trimming roots, 248.

Triumph pomelo, 105.

Triphasia trifolia, 30.

Trucks, 384.

Turning under cover-crops, 269, 271, 276.

Turpentine dross, 339.

Turtle-back scale, 437.

Twine, waxed, 178.

Tying nursery trees, 188.

Umbrella tree, 449.

Unarmored scales, 437.

Union of trifoliate orange, 209.

United States citrus fruit grades, 396.

Weather Bureau, 322.

Unshiu orange, 74 .

Valencia orange, 67.

Value of humus, 257, 258.

of rough-lemon stock, 204.

of sour-orange stock, 200.

of top-working, 195.

of water protection, 224 .

Varieties for planting, 139.

for pots, 365 .

hardiness of, 327 .

on trifoliate orange, 211.

selection of, 241.

Vegetables in citrus groves, 235.

Velvet beans, 269, 271, 272.

Verticillium heteroclodum, 538.

Vetch, 269.

Vigna sinensis, 271.

Villafranca lemon, 130.

Volkamer, 48.

Wagons, 384.

Walls, 344 .

Walters pomelo, 105.

Wampi, 27.

Washing fruit, 392 . machine, 392.

Washington Navel orange, 71.
Wasps, parasitic, 546.

Water distribution, 311.

-holding capacity, 257.

in cultivated soil, 258 .

in uncultivated soil, 258.

protection, $224,227,345$.

required, 304 .

sprouts, 355 .

vapor, 321.

Watering pot plants, 366 .

Watson, Alexander quoted, 97.

J. R., quoted, 450 .

Wax scale, 439.

Waxed cloth, 175.

twine, 178.

Waxes, 175 .

Weather, best for picking, 388 .

Webber, H. J., 35.

Weeds, 263.

Weight of citrus seeds, 162 .

Western Florida soils, 218.

Whale-oil soap, 515 . and nicotine sulfate, 516 .

When to graft, 191. to prune, 359 .

Whip-grafting, 193.

Whitaker orange, 68 .

Whitefly, 446.

White frost, 319.

orange, 68 .

scale, 439 .

W. N., quoted, 97.

Whitewashing top-worked trees, 197.

Wickson quoted, 243.

Willits, 39.

Willow oak, 216.

Windbreaks, 225, 334.

in California, 226.

in Florida, 226.

Wire in laying out, 239.

Wiring citrus sprouts, 353 .

Wither-tip, 254, 472, 473.

Woglum, R. S., quoted, 528-531.

Wood-fires, 338.

Woolly whitefly, 450 .

Wound protection, 357 .

Wounds from freezing, 350 .

Wrapping trees, 335 .

paper, 402.

Xanthoxylum, 25.

Yellow Aschersonia, 538.

Yellow-lined grasshopper, 426.

Yothers, W. W., 513. 
